
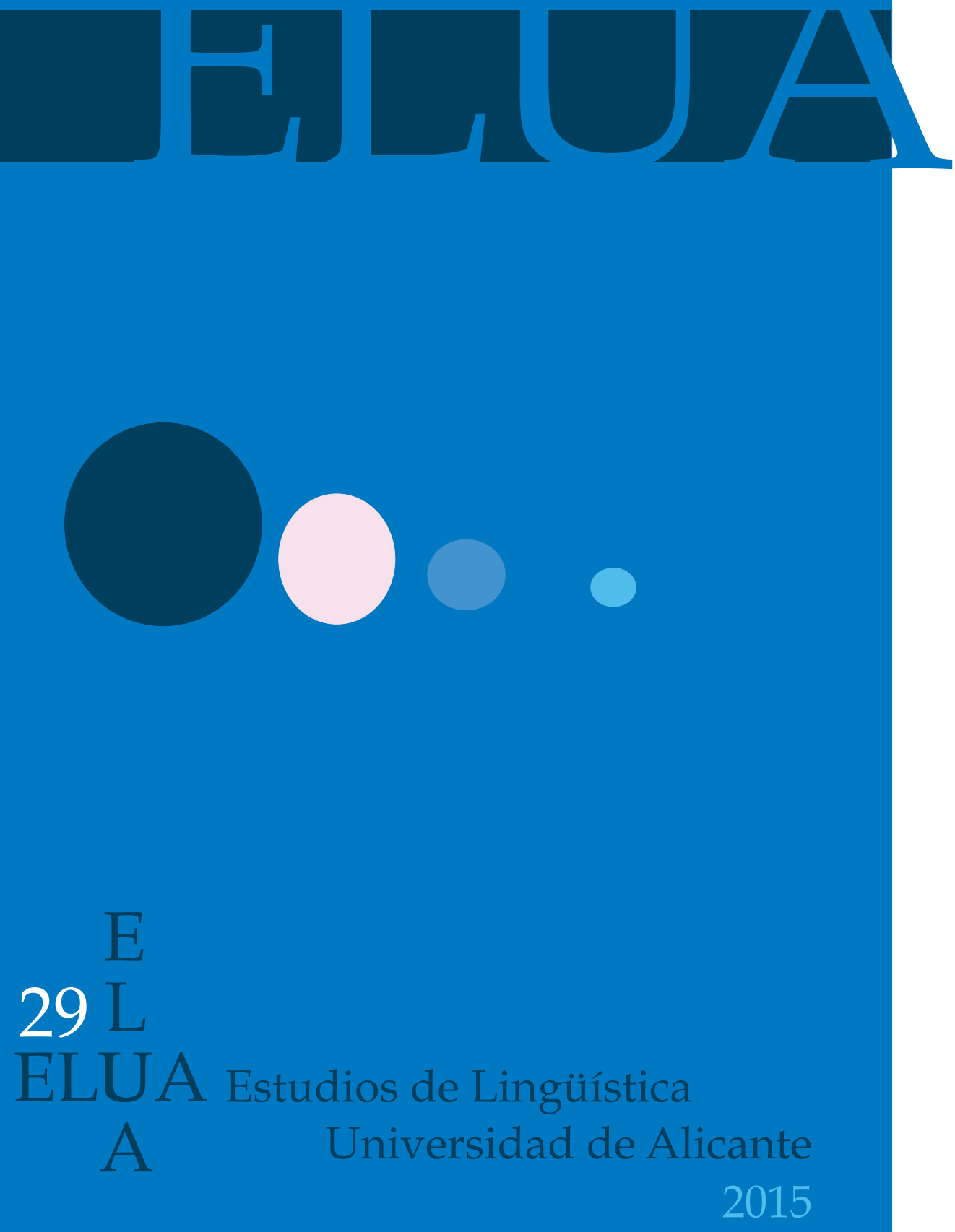


\section{Estudios DE LINGÜíSTICA \\ Universidad de Alicante \\ (ELUA)}

2015

NúMERO 29

\footnotetext{
Revista de Lengua Española

y LinGǗsTICA GENERAL
}

\section{Universitat d'Alacant \\ A Universidad de Alicante}




\section{DIRECTORA}

\section{Leonor Ruiz Gurillo}

\section{SECRETARIA}

Larissa Timofeeva Timofeev

\section{Consejo de Redacción}

$\mathrm{M}^{\mathrm{a}}$ Belén Alvarado Ortega (U. Alicante)

Elisa Barrajón López (U. Alicante)

Cristina Cacciari (U. Modena and Reggio Emilia)

Pilar Díaz de Revenga Torres (U. Murcia)

Dmitrij O. Dobrovol'skij (Academia de Ciencias de Rusia)

Jorge Fernández Jaén (U. Alicante)

Catalina Fuentes Rodríguez (U. Sevilla)

$\mathrm{M}^{\mathrm{a}}$ Mar Galindo Merino (U. Alicante)

Elena Hoicka (U. Sheffield)

Johannes Kabatek (U. Zürich)

Ruth Lavale Ortiz (U. Alicante)

Óscar Loureda Lamas (U. Heidelberg)

Carmen Marimón Llorca (U. Alicante)

José Joaquín Martínez Egido (U. Alicante)
$\mathrm{M}^{\mathrm{a}}$ Antonia Martínez Linares (U. Alicante)

Francisco Matte Bon (U. Luspio)

Elena de Miguel Aparicio (U. Autónoma Madrid)

Inés Olza Moreno (U. Navarra)

Xose Padilla García (U. Alicante)

Susana Pastor Cesteros (U. Alicante)

Inmaculada Penadés Martínez (U. Alcalá)

Herminia Provencio Garrigós (U. Alicante)

Susana Rodríguez Rosique (U. Alicante)

Ventura Salazar García (U. Jaén)

Isabel Santamaría Pérez (U. Alicante)

Augusto Soares da Silva (U. Católica Portuguesa)

Alexandre Veiga Rodríguez (U. Santiago de Compostela)

\section{Consejo Asesor}

Manuel Alvar Ezquerra (U. Complutense Madrid)

Dolores Azorín Fernández (U. Alicante)

Ignacio Bosque Muñoz (U. Complutense de Madrid y RAE)

Antonio Briz Gómez (U. Valencia)

José Luis Cifuentes Honrubia (U. Alicante)

Nicole Delbecque (U. Católica Lovaina)

Milagros Fernández Pérez (U. Santiago de Compostela)

Francisco Gimeno Menéndez (U. Alicante)

Salvador Gutiérrez Ordónez (U. León y RAE)

Günther Haensch (U. Ausburgo)

Ángel López García (U. València)
Humberto López Morales (Real Academia Española)

María Antonia Martín Zorraquino (U. Zaragoza)

Ana Isabel Navarro Carrasco (U. Alicante)

Neal R. Norrick (U. Saarland)

Lourdes Ortega (U. Hawai en Manoa)

$M^{a}$ Elena Placencia (U. Londres)

Estanislao Ramón Trives (U. Murcia)

Emilio Ridruejo Alonso (U. Valladolid)

Agustín Vera Luján (UNED)

Juan Andrés Villena Ponsoda (U. Málaga)

Gerd Wotjak (U. Leipzig)

Jef Verschueren (U. Amberes)

ISSN: 0212-7636

Depósito legal: A-15-1985

Diseño de la cubierta: Xose. A. Padilla García

Publicada gracias a las ayudas para la publicación de revistas científicas de la Facultad de Filosofía y Letras y del Vicerrectorado de Investigación, Desarrollo e Innovación de la Universidad de Alicante.

Fotocomposición e impresión: Compobell, S.L.

Normas para envío, evaluación y edición de contribuciones:

http://dfelg.ua.es/estudios-linguistica/ 


\section{ÍNDICE}

\section{Artículos}

La marcación variable de los objetos en español. Prominencia cognitiva y elección gramatical.

Miguel Ángel Aijón Oliva

Construcciones preposicionales en oraciones escindidas: el valor "existencial"

Emilio Cabezas Holgado

Acentos tonales y variantes: declarativas en habla formal y espontánea de La Gomera (Islas Canarias)

Chaxiraxi Díaz Cabrera y Josefa Dorta Luis

Oralidad y escritura en la red: testimonios de (orto)grafía regiolectal en un corpus de twitter

Elena Fernández de Molina Ortés

Repensar las fronteras lingüísticas del territorio español: Melilla, entre mosaico sociológico y paradigma lingüístico

Alicia Fernández García

Mecanismos multimodales de focalización de la información en la prensa digital del campo científico y jurídico: la negrita

M. ${ }^{a}$ Ángeles García Asensio, Fernando Polanco Martínez e Irene Yúfera Gómez

La motivación léxica en el ámbito de la glosodidáctica.

Juan Manuel García Platero

Black women through Alice Walker's poetry (A characterization of the valuating subjects of her poems)

Yeni Hechavarría Urquiaga and Yadelys Garriga Cruz

El disco está besado por Justin, la novela ya está leída: a propósito de las construcciones resultativas con estar

\section{$M^{a}$ Antonia Martínez Linares}

Fraseología y lingüística cognitiva. Estudio interdisciplinar de la fraseologización de la locución somática de boca en boca 
Implicaciones de la frecuencia de uso de las locuciones en la elaboración de un diccionario

Enunciados figurados en textos turísticos del ámbito institucional: análisis semánticopragmático en folletos y anuncios de la campaña Región de Murcia no-typical.........

Carmen Sánchez Manzanares

Los sufijos -dad, -tad, -icia, -eza, -ez, -tud y -dumbre en voces neológicas del castellano oriental del siglo XV

Matthias Raab

Las formas de tratamiento en un corpus de entrevistas semidirigidas de español de Galicia

María Sampedro Mella

Un modelo para el análisis semántico-discursivo de la causalidad

Ernesto Wong García

Análisis comparativo de la manipulación fraseológica en las lenguas china y española. 359 Wu Fan

\section{RESEÑAS}

Josefina Prado Aragonés y M $\mathrm{M}^{\mathrm{a}}$ Victoria Galloso (2014): El léxico disponible de Extremadura y comparación con el de Andalucía. Huelva: Servicio de Publicaciones de la Universidad de Huelva (Javier de Santiago Guervós)

Beatriz Gallardo Paúls y Carlos Hernández Sacristán (2013): Lingüística clínica. Un enfoque funcional sobre las alteraciones de lenguaje. Madrid: Arco/Libros (Inmaculada Bleda García). 


\section{INDEX}

\section{Articles}

Variable object marking in spanish. Cognitive salience and grammatical choice Miguel Ángel Aijón Oliva

Prepositional constructions in Cleft Sentences. The 'existential' value

Emilio Cabezas Holgado

Pitch accents and variants: declarative sentences in formal and spontaneous speaking of la Gomera (Canary Islands)

Chaxiraxi Díaz Cabrera and Josefa Dorta Luis

Orality and writing in the network: the testimony of regiolectal spellings of a corpus of Twitter

Elena Fernández de Molina Ortés

Redefining Spanish linguistic borders: Melilla, between sociological mosaic and linguistic paradigm

Alicia Fernández García

Multimodal resources for emphasizing information in the scientific and legal digital press: the bold typeface

M. ${ }^{a}$ Ángeles García Asensio, Fernando Polanco Martínez and Irene Yúfera Gómez

Lexical transparency in language methodology

Juan Manuel García Platero

Black women through Alice Walker's poetry (A characterization of the valuating subjects of her poems)

Yeni Hechavarría Urquiaga and Yadelys Garriga Cruz

El disco está besado por justin, la novela ya está leida. On resultative constructions with estar

\section{$M^{a}$ Antonia Martínez Linares}

Phraseology and cognitive linguistics. Interdisciplinary study of the phraseologization of the somatic idiom de boca en boca 
Implications of the frequency of use of idioms in the compilation of a dictionary .... Inmaculada Penadés Martínez

Figurative meaning in tourist texts within an institutional context: semantic-pragmatic analysis in brochures and advertisements in the campaign advertisement Región de Murcia no-typical

Carmen Sánchez Manzanares

The suffixes -dad, -tad, -icia, $-e z a$, $-e z$, $-t u d$ and -dumbre in neological items from $15^{\text {th }}$ century's Spanish used in the Crown of Aragon

Matthias Raab

Address forms in a semi directive corpus of Spanish in Galicia María Sampedro Mella

A model for the semantic and discourse analysis of causality Ernesto Wong García

Creative manipulation of phraseological units in Chinese and Spanish 359 Wu Fan

\section{BooK REVIEWS}

Josefina Prado Aragonés y M $\mathrm{M}^{\mathrm{a}}$ Victoria Galloso (2014): El léxico Disponible de Extremadura y Comparación con el de Andalucía. Huelva: Servicio de Publicaciones de la Universidad de Huelva (Javier de Santiago Guervós).

Beatriz Gallardo Paúls y Carlos Hernández Sacristán (2013): Lingüística clínica. Un enfoque funcional sobre las alteraciones de lenguaje. Madrid: Arco/Libros (Inmaculada Bleda García)..... 
ARTÍCULOS 



\title{
LA MARCACIÓN VARIABLE DE LOS OBJETOS EN ESPAÑOL. PROMINENCIA COGNITIVA Y ELECCIÓN GRAMATICAL
}

\author{
Miguel Ángel Aijón Oliva \\ Universidad de Salamanca
}

Recibido: 29/04/2015

Aceptado: 02/09/2015

\begin{abstract}
Resumen
La marcación de los objetos con la partícula $a$ es un hecho de variación gramatical que se ha abordado desde diversas perspectivas analíticas, pero que no ha recibido una explicación teórica general que permita dar cuenta de todos los contextos, categóricos y variables, del fenómeno. En este trabajo se propone un modelo funcional-cognitivo basado en la prominencia de los referentes, tanto la de carácter inherente como la adquirida en el contexto discursivo, frente a otras propuestas que enfatizan la transitividad del evento descrito por la cláusula. El referente del objeto establece un contraste de prominencia con el del sujeto y con otros posibles participantes del evento. Por ello, la marcación con $a$ posee una doble función: señalar su especial prominencia, que lo aleja de los rasgos prototípicos del objeto no marcado, y distinguirlo a su vez del sujeto, con el que compite cognitivamente. La marcación resulta ser, así, uno de los principales rasgos formales y funcionales en que se manifiesta la variabilidad inherente al régimen verbal.
\end{abstract}

PALABRAS CLAVE: variación, objeto, marcación, régimen, prominencia

\begin{abstract}
The marking of Spanish objects with $a$ is a fact of grammatical variation that has been approached from an array of analytical perspectives, but has not yet received a general theoretical explanation with the power to account for all its possible contexts, whether categorical or variable. This paper proposes a functional-cognitive model based on the notion of referent salience, be it of an inherent kind or acquired within the context, as against proposals emphasizing the transitivity of the event described by the clause. The referent of the object establishes a contrast of salience with the subject as well as other possible participants of the event. $A$-marking has therefore a dual role: it signals the special salience of the referent, which moves away from the prototypical features of unmarked objects, but at the same time distinguishes it from the subject it cognitively competes with. This makes object marking one of the most relevant formal and functional traits through which the inherent variability of verbal government is made manifest.
\end{abstract}

KEYWORDS: variation, object, marking, government, salience.

\section{Un hecho de variación morfosintáctica ${ }^{1}$}

La variabilidad en la formulación de la partícula $a$ ante ciertos objetos verbales (los asimilables a la función de directo) es probablemente una de las cuestiones más extensamente discutidas en la investigación gramatical del español, sin que se haya llegado a

1 Este trabajo forma parte del proyecto de I+D "Desarrollo conceptual y análisis empírico de la variación sintáctica en español: los objetos verbales y las estructuras de pasiva" (Ref. FFI2013-41250-P), financiado por el Ministerio de Economía y Competitividad de España. Agradezco a dos revisores anónimos sus comentarios y sugerencias sobre una versión anterior. 
configurar un modelo teórico explicativo de las pautas de elección observadas ${ }^{2}$. Ello se debe a la gran variedad de contextos en que se da el fenómeno y a la dificultad de precisar y jerarquizar los factores sintácticos, semánticos y discursivos que intervienen en ellos. Como se sabe, la marcación resulta obligatoria si el objeto expreso aparece en forma de pronombre tónico, lo que incluye obviamente a la primera y a la segunda persona. La situación es más compleja con los referentes de tercera persona que aparecen formulados como sintagmas léxicos. De modo general, a menor animacidad, individuación y/o especificidad referencial de estos últimos, menor es la preferencia por la formulación de la partícula.

(1) Te buscaba *(a) ti

(2) Buscaba *(a) mi hermano /*(a) Pablo

(3) Buscaba (a) un voluntario

(4) Buscaba (?a) voluntarios

(5) Buscaba $(* a)$ mi chaqueta

Los dos primeros ejemplos representan casos típicos de objetos altamente animados e individualizados, en los que la formulación de $a$ es obligada. En (3) es posible percibir la interacción de la referencialidad con una u otra elección. El uso de $a$ favorece una interpretación específica del referente: se tenderá a interpretar que ese voluntario es una persona ya conocida, lo que no ocurre en la alternativa Buscaba Ø un voluntario. De modo similar, en (4), la inespecificidad del objeto, indicada en este caso por la ausencia de determinación, hace menos esperable la marcación. Finalmente, en (5) se observa la imposibilidad de dicha variante cuando el referente es inanimado (aun siendo referencialmente específico), a no ser que en el contexto se le atribuyan, por alguna razón, rasgos de animacidad.

Si bien gran parte de los contextos potencian fuertemente una de las dos soluciones y hacen atípica o inaceptable la otra, abundan también los casos de variabilidad ${ }^{3}$. Un problema bastante evidente de muchos estudios sobre el fenómeno es que pretenden dilucidar sus verdaderas motivaciones recurriendo a juicios de gramaticalidad, lo que suele dar lugar a discrepancias y a generalizaciones de dudosa validez (véanse, por ejemplo, Torrego, 1999: 1784ss; Fábregas, 2013: 25-27). Una teoría general debería ser capaz de dar cuenta de los casos que exigen categóricamente una u otra solución, pero también de los que parecen admitir ambas, incluso cuando la elección que se produce no es la más esperable. La situación en el uso es compleja y depende en gran medida de las características de los referentes involucrados en el evento verbal, así como de la concepción de este último y de la relación que, por medio de él, se ve establecida entre dichos referentes. Se trata,

2 Pensado (1995) y, más recientemente, Fábregas (2013) presentan estados de la cuestión con abundante bibliografía. A lo largo del texto utilizaremos el término partícula para describir el elemento $a$, por considerarlo menos controvertido que preposición cuando se trata de designar una marca funcional de contenido semántico muy debilitado (cfr. Ormazabal y Romero, 2013: 223), si bien la discusión terminológica no es objeto primordial de este trabajo.

3 Se ha llegado a afirmar que, excepto en los casos de posible ambigüedad, "la libertad de uso u omisión de $a$ es casi total" (Montes Giraldo, 2006: 74). Más exacto sería afirmar que apenas hay factores que lleven a una solución categórica, pero no es menos cierto que en muchos contextos una de las dos variantes resulta obligada o claramente favorecida. En cualquier caso, la tarea de la investigación gramatical debería ser la de buscar una explicación unitaria para todos los contextos, categóricos y variables. Recuérdense a este respecto las palabras de García (1985: 204): "by splitting up the uses of a form into 'variable' vs. 'obligatory' (or 'categorical') the analyst runs the risk of missing the significant generalization which would enable him to motivate the observed alternation". 
pues, de un hecho de variación formal que resulta de interés desde un enfoque funcionalcognitivo, ya que atañe a la propia percepción del contenido descrito por la cláusula.

Hay que subrayar que la partícula $a$ es el índice funcional común a los objetos centrales o concordables, esto es, aquellos que pueden reproducirse junto al núcleo verbal por medio de un clítico correferencial que funciona como morfema de concordancia objetiva (cfr. Aijón Oliva, 2006a: cap. 4; García, 2009: 79-81). Tales objetos se han denominado tradicionalmente directos e indirectos, si bien, como se argumentará más adelante, estas funciones constituyen en realidad meros prototipos en un continuum sintáctico-semántico. Es necesario asumir que todos los contextos en que se produce la marcación del objeto deben poseer un núcleo significativo común, derivado de la propia identidad formal de la partícula. Por la misma razón, aquellos otros contextos en que no se marque un objeto con $a$ deberán estar unidos por un valor general y diferente al anterior; y los abundantes casos que admiten ambas variantes se acercarán a unos u otros significados dependiendo de la elección adoptada. Es decir, no se trata tanto de discutir si en un contexto es posible o no la formulación de $a$, sino del significado que se puede construir en dicho contexto por medio de su formulación o de su omisión.

De hecho, las intuiciones tradicionales sobre los factores formales y semánticos que propician la marcación del objeto (animacidad, especificidad, etc.) pueden ser sustancialmente correctas, si bien deben integrarse en un enfoque que supere tanto la mera descripción como un formalismo basado en la deducción de reglas de aplicación categórica. Mientras que los modelos formalistas tenderán a disminuir la relevancia de factores semánticos como la animacidad del referente, simplemente porque también hay contextos de objeto inanimado con a (así, Esta ley sustituye a la anterior), consideramos que la correlación de cada elección con determinados aspectos formales y semánticos del contexto es precisamente lo que hace posible descubrir los significados que comportan las variantes y, a partir de ellos, interpretar los nuevos casos que se descubran en el uso real, para confirmar, desmentir o perfeccionar las hipótesis planteadas.

A pesar de todo, es cierto que las motivaciones y repercusiones significativas de cada elección son a menudo sutiles y difíciles de explicitar (como es frecuente en los fenómenos de variación morfosintáctica; cfr. Aijón Oliva y Serrano, 2013: 11-15). Es necesario realizar un análisis detenido de las características discursivas y contextuales de ejemplos de uso real. En el presente estudio, tales ejemplos se tomarán del Corpus de Lenguaje de los Medios de Comunicación de Salamanca (MEDIASA), tanto en su sección de prensa escrita como en la de discurso radiofónico ${ }^{4}$. Se recurrirá ocasionalmente a fuentes adicionales que ofrezcan otros casos de interés, siempre citando su procedencia. El objetivo es avanzar hacia una explicación del significado básico de la marcación variable de los objetos, a través de un factor cognitivo general (el de la prominencia) que permita explicar sus repercusiones en los planos morfosintáctico, semántico y discursivo.

En la sección 2 se desarrolla la noción de prominencia como factor cognitivo que fundamenta la marcación del objeto, y se contrasta con la variación de este fenómeno observada habitualmente en relación con factores semántico-referenciales. Se propone, finalmente, una serie de criterios para evaluar la prominencia de un referente en contraste con la de otros presentes en el contexto. Ello permite, en la sección 3, extender el análisis al plano de la cláusula, diferenciando entre los casos con un solo objeto concordable, de interpretación

4 El tamaño total del corpus es algo superior a las 300000 palabras; su texto completo se recoge como anexo en Aijón Oliva (2006a). 
generalmente más compleja, y aquellos en que se establece un contraste de prominencia entre dos objetos; en todos ellos se observará la relación entre la marcación o no marcación del objeto y la interpretación del evento descrito por el verbo, así como de las relaciones que se establecen entre los participantes. La sección 4 reexamina los conceptos de régimen verbal y funciones sintácticas desde la óptica de la variabilidad como característica inherente a la gramática. Finalmente, la sección 5 resume las principales conclusiones del estudio.

\section{La marcación del objeto como índice de prominencia cognitiva}

La prominencia puede entenderse como la relevancia de un determinado elemento en la percepción que los hablantes poseen de las escenas y eventos descritos por medio del lenguaje (Croft y Cruse, 2004: 49-50). Se asocia a aquellos referentes discursivos que se hallan más activados en la consciencia, e implica una mayor integración de estos en el contexto discursivo, de tal forma que resultan más básicos para la comprensión global de dicho contexto; de ahí las habituales caracterizaciones de los elementos prominentes como conocidos, recuperables o predecibles (Chafe, 1994: 71ss). Podemos considerar que los referentes del discurso poseen un grado determinado de prominencia inherente, dados sus caracteres semántico-referenciales y su formulación sintagmática. Así, los participantes directos, indexados con formas de primera y segunda persona, son más prominentes que los entes externos a la interacción; de entre estos últimos, los humanos o animados serán a priori más prominentes que los animados, etc. Existe, asimismo, un tipo de prominencia que surge del estatus alcanzado por los referentes en un contexto discursivo, teniendo en cuenta su posición, la existencia de menciones previas, la posibilidad de deducir su existencia, etc., lo que puede concretarse en su grado de accesibilidad contextual (cfr. Ariel, 1990, 2001; Gundel y Fretheim, 2009). Ambos tipos de prominencia, aunque distinguibles en un plano teórico, se hallan obviamente muy relacionados en el uso: las características inherentes a un referente tenderán a condicionar sus posibilidades de alcanzar prominencia en un contexto determinado y, a la inversa, su estatus discursivo influirá en su propia naturaleza perceptual.

La prominencia no es en sí una magnitud fácilmente mensurable, dado su carácter abstracto y el hecho de que puede manifestarse simultáneamente en cualquier nivel de análisis lingüístico. No obstante, se han propuesto diversas escalas de prominencia (o de nociones relacionadas, como la topicalidad o la accesibilidad) para dar cuenta del hecho de que no todos los referentes discursivos poseen la misma importancia para los hablantes. A partir de propuestas como las de Silverstein (1976: 122), Givón (1983: 22), Ariel (1990: 73) o Aissen (2003: 437), se pueden deducir jerarquías como las siguientes (el signo $>$ debe leerse como 'más prominente que'):

a) Persona gramatical: primera $>$ segunda $>$ tercera

b) Modo de formulación o indexación: desinencia verbal $>$ clítico $>$ pronombre personal $>$ sintagma léxico

c) Posición en la cláusula: posición preverbal > posición posverbal

d) Determinación y especificidad: determinado específico $>$ determinado inespecífico $>$ indeterminado

e) Función sintáctica: sujeto $>$ objeto indirecto (o dativo) $>$ objeto directo (o acusativo)

f) Papel semántico: agente $>$ experimentante $>$ paciente o tema

g) Animacidad: humano $>$ animal $>$ inanimado 
Se trata, por lo tanto, de una noción compleja que afecta a una gran variedad de aspectos formales, semánticos y discursivos; en este carácter abarcador reside, a la vez, su poder explicativo. De hecho, los estudios sobre la marcación de los objetos en español permiten intuir que todas las jerarquías anotadas se manifiestan de algún modo en ella. La formulación de $a$ es categórica con las dos primeras personas, con los pronombres personales en general y con aquellos objetos asimilables al prototipo funcional de objeto indirecto, además de verse favorecida por la animacidad, la especificidad y la colocación preverbal en los demás casos, como se revisará a lo largo de esta sección.

Se han propuesto ya aproximaciones a la marcación variable de los objetos desde puntos de vista funcionales y cognitivos relacionados con la prominencia. Así, Dumitrescu (1998: 145) asocia el fenómeno al factor discursivo de la topicalidad. La autora considera que la aparición de la marca funcional se deriva de los propios caracteres formales y semánticos del referente: a mayor animacidad y/o definitud, mayor topicalidad $\mathrm{y}$, con ello, probabilidad de ser marcado. No obstante, comprobaremos que el contexto sintáctico-discursivo puede propiciar la aparición de $a$ en contextos donde no sería esperable teniendo en cuenta únicamente dichos caracteres inherentes, como también sugiere Laca (2006). Enghels (2013: 49-51), en un estudio sobre los verbos de percepción visual y auditiva, argumenta que el objeto con $a$ se concibe como más dinámico o agentivo, ya que de hecho se entiende como generador de dicha percepción y no como simple tema o paciente de esta.

En el resto de esta sección se analizará la interacción de la marcación de objeto con los aspectos relativos al referente más repetidos en la bibliografía: la animacidad y la especificidad-individuación, entendidas aquí como manifestaciones de la prominencia cognitiva. Se revisarán, además, otros posibles factores en los planos discursivo e interaccional. De aquí se deducirá una serie de criterios operativos para caracterizar los diversos referentes de acuerdo con su prominencia. Todo ello constituirá el punto de partida para desarrollar, en las secciones 3 y 4 , un enfoque integrador que tenga en cuenta todas las circunstancias contextuales de la marcación del objeto, y permita caracterizar esta variante como una elección gramatical dotada de significado intrínseco.

\subsection{Animacidad}

Parece lógico que para la percepción humana sea, de entrada, más relevante aquello que posee vida, y en particular las propias personas (Givón, 2001: 56-57; Aissen, 2003: 437). En lo que respecta a la marcación del objeto, dos referentes netamente distintos en cuanto a este rasgo pueden dar lugar, categóricamente, a soluciones diferentes:

(6) a. El niño golpeó Ø el cristal

b. El niño golpeó $a$ su hermano

Verbos como golpear hacen casi obligatoria la partícula cuando el referente del objeto es animado, incluso en casos de indeterminación (?El desequilibrado golpeaba Ø gente por la calle), mientras que la desfavorecen con objetos o vegetales; aun así, son posibles ejemplos como El desequilibrado golpeó al árbol, en el que la propia presencia de a quizá sugiere cierta animacidad. En la misma línea, la mayoría de los verbos tienden a marcar su objeto 
cuando este es animado, y especialmente si es humano, y a prescindir de la marca en caso contrario. Estos ejemplos del corpus con el verbo visitar lo ilustran:

(7) Fernando Pablos, junto a varios concejales del PSOE, visita hoy a comerciantes y vecinos de la zona afectada por las obras. $<$ Not-Ad-121203-3 $>$

(8) Las organizadoras esperan superar la recaudación total [...] y animan a todos los salmantinos a visitar $\varnothing$ el Rastrillo y colaborar. $<$ Not-Ga-121203-19>

Tan clara parece la asociación de la marca funcional a dicho rasgo, que permite incluso distinguir el contenido referencial de un topónimo en pares mínimos como el de (9). De hecho, los nombres propios exigen el uso de $a$ cuando designan, ya sea literal o metafóricamente, a seres animados 5 . Por otro lado, en (10) es fácil percibir el significado que genera la marca en favorecer al comercio: se alude al conjunto de las personas involucradas en la actividad comercial, más que a dicha actividad en sí misma.

(9) a. Conoce $\varnothing$ toda Salamanca ( $\approx$ 'todos los lugares de la ciudad')

b. Conoce $a$ toda Salamanca ( $\approx$ 'a todos los habitantes de la ciudad')

(10) Lamentan la falta de subvenciones, son pesimistas sobre el futuro del sector y consideran necesario un plan integral para favorecer al comercio. <Art-Ga-290104-3b $>$

Pero, para la explicación de estos casos, también se puede tener en cuenta la competencia entre referentes dentro de la cláusula, aspecto que se hallaría ya en el punto de encuentro entre la prominencia inherente y la adquirida en el contexto. Volviendo al par del ejemplo (6), mientras que en (6a) un objeto directo como el cristal no requiere la marca, ya que de por sí establece un claro contraste perceptivo con el sujeto el niño, parece más necesario delimitar de modo explícito los papeles sintáctico-semánticos en escenas de posible conflicto entre referentes de análoga prominencia inherente como los de (6b): el niño y su hermano, ambos animados y claramente individualizados (cfr. Keenan, 1976), pero que en el contexto adquieren roles netamente distintos. Junto a la hipótesis tradicional de que la marcación del objeto se debe a la necesidad de distinguirlo del sujeto en casos de posible ambigüedad (Alarcos, 1994: §335; Torrego, 1999: 1784), es igualmente posible plantear que su objetivo es distinguir objetos no prototípicos de otros que sí lo son (como también da a entender Alarcos, ibid.). Esa falta de prototipicidad se debe, principalmente, a las características de su referente, concebido como relativamente autónomo con respecto al sujeto (véase \$3.1).

\subsection{Especificidad-individuación}

Es evidente, por otro lado, que la animacidad no explica todos los casos posibles; en muchos casos parece ser más relevante el hecho de que el objeto aluda a seres que el hablante conoce y puede identificar (especificidad referencial) o que, al menos, se entienden como individuos concretos (individuación) (cfr. Laca, 1995; NGRAE, 2009: §34.9c-h). Y

$5 \mathrm{Y}$, a la inversa, toda realidad a la que se le aplica un antropónimo, apodo, etc., requiere la partícula: $H e$ llevado *(a) Kit al taller (refiriéndose a un coche). Obviamente, tal denominación impone una percepción del objeto como animado, además de específico. 
ello porque es frecuente la ausencia de marca cuando el referente, aunque animado, se interpreta como genérico (El ogro secuestraba $[a]$ niños) o cuando no alude a un ser específico y conocido, sino a cualquiera que virtualmente posea unos determinados rasgos (Necesito [a] un ayudante). El plano semántico-referencial interactúa con el sintagmático, dado que la interpretación del referente se ve condicionada por el hecho de que exista determinación y de qué tipo sea esta, como se observa en este ejemplo con el indefinido otros:

(11) al final han sido los profesionales los que han completado la: / convocatoria / y si el partido va mal: y hay que: buscar / Ø otros pistoleros / e / para esos último:s: e cartuchos no los tenemos <Dep-Pu-191204-18:05>

El objeto sin $a$ se entiende más como clase o como conjunto de propiedades que como individuo en sí, lo que revela una distinta prominencia. Los nombres propios designan realidades altamente específicas e individualizadas; pero, a su vez, los seres humanos o animados pueden considerarse superiores en este sentido a otros tipos de realidades, con lo cual el rasgo de la animacidad podría ser, en realidad, una manifestación particular de la individuación ${ }^{6}$. El siguiente ejemplo permite observar cómo el uso de $a$ es más esperable en el segundo contexto, con el paso de la clase especialistas al individuo uno:

(12) Estaba buscando (?a) especialistas y finalmente encontré (a) uno

De existir un contexto posterior al citado ejemplo, en el que se siguiera hablando del especialista en cuestión, probablemente se reforzaría su especificidad y, si siguiera codificándose como objeto sintáctico, la marca resultaría ya categórica (más aún teniendo en cuenta que, dada su prominencia en el contexto, se tendería a designarlo con pronombres tónicos: él, este).

De hecho, la distinta especificidad puede interactuar con el significado del propio evento verbal, como sugiere la diferencia entre Ana espera $\varnothing$ un niño y Ana espera a un niño. En el primer caso, el objeto inespecífico parece tender a la lexicalización con el verbo, dando lugar a un significado particular de esperar ('estar embarazada'), frente a la interpretación más composicional de la variante con marca y objeto específico. Es decir, en aquel caso el objeto no se percibe realmente como un participante del evento, y este se entiende como atélico o no terminativo (cfr. Torrego, 1999: 1789). La menor autonomía del objeto, que tiende a integrarse en el evento verbal, se refleja en la ausencia de $a$, marca que establece icónicamente una separación entre los participantes. Se discutirá este aspecto más extensamente a la luz de ejemplos posteriores.

Como ocurre con los referentes humanos inespecíficos o escasamente activos, también se detecta variación en el caso de los animales, y los factores que interactúan con la elección pueden fundamentarse de nuevo en su prominencia inherente y contextual. Los que se codifican por medio de nombres propios, que de por sí comportan individuación, exigen la marca.

6 Si bien la marcación de los nombres propios de persona resulta prácticamente categórica, Montes Giraldo (2006: 73) recoge el ejemplo "También empezamos a leer $a$ García Márquez [...] Ellos, en cambio, leían Ø Isaac”. El autor se limita a comentar que en el segundo caso se ha podido elidir la marca porque "el contexto impide toda ambigüedad" (ibid., 74), pero diríamos que en realidad se debe a una reinterpretación metonímica de Isaac como 'los textos, etc. de Isaac' (de hecho, eso es obviamente lo que significa leer a García Márquez; cfr. NGRAE, 2009: $\S 34.8 \mathrm{j})$. No hay duda de que, incluso en este contexto, generalmente se optaría por la marcación. 
Asimismo, si son específicos y aparecen involucrados en eventos que también podrían tener un objeto humano (así, en este ejemplo con el verbo cuidar), resulta esperable la misma elección:

(13) Algunos años Miguel ha pasado el 24 de diciembre perdido en el campo y con la única compañía que [sic] las cabras $a$ las que cuidaba $<$ Rep-Ga-221203-17>

Cabe apuntar, con respecto a (13), que el hecho de que la función de objeto la desempeñe un nexo relativo haría mucho más tolerable que en otros contextos la ausencia de $a$ : las cabras Ø que cuidaba (de hecho, es una solución normal incluso con referente humano: los niños $\varnothing$ que cuidaba). Y, no obstante, se ha optado por dicha marcación, reforzando así su especificidad. En otros casos se opta por la solución alternativa, potenciando significados diferentes. Puede resultar llamativo lo que ocurre en esta noticia externa al corpus analizado; en ella se evita la partícula cada vez que se codifica a los animales como objeto sintáctico. La elección es especialmente atípica en el propio titular, con un objeto singular y específico:

(14) Una joven fallece al intentar salvar $\varnothing$ el perro de su jefe ${ }^{7}$

[...] No sólo invertía su tiempo en ello sino que también cuidaba Ø los perros de su jefe en su tiempo libre. Desgraciadamente, un día, cuando precisamente paseaba $\varnothing$ los animales de [su] superior, falleció de forma trágica. (La Gaceta de Salamanca, 1/9/2014)

Es probable que en la elección haya primado la conciencia de que los referentes no son humanos. Ello indica que la percepción de la animacidad, como la de la especificidad-individuación, está sujeta a gradualidad, y que ambos rasgos interactúan frecuentemente en el uso.

\subsection{Otros posibles rasgos del referente}

Se ha llamado también la atención sobre el valor afectivo que puede sugerir la partícula al aplicarse a entidades concretas. Con respecto precisamente a los referentes animales, el DPD (2005, s. v. $a$ ) alude a la "proximidad afectiva" como factor determinante y comenta, sin ofrecer ilustración de ello, que "es muy frecuente el uso de la partícula con los nombres que designan animales domésticos, mientras que los nombres que designan animales no domésticos normalmente no admiten la preposición". Si bien tal afirmación dista de ser convincente, la posible relación de $a$ con la afectividad también se explicaría como proyección, en este caso en un plano semiótico interaccional, de su asociación a los elementos de mayor relevancia cognitiva. En estos ejemplos se observa cómo la marca aparece en contextos de clara dignificación de los referentes (gente, personas), los cuales se individualizan por medio de la marca, a pesar de que, dadas sus características inherentes, sería fácil tratarlos como clases ${ }^{8}$.

(15) Respecto a la actitud de la gente de la calle con las personas de Aspace, encuentran $a$ gente que te ayuda enseguida si nos surge algún problema. $<$ Rep-Ga-260804-15>

7 Un informante nos hace ver la posible ambigüedad, con efecto cómico incluido, que entrañaría la alternativa salvar al perro de su jefe, debido, precisamente, a la tendencia habitual a atribuir rasgos humanos a los objetos con $a$. Sin negar que esto pueda haber promovido la redacción atípica del titular, no explicaría de todas formas los otros ejemplos sin marca en el texto.

8 La capacidad de las variantes sintácticas para actuar como recursos de (des)cortesía verbal se desarrolla en Aijón Oliva (2006b) y Serrano y Aijón Oliva (2010). 
(16) Por su parte, el director gerente del hotel, Marcelino Martín afirma que "el Regio siempre ha echado una mano en lo que ha podido". Así lo demostró al acoger a los evacuados. "Tenemos $a 142$ personas alojadas". <Rep-Ad-051104-4>

No se pretende con ello afirmar que los hablantes manejen conscientemente la marcación del objeto como un rasgo de cortesía o dignificación; en los ejemplos transcritos se podrían señalar otros rasgos sintáctico-semánticos concurrentes que favorecerían esta variante. El análisis de (15) resulta de por sí complejo, por la variedad de referentes y personas gramaticales que se combinan en el enunciado; pero el hecho de que gente actúe como antecedente de una cláusula subordinada puede estar reforzando su prominencia. De modo similar, la presencia de un predicativo del objeto, como es el caso de alojadas en (16), parece ser uno de los factores que potencian la marcación, al convertirlo en sujeto de una cláusula reducida (véase una discusión más extensa sobre estos tipos de objetos en §3.1). A pesar de todo, como hemos apuntado, los rasgos típicamente asociados a la formulación de $a$ pueden llevar a su uso en contextos en que no sería gramaticalmente necesaria, y una posible interpretación contextual de dicha elección sería el intento de dignificar al referente.

En el plano sintáctico-discursivo, se ha señalado que la colocación preverbal del objeto también favorece su marcación (Laca, 1995: 84-85; NGRAE, 2009: §34.8c). Los elementos preverbales ocupan la posición prototípica del sujeto y tienden a constituir información conocida o temática en el contexto. Así, la marca parece algo más aceptable en Cuando a un árbol consiguen matarlo que en Cuando consiguen matar a un árbol. No obstante, en este caso el propio verbo matar, por su semántica, incide en la animacidad del referente, lo que hace que tampoco la variante en posposición resulte atípica. Compárese con, por ejemplo, ?Cuando a un árbol consiguen talarlo, en que resulta más obvia y forzada la asignación de rasgos animados. No obstante, cabe estar de acuerdo en que un objeto preverbal tenderá a poseer mayor prominencia discursiva que uno posverbal, lo que de modo general favorecerá la formulación de $a^{9}$. En realidad, todos los rasgos que promueven la marcación del objeto se relacionan típicamente con la información conocida o topical en el discurso: referentes animados y específicos, pronombres de primera y segunda persona, nombres propios, etc. Por lo general, la prominencia y la informatividad de un elemento en cierto contexto son inversamente proporcionales (Serrano, 2013). En el esquema sintáctico no marcado de la cláusula declarativa, (S)VO, la mayor prominencia se asocia al sujeto y la mayor informatividad al objeto.

La revisión realizada a lo largo de estas subsecciones permite concluir que la tendencia a usar $a$ como marca de un objeto se relaciona directamente con la prominencia de su referente, manifestada esta en aspectos más particulares como su animacidad, su especificidadindividuación o, en algunos casos, la afectividad-dignificación que se le atribuye, junto a su posición sintáctica y al grado de tematicidad que adquiere en el contexto. Ninguno de estos factores lleva a una solución categórica, dado que ellos mismos son de carácter variable; se trata de rasgos que permiten situar a un referente en un punto concreto del continuum más

9 No obstante, Sanz (2011) observa que en el español mexicano es relativamente frecuente la ausencia de marca con los objetos de referente humano dislocados a la izquierda: Ø Ese lo mataron. En realidad, y en contra de lo que propone la autora, creemos que en este caso el objeto es en realidad un tópico externo a la predicación y que, por ello, puede prescindir de cualquier marca de función. Su prominencia es, en todo caso, análoga a la de un sujeto, lo que lleva a su asimilación formal a este (no al objeto $\sin a$ ). Prueba de ello es que $a$ puede omitirse incluso con pronombres personales: Ø Nosotros nos perseguían (ibid); no sería posible tal omisión si el pronombre perteneciera a la esfera argumental del verbo. 
general de la prominencia. La formulación u omisión de a no es un mero resultado de dicha prominencia, sino que, como elección significativa que es, puede contribuir por sí misma a aumentarla o a disminuirla.

No obstante, con vistas a una explicación general de la variación observada, resultan tanto o más relevantes las relaciones que establece el objeto con los demás participantes de la cláusula, así como la propia naturaleza del evento verbal, aspectos que serán objeto de estudio en la sección 3. Para ello, conviene precisar de manera más clara cómo se puede evaluar y comparar de una manera sistemática la prominencia de los distintos participantes de una cláusula.

\subsection{La evaluación contextual de la prominencia}

El análisis subsiguiente se centra, como hasta ahora, en objetos expresos de tercera persona, no pronominales y no claramente asimilables a la función de indirecto (a priori, las únicas condiciones que permiten variabilidad en la marcación), y pretende observar si las elecciones efectuadas en cada contexto se relacionan con el contraste entre la prominencia del referente y la que poseen otros elementos de la cláusula, principalmente el sujeto (ya que, cuando hay a la vez dos objetos concordables, el contraste entre ellos suele ser claro; cfr. §3.2). No se tendrá en cuenta la función sintáctica de los elementos como factor coadyuvante a la prominencia, ya que siempre supondrá una ventaja para el sujeto. En cambio, otros factores aludidos nos permiten formular los siguientes criterios para evaluar y comparar la prominencia de los diversos referentes. Estos criterios se hallan ordenados jerárquicamente y deben aplicarse de modo sucesivo; así, por ejemplo, la persona gramatical se considera el rasgo más determinante (un participante directo siempre será más prominente que una tercera persona); aun así, un referente terciopersonal puede aproximarse en diversos grados a la prominencia de la primera y la segunda persona, dependiendo de que sea específico, animado, etc. ${ }^{10}$

1. Un referente de primera o segunda persona es más prominente que uno de tercera.

2. Un referente de tercera persona indexado únicamente por morfemas es más prominente que uno formulado como pronombre, y este que uno formulado como sintagma léxico.

3. Un referente referencialmente específico es más prominente que uno inespecífico.

4. Un referente humano es más prominente que uno animal, y este que uno inanimado.

5. Un referente con el papel semántico de agente es más prominente que uno con el papel de experimentante, y este que uno con el papel de paciente $u$ otros.

6. Un referente colocado en posición preverbal es más prominente que uno colocado en posición posverbal.

Aunque en gran parte de los contextos resultarán bastante claras las diferencias de prominencia entre los participantes, lo relevante es observar hasta qué punto es posible percibir una nivelación entre ellos, gracias a rasgos que contribuyan a aumentar la prominencia del objeto. No se trata solo, pues, de que el objeto sea más o menos prominente que el sujeto (en la mayor parte de los casos lo será menos, por los propios rasgos asociados prototípi-

10 Un planteamiento de este tipo deja cierto espacio para la interpretación de cada contexto específico, y parece preferible a la formulación de un algoritmo de la prominencia, opción que resultaría complicada y conllevaría, quizá, decisiones arbitrarias. Como se podrá comprobar a lo largo de la sección siguiente, referentes a priori muy distintos en su prominencia pueden aproximarse entre sí por elecciones contextuales a veces muy sutiles. 
camente a los objetos), sino de en qué medida esté capacitado para establecer una suerte de competición cognitiva con este; dicha competición, como se verá, es lo que realmente fundamenta la aparición de la marca de objeto.

\section{El evento verbal y el contraste de prominencia entre los participantes}

Se ha sugerido que existe una conexión entre el uso de $a$ y la mayor transitividad del evento verbal (Delbecque, 1999, 2002; Torrego, 1999: 1785). Diversos autores consideran que los referentes específicos e individualizados resultan más aptos para desempeñar el papel semántico de 'paciente', y que su presencia refuerza la transitividad (cfr. Malchukov, 2008: 209), aunque no hay unanimidad a este respecto (Enghels, 2013: 38). Desde nuestro punto de vista, y una vez establecido que la marcación del objeto se relaciona con una prominencia más elevada del referente, la variante debería suponer una mayor autonomía de este con respecto al sujeto; de hecho, veremos que existen importantes contraargumentos a la supuesta relación de $a$ con la transitividad. Sin embargo, el modo en que se perciba dicha autonomía puede depender del evento concreto. Conviene analizar por un lado los contextos (más frecuentes y, en general, de mayor complejidad) en que solo hay un objeto concordable $\mathrm{y}$, por otro, aquellos en los que aparecen dos objetos entre los que tiende a establecerse un contraste de prominencia.

\subsection{Cláusulas de un solo objeto concordable}

Cabría comenzar por un contexto sintáctico especial que se ha abordado a partir de la noción de transitividad, pero que en realidad no parece ser pertinente para el análisis de la marcación del objeto: el de las cláusulas de haber impersonal. En ellas nunca se formula la marca: Hay (*a) dos personas en el vestíbulo, lo que podría interpretarse como manifestación de su carácter estativo, sin transacción alguna de energía. Desde nuestro punto de vista, se debe tener en cuenta, en primer lugar, que se trata de construcciones presentativas que casi siempre seleccionan objetos inespecíficos e indeterminados, los cuales constituyen información nueva: es raro ?Hay la mesa, y no parecen posibles *Hay (a) Juan y Pedro, *Lo hay (a) él. Pero, además, no existe un sujeto, ni siquiera en el nivel lógico, con el que pueda entrar en contraste el objeto; tampoco hay otro objeto concordable que ayude a establecer niveles de prominencia (cfr. §3.2), con lo que el referente en cuestión queda, generalmente, como único participante de la escena. Tales cláusulas ni siquiera pueden considerarse eventivas; únicamente sirven para situar un elemento en la escena discursivo-cognitiva, el cual podría de hecho interpretarse como sujeto ${ }^{11}$. No parece, pues, que se trate de un contexto equiparable a los que analizaremos a partir de este punto.

11 Lo único que permite afirmar que el participante de estas construcciones es un objeto (directo) es la posibilidad de indexación con un clítico de acusativo, que de todas formas es una solución rara en muchos contextos: Necesitaba aspirinas, pero no (?las) había. Por contra, en diversas variedades se observan reinterpretaciones antinormativas de este objeto como sujeto: Hubieron terremotos, a veces incluso haciendo concordar la forma de presente hay: En el centro también hayn cafés (DPD, 2005, s. v. haber); Aqui habemos muchas personas, etc., soluciones motivadas por el carácter atípico de una construcción que parece seleccionar un objeto donde no hay posibilidad de concebir un sujeto distinto de él. Muy distintas son otras impersonales como las de se, en las que, aun no existiendo sujeto sintáctico, se concibe un agente humano que entra en relación con un paciente, normalmente también humano: Se encontró a los niños. En la sección 4 se aborda más detenidamente la relación entre las construcciones con se y la marcación de los objetos. 
De modo general, el objeto introducido por $a$, al ser más prominente, debería resultar más autónomo o menos afectado por el evento verbal. De hecho, llama la atención que una función aparentemente bien definida como la de objeto directo siempre resulte formalmente sincrética, bien con el sujeto (cuando no lleva $a$ ), bien con el objeto indirecto (en el caso contrario). Con frecuencia se ha intuido que, cuando aparece la partícula, es porque existe una mayor necesidad de marcar diferencias entre los dos participantes principales del evento. Ello se deberá, generalmente, a que sus caracteres cognitivos se perciben como similares. Así es posible interpretar, por ejemplo, la diferencia de significado eventivo que promueve la marcación en el segundo enunciado de este par (Fábregas, 2013: 23-24):

\section{(17) a. Tengo Ø una hija}

b. Tengo $a$ una hija

Mientras que el valor del verbo en el primer caso es el estativo de posesión (no material), que predica una propiedad del sujeto, (17b) se podría parafrasear como 'Puedo contar con mi hija (en caso de necesidad, etc.)'. Esta segunda construcción rige, aparentemente, una cláusula subordinada elidida: Tengo a una hija (para ayudarme / esperando, etc.), de la que una hija actuaría como sujeto. Es obvio que en este caso el referente no se ve como mera posesión, sino que se le supone cierto potencial agentivo, además de capacidad de interacción con el sujeto, al actuar él mismo como sujeto en una cláusula de nivel inferior. Cabe interpretar de igual manera el ejemplo (18), en que se pregunta a una dirigente regional por qué no tiene $a$ más mujeres actuando como diputadas en su administración; se ha optado por marcar el objeto, aunque la elisión también sería posible:

(18) - ¿Por qué usted no tiene $a$ más diputadas?

-Todo eso va despacio. Ahora son diputadas nuevas, pero tampoco me quedo contenta con lo que hay. $<$ Ent-Ad-070404-9>

Obsérvese ahora este otro par con el verbo llevar, en que se proponen dos referentes que a priori solo se diferencian por su edad (y el tipo de relación familiar que tienen con el sujeto):

(19) a. Juan llevó ( $a l /$ el) niño al médico

b. Juan llevó (al / ??el) padre al médico

Aunque para muchos hablantes pueda ser más natural al en ambos casos, no cabe duda de que la ausencia de marca resulta más tolerable en el primero. En el contexto sugerido se atribuye al niño cierto carácter objetual, desprovisto de autonomía, que parecería atípico en el caso del padre. Puede influir, asimismo, el que llevar el niño (al médico, al colegio) se entienda como una acción más habitual o consabida, con cierta tendencia a la lexicalización (como ya se observó anteriormente en el ejemplo Ana espera Ø un niño). El objeto $\sin a$ se percibe más integrado en la acción, como sugiere su propia adyacencia al verbo, sin la distancia que icónicamente marca la partícula. Por otro lado, con un determinante posesivo, que aumentaría la individuación del objeto, resultaría más esperable la a: Juan llevó a (su padre / su niño) al médico.

El análisis sugiere, pues, que para la elección es muy relevante el contraste de prominencia entre los dos participantes principales del evento. A mayor prominencia del objeto 
en relación con el sujeto, mayor probabilidad de que se formule $a$. El caso más evidente es el de los verbos que indican procesos psicológicos generados por un sujeto inanimado y experimentados por un objeto humano: aburrir, asustar, emocionar, interesar, etc., normalmente exigen la marcación: Esas películas asustan * (a) muchos espectadores (NGRAE, 2009: §34.10c). De hecho, el objeto de estos verbos se halla bastante alejado del prototipo de objeto directo o, en nuestros términos, no marcado; entre otros aspectos, se observa una fuerte tendencia a su cliticización con le y les (véase la sección 4), además de a colocarlos en posición preverbal.

Asimismo, cuando la prominencia de un objeto inanimado es equivalente o superior a la del propio sujeto (por ser este también inanimado, o debido a las características particulares del evento verbal), no es infrecuente la marcación. Así se comprueba en los siguientes ejemplos:

(20) El buen tiempo quiso acompañar a estos caminantes durante el recorrido, eclipsando $a$ la niebla y el frío que han reinado en la capital durante las últimas jornadas. $<$ RepAd-131204-10>

(21) Ayer los termómetros del observatorio de Matacán registraron una temperatura mínima de 2'8 grados bajo cero a las 04:15 de la madrugada, cifra que supone un descenso de dos décimas respecto al domingo y que convierte al día de ayer en el más frío de los últimos ocho meses y de la presente estación de otoño. $<$ Not-Ga-171104-19>

En (20), el propio verbo eclipsar sugiere una competición entre fuerzas análogas. El sujeto el buen tiempo apenas supera en prominencia a la niebla y el frío, según los criterios propuestos en $\$ 2.4$ (solo en cierta agentividad metafórica y el hecho de ocupar la posición preverbal), lo que hace natural el uso de $a$ en el objeto. Por otro lado, en (21) el sujeto la cifra constituye una mera circunstancia que convierte al día referido en el más frío; no se interpreta convertir en su sentido de acción transformadora, ni al objeto como paciente. Además, se trata de un contexto de causatividad en que dicho objeto puede interpretarse a su vez como sujeto de una cláusula inferior: 'Hace que el día de ayer sea el más frío'.

Este uso de convertir figura entre otros verbos de sentido estativo que expresan una relación espacial o temporal entre dos entes: preceder, seguir, caracterizar, sustituir o reemplazar, y que a menudo se han señalado como de marcación obligatoria (cfr. Torrego, 1999: 1788). Hay que notar que se trata de verbos que casi siempre ponen en relación un sujeto y un objeto con el mismo grado de prominencia inherente (una persona sustituye $a$ otra, un día sigue $a$ otro...), o en los que el sujeto es incluso menos prominente, al ser un mero rasgo del objeto (la bondad caracteriza $a$ una persona). Ello apoya la hipótesis de que la marcación se ve potenciada siempre que la prominencia del objeto es similar o incluso superior a la del sujeto, en parte por la tendencia a evitar la ambigüedad en la asignación de papeles semánticos. Contextos estativos como los aludidos son un claro contraargumento a la hipótesis de que $a$ se relaciona con la mayor transitividad del evento o con su telicidad aspectual (Fábregas, 2013: 67-68). Lo que en realidad indica la partícula es una mayor posibilidad del objeto de competir cognitivamente con el sujeto, e incluso de superarlo ${ }^{12}$.

12 Por todo ello, parece necesario matizar apreciaciones como las de Torrego (1999: 1785), para quien es la agentividad del sujeto el factor que determina la aparición de $a$, lo que a su juicio hace agramatical Esta montaña 
A pesar de todo, en contextos de este tipo puede darse también la omisión de la marca, si para el hablante resultan más relevantes los rasgos inherentes del referente que su contraste con los del sujeto. En (22) encontramos ausencia de marcación con sustituir, la cual resultaría mucho más atípica con objeto humano.

(22) [...] otros pueblos de la zona cuya comunicación con la autovía se ve dificultada por la inexistencia de carreteras decentes que sustituyan $\varnothing$ los actuales caminos de cabras. $<$ Car$\operatorname{Tr}-041104-8 \mathrm{~b}>$

Del mismo modo, se observa variación con otros verbos como beneficiar y perjudicar, que típicamente se construyen con $a$; estos dos ejemplos muestran soluciones diferentes con respecto al segundo de ellos:

(23) La delegada provincial de la organización sindical, María García, critica el proceso de transferencias de competencias que se llevó a cabo en 2002 y que perjudicó especialmente al capítulo económico $<$ Not-Tr-060804-9>

(24) Yo siempre he pensado que al conseller Rovira lo harían cambiar de actitud los propios catalanes en cuanto su tono insultante para el resto de España perjudicara $\varnothing$ sus bolsillos. $<$ Car-Ga-201204-8>

Otros ejemplos pueden resultar más sutiles, y su interpretación tiene que ver con el lexema verbal particular y las características del evento que designa; aun así, se detectan los mismos factores subyacentes. En (25), a pesar de contar con un sujeto humano y activado en el contexto, frente a un objeto inanimado y abstracto, aparece $a$ por la asociación típica de temer a objetos animados, así como por el hecho de que se describa un proceso psicológico en el que el sujeto se interpreta como experimentante y no como agente, mientras que al objeto sí se le atribuye cierta agentividad (la construcción no es nocionalmente muy diferente de No le da miedo la rapidez..., en que esta sería ya sujeto).

(25) Asegura que no teme $a$ la rapidez con la que se ha desarrollado su trayectoria $<$ NotAd-031204-72>

El verbo consentir en el sentido de 'malcriar' se acompaña de un objeto animado (un niño o una mascota, por lo general). Es obvio, por ello, el valor metafórico de (26), en que la partícula parece necesaria para la propia comprensión del evento (Han consentido Ø la memoria se interpretaría, en todo caso, en otro sentido).

(26) Las agendas electrónicas, los cuadernos de notas o los móviles de última generación, con múltiples funciones de cálculo o almacenamiento, han consentido $a$ la memoria, hasta el punto de creer que es innecesaria o no es fiable. $<$ Rep-Ad-070404-17>

escondió a muchos prisioneros. La oración nos resulta totalmente aceptable y, si bien es cierto que parece atribuir agentividad o volición a la montaña, ello no tiene que ver tanto con la partícula en sí (cuya función es subrayar la relativa prominencia del objeto humano frente a un sujeto inanimado) como con el propio lexema verbal y el aspecto perfectivo (compárese con Esta montaña esconde Ø muchos secretos). 
Por lo tanto, hay una gran cantidad de casos en que la obligatoriedad de la partícula o la preferencia por ella no parece independiente de la tendencia del verbo (derivada, claro está, de su propio significado) a construirse con objetos humanos o animados, lo que a su vez atañe al contraste de prominencia entre el sujeto y el objeto. Esto no se limita a los citados verbos de afección psíquica; lo mismo ocurre con otros muchos como acusar, agredir, encarcelar, insultar, invitar, perdonar, saludar, etc. (cfr. Fernández Ramírez, 1986[1951]: $\S 23)$. A la inversa, ya hemos observado que en ocasiones parece posible la ausencia de marcación con verbos que normalmente llevan objeto inanimado y que se aplican metafóricamente a humanos, como en el ejemplo de leer (nota 6), pero también con el propio tener (ejemplo 17), dependiendo de cómo se interprete su naturaleza eventiva.

Otros lexemas verbales tienden a exigir la marcación por la propia peculiaridad de su estructura argumental y requerirían un estudio más particularizado, pero en ellos la elección sintáctica puede explicarse desde el mismo punto de vista. Un caso claro es el de llamar, tanto en su construcción de un objeto (en la que este es necesariamente animado: Llamé al niño; Llamé al perro) como en la de doble acusativo: ¿Cómo llamas?(a) esta construcción? (Fábregas, 2013: 15). La estructura argumental en este segundo caso es confusa; los dos objetos podrían caracterizarse, en términos funcionales tradicionales, como directo y predicativo (27a), o bien como indirecto y directo (27b), lo que se observa en las respectivas conmutaciones.

(27) a. Llaman a María genio $\sim$ La llaman así

b. Llaman a María genio $\sim$ Le (¿La?) llaman genio $\sim$ Se lo llaman

No obstante, la propia elección de los clíticos resulta bastante fluctuante, lo que incide en la dificultad (y la escasa utilidad) de diferenciar el objeto directo del indirecto en contextos de variabilidad gramatical, como si se tratara de nociones discretas (véase también la sección 4). El uso categórico de $a$ se debe, casi con seguridad, a la necesidad de diferenciar formalmente los dos objetos de la cláusula, resaltando la mayor prominencia del que recibe la marca. Por otro lado, no parece que las construcciones (27a) y (27b) sean intercambiables: la segunda es habitual cuando llamar posee el sentido de 'motejar' o 'tildar de', pero resulta rara con el valor propiamente denominativo del verbo, que claramente optaría por (27a): Llamaron al niño David > ??Se lo llamaron. Muestran similares fluctuaciones otros verbos al construirse con un complemento predicativo, como hacer, dejar o volver, así como hacer y dejar en su uso causativo, los verbos de percepción como ver u oír en construcción de acusativo e infinitivo, etc. (cfr. Mendikoetxea, 1999: 1692-1693; Enghels, 2013).

También con ayudar, señalado a menudo por ser regente de dativo en latín y haber experimentado posteriormente una transición hacia el acusativo, el uso de $a$ es prácticamente categórico, incluso con referentes inanimados ( ${ }^{*}$ Las políticas actuales no ayudan $\varnothing$ el desarrollo) y en que es frecuente el uso de clíticos de dativo, con vacilación incluso en hablantes que por lo general se ajustan al sistema casual (A María la / le ayudé con los deberes). La NGRAE (2009: $\$ 34.10 b)$ y Pineda (2013: 70ss) sugieren que forma parte de un grupo de verbos que se asimilan a construcciones más o menos sinónimas de verbo y objeto directo, en las que la entidad beneficiaria se codificará necesariamente como objeto marcado: ayudar a alguien dar ayuda a alguien; acusar a alguien hacer una acusación a alguien, etc. Esto hace que, cuando solo hay un objeto, este tienda a asimilarse también a esos rasgos. Lo mismo podría decirse de educar, enseñar, etc. 
Es especialmente destacable que la mayor parte de los lexemas verbales citados sean causativos que incorporan en su estructura un predicativo o una cláusula subordinada, que a menudo no se formula, y de los cuales el objeto marcado actuaría como sujeto o regente; recuérdese también (17b): Tengo a una hija (para ayudarme / esperándome / enferma, etc.), así como otros contextos ya señalados. Nuestro enfoque permite explicar la preferencia por la marcación debido a que se trata de contextos en que se altera la prominencia asociada a los objetos prototípicos. El hecho de que un mismo referente actúe simultáneamente como objeto de la cláusula principal y como sujeto de una cláusula reducida hace que se distancie de la objetualidad más propia de los objetos sin marca. En el caso de los verbos de percepción visual y auditiva, Enghels (2013: 50-52) observa que el grado de agentividad o dinamicidad que se atribuye a los referentes en la cláusula subordinada se relaciona directamente con su tendencia a marcarse con $a$ en la principal; así, obtiene ejemplos como Ver llegar al coche de Clara (más dinámico) frente a Ve constituirse en Santander Ø una empresa productora.

Podemos concluir que todos los lexemas verbales revisados contemplan en su estructura argumental un objeto que, si bien podría caracterizarse como directo, dista mucho de poseer los rasgos prototípicos asociados a esta función, sobre todo por no existir otro objeto con el que pueda establecer un contraste claro de prominencia, así como por el hecho de que, en los contextos de causatividad, se interpreten a su vez como sujetos de una cláusula subordinada. La naturaleza sintáctica y cognitiva de estos objetos solo puede contemplarse adecuadamente desde una óptica de variabilidad en la que la elección formal irá aparejada al tipo de significados que se potencien en el contexto. Cuanto mayor sea la preferencia de un verbo por el uso de la partícula, más cerca se hallará su estructura eventiva de los rasgos funcionales y semánticos asociados a las de los verbos que (casi) necesariamente rigen un objeto marcado.

En todos los casos parece posible recurrir a la prominencia del objeto y a su contraste con el sujeto, en el marco del evento descrito por la cláusula, para explicar la elección concreta. Aunque en ocasiones se haya señalado que la marcación se relaciona con una mayor transitividad de dicho evento (y, en consecuencia, con una mayor afectación del objeto), hemos observado que abundan los ejemplos de transitividad muy baja que, sin embargo, optan por la formulación de $a$. Ello nos hace pensar que, en realidad, esta variante tiene más que ver con la propia prominencia del objeto, en contraste con la del sujeto; cuanto más prominente y autónomo se perciba aquel, más frecuente resultará su marcación.

\subsection{Cláusulas de dos objetos concordables}

Es necesario atender también a los contextos de tres participantes que se codifican como funciones concordables (esto es, sujeto y objetos directo e indirecto). Por lo general, en estos casos el contraste de prominencia entre los elementos es mucho más claro, y cada uno de ellos se ajusta a un prototipo de función, lo que hace muy infrecuente la marcación del que asume la de objeto directo ${ }^{13}$. La escasez de contextos de dos objetos marcados con $a$ se debe, con toda probabilidad, a las dificultades que ocasiona esta situación para

13 "La selección del objeto indirecto implica en la inmensa mayoría de los casos que el predicado selecciona ya un objeto directo [...]. En otras palabras, el objeto indirecto prototípico presupone la presencia de otro objeto y entra preferentemente en una estructura trivalente" (Roegiest, 2005: 176). 
el procesamiento de la cláusula, en particular si los caracteres semántico-referenciales de ambos son similares y si cualquiera de las interpretaciones posibles parece válida:

(28) Entregaron al mafioso al policía

(29) Le presenté $a$ Pedro $a$ Juan

(30) Recomendaron $a$ la directora $a$ Maite

Es evidente la ambigüedad que se plantea acerca del papel desempeñado por cada referente en estos eventos. La necesidad de establecer diferencias de prominencia entre los objetos explica que en algunos casos sea posible (con muchas restricciones) suprimir la marca del directo, para facilitar el procesamiento de la cláusula, como en el conocido ejemplo de Bello (1847: §900): Presentaron Ø la cautiva Zenobia al vencedor, lo que no obstante resultaría difícil si el objeto consistiera únicamente en el nombre propio. Si además el indirecto establece concordancia verbal por medio de un clítico, la marcación del otro objeto puede resultar incluso desfavorecida, ya que se añadiría la ambigüedad sobre cuál es el objeto correferente de dicho clítico: Le enviaron (?a) todos los heridos a la doctora (Ormazabal y Romero, 2013: 224, para quienes la marcación es agramatical en este contexto).

No obstante, en muchos casos, debido a los propios rasgos de los referentes, ni siquiera es tolerable esa supresión de la marca: *Presentaron $\varnothing$ Pedro a Juan. Cabe sospechar que, a menudo, la solución es evitar directamente las construcciones de dos objetos con referente humano. Hay que tener en cuenta que la gran mayoría de las cláusulas con objeto humano, como las revisadas en el subapartado anterior, no poseen un segundo objeto concordable, lo que hace que aquel tienda a asimilarse formal y semánticamente al indirecto ${ }^{14}$. Frente a los rasgos prototípicos del acusativo, los referentes de los objetos con $a$ son normalmente animados, se hallan altamente individualizados (así ocurre, por ejemplo, cuando se codifican como pronombres personales) o, en todo caso, poseen cierto grado de prominencia en el contexto.

Ormazabal y Romero (2013: 222) proponen una teoría formal de la marcación de objeto, basada en la asignación de caso y la concordancia. Ello les permite observar la relevancia de los contextos ditransitivos aludidos en este subapartado, en los que se produce una competición entre dos argumentos verbales. La supuesta distinción entre dativos y acusativos en español sería, en realidad, una distinción entre elementos que han entrado en relación de concordancia con el verbo y otros que no. No obstante, al no existir en su trabajo una interpretación semántico-cognitiva de dicha competición entre referentes, se pierde la posibilidad de alcanzar una explicación general y no sujeta a juicios de gramaticalidad. Así, no nos queda claro que, como afirman los autores (ibid., 224), sea incompatible la cliticización

14 A pesar de todo, sí se encuentran casos de dos objetos humanos con $a$ y en los que no queda clara la asignación de funciones: "Cristiano Ronaldo presenta $a$ su hijo $a$ Messi durante la gala del Balón de Oro" (Informativos Telecinco, www.telecinco.es, 13/1/2015). El enunciado, similar a nuestro ejemplo (29), es ciertamente ambiguo, si bien, dadas las propias características del evento y la baja distinguibilidad en cuanto a la afectación sufrida por los participantes, no se trata de una ambigüedad que afecte grandemente a su comprensión; para el hablante no ha sido necesario sugerir distinciones de estatus sintáctico y semántico-cognitivo. Aun así, rasgos como el distinto control que se supone al sujeto sobre cada uno de estos referentes hacen que quizá resulte más fácil la interpretación de su hijo como objeto menos autónomo que Messi. Más problemática resultaría la situación en un tipo de evento en que no fuera posible entender reciprocidad entre los objetos humanos (así, con entregar o recomendar); no hemos encontrado ejemplos en el corpus manejado ni en fuentes secundarias. 
del objeto indirecto con la marcación del directo: ?Le presentaron a Pedro a Juan, o en el ejemplo ya aludido Le enviaron (?a) todos los heridos a la doctora. Se trata de construcciones atípicas de por sí, por la ya comentada dificultad de procesar adecuadamente los eventos descritos, pero no es seguro que la presencia del clítico impida necesariamente ese procesamiento. Como se anotaba en la sección 1, los enfoques basados en la categoricidad difícilmente pueden resolver los hechos de variabilidad gramatical. Por ello, en la sección siguiente, como último paso de la discusión, se reformularán como variables las propias nociones de objeto directo e indirecto (o de acusativo y dativo) manejadas habitualmente.

\section{La marcación del objeto en el continuum del régimen verbal}

En esta sección se pretende situar la marcación del objeto en una visión más amplia del régimen verbal y las funciones sintácticas como dimensiones inherentemente variables. La formulación de $a$ pertenece a una serie de manifestaciones formales que revelan la interacción entre la morfosintaxis, el discurso y la cognición.

En primer lugar, $a$ es una de las partículas más frecuentes y semánticamente difuminadas en español. Si en contextos de función no concordable aún es posible percibir el valor espacial o direccional de su étimo latino $\mathrm{AD}$ (Se sentó a la sombra; Lo enviaron a un lugar desconocido), en otros se ha gramaticalizado como marca morfológica de objeto. Su uso como marca de caso junto a los pronombres personales se observa regularmente desde los primeros textos castellanos (Lapesa, 1964: 80; Pensado, 1995: 19-20). En una oración como Juan besó a su madre, se identifica el objeto sintáctico y paciente semántico a partir del orden no marcado SVO de la cláusula declarativa transitiva, pero también, y especialmente, debido a la presencia de $a$, que funciona como un marcador de función no-sujeto que impide la coindización del SN María con la desinencia verbal -ó. Gimeno Menéndez (1995: 146) sugiere que "la marcación del objeto seleccionaría primariamente aquel nombre que desempeña en la oración la función inherente de objeto frente a un nombre no marcado con la función de sujeto". Lo interesante es que, como ya hemos apuntado, el valor de la marca puede contemplarse desde la perspectiva inversa: no sirve solo para distinguir el objeto del sujeto, sino para destacarlo sobre otros objetos de menor prominencia cognitiva. Y así lo sugieren los casos en que el uso de $a$ parece indicar afectividad o estrategias de dignificación del referente, a los que se aludió en $\$ 2.3$.

Por otro lado, la caracterización del objeto marcado como no-sujeto es importante porque no existe una distinción neta entre los tipos de objetos concordables que pueden recibir $a$ (los denominados tradicionalmente directo e indirecto); la marcación variable solo es uno de los índices que ayudan a situar un objeto en un punto del continuum formal y semántico. Moure (1995: 294) sugiere la existencia de "una metacategoría objeto que recubre un solo modelo constructivo". El uso de $a$ es una elección formal que contribuye a desplazar un objeto hacia los rasgos perceptivos asociados al indirecto, aumentando su prominencia y autonomía con respecto al sujeto oracional y reforzando, con ello, su contraste con este último. Es decir, la marca del objeto tiene la doble función de resaltar su prominencia frente a objetos directos más prototípicos y de distinguirlo del sujeto (cfr. también Malchukov, 2008: 208ss). Las funciones sintácticas son, en realidad, conjuntos ideales de rasgos a los que los elementos de las cláusulas reales se acercan en diversos grados, dependiendo de su estatus discursivocognitivo. Entre tales rasgos figuran otros que se revisarán brevemente a continuación. 
Se ha señalado, al menos desde Lapesa (1964), la relación que existe entre el uso de $a$ y el de los clíticos le y les. Todos ellos son formas asociadas prototípicamente al caso dativo, y que se han interpretado como indicios de la extensión diacrónica de este caso hacia el terreno ocupado originalmente por el acusativo (Company, 2001: 36). Por lo mismo, desde nuestro enfoque suponen índices de prominencia frente a los objetos que no llevan marca funcional y que, generalmente, utilizan los clíticos de acusativo para establecer concordancia con el núcleo verbal. El ejemplo más claro son los ya citados verbos de afección psíquica, que codifican al experimentante humano como objeto. Junto a los que rigen un objeto que en la mayoría de las variedades requiere claramente le $(s)$ (así, gustar o encantar), hay otros muchos que vacilan en su régimen, aunque presentan mayor preferencia por las formas de dativo cuanto mayor es la prominencia del objeto en relación con la del sujeto:

(31) a. A María la asustó Carlos al acercarse por detrás

b. A María le asusta pensar en el futuro

En este par, la distinta prominencia del referente María, paralela a un distinto grado de afectación, se deriva del papel semántico desempeñado por el sujeto y de la diferencia aspectual entre asustó y asusta, así como del propio clítico elegido en cada caso. En el primero, María se interpreta como paciente, papel asociado prototípicamente a la función de objeto; en el segundo actúa como experimentante, en un esquema habitual en la sintaxis del español según el cual se adjudica este rol a un objeto con $a$ que, no obstante, se interpreta como sujeto lógico (cfr. Vázquez Rozas, 2006). De ahí la mayor naturalidad en (31b) de le, clítico de dativo y que atribuye mayor prominencia a su referente. Se trata, no obstante, de una cuestión gradual, y en ambos casos serían posibles las soluciones opuestas, las cuales matizarían la manera en que se percibe el evento (así, A María la asusta pensar en el futuro sugeriría que María se ve más afectada por ese pensamiento, es en cierto modo paciente de él; cfr. Aijón Oliva, 2006a: 369) ${ }^{15}$.

De nuevo, no solo en los verbos de afección psíquica se observa la preferencia por le o les cuando el objeto resulta más prominente que el sujeto de la cláusula. En el siguiente ejemplo, un referente humano y femenino (una deportista) se indexa dos veces con el clítico le, en retrasar e imposibilitar. Ello es indicio de su mayor prominencia frente al sujeto inanimado (la lesión).

(32) [Beatriz] Se considera un poquito impaciente pero sabe que poco a poco saldrá de esta lesión que le ha retrasado pero no le imposibilita. <Not-Tr-041104-58>

Es aún más significativo que en diversos contextos se utilicen las formas de dativo con supuestos objetos directos de referente inanimado, lo que teóricamente no podría ocurrir en variedades no leístas. Obsérvese, en (33), cómo el referente Madrid se recupera con el

15 Resulta llamativo encontrar en Twitter la cita "Dijo que la estresaba estar atada" bajo el epígrafe Cincuenta laismos de Grey (@JotDownSpain,www.twitter.com, 14-2-2015). Si bien es cierto que los informantes a los que hemos consultado sobre este ejemplo consideran algo más natural le estresaba, no parece que la alternativa pueda censurarse como laísmo propiamente dicho, ya que se trata de un verbo con régimen de por sí variable, como la mayoría de los de afección psíquica. 
clítico le en le sigue, lo que sin duda no es independiente de la fuerte tendencia del verbo seguir a marcar su objeto con $a(\S 3.1)$. El segundo caso, con convertir, puede recibir una explicación análoga a la de ejemplos ya revisados; de nuevo el referente del clítico (la biomasa) resulta más prominente que el del sujeto, el cual constituye de hecho una mera característica de aquel (su limpieza). En ambos casos parece claro que el objeto tónico correspondiente, de formularse, llevaría la marca (*Barcelona sigue Ø Madrid; ??Su limpieza convierte Ø la biomasa en el principal combustible de futuro).

(33) Madrid se lleva la palma, hasta en 69 ocasiones ha recaído el primer premio de la Lotería de Navidad en la capital del país. Le sigue Barcelona, afortunada en 37 años $<$ RepGa-221203-10>

(34) A Salamanca va a llegar [la biomasa] en sustitución de un producto cada vez menos utilizado, como es el carbón, ya que su limpieza unida a su función ecológica le convierte en el principal combustible de futuro para la ciudad $<$ Not-Ga-201204-15>

Por último, en (35) aparece le acompañe en un contexto en que tanto el sujeto como el objeto son inanimados (este último, además, de género gramatical neutro, lo que en la mayoría de los contextos haría imposible el uso de le). No obstante, el carácter temático del referente esto, colocado en la posición preverbal, contribuye a la aceptabilidad del clítico de dativo.

(35) Miñambres espera que el equipo no frene la mejoría de juego de los últimos choques y que a esto le acompañe una victoria. $<$ Not-Ga-230804-43>

La tendencia a marcar un objeto con $a$ y a cliticizarlo con le son las manifestaciones formales más claras de la prominencia que puede alcanzar un referente codificado como objeto. Estos rasgos permiten analizar la variabilidad en el continuum de las funciones sintácticas como manifestación de factores discursivo-cognitivos.

Aun así, no queda del todo claro, por ejemplo, por qué en los referentes inanimados no se reproduce la asimetría que se da en los humanos con respecto al uso de le según el género gramatical: en las variedades del castellano central peninsular, los referentes masculinos poseen por lo general mucha mayor facilidad que los femeninos para emplear el clítico de dativo ( $A$ Pedro le vi / A María la vi). Aquí, sin embargo, hemos comprobado que referentes inanimados femeninos como la capital del país y la biomasa, cuando resultan prominentes, pueden recurrir a le. Tampoco se debe perder de vista que los pronombres tónicos de tercera persona, que cuando son objetos se marcan siempre con $a$ y que designan generalmente referentes humanos, se duplican en muchos casos con clíticos de acusativo ( $A$ él lo vi / A ellas las vi). Es decir, la relación entre la marcación del objeto y el uso de le / les debe verse como una tendencia y no como una regla categórica; sus efectos resultan especialmente patentes en los contextos de variabilidad.

Otro fenómeno que se ha puesto en relación con la marcación variable del objeto es la construcción pasiva refleja con se. Se ha afirmado habitualmente que esta solo puede tener como sujeto a un referente inanimado (36a) o, con restricciones, animal (36b); si el referente es humano, los hablantes optarán generalmente por una interpretación reflexiva o recíproca del evento, no por la pasiva (36c). 
(36) a. Se ocultaron las joyas en un lugar seguro

b. (\#)Se ocultaron las vacas en un lugar seguro

c. \#Se ocultaron los niños en un lugar seguro ${ }^{16}$

No obstante, el factor que desfavorece dicha interpretación pasiva no parece ser la animacidad por sí misma, sino, precisamente, el que el referente tienda a marcarse con $a$ cuando desempeña la función de objeto (Mendikoetxea, 1999: 1688; Fábregas, 2013: 42-43), si bien, obviamente, ambos aspectos guardan relación entre sí. Los referentes que requieren $a$ en la cláusula activa solo pueden interpretarse como pacientes en una construcción con se si esta se vuelve impersonal y el referente se degrada a la función de objeto (37). Por el contrario, el papel de sujeto paciente sí puede ser desempeñado por objetos humanos inespecíficos (38) e incluso determinados, si se entienden como clases y el contexto no favorece una interpretación reflexiva (39).

(37) Se ocultó a los niños en un lugar seguro

(38) En esa guerra incluso se mataron niños

(39) Ya se han elegido los delegados de curso

Asimismo, se ha observado que es posible la ascensión del objeto humano sin marca a sujeto pasivo cuando en la cláusula figura otro objeto concordado con le: Se le llevaron los enfermos a la doctora (Ormazabal y Romero, 2013: 225-226), entendiendo a la doctora como destinatario del traslado. De nuevo, ello se explica por el contraste de prominencia establecido: se tiende a interpretar a los enfermos como mero objeto transportado hacia la doctora, la cual resulta notoriamente más prominente.

En resumen, todos aquellos referentes con prominencia suficiente para ser marcados con $a$ tienden a rechazar la posibilidad de ser interpretados como sujeto paciente en una construcción con se: los hablantes preferirán la interpretación agentiva, ya sea reflexiva o recíproca. Por el contrario, la pasiva refleja es una estructura que permite aumentar la prominencia de aquello que no la posee de modo inherente, al convertirlo en sujeto de la cláusula.

De todo lo anterior se concluye que, en efecto, en el uso real existe un continuum de posibilidades entre los prototipos de objeto no marcado (el denominado tradicionalmente directo) y marcado (indirecto), el cual se manifiesta en aspectos de todos los planos de análisis lingüístico, y puede interpretarse cognitivamente con arreglo a la prominencia de los referentes ${ }^{17}$. La marcación variable con $a$ resulta ser un rasgo formal que actúa en paralelo a otros muchos aspectos formales y semánticos, como intenta ilustrar la figura 1. Ninguno de los rasgos aquí citados es condición necesaria ni suficiente para asimilar un objeto a uno de los prototipos; es la interacción entre ellos lo que propicia una determinada interpretación sintáctico-cognitiva del referente y del evento en el que participa.

16 El cruce de estructuras análogas puede llevar a soluciones llamativas: "no nos gusta que se detenga $\varnothing$ alcaldes o cargos políticos en ningún país ni en ningún lugar del mundo" (Europa Press, www.europapress.es, 232-2015). A pesar de la ausencia de la marca de objeto (debida a la inespecificidad e indeterminación de este), se ha optado por la construcción con verbo impersonal, en lugar de por la pasiva refleja con concordancia.

17 Por su parte, Company (2001) sugiere una distinción entre objeto primario y secundario, análoga a la que existe en otras lenguas: resultaría gramaticalmente más relevante la interacción entre dos participantes autónomos (el sujeto y el objeto marcado) que la manipulación de un paciente (el objeto no marcado). 


\begin{tabular}{|c|c|c|}
\hline \multirow{4}{*}{$\begin{array}{c}\text { Rasgos formales } \\
\text { Prototipo de } \\
\text { objeto no marcado }\end{array}$} & \multicolumn{1}{|c|}{ Prominencia } \\
\cline { 2 - 2 } & $\begin{array}{c}\text { Marcación con } a \\
\text { Concordancia clítica de dativo } \\
\text { Colocación preverbal } \\
\text { Dificultad de pasiva refleja }\end{array}$ & $\begin{array}{c}\text { Prototipo de } \\
\text { objeto marcado }\end{array}$ \\
\cline { 2 - 3 } & $\begin{array}{r}\text { Rasgos semántico-discursivos } \\
\text { Animacidad } \\
\text { Especificidad-individuación } \\
\text { Tematicidad }\end{array}$ & \\
& Autonomía con respecto al sujeto & \\
\hline
\end{tabular}

Figura 1. El continuum formal y semántico-discursivo entre los prototipos de objetos concordables

Dicho continuum es parte, a su vez, de otro más general que incluye a todas las funciones sintácticas, desde la que a priori posee mayor prominencia (el sujeto) hasta las que resultan más periféricas gramatical y cognitivamente. Si bien no es posible profundizar en ello dentro de los límites del presente trabajo, sin duda se trata de una cuestión de gran relevancia para el desarrollo de un modelo teórico de la variabilidad morfosintáctica.

\section{Conclusiones}

La marcación variable de los objetos con $a$ es un fenómeno que muestra cómo en la elección morfosintáctica confluyen diversos factores formales, semánticos y discursivos, siendo todos ellos manifestaciones particulares de la prominencia cognitiva de los referentes. Resultan relevantes tanto los aspectos sintagmáticos y semántico-referenciales inherentes, señalados desde hace mucho en la descripción gramatical (determinación, animacidad, especificidad-individuación), como otros derivados de la cláusula y el contexto (papel semántico, relación con el sujeto, posición preverbal o posverbal).

En los contextos de mayor variabilidad, es necesario atender a las características del evento verbal y a las relaciones que se establecen entre los participantes de este. Si bien otras aproximaciones funcionales y cognitivistas han relacionado la formulación de $a$ con la mayor transitividad del evento, abundan los contextos favorecedores de la marcación en los que dicha transitividad resulta muy escasa; así, en los usos estativos de verbos como preceder, seguir o caracterizar. Por el contrario, la prominencia atribuida al objeto en contraste con la del sujeto, así como con la de otro objeto concordable en los casos en que este aparece, permite dar cuenta mucho más satisfactoriamente de la amplia gama de contextos de marcación o de ausencia de ella. Explica la aparente categoricidad de $a$ con los pronombres personales y con los referentes determinados, animados y específicos, pero también su formulación con otros que no reúnen todas o algunas de esas características, cuando se dan las condiciones contextuales adecuadas para ello. El hecho de que un objeto no desempeñe el rol de paciente, sino el de experimentante, o el que aparezca antepuesto al verbo, 
son factores asociados a la marcación; lo mismo ocurre cuando el sujeto no posee carácter agentivo, cuando es inanimado, etc. Es decir, las probabilidades de marcación parecen aumentar en todos aquellos contextos que por algún motivo se alejan de la cláusula transitiva prototípica. Se ha observado también la recurrencia de esta elección cuando el objeto va acompañado de un predicativo o de una cláusula subordinada, expresa o no: el hecho de actuar como regente de un elemento inferior es otro rasgo contextual que aleja a un referente de los rasgos prototípicamente asociados a los objetos sintácticos y aumenta su prominencia.

Del análisis se concluye que la partícula $a$ es un índice de función no-sujeto especialmente apto para referentes que poseen cierta prominencia y tienden, por ello, a competir cognitivamente con el sujeto de la cláusula. Al mismo tiempo, lleva aparejada la sugerencia de que el objeto en cuestión no es asimilable a los rasgos sintáctico-semánticos asociados al prototipo de objeto directo o no marcado (inanimado, escasamente autónomo, tendente a la posición posverbal, etc.). Si los objetos más cercanos a dicho prototipo no se marcan es, sobre todo, porque no entran en un conflicto cognitivo con el sujeto; se entienden como supeditados a la influencia de este, y a veces como integrados en el propio evento verbal, más que como participantes autónomos. Por su parte, el referente marcado con $a$ se aproxima a un prototipo sintáctico-semántico especial, situado entre el sujeto y el objeto no marcado en la escala de prominencia, y que hemos denominado objeto marcado.

Hay que subrayar un aspecto importante, y es que la marca del objeto es en sí misma un rasgo formal asociado a su prominencia cognitiva, que actúa en conjunción con otros muchos rasgos, y no un mero efecto de estos últimos, como generalmente se ha dado por supuesto. Los enfoques formalistas llevan casi inevitablemente a inferir relaciones de causaefecto: la partícula aparece porque el objeto es animado, específico, etc. Por el contrario, una visión de las formas y construcciones lingüísticas como portadoras de significado intrínseco permite contemplar el uso de $a$ como una elección creativa, que refuerza contextualmente la prominencia del referente al que se adjunta, lo que explica que pueda aparecer junto a referentes que la harían poco esperable si solo tenemos en cuenta sus rasgos inherentes. A la inversa, su ausencia en otros casos favorecerá una interpretación del referente como menos individualizado y autónomo. Así pues, tanto los contextos de solución (semi)categórica como aquellos que admiten variabilidad interactúan con los mismos factores formales, semánticos y discursivos, lo que constituye un hecho relevante con vistas al desarrollo de una teoría explicativa de la elección gramatical y de su potencial significativo.

\section{Referencias bibliográficas}

Aijón Oliva, M. A. (2006a): Variación morfosintáctica e interacción social: análisis del paradigma de los clíticos verbales españoles en los medios de comunicación. Salamanca, Ediciones Universidad de Salamanca.

Aijón Oliva, M. A. (2006b): "La variación morfosintáctica como recurso de cortesía verbal: acerca del paradigma de los clíticos españoles", Lingüística Española Actual, 28, págs. 221-246.

Aijón Oliva, M. A. y M. J. Serrano (2013): Style in syntax: investigating variation in Spanish pronoun subjects. Bern, Peter Lang.

Aissen, J. (2003): “Differential object marking: iconicity vs. economy", Natural Language and Linguistic Theory, 21, págs. 435-483. 
Alarcos Llorach, E. (1994): Gramática de la lengua española. Madrid, Espasa Calpe.

Ariel, M. (1990): Accessing noun-phrase antecedents. London, Routledge.

Ariel, M. (2001): “Accessibility theory: an overview”. En Sanders, T., J. Schilperoord y W. Spooren (eds.): Text representation: linguistic and psycholinguistic aspects. Amsterdam, John Benjamins, págs. 29-87.

Bello, A. (1847): Gramática de la lengua castellana destinada al uso de los americanos. En J. J. Gómez Asencio (ed., 2001): Antiguas gramáticas del castellano. Madrid, Colección Clásicos Tavera [CD-ROM].

Chafe, W. L. (1994): Discourse, conciousness and time. The flow and displacement of experience in speaking and writing. Chicago, University of Chicago Press.

Company Company, C. (2001): "Multiple dative-marking grammaticalization: Spanish as a special kind of primary object language”, Studies in Language, 25, págs. 1-47.

Croft, W. y D. A. Cruse (2004): Cognitive linguistics. Cambridge, Cambridge University Press.

Delbecque, N. (1999): "Two transitive construction frames in Spanish. The prepositional and the non-prepositional accusative". En De Stadler, L. y C. Eyrich (eds.): Issues in cognitive linguistics. Berlin, De Gruyter, págs. 407-424.

Delbecque, N. (2002): “A Construction Grammar approach to transitivity in Spanish". En Davidse, K. y B. Lamiroy (eds.): The nominative and accusative and their counterparts. Amsterdam, John Benjamins, págs. 81-130.

DPD, 2005 = Real Academia Española y Asociación de Academias de la Lengua Española (2005): Diccionario panhispánico de dudas. Madrid, Santillana.

Dumitrescu, D. (1998): “ $A$ personal, duplicación clítica y marcadez: español porteño vs. español madrileño”. En Ward, A. M. (ed.): Actas del XII Congreso de la Asociación Internacional de Hispanistas. Birmingham, The University of Birmingham, págs. 140-152.

Enghels, R. (2013): "Transitivity of Spanish perception verbs: a gradual category", Borealis. An International Journal of Hispanic Linguistics, 2.1, págs. 35-56.

Fábregas, A. (2013): "Differential object marking in Spanish: state of the art", Borealis: An International Journal of Hispanic Linguistics, 2.2, págs. 1-80.

Fernández Ramírez, S. (1986[1951]): Gramática española. Vol. 4: El verbo y la oración. Vol. preparado por I. Bosque. Madrid, Arco Libros.

García, E. C. (1985): “Shifting variation”, Lingua, 67, págs. 189-224.

García, E. C. (2009): The motivated syntax of arbitrary signs: cognitive constraints on Spanish clitic clustering. Amsterdam, John Benjamins.

Gimeno Menéndez, F. (1995): Sociolingüística histórica (siglos X-XII). Madrid, Visor / Universidad de Alicante.

Givón, T. (1983): “Topic continuity in discourse: an introduction”. En Givón, T. (ed.): Topic continuity in discourse. A quantitative cross-language study. Amsterdam, John Benjamins, págs. 5-41.

Givón, T. (2001): Syntax: an introduction. Amsterdam, John Benjamins.

Gundel, J. K. y T. Fretheim (2009): "Information structure”. En Brisard, F., J. O. Östman y J. Verschueren (eds.): Grammar, meaning and pragmatics. Amsterdam, John Benjamins, págs. 149-160.

Keenan, E. L. (1976): “Remarkable subjects in Malagasy”. En Li, C. N. (ed.): Subject and topic. New York, Academic Press, págs. 247-301. 
Laca, B. (1995): "Sobre el uso del acusativo preposicional en español”. En Pensado, C. (ed.), págs. 61-91.

Laca, B. (2006): "El objeto directo. La marcación preposicional". En Company Company, C. (coord.): Sintaxis histórica de la lengua española. Primera parte: la frase verbal. México DF, UNAM / Fondo de Cultura Económica, págs. 423-475.

Lapesa, R. (1964): "Los casos latinos: restos sintácticos y sustitutos en español”, Boletín de la Real Academia Española, 44, págs. 57-106.

Malchukov, A. L. (2008): “Animacy and asymmetries in differential case marking”, Lingua, 118, págs. 203-221.

Mendikoetxea, A. (1999): "Construcciones con se: medias, pasivas e impersonales". En Bosque, I. y V. Demonte (dirs.): Gramática descriptiva de la lengua española. Madrid, Espasa Calpe, vol. 2, págs. 1631-1722.

Montes Giraldo, J. J. (2006): "Sobre el objeto directo preposicional”, Boletín de Filología de la Universidad de Chile, 41, págs. 63-76.

Moure, M. T. (1995): "El estatus vacilante del complemento directo", Anuario de Lingüística Hispánica, 11, págs. 277-307.

NGRAE, 2009 = Real Academia Española y Asociación de Academias de la Lengua (2009): Nueva gramática de la lengua española. Madrid, Espasa Calpe.

Ormazabal, J. y J. Romero (2013): "Differential object marking, case and agreement”, Borealis: An International Journal of Hispanic Linguistics, 2.2, págs. 221-239.

Pensado, C. (1995): "El complemento directo preposicional. Estado de la cuestión y bibliografía comentada”. En Pensado, C. (ed.), págs. 11-59.

Pensado, C. (ed., 1995): El complemento directo preposicional. Madrid, Visor.

Pineda, A. (2013): "Double object constructions and dative / accusative alternations in Spanish and Catalan: a unified account". Borealis: An International Journal of Hispanic Linguistics, 2.1, págs. 57-115.

Roegiest, E. (2005): "Variación pronominal en español: el pronombre dativo entre sintaxis y semántica”. En Knauer, G. y V. Bellosta von Colbe (eds.): Variación sintáctica en español: un reto para las teorías de la sintaxis. Tübingen, Niemeyer, págs. 175-190.

Sanz, B. (2011): "La ausencia de marcación de caso en los objetos directos con referente humano en posición inicial”, Revista Signos, 44, págs. 183-197.

Serrano, M. J. (2013): "De la cognición al texto: el efecto de la prominencia cognitiva y la informatividad discursiva en el estudio de la variación de los sujetos pronominales", Estudios de Lingüística de la Universidad de Alicante, 27, págs. 275-299.

Serrano, M. J. y M. A. Aijón Oliva (2010): "La posición variable del sujeto pronominal en relación con la cortesía interactiva", Pragmalingüística, 18, págs. 170-204.

Silverstein, M. (1976): "Hierarchy of features and ergativity". En Dixon, R. M. W. (ed.): Grammatical categories in Australian languages. Canberra, Australian Institute of Aboriginal Studies, págs. 112-171.

Torrego Salcedo, E. (1999): “El complemento directo preposicional”. En Bosque, I. y V. Demonte (dirs.): Gramática descriptiva de la lengua española. Madrid, Espasa Calpe, vol. 2, págs. 1779-1805.

Vázquez Rozas, V. (2006): “Gustar-type verbs”. En Clements, J. C. y J. Yoon (eds.): Functional approaches to Spanish syntax. Lexical semantics, discourse and transitivity. Basingstoke, Palgrave Macmillan, págs. 80-114. 



\title{
CONSTRUCCIONES PREPOSICIONALES EN ORACIONES ESCINDIDAS: EL VALOR "EXISTENCIAL"
}

\author{
Emilio Cabezas Holgado \\ Universidad Complutense de Madrid
}

Recibido: 07/01/2015

Aceptado: 02/09/2015

\section{Resumen}

Las oraciones escindidas han sido descritas sobre la base de la relación predicativa 'especificativa' en el marco de las oraciones copulativas. Sin embargo, aquellas que se encuentran encabezadas por construcciones preposicionales presentan particularidades que afectan a las propiedades de concordancia, tanto de tiempo como de número, entre el elemento focalizado y la relativa libre, de modo que el valor que debe atribuirse al verbo ser en este tipo de secuencias es propiamente predicativo. Así, podrán distinguirse dos matices semánticos en relación con el sentido "existencial" de ser: el primero concierne a la noción de 'realidad concreta', mientras un segundo equivale a la de 'proceso de efectuación', constituyendo, a partir de este contraste, modos de acción 'atélicos' y 'télicos', respectivamente.

PALABRAS CLAVE: Preposición, predicación, sintaxis, escindida, foco

\begin{abstract}
Cleft Sentences have been described on the basis of the relationship 'predicative especificative' in the framework of the copulative sentences. However, those that are headed by prepositional constructions have characteristics which affect the properties of concordance, both time and number, between the cleaved element and the relative free construction, so that the value that must be attributed to the verb to be in this type of sequences is itself predicative. As well, may be distinguished two semantic nuances in relation to the direction "existential" to be: the first concerns the notion of 'reality', while a second is equivalent to the process of 'performance', forming, from this contrast, modes of action 'atelics' and 'telics', respectively.
\end{abstract}

\section{Introducción}

El estudio de las oraciones escindidas ha tratado de analizar el recurso de la focalización perifrástica como variante de construcciones copulativas con valor atributivo, o bien, de sentido identificativo especificativo ${ }^{1}$. Por lo tanto, ha quedado establecida una estructura

1 Fernández Leborans (2001) trata de distinguir adecuadamente la construcción escindida de la que no lo es, y de comprobar si, efectivamente, como se establece en la bibliografía, la estructura escindida puede inducir dos lecturas: la atributiva y la identificativa especificativa. En Fernández Leborans (1999) se señala que la interpretación atributiva de la oración copulativa con ser, el hablante asigna una propiedad o cualidad al sujeto, o lo adscribe a una clase (Juan es bueno; Mi hermano es biólogo); el orden de constituyentes es neutro, recto (el sujeto -que es la expresión referencial- aparece en posición inicial, y el predicado (el atributo, que es la expresión predicativa, descriptiva y, por tanto, no-referencial) ocupa la posición final. La interpretación identificativa puede ser de dos tipos: "descriptiva” (Juan es \{mi marido / el profesor de esgrima de mi hermano/ el padre de Julia) o "especificativa" ( $\{$ el culpable / el profesor de esgrima de mi hermano / el padre de Julia\} es Juan) 
sintáctica que "separa" un constituyente focal de naturaleza oracional o sintagmática a través de un verbo propiamente copulativo, permitiendo extraer una lectura bien diferenciada de aquella paráfrasis no circunlocutiva de la que deriva². Así:

(1) a. El que ha venido es Juan

b. Juan ha venido

(2) a. Es Juan el que me invitó

b. Juan me invitó

Obsérvese que las secuencias de (b) permiten inferir una relación de predicación canónica basada en: Referencia (Juan) + Descripción (ha venido/me invitó), mientras que sus derivadas (a) presentan una estructura de circunloquio (perifrástica) que conforma, a partir de una organización de la información relevante intencionadamente focalizada, un predicado de identificación especificativa; es decir, permiten que la Descripción (El que ha venido/el que me invitó) que conviene a la Referencia (Juan) restrinja un rasgo relativo al "reconocimiento de una entidad".

Resulta, por lo tanto, lógico que este tipo de oraciones haya recibido el tratamiento gramatical propio de las copulativas convencionales ${ }^{3}$. A saber, las particularidades sintácticas de concordancia flexiva y "armonía" categorial pueden probarse en cualquiera de las paráfrasis que corresponden a las secuencias de (1 a.) y (2 a.)

(3) a. Los que han venido son Juan y Luis

b. * Los que han venido es Juan

(4) a. Es él el vecino que llamó a la puerta

b. * Es hoy el vecino que llamó a la puerta

Tanto en ( 3 a.) como en (4 a.) puede cotejarse la flexión verbal con la naturaleza morfológica o sintáctica de número de los núcleos en relación de predicación: \{Los que + han venido + son + Juan y Luis $\} /\{$ Es + él + el vecino $+\ldots$ llamó... $\}$. Nótese la agramaticalidad de (3 b.) en este sentido. Por otro lado, es obligada, para alcanzar con éxito la conformidad semántica, la presencia de categorías nominales nucleares tanto en la expresión precopular como en la pospopular: $\{. . . e ́ l+$ el vecino... $\}$, de modo que la agramaticalidad de $(4 \mathrm{~b}$.) se desprende de la discordancia categorial que pretende identificar un núcleo nominal a partir de un adverbio temporal: $\{$...hoy + el vecino... $\}$

2 La Focalización es un procedimiento sintáctico o fonético que permite asignar la función de Foco de modo marcado a un determinado constituyente, por desplazamiento a posiciones anteriores o por asignación de prominencia fónica. Véase al respecto, Fernández Leborans (1991-92; 1999). En general, cuando se habla de construcciones escindidas se hace referencia al producto de una especie de proceso por el que se separa -se escinde- un constituyente de una oración y se sitúa antepuesto o pospuesto al verbo copulativo ser que se introduce en la construcción escindida. Dicho de otro modo, la 'escisión' sería un procedimiento sintáctico que permite derivar oraciones, denominadas escindidas, a partir de oraciones, digamos, indivisas (Fernández Leborans, 2001).

3 Para Plaza de la Ossa (2008) el verbo copulativo de las escindidas (VC) podría constituir un núcleo funcional de carácter presuposicional. "VC parece cumplir los requisitos que Abney enumeraba para caracterizar los núcleos funcionales: constituir clase léxica cerrada, ser fonológica y morfológicamente dependiente, permitir sólo un complemento en general que, además, no suele ser un argumento propiamente dicho sino un predicado, ser inseparable de su complemento y carecer de contenido descriptivo (más bien marcan rasgos gramaticales y/o relacionales)... En definitiva, esta situación aconseja orientar nuestra búsqueda hacia la suposición de que el VC contaría las mismas características de cualquier otro ser copulativo" 
Sin embargo, este análisis se hace extensivo a las oraciones escindidas encabezadas por construcciones preposicionales, a pesar de que estas presentan particularidades que contravienen, en primer lugar, la legitimidad de la relación de predicación basada en Referencia + Descripción (identificativa) y, en definitiva, no satisfacen las necesarias coincidencias sintácticas, en lo concerniente al rasgo flexivo de número (del que carecen los SSPP), y morfológicas, en relación con la categoría que se requiere para establecer una identificación especificativa entre núcleos de expresiones copulares ${ }^{4}$. Así:

(5) a. ?? A los que he llamado es a mis primos

b. ?? A mis primos es a los que he llamado

c. $*\{$ A los que he llamado/A mis primos $\}$ son $\{$ a mis primos/a los que he llamado

(6) a. ?? Con los que hablé es con Juan y Luis

b. ?? Con Juan y Luis es con los que hablé

c. ${ }^{*}\{$ Con los que hablé/Con Juan y Luis $\}$ son $\{$ con Juan y Luis/con los que hable $\}$

La dudosa gramaticalidad de (5 a./b.) y (6 a./b.) se debe a la concurrencia de diversos factores de naturaleza sintáctica, morfológica, semántica y pragmática, uno de los cuales, el que concierne a la concordancia, origina la agramaticalidad de (5 c.) y (6 c.), de modo que se hace necesario un análisis en mayor profundidad de los usos de ser en este tipo de oraciones.

Este trabajo tratará de presentar, desde una metodología descriptiva, datos que puedan arrojar luz acerca del estatus gramatical de las oraciones de "escisión" focalizadora que integran constituyentes de núcleo preposicional, de modo que sea posible determinar los valores semánticos que adquiere en estos casos el verbo ser, oscilantes entre los copulativos y los predicativos léxicos con sentido de "existencia", "acontecimiento", o bien, como se adoptará en este estudio, "proceder de un evento". Así, la organización de los contenidos se estructurará del siguiente modo:

El apartado 2 pondrá de manifiesto las diferencias fundamentales que afectan a la sintaxis y la semántica de las oraciones con ser copulativo y ser predicativo, haciendo especial hincapié en los usos de este último [2.1], descrito, frecuentemente, sobre la base de los contextos espacio-temporales. Por ello es por lo que estableceremos la división de dos clases fundamentales: la de aquellos que incluyen adjuntos y la que acoge construcciones "existenciales" que incorporan constituyentes predicativos [2.2]. Así, a lo largo del apartado 3 se describirá el comportamiento de las oraciones escindidas encabezadas por preposición, en oposición a aquellas que se construyen con núcleo nominal. Mostrando alternancias de flexión de tiempo podremos observar tendencias en relación con la concordancia en escindidas preposicionales y nominales [3.2], mientras que el contraste basado en la variación de la flexión de número resultará determinante para distinguir escindidas copulativas y escindidas predicativas [3.3].

Finalmente, en el apartado 4 analizaremos la gramaticalidad de las oraciones escindidas con preposición, atendiendo a la focalización del constituyente escindido y su valor sintáctico en el interior de la Relativa Libre $(\mathrm{RL})^{5}$.

4 En Fernández Leborans (2001) se concretan las particularidades de las denominadas oraciones escindidas (CopEs) y las pseudo-escindidas (RelEs) con constituyente escindido no preposicional

5 En Brucart (1999) se describen las relativas libres atendiendo a los contextos en los que puede aparecer este tipo de construcción, caracterizada por constituir el único representante fónico del SN en el que se insertan. 


\section{Valor predicativo de Ser}

2.1. El sentido de "existencia", "acontecimiento" o "sucesión de evento" en el verbo ser ha sido parcialmente descrito por los gramáticos a partir, fundamentalmente, de fórmulas introductorias convencionalizadas (Érase una vez...; Dios es; En el principio, era la palabra), de modo que se asocia a su valor predicativo la subcategorización de argumentos eventivos o complementos de localización espacio-temporal (El examen es esta tarde, La fiesta será en el piso de arriba, El registro de documentos es alli $)^{6}$.

Efectivamente, la distinción copulativo/predicativo radica en la especificación aspectual, relativa al 'modo de acción', que proporciona referencias de tipo 'estativo' a los usos copulativos y rasgos de 'dinamicidad' al valor predicativo, estableciendo una clara línea divisoria que separa dos entradas léxicas para ser. En este sentido, se ha argumentado que, en uso predicativo, ser, como verbo existencial o de acontecimiento, puede admitir expresiones locativas y/o temporales en calidad de complementos, no de predicados y es capaz de constituir predicado por sí mismo, sin que sea preciso interpretar complementos tácitos, supuestamente seleccionados: Eso no puede ser, Será lo que Dios quiera, Sea lo que sea ${ }^{7}$.

Sin embargo, es preciso determinar las clases estructurales que pueden presentar las oraciones de ser predicativo con complementación, diferenciando estas, a su vez, de las que no integran expresiones circunstanciales ${ }^{8}$.

Así, una primera división atiende a la incorporación de complementos de semántica diversa en un esquema $<$ ser $+(\mathrm{SD})+$ complemento/complemento $+(\mathrm{SD})+$ ser $>$, en oposición al que se muestra con la disposición $<\operatorname{ser}+(\mathrm{SD}) /(\mathrm{SD})+\operatorname{ser}>$.

Así, su distribución corresponde a la de los SSNN canónicos, de modo que cualquier núcleo léxico de SN puede ser conmutado por una relativa libre, siempre que el pronombre relativo que la encabece sea capaz de identificar los rasgos del antecedente vacío.

a. (La persona) Quien dice esto miente

b. (El lugar) Donde vive tu hermano es muy lejos

c. (El modo) Como lo dijo me pareció brusco

La Relativa Libre (RL) permite así focalizar la especificación de su antecedente tácito en una estructura de 'perifrástica' cuyos elementos constituyentes son: COP (CÓPULA) + CES (constituyente escindido) + RL (Relativa Libre). Véase Moreno Cabrera (1999).

6 La tradición gramatical vincula las expresiones locales con ser (es aquilno es muy lejos) al valor intransitivo originario de este verbo, que en la lengua medieval era frecuente Cfr: ¿dónde es la vaquera de la Finojosa? (recogido de Santillana, Serranillas, RAE 1973). Véase Bello 1847, Gili Gaya 1943 y RAE, 1973, 2009. La competencia con estar, relegó los usos de "existencia" de ser a las expresiones de convención bíblica.

7 En Fernández Leborans (1999) se señala que el verbo ser de acontecimiento o existencia es un verbo léxico, claramente distinto del verbo ser copulativo, que es, de hecho, la única cópula pura.

8 Entiéndase el término circunstancial desde un punto de vista semántico-interpretativo; es decir, relativo a la lectura que puede extraerse de secuencias del tipo: Eso es por tu bien (finalidad), Eso es sin querer (modal), Eso será si yo quiero (condicional), con independencia del estatus sintáctico que pueda asignarse a cada una de estas construcciones: ...por tu bien (adjunto),...sin querer (predicado),... si yo quiero (subordinación adjunta). 


\begin{tabular}{|l|l|}
\hline Ser + complementación & Ser $^{9}$ \\
\hline La reunión es \{esta tarde/a las diez/por la tarde/hoy\} & Eso (no) \{puede ser/es\} ${ }^{10}$ \\
El accidente fue \{en la calle Mayor/alli\} & Sea (lo que sea) \\
Aquello fue por culpa de Luis & Lo que es es \\
Esto es \{por una buena causa/para una buena causa\} & \\
Será si queremos todos & \\
Eso ha sido \{voluntariamente/así/sin mala intención/ & \\
con intención\} & \\
La discusión fue entre Juan y Luis & \\
\hline
\end{tabular}

Así, es posible conmutar por genuinos verbos de "existencia/acontecimiento", de forma natural, las secuencias de ser:

(7) a. Eso (no) \{puede \{suceder/existir/pasar\}/ \{sucede/existe/pasa\}\}

b. $\{$ Suceda/Exista/Pase $\}$ lo que $\{$ suceda/exista/pase $\}$

c. Lo que $\{$ sucede/existe/pasa\} \{sucede/existe/pasa\}

Sin embargo, puede observarse cierto matiz semántico en los datos de ser + complementación que aleja a estas construcciones de las anteriores, pues dicha estructura se asocia a la noción de 'efecto' u 'ocurrencia, mientras que la de ser se encuentra vinculada al sentido de 'realidad concreta de una entidad'. Por lo tanto, podría inferirse que la 'dinamicidad' propia del valor predicativo de ser se traduce en un modo de acción 'perecedero' en los usos con complementación, presentando así aspecto 'télico', mientras que la falta de complementos de naturaleza diversa (predicativa o adjunta) convierte a ser "existencial" en un verbo 'atélico'; es decir, una categoría que presenta aspecto léxico 'imperfectivo'. Adviértanse los contrastes de (8):

(8) a. $\{*$ Los dragones no $\{$ tienen lugar/ocurren/suceden $\}\}$ en nuestro mundo

b. Los dragones no \{existen/son reales\} (en nuestro mundo)

c. El accidente \{existió/fue real (* en la carretera de Extremadura)

d. $\{\#$ El accidente $\{$ tuvo lugar/ocurrió/sucedió\}\} en la carretera de Extremadura

La secuencia (8a.) resulta agramatical en ausencia de un complemento que sitúe espaciotemporal, modal, causal o condicionalmente la entidad que denota el SD los dragones, sin embargo, podría argumentarse que la agramaticalidad de la secuencia $<S D+$ verbo de acontecimiento $>$ radica en la naturaleza no eventiva de dicho SD. Nótese, no obstante, que la inclusión del complemento 'locativo' en nuestro mundo sí permite reinterpretar la semántica del sintagma los dragones como nombre de evento, similar a los casos siguientes:

9 Como señala Fernández Leborans (1999), no sería adecuado caracterizar el verbo ser de estas construcciones como verbo copulativo con predicados -atributos- tácitos.

10 No debe confundirse este uso con el propiamente copulativo de expresiones integradas en los contextos siguientes: Lo que me querías decir es que vendrías, ¿verdad? -Eso es -Ha dejado a su novia por mensaje y eso no es - Obsérvese que en estos casos sí podemos inferir un predicado atributivo implícito: -Es es (lo que te quería decir) -Eso no es (lógico/normal). 
(Las revueltas de) Los Claveles \{tienen lugar/ocurren/suceden\} en Portugal/ (Las batallas de) Los Trescientos \{tienen lugar/ocurren/suceden\} en las Termópilas/ (El desembarco de Normandia \{tiene lugar/ocurre/sucede\} entre la frontera de España y Holanda. Por otro lado, (8b.) puede integrar un complemento de la misma naturaleza conservando la gramaticalidad; no sin añadir un rasgo [+ dinámico] a la secuencia original que la acerca a la noción de 'proceso'. Cfr: Los dragones no \{existen/son reales\} en nuestro mundo, pero sí \{tienen lugar/ocurren\} en la mente de los niños ${ }^{11}$

Respecto a (8c.) la agramaticalidad se da con la aparición del complemento, debido a que este localiza la entidad de la que se predica la "acción de efectuarse" y se asocia a la propiedad léxica de un verbo de acontecimiento 'télico' como suceder u ocurrir. Así, con verbo de "existencia" la secuencia no requiere la presencia de complementos; caso contrario a (8d.), que resulta inapropiada en la interpretación de "acontecimiento perecedero" cuando no integra complemento, de modo que El accidente \{tuvo lugar/sucedió/ocurrió\} debe reinterpretarse como: El accidente \{existió/fue real\}

2.2. Por lo tanto, atendiendo a la naturaleza de los complementos que integran las construcciones de ser predicativo con sentido de "efecto" [2.1], podemos establecer una segunda división que distingue aquellas que expresan el "proceso" de un evento a partir de adjuntos 'circunstanciales' de las que lo hacen a través de un predicado de "posición/disposición". Así:

\begin{tabular}{|l|l|}
\hline Ser + complementación adjunta & Ser + complementación predicativa \\
\hline Esto es \{por una buena causa/para una buena & La reunión es \{en esta tardelen torno a las diez/ \\
causa\} & en Mayo\} \\
Será si queremos todos & La venta del artículo fue \{en mi casa/ante \\
Eso ha sido \{voluntariamentelasi\} & notario\} \\
& Eso ha sido \{con intención/sin intención\} \\
& La discusión fue entre Juan y Luis \\
\hline
\end{tabular}

El sentido de "proceso de efectuarse" al que hacemos referencia permite que la acción denotada por ser pueda enmarcarse en un campo espacial, temporal o coyuntural que determine el "desarrollo" del evento seleccionado por el verbo. Sin embargo, es preciso señalar que dicha determinación coyuntural puede interpretarse como el conjunto de "condicionamientos' que afectan directamente al "cumplimiento" de $\operatorname{ser}^{12}$, relativos a la temporalidad, la

11 Entiéndase como suceder u ocurrir en la mente como idea o concepto dragón. Como se recoge en DRAE (2014): Ocurrir:

6. prnl. Dicho de una idea: Venirse a la mente de repente y sin esperarla. Era u. $t$. c. intr.

En este último uso se asimila a ser predicativo.

En este sentido, ser se comporta como estar predicativo: Las tormentas están por todo el Norte. Véase Cabezas (2015).

12 Recuérdese que el sentido de ser léxico 'télico' es equivalente a efectuar

Efectuar.

prnl. Cumplirse, hacerse efectivo.

DRAE (2014) 
causa, la finalidad o la condición, de modo que las secuencias de $<$ Ser + complementación adjunta $>$ constituirían datos representativos de las siguientes circunstancias:

1.

La reunión es \{esta tarde/ a las diez/por la tarde/hoy\}:

Referencia temporal expresa a partir de SD (esta tarde), locución adverbial deíctica puntual (a las diez), locución adverbial deíctica amplia (por la tarde) y adverbio temporal pronominal (hoy)

\section{2.}

La venta del artículo fue \{desde casa/por Internet\}:

Referencia direccional expresa a partir de SP de 'origen' (desde casa) y SP de 'vía/ trayecto' $^{13}$ (por Internet)

\section{3.}

Aquello fue por culpa de Luis

Referencia causal expresa a partir de SP de 'vía/trayecto' (por culpa de Luis)

4.

Esto es \{por una buena causa/para una buena causa\}

Referencia final expresa a partir de SP de 'vía/trayecto' (por una buena causa) y SP de 'meta' (para una buena causa)

\section{5.}

Será si queremos todos

Referencia condicional expresa a partir de OSub.

\section{6.}

Eso ha sido \{voluntariamentelasi\}

Referencia modal expresa a partir de SAdv. (voluntariamente) y adverbio modal pronominal (asi)

Por otro lado, el valor léxico de ser "efectuación" puede completarse por medio de expresiones de 'estado resultante', 'situación' o 'ubicación'; es decir, predicados que indicarían el modo en que se presenta o resulta el evento (nombre eventivo) que integran las oraciones $<$ Ser + complementación predicativa $>$ :

\section{1.}

La reunión es \{en esta tardelen torno a las diez/en Mayo\}

Descripción espacial expresa a partir de SP 'locativo' de significación temporal inespecífica (en esta tarde), SP 'locativo’ de significación temporal específica (en torno a las diez) y SP 'locativo' ${ }^{14}$ de significación temporal amplia (en Mayo)

13 Sobre los valores léxicos de las preposiciones espaciales en español véase Cabezas (2015).

14 Consúltese la distinción 'locación'/'dirección' en relación con el estatus sintáctico de los SSPP espaciales en Cabezas $(2013,2015)$ 
2.

La venta del artículo fue \{en mi casa/ante notario\}

Descripción espacial expresa a partir de SP 'locativo' de significación de ubicación (en mi casa) y SP ‘locativo’ de significación de situación (ante notario)

3.

Eso ha sido \{con intención/sin intención\}

Descripción no espacial expresa a partir de SP de 'adición' (con intención) y SP de 'sustracción' ${ }^{15}$ (sin intención)

4.

La discusión fue entre Juan y Luis

Descripción espacial expresa a partir de SP 'locativo' de significación participativa ${ }^{16}$ (entre Juan y Luis)

Quedan, por lo tanto, establecidos los modelos estructurales que pueden asociarse al valor "existencial" télico de ser, de manera que sea posible analizar la sintaxis y la semántica de las oraciones escindidas encabezadas por construcciones preposicionales observando contrastes de gramaticalidad en función de las alternancias de flexión de tiempo y número.

\section{Escindidas copulativas y escindidas predicativas}

\subsection{Obsérvense los siguientes contrastes:}

(9) a. Juan es el que vino

b. Juan fue el que vino

c. Juan es el que vendrá

d. Juan será el que vendrá

(10) a. \# Con Juan es con quien vino

b. Con Juan fue con quien vino

c. \# Con Juan es con quien vendrá

d. Con Juan será con quien vendrá

Las secuencias de (9) muestran un comportamiento irrestricto respecto de la concordancia verbal entre el VC y el VR, pues se trata de construcciones escindidas en las que se especifica la referencia de un constituyente de naturaleza nominal; esto es, el elemento focalizado (ES) corresponde al antecedente nominal del pronombre integrado en la relativa (RL). El empleo de la concordancia pasada (pret. perf. = fue/vino) o futura (fut. imperf. =

15 Sobre el criterio de clasificación semántica de las preposiciones y, en particular, los valores léxicos de las preposiciones no espaciales véase Cabezas (2013, 2015)

16 En Cabezas $(2013,2014,2015)$ se describen los valores léxicos de la preposición entre sobre la base 'locativo-colectivo', de modo que todos los usos constituyen variantes de la propiedad de 'locación' en sentido recto o metaforizado. Así, la interpretación participativa se construye en la sintaxis como sigue: La discusión fue entre Juan y Luis = La discusión fue [(en [el espacio de confrontación]) [entre Juan y Luis]], donde el SP encabezado por en constituye el predicado del SD la discusión, integrando a su vez dicho SP una segunda relación de predicación a modo de CR (cláusula reducida): CR [el espacio de confrontación] [entre Juan y Luis] 
será/vendrá) en (9b.) y (9d.) supone la determinación del antecedente en el enclave de un tiempo específico, lo que no invalida el carácter de copulativa identificativa de la oración, ni la naturaleza aspectual 'atélica' de ser con este valor. Por otro lado, la ausencia de concordancia temporal en (9a.) y (9c.) señala, únicamente, un matiz estilístico en relación con el uso del tiempo presente, de modo que la expresión de 'intemporalidad' que este aporta puede traducirse como representativa de los denominados 'presentes gnómicos' ${ }^{17}$ o presentes del conocimiento, la universalidad o las verdades absolutas. Nótese que el contenido de cualquier construcción copulativa identificativa constituye una realidad o verdad 'estable"18.

(11) a. Juan es mi hermano/Mi hermano es Juan

b. Pedro Romero es el catedrático del departamento/El catedrático del departamento es Pedro Romero

c. Felipe de Habsburgo es Felipe I/Felipe I es Felipe de Habsburgo

d. Este es Luis/Luis es este

No obstante, los casos de concordancia en escindidas copulativas (con foco específico nominal) afectan, fundamentalmente, al aspecto verbal, pues es posible concertar el tiempo de la cópula (VC) y el tiempo de la relativa (VR) a través del matiz de 'continuidad' o 'resultatividad' que se extrae de la forma del verbo. Cfr: Juan fue el que había venido/* Juan era el que vino ${ }^{19}$. Por ello es por lo que se ha afirmado que el VC de este tipo de construcción

17 En Plaza de la Ossa (2008) se afirma: “...en este tipo de construcciones, el verbo copulativo es "intemporal'. De ahí que acepte con cualquier combinatoria la forma de presente de indicativo, la menos marcada temporalmente, puesto que el presente supone justamente la ausencia absoluta de precisión de tiempo, si bien, presenta un aspecto gramatical imperfectivo. Ese mismo presente de valor no temporal es utilizado en otros contextos: en aforismos, máximas, refranes, definiciones... Es lo que se conoce como "presente gnómico". Compárese:

a. Dos más dos suman cuatro

b. Tanto va el cántaro a la fuente, que al final se rompe

c. Es aquí donde tenía la tienda

c'. Era aquí donde tenía la tienda

c y c' serían semánticamente equivalentes, puesto que en ellas no se señala un lugar en el pasado. El acto de especificar el lugar se hace en tanto se está enunciando la frase. Cuando el VC va en imperfecto, mantiene ese valor de especificación ligada al enunciado y no a la existencia remota de la tienda en el pasado."

Moreno Cabrera (1999), por su parte, hace referencia al comportamiento irrestricto en relación con la concordancia de las escindidas copulativas haciendo hincapié en su carácter deíctico : "La PdR no describe [...] sino que señala este acto lingüístico de especificación y, por tanto, se trata de una construcción metalingüística: no señala nada sobre la realidad extralingüística, sino que es índice de una acción lingüística de que se deriva el peculiar comportamiento que acabamos de observar respecto de la concordancia temporal entre la cópula de las PdRs y el verbo principal de la oración expandida perifrástica"

18 En palabras de Fernández Leborans (1999), las oraciones copulativas con ser, en términos generales, contienen predicados 'estables' -predicados 'gnómicos' o predicados 'de individuos'.

19 La concordancia 'perfectivo'/'imperfectivo' se pone de manifiesto en secuencias análogas a las que se contrastan en Plaza de la Ossa (2008)

a. Fue aquí donde aparcaron a. *Fue aquí donde aparcaban

b. Era aquí donde aparcaron b. Era aquí donde aparcaban

c. Es aquí donde aparcaron c. Es aquí donde aparcaban

Como la autora señala: "mientras que si el VR es perfecto simple el VC puede aparecer en ese mismo tiempo, en presente de indicativo y en imperfecto de indicativo, si VR es imperfecto de indicativo sólo existe la opción de 
parece carecer de deixis temporal ${ }^{20}$, en contraposición a lo que se expresa en las secuencias de (10b.) y (10d.), en las que el verbo presenta rasgos léxicos propiamente temporales ${ }^{21}$ que pueden describirse del siguiente modo:

1.

Con Juan fue con quien vino

Lectura y paráfrasis: "El hecho de que (él/ella) viniera acompañado/a (junto a) \{de/ por\} alguien \{se produjo/se resolvió/se efectuó $\}$ acompañado/a (él/ella) (junto a) \{de/ por\} Juan"

Así \{se produjo/se resolvió/se efectuó\}\{Este/Ese/Aquel\} hecho

\section{2.}

Con Juan será con quien vendrá

Lectura y paráfrasis: "El hecho de que (é/ella) venga acompañado/a (junto a) \{de/ por\} alguien \{se producirá/se resolverá/se efectuará\} acompañado/a (él/ella) (junto a) $\{$ de/por\} Juan"

Así \{se producirá/se resolverá/se efectuará\} \{Este/Ese/Aquel\} hecho

Concluimos, a la luz de los datos, que las construcciones escindidas encabezadas por preposición constituyen usos de ser predicativo de aspecto 'télico' con la significación de "proceso de efectuación de un evento". Por otra parte, se trata de construcciones de $<$ ser + complementación adjunta $>$ que integran un complemento modal a la manera de

[6. Eso ha sido \{voluntariamente/asi\} Referencia modal expresa a partir de SAdv. (voluntariamente) y adverbio modal pronominal (asi)] [2.2]

Nótese que la relativa (RL) puede conmutarse por un logóforo pronominal y el elemento escindido (ES) se interpreta como adjunto ad-oracional de semántica modal: Eso \{fue/será\} así.

que VC sea presente o imperfecto de indicativo. Parece así que el VC concuerda temporalmente con el VR, pero no así en cuanto al aspecto. En este sentido, parece conservar el carácter imperfectivo de la forma de no tiempo del presente".

20 Tal afirmación se defiende en Plaza de la Ossa (2008): “... todo lo que podemos concluir es que este núcleo copulativo, al que por facilitar la identificación estamos llamando $\mathrm{VC}$, se trata en efecto de un núcleo donde los rasgos deícticos de tiempo parecen ausentes."

21 Las hipótesis de Bosque (1999) y Bošković (1997) que lo caracterizan como núcleo funcional parecen acordes con la observación que varios gramáticos tradicionales habían hecho acerca de la carencia de contenido semántico (de valor léxico, por tanto) de estas unidades. Navas Ruiz (1977) denomina a estos verbos "verbos de enlace o relación" y aclara:

Con objeto de poner de relieve o enfatizar un término de la oración, es frecuente en español sacarlo fuera de la misma y hacerlo depender de ser, que entonces no significa nada, reduciéndose a ser mero agente de enlace.

Recuérdese la polémica entre algunos gramáticos tradicionales como Navas Ruiz (1977) que agrupaban a los VC de las pseudocopulativas, por su nulo valor semántico, dentro de los usos predicativos o no copulativos del verbo "ser", y otros gramáticos actuales como Fernández Leborans (1999), quien considera que tal clasificación es una auténtica contradicción, dado que si los usos copulativos se distinguen por algo es por su carácter desemantizado frente a los usos predicativos donde se mantiene parte del significado léxico de su base latina ESS-RE. 
Por lo que respecta a las secuencias de (10a.) y (10c.), se han señalado como inapropiadas en la interpretación deseada por no presentar la concordancia temporal o aspectual que caracteriza a las anteriores ${ }^{22}$. De este modo, es lógico inferir que el valor "existencial" de $\operatorname{ser}$ en este uso deriva del sentido de 'realidad concreta de una entidad' ("existencia") propios de los que se estructuran por medio del esquema $<\operatorname{Ser}>$ (sin complementación) [2.1]. Es preciso, sin embargo, determinar en estos casos el estatus del elemento escindido (ES) con Juan en relación con ser predicativo. Pues bien, lo cierto es que en (10a.) y (10b.) el verbo ser expresa la "certeza de un hecho" que se interpreta con independencia del "proceso". Así"

\section{3.}

Con Juan es con quien vino

Lectura y paráfrasis: " $\{$ Es cierto/Es real $\}$ que con quien vino (él/ella) fue Juan” Eso es/Así es

\section{4.}

\section{Con Juan es con quien vendrá}

Lectura y paráfrasis: " $\{$ Es cierto/Es real $\}$ que con quien vendrá (él/ella) será Juan” Eso es/Así es

Véase que la estructura oracional disloca el constituyente que contiene el antecedente de la relativa $(\mathrm{RL})$ por cuestiones de focalización ${ }^{23}$, sin que este constituya complemento

22 Téngase en cuenta que las secuencias de (10b.) y (10d.) también admiten con naturalidad el concierto aspectual que señalábamos para las escindidas copulativas. Así:

a. Con Juan fue con quien había venido/* Con Juan era con quien vino

b. Con Juan será con quien venga/* Con Juan será con quien habrá venido

Como se indica, la solidaridad aspectual permite relacionar tiempos perfectos simples y compuestos en (a), así como futuros imperfectos y presentes de modo 'conjetural' o 'potencial' (b). Así, las variantes agramaticales resultan de la discordancia de aspecto en pasados de naturaleza 'atélica/télica' y en futuros cuya prospección encuentra continuidad o término respecto de la acción denotada por el verbo.

23 La dislocación en este sentido puede encontrase en construcciones 'de ascenso', en las que, por razones discursivas se sitúa en posición "prominente" un elemento extraído de un constituyente oracional subcategorizado: Vi a Juan salir de su casa = Vi que Juan salía de su casa.

Aunque no resultará determinante en nuestro estudio, dentro de las construcciones escindidas se han distinguido tres tipos atendiendo a su estructura:

- Oraciones escindidas: Es Pedro el que viene

- Oraciones pseudoescindidas: El que viene es Pedro

- Oraciones pseudoescindidas inversas: PEDRO es el que viene.

Como recuerda Fernández Leborans (2001), la terminología para referirse a cada una de las clases de escindidas varía según autores y escuelas: 'oraciones perifrásticas con ser' (Esbozo de la RAE), 'fórmulas perifrásticas de relativo’ (Fernández Ramírez), oraciones ecuacionales (Alarcos, entre otros). La bibliografía anglosajona usa el término 'cleft sentences' para referirse tanto a 'cleft o it-sentences' (escindidas o hendidas) como a 'pseudocleft o wh-sentences' (pseudoescindidas o pseudohendidas). Por su parte, Moreno Cabrera (1999) habla de PdR RL (pseudoescindida), PdR CES (pseudoescindida inversa) y PdR COP-CES (escindida).

En este sentido, Fernández Leborans (2003) señala que las oraciones escindidas son estructuras de "enfatización", pues el hablante atribuye al constituyente focal la relevancia contextual desde el punto de vista informativo, 
adjunto asociado a ser predicativo. Cfr: A París será a donde vaya = Así se resolverá la cuestión/A París es a donde vaya $=\#$ Así se resuelve la cuestión $=$ Así es $=($ Que a donde vaya sea a París) $e^{24}$.

\subsection{Téngase en consideración el siguiente contraste:}

(12) a. Juan es quien habla/*Juan y Luis es quien habla

b. Juan y Luis son quienes hablan/* Juan son quienes hablan

c. Todos son \{??quienes/los que\} hablan

(13) a. Con Juan es con quien hablo

b. * Con Juan y Luis son con quienes hablo/Con Juan y Luis es con \{quien/quienes\} hablo

c. ${ }^{*}$ Con todos son con $\{? ? q u i e n e s / l o s ~ q u e\}$ hablo/Con todos es con $\{?$ ?quienes/quien/los que/*el que\} hablo

Como puede inferirse, la concordancia en la flexión de número no solo se produce con absoluta naturalidad en las oraciones escindidas copulativas, sino que dicha relación de concordancia se presenta obligada, de modo que es clara la relación de predicación que se establece entre el núcleo nominal "focalizado" y la expresión descriptiva que constituye la construcción relativa. Cfr: [Juan] [quien habla]/ [Juan y Luis] [quienes hablan]. Nótese, no obstante, que en (12c.) el elemento nominal representado por pronombre indefinido (cuantificador universal ${ }^{25}$ ) difícilmente puede ser descrito a partir de un relativo de rasgo [+ animado [+ humano]] sin comportar dudosa gramaticalidad, por lo que resulta conveniente la asociación a un relativo [+ animado [inespecífico]]

Respecto a las secuencias de (13), hay que señalar que la concordancia de número entre el verbo ser predicativo (con sentido de "proceso de efectuación") y cualquiera de las expresiones - preverbales o posverbales- conlleva la agramaticalidad de toda la construcción. Sin embargo, es interesante indicar la lectura y paráfrasis correspondiente de estos usos.

de modo que, una oración escindida es, por definición, una estructura de "focalización". Así, aquellas que llevan el constituyente focal antepuesto son, de modo habitual, escindidas de Foco Contrastivo, sin que por ello comporten necesariamente información nueva.

24 En Fernández Leborans (2001) se define un tipo especial de construcción escindida: "Escindidas discontinuas; son oraciones íntegramente remáticas: tanto el «valor» como la «variable» contienen información 'nueva'. A diferencia de los otras dos subclases, en las que la función semántica de 'Especificación' no resulta subsidiaria respecto a la función pragmática de 'Focalización' o ‘Enfatización'...”, de modo que se presentan ejemplos de escindidas copulativas acompañadas de expresiones "existenciales” de naturaleza 'atélica': Quien redactó el proyecto fue José Antonio, ¿no es así?

25 Se comportan como todos los cuantificadores llamados "universales", cuya cardinalidad coincide con la totalidad del conjunto definido al que cuantifican. Frente a ellos, los "no universales" o "indefinidos" propiamente dichos denotan una parte indeterminada de un conjunto definido (en su interpretación partitiva) (a) o bien miden el tamaño de un conjunto indefinido de elementos (en su interpretación cardinal) (b). Véase Cabezas (2013) a partir de Sánchez López (1999).

a) Varios edificios fueron demolidos durante las obras

b) Algunos pensaban que deberían aplazarse las obras 
1. /2./3.

Con \{Juan/Juan y Luis/todos\} es con \{quien/quienes/los que\} hablo

Lectura y paráfrasis: "El hecho de que (yo) hable con \{alguien/algunas personas\} \{se produce/se resuelve/se efectúa\} hablando (yo) con $\{$ Juan/Juan y Luis/todos\}"

Asi \{se produce/se resuelve/se efectúa\} este hecho

Nótese que el vínculo entre elemento relativo y antecedente es problemático en (13c.), pues, a diferencia de (13b. $)^{26}$, presenta irregularidad gramatical. Cfr: Con Juan y Luis es con quien hablo/* Con todos es con el que hablo. El sorprendente contraste que se muestra en las secuencias anteriores se debe a la particularidad léxica de la preposición con, pues esta no selecciona (a diferencia de la preposición entre) un elemento nominal coordinado de naturaleza colectiva $^{27}$, sino que únicamente puede ser interpretada dicha coordinación como constituyente de carácter plural. Por ello es por lo que un sintagma como Juan y Luis, como argumento de preposición con, no expresa "conjunto", de modo que la lectura que corresponde a la construcción en la que se integra es la que sigue: "Con Juan y (con) Luis hablo/Es con Juan con el que hablo y también con Luis (con el que hablo)". Por el contrario, el cuantificador todos argumento de con sí puede atraer la concordancia plural del antecedente relativo: "Con todos hablo/Es con todos con los (seres humanos) que hablo", a pesar de que también permite ser interpretado como nombre 'colectivo': "Es con todos con quien (la entidad grupal que) hablo".

Concluimos, por lo tanto, que la concordancia de número resulta rasgo identificador determinante en la distinción entre oraciones escindidas copulativas y predicativas, atribuyendo a las primeras el concierto de número obligado y caracterizando las segundas a partir de la independencia flexiva del verbo regente (ser predicativo) respecto del verbo subordinado integrado en la relativa $(\mathrm{RL})^{28}$.

\section{El Foco preposicional en las escindidas}

El elemento focalizado en la construcción escindida (o pseudoescindida inversa) constituye la expresión remática (que contiene información nueva) en relación con la estructura argumental de la relativa, la cual proporciona información 'dada' (información' vieja') en el contexto precedente y determina un Tópico que es continuación de la línea temática

26 La secuencia de (13b.) Con Juan y Luis es con quienes hablo resulta gramatical aplicando la misma lectura que en Con Juan y Luis es con quien hablo: "Hablo con Juan y con Luis/Hablo con ambos/Hablo con dos personas", de modo que interpretamos más de un evento hablar - simultáneo o no-.

27 Véase Cabezas $(2013,2014)$ para la propiedad 'colectiva' asociada a la preposición entre, así como para profundizar en el valor de los sintagmas coordinados como argumentos de dicha preposición.

28 Plaza de la Ossa (2008) recuerda que Bosque (1999) y Fernández Leborans (2003) se refieren a la concordancia de número, señalando el primero la opcionalidad de la concordancia de número tanto en las escindidas como en las estructuras de focalización del español caribeño y precisando la segunda que solo en las pseudoescindidas inversas el Foco no atrae la concordancia de VC:

a. Lo que compraba eran legumbres

b. Eran legumbres lo que compraba

c. Legumbres era lo que compraba

Preferimos, en este estudio, trabajar con este último modelo de escindida por considerar que constituyen los casos de focalización más marcada, de modo que permite revelar el comportamiento sintáctico más dispar en relación con el contraste entre escindidas nominales y preposicionales. 
precedente ${ }^{29}$. Así, resulta obligado clasificar los SSPP "focalizadores" que encabezan las oraciones escindidas predicativas, así como determinar las relaciones sintácticas que se establecen entre estos y los elementos que integra la relativa libre (RL).

\begin{tabular}{|c|c|c|}
\hline Foco argumental & Foco adjunto & Foco predicativo \\
\hline $\begin{array}{l}\text { A Juan es a quien veo } \\
\text { De Gramática fue de lo que me } \\
\text { habló } \\
\text { Desde Madrid era desde donde } \\
\text { venía } \\
\text { Hacia Madrid es hacia donde } \\
\text { me dirijo } \\
\text { Hasta Mallorca fue hasta } \\
\text { donde llegó } \\
\text { Por la costa era por donde } \\
\text { cruzaban } \\
\text { Contra mi es contra quien se } \\
\text { enfrenta }\end{array}$ & $\begin{array}{l}\text { Desde mi casa es desde } \\
\text { donde me gusta comprar } \\
\text { antigüedades } \\
\text { Desde el año } 1990 \text { fue desde } \\
\text { cuando empezó a cantar } \\
\text { Hasta el año } 1990 \text { era hasta } \\
\text { cuando permanecía vigente su } \\
\text { contrato }\end{array}$ & $\begin{array}{l}\text { Ante mi es ante quien debe } \\
\text { postrarse } \\
\text { Con mi madre fue con quien } \\
\text { viajó a Mérida } \\
\text { En mi casa era donde se } \\
\text { encontraba } \\
\text { Sin ropa es como lo encontré } \\
\text { Sobre mis hombros fue como } \\
\text { entró en la ciudad } \\
\text { Tras mi séquito era donde } \\
\text { caminaba su hermano }\end{array}$ \\
\hline
\end{tabular}

Interesante contraste es el que puede observarse en el cuadro clasificatorio que presentamos arriba, pues las restricciones sintácticas que se infieren sobre la base de la presencia o ausencia de determinados SSPP como Focos de construcción escindida se desentrañan del siguiente modo:

\section{1. $\mathbf{F A}^{30}$}

Se trata, en su mayoría, de SSPP 'direccionales', de modo que establecen relaciones argumentales a partir de verbos de "desplazamiento" 31 que subcategorizan complementos regidos de 'origen': Desde Madrid era desde donde venía, 'meta': Hacia Madrid es hacia donde me dirijo (orientada) /Hasta Mallorca fue hasta donde llegó (alcanzada) o 'vía/trayectoria': Por la costa era por donde cruzaban. Nótese que las variantes de significación "temporal" en este tipo de construcción pasan a relacionarse como adjuntos verbales con el verbo de la relativa, constituyendo antecedentes de naturaleza adverbial. Sin embargo, tan solo los complementos 'direccionales' que señalan "punto específico" en relación con el segmento temporal expresado conservan el núcleo preposicional sintagmático. Cfr: Hacia las doce es cuando debe ocultarse/Por Navidad era cuando se atrevía a viajar.

Por otro lado, los objetos directos de persona y los complementos regidos canónicos pueden focalizarse a partir de SSPP encabezados por las preposiciones de 'restricción' ${ }^{32}: a$, o de 'dirección': de/contra con sentido figurado o "metaforizado" (de Gramática (hablar)/ contra mi (enfrentarse)).

\footnotetext{
29 Véase Fernández Leborans (2001).

30 Foco Argumental.

31 Véase Cabezas (2015).

32 En Cabezas (2014, 2015).
} 


\section{FAd ${ }^{33}$}

Como se ha señalado, únicamente SSPP de 'dirección' que señalen "puntos específicos” de referencia espacial o temporal pueden conservar su núcleo sintagmático tanto en posición de Foco como en el interior de la relativa: Desde casa...desde donde/Desde el año 1990... desde cuando/Hasta el año 1990...hasta cuando. Cfr: * Hacia las doce es hacia cuando....* Por Navidad era por cuando...

\section{3. $\mathbf{F P}^{34}$}

En todos los casos nos encontramos con SSPP 'locativos'/'situacionales' que presentan la particularidad de constituir antecedentes de relativos adverbiales. Dichos relativos describen 'estado' o 'disposición' de un argumento Objeto ${ }^{35}$ integrado en la relativa libre. Cfr: En mi casa...donde (estaba)/Sin ropa...como (estaba)/Sobre mis hombros...como (estaba)/ Tras mi séquito...donde (estaba). La excepción la representa la preposición con, pues como preposición 'aditiva' permite encabezar sintagmas que puedan interpretarse como "participantes complementarios" del argumento del que predican y con el que se asocian al evento denotado por el verbo: Con mi madre...con quien (viajaba) = Mi madre y él viajaban (juntos).

Respecto a la preposición entre, habría que señalar que su aparición en escindidas se limita a contextos "cooperativos" (de valor "sumativo'36), constituyendo así antecedente de un relativo adverbial modal: Entre todos fue como levantamos el piano. Nótese que su aparición en la relativa libre supone interpretar 'estado' orientado al sujeto (no al objeto directo el piano): Entre todos fue entre quienes levantamos el piano, con la lectura: "Nosotros levantamos el piano estando entre (en medio de) todos". Análogo comportamiento presentan los SSPP(con): Con Luis es con quien vi a María = "Vi a María estando (yo) con Luis".

Por último, es preciso hacer referencia al contraste sintáctico y semántico entre construcciones escindidas del tipo de (14) y (15).

(14) a. Allí es donde nos conocimos

b. Hoy es cuando vienen a recogerme

c. Así es como lo hago

(15) a. En Madrid fue donde nos conocimos

b. Sobre las dos es cuando vienen a recogerme

c. Sin herramientas era como lo hacía

Adviértase que las secuencias de (14) especifican un espacio local o temporal, o bien un modo a partir de la relación entre un elemento de naturaleza pronominal y un SD tácito: El lugar (donde)/El momento (cuando)/El modo (como). Por su parte, los datos de (15) se

33 Foco adjunto.

34 Foco predicativo.

35 El 'estado' de posición o situación se atribuye a un argumento que desempeña la función semántica (o papel temático) de Tema/Objeto, pues dicho argumento se comporta como agente en relación con un verbo como entrar o caminar, pero como objeto paciente en asociación con estar o encontrarse.

36 Cabezas (2015). 
encuentran encabezadas por expresiones de 'ubicación' espacial y temporal, así como por una construcción predicativa de 'situación': En Madrid/Sobre las dos/Sin herramientas, de modo que fuerzan la lectura de "proceso de efectuación" para ser, constituyendo oraciones escindidas de valor predicativo.

\section{Conclusiones}

Hemos descrito las oraciones escindidas encabezas por construcciones preposicionales atendiendo al valor "existencial" del verbo ser en este uso. Para ello establecemos una división que recoja los usos de "existencia" de las construcciones con ser, distinguiendo aquellas que presentan complementación de las que carecen de adjuntos 'circunstanciales'. De la inferencia que nos permite atribuir a las escindidas preposicionales un sentido de "proceso de efectuación”, podemos asociar aspecto ‘télico' al verbo regente, así como determinar contrates en relación con la concordancia de tiempo y número. Finalmente, hemos podido clasificar los Focos preposicionales de las escindidas predicativas atendiendo a su relación sintáctica con el argumento que integra la relativa libre.

\section{Referencias bibliográficas}

Bello, A. (1847): Gramática de la lengua castellana destinada al uso de los americanos, Edición crítica de R. Trujillo, Tenerife, Aula de Cultura de Tenerife, 1981.

Boscovic, Z.: "Pseudoclefts", Studia Linguistica, 51 (1997), pp. 235-277.

Bosque, I.: "On Focus vs. Wh- Movement: The Case of Caribbean Spanish", Sophia Linguistica Working Papers in Linguistics, 44/45 (1999), pp. 1-31.

Brucart, J. M.: "La estructura del sintagma nominal: las oraciones de relativo", en Ignacio Bosque y Violeta Demonte (eds.), Gramática descriptiva de la lengua española, Madrid, Espasa-Calpe, 1999, pp. 395-522.

Cabezas Holgado, E. (2013): La predicación: las construcciones “en abanico”: aplicaciones al español. Tesis Doctoral. Universidad Complutense de Madrid, http://eprints.ucm. es/22365/.

Cabezas Holgado, E. (2014). Sobre usos de la preposición entre: el sentido realizativo. Círculo de Lingüistica Aplicada a la Comunicación 58, 3-21.

Cabezas Holgado, E. (2014). 'Entre' la locación y la colección. Sobre las propiedades léxicas de una preposición bivalente DICENDA. Cuadernos de Filología Hispánica. 32, 7-31.

Cabezas Holgado, E. (2014) Construcciones encabezadas por la preposición entre. Valores y restricciones sintácticas" ELUA. Estudios de Lingüística de la Universidad de Alicante 28, 39-56.

Cabezas Holgado, E. La preposición I (2015) Colección Cuadernos de Lengua Española Madrid, Arco Libros.

Cabezas Holgado, E. La preposición II (2015) Colección Cuadernos de Lengua Española Madrid, Arco Libros.

Gili Gaya, S. (1943): Curso superior de sintaxis española, Barcelona, Biblograf, 1964.

Fernández Leborans, M. J.: "La predicación: las oraciones copulativas", en Ignacio Bosque y Violeta Demonte (eds.), Gramática descriptiva de la lengua española, Madrid, Espasa-Calpe, 1999, pp. 2357-2460. 
Fernández Leborans, M. J.: "Sobre formas de ambigüedad de las oraciones escindidas: sintaxis y discurso", Estudios de Lingüística de la Universidad de Alicante, 15 (2001), pp. 285-305.

Fernández Leborans, M. J.: "Sobre foco y concordancia en las perífrasis de relativo", en José Luis Girón Alconchel [et al.] (eds.), Estudios ofrecidos al profesor José Jesús de Bustos Tovar, Madrid, Universidad Complutense, 2003, pp. 99-113.

Moreno Cabrera, J.C. (1999): "Las funciones informativas: las perífrasis de relativo y otras construcciones perifrásticas", en I. Bosque y V. Demonte (comps.), Gramática Descriptiva de la Lengua Española. Madrid: Espasa-Calpe, vol. 3º cap. 65, 4245-4302.

Navas Ruiz, R.: Ser y estar, Salamanca, Ediciones Almar, 1977.

Plaza de la Ossa, M.: "Efectos de concordancia en las oraciones escindidas del español" DICENDA. Cuadernos de Filología Hispánica 2008, vol. 26 193-218.

Real Academia Española (1973): Esbozo de una nueva gramática de la lengua española, Madrid, Espasa-Calpe.

Real Academia Española (2001): Diccionario de la lengua española, 22 a edición, Madrid, Espasa-Calpe [DRAE-2001].

Real Academia Española (2009): Nueva Gramática de la Lengua Española, Madrid, Espasa Calpe.

Real Academia Española (2014): Diccionario de la lengua española, 23 a edición, Madrid, Espasa-Calpe [DRAE-2014].

Sánchez López, C. (1999): "Los cuantificadores: clases de cuantificadores y estructuras cuantificativas", en I. Bosque y V. Demonte (eds.): Gramática Descriptiva de la Lengua Española, vol. 1, 1025-1128. Madrid, Espasa Calpe. 



\title{
ACENTOS TONALES Y VARIANTES: DECLARATIVAS EN HABLA FORMAL Y ESPONTÁNEA DE LA GOMERA (ISLAS CANARIAS)
}

\author{
Chaxiraxi Díaz Cabrera \\ Josefa Dorta Luis \\ Universidad de La Laguna \\ Laboratorio de Fonética \\ chadiaz@edu.ull.es jdorta@edu.ull.es
}

Recibido: $19 / 05 / 2015$

Aceptado: 08/09/2015

\begin{abstract}
Resumen
Este trabajo está realizado en el marco del proyecto Estudio comparativo de la entonación y del acento en zonas fronterizas del español (FFI2014-52716-P) vinculado a AMPER (Atlas Multimédia Prosodique de l'Espace Roman). El objetivo de esta investigación es hacer un estudio fonético-fonológico de oraciones declarativas (La Gomera, Islas Canarias) emitidas en dos estilos de habla, formal y espontáneo. Las oraciones fueron analizadas con subrutinas de Matlab (López Bobo et $a l, 2007)$ para extraer los valores de F0 en el núcleo de las sílabas. El etiquetaje fonético-fonológico sigue las directrices del sistema Sp_ToBI según la propuesta de Dorta ed. (2013). Se usó el umbral psicoacústico de 1,5 semitonos (Rietveld y Gussenhoven, 1985; Pamies Bertrán et al., 2002) para cuantificar la importancia de las variaciones tonales. Los resultados obtenidos permiten afianzar y ampliar la propuesta de etiquetaje fonológico postulada para el español en Dorta ed. (2013) en donde se diferenciaban tres invariantes monotonales y dos bitonales con sus correspondientes variantes para los acentos tonales de las zonas estudiadas.

PALABRAS CLAVE: entonación, acento, Sp_ToBI, corpus experimental, corpus espontáneo.
\end{abstract}

\begin{abstract}
This work has been carried out within the framework of the project Comparative study of intonation and accent in Spanish border areas (FFI2014-52716-P), which is associated to AMPER (Atlas Multimédia Prosodique de l'Espace Roman). The objective of this paper is undertaking a phonetic-phonological study of declarative sentences (La Gomera, Canary Islands) uttered in two different speaking styles; i.e. formal and spontaneous. Sentences were analyzed using Matlab sub-routines (López Bobo et al, 2007) to extract F0 values from the syllables' nuclei. The phonetic-phonological tagging follows the rules of the Sp_ToBI system according to the proposal by Dorta ed. (2013). A psycho-acoustic threshold of 1.5 semi-tones (Rietveld y Gussenhoven, 1985; Pamies Bertrán et al., 2002) was used to quantify the importance of tonal variations. Results obtained allow consolidating and broadening the proposal for phonologic tagging in Spanish by Dorta ed. (2013) that distinguishes three mono-tonal and two bi-tonal invariants with their corresponding variants for tonal accents in the study areas considered.
\end{abstract}

KEY WORDS: intonation, stress, Sp_ToBI, experimental corpus, spontaneous corpus.

\section{Introducción}

El sistema ToBI (Tones and Break Indices) en el marco del modelo Métrico-Autosegmental (Pierrehumbert, 1980) es aplicado por primera vez al español bajo la denominación de Spanish ToBI (Sp_ToBI) con la propuesta de transcripción entonativa de Beckman et al. (2002). A 
partir de entonces se sucedieron diferentes revisiones del sistema, como la de Hualde (2003), Fernández Planas y Martínez Celdrán (2003) o Pierrehumbert (2007). Entre las más recientes destacamos las de Estebas y Prieto (2008), Prieto y Roseano (2010) y Dorta (ed. 2013).

La propuesta de Estebas y Prieto (2008) fue aplicada durante años en diversos trabajos. Dicha propuesta se basó en investigaciones tradicionales sobre la entonación del español, en una revisión de artículos anteriores sobre el Sp_ToBI y en un análisis sistemático de las variedades de español peninsular de Madrid y Sevilla y de la variedad de Ciudad de México. En ella figuran las unidades fonológicas siguientes:

1) Acentos tonales (figura 1): monotonales $\left(\mathrm{L}^{*} ; \mathrm{H}^{*}\right)$ y bitonales $\left(\mathrm{L}^{*}+\mathrm{H} ; \mathrm{L}+\mathrm{H}^{*} ; \mathrm{L}+>\mathrm{H}^{*} ; \mathrm{H}+\mathrm{L}^{*}\right)$. Los tonos altos $(\mathrm{H})$ pueden presentar escalonamiento ascendente $(\mathrm{i})$ o descendente $($ !).

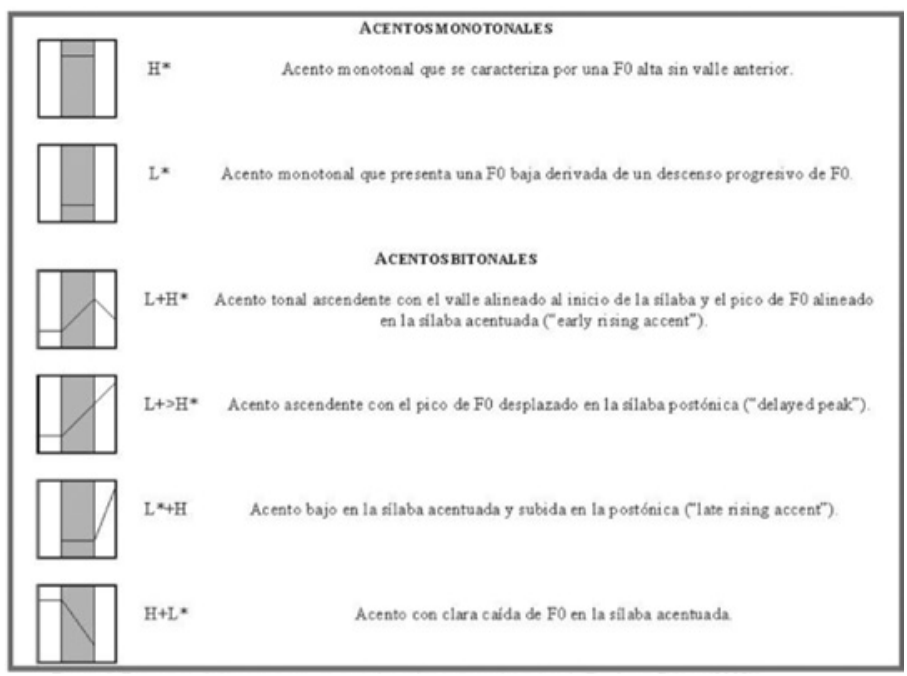

Figura 1. Esquemas de los acentos monotonales y bitonales adaptados de Estebas y Prieto (2008).

2) Tonos de frontera (figura 2): monotonales (L\%; H\%; M\%), bitonales (LH\%; HL\%; HH\%) y tritonales (LHL\%).

Posteriormente, en el 4th Sp_ToBI Workshop, celebrado en el marco del "Phonetics and Phonology in Iberia 2009”, se demostró la eficacia de las versiones revisadas del sistema ${ }^{1}$. Así, con el objetivo de presentar descripciones de una amplia variedad de enunciados en distintos dialectos del español (de España y América) con la misma metodología, se llegó a la conclusión de que existían rasgos compartidos de la lengua pero, asimismo, variación dialectal. Prieto y Roseano (2010) recogen los siguientes acentos tonales (figura 3) y tonos de frontera final (figura 4).

1 Los criterios de anotación pueden consultarse en el curso online Sp-ToBI Training Materials, en la dirección electrónica: http://prosodia.upf.edu/sp_tobi/en/ 


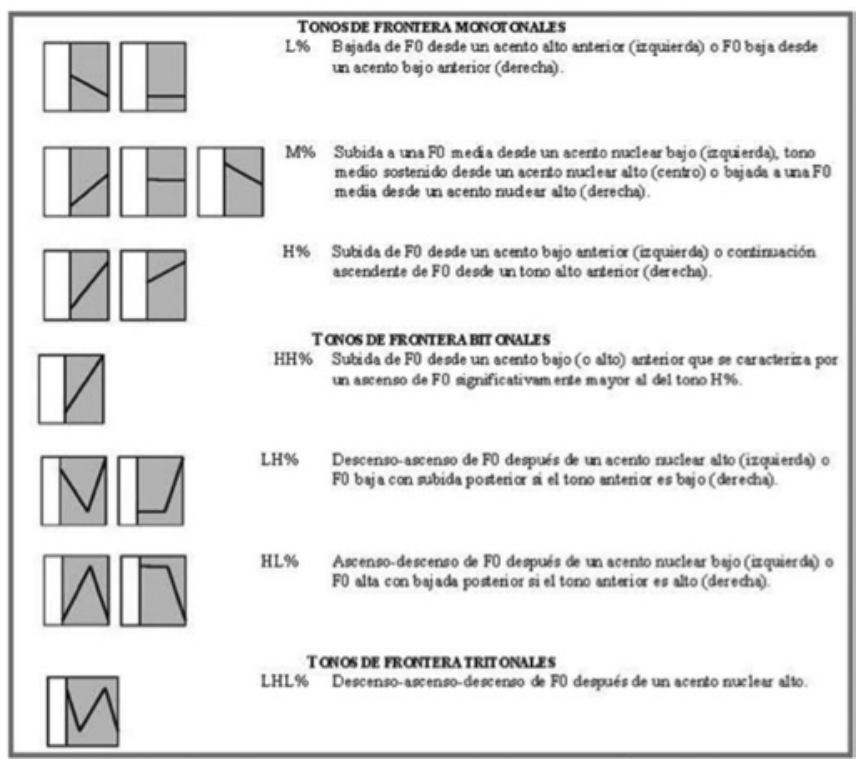

Figura 2. Esquemas de los movimientos tonales de frontera adaptados de Estebas y Prieto (2008).

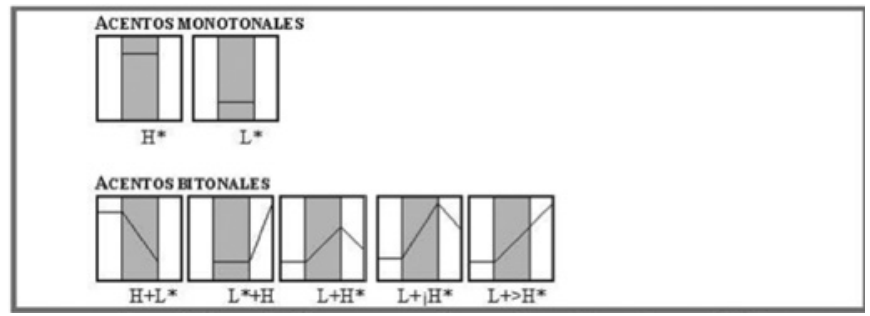

Figura 3. Adaptación de los acentos tonales recogidos en Prieto y Roseano (2010)

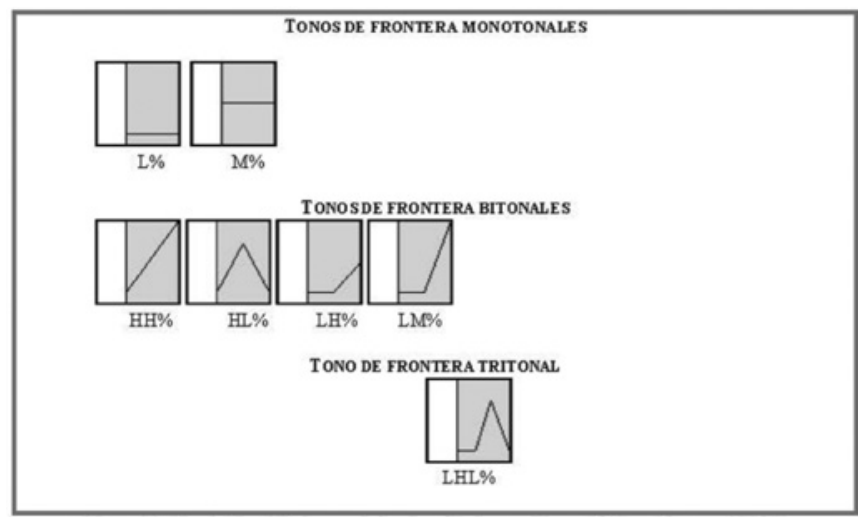

Figura 4. Adaptación de los tonos de frontera final recogidos en Prieto y Roseano (2010) 
Más recientemente, en Dorta (ed. 2013) surge una nueva propuesta de etiquetaje como resultado de la discrepancia que existía hasta entonces entre los distintos autores en los aspectos metodológicos. Esta propuesta se presenta como provisional en tanto que se deriva del análisis fonético de un corpus experimental procedente de mujeres canarias, cubanas y venezolanas. En ella se diferencian tres invariantes monotonales y dos bitonales con sus correspondientes variantes para los acentos tonales ${ }^{2}$ de las zonas canarias, venezolanas y cubanas estudiadas (figura 5) ${ }^{3}$. Nuestra pretensión, como se indica en el apartado 2, es revisar esta última propuesta a partir de análisis más exhaustivos, tanto de corpus experimental como espontáneo (véase en el apartado 3.4. "El etiquetaje prosódico" nuestro posicionamiento al respecto).

\begin{tabular}{|c|c|c|}
\hline ISTRUCTURA RKONUNDA & ESTRUCTURA SUTERTICHAL & NIVELACOSTICO \\
\hline Tnvariante fonologica & Variantes & Esquema del contorno tonal \\
\hline \multirow{2}{*}{$/ \mathbf{L} * \mathbf{H} /$} & {$\left[\mathrm{L}^{*++11]}\right.$} & \\
\hline & {$\left[L^{*+}+111\right]$} & \\
\hline \multirow{2}{*}{$/ \mathbf{L}+\mathbf{H}^{*} /$} & {$\left[\mathrm{L}+\mathrm{H}^{*}\right]$} & \\
\hline & {$\left[1+>11^{*}\right]$} & \\
\hline \multirow{2}{*}{$/ \mathbf{1} *$} & {$[\mathrm{~L} *]$} & \\
\hline & {$\left[: \mathbf{H}+\mathrm{L}^{*}\right]$} & \\
\hline \multirow{5}{*}{$/ \mathbf{H}^{*} /$} & {$\left[\mathrm{H}^{*}\right]$} & \\
\hline & {$\left[: \mathrm{H}^{*}\right]$} & \\
\hline & {$\left[! \mathrm{H}^{*}\right]$} & \\
\hline & {$\left[\mathbf{L}+\mathbf{I} \mathbf{I}^{*}\right]$} & \\
\hline & {$\left[\mathrm{L}+; \mathrm{H}^{*}\right]$} & \\
\hline$! \mathrm{H}^{*}$ & {$\left[\mathbf{L}+: \mathbf{H}^{*}\right]$} & \\
\hline
\end{tabular}

Figura 5. Representación de la estructura profunda, superficial y esquema acústico de los acentos tonales (Dorta ed., 2013)

2 Solo en una zona de las tres que consideran en Venezuela (Mérida) se da la particularidad de que la oposición $/ ! \mathrm{H}^{*} /$ vs. $/ \mathrm{H}^{*} /$ es funcional. Por tanto, si no se diera esta circunstancia, solo tendríamos cuatro acentos tonales invariantes, dos monotonales y dos bitonales.

3 La pretensión de los autores es revisar la propuesta a partir de análisis más exhaustivos, tanto de corpus experimental como espontáneo. 
Asimismo, el tono de frontera final tiene tonos invariantes y sus correspondientes variantes (figura 6).

\begin{tabular}{|c|c|c|}
\hline ESTRUCTURA PROFUNDA & ESTRUCTURA SUPERFICIAL & NIVEL ACUSTICO \\
\hline Invariante fonológica & Variantes & Esquema del contorno tonal \\
\hline \multirow{2}{*}{$/ \mathrm{H} \%$} & [H\%] & $\mathrm{TM}$ \\
\hline & [MH\%] & TM \\
\hline \multirow{3}{*}{ L\%/ } & [L\%] & $\mathrm{TM}$ \\
\hline & [ML\%] & $\mathrm{TM}$ \\
\hline & {$\left[\mathrm{H}_{\mathrm{L}} \%\right]$} & M \\
\hline
\end{tabular}

Figura 6. Representación de la estructura profunda, superficial y esquema acústico de los tonos de frontera (Dorta ed., 2013)

\section{Objetivo}

El objetivo de este trabajo es realizar un estudio fonético-fonológico de la modalidad oracional declarativa del habla de la isla de La Gomera en el marco del proyecto Estudio comparativo de la entonación y del acento en zonas fronterizas del español (FFI201452716-P) vinculado a AMPER (Atlas Multimédia Prosodique de l'Espace Roman). Pretendemos revisar y aplicar los supuestos teóricos esbozados en Dorta (ed. 2013) ampliando el corpus experimental a las oraciones con expansión en los sintagmas de frontera añadiendo, además, un corpus de tipo espontáneo. De este modo, nos proponemos determinar las estructuras tonales del nivel fonológico (invariantes) a partir de las estructuras superficiales (variantes).

\section{Metodología}

\subsection{Informantes}

Los informantes seleccionados para este trabajo son seis con edades comprendidas entre los 18 y los 55 años, con estudios y sin estudios superiores, procedentes de zonas urbanas y rurales de la isla colombina. Véase la tabla número $1^{4}$.

4 En la tabla, + corresponde a estudios superiores; - equivale a sin estudios superiores. 


\begin{tabular}{|c|c|c|c|}
\hline \multicolumn{4}{|c|}{ INFORMANTES } \\
\hline \multicolumn{2}{|c|}{ Zona urbana: San Sebastián } & \multicolumn{2}{c|}{ Zona Rural: Valle Gran Rey } \\
\hline SEXo & NiVEL DE ESTUDIOs & SEXo & NIVEL DE ESTUDIOS \\
\hline Mujer & - & Mujer & - \\
\hline Hombre & - & Hombre & - \\
\hline Mujer & + & & \\
\hline Hombre & + & & \\
\hline
\end{tabular}

Tabla 1

\subsection{Corpus}

\subsubsection{Corpus experimental}

Está constituido por dos conjuntos de oraciones emitidas mediante elicitación textual sin matices emocionales: el primero lo integran oraciones SVO de 11 sílabas del tipo $S N$ (sintagma nominal) $+S V$ (sintagma verbal) + SPrep (sintagma preposicional) sin expansión en los sintagmas nominal o preposicional como por ejemplo: el saxofón se toca con obsesión; el otro conjunto consta de oraciones de 14 y de 15 sílabas con expansión en los sintagmas de frontera. En el sintagma nominal y en el preposicional el núcleo lo forma una palabra trisílaba de diferente tipología acentual. Todas estas combinaciones dan como resultado 63 oraciones declarativas, lo que supone 378 secuencias teniendo en cuenta el conjunto de los seis informantes considerados en este estudio; al haberse realizado tres repeticiones de cada oración el corpus implica 1134 oraciones. La importancia de este tipo de corpus radica en que será el único que estará representado en la base de datos de AMPER internacional con sede en Grenoble (Francia) ya que permite comparar mejor la prosodia de todas las variedades y lenguas románicas al estar constituido por idénticas estructuras en todas ellas. En la tabla 2 se presenta un resumen.

\begin{tabular}{|c|c|c|c|c|}
\hline \multicolumn{7}{|c|}{ CorPus EXPERIMENTAL } \\
\cline { 1 - 4 } Tipo de oración & 3 repeticiones & 6 informantes & \multirow{2}{*}{ Total } \\
\hline Sin expansión & 9 & 27 & 162 & \multirow{2}{*}{1134} \\
\cline { 1 - 3 } Con expansión en el sujeto & 27 & 81 & 486 & \\
\cline { 1 - 3 } Con expansión en el objeto & 27 & 81 & 486 & \\
\hline
\end{tabular}

Tabla 2

\subsubsection{Corpus espontáneo}

Por otro lado, se consideró un corpus más espontáneo de dos tipos: semiespontáneo o inducido (CS) y espontáneo o map task (CE) cuya importancia estriba en que permitirá 
contrastar los resultados obtenidos en el corpus experimental y, por tanto, ver la representatividad de estos últimos. El primero (CS) está constituido por frases que se obtienen mediante el planteamiento al informante de cuestiones de uso muy cotidiano. Por ejemplo: "Estás almorzando con unos amigos y quieres pan: ¿Cómo lo pedirías?”. La respuesta previsible puede ser: "por favor, pásame el pan"; "dame el pan”, etc. El segundo tipo de corpus (CE) se obtiene mediante un sistema de recogida de datos que se plantea a partir de mapas: el informante y el entrevistador deben salir de un punto geográfico y llegar a un destino especificado. Puesto que los dos mapas no son idénticos, ello motivará una serie de preguntas y respuestas por parte de ambos intervinientes. El corpus definitivo está formado por 71 oraciones declarativas con esquema acentual llano en su mayoría y, en menor medida, agudo; en ningún caso fue esdrújulo. Véase en la tabla 3 la distribución del corpus.

\begin{tabular}{|c|c|c|}
\hline \multicolumn{2}{|c|}{ CoRPuS ESPONTÁNEO } \\
\hline \multicolumn{2}{|c|}{ Tipo de corpus } & \multirow{2}{*}{ Total } \\
\cline { 1 - 2 } Semiespontáneo & 52 & \\
\hline Espontáneo & 19 & \\
\hline
\end{tabular}

Tabla 3

Por otra parte, para la delimitación de las oraciones declarativas consideramos el relieve tonal de la frase teniendo en cuenta el trabajo de Torres Álvarez 20005. Por ello, separamos las declarativas que tienen un solo pico tonal máximo, cuya extensión va generalmente de 1 a 7 sílabas (71,1\% en el corpus CS y un 92,8 \% en el CE), de las que presentan más de una cumbre tonal máxima y que superan dichas cifras (+7 sílabas; suponen el $100 \%$ en ambos tipos de corpus).

\subsection{Extracción y análisis acústico de los datos}

El corpus se grabó con una grabadora Marantz PMD 222 y un micrófono direccional Shure SM 48 en un entorno cómodo para el informante. La señal analógica grabada se digitalizó con el programa Goldwave (versión 4.25) convirtiendo cada una de las frases en ficheros .wav, una vez eliminados los posibles ruidos y optimizada la señal resultante que tiene una frecuencia de muestreo de $18.000 \mathrm{~Hz}$. Los ficheros .wav se etiquetaron según la codificación de AMPERCan de la manera siguiente: 9 dígitos + extensión ${ }^{6}$.

5 En el estudio sobre las declarativas del español de Canarias, Torres Álvarez (2000) corrobora que en un $86,28 \%$ las oraciones monocumbres son cortas (de 1 a 7 sílabas) y en un 92,31\% que las oraciones bicumbres son largas (+7 sílabas).

6 Los 9 dígitos de la codificación tienen el siguiente significado: W (dominio lingüístico español); C (variedad español de Canarias); o (isla de La Gomera); número impar (mujer) y número par (hombre): los números 1-2 corresponden a zona urbana sin estudios superiores; los números 3-4 se adjudican a zona rural sin estudios superiores y los números 5-6 a zona urbana con estudios superiores. Los dígitos 5, 6, 7 son letras para identificar cada oración; con el dígito 8 se representa la modalidad: a (declarativa)/i (interrogativa) y, por último, con el dígito 9 se indica el número de repetición de la frase (1, 2 ó 3). P.ej.: una oración codificada como WCo1kwka1 nos da la siguiente información: primera repetición de la oración declarativa con estructura SN A + SPrep A (sintagma nominal agudo más sintagma preposicional agudo) emitida por una mujer urbana sin estudios superiores de la 
El análisis acústico del corpus experimental se realizó con rutinas creadas ad hoc en el año 2006 por el Laboratorio de Fonética de la Universidad de Oviedo (grupo AMPERAstur) para el entorno Matlab (versión 7.0.4.7); para el análisis del corpus semiespontáneo y espontáneo, en cambio, se empleó un script para Praat proporcionado por el Centre de Dialectologie de l'Universitè Stendhal-Grenoble III (AMPER Internacional).

\subsection{El etiquetaje prosódico}

Como todos sabemos, hay elementos que son normales en el habla de una comunidad sin que por ello pertenezcan al sistema. Esta vertiente intermedia la definía Coseriu como "norma":

La norma refleja el equilibrio del sistema en un determinado momento y, cambiando la norma, cambia ese equilibrio, hasta volcarse totalmente de un lado o de otro. [...] En latín clásico era normal la declinación desinencial, pero en muchos casos se empleaban, además, preposiciones que ya de por sí indicaban suficientemente la función: la norma se desplazó cada vez más hacia el empleo de las preposiciones, hasta que el equilibrio del sistema se volcó, quedando de la antigua declinación, en la mayoría de las lenguas romances actuales, apenas la oposición entre singular y plural (Coseriu, 1962: 107-108).

Se aleja así este autor de la dicotomía saussureana que ignora el punto en el que lengua y habla se encuentran, estableciendo un "sistema normal" distinto del "funcional" representado por la lengua. Por tanto, siguiendo a Coseriu, la norma lingüística supone un primer grado de abstracción y el sistema el segundo. A propósito, Sosa señala lo siguiente en el plano de la entonación:

Ahora bien, como en español varias de esas secuencias tonales básicas varían drásticamente de un dialecto a otro, se debe concluir que elementos con el mismo valor pueden tener distinta forma fónica de acuerdo al dialecto. En los casos en que esto ocurre, estas diferencias son tan notorias y constantes que por lo menos algunas de estas deben ser igualmente sistemáticas (Sosa, 1999: 181).

En la presente investigación intentaremos acercarnos al primer grado de abstracción, representado por la norma, con el objetivo de sistematizar la variación entonativa en la comunidad lingüística canaria de La Gomera. Nuestra propuesta de etiquetaje prosódico variantes ha sido aplicada en trabajos recientes del grupo ProFonDis (Dorta ed., 2013) y comparte algunos de los principios ya defendidos en Fernández Planas y Martínez Celdrán (2003) como, por ejemplo, que debe llegarse a las estructuras profundas o invariantes a partir de las estructuras superficiales.

isla de La Gomera. WCo1: zona urbana sin estudios superiores en voz femenina; WCo2: zona urbana sin estudios superiores en voz masculina; WCo3: zona rural sin estudios superiores en voz femenina. WCo4: zona rural sin estudios superiores en voz masculina. WCo5: zona urbana con estudios superiores en voz femenina. WCo6: zona urbana con estudios superiores en voz masculina.

7 Licencia $n^{\circ}$ 256105. Para más información sobre el programa y las subrutinas creadas por el Centre de Dialectologie de Grenoble véase Romano et al. (2005); sobre la adaptación realizada por el grupo Amper-Astur, véase López-Bobo et al. (2007). 
Hay que destacar, por otro lado, que como es usual en el campo que estudiamos, hemos considerado el umbral psicoacústico situado en 1,5 semitonos (Rietveld y Gussenhoven, 1985; Pamies Bertrán et al., 2002) con la finalidad de que las variaciones tonales puedan ser cuantificables. No obstante, a diferencia de Fernández Planas y Martínez Celdrán (2003) o Toledo (2006), por ejemplo, no nos centramos en las diferencias que se establecen entre las vocales que forman los grupos tónicos (pretónica-tónica-postónica) para etiquetar los acentos tonales de las oraciones, sino que consideramos los cambios en la trayectoria de $\mathrm{F}_{0}$, esto es, los movimientos de ascenso y descenso. Por ejemplo, etiquetamos $\left[\mathrm{L}^{*}+\mathrm{H}\right]$ en el primer acento tonal de la oración si el ascenso inicial culmina después de la tónica y el movimiento no alcanza el semitono y medio en el intervalo valle-tónica; si por el contrario alcanza el umbral perceptivo etiquetaremos $\left[\mathrm{L}+>\mathrm{H}^{*}\right]$. En lo que respecta al tono de frontera final, tomamos como referencia el tono medio del informante distinguiendo, por ello, diferentes tonos invariantes ( $\mathrm{H} \% ; \mathrm{L} \% ; \mathrm{M} \% /)$ en función de si el final supera o no la media: detallaremos la relevancia más o menos perceptiva de la relación final-media a partir de los diferentes alótonos considerados en la frontera final. Asimismo, teniendo en cuenta que en la caracterización tonal de las unidades mínimas tonales del AM se excluyen explícitamente del análisis toda referencia a elementos extratonales -como la longitud relativa de las vocales (Sosa, 1999:70)-, en nuestra caracterización fonológica no se considerará la duración vocálica (ni la intensidad) como por ejemplo sucede en Fernández Planas y Martínez Celdrán (2003). En definitiva, como se ha dicho ya, aplicaremos la propuesta que hace el grupo ProFonDis en Dorta (ed. 2013) para representar lo fonético (estructura superficial) y lo fonológico (estructura profunda).

\section{Descripción fonológica de las declarativas}

Teniendo en cuenta que el modelo fonológico en que vamos a basar nuestro estudio es el sistema ToBI (Tones and Break Indices) en el marco del modelo Métrico-Autosegmental (Pierrehumbert, 1980), en los apartados que se insertan a continuación describiremos las propuestas de etiquetaje más recientes (v.gr. Prieto y Roseano eds., 2010 o Dorta ed., 2013).

\subsection{El español general}

En Prieto y Roseano (eds. 2010) ${ }^{8}$, Estebas y Prieto (capítulo 2: 17-48), por un lado, y López-Bobo y Cuevas Alonso (capítulo 3: 49-85), por otro, describen las oraciones declarativas neutras de foco amplio en el español madrileño y cántabro, respectivamente. En las dos zonas del español peninsular las declarativas se caracterizan por un contorno $\mathrm{L}+>\mathrm{H}^{*}$ en el acento prenuclear y $\mathrm{L}^{*} \mathrm{~L} \%$ en el nuclear y tono de frontera final, es decir, el contorno entonativo está formado por un acento prenuclear ascendente, cuyo pico está desplazado a la sílaba postónica y un acento nuclear bajo en la sílaba tónica seguido de un tono de frontera bajo. Véase la figura 7 con la que ilustran Estebas y Prieto el contorno declarativo (Prieto y Roseano eds., 2010 capítulo 2: 24).

8 Los datos se pueden consultar igualmente en el Atlas Interactivo de la entonación del español: http://prosodia.upf.edu/atlasentonacion/cerca/index.php 


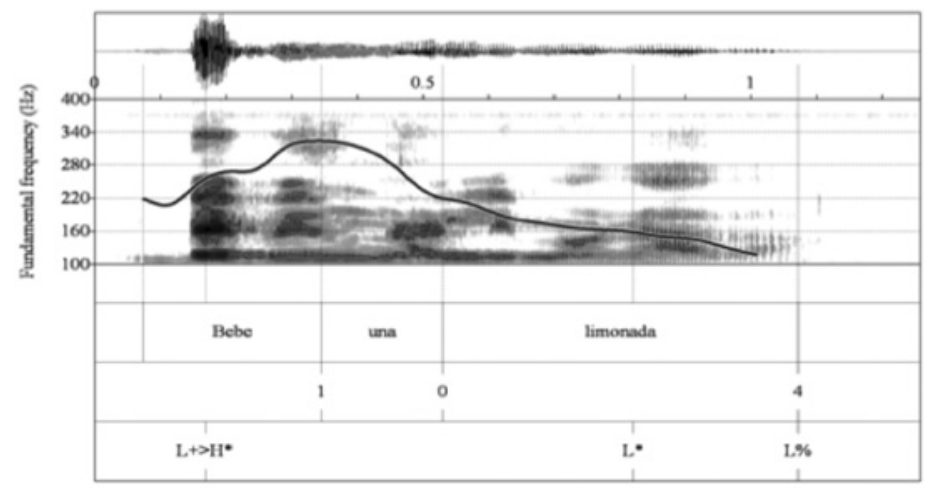

Figura 7. Contorno declarativa de foco amplio. Prieto y Roseano (eds. 2010, capítulo 2:24).

\subsection{El español hispanoamericano}

En Prieto y Roseano (eds. 2010) se describe el español andino de Mérida (en Venezuela, Astruc et al., capítulo 7: 191-226) y Quito (en Equador, O’Rourke, capítulo 8: 227-253), el argentino de Buenos Aires (Christoph et al., capítulo 10: 285-317) y el caribeño de San Juan de Puerto Rico (Armstrong, capítulo 6: 155-189) y de Santiago de los Caballeros en Santo Domingo (Willis, capítulo 5: 123-153); además se aportan datos de Santiago de Chile (Héctor Ortiz et al., capítulo 9: 255-283) y México D.F. (de la Mota et al., capítulo 11: 319350). En relación con las declarativas neutras, en la mayor parte de estos trabajos el patrón no difiere del propuesto para el español general en tanto que el primer acento es $\mathrm{L}+>\mathrm{H}^{*}$, el nuclear $\mathrm{L}^{*}$ y el tono de frontera final $\mathrm{L} \%$. No obstante, se dan algunas diferencias:

a) El primer acento en Buenos Aires es $\mathrm{H}^{*}$ y en Puerto Rico $\mathrm{L}^{*}+\mathrm{H}$ y no el desplazado $\mathrm{L}+>\mathrm{H}^{*}$.

b) El acento nuclear presenta un movimiento ascendente en Mérida (! $\left.\mathrm{H}^{*}\right)$, Santiago de los Caballeros $\left(\mathrm{L}+\mathrm{H}^{*}\right)$ y Santiago de Chile $\left(\mathrm{L}+\mathrm{H}^{*}\right)$ aunque, salvo en la variedad dominicana, desciende finalmente.

Podemos ver un ejemplo en la figura 8 correspondiente a la zona andina venezolana (Astruc et al., capítulo 7: 197).

Respecto del español de Cuba, en Dorta (ed. 2013) se etiqueta en líneas generales el último acento de la frase y el tono de frontera final acorde con el patrón esbozado para el español general, esto es, descendente ( $\mathrm{L}^{*} \mathrm{~L} \%$ ); en cambio, para el primer acento tonal de las declarativas cubanas (y venezolanas) ${ }^{9}$, se propone la invariante $/ \mathrm{L}+\mathrm{H}^{*} /$ cuya variación puede ser $\left[\mathrm{L}+>\mathrm{H}^{*}\right]$ o $\left[\mathrm{L}+\mathrm{H}^{*}\right]$, es decir, se determina un movimiento ascendente durante el primer acento que puede concluir o no en la tónica. A idénticas conclusiones se llegó en un estudio posterior en el que, aplicando la propuesta esbozada en el libro de referencia, se comparó la zona andina de Mérida con la de Medellín (Díaz et al., en prensa).

9 También para Canarias como veremos en el apartado que sigue a continuación (4.3.). 


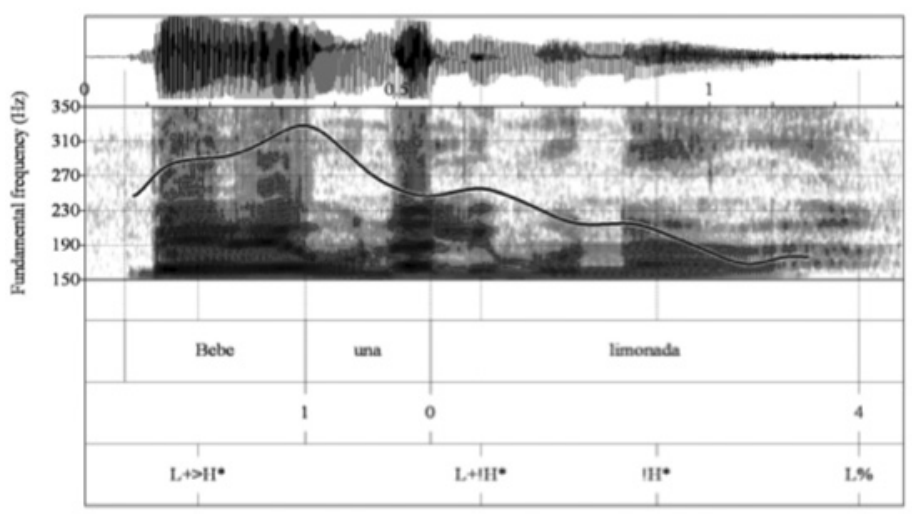

Figura 8. Contorno declarativa de foco amplio. Prieto y Roseano (eds. 2010, capítulo 7: 197).

\subsection{El español de Canarias}

En lo que se refiere a Canarias, en el estudio de Cabrera y Vizcaíno (Prieto y Roseano eds. 2010, capítulo 4: 87-121), se describen las declarativas de Las Palmas de Gran Canaria de acuerdo con los presupuestos teóricos de otros autores del libro en el que se inserta el estudio. Así, las declarativas neutras se caracterizan por un patrón tonal que no se aleja del propuesto para el español peninsular, esto es, con un ascenso en el prenúcleo que finaliza con un pico desplazado a la derecha del acento $\left(\mathrm{L}+>\mathrm{H}^{*}\right)$ y un descenso durante el núcleo que llega hasta el final absoluto (L* L\%). En la figura 9 se ilustra el contorno señalado por los autores.

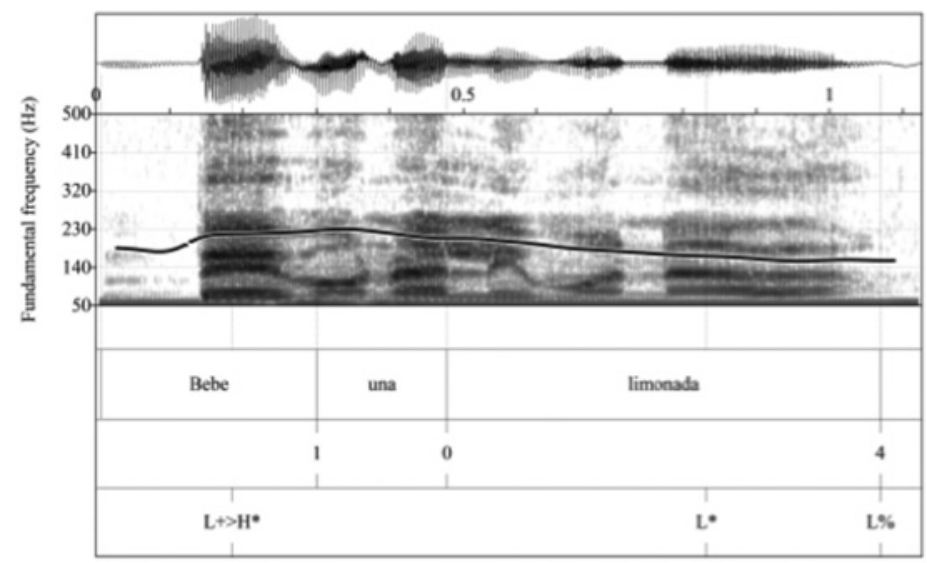

Figura 9. Contorno declarativa de foco amplio. Prieto y Roseano (eds. 2010, capítulo 4: 93).

Los estudios de tipo fonológico en el ámbito de AMPER en Canarias, si bien son más recientes, coinciden con los autores en el etiquetaje fonológico del último acento de la 
oración así como el tono de frontera final para todas las islas del archipiélago (Dorta ed., 2013), con la salvedad del primer acento tonal en el que, como apuntábamos en el apartado anterior, se concibe que la invariante es $\mathrm{L}+\mathrm{H}^{*}$ (y no $\mathrm{L}+>\mathrm{H}^{*}$ ) cuya variación puede ser $\left[\mathrm{L}+>\mathrm{H}^{*}\right]$ o $\left[\mathrm{L}+\mathrm{H}^{*}\right]$.

\section{La interpretación de los movimientos tonales en las declarativas de La Gomera}

\subsection{Corpus experimental}

\subsubsection{Sin expansión}

De acuerdo con la propuesta que aplicamos, el etiquetaje fonético de los tres acentos tonales de este tipo de oraciones y del tono de frontera final de las curvas de los seis informantes gomeros es el que mostramos en la tabla 4 .

\begin{tabular}{|c|c|c|c|c|c|c|c|c|c|c|}
\hline \multirow{3}{*}{\multicolumn{2}{|c|}{ INFORMANTES }} & \multicolumn{9}{|c|}{ Variantes } \\
\hline & & \multicolumn{3}{|c|}{ AGUDO } & \multicolumn{3}{|c|}{ LLANO } & \multicolumn{3}{|c|}{ ESDRÚJULO } \\
\hline & & SN & SV & SPrep & SN & SV & SPrep & SN & SV & SPrep \\
\hline \multirow{2}{*}{$\begin{array}{c}\text { Zona urbana } \\
\text { sin estudios }\end{array}$} & WCo1 & $\mathrm{L}+>\mathrm{H}^{*}$ & $\mathrm{~L}^{*}+\mathrm{H}$ & L*L\% & $\mathrm{L}^{*}+\mathrm{H}$ & $\mathrm{L}^{*}+\mathrm{H}$ & $\mathrm{L} * \mathrm{~L} \%$ & $\mathrm{~L}+>\mathrm{H}^{*}$ & $\mathrm{~L}^{*+\mathrm{H}}$ & L*L\% \\
\hline & $\mathrm{WCo} 2$ & $\mathrm{~L}+>\mathrm{H}^{*}$ & $\mathrm{~L}^{*}$ & $\mathrm{~L} * \mathrm{~L} \%$ & $\mathrm{~L}+>\mathrm{H}^{*}$ & $\mathrm{~L}^{*}$ & $\mathrm{~L} * \mathrm{~L} \%$ & $\mathrm{~L}+>\mathrm{H}^{*}$ & $\mathrm{~L}^{*}$ & $\mathrm{~L} * \mathrm{~L} \%$ \\
\hline \multirow{2}{*}{$\begin{array}{c}\text { Zona rural } \\
\text { sin estudios }\end{array}$} & WCo3 & $\mathrm{L}+>\mathrm{H}^{*}$ & $\mathrm{H}^{*}$ & L*L\% & $\mathrm{L}+>\mathrm{H}^{*}$ & $\mathrm{~L}^{*}$ & $\mathrm{~L} * \mathrm{~L} \%$ & $\mathrm{~L}+>\mathrm{H}^{*}$ & $\mathrm{~L}^{*}$ & $\mathrm{~L} * \mathrm{~L} \%$ \\
\hline & WCo4 & $\mathrm{L}+\mathrm{H}^{*}$ & $\mathrm{H}^{*}$ & L*L\% & $\mathrm{L}+>\mathrm{H}^{*}$ & $\mathrm{H}^{*}$ & $\mathrm{~L} * \mathrm{~L} \%$ & $\mathrm{~L}+>\mathrm{H}^{*}$ & $\mathrm{H}^{*}$ & L*L\% \\
\hline \multirow{2}{*}{$\begin{array}{l}\text { Zona urbana } \\
\text { con estudios }\end{array}$} & WCo5 & $\mathrm{L}+\mathrm{H}^{*}$ & $\mathrm{~L}^{*}$ & $\mathrm{~L} * \mathrm{~L} \%$ & $\mathrm{~L}+>\mathrm{H}^{*}$ & $\mathrm{~L}^{*}$ & $\mathrm{~L} * \mathrm{~L} \%$ & $\mathrm{~L}+\mathrm{H}^{*}$ & $\mathrm{~L}^{*}$ & $\mathrm{~L} * \mathrm{~L} \%$ \\
\hline & WCo6 & $\mathrm{L}+\mathrm{H}^{*}$ & $\mathrm{~L}^{*}$ & L*L\% & $\mathrm{L}+>\mathrm{H}^{*}$ & $\mathrm{~L}^{*}+\mathrm{H}$ & $\mathrm{L} * \mathrm{~L} \%$ & $\mathrm{~L}+>\mathrm{H}^{*}$ & $\mathrm{~L}^{*}$ & $\mathrm{~L}^{*} \mathrm{~L} \%$ \\
\hline
\end{tabular}

\section{Tabla 4}

En la tabla precedente puede observarse que las declarativas sin expansión están constituidas por dos acentos prenucleares y uno nuclear:

a) En el prenúcleo, determinamos como invariante del primer acento (SN) un contorno ascendente bitonal $\left(/ \mathrm{L}+\mathrm{H}^{*} /\right)$ que puede realizarse dentro de los límites de la tónica ([L+H*], $22,2 \%$ ) o con el pico desplazado a la postónica ([L+> $\left.\mathrm{H}^{*}\right], 72,2 \%$ ); el segundo acento del pretonema (SV) presenta mayor variabilidad que el anterior en tanto que encontramos dos variantes monotonales $\left(\left[\mathrm{H}^{*}\right]\right.$ y $\left.\left[\mathrm{L}^{*}\right]\right)$ y una bitonal $\left(\left[\mathrm{L}^{*}+\mathrm{H}\right]\right)$.

En lo que respecta a las variantes monotonales, observamos lo siguiente:

$\left.1^{\circ}\right)\left[\mathrm{H}^{*}\right]\left(/ \mathrm{H}^{*} /\right)$ : se reduce al ámbito rural (no siempre en todas las combinaciones [22,2\%] $v$. $g r$ WCo3) por lo que parece una característica de este tipo de habla. Recordemos que Sosa indicaba (1999:228) que la impresión de "agudo o grave" que puede connotar un dialecto guarda relación con la frecuencia de uso de tonos $\mathrm{H}^{*}$.

$\left.2^{\circ}\right)\left[\mathrm{L}^{*}\right]\left(/ \mathrm{L}^{*} /\right)$ : esta variante es la más sistemática en la configuración del segundo acento prenuclear de las declarativas puesto que cuenta con el mayor porcentaje de realización (55,5\% de los casos). 
La variante bitonal $\left[\mathrm{L}^{*+\mathrm{H}}\right]\left(/ \mathrm{L}^{*+\mathrm{H}} /\right)$, esto es, la caracterizada por un acento bajo durante la tónica seguido de un tono alto, se da en un $22,2 \%$. Nótese que se registra en las tres combinaciones de la mujer de zona urbana sin estudios (WCo1).

b) El acento nuclear de las declarativas es descendente y culmina con un tono de frontera bajo en todos los casos $(/ \mathrm{L} * \mathrm{~L} \% /)$.

En la taba 5 incluimos las invariantes y sus variantes más frecuentes con los porcentajes de aparición ${ }^{10}$.

\begin{tabular}{|c|c|c|c|c|c|c|c|}
\hline \multicolumn{2}{|c|}{ Invariantes y variantes } \\
\hline \multicolumn{2}{|c|}{ SN } & \multicolumn{2}{|c|}{ SV } & \multicolumn{4}{c|}{ SPrep } \\
\hline \multicolumn{2}{|c|}{ Acento 1 } & \multicolumn{2}{|c|}{ Acento 2 } & \multicolumn{2}{|c|}{ Acento 3 } & \multicolumn{2}{c|}{$\%$} \\
\hline $\mathbf{I}$ & $\mathbf{V}$ & $\mathbf{I}$ & $\mathbf{V}$ & $\mathbf{I}$ & $\mathbf{V}$ & $\mathbf{I}$ & $\mathbf{V}$ \\
\hline & $\mathrm{L}+\mathrm{H}^{*} 22,2 \%$ \\
$\mathbf{L}+\mathbf{H}^{*}$ & $\mathrm{~L}+>\mathrm{H}^{*} 72,2 \% 0^{11}$ & $\mathbf{L}^{*}$ & $\mathrm{~L}^{*} 55,5 \%{ }^{12}$ & $\mathbf{L}^{*}$ & $\mathrm{~L}^{*} 100 \%$ & $\mathbf{L} \%$ & $\mathrm{~L} \% 100 \%$ \\
\hline
\end{tabular}

\section{Tabla 5}

Finalmente, de acuerdo con la propuesta aplicada, ofrecemos en la tabla 6 la interpretación de los dos acentos prenucleares de las declarativas sin expansión ( $\mathrm{SN}$ y SV) y, asimismo, del acento nuclear y tono de frontera final (SPrep), esto es, las invariantes.

\begin{tabular}{|c|c|c|}
\hline \multicolumn{3}{|c|}{ Invariantes } \\
\hline SN & SV & SPrep \\
\hline $\mathrm{L}^{*} \mathrm{H}^{*}$ & $\mathrm{~L}^{*}$ & $\mathrm{~L} * \mathrm{~L} \%$ \\
\hline
\end{tabular}

\section{Tabla 6}

De lo anterior, podemos concluir que lo que caracteriza a las declarativas sin expansión de manera sistemática es un ascenso durante el primer acento tonal que deja a la tónica en un tono alto $\left(/ \mathrm{L}+\mathrm{H}^{*} /\right)$; un acento final descendente que culmina en un tono de frontera bajo $\left(/ \mathrm{L}^{*} \mathrm{~L} \% /\right) \mathrm{y}$, generalmente, la presencia de un tono bajo $(/ \mathrm{L} * /)$ en el último acento prenuclear, tal como se ilustra en las figuras 10 y 11 correspondientes a una mujer (WCo5) y a un hombre (WCo2).

10 No hay que olvidar que al tratarse de las curvas de cada informante y no de las medias del conjunto de los informantes como se ha hecho en trabajos anteriores (v.gr. Dorta, Martín y Díaz, 2015) hay mayor probabilidad de variación.

11 El 5,6\% restante corresponde al etiquetaje $\left[\mathrm{L}^{*}+\mathrm{H}\right]$ que de ninguna manera podemos considerar variante de $\left[\mathrm{L}+\mathrm{H}^{*}\right]$ sino una realización esporádica como indica el propio porcentaje.

12 El 44,4\% que falta en la casilla corresponde a la realización $\left[\mathrm{H}^{*}\right](22,2 \%)$ y [L*+H] $(22,2 \%)$. 


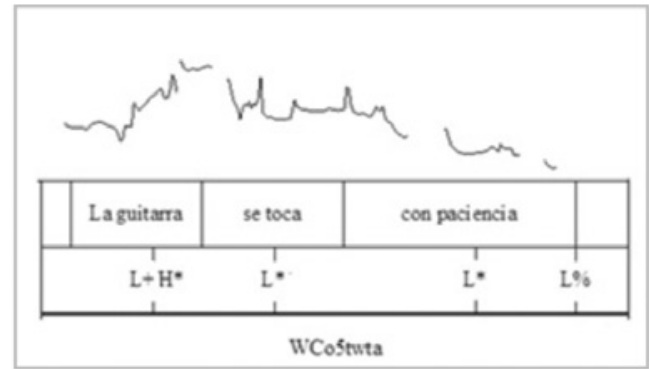

WCo5 (Sexo femenino)
Figuras 10-11

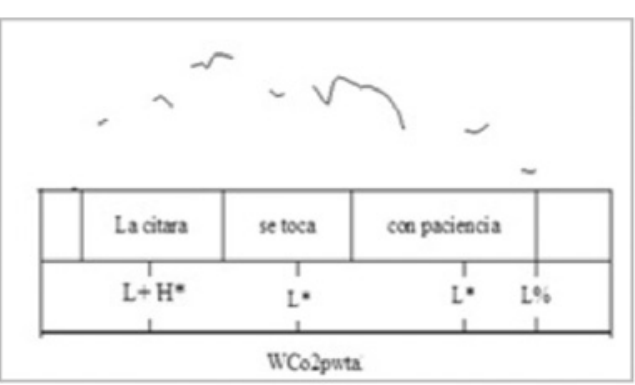

WCo3 (Sexo masculino)

\subsubsection{Con expansión en los sintagmas de frontera}

a) El sintagma sujeto consta ahora de un núcleo (N) seguido de una expansión (Exp); en ambos casos aparecen los tres acentos característicos del español (agudo -A-, llano -LL-, y esdrújulo -E-). El resultado de la notación prosódica de los dos primeros acentos tonales de la oración es el que se muestra en las tablas 7-9.

\begin{tabular}{|c|c|c|c|c|c|c|c|}
\hline \multirow{2}{*}{\multicolumn{2}{|c|}{ INFORMANTES }} & \multicolumn{7}{|c|}{ NÚCLEO AGUDO } \\
\cline { 2 - 8 } & $\mathbf{N}$ & Exp A & N & Exp LL & N & Exp E \\
\hline \multirow{2}{*}{$\begin{array}{c}\text { Zona urbana } \\
\text { sin estudios }\end{array}$} & WCo1 & $\mathrm{L}+>\mathrm{H}^{*}$ & $\mathrm{~L}^{*}+\mathrm{H}$ & $\mathrm{L}+\mathrm{H}^{*}$ & $¡ \mathrm{H}^{*}$ & $\mathrm{~L}+>\mathrm{H}^{*}$ & $\mathrm{H}^{*}$ \\
\cline { 2 - 8 } & $\mathrm{WCo} 2$ & $\mathrm{~L}+\mathrm{H}$ & $\mathrm{H}^{*}$ & $\mathrm{~L}+>\mathrm{H}^{*}$ & $\mathrm{H}^{*}$ & $\mathrm{~L}+>\mathrm{H}^{*}$ & $\mathrm{H}^{*}$ \\
\hline \multirow{2}{*}{$\begin{array}{c}\text { Zona rural } \\
\text { sin estudios }\end{array}$} & $\mathrm{WCo} 3$ & $\mathrm{~L}+>\mathrm{H}^{*}$ & $\mathrm{H}^{*}$ & $\mathrm{~L}+>\mathrm{H}^{*}$ & $\mathrm{H}^{*}$ & $\mathrm{~L}+>\mathrm{H}^{*}$ & $\mathrm{H}^{*}$ \\
\cline { 2 - 8 } & $\mathrm{WCo} 4$ & $\mathrm{~L}+\mathrm{H}^{*}$ & $\mathrm{H}^{*}$ & $\mathrm{~L}+\mathrm{H}^{*}$ & $\mathrm{H}^{*}$ & $\mathrm{~L}+>\mathrm{H}^{*}$ & $\mathrm{H}^{*}$ \\
\hline $\begin{array}{c}\text { Zona urbana } \\
\text { con estudios }\end{array}$ & $\mathrm{WCo5}$ & $\mathrm{L}+>\mathrm{H}^{*}$ & $\mathrm{H}^{*}$ & $\mathrm{~L}+>\mathrm{H}^{*}$ & $\mathrm{H}+\mathrm{L}^{*}$ & $\mathrm{~L}+\mathrm{H}^{*}$ & $\mathrm{H}^{*}$ \\
\cline { 2 - 8 } & $\mathrm{WCo} 6$ & $\mathrm{~L}+>\mathrm{H}^{*}$ & $\mathrm{H}+\mathrm{L}^{*}$ & $\mathrm{~L}+\mathrm{H}^{*}$ & $\mathrm{H}^{*}$ & $\mathrm{~L}+>\mathrm{H}^{*}$ & $\mathrm{H}^{*}$ \\
\hline
\end{tabular}

Tabla 7

\begin{tabular}{|c|c|c|c|c|c|c|c|}
\hline \multirow{2}{*}{\multicolumn{2}{|c|}{ INFORMANTES }} & \multicolumn{6}{|c|}{ NÚCLEO LLANO } \\
\hline & & \multirow{2}{*}{$\frac{\mathbf{N}}{\mathrm{L}^{*+\mathrm{H}}}$} & \multirow{2}{*}{$\begin{array}{c}\operatorname{Exp~A~} \\
L^{*}+H\end{array}$} & \multirow{2}{*}{$\begin{array}{c}\mathbf{N} \\
\mathrm{L}^{*}+\mathrm{H}\end{array}$} & \multirow{2}{*}{$\begin{array}{c}\operatorname{Exp} \mathbf{L L} \\
\mathrm{L}^{*}+\mathrm{H}\end{array}$} & \multirow{2}{*}{$\frac{\mathbf{N}}{\mathrm{L}^{*}+\mathrm{H}}$} & \multirow{2}{*}{$\begin{array}{c}\operatorname{Exp} \mathbf{E} \\
H^{*}\end{array}$} \\
\hline Zona urbana & WCo1 & & & & & & \\
\hline sin estudios & WCo2 & $\mathrm{L}+>\mathrm{H}^{*}$ & $\mathrm{~L}^{*}+\mathrm{H}$ & $\mathrm{L}+>\mathrm{H}^{*}$ & $\mathrm{H}^{*}$ & $\mathrm{~L}+>\mathrm{H}^{*}$ & $\mathrm{H}^{*}$ \\
\hline \multirow{2}{*}{$\begin{array}{c}\text { Zona rural } \\
\text { sin estudios }\end{array}$} & WCo3 & $\mathrm{L}^{*+\mathrm{H}}$ & $\mathrm{H}^{*}$ & $\mathrm{~L}+>\mathrm{H}^{*}$ & $\mathrm{H}^{*}$ & $\mathrm{~L}+>\mathrm{H}^{*}$ & $\mathrm{H}^{*}$ \\
\hline & WCo4 & $\mathrm{L}+>\mathrm{H}^{*}$ & $\mathrm{~L}^{*}+\mathrm{H}$ & $\mathrm{L}+\mathrm{H}^{*}$ & $\mathrm{H}^{*}$ & $\mathrm{~L}+>\mathrm{H}^{*}$ & $\mathrm{H}^{*}$ \\
\hline \multirow{2}{*}{$\begin{array}{l}\text { Zona urbana } \\
\text { con estudios }\end{array}$} & WCo5 & $\mathrm{L}+>\mathrm{H}^{*}$ & $\mathrm{H}^{*}$ & $\mathrm{~L}+>\mathrm{H}^{*}$ & $\mathrm{H}^{*}$ & $\mathrm{~L}+>\mathrm{H}^{*}$ & $\mathrm{H}^{*}$ \\
\hline & WCo6 & $\mathrm{L}+>\mathrm{H}^{*}$ & $\mathrm{~L}+\mathrm{H}^{*}$ & $\mathrm{~L}+>\mathrm{H}^{*}$ & $\mathrm{~L}^{*}+\mathrm{H}$ & $\mathrm{L}+>\mathrm{H}^{*}$ & $\mathrm{~L}^{*}+\mathrm{H}$ \\
\hline
\end{tabular}

Tabla 8 


\begin{tabular}{|c|c|c|c|c|c|c|c|}
\hline \multirow{2}{*}{\multicolumn{2}{|c|}{ INFORMANTES }} & \multicolumn{6}{|c|}{ NÚCLEO ESDRÚJULO } \\
\hline & & \multirow{2}{*}{$\frac{\mathbf{N}}{\mathrm{L}+>\mathrm{H}^{*}}$} & \multirow{2}{*}{$\frac{\operatorname{Exp} \mathbf{A}}{L+>_{i} H^{*}}$} & \multirow{2}{*}{$\frac{\mathbf{N}}{\mathrm{L}+>\mathrm{H}^{*}}$} & \multirow{2}{*}{$\begin{array}{c}\operatorname{Exp} \mathbf{L L} \\
\mathrm{L}^{*}+\mathrm{H} \\
\end{array}$} & \multirow{2}{*}{$\frac{\mathbf{N}}{\mathrm{L}+>\mathrm{H}^{*}}$} & \multirow{2}{*}{$\frac{\operatorname{Exp} \mathbf{E}}{\mathrm{H}^{*}}$} \\
\hline Zona urbana & WCo1 & & & & & & \\
\hline sin estudios & $\mathrm{WCo} 2$ & $\mathrm{~L}+>\mathrm{H}^{*}$ & $\mathrm{~L}+\mathrm{H}^{*}$ & $\mathrm{~L}+>\mathrm{H}^{*}$ & $\mathrm{H}^{*}$ & $\mathrm{~L}+>\mathrm{H}^{*}$ & $\mathrm{H}^{*}$ \\
\hline \multirow{2}{*}{$\begin{array}{c}\text { Zona rural } \\
\text { sin estudios }\end{array}$} & WCo3 & $\mathrm{L}+>\mathrm{H}^{*}$ & $\mathrm{~L}^{*+\mathrm{H}}$ & $\mathrm{L}+>\mathrm{H}^{*}$ & $\mathrm{H}^{*}$ & $\mathrm{~L}+>\mathrm{H}^{*}$ & $\mathrm{H}^{*}$ \\
\hline & WCo4 & $\mathrm{L}+>\mathrm{H}^{*}$ & $\mathrm{~L}^{*+\mathrm{H}}$ & $\mathrm{L}+>\mathrm{H}^{*}$ & $\mathrm{~L}+>\mathrm{H}^{*}$ & $\mathrm{~L}+>\mathrm{H}^{*}$ & $\mathrm{H}^{*}$ \\
\hline \multirow{2}{*}{$\begin{array}{l}\text { Zona urbana } \\
\text { con estudios }\end{array}$} & WCo5 & $\mathrm{L}+>\mathrm{H}^{*}$ & $\mathrm{H}^{*}$ & $\mathrm{~L}+>\mathrm{H}^{*}$ & $\mathrm{H}^{*}$ & $\mathrm{~L}+>\mathrm{H}^{*}$ & $\mathrm{H}^{*}$ \\
\hline & WCo6 & $\mathrm{L}+>\mathrm{H}^{*}$ & $\mathrm{~L}+\mathrm{H}^{*}$ & $\mathrm{~L}+>\mathrm{H}^{*}$ & $\mathrm{~L}^{*}+\mathrm{H}$ & $\mathrm{L}+>\mathrm{H}^{*}$ & $\mathrm{~L}^{*}+\mathrm{H}$ \\
\hline
\end{tabular}

Tabla 9

Como se observa en las tablas, el primer acento de las declarativas es ascendente con el pico desplazado a la postónica $\left[\mathrm{L}+>\mathrm{H}^{*}\right]$ en prácticamente todos los casos $(79,6 \%)$. Esta realización, como hemos visto para las declarativas sin expansión, la consideramos variante del contorno bitonal $/ \mathrm{L}+\mathrm{H}^{*} /$ puesto que lo relevante es que el ascenso inicial de la $\mathrm{F}_{0}$ alcance la tónica aunque culmine después de esta; solo puntualmente el ascenso inicial se origina después de la tónica $([\mathrm{L} *+\mathrm{H}] 9,3 \%)$.

La expansión, en cambio, presenta frecuentemente un acento tonal alto $\left(/ \mathrm{H}^{*} /\right)$ que se manifiesta con variantes o estructuras superficiales monotonales $\left(\left[\mathrm{H}^{*}\right]\right.$ o $\left.\left[{ }_{i} \mathrm{H}^{*}\right]\right)$ o bitonales $\left(\left[\mathrm{L}+\mathrm{H}^{*}\right] ;\left[\mathrm{L}+>\mathrm{H}^{*}\right] ;\left[\mathrm{L}+>_{i} \mathrm{H}^{*}\right]\right)$ puesto que la $\mathrm{F}_{0}$ asciende de manera brusca en el primer elemento del sintagma (núcleo sintagmático) estabilizando su movimiento en la expansión; por ello, en pocos casos el segundo ascenso de la frecuencia presenta un valle con suficiente profundidad ( $\geq 1,5 \mathrm{st}$ ) como para que podamos etiquetar $/ \mathrm{L} /$ en la estructura profunda $\left(\left[\mathrm{L}+\mathrm{H}^{*}\right]\right.$ $5,6 \% ;\left[\mathrm{L}+>\mathrm{H}^{*}\right] 1,8 \%$ o [L+> $\left.\left.\mathrm{H}^{*}\right] 1,8 \%\right)$ o que la tónica se encuentre baja $(/ \mathrm{L} * /:[\mathrm{L} *+\mathrm{H}] 22,2$ $\%$; $\left[\mathrm{H}+\mathrm{L}^{*}\right] 3,7 \%$ ). En la tabla 10 podemos ver un resumen de lo expuesto en las tablas 7-9.

\begin{tabular}{|c|c|c|c|}
\hline \multicolumn{4}{|c|}{ Invariantes y variantes } \\
\hline \multicolumn{4}{|c|}{ SN } \\
\hline \multirow{2}{*}{\multicolumn{2}{|c|}{$\begin{array}{c}\mathrm{N} \\
\text { Acento } 1 \\
\end{array}$}} & \multicolumn{2}{|c|}{$\operatorname{Exp}$} \\
\hline & & \multicolumn{2}{|c|}{ Acento 2} \\
\hline I & $\mathbf{V}$ & I & $\mathbf{V}$ \\
\hline $\mathrm{L}+\mathrm{H}^{*}$ & $\begin{array}{c}\mathrm{L}+\mathrm{H}^{*} 11,1 \% \\
\mathrm{~L}+>\mathrm{H}^{*} 79,6 \% 13\end{array}$ & $\mathrm{H}^{*}$ & $\begin{array}{c}\mathrm{H}^{*} 63 \% \\
¡ \mathrm{H}^{*} 1,8 \% \\
\mathrm{~L}+\mathrm{H}^{*} 5,6 \% \\
\mathrm{~L}+>\mathrm{H}^{*} 1,8 \% \\
\mathrm{~L}+>_{i} \mathrm{H}^{*} 1,8 \%{ }^{14}\end{array}$ \\
\hline
\end{tabular}

Tabla 10

13 El 9,3\% restante que falta en la casilla corresponde al etiquetaje [L*+H].

14 El 26\% restante corresponde al etiquetaje $\left[\mathrm{L}^{*}+\mathrm{H}\right](22,2 \%)$ y $\left[\mathrm{H}+\mathrm{L}^{*}\right](3,7 \%)$ realizaciones más esporádicas. 
En definitiva, el núcleo del sintagma nominal se caracteriza por presentar en su estructura profunda un acento ascendente $\left(/ \mathrm{L}+\mathrm{H}^{*} /\right)$ seguido de un acento alto en la sílaba tónica $\left(/ \mathrm{H}^{*} /\right)$ durante la expansión, tal como reflejamos en la tabla 11 e ilustramos en las figuras 12 y 13 .

\begin{tabular}{|c|c|}
\hline \multicolumn{2}{|c|}{ Invariantes } \\
\hline \multicolumn{2}{|c|}{ SN } \\
\hline $\mathbf{N}$ & $\mathbf{E x p}$ \\
\hline $\mathrm{L}+\mathrm{H}^{*}$ & $\mathrm{H}^{*}$ \\
\hline
\end{tabular}

Tabla 11

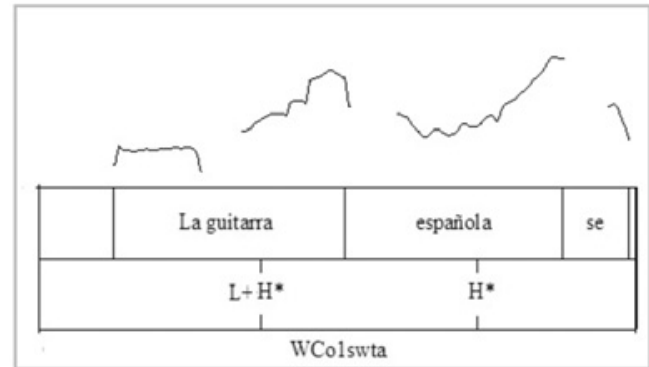

WCo1 (Sexo femenino)
Figuras 12-13

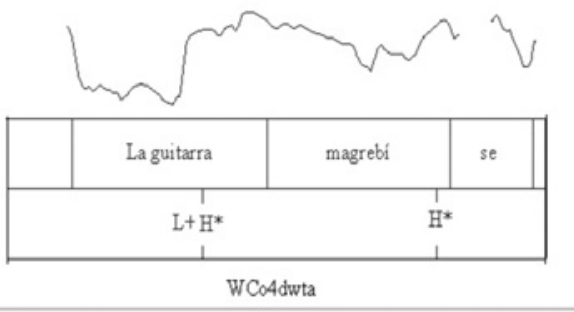

WCo4 (Sexo masculino)

b) Las tablas 12-14 reflejan la interpretación de los dos últimos acentos tonales de las declarativas con expansión en el objeto y el tono de frontera final de los seis informantes. La tabla 15 resume las invariantes que aparecen en dichas tablas, así como sus realizaciones con el correspondiente porcentaje de aparición.

\begin{tabular}{|c|c|c|c|c|c|c|c|}
\hline \multirow{2}{*}{\multicolumn{2}{|c|}{ INFORMANTES }} & \multicolumn{7}{|c|}{ NÚCLEO AGUDO } \\
\cline { 2 - 8 } & N & Exp A & N & Exp LL & N & Exp E \\
\hline \multirow{2}{*}{$\begin{array}{c}\text { Zona urbana } \\
\text { sin estudios }\end{array}$} & WCo1 & $\mathrm{L}+>\mathrm{H}^{*}$ & $\mathrm{~L} * \mathrm{~L} \%$ & $\mathrm{~L}+! \mathrm{H}^{*}$ & $\mathrm{~L} * \mathrm{~L} \%$ & $\mathrm{~L}+! \mathrm{H}^{*}$ & $\mathrm{~L} * \mathrm{~L} \%$ \\
\cline { 2 - 8 } & $\mathrm{WCo} 2$ & $\mathrm{~L}+\mathrm{H}^{*}$ & $\mathrm{~L} * \mathrm{~L} \%$ & $\mathrm{~L}+>\mathrm{H}^{*}$ & $\mathrm{~L} * \mathrm{~L} \%$ & $\mathrm{~L}+\mathrm{H}^{*}$ & $\mathrm{~L} * \mathrm{~L} \%$ \\
\hline $\begin{array}{c}\text { Zona rural } \\
\text { sin estudios }\end{array}$ & $\mathrm{WCo} 3$ & $\mathrm{~L}+>\mathrm{H}^{*}$ & $\mathrm{~L} * \mathrm{~L} \%$ & $\mathrm{~L}+>\mathrm{H}^{*}$ & $\mathrm{~L} * \mathrm{~L} \%$ & $\mathrm{~L} *$ & $\mathrm{~L} * \mathrm{~L} \%$ \\
\cline { 2 - 8 } & $\mathrm{WCo} 4$ & $\mathrm{~L} * \mathrm{H}$ & $\mathrm{L} * \mathrm{~L} \%$ & $\mathrm{~L}+\mathrm{H}^{*}$ & $\mathrm{~L} * \mathrm{~L} \%$ & $\mathrm{~L}+! \mathrm{H}^{*}$ & $\mathrm{~L} * \mathrm{~L} \%$ \\
\hline $\begin{array}{c}\text { Zona urbana } \\
\text { con estudios }\end{array}$ & $\mathrm{WCo} 5$ & $\mathrm{~L}+\mathrm{H}^{*}$ & $\mathrm{~L} * \mathrm{~L} \%$ & $\mathrm{~L}+\mathrm{H}^{*}$ & $\mathrm{~L} * \mathrm{~L} \%$ & $\mathrm{~L}+\mathrm{H}^{*}$ & $\mathrm{~L} * \mathrm{~L} \%$ \\
\cline { 2 - 8 } & $\mathrm{WCo} 6$ & $\mathrm{~L}+! \mathrm{H}^{*}$ & $\mathrm{~L} * \mathrm{~L} \%$ & $\mathrm{~L}+! \mathrm{H}^{*}$ & $\mathrm{~L} * \mathrm{~L} \%$ & $\mathrm{~L}+\mathrm{H}^{*}$ & $\mathrm{~L} * \mathrm{~L} \%$ \\
\hline
\end{tabular}

Tabla 12 


\begin{tabular}{|c|c|c|c|c|c|c|c|}
\hline \multirow{2}{*}{ INFORMANTES } & \multicolumn{7}{|c|}{ NÚCLEO LLANO } \\
\cline { 2 - 8 } & N & Exp A & N & Exp LL & N & Exp E \\
\hline \multirow{2}{*}{$\begin{array}{c}\text { Zona urbana } \\
\text { sin estudios }\end{array}$} & $\mathrm{WCo} 1$ & $\mathrm{~L}+>\mathrm{H}^{*}$ & $\mathrm{~L} * \mathrm{~L} \%$ & $\mathrm{~L} *+\mathrm{H}$ & $\mathrm{L} * \mathrm{~L} \%$ & $\mathrm{~L} *+\mathrm{H}$ & $\mathrm{L} * \mathrm{~L} \%$ \\
\cline { 2 - 8 } & $\mathrm{WCo} 2$ & $\mathrm{H}^{*}$ & $\mathrm{~L} * \mathrm{~L} \%$ & $\mathrm{H}^{*}$ & $\mathrm{~L} * \mathrm{~L} \%$ & $\mathrm{H}^{*}$ & $\mathrm{~L} * \mathrm{~L} \%$ \\
\hline $\begin{array}{c}\text { Zona rural } \\
\text { sin estudios }\end{array}$ & $\mathrm{WCo} 3$ & $\mathrm{~L}+>\mathrm{H}^{*}$ & $\mathrm{~L} * \mathrm{~L} \%$ & $\mathrm{~L} *+\mathrm{H}$ & $\mathrm{L} * \mathrm{~L} \%$ & $\mathrm{~L}+>\mathrm{H}^{*}$ & $\mathrm{~L} * \mathrm{~L} \%$ \\
\cline { 2 - 8 } & $\mathrm{WCo} 4$ & $\mathrm{~L}+>\mathrm{H}^{*}$ & $\mathrm{~L} * \mathrm{~L} \%$ & $\mathrm{~L} *+\mathrm{H}$ & $\mathrm{L} * \mathrm{~L} \%$ & $\mathrm{~L} *$ & $\mathrm{~L} * \mathrm{~L} \%$ \\
\hline $\begin{array}{c}\text { Zona urbana } \\
\text { con estudios }\end{array}$ & $\mathrm{WCo} 5$ & $\mathrm{~L}+\mathrm{H}^{*}$ & $\mathrm{~L} * \mathrm{~L} \%$ & $\mathrm{~L}+>\mathrm{H}^{*}$ & $\mathrm{~L} * \mathrm{~L} \%$ & $\mathrm{~L}+>\mathrm{H}^{*}$ & $\mathrm{~L} * \mathrm{~L} \%$ \\
\cline { 2 - 8 } & $\mathrm{WCo} 6$ & $\mathrm{~L}+>\mathrm{H}^{*}$ & $\mathrm{~L} * \mathrm{~L} \%$ & $\mathrm{~L}+>\mathrm{H}^{*}$ & $\mathrm{~L} * \mathrm{~L} \%$ & $\mathrm{~L}+>\mathrm{H}^{*}$ & $\mathrm{~L} * \mathrm{~L} \%$ \\
\hline
\end{tabular}

Tabla 13

\begin{tabular}{|c|c|c|c|c|c|c|c|}
\hline \multirow{2}{*}{\multicolumn{2}{|c|}{ INFORMANTES }} & \multicolumn{6}{|c|}{ NÚCLEO ESDRÚJULO } \\
\hline & & \multirow{2}{*}{$\frac{\mathbf{N}}{\mathrm{L}^{*+}+{ }_{\mathrm{i}} \mathrm{H}}$} & \multirow{2}{*}{$\begin{array}{l}\operatorname{Exp} \mathbf{A} \\
L * L \% \\
\end{array}$} & \multirow{2}{*}{$\frac{\mathbf{N}}{\mathrm{L}^{*}+\mathrm{H}}$} & \multirow{2}{*}{$\frac{\operatorname{Exp} \mathbf{L L}}{\mathrm{L} * \mathrm{~L} \%}$} & \multirow{2}{*}{$\frac{\mathbf{N}}{\mathrm{L}^{*+\mathrm{H}}}$} & \multirow{2}{*}{$\frac{\operatorname{Exp} \mathbf{E}}{L * L \%}$} \\
\hline Zona urbana & WCo1 & & & & & & \\
\hline sin estudios & WCo2 & $\mathrm{L}^{*}+\mathrm{H}$ & $\mathrm{L} * \mathrm{~L} \%$ & $\mathrm{H}^{*}$ & $\mathrm{~L} * \mathrm{~L} \%$ & $\mathrm{H}^{*}$ & $\mathrm{~L} * \mathrm{~L} \%$ \\
\hline \multirow{2}{*}{$\begin{array}{l}\text { Zona rural sin } \\
\text { estudios }\end{array}$} & WCo3 & $\mathrm{H}^{*}$ & $\mathrm{~L} * \mathrm{~L} \%$ & $\mathrm{H}^{*}$ & $\mathrm{~L} * \mathrm{~L} \%$ & $\mathrm{H}^{*}$ & $\mathrm{~L} * \mathrm{~L} \%$ \\
\hline & WCo4 & $\mathrm{H}^{*}$ & $\mathrm{~L} * \mathrm{~L} \%$ & $\mathrm{~L}^{*+\mathrm{H}}$ & $\mathrm{L} * \mathrm{~L} \%$ & $\mathrm{H}^{*}$ & $\mathrm{~L} * \mathrm{~L} \%$ \\
\hline \multirow{2}{*}{$\begin{array}{l}\text { Zona urbana } \\
\text { con estudios }\end{array}$} & WCo5 & $\mathrm{L}+>_{i} \mathrm{H}^{*}$ & $\mathrm{~L} * \mathrm{~L} \%$ & $\mathrm{~L}+>\mathrm{H}^{*}$ & $\mathrm{~L} * \mathrm{~L} \%$ & $\mathrm{~L}+>\mathrm{H}^{*}$ & $\mathrm{~L} * \mathrm{~L} \%$ \\
\hline & WCo6 & $\mathrm{H}^{*}$ & $\mathrm{~L} * \mathrm{~L} \%$ & $\mathrm{~L}^{*}+\mathrm{H}$ & $\mathrm{L} * \mathrm{~L} \%$ & $\mathrm{~L} *+\mathrm{H}$ & $\mathrm{L} * \mathrm{~L} \%$ \\
\hline
\end{tabular}

Tabla 14

\begin{tabular}{|c|c|c|c|c|c|}
\hline \multicolumn{6}{|c|}{ Invariantes y variantes } \\
\hline \multicolumn{6}{|c|}{ SPrep } \\
\hline \multirow{2}{*}{\multicolumn{2}{|c|}{$\begin{array}{c}\text { N } \\
\text { Acento } 3\end{array}$}} & \multicolumn{4}{|c|}{ Exp } \\
\hline & & \multicolumn{2}{|c|}{ Acento 4} & \multicolumn{2}{|c|}{$\%$} \\
\hline $\mathbf{I}$ & $\mathbf{V}$ & $\mathbf{I}$ & $\mathbf{V}$ & I & $\mathbf{V}$ \\
\hline $\mathbf{H}^{*}$ & $\begin{array}{c}\mathrm{H}^{*} 20,4 \% \\
\mathrm{~L}+\mathrm{H}^{*} 14,8 \% \\
\mathrm{~L}+! \mathrm{H}^{*} 9,3 \% \\
\mathrm{~L}+\mathrm{H}^{*} 25,9 \% \\
\mathrm{~L}+>_{i} \mathrm{H}^{*} 3,7 \% 15\end{array}$ & $\mathbf{L}^{*}$ & $\mathrm{~L}^{*} 100 \%$ & $L \%$ & L\% $100 \%$ \\
\hline
\end{tabular}

Tabla 15

15 El $25,9 \%$ restante corresponde al etiquetaje $\left[\mathrm{L}^{*}\right](3,7 \%),\left[\mathrm{L}^{*+} \mathrm{H}\right](20,4 \%)$ y $\left[\mathrm{L}^{*+}{ }_{\mathrm{i}} \mathrm{H}\right](1,8 \%)$ realizaciones más esporádicas. 
En las tablas precedentes puede verse que la expansión del objeto constituye ahora el acento nuclear de la frase que sigue asociándose a un tono bajo $\left(/ \mathrm{L}^{*} /\right)$ seguido de un tono de frontera igualmente bajo (/L\%/). Por tanto, sigue manteniéndose la configuración tonemática de las oraciones más breves: $/ \mathrm{L} * \mathrm{~L} \% /$. La diferencia la plantea el último acento prenuclear (tercero de la oración) que en este tipo de oraciones es el núcleo del sintagma preposicional. Ya veíamos en el apartado de las declarativas sin expansión (5.1.1., tabla 4) que si bien la invariante detectada en el SV se caracterizaba por presentar generalmente un acento bajo en la sílaba tónica -to- (se toca $\left./ \mathrm{L}^{*} /\left[\mathrm{L}^{*}\right]\right)$, también podía presentarse un tono bajo seguido de un

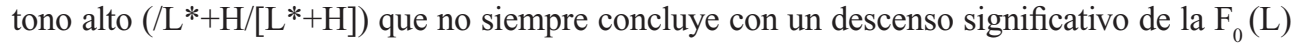
generando la estructura superficial $\left[(\mathrm{L}+) \mathrm{H}^{*}\right]$. De ahí que la forma invariante que proponemos para el tercer acento sea $/ \mathrm{H}^{*} /$ y no $/ \mathrm{L}+\mathrm{H}^{*} /$, es decir, lo frecuente en este punto de la curva (último acento prenuclear) es que la tónica quede alta como consecuencia del mantenimiento del tono desde el acento anterior o por un nuevo ascenso de la frecuencia fundamental; solo ocasionalmente (en un 25,9\%) encontramos una tónica baja $\left(\left[\mathrm{L}^{*}\right] ;[\mathrm{L} *+\mathrm{H}] ;\left[\mathrm{L}^{*}+{ }_{j} \mathrm{H}\right]\right.$ ).

Teniendo en cuenta lo expuesto, nuestra propuesta para los dos últimos acentos de las declarativas con expansión en el objeto es la que reflejamos en la tabla 16 e ilustramos en las figuras 14 y 15 donde se puede ver la trayectoria de la F0 en dichos acentos.

\begin{tabular}{|c|c|}
\hline \multicolumn{2}{|c|}{ Invariantes } \\
\hline \multicolumn{2}{|c|}{ SPrep } \\
\hline $\mathbf{N}$ & $\mathbf{E x p}$ \\
\hline $\mathrm{H}^{*}$ & $\mathrm{~L}^{*} \mathrm{~L} \%$ \\
\hline
\end{tabular}

Tabla 16

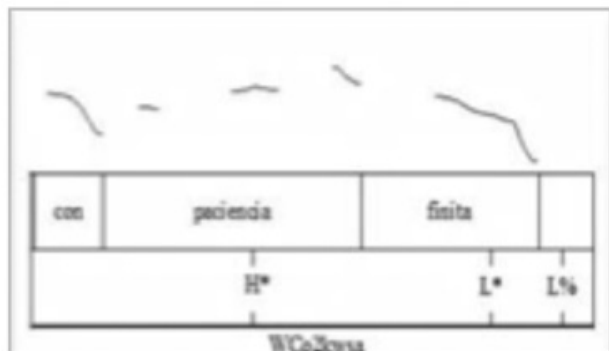

WCo2 (Sexo femenino)

Figuras 14-15

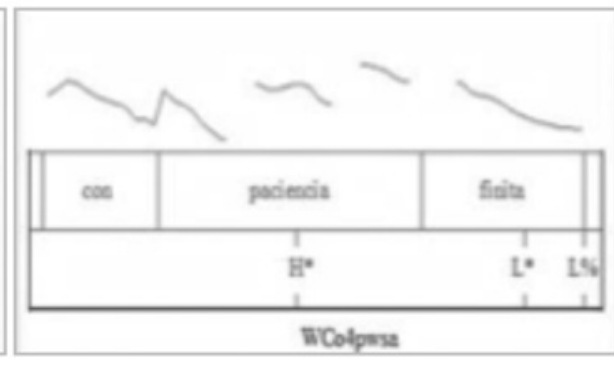

WCo4 (Sexo masculino)

\subsection{Corpus semiespontáneo y espontáneo}

\subsubsection{Oraciones con un solo pico máximo}

Después de analizar los intervalos de F0 en el corpus situacional o semiespontáneo (CS) y comprobar si superan o no el umbral perceptivo de $1,5 \mathrm{st}$, ofrecemos en la tabla 17 los resultados globales del etiquetaje de los acentos tonales inicial y nuclear, así como el tono 
de frontera final de las curvas. Reflejamos en ella solo las invariantes más frecuentes con sus respectivas variantes y los porcentajes de aparición de estas últimas.

\begin{tabular}{|c|c|c|c|c|c|}
\hline \multicolumn{5}{|c|}{ Invariantes y variantes } \\
\hline \multicolumn{2}{|c|}{ ACENTO INICIAL ${ }^{\mathbf{1 6}}$} & \multicolumn{2}{|c|}{ ACENTO NUCLEAR } & \multicolumn{1}{c|}{} \\
\hline I & $\mathbf{V}$ & $\mathbf{I}$ & $\mathbf{V}$ & I & V \\
\hline $\mathbf{L}^{*}+\mathbf{H}$ & $\mathrm{L}^{*}+\mathrm{H} 50 \%{ }^{17}$ & $\mathbf{L}^{*}$ & $\begin{array}{c}\mathrm{L}^{*} 94,7 \% \\
\mathrm{H}+\mathrm{L}^{*} 2,6 \%\end{array}$ & $\mathbf{L} \%$ & $\begin{array}{c}\mathrm{L} \% 70,3 \% \\
\mathrm{ML} \% 24,3 \%\end{array}$ \\
\hline
\end{tabular}

Tabla 17

Según nuestros resultados, en las declarativas monocumbres existe variabilidad en el primer acento, aunque el porcentaje mayor es el de $/ \mathrm{L} *+\mathrm{H} /(50 \%)$ reflejado en la tabla debido, en parte, a la variación silábica de las palabras en posición inicial ${ }^{20}$. Menores porcentajes se registran para el contorno ascendente bitonal $\left(/ \mathrm{L}+\mathrm{H}^{*} /\right)$ que puede realizarse con el pico desplazado a la postónica ([L+> $\left.\left.\mathrm{H}^{*}\right] 33,3 \%\right)$ o dentro de los límites de la tónica $\left(\left[\mathrm{L}+\mathrm{H}^{*}\right]\right.$ $5,6 \%)$. Puntualmente puede llegar a aparecer la variante monotonal $\left[\mathrm{H}^{*}\right](11,1 \%)$ debido a que el rango del pico inicial no alcanza el semitono y medio.

El último acento es frecuentemente bajo en la tónica $\left(/ \mathrm{L}^{*} /\right)$ seguido de un tono bajo (/L\%/ [L\%]; [ML\%] 94,6\%); puntualmente encontramos un tono de frontera alto o medio ([H\%] 2,7\%; [M\%] 2,7\%). No obstante, cuando la frase solo tiene un acento se presentan dos alternativas antes del descenso final: la primera es que se dé un acento descendente durante la tónica precedida de un tono alto $\left(\left[\mathrm{H}+\mathrm{L}^{*}\right] 2,6 \%\right)$ por lo que seguiríamos estando ante una variante de $/ \mathrm{L} *$; la segunda opción es que, debido al escaso espacio por la reducción de los acentos, la tónica presente un tono alto $\left(\left[\mathrm{H}^{*}\right] 2,6 \%\right)$. Estas dos alternativas están ligadas a la producción y no son características dialectales puesto que si ampliáramos el número de acentos se generaría un contorno tonal descendente durante la tónica.

Por otra parte, en el corpus espontáneo o map task $(C E)$ se da un movimiento ascendente en el acento inicial que incide mayoritariamente en la acentuada $\left(/ \mathrm{L}+\mathrm{H}^{*} /\right)$; en algunos casos la $\mathrm{F}_{0}$ continúa ascendiendo $\left(\left[\mathrm{L}+>\mathrm{H}^{*}\right] 11,1 \%\right)$. En menores ocasiones el ascenso es bajo en la tónica seguido de un tono alto $\left(\left[\mathrm{L}^{*}+\mathrm{H}\right] 33,3 \%\right)$ y, más esporádicamente aún, un tono sostenido ([H*] 22,2\%). Véase la tabla 18.

16 Excluimos del acento inicial las frases con un solo acento puesto que la configuración tonal de este tipo de oraciones corresponde, como hemos visto en la descripción fonética, con el núcleo entonativo.

17 El $50 \%$ restante corresponde al etiquetaje $/ \mathrm{H}^{*} /\left(\left[\mathrm{H}^{*}\right] 11,1 \%\right) ; / \mathrm{L}+\mathrm{H}^{*} /\left(\left[\mathrm{L}+\mathrm{H}^{*}\right]\right.$ 5,6 \% y $\left[\mathrm{L}+>\mathrm{H}^{*}\right] 33,3$ $\%$; invariantes con menor porcentaje de aparición de sus variantes.

18 El 2,6 \% restante corresponde al etiquetaje [ $\left.\mathrm{H}^{*}\right]$ (de la invariante $/ \mathrm{H}^{*} /$ ) realización esporádica como indica el propio porcentaje en las oraciones con un solo acento. Recordemos que, como indicamos en la descripción fonética, la solución de este tipo de declarativas es el alineamiento tonal del pico en el único acento de la frase $\left(\left[\mathrm{H}^{*}\right]\right)$ o el adelantamiento a la pretónica $\left(\left[\mathrm{H}+\mathrm{L}^{*}\right] / \mathrm{L}^{*} /\right)$.

19 El porcentaje restante corresponde a [M\%] 2,7 \% y [H\%] 2,7 \% variantes de /M\%/ y /H\%/, respectivamente.

20 Es evidente que el corpus más espontáneo, frente al experimental que contaba con trisílabos iniciales, no tiene un número de sílabas fijo en posición inicial y es frecuente encontrar palabras llanas con dos sílabas como por ejemplo Hace, cobro, carne, etc. Ello facilita que la posición de la tónica se encuentre baja en algunas oraciones. Pero como veremos en la tabla 20, si consideramos conjuntamente los dos tipos de corpus (semiespontáneo y espontáneo) en las oraciones monocumbres, el esquema $/ \mathrm{L} * \mathrm{H} /$ alterna con $/ \mathrm{L}+\mathrm{H}^{*} /$. 


\begin{tabular}{|c|c|c|c|c|c|}
\hline \multicolumn{6}{|c|}{ Invariantes y variantes } \\
\hline \multicolumn{2}{|c|}{ ACENTO INICIAL ${ }^{\mathbf{2 1}}$} & \multicolumn{2}{|c|}{ ACENTO NUCLEAR } & \multicolumn{2}{c|}{} \\
\hline I & $\mathbf{V}$ & I & V & I & V \\
\hline L+H* & $\begin{array}{c}\mathrm{L}+\mathrm{H}^{*} 33,3 \% \\
\mathrm{~L}+>\mathrm{H}^{*} 11,1 \% \%^{22}\end{array}$ & $\mathbf{L}^{*}$ & $\mathrm{~L}^{*} 92,9 \% \%^{23}$ & $\mathrm{~L} \%$ & $\begin{array}{c}\mathrm{L} \% 73,3 \% \\
\mathrm{ML} \% 13,3 \%{ }^{24}\end{array}$ \\
\hline
\end{tabular}

Tabla 18

En el núcleo final, se registra un descenso de la frecuencia $(/ \mathrm{L} * /)$ seguido de un tono bajo (/L\%/ [L\%]; [ML\%] 86,6 \%) si la oración tiene más de un acento; si tiene solo uno, como en el corpus semiespontáneo, se puede dar un tono alto durante la tónica $\left(\left[\mathrm{H}^{*}\right] 7,1 \%\right)$ antes del descenso final.

A partir de los resultados obtenidos en las oraciones declarativas con un solo pico tonal en los dos tipos de corpus ( $C S$ y $C E$ ), hemos realizado los promedios de los porcentajes de realización en las distintas variantes o estructuras superficiales con el objetivo de obtener el mayor número de realizaciones posibles a la hora de determinar las invariantes o estructuras profundas representativas de los acentos de frontera. Véanse los resultados en la tabla 19.

\begin{tabular}{|c|c|c|c|c|c|}
\hline \multicolumn{6}{|c|}{ Invariantes y variantes } \\
\hline \multicolumn{2}{|c|}{ ACENTO INICIAL ${ }^{25}$} & \multicolumn{2}{|c|}{ ACENTO NUCLEAR } & \multicolumn{2}{|c|}{ TONO DE FRONTERA\% } \\
\hline I & $\mathbf{V}$ & I & $\mathbf{V}$ & I & $\mathbf{V}$ \\
\hline $\mathbf{L}+\mathbf{H}^{*}$ & $\begin{array}{c}\mathrm{L}+\mathrm{H}^{*} 19,4 \% \\
\mathrm{~L}+>\mathrm{H}^{*} 22,2 \%\end{array}$ & \multirow[t]{2}{*}{$\mathbf{L}^{*}$} & \multirow{2}{*}{$\begin{array}{c}\mathrm{L} * 93,7 \% \\
\mathrm{H}+\mathrm{L} * 1,3 \%{ }^{26}\end{array}$} & \multirow[t]{2}{*}{ L\% } & \multirow{2}{*}{$\begin{array}{c}\mathrm{L} \% 71,8 \% \\
\mathrm{ML} \% 8,8 \%\end{array}$} \\
\hline $\mathbf{L}^{*+\mathbf{H}}$ & $\mathrm{L}^{*}+\mathrm{H} 41,6 \%{ }^{28}$ & & & & \\
\hline
\end{tabular}

Tabla 19

Según estos resultados, el acento inicial de las declarativas con un solo pico máximo muestra la coexistencia de dos invariantes: $/ \mathrm{L}+\mathrm{H}^{*} / \mathrm{y} / \mathrm{L} *+\mathrm{H} /$. En cambio, el nuclear es siempre bajo $\left(/ \mathrm{L}^{*} /\right)$ seguido generalmente de un tono de frontera final, igualmente, bajo $(/ \mathrm{L} \% /$ [L\%]; [ML\%] 90,6 \%): puntualmente encontramos un tono de frontera alto o medio ([H\%] $8 \%$; [M\%] 1,4 \%). En definitiva, los acentos tonales más característicos de este tipo de oraciones son los que se incluyen en la tabla 20 ilustrados en las imágenes 16 y 17.

21 Excluimos del acento inicial las frases con un solo acento puesto que su configuración está vinculada al núcleo entonativo.

22 El 55,5\% restante corresponde al etiquetaje $\left[\mathrm{L}^{*}+\mathrm{H}\right](33,3 \%)$ y $\left[\mathrm{H}^{*}\right](22,2 \%)$ variantes de $/ \mathrm{L}^{*}+\mathrm{H} / \mathrm{y} / \mathrm{H}^{*} /$, respectivamente que tienen menor porcentaje de aparición que las variantes de $/ \mathrm{L}+\mathrm{H}^{*} /$.

23 El 7,1 \% restante corresponde al etiquetaje $\left[\mathrm{H}^{*}\right]$ (de la invariante $/ \mathrm{H}^{*} /$ ) realización esporádica como indica el propio porcentaje de las oraciones con un solo acento.

24 El porcentaje restante corresponde a [H\%] 13,3\% variante de $/ \mathrm{H} \% /$.

25 Excluimos del acento inicial las frases con un solo acento puesto que la configuración tonal de este tipo de oraciones corresponde, como hemos visto en la descripción fonética, con el núcleo entonativo.

26 El 4,8 \% restante corresponde al etiquetaje [H*] (de la invariante $/ \mathrm{H}^{*} /$ ), realización de las oraciones con un solo acento.

27 El porcentaje restante corresponde a [M\%] 1,4\% y [H\%] $8 \%$ variantes de $/ \mathrm{M} \% / \mathrm{y} / \mathrm{H} \% /$, respectivamente.

28 El 16,7 \% restante corresponde al etiquetaje $\left[\mathrm{H}^{*}\right]$ realización de $/ \mathrm{H}^{*} /$ con menor frecuencia. 


\begin{tabular}{|c|c|}
\hline \multicolumn{2}{|c|}{ Invariantes } \\
\hline ACENTO INICIAL & ACENTO NUCLEAR Y TONO DE FRONTERA \\
\hline $\mathrm{L}+\mathrm{H}^{*} / \mathrm{L} *+\mathrm{H}$ & $\mathrm{L} * \mathrm{~L} \%$ \\
\hline
\end{tabular}

Tabla 20

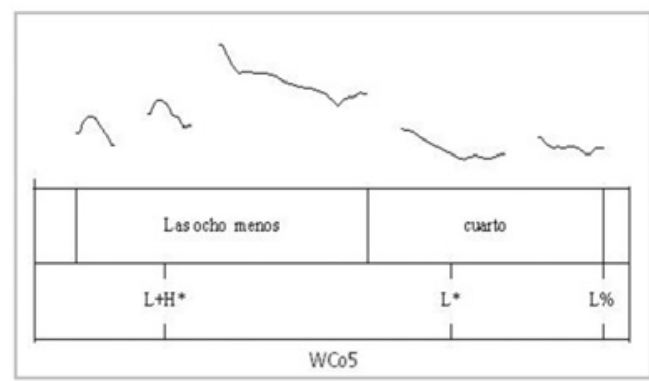

WCo5 (Sexo femenino)

Figuras 16-17

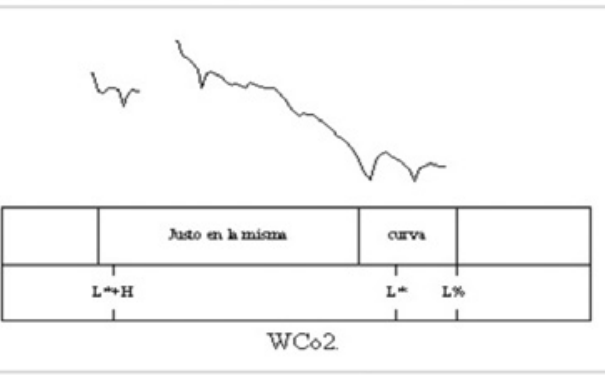

WCo2 (Sexo masculino)

\subsubsection{Oraciones con más de un pico máximo}

Mostramos en la tabla 21 los resultados obtenidos para el corpus situacional semiespontáneo $(C S)$ más extenso. La tabla contiene la interpretación de los acentos tonales inicial y nuclear y del tono de frontera final teniendo en cuenta las invariantes más frecuentes con los porcentajes de aparición de sus variantes.

\begin{tabular}{|c|c|c|c|c|c|}
\hline \multicolumn{5}{|c|}{ Invariantes y variantes } \\
\hline \multicolumn{2}{|c|}{ ACENTO INICIAL } & \multicolumn{2}{|c|}{ ACENTO NUCLEAR } & \multicolumn{2}{c|}{} \\
\hline I & $\mathbf{V}$ & I & V & I & V \\
\hline & & & & & $\mathrm{L} \% 92,9 \%$ \\
$\mathbf{L}^{*}+\mathbf{H}$ & $\mathrm{L}^{*}+\mathrm{H} 50 \% 29$ & $\mathbf{L}^{*}$ & $\mathrm{~L}^{*} 100 \%$ & $\mathbf{L} \%$ & $\mathrm{ML} \% 7,1 \%$ \\
\hline
\end{tabular}

Tabla 21

En este tipo de oraciones, el primer acento se caracteriza por presentar diferentes tendencias. Así, lo más frecuente es que el ascenso inicial se localice en la postónica por lo que la tónica se encuentra baja $\left(\left[\mathrm{L}^{*}+\mathrm{H}\right] 50 \%\right)$; no obstante, también puede darse, aunque con menor frecuencia, un acento ascendente invariante durante la tónica $\left(/ \mathrm{L}+\mathrm{H}^{*} /\right)$ que puede desplazarse o no a la postónica ([L+>H*] 7,1\%; [L+H*] 35,8\%); otra posibilidad, aunque muy puntual, es que el ascenso inicial tienda a ser un tanto sostenido $\left(\left[\mathrm{H}^{*}\right] 7,1 \%\right)$. El acento nuclear es siempre descendente $\left(/ \mathrm{L}^{*} /\right)$ y finaliza siempre con un tono de frontera bajo $(/ \mathrm{L} \% /$ [L\%]; [ML\%] $100 \%)$.

29 El $50 \%$ restante corresponde al etiquetaje $/ \mathrm{H}^{*} /\left(\left[\mathrm{H}^{*}\right]\right.$ 7,1 \%) y $/ \mathrm{L}+\mathrm{H}^{*} /\left(\left[\mathrm{L}+\mathrm{H}^{*}\right]\right.$ 35,8 \% y $\left[\mathrm{L}+>\mathrm{H}^{*}\right]$ 7,1 $\%)$; invariantes con menor porcentaje de aparición de sus variantes. 
En las oraciones procedentes del corpus espontáneo $(C E)$ se obtuvieron los resultados de la tabla 22.

\begin{tabular}{|c|c|c|c|c|c|}
\hline \multicolumn{6}{|c|}{ Invariantes y variantes } \\
\hline \multicolumn{2}{|c|}{ ACENTO INICIAL } & \multicolumn{2}{|c|}{ ACENTO NUCLEAR } & \multicolumn{2}{c|}{$\%$} \\
\hline I & $\mathbf{V}$ & $\mathbf{I}$ & $\mathbf{V}$ & $\mathbf{I}$ & V \\
\hline $\mathbf{L}+\mathbf{H}^{*}$ & $\begin{array}{c}\mathrm{L}+\mathrm{H}^{*} 25 \% \\
\mathrm{~L}+>\mathrm{H}^{*} 50 \%{ }^{30}\end{array}$ & $\mathbf{L}^{*}$ & $\mathrm{~L} * 100 \%$ & $\mathbf{L} \%$ & $\mathrm{~L} \% 100 \%$ \\
\hline
\end{tabular}

Tabla 22

En el prenúcleo, el primer acento es ascendente durante la tónica $\left(/ \mathrm{L}+\mathrm{H}^{*} /\right)$; en pocos casos el ascenso se produce después de esta $\left(\left[\mathrm{L}^{*}+\mathrm{H}\right] 25 \%\right)$. El acento nuclear, en cambio, es descendente ([L*] 100\%) y culmina con un tono de frontera bajo (/L\%/ [L\%] $100 \%)$.

En definitiva, si hallamos las medias de los porcentajes de realización de las distintas variantes en los dos tipos de corpus analizados (CS y CE) con el propósito de determinar los contornos invariantes, los resultados en las oraciones declarativas con más de un pico tonal son los que mostramos en la tabla 23.

\begin{tabular}{|c|c|c|c|c|c|}
\hline \multicolumn{6}{|c|}{ Invariantes y variantes } \\
\hline \multicolumn{2}{|c|}{ ACENTO INICIAL } & \multicolumn{2}{|c|}{ ACENTO NUCLEAR } & \multicolumn{2}{c|}{$\%$} \\
\hline I & $\mathbf{V}$ & $\mathbf{I}$ & $\mathbf{V}$ & $\mathbf{I}$ & $\mathbf{V}$ \\
\hline & $\mathrm{L}+\mathrm{H}^{*} 30,4 \%$ & & & & $\mathrm{~L} \% 96,5 \%$ \\
$\mathbf{L}+\mathbf{H}^{*}$ & $\mathrm{~L}+>\mathrm{H}^{*} 28,5 \% 0^{31}$ & $\mathbf{L}^{*}$ & $\mathrm{~L} * 100 \%$ & $\mathbf{L} \%$ & $\mathrm{ML} \% 3,6 \%$ \\
\hline
\end{tabular}

Tabla 23

Por tanto, estas declarativas más largas se caracterizan por presentar un acento inicial invariablemente ascendente representando por el bitonal $/ \mathrm{L}+\mathrm{H}^{*} /$ y un acento nuclear bajo seguido de un tono bajo (/L*//L\%/). Véanse las invariantes en la tabla 24 , ilustradas en las figuras 18 y 19.

\begin{tabular}{|c|c|}
\hline \multicolumn{2}{|c|}{ Invariantes } \\
\hline ACENTO INICIAL & ACENTO NUCLEAR Y TONO DE FRONTERA \\
\hline $\mathrm{L}^{+} \mathrm{H}^{*}$ & $\mathrm{~L}^{*} \mathrm{~L} \%$ \\
\hline
\end{tabular}

Tabla 24

30 El $25 \%$ restante corresponde al etiquetaje $\left[\mathrm{L}^{*}+\mathrm{H}\right]$ realización con menor índice de aparición de $/ \mathrm{L} *+\mathrm{H} /$ que las variantes de $/ \mathrm{L}+\mathrm{H}^{*} /$.

31 El $41 \%$ restante corresponde al etiquetaje $\left[\mathrm{L}^{*}+\mathrm{H}\right](37,5 \%)$ y $\left[\mathrm{H}^{*}\right](3,5 \%)$ variantes de $/ \mathrm{L}^{*}+\mathrm{H} / \mathrm{y} / \mathrm{H}^{*} /$, respectivamente que tienen menor porcentaje de aparición que las variantes de $/ \mathrm{L}+\mathrm{H}^{*} /$. 


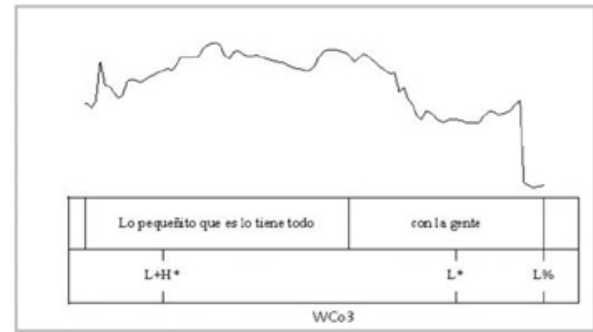

WCo3 (Sexo femenino)
Figuras 18-19

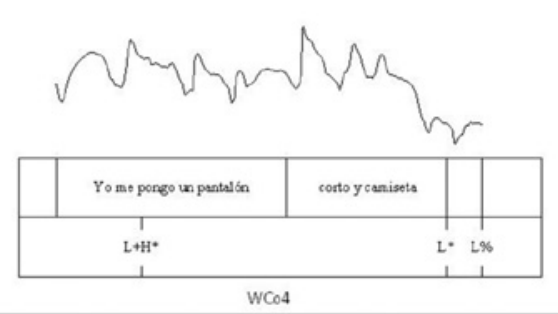

WCo4 (Sexo masculino)

\subsection{Invariantes: corpus experimental vs. espontáneo}

\subsubsection{Corpus experimental}

Según el análisis realizado, las oraciones SVO del corpus experimental se caracterizan por un patrón tonal inicial ascendente durante la vocal tónica $\left(/ \mathrm{L}+\mathrm{H}^{*} /\right)$, mientras que el último acento tiene un patrón descendente seguido de un tono de frontera bajo $(/ \mathrm{L} * \mathrm{~L} \% /)$. Como se puede observar en la figura 20, el hecho de que el sujeto presente expansión, no modifica el contorno del núcleo sintagmático que sigue siendo ascendente. En cambio, en las oraciones con expansión en el objeto, si bien el contorno final sigue siendo / $\mathrm{L}^{*} \mathrm{~L} \% /$, hay que tener en cuenta que este final corresponde a la expansión del sintagma y no a su núcleo que es $/ \mathrm{H}^{*} /$. Por tanto, la mayor extensión modifica la configuración del núcleo del sintagma final aunque no la del contorno tonal final de la oración.

\begin{tabular}{|c|c|c|c|c|}
\hline \multirow{2}{*}{ Tipo de oración } & \multicolumn{2}{|c|}{ SiNTAGMA NOMINAL } & \multicolumn{2}{|c|}{ SINTAGMA PREPOSICIONAL } \\
\hline & $\mathbf{N}$ & $\operatorname{Exp}$ & $\mathbf{N}$ & $\operatorname{Exp}$ \\
\hline \multicolumn{5}{|l|}{ Sin expansión } \\
\hline & & & $\mathbf{L} * \mathbf{L} \%$ & \\
\hline \multirow{2}{*}{$\begin{array}{l}\text { Con expansión } \\
\text { en sintagmas de } \\
\text { frontera }\end{array}$} & & & & \\
\hline & & $\mathbf{H}^{*}$ & $\mathbf{H}^{*}$ & $\mathbf{L}^{*} \mathbf{L} \%$ \\
\hline
\end{tabular}

Figura 20

\subsubsection{Corpus espontáneo}

Hemos visto que con frecuencia se recoge en este corpus de contraste un acento inicial ascendente durante la tónica $\left(/ \mathrm{L}+\mathrm{H}^{*} /\right)$, aunque si las oraciones tienen un solo pico tonal este esquema alterna con el ascenso después del acento $\left(/ \mathrm{L}^{*}+\mathrm{H} /\right)$. El final de las oraciones, en cambio, 
se caracteriza siempre por un tono de frontera bajo $(/ \mathrm{L} \% /)$ y la altura del contorno del acento nuclear es, asimismo, bajo (/L*/). Véanse las invariantes y sus ilustraciones en la figura 21 .

\begin{tabular}{|c|c|c|}
\hline Tipo de oración & Acento inicial & Acento nuclear y tono de frontera \\
\hline \multirow{2}{*}{$-1 P M x$} & $\mathbf{L} * \mathbf{H}$ & \\
\hline & $\mathbf{L}+\mathbf{H}^{*}$ & \multirow[t]{3}{*}{$\mathbf{L} * \mathbf{L} \%$} \\
\hline \multirow[t]{2}{*}{$+1 P M x$} & & \\
\hline & $\mathbf{L}+\mathbf{H}^{*}$ & \\
\hline
\end{tabular}

Figura 21

\subsection{Invariantes $y$ variantes}

El análisis realizado permite completar la propuesta tonal esbozada en Dorta (ed. 2013). Véanse, en primer lugar, los acentos tonales en la figura 22.

\begin{tabular}{|c|c|c|}
\hline \multicolumn{3}{|c|}{ ACENTOS TONALES } \\
\hline \multicolumn{2}{|c|}{ ESTRUCTURA PROFUNDA } & JRA SUPERFICIAL \\
\hline \multicolumn{2}{|c|}{ Invariante fonológica } & Variante \\
\hline$/ \mathrm{L}^{*}+\mathrm{H} /$ & & {$\left[\mathrm{L}^{*}+\mathrm{H}\right]$} \\
\hline$/ \mathrm{L}+\mathrm{H}^{*} /$ & & $\begin{array}{c}{\left[\mathrm{L}+\mathrm{H}^{*}\right]} \\
{\left[\mathrm{L}+>\mathrm{H}^{*}\right]}\end{array}$ \\
\hline$/ \mathrm{H}^{*} /$ & & $\begin{array}{c}{\left[\mathrm{H}^{*}\right]} \\
{\left[\mathrm{i}^{*}\right]} \\
{\left[\mathrm{L}+\mathrm{H}^{*}\right]} \\
{\left[\mathrm{L}+>\mathrm{H}^{*}\right]} \\
{\left[\mathrm{L}+! \mathrm{H}^{*}\right]} \\
{\left[\mathrm{L}+{ }^{\circ} \mathrm{H}^{*}\right]}\end{array}$ \\
\hline$/ \mathrm{L} * /$ & & $\begin{array}{c}{\left[\mathrm{L}^{*}\right]} \\
{\left[\mathrm{H}+\mathrm{L}^{*}\right]}\end{array}$ \\
\hline
\end{tabular}

Figura 22. Representación de la estructura profunda y superficial de los acentos tonales 
$\left.1^{\circ}\right)$ Las invariantes bitonales $/ \mathrm{L}+\mathrm{H} / \mathrm{y} / \mathrm{L}+\mathrm{H}^{*} /$ solo aparecen en el acento inicial: $/ \mathrm{L}+\mathrm{H}^{*} /$ es la invariante más general en los dos tipos de corpus ( $C E$ y $C S)$, pero en el espontáneo interactúa con $/ \mathrm{L}^{*}+\mathrm{H} / \mathrm{si}$ las oraciones son breves.

$2^{\circ}$ ) Cuando se trata de la expansión del sintagma sujeto o del núcleo del sintagma objeto aparecen las variantes del acento monotonal alto $/ \mathrm{H}^{*} /$ anotadas en Dorta (ed. 2013), esto es, $\left[\mathrm{H}^{*}\right],\left[\mathrm{iH}^{*}\right]$ y $\left[\mathrm{L}+\mathrm{H}^{*}\right]$-para describir otro tipo de posiciones ${ }^{32}$ - junto a $\left[\mathrm{L}+>\mathrm{H}^{*}\right] ;\left[\mathrm{L}+\mathrm{H}^{*}\right]$ y $\left[\mathrm{L}+>{ }_{i} \mathrm{H}^{*}\right]$.

$\left.3^{\circ}\right)$ Por último, el acento monotonal $/ \mathrm{L}^{*} /$ presenta dos variantes: [L*]: aparece en el sintagma verbal de las oraciones sin expansión del corpus experimental y en el núcleo final de prácticamente todas las oraciones, mientras que la existencia de $\left[\mathrm{H}+\mathrm{L}^{*}\right]$ se reduce a las oraciones espontáneas más breves, esto es, la de un una cumbre tonal.

En relación con los tonos de frontera (figura 23), tal como sucedía en Dorta (ed. 2013), $/ \mathrm{L} \% /$ marca la trayectoria descendente en el final de las declarativas con dos variantes: [L\%], que aparece en los dos tipos de corpus y [ML\%], que solo se registró en las oraciones más espontáneas.

\begin{tabular}{|c|c|c|}
\hline \multicolumn{3}{|c|}{ TONOS DE FRONTERA } \\
\hline \multicolumn{2}{|c|}{ ESTRUCTURA PROFUNDA } & ESTRUCTURA SUPERFICIAL \\
\hline \multicolumn{2}{|c|}{ Invariante fonológica } & Variante \\
\hline$/ \mathrm{L} \% /$ & {$\left[\begin{array}{c|c}\mathrm{[L} \%] \\
{[\mathrm{ML} \%]}\end{array}\right.$} \\
\hline
\end{tabular}

Figura 23. Representación de la estructura profunda y superficial de los tonos de frontera

En Dorta (ed. 2013) la variante [ML\%] solo se registró puntualmente en la modalidad declarativa (agudos de Caracas) y en las interrogativas circunflejas agudas de las zonas venezolanas (Caracas y Bolívar).

\section{Conclusiones y discusión de los resultados}

En este trabajo hemos intentado sistematizar la variabilidad tonal de las declarativas en el marco del Sp_ToBI para poder extraer las invariantes más frecuentes. Destacamos aquí el comportamiento tonal en el inicio y en el final de las curvas.

$\left.\mathbf{1}^{\mathbf{0}}\right)$ En relación con el primer acento tonal, hemos encontrado como tendencia más general $/ \mathrm{L}+\mathrm{H}^{*} /$ (estructura profunda o invariante), tanto en el corpus experimental como en el de contraste, si bien en este último corpus dicho acento alterna con el esquema fonológico $/ \mathrm{L}^{*}+\mathrm{H} /$ en las oraciones monocumbres. Por tanto, los resultados han evidenciado que si bien la secuencia LH se actualiza generalmente dentro de los límites de la tónica, con ascenso

32 En Dorta ed. 2013 la invariante $/ \mathrm{H}^{*} /$ se localizaba en el primer acento agudo de Santiago de Cuba y en el segundo de todas las variedades $\left(\left[\mathrm{H}^{*}\right]\right)$; también aparece en el acento nuclear de las interrogativas sin expansión: $\left[\mathrm{H}^{*}\right] ;\left[{ }_{i} \mathrm{H}^{*}\right]$ o $\left[\mathrm{L}+\mathrm{H}^{*}\right]$. Hay que tener en cuenta que en este libro solo se analizan oraciones del tipo SVO y no las de expansión en los sintagmas de frontera como se ha hecho en el presente trabajo. 
posterior $\left(\left[\mathrm{L}+>\mathrm{H}^{*}\right]\right)$ o sin él $\left(\left[\mathrm{L}+\mathrm{H}^{*}\right]\right)$ (estructuras superficiales o variantes), lo relevante es que, salvo la excepción anotada, el crecimiento del ascenso tonal incide en la vocal acentuada: $/ \mathrm{L}+\mathrm{H}^{*} /$.

Por tanto, nuestros resultados coinciden generalmente con los de Dorta ed., 2013; Díaz et al. en prensa; Dorta, Díaz y Hernández en prensa o Dorta, Martín y Díaz, 2015 en los que se aborda el etiquetaje prosódico del español de la zona urbana de Canarias, Cuba, Venezuela y Colombia en estilo formal y/o espontáneo. En efecto, como en los citados trabajos, consideramos que la invariante tonal del primer acento para declarativas es frecuentemente $/ \mathrm{L}+\mathrm{H}^{*} /$ y no su variante $\left[\mathrm{L}+>\mathrm{H}^{*}\right]$, tal como apuntan algunos autores para las declarativas de los dialectos peninsulares (Prieto y Roseano eds., 2010: Estebas y Prieto, capítulo 2 y López-Bobo y Cuevas Alonso, capítulo 3), de los hispanoamericanos, como la zona andina de Venezuela o Ecuador (Mérida y Quito. Prieto y Roseano eds., 2010: Astruc et al., capítulo 7 y O'Rourke, capítulo 8), Santiago de los Caballeros (Santo Domingo. Prieto y Roseano eds., 2010: Willis, capítulo 5) y México D.F. (Prieto y Roseano eds., 2010: de la Mota et al., capítulo 11) o de la variedad canaria del español de Gran Canaria (Prieto y Roseano eds., 2010: Cabrera y Vizcaíno capítulo 4).

$\left.2^{\mathbf{0}}\right)$ El acento nuclear y el tono de frontera final se caracterizan siempre en el corpus experimental como $/ \mathrm{L} * / / \mathrm{L} \% /$. En el corpus de contraste sucede lo mismo, aunque $/ \mathrm{L} * /$ puede actualizarse en las oraciones que constan de un único acento con la variante $\left[\mathrm{H}+\mathrm{L}^{*}\right]$ y no [L*].

Por tanto, las declarativas de La Gomera presentan por lo general en ambos corpus un tono bajo durante la tónica y un tono de frontera bajo (/L* $\mathrm{L} \% /)$, tal como refleja la bibliografía más reciente correspondiente al español de Canarias (Prieto y Roseano eds., 2010: Cabrera y Vizcaíno, capítulo 4; Dorta ed., 2013). Este esquema descendente es el más frecuente en el español general (Sosa, 1999; Prieto y Roseano eds., 2010: Estebas y Prieto, capítulo 2 y López-Bobo y Cuevas-Alonso, capítulo 3) y en la mayor parte de dialectos hispanoamericanos (Sosa, 1999; Dorta ed., 2013; Díaz et al., en prensa; Dorta, Díaz y Hernández, en prensa) en los que, incluso cuando se da un contorno circunflejo final, esto es, $/ \mathrm{H}^{*} \mathrm{~L} \% / \mathrm{o} / \mathrm{L}+\mathrm{H}^{*} \mathrm{~L} \% /$, este no impide la trayectoria descendente del contorno final. $\mathrm{Al}$ respecto, Sosa llega a la conclusión de que la configuración $\mathrm{H}^{*} \mathrm{o} \mathrm{L}+\mathrm{H}^{*}$ en el último segmento tónico solo tiene cierta relevancia en Ciudad de México (1999: 196-197).

\section{Bibliografía}

Beckman, M.; M. Díaz Campos; J. T. McGory y A. M. Terrell (2002): "Intonation across Spanish in the Tones and Break Indices framework", Probus 14, págs. 9-36.

Coseriu, E. (1962): Teoría del lenguaje y lingüistica general, Madrid, Gredos.

Díaz, Ch. (2013): Contribución al Atlas Prosódico de Canarias (AMPERCan): Declarativas e interrogativas de La Gomera (Islas Canarias), Tesis doctoral, Santa Cruz de Tenerife, Universidad de La Laguna.

Díaz, CH. y J. Dorta (en prensa): “¿Coexistencia de configuraciones tonales en la variedad isleña de La Gomera?».

Díaz, CH.; J. Dorta; E. Mora y M. Muñetón (en prensa): «Intonation in border areas of the northern Andes: Mérida (Venezuela) and Medellin (Colombia)». Issues in Hispanic and Lusophone Linguistics. John Benjamins. 
Dorta, J. (2000): “Entonación Hispánica: No pronominales vs. Pronominales", Lingüística Española Actual, Madrid, Arco/ Libros, págs. 51-76.

Dorta, J. (2013): «Estudio fonético-fonológico de la entonación declarativa e interrogativa canaria en voz femenina». En A. Pamies (ed.): De lingüística, traducción y léxico-fraseología. Homenaje a Juan de Dios Luque Durán. Interlingüística 111, págs. 173 - 197.

Dorta, J. (ed. 2013): Estudio comparativo preliminar de la entonación de Canarias, Cuba y Venezuela. La Página ediciones S. L. /Colección Universidad, Madrid-Tenerife. Participan: Josefa Dorta, Elsa Mora, Beatriz Hernández Díaz, Chaxiraxi Díaz Cabrera, Nelson Rojas, José Antonio Martín Gómez y Carolina Jorge.

Dorta, J. y CH. Díaz (2014): "Reconocimiento perceptivo de patrones interrogativos coexistentes en Canarias", Fortunatae, Homenaje al Dr. Fremiot Hernández González, págs. 115-127.

Dorta, J., CH. Díaz y B. Hernández (2015): “La entonación cubana en zonas rurales: La Habana y Santa Clara”. En A. Cabedo Nebot (ed.): Perspectivas actuales en el análisis fónico del habla: tradición y avances en la fonética experimental, anejo $\mathrm{n}^{\mathrm{o}} 7$ de la revista Normas. Revista de Estudios Lingüísticos Hispánicos, págs. 45-55.

Dorta, J., J. A. Martín Gómez y CH. Díaz (2015): “Continuidad prosódica en habla experimental y espontánea de Canarias y Cuba: variación y rango tonal en las interrogativas no pronominales". En Kirsten Jeppesen Kragh, Jan Lindschouw (éds.): Les variations diasystématiques et leurs interdépendances dans les langues romanes. Travaux de Linguistique Romane. Sociolinguistique, dialectologie, variation. Collection dirigée par Emili Casanova (València), Jean-Paul Chauveau (Nancy, ATILF), Hans Goebl (Salzbourg). Ouvrage publié avec l'appui de l'Académie Royale des Sciences et Belleslettres de Danemark et du Lektor Knud Henders Legatfond. Strasbourg, págs. 145-159.

Estebas Vilaplana, E. y P. Prieto (2008): “La notación prosódica del español: una revisión del Sp_ToBI", Estudios de Fonética Experimental, 17, Barcelona, págs. 265-283.

Face, T. y P. Prieto (2007): "Rising accents in Castilian Spanish: a revision of Sp-ToBI". En G. Elordieta y M. Vigário (eds.): Journal of Portuguese Linguistics (special issue on Prosody of Iberian Languages), 6.1, págs. 117-146.

Fernández Planas, A. M. y E. Martínez Celdrán (2003): “El tono fundamental y la duración: dos aspectos de la taxonomía prosódica en dos modalidades de habla (enunciativa e interrogativa) del español", Estudios de Fonética Experimental, 12, Barcelona, págs. 165-200.

Hernández, B; CH. Díaz y C. Jorge (2014): «Declarativas e interrogativas en zonas rurales de Canarias». En Y. Congosto Martín, M. L. Montero Curiel y A. Salvador Plans (eds.): Fonética Experimental, Educación Superior e Investigación. T. III. Prosodia. Madrid, Editorial Arco Libros, S.L., págs. 245-265.

Hernández Díaz, B.; J. Dorta y CH. Díaz (2011): “La entonación de las declarativas simples en voz femenina. Zonas urbanas de las islas canarias". En A. Hidalgo, Y. Congosto y M. Quilis (eds.): El estudio de la prosodia en España en el S. XXI. Perspectivas y Ámbitos; Anejos de Quaderns de Filologia de la Universitat de València, págs. 109-124.

Hualde, J. I. (2003): “El modelo métrico y autosegmental”. En P. Prieto (ed.): Teorías de la entonación, Barcelona, Ariel, págs. 155-184.

López Bobo, M. J.; C. Muñiz Cachón; L. Díaz Gómez; N. Corral Blanco; D. Brezmes Alonso y M. Alvarellos Pedrero (2007): "Análisis y representación de la entonación. Replanteamiento metodológico en el marco del proyecto AMPER”. En J. Dorta (ed.): 
La prosodia en el ámbito lingüistico románico, Santa Cruz de Tenerife: La Página Ediciones, S.L. (Colección Universidad), págs. 17-34.

Pamies-Bertrán, A; A.M. Fernández-Planas; E. Martínez-Celdrán; A. Ortega-Escandell y M. C. Amorós (2002): “Umbrales tonales en español peninsular”. En J. Díaz García (ed.): Actas del II Congreso de Fonética Experimental, Sevilla, Universidad de Sevilla, págs. 272-278.

Pierrehumbert, J. (1980): The phonetics and phonology of English intonation, tesis doctoral, MIT.

Prieto, P. y P. Roseano (eds. 2010): Transcription of Intonation of the Spanish Language, Lincom Europa: München.

Romano, A; J.P. Lai y S. Roullet (2005): “La méthodologie AMPER”, Géolinguistique Hors Serie 3, págs. 1-5.

Rietveld, A. y C. Gussenhoven (1985): "On the relation between pitch excursion size and prominence", Journal of Phonetics, New York, Academic Press, 13, págs. 299-308.

Sosa, J.M. (1999): La entonación del español, su estructura fónica, variabilidad y dialectología, Madrid, Cátedra.

Toledo, G. (2006): “Tonos estrellados: una argumentación”, Estudios de Fonética Experimental, 15, Barcelona, págs. 101-131.

Torres Álvarez, M.I. (2000): “Oraciones cortas vs. Oraciones largas: diferencias en el patrón entonativo", Revista de Filología de la Universidad de La Laguna, 18, págs. 383-397.

http://prosodia.upf.edu/sp_tobi/en/ (20-06-2013)

http://www.fon.hum.uva.nl/praat/ (03-03-2012)

http://prosodia.upf.edu/atlasentonacion/cerca/index.php (20-06-2013) 


\title{
ORALIDAD Y ESCRITURA EN LA RED: TESTIMONIOS DE (ORTO)GRAFÍA REGIOLECTAL EN UN CORPUS DE TWITTER
}

\author{
Elena Fernández de Molina Ortés \\ Universidad de Burgos
}

Recibido: 22/04/2015

Aceptado: 02/09/2015

\begin{abstract}
Resumen
El uso de las nuevas tecnologías y la presencia cada vez más común de las redes sociales en la actividad diaria de la población mundial ha producido una modificación de la interacción comunicativa del siglo XXI. Los usuarios, mediante la escritura, comparten sus estados de ánimo, sus experiencias y sus preocupaciones con los demás miembros de su red social; en este tipo de comunicación, como se ha podido comprobar desde la aparición de los servicios de mensajería instantánea así como en la escritura en foros virtuales o en blogs, se representan rasgos de oralidad en los que, creemos, deben incluirse las variedades regionales como testigos directos de estas tendencias. Por ello, en esta investigación se realizará un estudio de un corpus de mensajes de una red social concreta, Twitter, para comprobar si los rasgos lingüísticos de ciertas zonas geográficas de España aparecen en los mensajes de los usuarios de esta plataforma de comunicación virtual.
\end{abstract}

PALABRAS CLAVE: redes sociales, variación lingüística, Twitter, variación lingüística

\begin{abstract}
The use of new technologies and permanence of social media in the daily activities of the global population has been a change of communicative interaction of the $21^{\text {st }}$ century. Users, through writing, share their states of mind, their experiences and concerns with other members of their social media; in this type of communication (as has been proved since the advent of instant messaging and writing in online forums and blogs) are represented features of orality in which we include regional varieties because the are direct witnesses of these trends. Therefore, in this research we will make a study of a corpus of messages from a particular social media, Twitter, to check if the linguistic features of some geographical areas of Spain appear in the messages from users of this platform of virtual communication will take place.
\end{abstract}

KEY WORDS: social media, linguistic variation, Twitter, language variation

\section{Las redes sociales. Una nueva forma de comunicación a través de internet}

La llegada de las redes sociales ${ }^{1}$ a la sociedad 2.0. ha supuesto una modificación completa de las formas de interacción social del siglo XXI. Estas plataformas de comunicación

1 En la actualidad, las redes sociales más populares están compuestas por millones de usuarios en todo el mundo. Según los datos del V Estudio Anual de Redes Sociales de la IAB, en España, en el año 2014, las más usadas fueron Facebook (94\%), Youtube (68\%) y Twitter (41\%); otras como Linkedin, Tuenti, Instagram o Spotify, aun estando integradas por un menor número de usuarios, son igualmente populares. Actualmente, además, no se puede olvidar la expansión de la aplicación de mensajería instantánea Whatsapp, que cuenta ya con 400 millones de usuarios, una cifra similar a la de Twitter. 
agrupan a usuarios con intereses comunes, personales y profesionales, creando un espacio online donde comparten experiencias, contenidos e informaciones relevantes ${ }^{2}$ y en el que, además, el uso de la escritura virtual toma un papel fundamental.

La expansión de estas nuevas formas de comunicación virtual, favorecida durante los últimos años por el acceso a internet desde cualquier dispositivo electrónico (smartphone, tablet), ha producido, incluso, que las relaciones sociales se modifiquen y se cree un espacio paralelo de interacción, un espacio virtual.

Las comunidades en entornos físicos están sujetas a un proceso incesante de virtualización, es decir, han perdido definitivamente el anclaje físico que las limitaba y el peso que antaño poseían en la vida cotidiana de los ciudadanos (...) ahora más que nunca, las personas buscan redes sociales físicas en lugares ubicados geográficamente de forma dispersa. Además, utilizan masivamente tecnologías como el teléfono móvil, que suprime claramente el anclaje físico del receptor y subraya, en su lugar, la importancia del destinatario con independencia de su ubicación física. Entornos de interacción tan tradicionales como el bar, la plaza, la comunidad de vecinos, etc., han dejado de ser esenciales para la realización de las necesidades comunitarias o interactivas de los ciudadanos del siglo XXI (Yus, 2011: 51).

Con esta afirmación, Yus representa, en parte, el panorama de comunicación actual; como advierte el autor, cada vez es mayor la comunicación y socialización de grupos de amigos o familiares mediante la virtualización de sus relaciones. Sin embargo, aunque es cierto que internet y sus utilidades (redes sociales, páginas web, blogs, periódicos digitales) forman parte de la actividad diaria de la mayor parte de la población mundial, su extensión debe ser considerada como una forma de comunicación alternativa a otras formas de interacción social. Es cierto que cada vez es más común ver a grupos de jóvenes (y no tan jóvenes) sentados en una mesa sin hablar entre ellos pero sí a través del móvil pero, de igual manera, podemos continuar viendo a un grupo de amigos que se divierten en un bar o en un restaurante. Ello no quiere decir que, mientras tanto, no usen las redes sociales o el móvil sino que, aunque la comunicación virtual está presente, también lo está la presencial.

Además, y como se podrá comprobar a lo largo de esta investigación, es necesario tener en cuenta que toda comunicación virtual es una verbalización de la lengua oral; basándonos en este precepto y tras realizar una descripción de las principales características de la escritura online, presentaremos los resultados de la investigación sobre la presencia de la variación regiolectal en las redes sociales, más concretamente, en la plataforma de microblogging Twitter, para comprobar si uno de los testimonios de oralidad más auténticos, las variedades regionales, aparecen en la escritura de esta red social.

2 Castañeda y Gutiérrez (2010 citado en Cassany, 2011: 233), establece una distinción entre tres tipos de redes sociales según el enfoque de cada una de ellas. En las primeras, el autor destaca aquellas que se basan en la interacción virtual entre personas (Facebook, Tuenti); por otra parte, hace referencia a aquellas en las que existe un mayor interés por el intercambio de experiencias, noticias, sitios o actividades (Twitter) y, finalmente, existen otras plataformas dirigidas a compartir contenidos como textos, fotos o vídeos encabezadas, en estas casos, por redes como Youtube, Pinterest o Slideshare entre otras. A estas, y según Davis y Merchan (2009), habría que añadir las redes sociales de tipo profesional (Linkedin) y académico (Academia.edu). 


\section{La oralidad y la escritura en la red}

Independientemente del tipo de red social que utilice el usuario, la función y el objetivo que estas cumplen es siempre el mismo: comunicar. La escritura de las redes sociales, heredera -en parte- de la de los servicios de mensajería electrónicos (IRC, Messenger), es la vía de comunicación que millones de personas eligen para compartir sus mensajes con individuos conocidos y, en mucho casos, también desconocidos. No obstante, si bien es cierto que en estas plataformas es cada vez más común encontrar información mediante contenidos, el texto es un elemento esencial que introduce las imágenes, los vídeos o los enlaces de interés que comparten los usuarios con sus seguidores, permitiendo presentar dichos contenidos, describirlos, valorarlos e, incluso, criticarlos.

Pero en este tipo de textos, sin embargo, se rompe con la idea tradicional de que el discurso escrito se corresponde con un modo de expresión reflexivo y formal (López Quero, 2013: 80-81); en estas interacciones, que forman parte de los géneros electrónicos, se advierte una tendencia hacia la oralización de los mensajes que escriben los usuarios. Algunos autores han afirmado que los textos escritos en la red son "textos escritos oralizados" (Yus, 2001, 2011; Gómez Torrego, 2006); otros investigadores han acuñado los términos "conversación escrita" (Merchant, 2001, Blanco, 2002, López Quero, 2013) o “conversación tecleada" (Stein, 2006) para referirse a este tipo de comunicación pero, independientemente de la denominación ofrecida para representar esta realidad, en todos los casos se incide en la existencia de una naturaleza híbrida entre lo oral y escrito en los textos utilizados en la red, tal como afirma Yus en las siguientes líneas:

El aspecto más sobresaliente de esta variedad de comunicación electrónica [conversación virtual o chat] es la oralización del texto, esto es, la sensación de que los usuarios escriben lo que desearían estar diciendo, y leen lo que les gustaría estar oyendo (Yus, 2001).

Sin embargo, aunque es evidente la presencia de la lengua oral en los textos virtuales, existen diferentes tipos de escritura oralizada en la red. Esta realidad está determinada, entre otros factores, por el tipo de comunidad virtual en la que los individuos escriben sus mensajes $^{3}$. Yus (2001: 34-35), partiendo de la distinción de Cicognani (1998), hace referencia a dos tipos de comunidades basándose en el carácter más o menos efímero de las comunicaciones realizadas en cada una de ellas. Por una parte, en las comunidades sincrónicas (chats) se establecen diálogos interactivos que desaparecen en el momento en el que los usuarios abandonan la conversación por lo que, en este caso, no existe una huella de la presencia del escritor en la red; en cambio, en las comunidades asincrónicas (foros de debates, correos electrónicos), se registra un historial de nuestros textos que pueden ser cotejados, en momentos posteriores, por el propio escritor pero, también, por usuarios externos.

Esta distinción influye, según López Quero (2004: 66), en el uso de mensajes más o menos oralizados en la red. Por una parte, el carácter transitorio y el anonimato de los escritores de los chats o, como polo opuesto, la cercanía de los interlocutores que realizan sus interacciones mediante los servicios de mensajería instantánea (Whatsapp o SMS) implica que los usuarios de este tipo de plataformas tengan una menor presión lingüística $\mathrm{y}$, como

3 Tascón (2012: 157) indica que otros factores que influyen en la mayor o menor informalidad de los textos de los usuarios serían el tipo de red, su función y el tipo de usuario. 
consecuencia, haya una mayor presencia de muestras de oralidad. En cambio, otras plataformas como los correos electrónicos o los blogs, por ejemplo, donde el texto escrito sí se convierte en una seña de identidad del usuario en mensajes que, además, serán permanentes en la red, exigen una mayor reflexión lingüística por parte del escritor ${ }^{4}$.

En las redes sociales, en cambio, la interacción lingüística entre los interlocutores es diferente; en estas plataformas, el grado de oralidad que los emisores representan en sus mensajes se sitúa en un punto intermedio entre la conversación del chat y la escritura, por ejemplo, de un correo electrónico o de una entrada en un blog. Por una parte, hay que tener en cuenta que, en las redes sociales, los usuarios suelen tener una relación común que, en muchos casos, es cercana (relaciones de parentesco, amistad), lo cual contribuye a una mayor cercanía comunicativa entre los interlocutores y, por tanto, a un mayor índice de oralidad en sus comentarios. La oralidad representada en estos casos se basa en la transmisión de información, que viene marcada por la inmediatez comunicativa y la simultaneidad de emisión y recepción del mensaje (Bustos Tovar, 1995: 14).

En cambio, también es necesario advertir que las redes sociales son comunidades virtuales asincrónicas (Cigognani, 1998; Yus, 2001) en las que los mensajes creados por cada usuario permanecen en la red y marcan su identidad lingüística ante su grupo de amigos o seguidores ${ }^{5}$. Por ello, aunque en las redes sociales se pueden hallar textos escritos oralizados, igualmente existirá una preferencia por una escritura más reflexiva y cuidada que en otras plataformas de interacción comunicativa virtual ${ }^{6}$. A partir de estas consideraciones, a continuación destacaremos las principales características y funciones comunicativas de la red social Twitter para esbozar una primera aproximación sobre qué elementos lingüísticos podremos encontrar en los comentarios de sus usuarios centrándonos, más concretamente, en las características de la (orto)grafía regional y su representación en esta red social.

\subsection{La escritura en la red social Twitter}

Twitter es un servicio en línea de microblogging que permite enviar y recibir mensajes de 140 caracteres describiendo “¿qué está pasando?”. En esta red social, los usuarios pueden conocer las novedades que comparten amigos y familiares, personajes públicos e, incluso, noticias relevantes según los gustos e intereses del individuo (deportes, política, televisión

4 Gómez Torrego (2006) distingue entre la escritura en papel y en internet; el autor advierte que, frente a la actitud "litúrgica" y reflexiva de la escritura de una carta en papel, por ejemplo, donde importa no solo el contenido escrito sino también la estructura y las características estilísticas del texto, en un correo electrónico la escritura se realiza con una mayor precipitación, olvidando la estructura narrativa. En estos casos, tanto al escritor como al receptor no les interesa la forma en la que está expresado y estructurado el mensaje sino, únicamente, el contenido.

5 En las redes sociales, al igual que ocurre en las conversaciones en tiempo real a través de chats, muchos usuarios olvidan el testimonio lingüístico que ofrecen en estas plataformas de comunicación y revelan la falta de concentración o la dejadez de quien escribe desde la proximidad comunicativa (Mancera, Pano, 2014: 310).

6 Además, el mayor o menor grado de oralización de los textos escritos en las redes sociales estarán determinados, también, por el tipo de red social en la que se produce la comunicación (profesional o personal), la función que cumple (compartir contenidos o experiencias -Facebook-) así como el tipo de usuario que está integrado en dicha comunidad. Un ejemplo de ello puede ser la red social Tuenti, compuesta fundamentalmente por adolescentes y universitarios en cuyos comentarios podemos advertir una mayor tendencia a la oralización textual; así se puede advertir en la presencia de heterografias o cambios ortográficos voluntarios que utilizan los usuarios de esta red social para realizar representaciones orales en sus comentarios (Fernández de Molina, 2015). 
etc.). Además, en sus mensajes describen ideas y experiencias pero, también, comparten realidades que han escrito otros usuarios haciendo un retuit de un mensaje externo o marcándolo como favorito. Por otra parte, es necesario advertir que Twitter se ha convertido, igualmente, en una plataforma de información sobre la actualidad social; mediante los llamados Trending Topic, los usuarios pueden conocer las tendencias y los temas más importantes del país pero, también, pueden encontrar comentarios mundiales sobre un asunto preferido a partir de los hashtags o etiquetas creados por otros usuarios de la red (mediante la escritura del símbolo \#) ${ }^{7}$.

Como afirma Tíscar Lara (2012), Twitter es una plataforma que, aunque en un primer momento representa un espacio privado, al interactuar en la red escribiendo mensajes o, simplemente, retuiteando los contenidos de otras personas, la información personal del usuario se convierte en pública. La autora identifica varias funciones comunicativas de esta red social como la del reconocimiento, que se produce al retuitear mensajes de otros reconociendo su autoridad y atribuyendo, además, una responsabilidad sobre lo compartido; incide la autora, de igual forma, en la función dialógica y la apelativa de Twitter, representada mediante el uso de la estructura “@nombre” que sirve, bien como referencia a un usuario o, simplemente, para conversar entre una o más personas y, finalmente, destaca que el uso de etiquetas mediante la unión de la almohadilla y una palabra clave (\#palabraclave) permite a los usuarios relacionar conversaciones e ideas de un tema común con otros individuos en la red social e, incluso, "entrar espontáneamente en conversaciones ajenas con el simple uso de su misma palabra clave" (Lara, 2012).

En este servicio, por tanto, los usuarios producen pero también reciclan información para comunicar (a partir de los retuits), es decir, no son receptores de información sino que se convierten en productores, comentadores y consumidores de la misma (Galindo, 2014; Mancera y Pano, 2013). No obstante, hay que tener en cuenta que esta red social es, como se indicó en secciones anteriores, una comunidad virtual asincrónica en la que los usuarios tienen muy en cuenta cómo y qué escriben en su perfil aunque es cierto que se advierte una tendencia general hacia el uso del registro coloquial en las interacciones entre usuarios ${ }^{9}$ rompiendo, según la perspectiva de Koch y Oesterreicher (1985), con la dicotomía entre lo oral y escrito en la red y representando un continuum lingüístico de uso entre la distancia y la inmediatez comunicativa. Según la clasificación de los autores, existen grados que influyen en la mayor o menor presencia de oralidad en los textos: la privacidad o el carácter público del discurso, el nivel de emotividad y participación de los interlocutores, la posición local o situacional de los hablantes, la cooperación, la espontaneidad o la determinación del tema tratado en la conversación. Teniendo en cuenta que estos factores son graduales, Briz (2010) afirma que lo coloquial estaría directamente relacionado con la inmediatez comunicativa, en la que, entre otras características, los temas tratados en la conversación son presentados

7 El principal motivo para usar Twitter, según Mancera y Pano (2013:14) es “informarse y promover o apoyar causas sociales y solidarias además de seguir a personajes famosos" a diferencia de Facebook o Tuenti, que se emplean para reforzar el contacto con el círculo social cercano, actualizando el perfil y compartiendo fotografías".

8 Hay que tener en cuenta, además, que Twitter es una red social considerada simétrica, es decir, no existen diferencias jerárquicas entre los usuarios, que pueden interactuar con cualquier individuo de la red que tenga su perfil abierto (Galindo, 2004).

9 Se debe entender el registro coloquial desde un punto de vista diafásico del uso de la lengua, esto es, teniendo en cuenta el contexto comunicativo en el que el hablante actúa y rechazando la consideración de este tipo de registro o nivel de habla como formas vulgares o populares. 
espontáneamente, la comunicación se planea sobre la marcha (a diferencia, por ejemplo, de un discurso público) o el fin de la conversación y el tono utilizado son menos formales.

Según esta perspectiva, en Twitter se podrá observar ese continuum entre lo oral y escrito en diversas situaciones; así, teniendo en cuenta que los mensajes publicados suelen estar dirigidos a usuarios conocidos pero, también, desconocidos (que pueden encontrar los tuits, por ejemplo, mediante etiquetas), en los mensajes de la red social se podrán observar interacciones menos coloquiales en el segundo de los casos pero, también, más coloquiales, sobre todo en las conversaciones realizadas entre individuos conocidos que mantienen gustos e intereses comunes.

\subsection{La (orto)grafía regiolectal y su presencia en Twitter}

Teniendo en cuenta la tendencia que existe en las redes sociales por representar de forma escrita mensajes orales, Yus (2012), a partir de la clasificación de Androutsopoulos (2000: 521-522), identifica varios tipos de rasgos (orto)gráficos que se pueden encontrar en los géneros electrónicos: (orto)grafía fonética, regiolectal, prosódica, interlingüística e incluye, además, el uso de abreviaciones, elipsis e, incluso, faltas de ortografía.

Aunque si bien es cierto que en la red social Twitter se pueden encontrar ejemplos de fenómenos estudiados, sobre todo, en los análisis sobre las conversaciones virtuales como el uso de la grafía $k$ para representar la qu (ke pasa), la $x$ para el dígrafo ch (dixo), la ausencia de vocal ( $k$ 'que'), la $w$ para el sonido velar /g/ (iwal), la omisión de la $h$ (aora) y algunas vocales ( $b n$ 'bien', tekero 'te quiero') que suelen atribuirse a la economía lingüística (Mancera, Pano, 2013 $)^{10}$ y que, según Martínez de Sousa (2004), se tratarían de heterografías, es decir, errores ortográficos que no se cometen por el desconocimiento de la norma sino por la discrepancia de uso con las reglas ortográficas en el momento de la escritura, en nuestra investigación nos centraremos, concretamente, en el uso de la (orto)grafía regiolectal, es decir, en las representaciones gráficas de las variaciones regionales de una lengua (Yus, 2011: 199) porque, si bien es cierto que la escritura en las comunidades virtuales está directamente relacionada con la oralidad, creemos que uno de los rasgos que constituyen la auténtica oralidad es la representación de variantes regionales o locales de una comunidad.

Además, en este tipo de (orto)grafía -también denominada dialecto visual (eye dialect) (Yus, 2011: 199)-, aparecen integrados otros tipos de (orto)grafías como la fonética, cuando los usuarios representan el discurso tal y como sería pronunciado de forma oral (¿qué hase illo?), la coloquial, en la que los escritores usan recursos como las reducciones de palabras, tal como ocurriría en la lengua oral (esto es to lo que te tengo que decir) o la prosódica, mediante la repetición de letras para reproducir, por ejemplo, enunciados interrogativos (pero, ¿qué pasaaaaa?) o exclamativos (achooooo, iqué fuerte!).

Aunque es cierto que, como hemos visto, en Twitter los usuarios poseen una mayor conciencia de su identidad lingüística, también creemos que, al igual que en otras redes sociales, en esta plataforma los mensajes oralizados seguirán estando presentes en la comunicación de los usuarios y, entre ellos, aparecerán muestras lingüísticas de sus variedades regionales.

10 En el ejemplo de Twitter, esta tendencia a la economía lingüística viene justificada por la limitación de caracteres a la hora de escribir los mensajes en la red social. 


\section{Metodología}

Para obtener resultados que garantizasen la evidencia de la oralización de la escritura en la red social Twitter a partir de los usos regiolectales que utilizan los usuarios en sus comentarios, primeramente se obtuvo un corpus de tuits de esta red social en un área geográfica determinada a partir del cual, posteriormente, se pudieron realizar los análisis pertinentes. A continuación se detallarán las fases de recopilación de datos.

\subsection{Selección del área geográfica de estudio}

En un primer momento, y teniendo en cuenta que el objetivo fundamental de la investigación era recopilar mensajes de los usuarios de Twitter que utilizaban variedades regionales, se establecieron las zonas geográficas que iban a ser objeto de estudio. En esta investigación se seleccionaron dos variedades regionales concretas, el extremeño y el andaluz, presentes en las comunidades autónomas de Extremadura y Andalucía respectivamente. Para realizar la distribución que nos permitiera recopilar los tuits de ambas regiones, se establecieron puntos geográficos concretos:

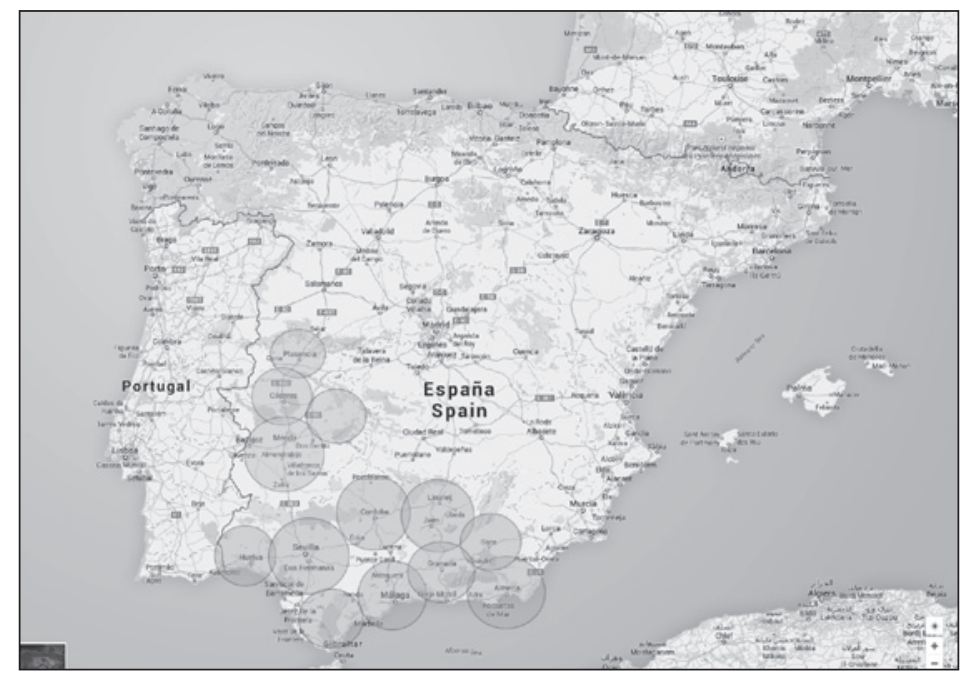

Imagen 1. Distribución geográfica de geolocalización para la recopilación de tuits.

Como se puede advertir en la imagen 1, en Extremadura se seleccionaron 4 centros geográficos y se trazó un radio de entre 30 y 60 km que incluyó las áreas de Plasencia (40 $\mathrm{km})$, Cáceres $(60 \mathrm{~km})$, Almendralejo $(30 \mathrm{~km})$ y Valdecaballeros $(30 \mathrm{~km})$. En Andalucía, en cambio, y debido a la mayor extensión de la comunidad autónoma, se seleccionaron 9 centros: Huelva $(50 \mathrm{~km})$, Sevilla $(70 \mathrm{~km})$, Algeciras $(50 \mathrm{~km})$, Málaga $(40 \mathrm{~km})$, Córdoba (40 $\mathrm{km})$, Granada $(60 \mathrm{~km})$, Almería $(60 \mathrm{~km})$, Jaén $(50 \mathrm{~km})$ y Baeza $(50 \mathrm{~km})^{11}$.

11 Como se puede comprobar, en Extremadura no se seleccionaron las capitales de provincia (únicamente Cáceres) sino que se utilizaron puntos geográficos que permitieran estudiar, en su conjunto, toda la región, independientemente del centro geográfico utilizado. 


\subsection{Recopilación del corpus}

Una vez distribuidos los puntos geográficos que iban a ser objeto de estudio, se utilizó la API Streaming de Twitter (Versión 1.1.) para la recopilación de los tuits. De esta forma, añadiendo las coordenadas de cada área estudiada (que fueron obtenidas a partir de Google Earth), pudimos completar la primera parte de recogida de datos ${ }^{12}$.

Además, y para cumplir con el objetivo de la investigación, se seleccionaron 10 palabras clave que nos permitieran extraer comentarios realizados por los usuarios intentando, en todo caso, que en ellos aparecieran variantes regionales. Este tipo de etiquetas representaban aspectos relativos a la vida diaria de los usuarios de la red social como actividades de ocio (fútbol, cerveza, viaje, casa), actividades profesionales y del ámbito educativo (trabajo, deberes, examen) o cuestiones atmosféricas (frío), que siempre influyen en el estado de ánimo de los individuos y, por tanto, en sus mensajes en la red. Además, se incluyó la expresión jajaja, que nos permitía encontrar mensajes irónicos y despreocupados y en los que podrían aparecer, al igual que en los demás temas, registros del habla oral y, por extensión, casos de variación regional.

Por otra parte, es necesario advertir que, para la recopilación de tuits, los usuarios de la red social debían tener su perfil desbloqueado (para poder acceder a sus mensajes) y, además, debían haber activado la opción de geolocalización de su cuenta de Twitter para obtener los datos por zonas geográficas; este último requisito fue uno de los más problemáticos porque muchos individuos no seleccionan esta opción al crear su cuenta en la red social, bien por causas personales (no querer ser localizados durante la publicación del tuit) o bien por motivos externos, como el consumo de batería de los aparatos electrónicos utilizados.

Finalmente, para analizar los resultados del corpus obtenido, utilizamos el parametrizador de textos en línea PARAMTEXT TIP (Carreras, Santana, 2011), una herramienta que permite extraer los datos lingüísticos mediante diversos formatos (.docx, .xlsx, .pdf etc.); este recurso ofrece informes detallados de los resultados (número de oraciones, palabras, palabras diferentes etc.) pero, además, permite obtener una lista con todas las voces obtenidas y su frecuencia de aparición que nos permitía, en nuestro caso, poder extraer y organizar (manualmente) las variantes del corpus utilizado.

\section{La conciencia lingüística de los usuarios de las redes sociales}

Antes de comenzar el análisis de datos y el procesamiento de los resultados obtenidos de Twitter, creímos conveniente conocer qué conciencia lingüística tenían los usuarios de redes sociales sobre el uso de la escritura en internet, es decir, queríamos comprobar cómo creían que era su escritura en estas plataformas de comunicación. Pero, además, consideramos que la conciencia lingüística (positiva o negativa) que tiene el hablante de su variación lingüística regional puede influir en su uso de la red social.

Por una parte, en cuanto a la consideración de la conciencia lingüística del hablante, como se ha podido comprobar en la sección metodológica de este estudio, para obtener los datos lingüísticos se utilizará un corpus de Twitter compuesto por los mensajes de usuarios de Andalucía y Extremadura, esto es, por individuos cuya variación lingüística se incluye dentro de las hablas meridionales. En estos casos se puede afirmar que, por una parte, el

12 Los tuits recopilados para esta investigación fueron recogidos durante el mes de febrero del año 2015. El procesamiento de datos fue realizado por la empresa informática JAEPREL S.L. 
hablante andaluz suele conservar los rasgos lingüísticos de variedad porque su conciencia lingüística suele ser grande, es decir, se siente orgulloso de su forma de hablar ${ }^{13}$; en cambio, el extremeño no tiene buena conciencia de su variedad regional por lo que intenta ocultar o corregir los rasgos lingüísticos que considera incorrectos aunque realmente formen parte de su variación lingüística (Ariza, 1987: 21-22). Si partimos de la concepción de que el habla en las redes sociales es un continuum entre lo oral y lo escrito y que en algunas áreas los individuos intentan omitir sus características lingüísticas, será más probable que los andaluces no reparen en ocultar sus formas lingüísticas en Twitter frente a los integrantes de Extremadura que, por una parte, intentarán excluir estos rasgos en su escritura pero que, además, no reconocerán usarlas en la red social.

Para conocer si, desde el punto de vista del propio usuario, estos emplean formas orales propias de su variación lingüística en las redes sociales, se creó un cuestionario con la herramienta online Typeform en el que se propusieron 22 preguntas divididas en cuatro áreas temáticas: información personal de los individuos (edad, sexo, comunidad autónoma de procedencia... $)^{14}$, el uso de internet (con qué frecuencia se conectaba el usuario a la red, para qué...), la conciencia lingüística de los usuarios en las redes sociales (qué tipo de escritura usa -oral o escrita-, cómo escribe el propio usuario y sus seguidores, la aparición de rasgos lingüísticos regionales etc.) y, por último, el uso concreto de las variaciones lingüísticas regionales en estas plataformas de comunicación.

El cuestionario fue completado por 103 individuos de las regiones de Castilla la Mancha, Castilla y León, Murcia, Extremadura y Andalucía aunque, no obstante, la mayor parte de individuos pertenecían a las dos últimas. Para la difusión del cuestionario se utilizó, primero, un evento creado en Facebook mediante el cual se invitó a amigos y conocidos de la investigadora de este estudio, que realizaron la encuesta pero que, también, la difundieron entre sus contactos. Además, y para obtener más información, durante 15 días se publicó el enlace web de la encuesta en Twitter, incluyendo en los comentarios etiquetas con los Trending Topic del día para que pudieran realizar la encuesta personas anónimas de esta red social.

Las encuestas fueron realizadas por hombres (36\%) y mujeres $(64 \%)$ de edades comprendidas, fundamentalmente, entre los 21 y 29 años (48,03\%); no obstante, también respondieron el cuestionario grupos de jóvenes menores de 19 años $(12,74 \%)$, individuos de entre 30 y 49 años $(21,56 \%)$ y usuarios mayores de 50 años (17,64\%). El 71\% había realizado estudios universitarios y el $25 \%$ educación secundaria y ciclos formativos.

Según las respuestas obtenidas, se pudo comprobar que la mayor parte de los encuestados $(83 \%)$ usan internet varias veces al día, fundamentalmente para la comunicación con familiares y amigos (85\%), por motivos laborales (48\%) y para sus estudios $(50 \%) \mathrm{u}$ otras actividades de ocio como realizar compras, ver películas, buscar información e, incluso, para jugar en línea. Además, según los datos recopilados, el 100\% de los informantes afirmaron ser miembros de las redes sociales, entre las que destacan Facebook (93\%), Twitter (60\%) e Instagram (31\%).

13 Hay fenómenos como el ceceo que, como veremos en los siguientes apartados, no gozan de tanto prestigio por lo que, en muchas ocasiones, los hablantes tienen una conciencia lingüística negativa de su variedad lingüística e intentan ocultar estas realizaciones.

14 Las encuestas eran totalmente anónimas; no obstante, datos como la edad o la procedencia geográfica de los informantes podían ser de gran utilidad para establecer comparaciones con las respuestas obtenidas sobre el uso de las redes sociales y la conciencia lingüística de los usuarios. 
Para conocer la conciencia lingüística de los usuarios, se plantearon algunas preguntas, tal como se puede observar a continuación:

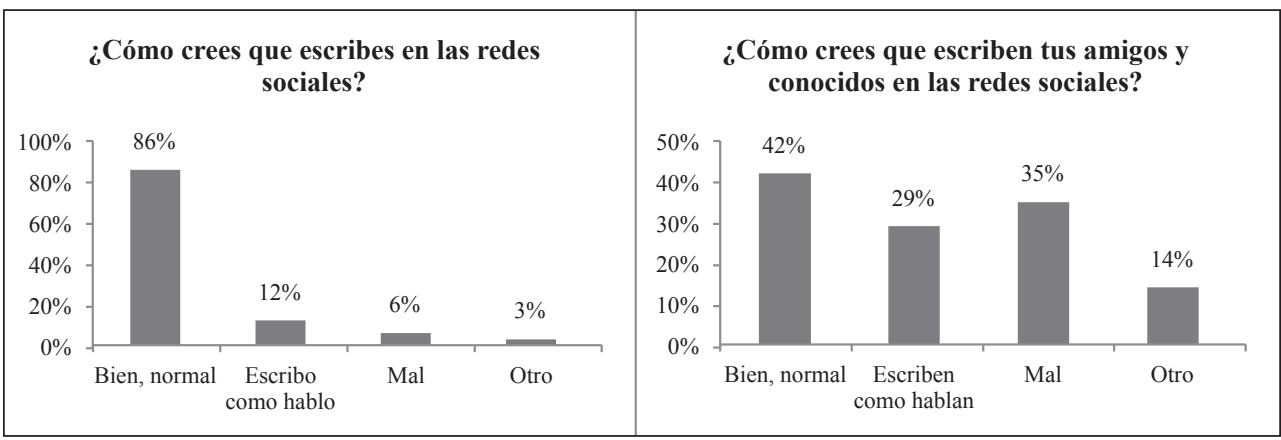

Gráficos 1 y 2. Resultados sobre la conciencia lingüística en las redes sociales.

Aspectos generales.

Según los resultados de los gráficos 1 y 2, existen diferencias evidentes entre la percepción que tienen los usuarios de cómo escriben en la red y de cómo escriben sus seguidores. Por una parte, los individuos suelen tener una conciencia lingüística positiva de su escritura (el 86\% consideran que escriben "bien") pero, en cambio, es realmente notable que únicamente el $42 \%$ piense que sus amigos escriben "bien" frente a un $35 \%$ que consideran que lo hacen "mal". Igualmente significativas son las respuestas sobre la oralización de la escritura y el uso que hacen los individuos de este tipo de lenguaje en internet.

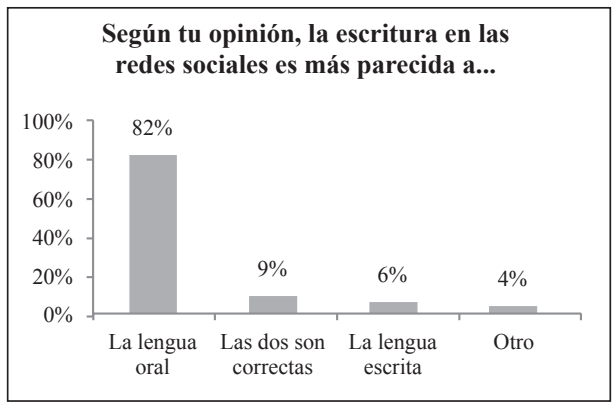

Gráfico 3. La escritura oral en las redes sociales. Opiniones de los encuestados.

En el gráfico 3 se puede comprobar que la mayor parte de los individuos declaran que la escritura en las redes sociales representa la lengua oral (82\%) y no la lengua escrita (6\%). Estas contestaciones difieren, no obstante, de las obtenidas en los gráficos 1 y 2, donde únicamente el $12 \%$ de los encuestados afirmaban "escribir como hablan" en estas plataformas de comunicación. Esta diferencia puede estar determinada por el hecho de que los usuarios, aunque aseguran que la escritura en las redes sociales tiene una relación directa con la lengua oral, no reconocen que emplean este tipo de variación en sus comentarios (aunque sí advierten este tipo de escritura en sus seguidores, tal como se ha podido comprobar en el gráfico 2) e intentan encubrir el uso lingüístico que hacen, verdaderamente, en estas plataformas de comunicación. 
Teniendo en cuenta estas consideraciones, se procedió a preguntar a los usuarios sobre el tema del trabajo de investigación: “¿utilizas variantes regionales (andaluz, extremeño, murciano, otros) en las redes sociales?".

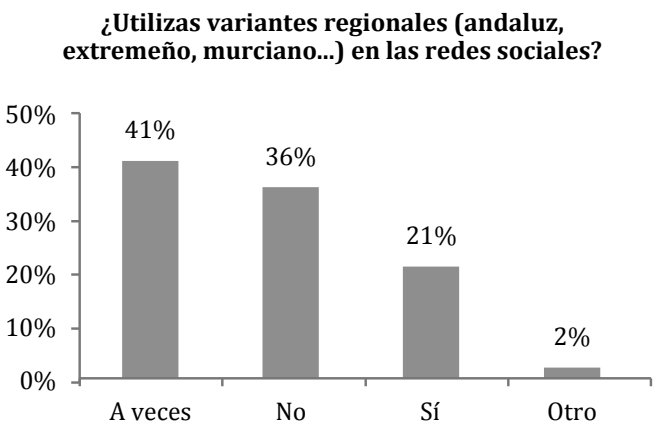

Gráfico 4. Opiniones sobre el uso de variantes regionales en las redes sociales.

Las contestaciones obtenidas, en este caso, se relacionan con las recopiladas en el gráfico 3. Ante la pregunta sobre el uso de formas regionales que, en un primer momento, debería haber producido un posible encubrimiento lingüístico por parte de los informantes pues el uso de este tipo de variantes es una representación de la lengua oral en la escritura, los encuestados afirmaron utilizarlas en un $62 \%$ de los casos; más concretamente, el $41 \%$ de los individuos respondieron que las utilizaban "a veces" y un $21 \%$ utilizaron la respuesta afirmativa.

Además, y según los resultados de la siguiente pregunta: "si has respondido "sí" o "a veces"... ¿con qué grupos las usas?", los informantes precisaron que, sobre todo, este tipo de variantes eran comunes en conversaciones con amigos (91\%) y familiares (46\%) e, incluso, en las realizadas con compañeros de trabajo o de clase (24\%). En este caso, por tanto, el uso de la lengua oral, proyectada concretamente mediante la selección de variantes regionales, aparece sobre todo en las interacciones de grupos integrados por personas conocidas y cercanas a los usuarios de la red social pero, en ningún caso, entre personas desconocidas. Este ejemplo constata la importancia de la identidad lingüística que se forja en estas plataformas de comunicación a través de la escritura de sus usuarios.

Finalmente, y para comprobar qué tipo de variantes regionales podían ser más o menos habituales en las redes sociales, se presentaron tres propuestas:

(1) Imagina que estás escribiendo en el muro o en una foto de un amigo o un familiar cercano en Facebook o Twitter. ¿Con qué comentario te sientes más identificado?

a. Acho, mañana vemos el partido no?

b. Illo, no sé si podré ir mañana pero cuando lo sepa te escribo

c. Ninguna de las dos son correctas

d. Otro

(2) Y entre las siguientes, ¿cuál utilizarías?

a. Hemos quedado sobre las tres y cuarto, ¿vienes?

b. Hemos quedao sobre las tres y cuarto, ¿vienes?

c. Otro 
(3) Selecciona la opción que usarías en una red social
a. Está la cosa muy mala
b. Está la cosa $m u$ mala
c. Ninguna de las dos son correctas
d. Otro

En cada pregunta se planteaba el uso de algunas de las variantes regionales más comunes sobre la escritura oralizada en internet; entre ellas quisimos destacar el uso de formas apelativas como illo para el andaluz y acho para el extremeño, el uso de la (orto)grafía fonética, representada por la pérdida de la -/d/- en posición intervocálica en la terminación -ado que, aunque es habitual en ambas regiones, está igualmente extendida por gran parte del español peninsular y, finalmente, la (orto)grafía coloquial, utilizada también en ambas regiones, con el uso de la reducción del adverbio muy.
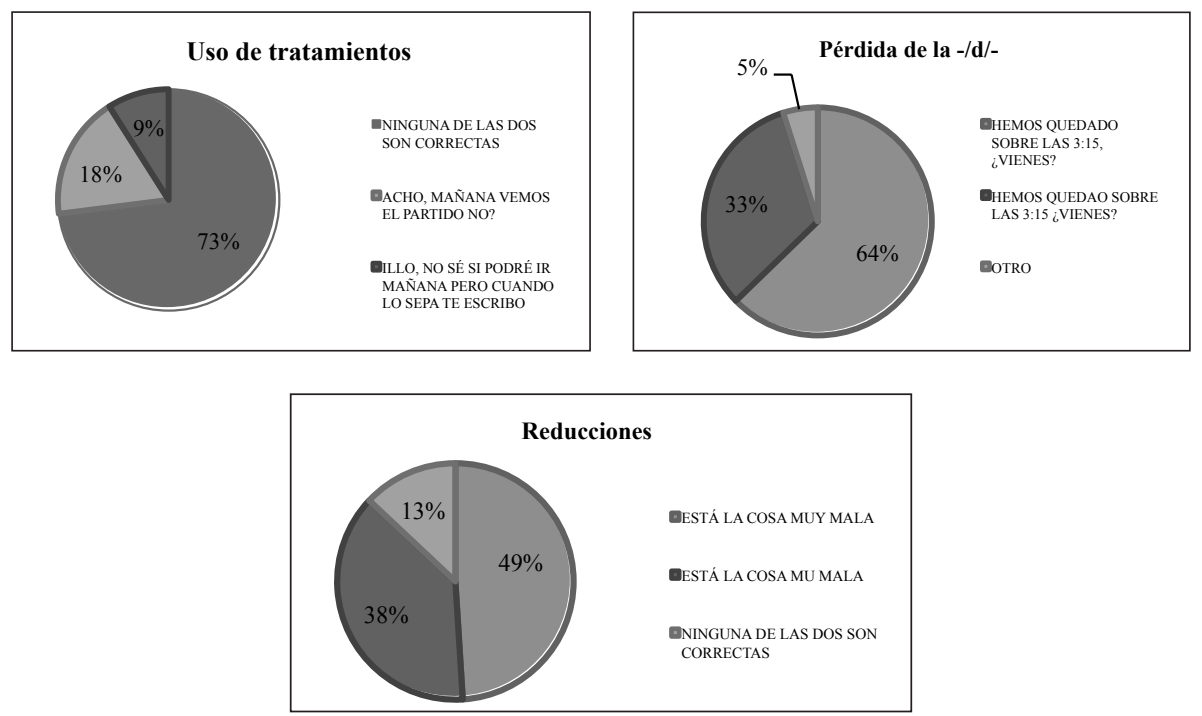

Gráficos 5, 6 y 7. Opiniones sobre el uso de (orto)grafía regiolectal en las redes sociales.

Según los resultados obtenidos de las opiniones de los encuestados, en las redes sociales no usan habitualmente tratamientos apelativos como acho, illo (gráfico 5) pero, en cambio, los usuarios sí confirman la presencia de la pérdida de la -/d/- en posición intervocálica (33\%) (gráfico 6) y las reducciones (38\% del 49\% de respuestas correctas) (gráfico 7). Por ello, y según estas consideraciones, en nuestro corpus de comentarios de Twitter será más habitual encontrar variaciones de tipo fonético -(orto)grafía fonética- que las referencias directas de rasgos regionales como representan los apelativos acho, illo y sus variaciones (killo, chacho...). Además, los informantes corroboraron las advertencias realizadas anteriormente: estas variantes son usadas, fundamentalmente, con familiares y amigos $(88 \%)$. 
Finalmente, para concluir las encuestas se realizó una pregunta fundamental para conocer si existían diferencias entre los tipos de interacciones lingüísticas que se producen en algunas redes sociales. Nuestro objetivo era comprobar si los usuarios utilizaban distintas formas de comunicación en dos de las redes sociales más populares en España, Facebook y Twitter que, como se ha podido comprobar en secciones anteriores, presentan ciertas diferencias tanto en sus objetivos como en los contenidos que en ellas se reproducen.

\section{¿Con qué frecuencia usas variantes regionales en Facebook y Twitter?}

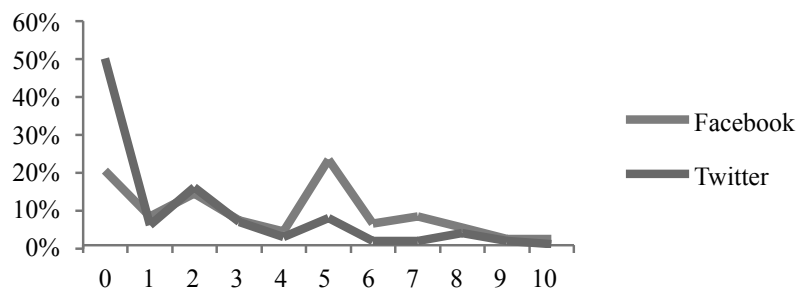

Gráfico 8. Frecuencia de uso de variantes regionales en Facebook y Twitter.

Según los datos que se presentan en el gráfico 8, la mayor parte de los encuestados afirmaron que, en la red social Twitter, "nunca" utilizarían variantes regionales; no obstante, si se observan los datos sobre Facebook, únicamente un $20 \%$ de los indiviudos no usarían "nunca" este tipo de formas en la red social y un $23 \%$ las usarían "a veces".

De nuevo, estos resultados avalan las hipótesis anteriormente planteadas: aunque Twitter es una plataforma de comunicación virtual, el carácter asincrónico de la red social, la relación de los usuarios con sus seguidores (que no son siempre amigos y familiares como parece ocurrir en Facebook sino que, en muchos casos, son personas desconocidas) y, además, la identidad lingüística que representa el individuo en sus interacciones en la red social, que se crea a través de los mensajes que escribe para relacionarse con sus seguidores, implica el uso de una escritura oralizada más reflexiva que en otros servicios de comunicación virtual.

A continuación comprobaremos si estas afirmaciones se corresponden con los resultados obtenidos del corpus analizado para esta investigaicón.

\section{Análisis y resultados}

Tras la parametrización automática de los mensajes obtenidos de Twitter, el análisis del corpus se realizó manualmente; a través de los datos que nos ofrecía la herramienta PARAMTEXT TIP se interpretaron los casos que habían aparecido en los resultados centrándonos, evidentemente, en las variantes regionales utilizadas en los tuits recopilados. A continuación, tras la descripción general de los rasgos más significativos encontrados en los mensajes de Twitter, se presentarán los resultados sobre el uso de la (orto)grafía regiolectal a partir de la representación (orto)gráfica de rasgos fonéticos, morfológicos y léxicos; en este último apartado, además, se ofrecerán casos de expresiones que pueden ser consideradas, igualmente, regionales, para completar así los resultados de la investigación. 


\subsection{Resultados totales}

El corpus utilizado para el estudio de las variedades regionales en las redes sociales estuvo compuesto por un total de 14299 tuits; a continuación se puede comprobar el índice de frecuencia de aparición de las palabras clave utilizadas para obtener los resultados:

\begin{tabular}{|cc|}
\hline \multicolumn{2}{|c|}{ CORPUS TOTAL: } \\
14299 TWEETS \\
\hline jajaja & 3383 \\
\hline casa & 3293 \\
\hline fútbol & 2489 \\
\hline frío & 1251 \\
\hline examen & 1197 \\
\hline trabajo & 1115 \\
\hline viaje & 561 \\
\hline compras & 473 \\
\hline cerveza & 348 \\
\hline deberes & 210 \\
\hline
\end{tabular}

Tabla 1. Palabras clave y frecuencia de aparición.

Como se puede observar en la tabla 1, las palabras clave que nos permitieron recopilar más tuits fueron "jajaja", que compone el 23,62\% del corpus, "casa" (22,99\%), y "fútbol" (17,38\%); este tipo de variables se refieren a actividades sociales y de ocio, temas que predominan en los mensajes que los usuarios suelen utilizar para expresar sus actuaciones diarias en la red social ${ }^{15}$.

Por otra parte, en cuanto al uso de formas regionales en el corpus recopilado, se obtuvo un total de 1402 variantes, que corresponden a un 9,79\% de los datos recopilados.

\section{Resultados del análisis fonético, morfológico y léxico}

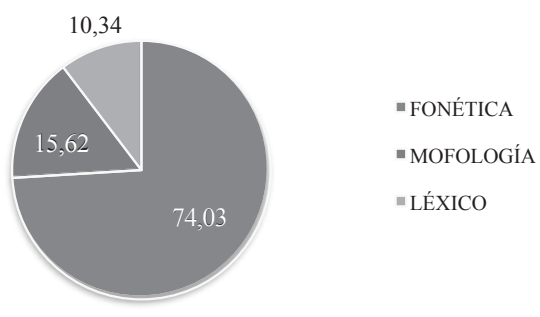

Gráfico 9. Resultados totales de las representaciones fonéticas, morfológicas y léxicas.

15 Es necesario advertir que, según el área estudiada, la mayor parte del corpus estuvo compuesto por mensajes procedentes de la comunidad autónoma de Andalucía, donde se recogieron un total de 12044 mensajes frente a los 2255 obtenidos de Extremadura. Esta diferencia proviene, evidentemente, de la mayor extensión geográfica de Andalucía. 
Entre las representaciones (orto)gráficas, tal como se puede comprobar en el Gráfico 9, predominan fundamentalmente los usos fonéticos $(74,03 \%)$ frente a los morfológicos $(15,62 \%)$ y los léxicos $(10,34 \%)$, que tienen un menor índice de aparición. Según estos resultados, se podría considerar, en un primer momento, que los usuarios que utilizaron este tipo de variantes sí emplearon, por tanto, formas de oralidad en sus mensajes escritos en la red social.

\subsection{Análisis y resultados lingüísticos}

A continuación se presentarán los resultados obtenidos sobre los usos fonéticos, morfológicos y léxicos en los mensajes de Twitter. Según los datos presentados en el apartado anterior, nos centraremos fundamentalmente en las variantes fonéticas, predominantes en el corpus, aunque, igualmente, analizaremos ciertos aspectos sobre las apariciones de formas morfológicas y léxicas.

\subsection{1. (Orto)grafia regiolectal. Rasgos fonéticos}

Tras el análisis del corpus realizado, se han obtenido las siguientes variantes fonéticas:

\section{Resultados totales fonética}

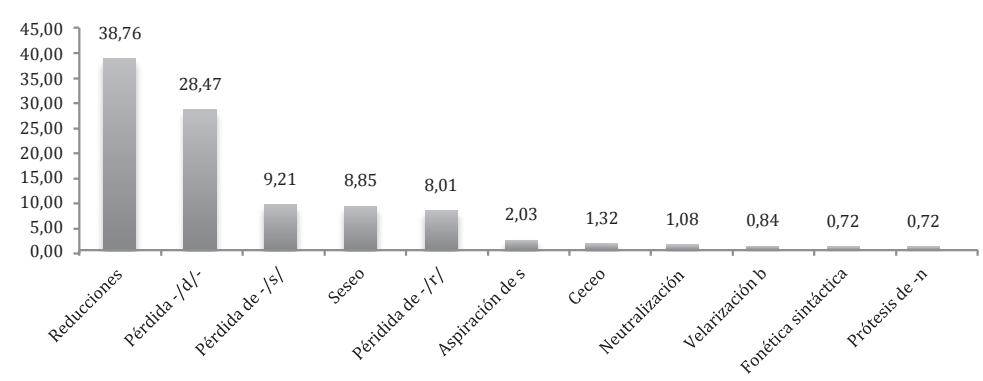

Gráfico 10. Resultados totales de rasgos fonéticos.

Como se puede comprobar en el gráfico 10, la mayor parte de los rasgos fonéticos recopilados pertenecen, sobre todo, al registro coloquial; entre ellos destacan, fundamentalmente, las reducciones de preposiciones y adverbios como para, todo o muy, que componen el $38,76 \%$ de los datos y la pérdida de la -/d/- en posición intervocálica $(28,47 \%)$ que, aunque es un fenómeno extendido por el español peninsular, tiene una mayor presencia en las hablas meridionales. Existen igualmente resultados de pérdida de consonantes finales como -/s/ (9,21\%) o -/r/ (8,01\%), de la aspiración de la -/s/ en posición implosiva (que los usuarios representaron con las grafías $h \mathrm{y} j$ ) y, también, casos de neutralización de l-r (arma), velarizaciones de la oclusiva /b/ en posición inicial (guenos días gente) o la prótesis de $-n$ en posición final, sobre todo en el adverbio "así" (asín). No obstante, estos últimos rasgos no son tan frecuentes y, además, aunque su uso ha sido generalmente asignado a las hablas meridionales, son formas características, preferentemente, del español vulgar. 
Finalmente, es necesario hacer referencia a la presencia del seseo y el ceceo en el corpus; como se puede observar en el gráfico, la representación del seseo $(8,85 \%)$ es mucho más frecuente que el ceceo (1,32\%). Estas formas fueron localizadas en Andalucía (área propia de este tipo de variación) pero, según los puntos geográficos que seleccionamos, no se ha podido observar una distribución lingüística homogénea de los fenómenos. Esta ausencia de localización uniforme de ambos rasgos puede reflejar que los usuarios pudieron escribir este tipo de variaciones sin atender a su variedad lingüística propia, es decir, presentaron el seseo y el ceceo independientemente del uso real que hacen de ambos fenómenos. Sin embargo, es necesario advertir que la mayor frecuencia del seseo frente al ceceo puede estar producida, seguramente, por el encubrimiento lingüístico de algunos individuos de la red social que existe, igualmente, en la lengua oral; esto ocurre porque, aunque estos rasgos representan lingüísticamente la zona meridional de la Península, es cierto que el seseo goza de mayor prestigio que el ceceo, lo que provoca, en algunos casos, el uso de ultracorrecciones e incluso de fenómenos como el ceseo o el seceo ${ }^{16}$. Por esta razón, se podría aceptar que usuarios que oralmente cecean, usaron el seseo para representar un fenómeno más prestigioso ligado a su variedad regional pero no a su variación lingüística individual.

Para observar la extensión de ciertos fenómenos, a continuación presentaremos los resultados de los rasgos que gozan de una mayor presencia en el corpus.

\section{a. Reducciones fonéticas}

En los análisis de los tuits utilizados como base para este estudio, las reducciones fonéticas de adverbios y preposiciones son las variantes regionales predominantes en el corpus $(38,76 \%)$.

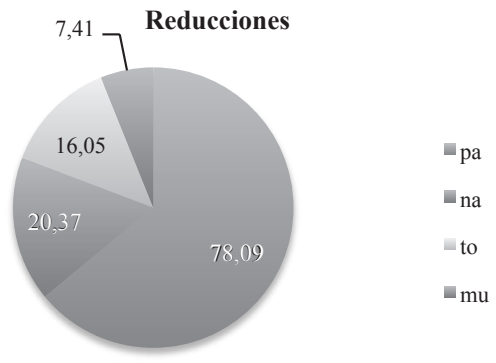

Gráfico 11. Resultados sobre reducciones fonéticas.

16 La zona seseante de Andalucía está compuesta por el área sur de Huelva, el norte de la provincia de Sevilla y algunas áreas de la ciudad de Sevilla; aparece también en el sur de la provincia de Córdoba, incluida la capital, en la parte norte de Málaga, en Jaén y el oeste de la provincia de Granada. El ceceo, en cambio, aparece sobre todo en la franja meridional de Andalucía; se encuentra, igualmente, en el sur de Huelva, la mayor parte de la provincia de Sevilla, la totalidad de la provincia de Cádiz y Málaga, el sur de Granada y en la zona costera occidental de Almería. Las zonas distinguidoras componen, únicamente, un tercio de la comunidad autónoma (Jiménez Fernández, 1999: 32). 
Como se ha afirmado anteriormente, aunque estas variantes forman parte del español coloquial, su extensión es más frecuente en las hablas meridionales, entre las que destacan el extremeño y el andaluz. Este tipo de (orto)grafía fonética incluye, primero, la reducción de la preposición "para", que parece ser la más habitual $(78,09 \%)$ en el corpus analizado; se han encontrado, igualmente, reducciones en adverbios como na 'nada' (20,37\%), to 'todo' $(16,05 \%) \mathrm{y}$, aunque con una menor frecuencia, se han localizado ejemplos de $m u$ para representar el adverbio 'muy' (7,41\%). Además, en los mensajes obtenidos de la red social se han podido advertir algunas reducciones que influyen en transformaciones por fonética sintáctica (para él>pal, todo el $>$ tol) e, incluso, se han encontrado formas como namá 'nada más' que influyen, además, en la representación fonética de la elisión de la -/s/ en posición final.

b. Pérdida de la $-/ d /-$

La ausencia de la -/d/- en posición intervocálica es, junto a las reducciones de adverbios y preposiciones, la representación (orto)regional más común en los mensajes obtenidos de la red social Twitter. En este caso, estudiaremos los contextos en los que desaparece la dental.

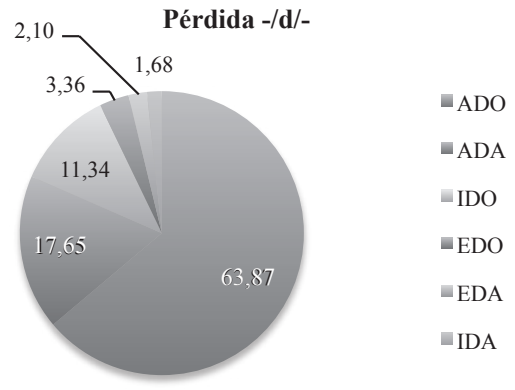

Gráfico 12. Resultados sobre la pérdida de la -/d/-.

Como se puede advertir en el gráfico 12, los resultados se observan, sobre todo, en el sufijo - ado (63,87\%) aunque, igualmente, es relevante la pérdida de la -/d/- en las terminaciones $-a d a$ e -ido. Este hecho, que forma parte, de nuevo, de la conversación coloquial, refleja cómo los hablantes incluyen la oralidad en la escritura de la red social. Además, aunque la ausencia de la dental en posición intervocálica es general sobre todo en los sufijos - $a d o,-a d a$, en el análisis del corpus se han localizado otros casos de pérdida de la -/d/- intervocálica (no tan frecuentes en otras áreas lingüísticas peninsulares) en ejemplos como amargaito 'amargadito', ajustaito 'ajustadito' o destrozaita 'destrozadita', que reflejan la extensión de la pérdida de la -/d/- en los sufijos - ado, -ada en los que se incluye un sufijo diminutivo -ito e -ita respectivamente.

\section{c. Pérdida del consonantismo final}

En cuanto a la representación gráfica de la ausencia de sonidos consonánticos en posición final, en el gráfico 10 se puede comprobar que, en el corpus utilizado, el fenómeno afecta a varios sonidos. 


\section{Pérdida consonantismo final}

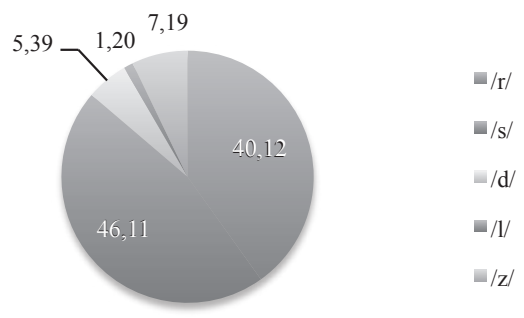

Gráfico 13. Resultados sobre la pérdida de consonantes finales.

La ausencia de grafías para representar la pérdida de consonantes en posición final aparece, fundamentalmente, en los sonidos líquidos -/r/ y -/l/ y dentales -/d/ y -/ / así como en la fricativa -/s/. No obstante, la pérdida no afecta a todos los sonidos de la misma forma; como se puede observar en el gráfico 13, el mayor porcentaje de elisión se presenta en la fricativa -/s/ $(46,11 \%)$ y en la líquida $-/ \mathrm{r} /(40,12 \%)$ y otros casos como la pérdida de la grafía $z$ para representar la interdental o la $d$ para la dental son más aislados $(7,19 \%$ y $5,39 \%$ respectivamente).

Como se puede advertir, por tanto, la inestabilidad de estos sonidos en la lengua oral se reproducen, igualmente, en la escritura en la red. No obstante, es cierto que, ante la ausencia de una grafía que represente el sonido, los usuarios emplean, en ocasiones, recursos gráficos como la reduplicación de vocales (aprendee, doloo, carnavalee, felisidá) o la acentuación de la última vocal de la palabra como ocurre en los casos ejemplos de porfavó, criticá o mujé para la -/r/ en posición final.

\subsection{2. (Orto)grafía regiolectal. Rasgos morfológicos}

Aunque como se advirtió al inicio de esta sección los rasgos morfológicos encontrados fueron escasos, únicamente presentes en el 15,62\% del total de variantes recopiladas, a continuación nos centraremos en el estudio de la presencia de los sufijos diminutivos en la red social para comprobar, en este caso, la frecuencia de uso de este tipo de formas gramaticales (propias de la oralidad) y, además, su extensión geográfica.

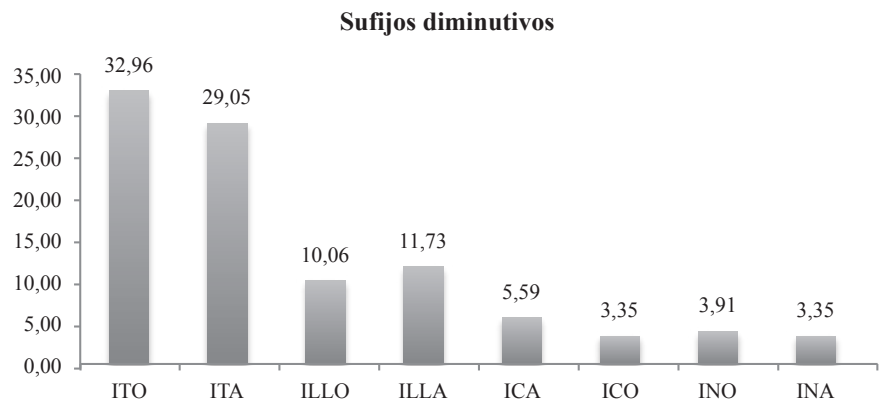

Gráfico 14. Frecuencia de uso de los sufijos diminutivos 
Como se observa en el gráfico 14, los sufijos más habituales en la red social fueron -ito (32,96\%), -ita $(29,05 \%)$ que, además, estuvieron presentes en los comentarios tanto de los extremeños como de los andaluces. En cambio, si observamos los sufijos siguientes, podemos establecer una distribución geográfica del uso de este tipo de formas que remiten, además, a zonas concretas de realización. Por una parte, los sufijos -illo e -illa fueron utilizados en las dos provincias pero, sobre todo, en la región andaluza; en cambio, si analizamos los sufijos-ica $(5,59 \%)$, -ico $(3,35 \%)$, -ino $(3,91 \%)$, -ina $(3,35 \%)$, aunque no son tan habituales su extensión geográfica sí es particular. Frente a -illo, -illa, sufijos que comprobamos que fueron utilizados en ambas regiones, los segundos, -ico, -ica, parecen ser seleccionados, únicamente, por los usuarios de la zona oriental andaluza (en los puntos geográficos de Granada, Almería, Jaén y Baeza) y las formas -ino, -ina fueron elegidas únicamente por hablantes extremeños (aunque encontramos un caso en Andalucía).

Gracias al uso de los sufijos, por tanto, podemos corroborar que en sus mensajes los usuarios de Twitter sí muestran rasgos de oralidad y que, además, este tipo de realizaciones pueden ayudar a establecer variaciones geográficas que determinan la estructura lingüística de ambas regiones.

\subsection{3. (Orto)grafía regiolectal. Léxico y expresiones}

Uno de los testimonios lingüísticos directos del uso del dialecto visual en las redes sociales es el empleo de variantes léxicas y expresiones propias de la región de procedencia de los individuos. En este caso, hay que tener en cuenta que, cuando un usuario de Twitter utiliza una palabra o una expresión regional lo hace, fundamentalmente, con otros usuarios de la misma región porque son estos los que conocen el significado de lo que quiere expresar y, evidentemente, porque la mayor parte de sus redes sociales se encuentran en esa zona geográfica.

Por una parte, y en cuanto al léxico recopilado, podemos destacar ciertas voces propias de las áreas meridionales que, fundamentalmente, han sido consideradas andalucismos pero que, de igual forma, pueden aparecer en el habla de Extremadura. Veamos algunos ejemplos:

(1) no creo killo q lo impidaa jajaja, seria una malaje mu grande... Pero si llueve me Meto debajo un chozajo y to solucionao

(2) \#NoSoportoEsasPersonasQue están todo el día en casa con los \#tacones \#comprateunasbabuchas malajeee

(3) si si eso es verdad son un poquito cansinos jajaja

(4) Venir jarto cerveza, y echarte una siesta de tres horas. \#placercruzcampo

(5) Un poco jartito de ver en todos los canales a cristiano trishte o enfandado. ¿Es que no hay futbol este fin demana?

(6) Toca poner rumbo a Arroyo. Este finde va a ser integro para el rey de mi casa, para mi canijo

(7) Por fin en casa picha QUE DIA MAS LARGO Y QUE PECHA ANDAR

(8)@usuario ${ }^{17}$ pecha de reir examen a las

Como se puede observar en los tuits aportados, hemos encontrado algunas variantes léxi-

17 En los casos en los que se hace referencia a un usuario, en esta investigación hemos preferido guardar su anonimato. 
cas como malaje (ejemplos 1 y 2) que se define como: "dicho de una persona: desagradable, que tiene mala sombra" (RAE, 2001). Según el diccionario académico se trata de un andalucismo que, concretamente, en nuestro corpus, apareció en las áreas de Sevilla y Cádiz.

Otra de las voces encontradas, cansino, vuelve a ser definido como un andalucismo que se refiere a una persona, "cansado, pesado"; en nuestro corpus, en cambio, esta voz se recogió en Almendralejo por lo que puede ser tratado, igualmente, como extremeñismo léxico.

En el ejemplo 4 se puede advertir la palabra jarto, uso que se refiere, en este caso, a una variante fonética de 'harto'; en cambio, esta palabra tiene otra variante semántica en las hablas meridionales que se refiere a "saciado, lleno" pero referido no solo a la comida sino al cansancio, tal como se puede comprobar en el ejemplo 5. Como sinónimo de jarto, podemos encontrar pecha, propuesta en los ejemplos 7 y 8 . En estos casos, y de nuevo como andalucismo, el significado de esta forma se refiere a "panzada, hartazgo" (RAE, 2001); en nuestro corpus, hemos recopilado esta variante en Sevilla y Málaga pero, también, en el área de Cáceres.

Por último, es necesario destacar el uso de canijo para referirse, simplemente, a un apodo o sobrenombre referido a persona; aunque en el caso del diccionario académico esta voz responde a una persona "débil, enfermiza", en las áreas meridionales suele utilizarse como forma afectuosa para denominar a una persona conocida.

Por otra parte, y en cuanto a las expresiones que se han recopilado, podemos resaltar varias de ellas:

(9) que miedo me da esta casa, ofú

(10) ofu que frio

(11) con todos mis respetos tu afición al futbol deja mucho que desear...; ahora anticule... Oju

(12) so guapo

(13) Lo dicho, J.C., telaaaa de mejora en el tema de las bebidas

(14) no entiendo como el Sevilla fc esta en el puesto que esta porque son malos jugando al futbol tela

(15) ala a comer patatas despues de un duro día jajaja

(16) ea tarde de futbol, ... hacer deporte porlo menos se despeja unooo

(17) miarmaa too ere increiblemente increibee

(18) novee que frio hace aquiii

Primeramente hay que hacer referencia a las expresiones ofú, ojú, utilizadas en los ejemplos 9, 10 y 11. Con estas variantes, los usuarios representan situaciones de miedo (ejemplo 9), cansancio (10) e incluso desesperación (11). Otras como la estructura so+adjetivo, que en nuestro corpus apareció representada como so guapo, es un recurso muy frecuente seleccionado, normalmente, junto a adjetivos valorativos. Igualmente, para intensificar un enunciado se utiliza la voz tela $(13,14)$ que, aunque usada como sustantivo, realmente se refiere a un adjetivo como 'mucho'.

El empleo de jala! (15) como variante de la interjección 'venga' es una expresión de origen árabe que ha sido adaptada al español aunque impera en las hablas meridionales; de igual forma, ea (16), como sinónimo de 'bueno', se usa para expresar aprobación o consentimiento de lo enunciado. Otros usos como miarma (17), en este caso con una neutralización de líquidas en la lengua oral y representada, igualmente, con una (orto)grafía fonética en la escritura virtual, es muy frecuente en andaluz; también lo es nove (18), que se refiere a la expresión 'no veas'. 
Finalmente, para completar este apartado, haremos referencia a algunos tratamientos que se han encontrado en el corpus analizado. Como se pudo comprobar en los resultados del cuestionario realizado sobre la conciencia lingüística y el uso de las variantes regionales en las redes sociales, la mayor parte de los informantes no reconocieron usar tratamientos como illo, acho (Gráfico 5). No obstante, en nuestro corpus sí hemos recopilado algunos tratamientos propios de las áreas meridionales, tal como se puede comprobar a continuación:

\section{Tratamientos}

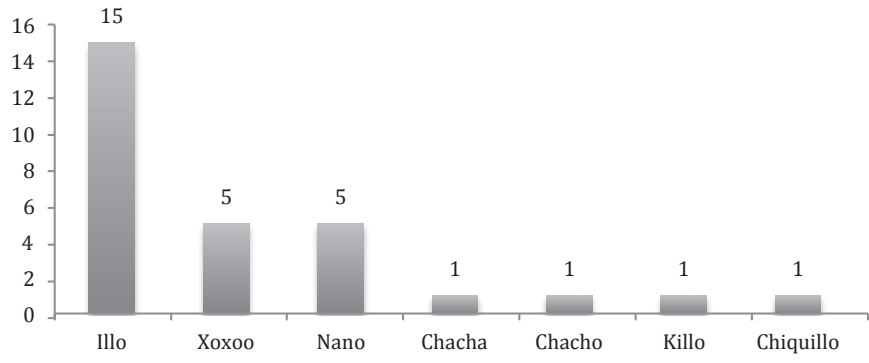

Gráfico 15. Frecuencia de aparición de tratamientos.

En el gráfico 15 se puede advertir las frecuencias absolutas de las formas de tratamiento que recogidas en los mensajes seleccionados ${ }^{18}$. Los datos revelan que el uso de illo y sus variantes (chiquillo, killo) son las más comunes (teniendo en cuenta que la mayor parte de los datos obtenidos proceden de Andalucía, era un resultado esperable). Se observan, además, formas como chacho y chacha, en este caso, localizados en Extremadura pero con una presencia muy escasa. Estos datos revelan que, aunque es cierto que los tratamientos están presentes en nuestro corpus, estas representaciones de las variedades regionales no son tan comunes como, por ejemplo, los rasgos fonéticos lo que corrobora, por tanto, nuestras primeras hipótesis de investigación.

\section{Conclusiones}

Como se ha podido comprobar a lo largo de este trabajo, la oralidad sigue aún hoy muy presente en la red, concretamente, en la escritura de los mensajes de las redes sociales. Según nuestros resultados, la (orto)grafía regional, testimonio directo de este tipo de representación gráfica de la oralidad en la escritura, sigue latente en estas nuevas plataformas de comunicación pero su extensión en Twitter es menor que en otras redes como, por ejemplo, Facebook.

En el corpus utilizado para este estudio se han encontrado este tipo de representaciones gráficas, sobre todo fonéticas; destacan rasgos como la pérdida de la -/d/- en posición intervocálica y del consonantismo en posición final (sobre todo de líquidas $r, l$ y de la fricativa $s$ ), las reducciones de preposiciones y adverbios e, incluso, la presentación de fenómenos meridionales como el seseo o el ceceo, con un predominio evidente del primero; se han

18 Se han utilizado las frecuencias absolutas de los resultados para poder representar la escasa presencia de este tipo de tratamientos en las redes sociales. 
recopilado, igualmente, usos de tratamientos como illo, killo, meridionalismos como canijo, malaje y expresiones como ojú, ofú en los comentarios.

No obstante, y tal como se advirtió al comienzo de esta investigación, el carácter asincrónico de esta red social y el tipo de interacciones que hacen los usuarios al escribir sus tuits influyen notablemente en el uso de un lenguaje mucho más reflexivo que en otras plataformas de comunicación. Estas afirmaciones ya se pudieron comprobar en las encuestas realizadas a los usuarios de redes sociales que afirmaban usar más variantes regionales en Facebook que en Twitter, por ejemplo.

Nuestros resultados avalan que, aunque la escritura oralizada está presente en esta red social, representada en este caso por el uso de variedades regionales, en Twitter existe una menor tendencia a emplear estas variantes que en otras plataformas. En este continuum entre la oralidad y la escritura en el que se incluye la comunicación de esta red social, los individuos suelen tener una mayor conciencia de la distancia comunicativa en el momento de escribir sus mensajes, que son públicos y que, además, pueden ser encontrados mediante el uso de etiquetas; en cambio, existirá una mayor inmediatez comunicativa en las conversaciones con amigos y familiares. Así, aceptando que en Twitter pueden ocurrir ambas situaciones, es lógico que únicamente se haya obtenido menos del $10 \%$ de casos de (orto) grafía regional en la red social pues, en numerosas ocasiones, prima el envío de mensajes públicos frente a las conversaciones entre usuarios conocidos.

Finalmente, y teniendo en cuenta estas consideraciones, sería deseable contrastar estos resultados con una investigación sobre el uso de las variedades regionales en Facebook que permitiera corroborar estas hipótesis o dilucidar nuevos resultados de investigación; este será, sin duda, un campo de estudio probable en próximas investigaciones.

\section{Referencias bibliográficas}

Androutsopoulos, J.K. (2000): "Non-standard spellings in media texts: The case of German fanzines", Journal of Sociolinguistics, 4, págs. 514-533.

Ariza, M. (1987): "La conciencia lingüísitca y el problema del habla de Extremadura". En Viudas Camarasa, A., Salvador Plans, A. y Ariza Viguera, M. El habla en Extremadura, Mérida, Editoria Regional, págs. 21-37.

Blanco, M. J. (2002): “El chat: la conversación escrita”, ELUA, 16, págs. 43-87.

Briz, A. (2010): "El registro como centro de la variedad situacional. Esbozo de la propuesta del grupo Val. Es. Co. Sobre las variedades diafásicas”. En Fonte, I. y L. Rodríguez Alfano (eds.). Perspectivas dialógicas en estudios del lenguaje. México, Universidad Autónoma de Nuevo León, págs. 21-56.

Bustos Tovar, J.J. (1995): "De la oralidad a la escritura”. En Cortés, L. (ed.), El español coloquial. Actas del I Simposio sobre Análisis del Discurso Oral. Almería, Universidad de Almería, págs. 11-28.

Carreras Riudavets, F; Santana Herrera, J.C.; Hernández Figueroa, Z.; Rodríguez Rodríguez, G. (2011): Parametrizador morfológico de textos -ParamText TIP. http://tip.dis.ulpgc.es

Cassany, D. (2011): En-línea. Leer y escribir en la red. Barcelona, Anagrama.

Castañeda, L. y Gutiérrez, I. (2010): "Redes sociales y otros tejidos online para conectar personas". En Castañeda, L. (coord.), Aprendizaje con Redes Sociales. Tejidos educativos en los nuevos entornos. Sevilla, MAD Eduforma. 
Cicognani, A. (1998): “On the linguistic nature of cyberspace and virtual communities", Virtual Reality, 3, págs. 16-24.

Fernández de Molina, E. (2015), "La interacción lingüística en las redes sociales. Aspectos ortográficos", en Montoro del Arco, E., Estudios sobre ortografía del español, Lugo, Axac, págs. 39-51.

Galindo, M. (2014): “Twitter y la Lingüísticia: apuntes para una comunicación 2.0”, en Cuadros, R., Villatoro, J. (eds.). Twitter en la enseñanza y aprendizaje de ELE, Digitalingua, Málaga, págs. 25-46.

Gómez Torrego, L. (2006): "La gramática en internet", Lengua y escritura en internet: tres décadas de "red-acción”. http://congresosdelalengua.es/valladolid/ponencias/nuevas_fronteras_del_espanol/4_lengua_y_escritura/default.htm (1-02-2015).

Jiménez Fernández, R. (1999): El andaluz. Madrid, Arco Libros.

Koch, P. y Oesterreicher, W. (1985): "Sprache der Nãhe-Sprache der Distanz. M ndlichkeit und Schriftlichkeit im Spannungsfeld von Sprachtheorie und Sprachgeschichte", Romanistisches Jahrbuch, 36, págs. 15-43.

Lara, T. (2012): “Twitter y sus funciones comunicativas”, BlogTíscar.com. http://tiscar. com/2012/03/11/twitter-y-sus-funciones-comunicativas $>(1-02-2015)$.

López Quero, S. (2004): "Foros de debate vs. Otros discursos electrónicos”, “Twitter y la Lingüísticia: apuntes para una comunicación 2.0”. Español actual: Revista de español Vivo, 82, págs. 53-76.

López Quero, S. (2013): "La conversación escrita en internet: caracterización pragmalingüística”, Sintagma 25, págs. 77-92.

Mancera Rueda, A. y Pano Alamán, A. (2013): El español coloquial en las redes sociales. Madrid, Arco Libros.

Mancera Rueda, A. y Pano Alamán, A. (2014): "Las redes sociales como corpus de estudio para el análisis del discurso mediado por ordenador”, Humanidades digitales: desafios, logros y perspectivas de futuro. Janus, Anexo 1, págs. 305-315.

Merchant, G. (2001): "Teenagers in Cyberspace: an investigation of language use and language change in internet chatrooms", Journal of Research in Reading, 24 (3), págs. 293-306.

Martínez de Sousa, J. (2004): Ortografía y ortotipografía del español actual. Gijón, Trea.

Stein, D. (2006): "E-mail, Internet, chatroom talk: Pragmatics". En Keith Brown (ed.) Encyclopedia of Language and Linguistics (2nd edition), Amsterdam, Elsevier, págs. 116-124.

Tascón, M. (2012): Escribir en internet. Guía para los nuevos medios y las redes sociales. Barcelona, Galaxia Gutenberg.

Yus, F. (2001): Ciberpragmática. Barcelona, Ariel.

Yus, F. (2011): Ciberpragmática 2.0: Nuevos usos del lenguaje en internet. Barcelona, Ariel 



\title{
REPENSAR LAS FRONTERAS LINGÜÍSTICAS DEL TERRITORIO ESPAÑOL: MELILLA, ENTRE MOSAICO SOCIOLÓGICO Y PARADIGMA LINGÜÍSTICO
}

\author{
Alicia Fernández García \\ Universidad de Paris X-Nanterre \\ Departamento de Lenguas Extranjeras Aplicadas \\ Centro de investigación CRIIA \\ (centro de investigación sobre el mundo ibérico e ibero-americano) \\ alis_carras@hotmail.com
}

Recibido: 10/03/2015

Aceptado: 07/07/2015

\begin{abstract}
Resumen
Este artículo presenta un estudio sociolingüístico de la ciudad de Melilla considerada, junto con Ceuta, como uno de los últimos resquicios del colonialismo español en África. Para ello, analizaremos los aspectos de la sociedad melillense que influyen en el uso de la lengua, entre los que destacamos las normas culturales y el contexto social. Melilla es una ciudad dotada de un valor único para la Sociolingüística por ser tanto un mosaico sociológico como un paradigma lingüístico. La convivencia entre judíos, cristianos y musulmanes que caracterizó a la Península ibérica se perpetúa aún en esta ciudad africana donde conviven diferentes comunidades, bereberes, españoles peninsulares, judíos e hindúes, convirtiéndola en heredera de la "España de las tres culturas". Sin embargo, el estudio de sus componentes sociales y demográficos y el análisis de los resultados del trabajo de campo realizado en la ciudad, cuyos resultados presentaremos a continuación, nos muestran cómo la diversidad cultural a Melilla queda acantonada a una mera folclorización y declaración formal de intenciones. Esta ciudad goza de una diversidad lingüística, ya que junto con el español también se habla tamazight, pero esta lengua ha sido marginalizada institucionalmente y socialmente, imponiéndose así un monolingüismo alimentado por el poder central español.

PALABRAS CLAVE: interculturalidad, actitudes y comportamientos sociolingüísticos, convivencia, marginalización, monolingüismo.
\end{abstract}

\begin{abstract}
This article presents a sociolinguistic study of the city of Melilla, considered with Ceuta, as one of the last Spanish colonial territories in Africa. To do so, we will analyze the aspects of Melilla's society that influence the usage of language, and especially the cultural norms and the social context. Melilla presents a unique value for Sociolinguistic given that this town constitutes a sociological mosaic and a linguistic paradigm. The peaceful coexistence between Jewish, Christians and Muslims which has characterized the Iberian peninsula, is still a reality in this African city where different communities live together, Berbers, Spanish from the peninsula, Jewish and Hindus, which has converted it into an inheritor of the historical "Spain of the three cultures". However, the study of its social and demographic components and the analysis of the results of an ethnographic fieldwork realized in the city, that we present below, show how Melilla's cultural diversity remains a matter of folklore and a declaration of intent. This city presents a linguistic diversity, given that Tamazight is also spoken alongside Spanish, even though the former language has been marginalized by local institutions and society, while a domination of the main language sustained by the Spanish central government has been imposed.

KEYWORDS: interculturality, sociolinguistic attitudes and behaviours, coexistence, marginalisation, monolingualism.
\end{abstract}




\section{Introducción}

Melilla, ciudad española por antonomasia aunque reivindicada sin cese por el reino alauita de Marruecos, presenta una diversidad lingüística y una pluralidad social que la alzan en pionera del eclecticismo cultural español (Moreno Cabrera, 2012: 334-358). En apenas $12 \mathrm{~km}^{2}$ conviven de manera pacífica una importante comunidad de bereberes, de lengua tamazight, que a día de hoy representa casi la mitad de la población de Melilla (Unice, 2015:7-8) ${ }^{1}$. Por otro lado, encontramos a los españoles llamados peninsulares, cuya instalación se debe tanto a la tradición migratoria en España, un fenómeno histórico de larga duración que comienza en la Edad Moderna (Nadal, 1966), como a la necesidad de afirmar la españolidad del enclave a través de un refuerzo de la presencia institucional y militar (Mir Berlanga, 1990). Así, situada en el continente africano y compartiendo la geografía pronunciada del Rif oriental marroquí, Melilla se convierte en un laboratorio sociolingüístico de las distintas culturas que allí conviven (Fernández García, 2014: 39-45). Esta ciudad se ha convertido en un lugar histórico de la geografía española, y actualmente, en frontera europea codiciada, un territorio enclavado cuyo recorrido sociohistórico merece una atención especial. Melilla cultiva divergencias religiosas, culturales, étnicas, pero muy especialmente lingüísticas desafiando así el puzle de las pertenencias y de las características lingüísticas de la España peninsular (García Mouton, 2006: 158-170). A través del estudio de las aptitudes y comportamientos lingüísticos de sus habitantes, esta contribución procederá a un análisis fino de las dinámicas socioculturales en primer lugar y de los comportamientos y actitudes lingüísticas de la población escolar de la ciudad en un segundo lugar. Para ello se parte de un trabajo etnográfico de dos meses cuyo objetivo ha sido el análisis de las percepciones manifestadas por los jóvenes de Melilla en torno a la realidad sociolingüística y cultural existente en su ciudad. Así, el indicador que nos va a servir de guía va a ser las lenguas habladas en Melilla, concretamente el español, lengua oficial, y el "tamazight", segunda lengua de la ciudad ${ }^{2}$. Partiendo de un enfoque sociolingüístico, estudiaremos los fenómenos lingüísticos relacionándolos con factores de tipo social tales como el grupo étnico, el lugar de residencia, el nivel socioeconómico y/o la religión. La finalidad será dar respuesta a dos cuestiones claves: ¿Cuál es el peso de un bilingüismo tamazight/español no reconocido oficialmente en la ciudad? Y ¿cuál es la proporción de locutores bilingües español/tamazight que el estado español priva de reconocimiento lingüístico? Este estudio se articula en dos movimientos, en primer lugar realizaremos un recorrido por la historia de Melilla que nos permitirá entender como se ha forjado su paisaje multicultural. La segunda parte estará consagrada a la presentación de los datos de la muestra y al análisis de los comportamientos y actitudes sociolingüísticas de los jóvenes entrevistados durante un trabajo de terreno en la ciudad.

1 El estudio realizado por la Comunidad islámica de España (UNICE) en colaboración con el Observatorio andalusí avanza la cifra de 32.289 hispanomusulmanes en Melilla.

2 Difícil ha sido calificar esta lengua hablada en Melilla y en la zona del Rif, ya que algunos la llaman tamazight y otros "chelja". En este trabajo vamos a emplear el nombre "tamazight", ya que es por este nombre como los peninsulares conocemos esta lengua y es con este nombre "tamazight" que los comunicados e intervenciones estatales hacen referencia a esta lengua hablada en Melilla. 


\section{Análisis socio-demográfico en Melilla: hacia la afirmación de una "multiculturalidad"}

Melilla es una ciudad española habitada por una población que no supera los 85.000 habitantes, su primera originalidad es sin duda su situación geográfica, ya que se trata de una ciudad situada en el continente africano, y más concretamente en la costa noroeste de la región del Rif de Marruecos, bordeada por el mar Mediterráneo y a menos de quince kilómetros de la vecina ciudad marroquí de Nador. Desde el Imperio Romano, esta región ha permanecido expuesta a los avatares de la expansión imperial, de la búsqueda de conquistas territoriales y del empeño por el control de puertos marítimos (González Callejas, 2013). Así las invasiones de vándalos, los asentamientos visigodos, la penetración árabe, los sucesivos conflictos entre las tribus bereberes autóctonas, así como el posterior establecimiento de una decena de dinastías musulmanas descendientes del reino marroquí, han hecho de la crónica histórica de Melilla una genealogía atrayente (Arques, 1966; Berenguer, 1997; Bravo Nieto, 2004).

\subsection{Hacia la crónica de Melilla: del orgullo nacional al reducto colonial}

En 1497, bajo las órdenes de Don Pedro de Estopiñán, la ciudad es tomada y sitiada militarmente por los hombres del gobernador de Gibraltar y duque de Medina Sidonia. Esta tentativa peninsular de expansión hacia el Mediterráneo en las postrimerías del siglo $\mathrm{XV}$ refleja una coyuntura particular y de índole diversa. Primeramente una coyuntura económica propia del siglo XV, periodo motivado por el afán de control del comercio marítimo tanto en el Mediterráneo como en el océano Atlántico y bajo la legitimidad proporcionada por la política del Mare clausum ${ }^{3}$. Afán también por controlar las rutas comerciales en el Mediterráneo, mar que se encontraba amenazado por la presencia cada vez más activa de piratas berberiscos que se habían convertido en la causa de las difíciles relaciones comerciales de España con sus numerosas posesiones mediterráneas. Bastará recordar que la corona española de inicios del siglo XVI poseía el control de la casi totalidad del litoral africano, desde Gibraltar hasta Trípoli, por lo que la seguridad marítima se convirtió en la condición sine qua non de la supervivencia de España como potencia naval en la carrera por el control de los mares. A la amenaza provocada por la piratería berberisca se le añadía la inquietante presencia de un rival temible en las aguas mercantilistas del Mediterráneo como fue el Imperio Otomano (Brogini \& Ghazali, 2006: 10). Una coyuntura también "civilizadora y divina", ya que una vez culminada la última fase de la Reconquista con la toma de Granada y nombrado don Fernando "Rey de la Cristiandad", había llegado el momento de incrementar las posesiones españolas no solamente en América sino también en África, ya que España, potencia cristiana, se debía enteramente a la propagación de su misión evangelizadora. Nos parece importante insistir en la existencia de una coyuntura geográfica favorable en los territorios vecinos del norte de África, según recoge la historiografía, la región de Melilla parece haber sido campo de enfrentamiento de las luchas entre dinastías regionales en un Marruecos asolanado por

3 Mare Clausum, expresión latina que significa "mar cerrado", es un término utilizado en derecho internacional para referirse a un mar, a un océano o espacio marítimo navegable que se encuentra bajo la jurisdicción de un Estado y que está por lo tanto cerrado a otros estados. La expresión "Mare clausum" se opone a la de "mare liberum", o mar libre, es decir, un espacio marítimo abierto a la navegación. 
las rivalidades dinásticas y dividido en dos: la hegemonía de la dinastía Saadi al sur y Wattasida al norte. Así, mientras que el Marruecos de los merídinas se perdía en luchas intestinas en un contexto marcado por la anarquía (Lugan, 2011: 25-36), la amenaza turca se propagaba en el gran Magreb y se consolidaba la presencia europea en suelo marroquí con el asedio de las ciudades de Tánger y de Ceuta a manos de los portugueses (Peres, 1960). La facilidad con la que fue tomada Melilla, supuesto "res nullius", ciudad vieja y ruinosa que había dejado de ser el centro del tráfico comercial, alimenta el deseo de conquista española. La ciudad se convierte pues en base arrière de la expansión colonial española en África, lo que permitirá posteriormente a los españoles tomar posesión del Sáhara Occidental. Sin embargo, los hándicaps de la corona española en su tentativa de "expansión hacia el Mediterráneo" y de "guerra santa contra el Islam" van a repercutir en esta plaza española. Melilla, que había sido hasta entonces patrimonio de la casa de Medina Sidonia, se convierte de facto et de jure en una posesión administrada directamente por la monarquía española, era el año 1556. Pero este cambio no implicó mejoría alguna para la ciudad que conocerá siglos sucesivos de marginalización instrumentalizados por el desinterés real, tanto de los últimos Habsburgo como por los primeros monarcas borbones, por las posesiones en el norte de África (Villalobos, 2004: 15). Primogénita en la conquista del Mediterráneo africano a finales del siglo XV, Melilla se transformará en las décadas posteriores en base militar defensiva y en purgatorio de los condenados (Domínguez Sánchez, 2004: 184-188).

\subsection{Aproximación al componente multicultural de Melilla}

Hacia mediados del siglo XIX, un periodo de nuevo animado por las tentativas coloniales, esta plaza africana va a recobrar su rol, convirtiéndose a la vez en un espacio físico privilegiado pero también en un espacio sociodemográfico diversificado. Gracias a la Ordenanza real de 1868 que abre el asentamiento civil en los límites de la ciudad y hace de la ciudad una colonia de población, Melilla asiste a un importante crecimiento de la población peninsular atraída por las potenciales ganancias del nuevo empuje colonial español en el continente africano. El censo de la población de 1874, seis años después de la publicación de las Ordenanzas, avanza la cifra de 2053 habitantes, entre los cuales 1500 militares y 553 civiles procedentes mayoritariamente de las regiones del sur peninsular (Salafranca Ortega, 1987: 65-69). Dichos datos reflejan la militarización de la población de la ciudad, pero también sugieren la aparición de la primera generación de "melillenses" y la gestación de una identidad en el enclave. En este censo se cuantifica también la presencia de 17 judíos en Melilla cuya presencia va a aumentar rápidamente en un corto periodo de tiempo. Esta rápida instalación de judíos en suelo melillense fue alentada por las persecuciones perpetradas en Marruecos contra la comunidad judía, todas ellas motivadas por el Roghi Bu Hamara, instigador de una de las más graves rebeliones durante el sultanato de Abd-el-Aziz. Esta auténtica cacería étnica provocó el rápido abandono de un gran número de judíos de las regiones marroquíes colindantes a Melilla y su rápida instalación en la ciudad en el barrio conocido como El Tesorillo (Salafranca Ortega, 1995: 60-72). Este censo no recoge ningún dato acerca de la presencia de la población bereber vecina puesto que su libre establecimiento en la ciudad no va a ser consentido hasta mediados del siglo XX. Sabemos un poco sobre su estancia en Melilla por 
los escritos de la época que nos hablan de la presencia de los llamados "Moros de paz", vecinos marroquíes transeúntes que dedicados a las actividades comerciales satisfacen las necesidades de la armada y las insuficiencias de la población. Una presencia temporal tolerada durante el día pero perseguida durante la noche (Planet Contreras, 1998: 25). Las travesías de esta población transfronteriza abastecieron y continúan abasteciendo de las más variadas mercancías a la ciudad de Melilla y hacen vivir a numerosos marroquíes de los territorios vecinos ${ }^{4}$. Los vaivenes de estos moros de paz, transeúntes, junto con la existencia de los judíos refugiados, dieron lugar al nacimiento de una lógica intercultural en las relaciones cotidianas de los habitantes de la ciudad (Ruiz Domínguez, 1998: 25).

La firma de diversos acuerdos hispano-marroquíes y los acontecimientos sucedidos a nivel nacional a finales del siglo XIX y principios del XX, trajeron consigo importantes cambios en la política exterior española. Las pérdidas de las últimas colonias y el reconocimiento de las independencias provocaron una profunda crisis nacional, sin embargo los fracasos políticos y los desastres militares de 1898 reavivaron el interés por las posesiones africanas que se convierten en la "única baraja" que poseía España en la partida de las relaciones internacionales. Según Villalobos, España no dudó en utilizar sus bosquejos históricos ni tampoco en servirse de sus "quintas" de jóvenes para salvar su reputación nacional: comienza la guerra del Rif (2004: 155-209). Así, las guerras que ritmaron el siglo XIX y parte del siglo XX entre una España obsesionada por salvaguardar sus últimos resquicios coloniales en África y un Rif rebelde y dispuesto a movilizar sus razias contra la codicia territorial española, tuvieron como consecuencia inmediata la instalación de vecinos bereberes en la periferia de la ciudad. Ellos abastecieron a las tropas enfrentadas tanto en productos alimentarios y de uso diario como en suministros y municiones. En 1927, la victoria española en la ofensiva contra los últimos núcleos de resistencia rifeña permitió la creación de una administración colonial española sobre los territorios del Rif y consolidó el protectorado español en esta zona de Marruecos (1912-1956) ${ }^{5}$. Por lo tanto, la paz de vuelta en Melilla fue favorable al crecimiento demográfico que estuvo estrechamente ligado al apogeo económico que vivió la ciudad como consecuencia de la riqueza minera del Rif disputada por los franceses y alemanes que desde mediados del siglo XIXI pugnaban por hacerse con su control (Madariaga,2000; 100-105). Por ello la necesidad de mano de obra de la ciudad se alza en prioridad local y la solución se encuentra en esos campamentos de fortuna creados en los perímetros de la ciudad. Esos rifeños acantonados tomaron posesión de los barrios más extremos y

4 En las fronteras de Beni-Enzar y de Barrio Chino de Melilla más de 8.000 porteadoras esperan cada día la apertura del paso peatonal que les permitirá entrar en la ciudad. Muchas de ellas trabajan como empleadas de hogar, otras se dedican a cuidar niños o a cocinar en los numerosos restaurantes y bares de la ciudad, muchas volverán a Marruecos a última hora del día mientras que otras se quedarán ilegalmente en algún piso patera. Un fenómeno que se conoce como "comercio atípico" y del que dependen la mayoría de los comerciantes de Melilla y que se estima genera más de 600 millones al año. Sobre este fenómeno leer el artículo de Yasim PUERTAS, "Porteadoras de la prosperidad", El Mundo, el 7 de abril del 2013.

5 Se entiende por protectorado español en Marruecos el régimen jurídico aplicado a una serie de territorios del Sultanato de Marruecos según los acuerdos franco-españoles del 27 de noviembre de 1912. Según dichos acuerdos, la soberanía sobre la población autóctona y sobre el territorio recaía en manos del sultán mientras que las fuerzas militares y policiales nativas, así como la propia figura del sultán, sus acciones y su sucesión eran competencias del ejército español. El protectorado en Marruecos se dividía en dos territorios: la zona Norte, que incluía las regiones del Rif y de Yebala con Tánger, Ceuta y Melilla como fronteras y la zona Sur administrada por Francia. 
abandonados de la ciudad, una comunidad de lengua beréber y de religión musulmana se instaló progresivamente a las afueras de la ciudad, en la zona hoy conocida como "La Cañada de la muerte". Los hombres se ocupaban de la actividad comercial de la ciudad, sacando provecho de la poca distancia que separa Melilla de las ciudades marroquís vecinas donde se abastecen a bajo coste de todo tipo de productos que venden después a un precio bastante superior a esa clase acomodada de funcionarios y de militares que poco a poco ha ido instalándose en la ciudad. Las mujeres también fueron de un gran provecho en esta Melilla que se recupera y vive al ritmo de las mejoras económicas del Estado español, ellas trabajarán como amas de casa y sirvientas en los diferentes hogares de los peninsulares. Hacia mediados de los años 1950, el aumento de esta población bereber estuvo acompañado de la llegada de un importante número de hindúes que huyendo de la guerra que azotaba a las poblaciones de la India y de Pakistán, buscan refugio en Melilla. Con la independencia de Marruecos en 1956, una nueva ola de judíos instalados en Marruecos emigra hacia Melilla. Sin embargo, la independencia marroquí fue nefasta para la ciudad y para el tráfico fronterizo, la administración española se retira, las tropas militares se reducen y el flujo comercial disminuye. Todo esto provocó un doble éxodo demográfico: la población de origen peninsular retorna a la península donde se resentían los primeros brotes del periodo de apertura franquista. La otra salida notoria por su número fue la inmigración de judíos atraídos por la fundación de Israel. Así, al apogeo experimentado entre 1940 y 1949 le sucedieron años de decadencia que comienza a finales de los años 50 y se perpetúa hasta mediados de los 80 (Salafranca Ortega, 1987: 163).

Otra fecha más reciente en la historia contemporánea de Melilla es el año 1986 en el que se aprueba una La ley de Extranjería, una ley que implica la regularización jurídica de la población de origen extranjero en España, Melilla se convierte así en el caballo de Troya de las reivindicaciones nacionales. La población bereber, hacinada ilegalmente en la Cañada, comienza una lucha reivindicativa alentada por el deseo de salir de la invisibilidad política y social y por el ardor de adquirir un reconocimiento como ciudadanos de Melilla. Una población mayoritariamente constituida por individuos que aun habiendo nacido en Melilla, no disponían de la nacionalidad española (Planet Contreras, 1998: 34-35). La lucha de este colectivo musulmán de Melilla logro una flexibilización de la ley y el inicio de un proceso de nacionalización, según las cifras disponibles, 5.710 habitantes marroquís de Melilla obtuvieron, entre 1987 y 1990, la nacionalidad española. Actualmente podemos decir que la ciudad se caracteriza desde un punto de vista sociodemográfico por la convivencia de cuatro culturas cuantitativamente mayoritarias y su establecimiento y repartición espacial en barrios responde a una dinámica "comunitaria", ya que en cada barrio existe una mayoría "étnica", una comunidad que representa al menos el $50 \%$ de la población lo que suscita la hipótesis de una relativa "guetoización". Así, veamos la siguiente tabla 6 .

6 Fuente: Elaboración propia a partir de los datos del análisis de Mayoral del Arno (2000: 21-40). 
Figura 1: Distribución espacial de la población en

Melilla en función de la comunidad de origen

\begin{tabular}{|c|c|c|c|c|c|}
\hline \multicolumn{7}{|c|}{ Culturas } \\
\hline Barrios & $\begin{array}{c}\text { \% Población } \\
\text { Total }\end{array}$ & Peninsular & Bereber & Judía & Mixta \\
\hline 1 & $3.8 \%$ & $82 \%$ & $12 \%$ & - & \\
\hline 2 & $8.5 \%$ & $52.9 \%$ & $35.3 \%$ & $5.9 \%$ & $5.9 \%$ \\
\hline 3 & $3.4 \%$ & $30 \%$ & $60 \%$ & - & $10 \%$ \\
\hline 4 & $10.5 \%$ & $14.3 \%$ & $81 \%$ & - & $4.8 \%$ \\
\hline 5 & $19.5 \%$ & $16.2 \%$ & $75.7 \%$ & - & $8.1 \%$ \\
\hline 6 & $6.3 \%$ & $61.5 \%$ & $15.4 \%$ & $7.6 \%$ & $15.4 \%$ \\
\hline 7 & $10.4 \%$ & $71.4 \%$ & $14.3 \%$ & - & $14.3 \%$ \\
\hline 8 & $37.5 \%$ & $73.6 \%$ & $19.4 \%$ & - & $6.9 \%$ \\
\hline
\end{tabular}

Fuente: Elaboración propia a partir de los datos del análisis de Mayoral del Arno (2000: 21-40).

\section{Melilla, estudio de un caso: análisis de los comportamientos y actitudes sociolingüísticos}

Antes de adentrarnos en la materia de nuestro análisis cabe recordar el peso de la escuela en un contexto multicultural. La escuela siempre ha sido la reveladora de la diversidad existente en un lugar, ya que ella alberga dentro de sus muros niños de diferentes edades, con sus características individuales, que pertenecen a diferentes medios sociales y que provienen de las diferentes minorías. Es precisamente a raíz de esta diversidad que se ha iniciado una reflexión motivada por la necesidad de ofrecer a dichos alumnos las respuestas educativas necesarias para asegurar su integración y su contribución a la sociedad (Vacas Moraga, 2005: 184-209). La España plural debe valorizar la diversidad y para ello organismos oficiales educativos se movilizan para tratar esta diversidad a través de diversos programas, la educación pasa a ser intercultural (Arroyo González, 1997: 13). En las escuelas de Melilla, la presencia de alumnos con una lengua materna diferente del español es una realidad bien conocida. Esta lengua que convive con el español es al mismo tiempo una lengua hablada por el conjunto de la comunidad beréber que vive en Melilla desde hace tiempo (Servier, 1990; Vermeren, 2002; Ghechoua, 2001: 100-06). De este modo, el mosaico lingüístico de Melilla se caracteriza por la convivencia de dos lenguas mayoritarias, una oficial, el español y la otra, el tamazight, lengua siempre calificada como "minoritaria", lo que le confiere un estatuto de inferioridad que va a condicionar sin duda los comportamientos y las actitudes de los tamazigófonos, convergiendo en la marginalización y en la minimización del uso de esta lengua (Boukous, 2000: 209-18; Gharsa, 2002; Boudribila, 2005: 31-55). Es acerca de esta dimensión de cohabitación lingüística desigual en Melilla que se centra nuestro estudio, ya que las lenguas se ven privilegiadas o al contrario relegadas por los actores políticos del momento (Mesa Franco, 1996). 


\subsection{Presentación y análisis de la muestra}

Esta investigación sociolingüística se estructura en torno a cuatro elementos principales a partir de los cuales vamos a obtener una descripción suficientemente representativa de la realidad social y lingüística de Melilla a partir de las respuestas dadas por los estudiantes entrevistados. El cuestionario propuesto se compone de 25 preguntas agrupadas en cuatro entradas temáticas: 1) las características sociodemográficas y socioeconómicas: años de escolarización, edad, profesión de los padres, movilidad familiar y creencias religiosas, 2) las actitudes manifestadas por los estudiantes en relación al aprendizaje de las lenguas, 3) las características lingüísticas del núcleo familiar y 4) las actitudes en relación al contexto multicultural de la ciudad. La preocupación de este estudio sociolingüístico es identificar cuáles son los procesos de cambio lingüístico en marcha y poder establecer así las 'fronteras sociales' de dichos usos lingüísticos. El número de cuestionarios recogidos ha sido de 144 y la distribución de los mismos ha tenido que ser adaptada al contexto "fuera del centro" lo que de algún modo ha complicado el análisis sociológico. De estos 144 cuestionarios, 91 han sido realizados a la salida de cinco institutos y 53 de entre ellos se han efectuado en el interior de un instituto, el instituto Rusadir situado en un barrio poblado mayoritariamente y según las estadísticas disponibles, por una población de origen bereber. Aunque quisimos superar la prohibición de la administración educativa a realizar investigaciones a título individual o académico centradas en el ámbito educativo, solicitando para ello el apoyo de los directores de los institutos sólo el director del insitituo Rusadir se ha mostrado dispuesto a pasar por alto las interdicciones fijadas por la administración educativa, ayudándonos así a llevar a cabo nuestra investigación. Dicho director ha querido justificar su apoyo denunciando la indiferencia de la administración nacional en relación a la realidad social de Melilla, según él: "La situación académica de Melilla continúa siendo alarmante y los programas de apoyo no son suficientes. Necesitamos estudios prácticos y empíricos a partir de los cuales poder basar los programas teóricos"

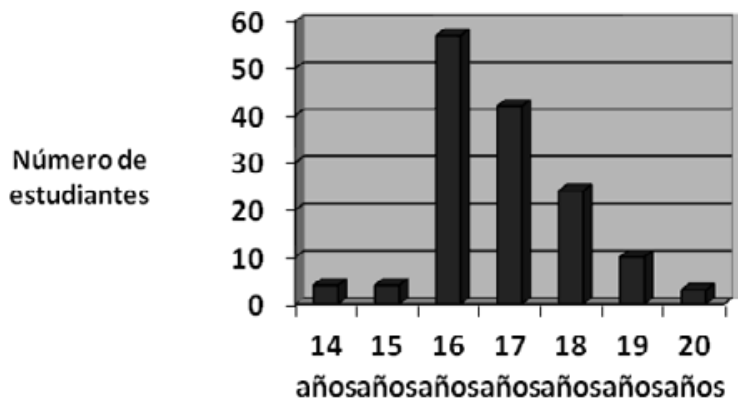

Edad de los estudiantes

Figura 2: Representación de la muestra en función de la edad (\%).

7 Extracto tomado de una entrevista realizada con el director del instituto Rusadir de Melilla, el jueves 29 de enero del 2009. 
La franja edad más representada de la muestra es la relativa a los estudiantes de 16 años, los cuales constituyen un tercio del total. Pese a esta sobrerrepresentación, la media de edad de nuestros jóvenes entrevistados se sitúa entre los 16 y los 19 años. Una segunda variable a considerar es la relativa al sexo. En términos absolutos, dos tercios de las personas interrogadas han sido chicas $(61.1 \%)$ mientras que sólo un tercio de la muestra global la representan los chicos (39.1\%). Esta "sobrerrepresentación" de las chicas estudiantes nos parece poner de manifiesto la hipótesis de una presencia mayoritariamente femenina en los centros educativos de Melilla, una feminización de la educación en la ciudad-frontera que parece acordarse con las estadísticas nacionales relativas a la feminización de la educación secundaria y del Bachiller. Los resultados de dichas estadísticas indican que las chicas tienden a superar tanto en número como en resultados a los chicos ${ }^{8}$. Por otro lado la variante según el sexo nos obliga a considerar el papel tradicional desempeñado por la mujer en las sociedades musulmanas y sus consiguientes repercusiones sociolingüísticas (Calvet, 1994: $269)^{9}$. En efecto la democratización de la educación y la urbanización del modo de vida de la población musulmana de la ciudad, originaria de las zonas rurales marroquís vecinas, ha contribuido a la transformación de la realidad de estas jóvenes y a su completa participación en los cambios lingüísticos (Vicente, 2005: 95).

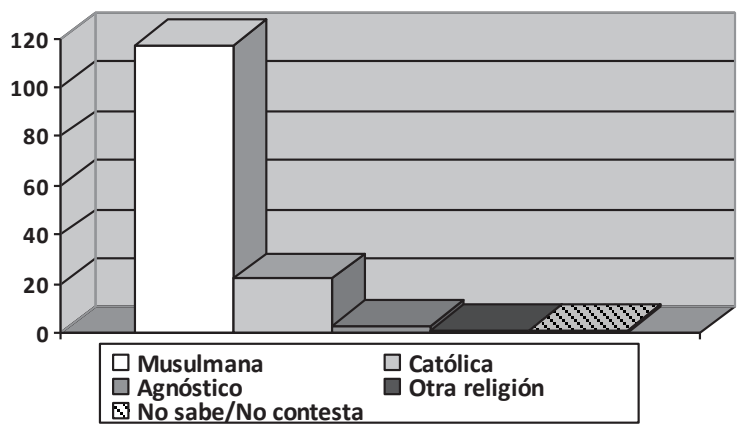

Figura 3: Creencias religiosas.

De los 144 estudiantes interrogados, 117 declaran ser de religión musulmana y sólo 22 de entre ellos dicen ser de religión católica, los resultados manifiestan un número de agnósticos insignificante, ya que solamente 3 alumnos declaran no tener ningún tipo de creencia religiosa. Del mismo modo, la práctica de otra religión distinta de las dos religiones nombradas anteriormente es también insignificante, un único alumno ha declarado practicar

8 Para una información más completa acerca de la escolarización femenina en el sistema educativo español, ver $V$ informe de España sobre la eliminación de todas las formas de discriminación contra la mujer, junio 2004. Disponible en línea: http://www.uv.es/igualtat/legislacioOnu/ONU_\%20V\%20Informe\%20Final.pdf, consultado el 10 agosto 2014.

9 En estas sociedades el hablar se considera como un instrumento de control moral que otorga respetabilidad y prestigio social. Una realidad que está cambiando con la aceleración de los procesos de urbanización y el éxodo rural que, así el estatuto social de las mujeres se ve invertido en las ciudades donde jóvenes relativamente independientes y con un elevado nivel de formación están remplazando la antigua mano de obra femenina rural y analfabeta. 
otra religión que no sea la católica o la musulmana. En nuestra opinión, este panorama religioso viene a confirmar por un lado la ausencia de alumnado de religión católica y de origen peninsular en los centros educativos públicos de la ciudad ${ }^{10}$. Por otra parte, estos datos reflejan un fuerte apego de los jóvenes de Melilla a los valores religiosos, las diferentes identificaciones nominalistas como "islámica", "Allah" para los musulamanes u otras como "Melilla" o "Dios" para los católicos nos permite constatar que se trata más bien de una pertenencia religiosa heredera del contexto familiar, vehiculada por un adjetivo o por un símbolo. Todo parece indicar que para dichos jóvenes la religiosidad se expresa simbólicamente con palabras-clave tales como "Allah" o "Dios", una identidad religiosa reducida a una palabra-fetiche estigmatizando con ello la pertenencia concebida no en términos de variables condicionantes sino a través de un viejo antagonismo: "o Moro o cristiano".

Según los datos de la muestra, el $84.7 \%$ de los estudiantes entrevistados afirma haber nacido en Melilla mientras que un $9.7 \%$ dice haberlo hecho en algún punto de la metrópoli española. El 83.3 \% declara haber vivido en Melilla la mayor parte de su vida (Fernández García, 2014: 215) ${ }^{11}$. Nuestros cuestionarios presentan así una mayoría de melillenses de nacimiento, inscritos desde una temprana edad en el sistema educativo local, el cual no ha contado con las posibles ventajas de la puesta en práctica de un bilingüismo infantil como es el caso en otras regiones o comunidades autónomas españolas caracterizadas también por el pluralismo lingüístico de sus habitantes. Un sistema educativo en el que, en Melilla, y como hace 40 años en todo el estado español, el grupo mayoritario continúa ejerciendo su hegemonía, de tal manera que la oferta educativa se orienta a partir del principio de identidad española y de hegemonía lingüística del español. Así, es difícil, incluso casi imposible, encontrar manifestaciones y acciones a favor de la promoción y del reconocimiento de la diversidad sociolinguísitca en las aulas de clase (Arroyo González, 1997: 95).

Con el objetivo de obtener una idea precisa de la evolución de la adaptación de la oferta educativa a la realidad social de Melilla, nos hemos procurado una lista de los programas pedagógicos diseñados en cada centro educativo, programas que buscan ante todo "compensar las diferencias ${ }^{12}$ ". Sin embargo, reconocer la igualdad es un principio indispensable, pero si la meta final es la promoción del emblema oficial, "Melilla, ciudad de las culturas", los instrumentos empleados deben superar el mero reconocimiento de la igualdad en una sociedad que se define como intercultural ${ }^{13}$. Los valores que deben guiar esta voluntad de cohabitación cultural deberían preconizar la conservación, la valorización y el desarrollo de legados culturales tales como la lengua tamazight o la riqueza cultural del pueblo bereber. Finalmente, siguiendo con la serie de cuestiones sociodemográficas abordadas por nuestros cuestionarios, debemos detenernos sobre la cuestión relativa a la profesión de los padres.

10 En un artículo titulado "Riesgo de fragmentación social en Melilla y Ceuta", miembro del Consejo Escolar del Estado por STEs-Intersindical advierte de la brecha existente entre los centros públicos y privados de las ciudades, de las enormes diferencias existentes entre el alumnado de dichos centros educativos y de la desventaja educativa en que se encuentra gran número de los jóvenes de Melilla y Ceuta, particularmente los de origen bereber y árabe. Artículo publicado en el periódico El País, el 14 de abril del 2013.

11 El estudio integral del trabajo de terreno llevado a cabo en la ciudad de Melilla se puede ver en la publicación de Alicia FERNANDEZ GARCIA, Melilla, mosaïque culturelle. Expériences interculturelles et relations sociolinguistiques d'une enclave espagnole, Paris, L'Harmattan, 2014.

12 Nuestra investigación se ha llevado a cabo en los cinco centros públicos de enseñanza secundaria existentes en la ciudad que son: La Escuela de Arte y los institutos Rusadir, Nieto Queipo, La Huerta y Miguel Hernández.

13 Estandarte cultural promovido por el ayuntamiento de Melilla. 
Los resultados obtenidos nos permiten subrayar que las madres de $45.8 \%$ de los estudiantes interrogados no trabajan, o mejor dicho, trabajan en casa, mientras que sólo un $22.9 \%$ de entre ellas realizan una actividad remunerada. Esta cuestión ha suscitado muchos "sin respuesta" y "otros casos", silencio preferido por el 17.3\% de los estudiantes interrogados, lo que parece sugerir el desconocimiento y las dudas de los adolescentes en lo referente a la situación laboral de sus madres. Según las respuestas de nuestros jóvenes, la categoría de "ama de casa" es mayoritaria, subrayando así el predominio en Melilla de un modelo de familia patriarcal. Una afirmación que también refleja la situación del mercado laboral en Melilla que está caracterizado por las disparidades pronunciadas entre la actividad masculina y femenina, ya que si la tasa de actividad masculina se sitúa en torno al 60\% la de las mujeres apenas alcanza un $29 \%{ }^{14}$.

\subsection{Por un análisis de las actitudes manifestadas hacia las lenguas}

Esta aproximación al contexto lingüístico de Melilla busca conocer el interés manifestado por los estudiantes en relación al tamazight y en relación a los últimos acontecimientos que han tenido lugar en materia de normalización gramatical de esta lengua. Así, la primera cuestión se propuso en términos de identificación gráfica de tres alfabetos, el griego, el tamazight y el árabe, para así poder apreciar el grado de conocimiento de los jóvenes interrogados de los alfabetos correspondientes a estas tres lenguas. Veamos pues el siguiente gráfico:

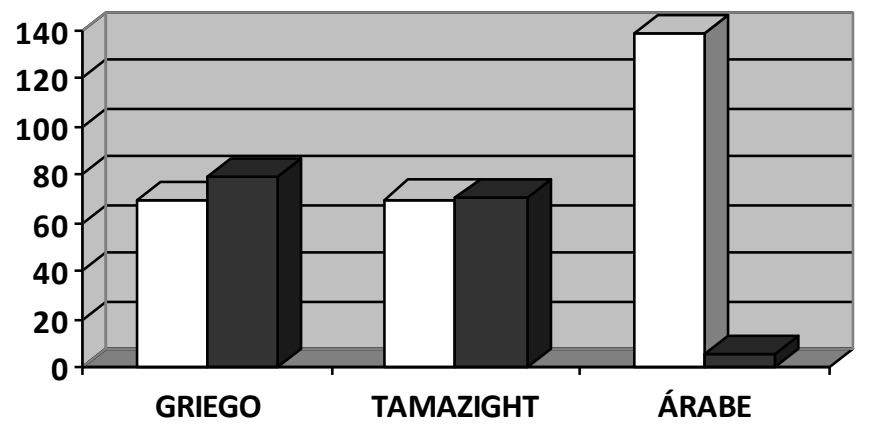

\section{$\square$ si ha reconocido el alfabeto $\quad \square$ no ha reconocido el alfabeto}

Figura 4: ¿A qué lenguas crees que pertenecen estos alfabetos?

Si la mayoría de nuestros estudiantes, 139 de los 144 efectivos, han identificado correctamente el alfabeto árabe, esta situación se invierte en el caso de la identificación de los otros dos alfabetos: el alfabeto griego y el tamazight, reconocidos respectivamente por 69 y 73 de nuestros jóvenes cuestionados. En lo que respecta al alfabeto griego, elegido para diversificar las opciones, debemos constatar la pérdida de interés por las lenguas de la

14 Datos tomados del análisis hecho por el Instituto nacional de estadística (INE) sobre las ciudades autónomas de Ceuta y de Melilla, año 2004. Disponible en internet sobre la página http://www.ine.es/prensa/np394.pdf consultado el 25 septiembre de 2014. 
antigüedad reforzada por la marginalización de estas lenguas en los programas educativos. En lo referente al tamazight, estos resultados nos conducen a formular una constatación: el tamazight continúa siendo una lengua reducida a su competencia oral, mantenida gracias a la tradición oral, cuyo alfabeto escrito es ampliamente desconocido por una gran mayoría de la muestra. Todo parece indicar que los últimos acontecimientos ocurridos en materia de codificación de esta lengua no parecen haber tenido repercusiones efectivas en el conjunto de la población de Melilla, o al menos, en el conjunto de la población escolar de Melilla ${ }^{15}$ . Si el gráfico muestra como casi la mayoría de la muestra ha reconocido el alfabeto tamazight, esta proporción es deficitaria si la comparamos con el uso oral y familiar que esta lengua parece tener a Melilla, como veremos, esta lengua parece ser lengua materna para un $24.4 \%$ de los alumnos interrogados y para un $7 \%$ el tamazight se emplea en casa de manera complementaria junto con el español. Así, si el desconocimiento del alfabeto griego resulta similar al del tamazight. De igual modo, durante la distribución de los cuestionarios, los alumnos han manifestado visibles muestras de interés por este alfabeto y muchos han conseguido identificarlo como resultado de las reacciones que esta cuestión suscitó. Este desconocimiento nos lleva a sospechar un desinterés en torno a esta lengua que choca con la activa disidencia que practica desde hace ya bastantes años una parte importante de la comunidad bereber. En efecto, una de los logros de esta lucha reivindicativa ha sido el "manifiesto bereber del $1^{\circ}$ mayo", un tipo de constitución del pueblo Imazighen, es decir, el pueblo bereber (Ghechoua, 2001: 100-06).

La segunda cuestión propuesta pretende conocer los gustos y preferencias de los alumnos hacia las diferentes realidades culturales. Para proceder a dicha información, la pregunta formulada ha sido la siguiente: “ ¿En qué lengua te gustaría poder leer? Ordena por orden de preferencia: Francés- árabe- inglés- tamazight-chino. Otras....”. Veamos los resultados obtenidos:

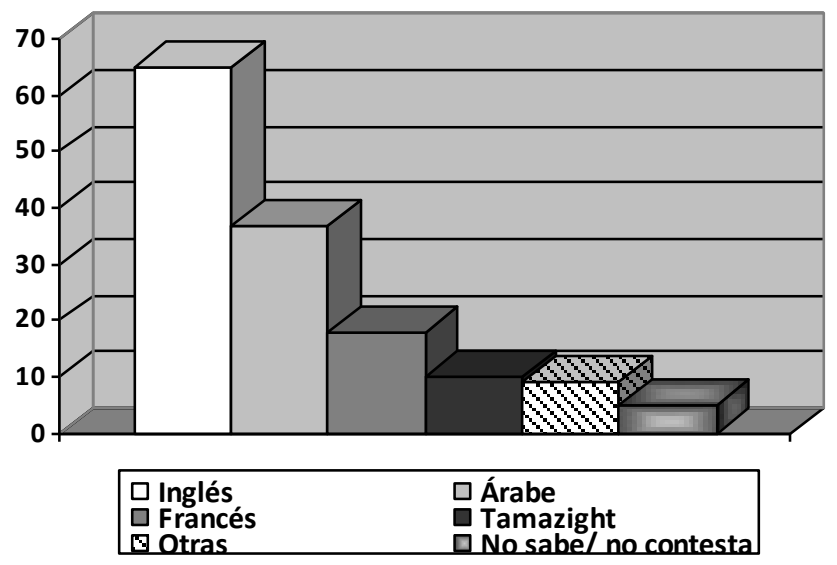

Figura 5

15 Los trabajos de Paul Moussard y de Agustín Bernard son relevantes de los estudios realizados en torno a la lengua bereber. Recomendamos también la lectura del libro de Bernard LUGAN titulado Histoire des berbères, des origines à nos jours: un combat identitaire plurimillénaire, Paris, 1'Afrique réelle, 2012. 
El hecho de estar situados en continente africano parece haber sensibilizado a nuestros estudiantes acerca de la importancia de la lengua árabe, lengua oficial del vecino Marruecos. Aunque teniendo en cuenta el contexto específico de Melilla, podríamos haber pensado que este interés por la lengua árabe sería claramente dominante, lo que no es el caso. Además, el hecho de vivir entre "berberófonos" o hablantes de la lengua tamazight no ha servido para reconocer la importancia de esta lengua ni tampoco para valorizarla como lengua deseada para leer libros, lo que muestra una actitud poco inclinada en favor de su reivindicación normativa. Las preferencias lingüísticas expresadas parecen más bien reproducir las asimetrías lingüísticas entre las dos comunidades dominantes en Melilla que ponerlas en causa.

\subsection{Aproximación al contexto familiar: desplazamientos y usos lingüísticos}

Para adentrarnos en el contexto lingüístico familiar de los jóvenes de Melilla, nuestra investigación ha abordado con los entrevistados una serie de cuestiones relativas a las lenguas habladas en el núcleo familiar. A través de cuestiones relativas a la lengua o las lenguas maternas pretendemos averiguar cuál es el lugar reservado a la lengua tamazight en el ámbito familiar de la población joven de Melilla y cuáles son, por lo tanto, las realidades lingüísticas susceptibles de caracterizar sus hogares. Una tentativa instrumentalizada a través de dos cuestiones: ¿cómo se transmite esta lengua?, y ¿cuál es su uso en los contextos familiares? Los gráficos siguientes, y a falta de estadísticas oficiales sobre el porcentaje de población que habla tamazight en Melilla, desvelan cuáles son las lenguas utilizadas por los padres, madre y padre, de los estudiantes cuestionados:

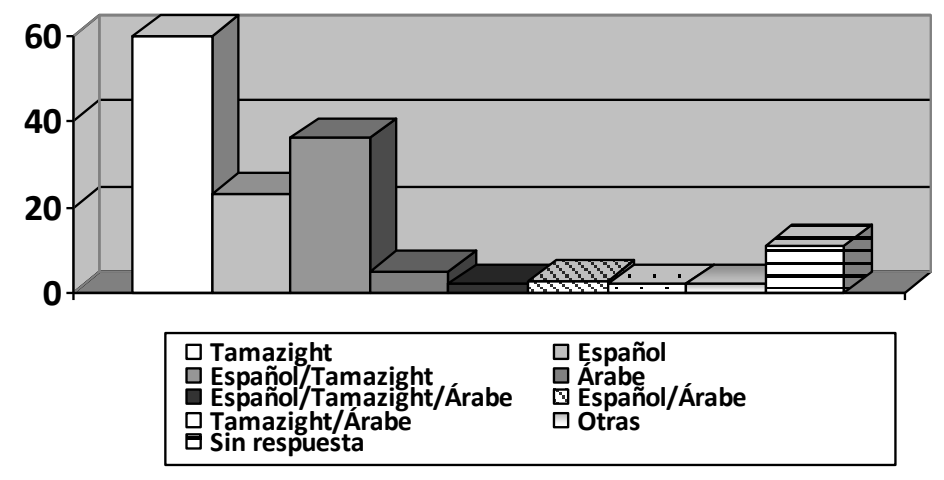

Figura 6: ¿Cuál es la lengua que tu madre habla en casa?

El gráfico 6 desvela en primer lugar que en lo que referente a las madres, es el uso del tamazight el que parece estar más difundido. Una segunda lectura nos muestra dos matices significativos a retener: 1) la repercusión de este hecho, es decir, la importancia potencial que tiene la lengua de la madre en la transmisión de esta lengua a los hijos; analizaremos más adelante esta repercusión y 2) la menor propensión de las madres a utilizar únicamente el español en el contexto familiar. Según los resultados obtenidos, todo parece indicar que las madres comunican principalmente en tamazight y en segundo lugar lo hacen en español o de manera bilingüe español-tamazight. El predominio del uso del español parece más nítido 
en los padres. Si el padre habla tamazight, todo parece indicar que normalmente es él quien habla más castellano, una situación que puede explicarse fácilmente, ya que, como hemos visto, en Melilla son los hombres los que disponen de un mayor acceso al mercado laboral.

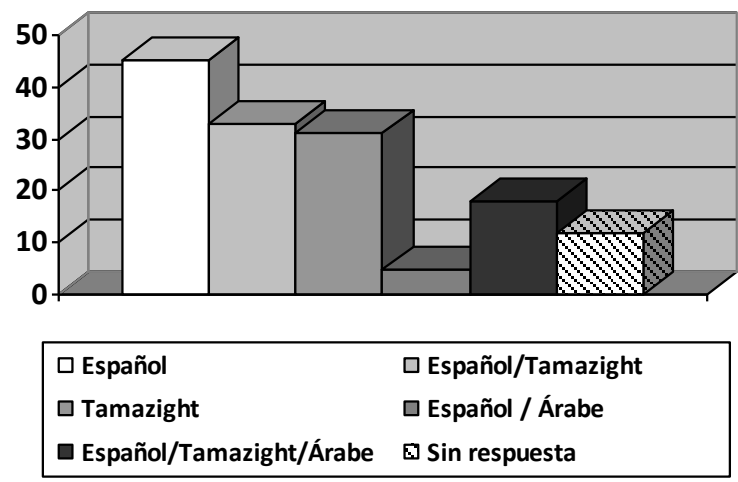

Figura 7: ¿Cuál es la lengua que tu padre habla en casa?

El siguiente gráfico presenta los resultados obtenidos sobre la lengua de comunicación entre padres, madres e hijos: 84 estudiantes del conjunto de los 144 interrogados declaran utilizar el castellano en sus relaciones con los padres, 29 alumnos afirman utilizar tanto el castellano como el tamazight siendo solamente 10 los que lo hacen en tamazight y 4 los que utilizan el árabe para comunicar con sus padres. El constante predominio del uso del español en el círculo familiar parece casi hegemónico. El bilingüismo, relativamente utilizado por los padres, se ve relegado a un segundo plano en el caso de los hijos. En fin, el uso exclusivo del tamazight como lengua mayoritariamente hablada en el núcleo familiar es casi inexistente en los hogares de nuestros 144 alumnos.

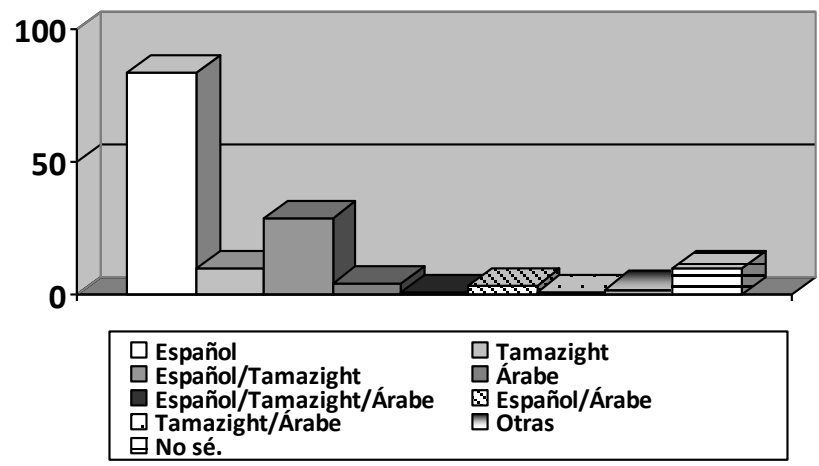

Figura 8: ¿Cuál es la lengua que hablas mayoritariamente con tus padres?

Todo parece indicar que a cada etapa el uso del tamazight es puesto en tela de juicio: mayoritariamente hablado por las madres $(41,7 \%)$ y utilizado junto al español por una pro- 
porción importante de los padres $(23 \%)$, esta lengua se encuentra relegada a un uso casi marginal en las relaciones entre padres e hijos. Si todo parece indicar que la mayor parte de los padres, madres y padres, hablan tamazight, esta lengua, aunque forma parte del espectro lingüístico familiar, no es utilizada como principal vehículo de comunicación en la familia. Por lo tanto, teniendo en cuenta esta pérdida sucesiva del uso del tamazight o del "chelja", como es popularmente conocido, las hipótesis sobre su futuro son más bien desalentadoras. Además, según los resultados de la muestra, y tal y como lo indica el siguiente gráfico 9 , hablar de "lengua materna" significa para la mayoría de los jóvenes interrogados, hablar el español: el 61.1\% (88 alumnos) declara tener como lengua materna el español y sólo el $24.3 \%$ confiesa tener el tamazight (35 estudiantes).

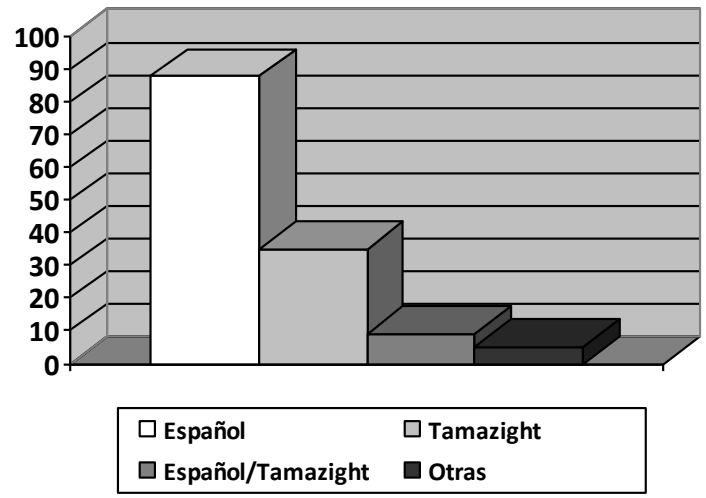

Figura 9: ¿Cuál es tu lengua materna?

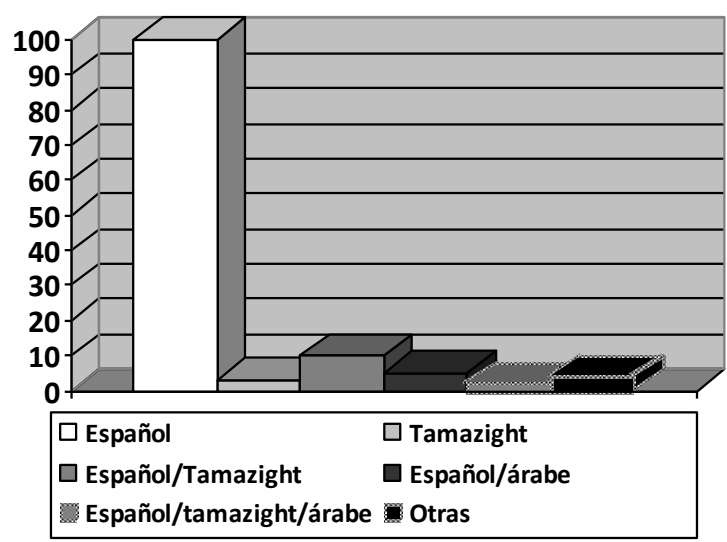

Figura 10: En la actualidad, ¿cuál de estas lenguas manejas mejor?

Existe por tanto una notable paradoja entre el hecho de que la lengua principalmente utilizada por las madres (gráfico 6) parece ser el tamazight, y el hecho de que los estudiantes 
declaren tener como "lengua materna" el español, al menos para una gran mayoría (gráfico 9). Podemos por lo tanto formular la siguiente hipótesis interpretativa: aunque en numerosos casos "la lengua materna objetiva" de la madre sea el tamazight ya que más del 69\% de las madres parecen hablarla en casa, la lengua "subjetivamente" transmitida por la madre a sus hijos es, paradójicamente, el español. Pero actualmente, ¿cuáles son sus competencias en tamazight? Las respuestas representadas en el gráfico 10 revelan una tendencia muy homogénea puesto que el $77.7 \%$ de los cuestionados (112 estudiantes) declaran mejor manejar el español que el tamazight y 6\% (10 estudiantes) se consideran bilingües, español-tamazight. Finalmente solo un 2\% (3 estudiantes) afirma mejor manejar el tamazight. De este modo, alrededor de $10 \%$ de los estudiantes se declaran bilingües o en la modalidad tamazightespañol (10 estudiantes) o en árabe-español (5 estudiantes).

\subsection{Hacia el descubrimiento del componente sociolingüístico: comportamientos y prácticas lingüísticas}

Continuando con nuestra tentativa empírica de conocer cuál es la realidad sociolingüística de Melilla partiendo de la integración y del uso de las lenguas habladas en la ciudad, la siguiente cuestión persigue desvelar la existencia de un predominio lingüístico a través de la percepción que los alumnos tienen de su propio entorno. Así, como nos confirma el gráfico siguiente, la lengua más hablada en Melilla sería ampliamente el español, o al menos es ésta la visión confesada por el $69.4 \%$ de los encuestados, mientras que un $11.8 \%$ considera que es más bien un bilingüismo español-tamazight lo que caracterizaría la realidad lingüística de la ciudad, y sólo un $11.1 \%$ afirma que es el tamazight la lengua más hablada en Melilla.

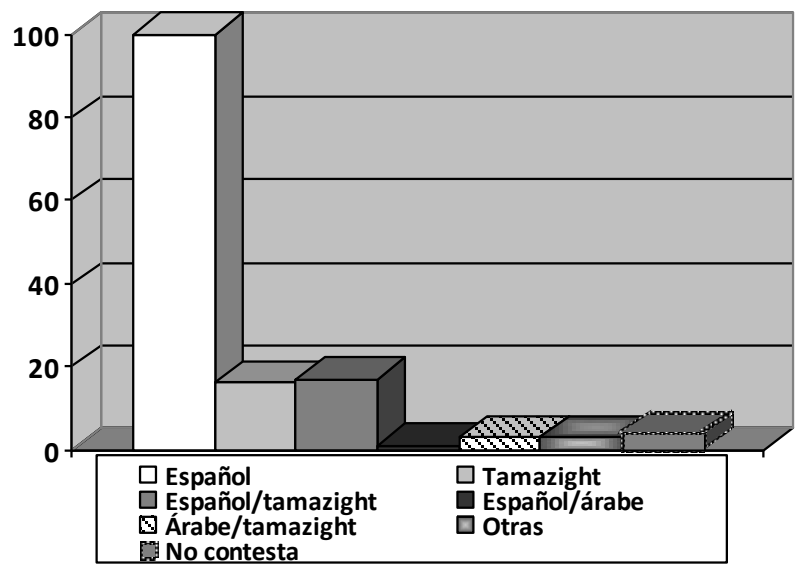

Figura 11: ¿Qué lenguas de las indicadas crees que es la más hablada en Melilla?

Sin embargo, estos resultados deben matizarse, ya que aunque los alumnos no consideren que el tamazight sea la lengua más hablada en Melilla, una gran mayoría de ellos, particularmente aquellos cuyos padres la utilizan, pueden comprender esta lengua. Llegamos a esta interpretación gracias a los resultados obtenidos en con la siguiente pregunta: 


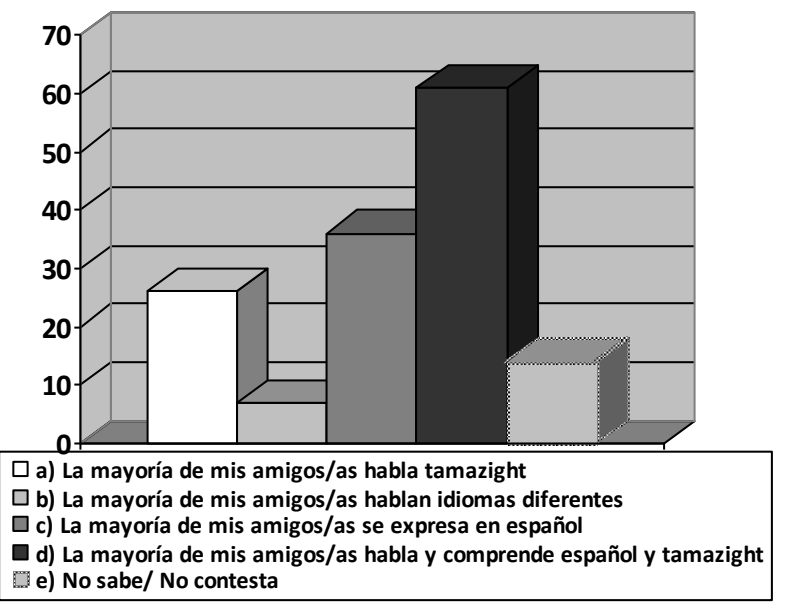

Figura 12: Consideras que fuera de la escuela:

La respuesta mayoritaria ha sido la opción d, así la visión estereotipada en torno al contexto sociolingüístico de la ciudad nos muestra que a pesar de una competencia débil en el uso oral de la lengua tamazight, los resultados obtenidos parecen indicar que la mayoría de nuestros alumnos son capaces de comunicar en tamazight y lógicamente son capaces también de comprender esta lengua; puede ser porque esta lengua es la lengua mayoritariamente hablada por sus madres y ampliamente utilizada por sus padres.

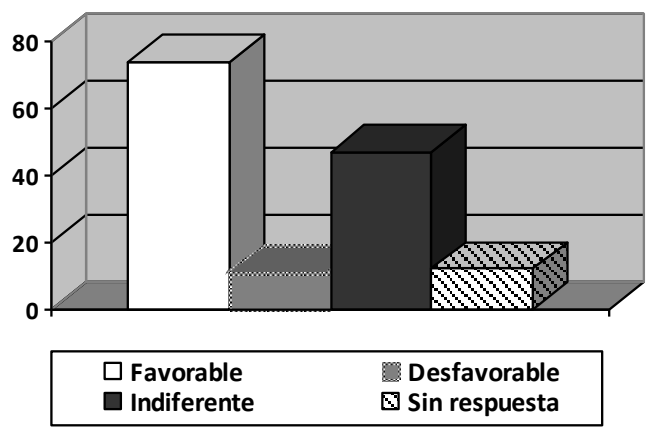

Figura 13: ¿Te gusta que en Melilla se hable tamazight?

Contrariamente, la tendencia a la dominación del español influye en las actitudes en relación con el uso del tamazight en la ciudad. Por ello, como respuesta a la cuestión: "¿Te gusta que se hable tamazight en Melilla?", los resultados recogidos nos muestran a primera vista una actitud globalmente positiva en relación con el uso del tamazight puesto que la mitad la muestra se considera favorable $(51.3 \%)$. Pero este porcentaje se acompaña de otro según el cual el desinterés se sitúa en segundo lugar: 32.6\% de los estudiantes entrevistados. Finalmente, el 7.6\% no se declara favorable al uso del tamazight en Melilla y un $8.3 \%$ prefiere no pronunciarse sobre el uso de esta lengua. La adición de estas tres opciones, la 
del desinterés, la del desacuerdo y la del silencio son mayoritarias, de tal manera que la muestra pone de relieve una actitud más bien pasiva del alumnado juvenil con respecto al uso del tamazight en su ciudad.

Finalmente, el gráfico 14 que mostramos a continuación nos ofrece una información suplementaria que tiene, a simple vista, todos los matices de desvelar cuáles son las actitudes acerca de la convivencia lingüística tamazight-español en la ciudad. Las respuestas dadas nos permiten comprender mejor el apoyo- o no- mostrado por los alumnos en lo relativo a la inversión en la enseñanza de la lengua tamazight y en una posible cooficialidad de esta lengua y del español. Hemos querido saber lo que los jóvenes quieren hacer con el tamazight en Melilla y que estatuto quieren otorgarle en la ciudad. Antes de sacar conclusiones veamos el gráfico siguiente:

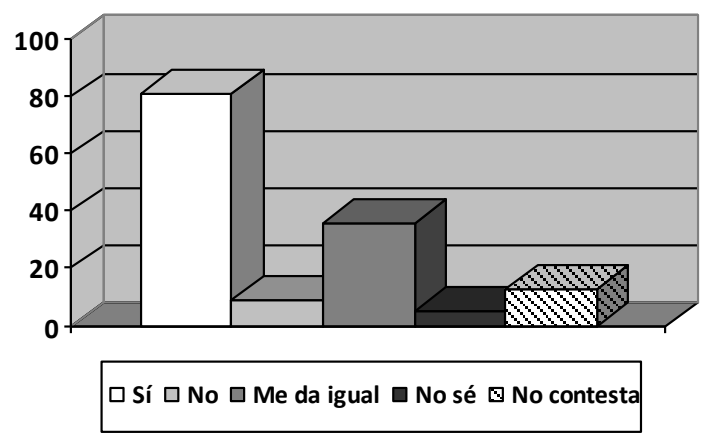

Figura 14: ¿Serías favorable a que el tamazight se enseñara en los centros escolares de Melilla?

Según estos datos, la mayoría de los estudiantes de la muestra se declara favorable a la enseñanza del tamazight en la ciudad, el «sí» corresponde a 81 de las respuestas dadas. Lo que nos permite constatar que al menos desde un punto de vista declarativo, una proporción importante de estudiantes no se opone a la enseñanza del tamazigh. Sin embargo, esta actitud mayoritaria no es unánime en razón de la amplitud de respuesta que el "no", el "me da igual", el "no sé" y los "no contesto" han obtenido, representando un total de 63 estudiantes. Anteriormente, habíamos subrayado una cierta pasividad en lo referente al reconocimiento del tamazight, y esta pasividad se refuerza de nuevo frente a esta cuestión relacionada con su aprendizaje: más de 35 estudiantes se dicen indiferentes a un posible aprendizaje de esta lengua en Melilla. La opción "no sé" ha obtenido 5 respuestas, 9 respuestas la opción del "no" y 13 han sido los estudiantes que no han contestado a la cuestión planteada. No podemos, por lo tanto, hablar ni de unanimidad, ni de homogeneidad, ni de consenso en lo referente al futuro del tamazight en la vida de los melillenses.

\section{Conclusiones}

Para lograr repensar las fronteras lingüísticas del territorio español, nuestra investigación se ha propuesto descubrir la ciudad de Melilla como un mosaico sociológico donde conviven 
diversas culturas, judíos, musulmanes, cristianos e hindús, y como un paradigma lingüístico, con una lengua oficial, el español y otra lengua oficiosa, el tamazight. Este trabajo ha buscado descubrir Melilla como una ciudad multicultural a través de un recorrido socio-histórico que nos ha permitido comprender cómo se ha ido forjando su idiosincrasia actual. Igualmente, la distribución de cuestionarios en seis institutos de la ciudad nos ha permitido obtener datos en torno a las actitudes y comportamientos sociolingüísticos que presenta la población escolar de Melilla. Dos cuestiones centrales han guiado esta investigación que persigue conocer cuál es el peso del bilingüismo tamazight-español en la ciudad de Melilla: 1) cómo las lenguas son percibidas por el conjunto de los estudiantes y 2) cuáles son las realidades lingüísticas susceptibles de caracterizar los entornos familiares de los jóvenes de Melilla. Como respuesta a estos interrogantes, debemos primeramente subrayar que la diversidad lingüística existente en Melilla es percibida de un modo más bien positivo y favorable por el conjunto de la muestra. Pero esta actitud favorable a la diversidad parece enmascarar una fractura, la del desinterés y la de la pasividad ya que las respuestas dadas pasan bruscamente de la estima a la indiferencia, lo que nos lleva a concluir que la pluralidad de las lenguas es ampliamente aceptada en Melilla pero sin demasiado interés manifestado en lo referente a su mantenimiento y a su valoración.

Sin embargo, hemos podido constatar que en lo relativo a los comportamientos lingüísticos, si es bien cierto que un número elevado de los estudiantes de la muestra comprende el tamazight, ya no es tan cierto el hecho de considerarse bilingües. De este modo, mirando los resultados obtenidos, esta carencia de competencias bilingües manifestada por la casi totalidad de la muestra puede considerarse como la consecuencia directa de la pérdida del uso del tamazight en el propio núcleo familiar: mayoritariamente hablado por la madre y también por el padre, el tamazight no es utilizado en la comunicación con sus hijos, reduciéndolo inevitablemente al estatuto de lengua secundariamente utilizada en la familia. En Melilla existe lo que los lingüistas consideran una práctica bilingüe imperfecta o diglósica, es decir, un bilingüismo desequilibrado en la medida en que una de las lenguas goza de mayor prestigio o de mayores privilegios sociales y/o políticos que la otra. Si consideramos que un hablante es bilingüe cuando es capaz de emplear dos lenguas con la misma competencia y en cualquier circunstancia con una eficacia parecida podemos afirmar que, en esta ciudad, se da una situación de bilingüismo pero en un medio diglósico en el que la lengua débil y desprestigiada es el tamazight. Las razones de esta diglosia puede encontrarse en el propio sistema educativo ya que detrás de los programas oficiales destinados a "compensar las diferencias", existe de facto un sistema que invalida las competencias bilingües de los alumnos; recordemos que los datos de la muestra indican que el tamazight es lengua materna para más del $30 \%$ de nuestros alumnos. Un sistema que excluye sus "bagajes" lingüísticos, que se opone a cualquier tipo de reforma educativa en favor de la interacción interlingüística de las lenguas habladas en Melilla y que parece hacer un tipo de detestatio sacrorum de toda investigación centrada en una mejor comprensión de la realidad sociolingüística del alumnado melillense. Destacaremos también que nuestros cuestionarios han sido realizados en tiempo de recreo escolar, ya que la Dirección Provincial de Melilla no nos ha concedido el permiso para realizar el cuestionario en las escuelas, hemos intentado conocer las razones y conocerlas de la mano de los especialistas y responsables de la educación en Melilla, pero los reveses manifestados, los ciertos "venga usted mañana" o "haga su estudio en otra ciudad española, porque aquí no hay nada que estudiar" nos han transmitido la falta de 
interés mostrada en explicar y dar a conocer cuál es la realidad sociolingüística existente en Melilla. Así, al entrar en contacto con esta escuela donde impera la supremacía lingüística del español, el alumnado tamazigófono procede a un reemplazamiento lingüístico de esta lengua por el español, esta última considerada como lengua dotada de prestigio social. De ahí el hecho de que aunque el tamazight es la lengua materna para el 32.1\% de la muestra, en la actualidad estos mismo jóvenes confiesan haber perdido su manejo ya que sólo un $8 \%$ considera hablarla mejor que el español o disponer de una competencia bilingüe en estas dos lenguas. Sin embargo, a la pregunta: "Consideras que fuera de la escuela: a) La mayoría de mis amigos y amigas hablan tamazight, b) Mis amigos hablan idiomas diferentes entre sí, c) La mayoría de mis amigos se expresa siempre en español y opción d) La mayoría de mis amigos habla y comprende el español y el tamazight", la respuesta mayoritaria ha sido la opción d lo que refleja que la mayoría de la muestra atribuye a su entorno la capacidad comunicar en tamazight y de comprender esta lengua, quizás porque se trata de una lengua mayoritariamente hablada por sus madres (grafico 6) y ampliamente utilizada por sus padres (gráfico 7).

La sociolingüística se interesa a las desigualdades sociales que se influyen en el uso de una lengua, en el contexto de Melilla, los jóvenes entrevistados afirman que es en sus barrios situados en los distritos 3, 4 y 5, zonas con una fuerte concentración de población de origen bereber, en donde consideran hablar más tamazight, procediendo así a la creación de su propia política lingüística ejemplarizada musicalmente por el apogeo de estilos musicales como el rap. Dichos distritos se caracterizan igualmente por una importante presión migratoria proveniente de las regiones marroquíes colindantes, lo que viene a reforzar la guetoización cultural y lingüística de la ciudad. Así, la indiferencia y la pasividad de la muestra a la pregunta “'Te gusta que en Melilla se hable tamazight?” (32.6\% de la muestra) es sintomática de la percepción de la ciudad como un espacio de conflicto de lenguas y de la interiorización de fronteras lingüístico urbanas.

\section{Referencias bibliográficas}

Arques, E. (1966): Las adelantadas de España: las plazas del litoral africano del Mediterráneo. Madrid, Consejo Superior de Investigaciones Científicas, Instituto de Estudios Africanos.

Arroyo González, R. (1997): Encuentro de culturas en el sistema educativo de Melilla. Melilla, Ensayos melillenses.

Berenguer, J. (1997): Melilla la codiciada. Melilla, La Biblioteca de Melilla.

Bernard, A. y P. Moussard (1924) : “Arabophones et berbérophones au Maroc”, Annales de géographie, 33, vol.183, págs. 267-282.

Boudribila, M. (2005) : “Toponymes et habitants anciens de l'Afrique du nord: origines et problématiques", AWAL. Cahiers d'études berbères, 32, págs. 31-55.

Boukous, A. (2000): "Marché linguistique et violence symbolique: le cas de l'amazigh", AWAL. Cahiers d'études berbères, 27-28, págs. 209-218.

Bravo Nieto, A. y P. Fernández Uriel (eds.) (2004): Historia de Melilla. Málaga, Conserjería de Cultura y Festejos de Almería.

Brogini, A. y M. Ghazali (2006) : "Un enjeu espagnol en Méditerranée: Tripoli et La Goulette au XVIème siècle”, Cahiers de la méditerranée, 1, vol.70, págs. 42-54. 
Domínguez Sánchez, C. (2004): Melillerías. Paseos por la historia de Melilla (siglos XV a $X X)$. Málaga, Servicio de publicaciones Biblioteca de Melilla.

Fernández García, A. (2014): Melilla, mosaïque culturelle. Expériences interculturelles et relations sociolinguistiques d'une enclave espagnole. Paris, L'Harmattan.

García Mouton, P. (2006): "El castellano hoy: sus principales rasgos lingüísticos. Variedades del español hablado en España. Teoría y práctica". En M. Aparicio (coord.), Las lenguas españolas: un enfoque filológico. Madrid, Ministerio de Educación y Ciencia.

Gharsa, C. (2002): “Amazigh et dialectique du même et de l'autre”, AWAL, Cahiers d'études berbères, 25, págs. 129-145.

Ghechoua, A. (2001) : “Que veulent les berbères ?”, Jeune Afrique-L'intelligent, 2012-2103, págs.100-106.

González Callejas, E. (2013): “Entre la fascination pour l'exotisme et la volonté de mission : orientalisme et africanisme espagnol au XIX ${ }^{\text {ème }}$ siècle" : http://periples.mmsh.univ-aix. $\mathrm{fr} /$ merepresentations/textes/gonzales/gonzales.html (20-03-2014).

López Belmonte, (2013) : "Riesgo de fragmentación social en Melilla y Ceuta", El País, $14 / 04 / 2013$.

Lugan, B. (2011) : Histoire du Maroc. Des origines à nos jours. Paris, Ellipses.

Lugan, B. (2012) : Histoire des berbères, des origines à nos jours : un combat identitaire plurimillénaire. Paris, L'Afrique réelle.

Madariaga, M.R. (2000): España y el Rif: crónica de una historia casi olvidada. Melila, UNED.

Mayoral del Arno, J. F. (2000): "El mosaico de Melilla". En Experiencias interculturales en Melilla. Granada, Sindicato Autónomo de Trabajadores de la Enseñanza SATE-STE.

Mesa Franco, M.C. (1966): Educación y situaciones bilingües en contextos interculturales. Estudio de un caso. Melilla, Granada: CINSA.

Mir Berlanga, F. (1990): Melilla la desconocida. Historia de una ciudad española. Melilla, publicaciones del Ayuntamiento de Melilla.

Moreno Cabrera, J. C. (2012) : "L'évolution du nationalisme linguistique espagnol depuis la transition démocratique". En A. Fernández García y M. Petithomme (dirs.), Les nationalismes dans l'Espagne contemporaine (1975-2011). Paris, Armand Colin, 334-358.

Nadal, J. (1984) : La población española (siglos XVI al XX). Barcelona, Ariel.

Peres, D. (1960): Historia dos descobrimentos portugueses. Coimbra, Alves.

Planet Contreras, A. I. (1998) : Ceuta y Melilla, espacios-frontera hispano-marroquíes. Melilla, Biblioteca Universitaria de Granada.

Puertas, Y. (2013): "Portadoras de la prosperidad", El País, 7/04/2013 .

Ruiz Domíngues, M. M. (1998): Estudio sociolingüístico del habla de Melilla (Tesis doctoral, Universidad de Almería, 1998).

Salafranca Ortega, J. (1987): Bosquejo histórico de la población y guarnición de Melilla (1497- 1874). Granada, La Gioconda.

Salafranca Ortega, J. (1995): Los judios en Melilla. Málaga, editorial Algazara.

Servier, J. (1990) : Les berbères. París, Presses Universitaires de France.

UNICE, 2015: Estudio demográfico de la población musulmana en España. http://observatorio.hispanomuslim.es/estademograf.pdf (03-02-2015)

Vacas Moraga, F. (2005): “Inmigración y educación”, Actas del seminario: Educación, diversidad cultural y ciudadanía. Granada, págs.184-209. 
Vermeren, P. (2002): Le Maroc en transition. París, La Découverte.

Vicente, A. (2005): Ceuta, une ville entre deux langues. Paris, L'Harmattan.

Villalobos, F. (2004): El sueño colonial. Las guerras de España en Marruecos. Barcelona, Ariel.

$\mathrm{V}$ Informe de España sobre la eliminación de todas las formas de discriminación contra la mujer, junio 2004. http://www.uv.es/igualtat/legislacioOnu/ONU_\%20V\%20Informe\%20Final.pdf (10-08- 2014) 


\title{
MECANISMOS MULTIMODALES DE FOCALIZACIÓN DE LA INFORMACIÓN EN LA PRENSA DIGITAL DEL CAMPO CIENTÍFICO Y JURÍDICO: LA NEGRITA*
}

\author{
M. á Ángeles García Asensio, Fernando Polanco Martínez, Irene Yúfera Gómez \\ Universitat de Barcelona \\ Grupo EDAP (Estudios del Discurso Académico y Profesional) \\ garciaasensio@ub.edu; polanco@ub.edu; iyufera@ub.edu
}

Recibido: 02/09/2014

Aceptado: 03/06/2015

\begin{abstract}
Resumen
Para satisfacer el derecho a la información, la prensa digital recurre a cuatro sistemas semióticos (verbal, gráfico, matemático y tipográfico) con los que construye, organiza y jerarquiza contenidos y guía al lector en sus procesos interpretativos de la realidad periodística. La tipografía, intrínseca a la expresión verbal escrita, aporta su potencial de significado a través de sus rasgos distintivos y de dos principios semióticos: la connotación y la metáfora. En este artículo analizamos cómo la letra negrita, con su rasgo grosor de la letra, es usada en la prensa digital. Se analizan 60 noticias publicadas en España. Los periódicos digitales no coinciden en el tipo de segmento que resaltan en negrita. Hay también inconsistencias. Con todo, la negrita satisface en los textos periodísticos las tres metafunciones propuestas por Halliday (1978): ideacional, interpersonal y textual, a través de la macrofunción de resalte.

PALABRAS CLAVE: multimodalidad, prensa digital, tipografía, negrita, metafunciones.
\end{abstract}

\begin{abstract}
To satisfy the right to information, the digital press combines four semiotic systems (verbal, graphic, mathematical and typographical) to build and organize news content and to guide readers to understand and interpret the journalistic reality. Typography, visual appearance and potential meaningful aspect of the written verbal expression, brings its meaning potential through its distinctive features and, also, through two semiotic principles: connotation and metaphor. In this paper we analyze how bold typeface, with its characteristic heavy weight and thickness of the letter, is used in the digital press. 60 news items published in Spain are analyzed: digital newspapers do not agree on the kind of fragment highlighted in bold. There is also inconsistencies. Yet the bold typeface is used in journalistic texts to convey the three metafunctions proposed by Halliday (1978): ideational, interpersonal and textual, through the macrofunction of salience.

KEYWORDS: multimodality, digital media, typography, bold, metafunctions
\end{abstract}

\section{Introducción}

Dado el entorno multimodal, interactivo, intertextual e hipertextual (Pajares, 2004; Salaverría y Sancho, 2007; Cassany, 2011: 30-34) de la prensa digital, es esperable que hoy

\footnotetext{
* Este trabajo se enmarca en el proyecto de investigación Estrategias de textualidad del discurso profesional en sorportes multimodales. Análisis y propuestas de mejora (FFI2011-28933), financiado por el Ministerio de Economía y Competitividad.
} 
los periodistas recurran a estrategias propias del soporte digital para divulgar con rigor y claridad contenidos complejos. Algunos de estos contenidos atañen a campos de especialidad como el científico y el jurídico. El periodista que se introduce en estos campos debe manejar conceptos relacionados con la ciencia y con la justicia que se expresan con lenguajes especializados. Para acercar al público a estos lenguajes y satisfacer su derecho a ser informado verazmente, se hace necesario desplegar mecanismos de clarificación de contenidos indefectiblemente ligados a un léxico terminológico (Yúfera, García y Polanco, 2014). También el periodista ha de organizar y jerarquizar el contenido que maneja en el espacio visual de la pantalla y ha de guiar al lector en sus procesos interpretativos a fin de diferenciar los aportes de información jerárquicamente más relevantes para la comprensión global de la pieza informativa, enfatizarlos y convertirlos en foco informativo.

En la perspectiva metodológica que ofrece el análisis del discurso y el análisis del discurso multimodal desarrollado desde la semiótica social (Kress y Van Leeuwen, 1992, 1996, 2001), en este trabajo estudiamos hasta qué punto uno de los modos semióticos que opera en la prensa digital generalista funciona como mecanismo argumentativo para conferir relevancia informativa y enfatizar información sobre la actualidad científica y jurídica. Este modo, de uso habitual en la escritura digital, es a la vez un elemento visual y un recurso semiótico con un potencial de significado propio (Van Leeuwen, 2006; Serafini y Clausen, 2012: 2528). Se trata del modo tipográfico. Concretamente, en este trabajo nos interesamos por uno de los rasgos tipográficos que más realce adquiere en la escritura en la pantalla: la negrita.

\section{El potencial de significado de la tipografía en la perspectiva del análisis multimodal}

La caracterización lingüística de los mecanismos de construcción textual de los discursos que se generan en entornos digitales no puede obviar una aproximación a estos discursos en una perspectiva multimodal que supera lo estrictamente verbal. Efectivamente, en la red es ya difícil que un texto carezca de una combinación sinérgica de discurso escrito con otros modos semióticos.

Se entiende por modo (Kress y Van Leeuwen, 1996, 2001) -modalidad o sistema semiótico (Parodi, 2010)- cualquier recurso, vía, medio o material disponible en el contexto comunicativo, que se emplee con el propósito de crear significado(s) (Kress, Leite-García y Van Leeuwen, 2000: 377-383). Todo modo o sistema semiótico está constituido por un repertorio de signos de una misma naturaleza (verbal, gráfica, matemática, etc.) y un tipo de sintaxis articulada por principios de organización funcional, semántica o morfológica que regulan su disposición y su uso del espacio dentro del texto (Parodi, 2010).

De esta forma, en un entorno digital, imágenes fijas, vídeos u otros artefactos multisemióticos (Jewit, 2009) como las infografías, que originan mapas, gráficos, esquemas o viñetas, etc., se conjugan con el sistema verbal para crear significados completos, semánticos y pragmáticos, y servir a unas determinadas intencionalidades comunicativas dentro de un contexto sociocultural determinado. La escritura digital es una forma de comunicación de naturaleza multisemiótica o, si se prefiere, multimodal (Jewit, 2009).

Concretamente, Van Leeuwen (2006), O’Halloran (2008) o Parodi (2010) subrayan la existencia de cuatro sistemas semióticos que interactúan en los textos escritos y originan múltiples artefactos multimodales: el sistema verbal, el gráfico, el matemático y el tipográfico. Estos sistemas no solo establecen relaciones intrasemióticas -hacia el interior de su 
sistema-; también sus relaciones son intersemióticas -entre sistemas-, según los significados que en cada momento se quieran expresar.

Forman el sistema verbal palabras, cláusulas y oraciones que construyen significados basados en lo lingüístico. El sistema gráfico se constituye a partir de trazos que conforman una representación pictórica y que permiten presentar datos en formatos distintos, normalmente combinando varios modos: fotografías, gráficos, diagramas, tablas, etc. El sistema matemático acoge grupos de grafías, signos o representaciones que permiten codificar significados de forma sintética: números romanos o árabes, letras griegas o latinas, operadores y signos de puntuación. El sistema tipográfico se presenta inseparable de los sistemas verbal, gráfico o matemático, y, de hecho, es intrínseco a la expresión verbal escrita: es la apariencia visual del sistema verbal. La introducción de los procesadores de texto ha sido el detonante que ha puesto de manifiesto el potencial de significado de las formas y de los colores de las letras: negritas, cursivas, mayúsculas, bajas (minúsculas), así como de su dimensión tipográfica uni, bi o tridimensional (Van Leeuwen, 2005a, 2006; Machin, 2007: 83-108; Norgaard, 2009; Parodi, 2010).

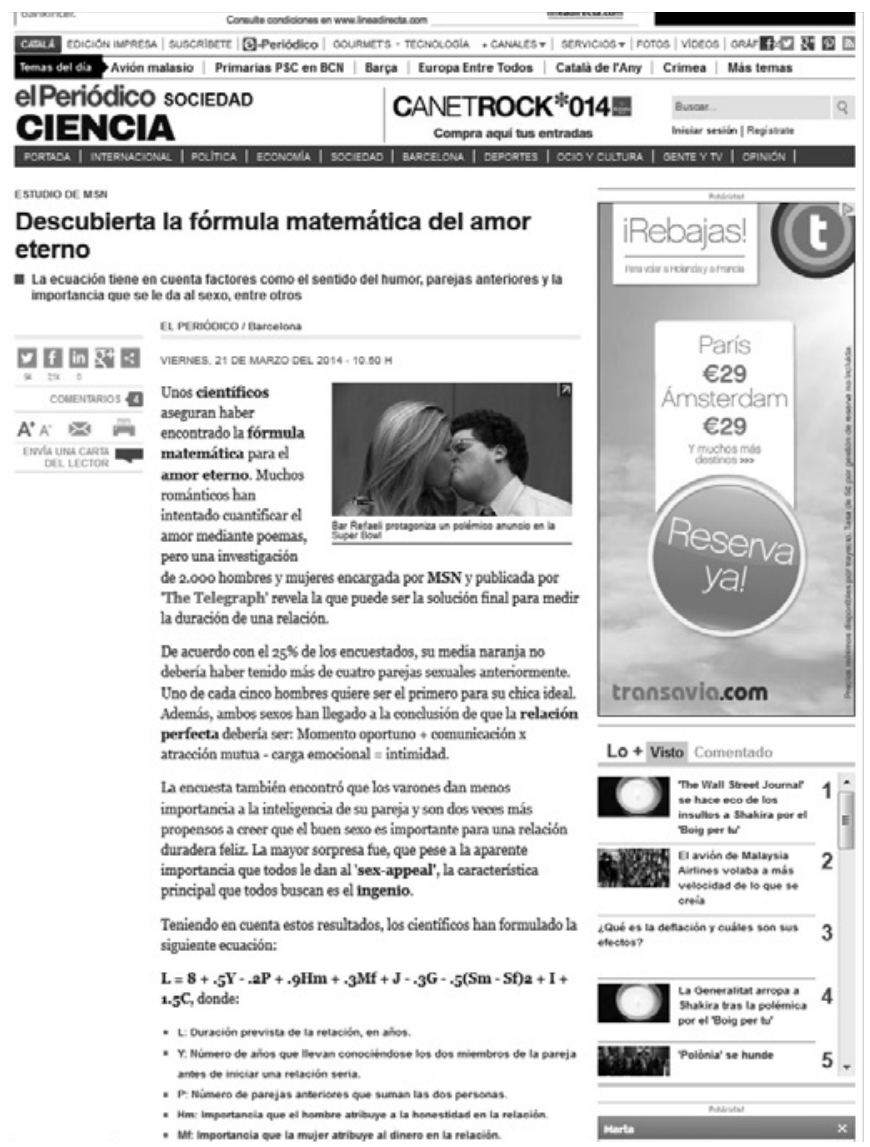

Figura 1. Modos semióticos en una crónica digital. Fuente: El periódico (Edición digital. 21/03/2014) 
En la figura 1 puede apreciarse cómo los distintos sistemas semióticos ocupan una posición en la arquitectura del espacio visual (layout) e interactúan en la construcción del significado global de una crónica científica publicada en la sección de Sociedad. Ciencia de la edición digital de El Periódico.

Así, teniendo en cuenta que el layout también aporta una carga de significado (Van Leeuwen, 2006: 139-141), en la muestra textual se observa cómo todos los modos (verbal, gráfico, matemático y tipográfico) interactúan en el cuerpo del relato periodístico, cuerpo que, a su vez, ocupa la columna central del espacio visual de la página. De este modo, de acuerdo con la semiótica social del espacio visual (Kress, Leite García, Van Leeuwen, 2000: 404-406), este espacio central, más ancho, pone de manifiesto la relevancia informativa, de densidad transaccional, del cuerpo del relato respecto de los aportes de información paratextual, que se ubican en los márgenes derecho e izquierdo de la arquitectura del espacio web. También en estos espacios marginales actúan los cuatro sistemas semióticos.

Se observa, además, cómo la fotografía de mayor tamaño (sistema gráfico) y su pie (sistema verbal y tipográfico) se ubican, también a su vez, en una relación con el texto del cuerpo de relato, de información conocida (texto del relato) a información nueva (fotografía y pie) (Kress y Van Leeuwen, 1996: 186-192): su ubicación en el margen superior del cuerpo del relato es, asimismo, significativa, pues es en este espacio donde se despliegan estrategias conducentes a llamar la atención sobre el propio texto y a mantener abierto el canal de interacción con el lector (espacio para fotografías, vídeos, entradilla).

Finalmente, la cabecera (Sociedad. Ciencia) y el encabezamiento (titulares) ocupan el margen superior de la página, al que forzosamente se le asocia la significación de satisfacer una función identificativa (García y Palomeque, 2012): los modos verbal y tipográfico son en este espacio superior altamente relevantes para satisfacer esta función identificativa, a la vez que de llamada de atención. El distinto tamaño de la fuente señala una mayor jerarquía informativa respecto del cuerpo del relato, dado que en los titulares se identifica el tema dominante de cada noticia y se anticipan otros contenidos relevantes, según las mediaciones cognitivas y la postura ideológica del medio. De esta manera se guía al lector en su proceso de interpretación de la información y en el establecimiento de la macroestructura semántica y de la coherencia global de cada relato periodístico (Van Dijk, 1998: 59).

Ahondando en el sistema tipográfico, al que la prensa escrita y la digital prestan una atención creciente (Machin, 2007: 83), fue Kress (2003) quien planteó considerarlo como un modo más, lejos de considerarlo como un mero elemento estético o únicamente como un rasgo que atañe a la legibilidad de un texto y que, por tanto, facilita o dificulta su lectura y su procesamiento (Serafini y Clausen, 2012). De hecho, hasta entonces las investigaciones lingüísticas realizadas en una perspectiva multimodal habían descuidado este modo. Van Leeuwen $(2005 \mathrm{a}, 2006)$ impulsa estas investigaciones y reivindica su estatuto de modo semiótico con entidad propia. Machin (2007), Norgaard (2009) o Serafini y Clausen (2012) subrayan su papel esencial en los procesos comunicativos.

Más aún, las investigaciones de Van Leeuwen (2006) pretenden indagar en la gramática de la tipografía, para lo que proponen una primera sistematización de sus rasgos distintivos y no distintivos (Van Leeuwen, 2006: 147-152). La enumeración de estos rasgos incluye el grosor del tipo de letra o fuente, su expansión, inclinación, curvatura, conexión, orientación respecto de la dimensión horizontal y regularidad, en tanto que rasgos distintivos; así como el trazo, el remate, las florituras o ligaduras, entre otros rasgos no distintivos. En Machin 
(2007) o en Norgaard (2009) se propone añadir a esta lista otros rasgos como la textura o el color, lo que implica, en este último caso, tener en cuenta la saturación cromática, la modulación, el contorno del texto, sombras, reflejos, bordes e iluminados, etc.

Junto con la sistematización de los rasgos tipográficos, dos son los principios semióticos clave propuestos por Kress y Van Leeuwen (2002) y por Van Leeuwen (2005a, 2005b) para explicar cómo estos rasgos, en el marco del modo tipográfico, aportan en un texto su potencial de significado: la connotación y la metáfora. El significado que potencialmente se construye a través de la connotación se origina de una importación discursiva de asociaciones desde el contexto al que pertenecía originalmente un tipo de letra al contexto en que esta letra es usada (Van Leeuwen, 2005a: 139), a fin de significar las ideas y los valores asociados al contexto de origen en el contexto de destino: una fuente Tivaldi puede evocar, por ejemplo, un tiempo en la historia en que la escritura era siempre manual, cuidada. Es un tiempo al que solemos asociar un ritmo vital más sosegado que el actual. La fuente Vivaldi puede connotar, pues, por asociación, valores de calma, sosiego, cuidado.

La metáfora tipográfica (Van Leeuwen, 2005b: 29-36; Van Leeuwen, 2006: 146-147) se basa, por su parte, en el principio de similitud entre la forma tipográfica, que es la forma visual del significante, y su significado. De este modo, una letra en negrita puede significar, metafóricamente $-\mathrm{o}$, si se prefiere, de acuerdo, también, con el concepto de icono desarrollado por Peirce (Norgaard, 2009: 147-154)- fuerza, solidez, asertividad: los objetos cotidianos de un grosor o de una anchura manifiesta suelen ser sólidos, fuertes, difíciles de romper ${ }^{1}$.

En cualquier caso, el proceso de decodificación del significado transmitido por un rasgo tipográfico implica siempre considerar su contexto y, por tanto, su interacción con otros significados aportados por otros elementos tipográficos o por otros sistemas que concurren simultáneamente en un sincretismo multimodal con tal rasgo tipográfico. El rasgo es un recurso con el que construir un significado. Su significado es potencial (Van Leeuwen, 2005a). En este sentido, para descodificar el significado de una negrita en una palabra de este modo destacada, deberá tenerse en cuenta el tamaño u otros rasgos tipográficos de las letras (la misma tipografía es multimodal); el propio significado léxico de la palabra destacada ${ }^{2}$, vehiculado por el sistema verbal; la presencia o no de comillas delimitadoras de cita enmarcando la palabra, etc. En este contexto, una negrita, portadora de un significado de aserción, fuerza o solidez, puede asimismo, por connotación, evocar un significado asociado de dogma o intransigencia y contribuir a dibujar, en un determinado texto, un personaje autoritario, inflexible o despiadado, que va a generar una actitud desvalorizante en el lector; o, al contrario, un personaje firme, estable e incluso audaz (Van Leeuwen, 2006: 148; Machin, 2007: 104).

Cabe, por último, especificar que el potencial de significado del sistema tipográfico ha de relacionarse con su potencial comunicativo. En Van Leeuwen (2006:142-143), Machin (2007: 89-92) o en Serafini y Clausen (2012: 28) se subraya que los rasgos tipográficos pueden, de hecho, satisfacer las tres metafunciones comunicativas descritas por Halliday (1978) en su teoría metafuncional sobre el lenguaje. De este modo, se sostiene que la tipografía puede usarse, pues, ideacionalmente, para representar el mundo y lo que en él ocurre, así

1 En Van Leeuwen (2006: 147-154) o en Machin (2007: 93-108) se ofrece un inventario de potenciales significados asociados a determinados rasgos tipográficos.

2 En Van Leeuwen (2006: 142) se cita a los diseñadores Bellantoni y Woolman (2000), que indican que la palabra escrita tiene dos niveles de significado: la 'word image'; es decir, la idea representada por la misma palabra, construida a partir de la cadena de letras, y la 'typographic image', la 'impresión visual holística'. 
como lo que ocurre en nuestras mentes (conceptos, cualidades y acciones); interpersonalmente, para representar y establecer relaciones sociales, y expresar las actitudes del emisor hacia lo representado; o textualmente, para organizar la estructura informativa de un texto, delimitar elementos textuales y crear vínculos cohesivos entre ellos o conferir mayor jerarquía informativa a determinados segmentos.

En definitiva, un contraste visual entre una tipografía regular y una tipografía marcada en un universo multimodal implicará siempre tanto diferencias de significado como diferencias funcionales.

\section{Las funciones comunicativas de la negrita}

El aumento de grosor de las letras es el rasgo tipográfico que caracteriza la letra negrita. La perspectiva de análisis multimodal vincula la tipografía a las metafunciones ideacional, interpersonal y textual, por lo que el uso de la negrita debe también relacionarse con estas metafunciones. No por ello cabe obviar que el recurso a la negrita se ha venido describiendo tradicionalmente en tanto que orientado al resalte de segmentos textuales y de contenidos $\mathrm{y}$, por tanto, a la focalización de la información. De hecho, tal vez haya que considerar que esta función de resalte es previa y ligada convencionalmente al uso de la negrita (Norgaard 2009: 150). Es significativo, al respecto, observar la definición que se ofrece para la entrada negrilla o negrita en el Diccionario de la lengua española (avance de la vigesimatercera edición) (RAE, 2001: s.v. negrilla) en su publicación en línea:

$\sim$ negrilla, o $\sim$ negrita.

1. f. letra gruesa que se destaca de los tipos ordinarios, resaltando en el texto.

Efectivamente, el aumento del grosor de la letra resalta el segmento de texto en negrita. Con este resalte, se llama la atención del lector sobre dicho elemento, que aumenta así su grado de prominencia (saliencia ${ }^{3}$ ) (Van Leeuwen, 2006: 148; Serafini y Clausen, 2012; 29) y cobra mayor relevancia en el contexto. El resultado es la generación de una expectativa acerca de su potencial importancia referencial y comunicativa.

En esta perspectiva, podría decirse, pues, que la negrita satisface en primer lugar y fundamentalmente una macrofunción de resalte informativo que crea una expectativa sobre la significatividad potencial de los elementos marcados. Es mediante este significado potencial como, en contexto, pueden satisfacerse las macrofunciones propuestas por Halliday (1978).

Creemos que es importante subrayar el concepto de significatividad potencial, en tanto que el hecho de resaltar un elemento informativo del texto no lo convierte necesariamente en una pieza relevante en el proceso interpretativo y comunicativo, sino solo en una pieza potencialmente relevante. En este sentido, ciertamente el elemento destacado en negrita llama la atención del lector y genera en él una determinada expectativa sobre su importancia contextual, expectativa que se verá cumplida si efectivamente este elemento supone un dato que aporte significatividad al texto. Con todo, pese a que esta interpretación se activa de forma automática, el significado de resalte informativo puede anularse contextualmente si, una vez centrada la atención sobre el elemento marcado, este

3 "Salience, making a given text element stand out from its immediate textual environment" (Van Leeuwen, 2006: 144). La saliencia o resalte se puede crear a través del color, el tamaño, el movimiento, una palabra o frase, etc. 
no cumple las expectativas generadas en el lector; esto es, si el resalte no se corresponde efectivamente con algún valor interpretable en ese sentido. Esto podría suceder si hay una sobremarcación de elementos informativos en el texto que impiden descubrir cuál es la finalidad perseguida por el escritor al seleccionar dichos elementos y, en definitiva, cuál es su relevancia contextual.

En definitiva, siendo el valor más prototípico de la negrita señalar la prominencia y, por tanto, la significatividad potencial de determinados elementos del texto, la negrita, se describe, entonces, efectivamente, como susceptible de satisfacer las tres metafunciones descritas por Halliday (1978). Así, podrá usarse para crear (i) significados ideacionales, mediante la connotación y la metáfora, como asertividad, solidez o fuerza, audacia; (ii) significados interpersonales relacionados con la actitud del emisor respecto del elemento marcado, que tratan de sugerir en el lector determinadas interpretaciones contextuales de carácter modal; y (iii) significados textuales asociados con la cohesión y la coherencia de los elementos informativos del texto. Estas interpretaciones, a diferencia del valor de resalte (saliencia), son mucho menos estables y dependen totalmente del contexto.

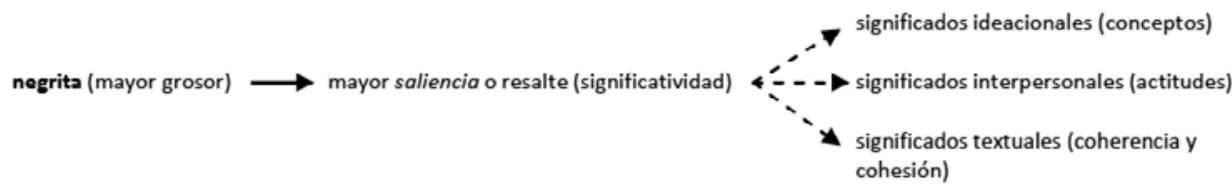

Figura 2. Esquema de las funciones comunicativas de la negrita.

La función de resalte (informativo) representa, pues, una función genérica o macrofunción que suele materializarse contextualmente en distintos usos más concretos que encajan dentro de alguna de las tres metafunciones comunicativas de Halliday (1978): ideacional, interpersonal y textual.

\section{Objetivos de la investigación}

Con el foco puesto en el periodismo digital, nos interesamos en este trabajo por determinar las metafunciones comunicativas que satisface la negrita en la redacción ciberperiodística en español, puesta al servicio de las necesidades comunicativas y de construcción textual de los periodistas. Estas necesidades vienen habitualmente regidas por el principio pragmático de conferir a los textos claridad, concisión y corrección (Martínez Albertos, 1997: 203).

Los teóricos del ciberperiodismo señalan a la negrita como la forma clásica de resaltar o destacar un texto (Palomo, 2005: 210), lo que corresponde a la macrofunción de saliencia o resalte, y alertan de las consecuencias de un abuso de este rasgo tipográfico para la legibilidad de los contenidos, especialmente cuando la negrita abarca un segmento demasiado extenso (Salaverría, 2006: 86; Steen, 2012: 298-299).

En Salaverría (2006: 86-87) o en Tascón (2012) se indican los usos que debería tener la negrita en la prensa digital: (i) señalar las palabras, secuencias léxicas o frases con fuerza argumentativa o carga significativa clave (sujetos protagonistas, núcleo informativo de la noticia), lo que implicará habitualmente resaltar nombres propios y términos especializados 
de diversa disciplinas científicas, médicas, judiciales; y (ii) derivado de este uso, facilitar que la noticia sea hallada por los motores de búsqueda a través de la etiqueta HTML $<$ strong $>$. Se apunta así a la metafunción textual, en tanto la negrita, con estos usos, contribuye a jerarquizar y a estructurar contenidos y facilita al lector el rápido rastreo de las ideas o argumentos principales de una noticia (lectura en skimming) o buscar una información específica (lectura en scanning).

Nuestro objetivo pretende confirmar los usos descritos por los teóricos del periodismo; pero no excluye documentar otras metafunciones (ideacional e interpersonal) y ahondar en la metafunción textual. Concretamente, dos son las preguntas de investigación que se derivan de este objetivo, sin que descartemos, en un análisis contrastivo, que las ediciones digitales de los distintos periódicos presenten diferencias en el uso de la negrita:

1. Desde un punto de vista formal: ¿qué segmentos textuales son resaltados en negrita?

2. Desde un punto de vista comunicativo: ¿la negrita satisface las tres metafunciones descritas para el sistema tipográfico?

\section{Metodología}

Fundamentamos el estudio en un análisis empírico y contrastivo de carácter cuanticualitativo realizado sobre un corpus compuesto por 60 noticias y crónicas publicadas en los principales periódicos españoles con edición digital: El País, La Vanguardia, Público, El Periódico, Abc y El Mundo ${ }^{4}$. De las piezas informativas que lo constituyen, 34 versan sobre asuntos legislativos y judiciales (J) y 26 son de contenido científico (C), como puede observarse en la siguiente tabla (tabla 1): el carácter especializado de los campos jurídico y científico puede favorecer el uso de la negrita para resaltar piezas léxicas que corresponden a términos de la especialidad, de acuerdo con lo señalado en Salaverría (2006: 86-87) y en Tascón (2012); de ahí que estos campos hayan sido objeto de nuestro interés.

\begin{tabular}{|c|c|c|c|c|c|c|c|}
\hline & El País & La Vanguardia & Público & El Periódico & $A B C$ & El Mundo \\
\hline \multirow{2}{*}{$\begin{array}{c}\mathbf{N}^{\mathbf{o}} \\
\text { crónicas }\end{array}$} & $\mathbf{J}$ & 7 & 5 & 7 & 5 & 5 & 5 \\
\hline & $\mathrm{C}$ & 6 & 4 & 4 & 4 & 5 & 3 \\
\hline \multicolumn{2}{|c|}{$N^{0}$ textos } & 13 & 9 & 11 & 9 & 10 & 6 \\
\hline \multicolumn{2}{|c|}{$\begin{array}{l}\mathrm{N}^{0} \text { total en el } \\
\text { corpus }\end{array}$} & \multicolumn{6}{|c|}{$34 J+26 C=60$} \\
\hline
\end{tabular}

Tabla 1. Número de piezas informativas según medio y campo temático.

En una primera fase de la investigación hemos identificado en el corpus los segmentos resaltados en negrita. De este modo, las noticias y crónicas estudiadas nos han proporcionado 227 segmentos resaltados en el cuerpo del texto. En este cómputo hemos desestimado los elementos destacados en negrita que no pertenecen al cuerpo textual del relato informativo: titulares, destacados, ladillos, pies de foto, entre otros. El cuerpo del relato es nuestro objeto

4 Las piezas forman parte de un corpus mayor constituido por noticias y crónicas publicadas entre diciembre de 2012 y marzo de 2014. 
fundamental de investigación. La distribución del total de segmentos considerados en el trabajo según el medio en que aparecen y el ámbito sobre el que versa la pieza informativa en que se hallan puede verse en la tabla que se incluye a continuación (tabla 2):

\begin{tabular}{|c|c|c|c|c|c|c|c|}
\hline \multicolumn{2}{|c|}{} & El País & La Vanguardia & Público & El Periódico & ABC & El Mundo \\
\hline \begin{tabular}{c}
$\mathbf{N}^{\mathbf{0}} \begin{array}{c}\text { segmentos } \\
\text { en negrita }\end{array}$ \\
\cline { 2 - 8 }
\end{tabular} & $\mathbf{J}$ & 0 & 28 & 26 & 26 & 30 & 62 \\
\hline $\begin{array}{c}\mathbf{N}^{\mathbf{0}} \text { total según } \\
\text { medio }\end{array}$ & $\mathbf{0}$ & $\mathbf{4 1}$ & $\mathbf{3 3}$ & $\mathbf{3 5}$ & $\mathbf{5 6}$ & $\mathbf{1 1}$ \\
\hline $\begin{array}{c}\mathbf{N}^{\mathbf{0}} \begin{array}{c}\text { total en el } \\
\text { corpus }\end{array} \\
\mathbf{y y y y y y y y}\end{array}$ & $\mathbf{1 6 1} \mathbf{~ J}+\mathbf{6 6} \mathbf{C}=\mathbf{2 2 7}$ \\
\hline
\end{tabular}

Tabla 2. Número de segmentos resaltados en negrita según medio y campo temático.

Con la finalidad de responder al objetivo y a las preguntas de investigación, el análisis de los segmentos en negrita documentados se ha organizado en dos fases: análisis de sus características formales, en primer lugar, que ha llevado a observar algunas inconsistencias; $y$, entonces, análisis de las funciones comunicativas. Los resultados se exponen a continuación.

\section{Resultados y discusión}

\subsection{Descripción formal}

El corpus analizado permite constatar que hay diferencias entre los distintos medios en cuanto al uso de la negrita. En las crónicas y noticias de El País, no se ha documentado el empleo de la negrita para realzar segmentos dentro del cuerpo del texto de las piezas informativas, si bien este recurso tipográfico se emplea, por ejemplo, en los despieces. En La Vanguardia, los segmentos en negrita se sitúan, mayoritariamente, en los dos primeros párrafos de los textos en que se desarrolla la información, y, junto con los de El Periódico, destacan, frente a los seleccionados en otros medios, por su brevedad: de promedio, constan de dos palabras. Además, las muestras de estos dos medios coinciden también en el hecho de tratarse en buena parte de elementos nominales y, con frecuencia, de nombres propios. Este empleo de la negrita parece responder, por lo tanto, en estos dos medios, a algunas decisiones tomadas al respecto en el consejo de redacción ${ }^{5}$. Así lo ilustran los siguientes ejemplos:

5 Estas decisiones no quedan recogidas en los libros de estilo de estos medios. De hecho, los libros de estilo de los periódicos que analizamos en este artículo todavía carecen de una reflexión exhaustiva y detallada acerca del uso concreto de la negrita en el cuerpo del texto de las piezas informativas en la edición digital, tanto en lo que atañe a la función comunicativa de la negrita como al alcance formal y a los límites de los segmentos destacados mediante esta tipografía. Los libros de estilo de $E l$ Mundo o de $A B C$ sí coinciden en señalar que, en el cuerpo de la pieza informativa, pueden marcarse en negrita los nombres propios que se desean destacar la primera vez que se citan, si bien en su edición digital el uso de la negrita supera esta indicación, según observamos en nuestro corpus de estudio y explicamos en este artículo: es, con todo, un uso recurrente que sí observamos en las piezas analizadas en nuestro trabajo procedentes de El Periódico o La Vanguardia. El manual de estilo de El Periódico no contempla, ni siquiera, en sus páginas ninguna reflexión sobre el uso de la negrita. 
(1) Barcelona. (Agencias). El fiscal Anticorrupción Pedro Horrach puede pedir hasta 17 años de prisión para el duque de Palma, Iñaki Urdangarin. En cambio, de no encausar a la Infanta, confirmando así una postura alejada de la mantenida en su imputación por el juez José Castro, Doña Cristina debería pagar un monto de 600.000 euros por responsabilidad civil.

Cuando se encara el tramo final del caso Nóos, y considerando los diferentes delitos de malversación, falsedad y otros fiscales que se juzgan en los juzgados de Palma de Mallorca, Horrach podría reclamar al Duque de Palma hasta 17 años de cárcel y considerar hasta 15 para su exsocio Diego Torres.

La Fiscalía considera un total de 132 años de cárcel para 16 de los 41 imputados en el caso Nóos, entre los que también se incluye al ex presidente Balear y ex ministro Jaume Matas. El Ministerio Fiscal no tendría intención de reclamar penas de prisión a Doña Cristina de seguir la postura mantenida hasta ahora, al igual que tampoco se incluiría a su secretario, Carlos García Revenga, ni tampoco a Ana María Tejeiro, la esposa de Torres.

En días anteriores se especuló igualmente con un pago de 600.000 euros que tendría que realizar la Infanta por responsabilidad civil como socia de Aizoon.

(La Vanguardia, http://www.lavanguardia.com/politica/20140210/54400110142/fiscaliacarcel-urdangarin.html)

(2) El juez José Castro ha imputado este martes a la infanta Cristina por delito fiscal y blanqueo de capitales en el 'caso Noos'. En un extenso auto de 227 folios, el titular del juzgado de instrucción número 3 de Palma concluye que hay indicios delictivos suficientes en el comportamiento de la hija del Rey y le cita a declarar el próximo 8 de marzo, a las 10 horas.

(El Periódico, http://www.elperiodico.com/es/noticias/politica/juez-castro-imputa-infantacristina-delito-fiscal-blanqueo-capitales-caso-noos-2988109)

Los criterios seguidos por los profesionales de Público, Abc y El Mundo respecto del uso de negritas, en cambio, resultan difíciles de identificar, pues las unidades realzadas pertenecen a categorías gramaticales muy variadas y se encuentran en cualquier lugar del texto. Cabe decir, no obstante, que tanto en $A b c$ como en $E l M u n d o$, es frecuente el realce de citas directas o de parte de ellas mediante negritas:

(3) Posteriormente, el 13 de marzo, el Parlament aprobó por una amplia mayoría, más de dos tercios de la Cámara (104 votos), una resolución en la que se instó al Gobierno de la Generalitat a «iniciar un diálogo» con el Ejecutivo central para celebrar una consulta de autodeterminación en Cataluña. Esta iniciativa fue votada a favor por CiU, ERC, ICVEUiA y PSC. http://www.abc.es/espana/20140214/abci-constitucional-catalua-201402140151.html)

(4) En su auto, el juez Castro insiste en cuestionar una y otra vez el argumento de que la Infanta Cristina desconocía las tareas y los negocios de su marido: "Presumir que quien supuestamente se ha lucrado de la manera anteriormente expuesta desconociera por completo de lo que se estaría hablando y que por ello no merecería la pena preguntarle no es de recibo". 
En cualquier caso, desde un punto de vista formal, el corpus de noticias y crónicas que hemos analizado contiene segmentos resaltados en negrita que pertenecen a categorías gramaticales muy variadas. La unidad mínima realzada mediante el recurso de la negrita es un nombre común. En este sentido, es frecuente que el periodista opte por no marcar en negrita el determinante que acompaña al sustantivo, como en el ejemplo (5):

(5) Irrumpir (sic) el embarazo volverá a dejar de ser un derecho, el Gobierno ha aprobado la ley del aborto más restrictiva de la democracia. De hecho, supone un retroceso de tres décadas, significa volver al año 1985.

El aborto solo será posible en dos casos: si se trata de una violación o si el embarazo supone un peligro para la salud física y psíquica de la mujer. En el mismo sentido, la presencia de malformaciones fetales no será motivo de aborto, sólo el efecto psicológico que suponga (sic) en la embarazada.

La reforma tendrá el nombre de Ley de Protección de la Vida Concebido (sic) y de los Derechos de la Mujer Embarazada, la cual ha sido creada, según el ministro de Justicia, Alberto Ruiz-Gallardón, para proteger "a los más débiles: los concebidos y no nacidos", aunque "siempre en interés de la mujer".

(El Periódico, http://www.elperiodico.com/es/noticias/sucesos-y-tribunales/nueva-ley-supone-retroceso-tresdecadas-2948349)

Numerosos son asimismo en el corpus los nombres propios en negrita, correspondientes a personas que protagonizan una determinada noticia, como en el ejemplo (6) o a organismos (National Ignition Facility (NIF)), instituciones, leyes, publicaciones o, como en (7), a instrumentos científicos como cohetes, sondas, naves o satélites.

(6) Barcelona. (EFE).-Mario Pascual Vives, el abogado de Iñaki Urdangarin, ha evitado hoy pronunciarse sobre la posible petición del fiscal para el duque de Palma -que según algunas informaciones podría ascender hasta los 19 años de cárcel- alegando que no se fía de nada hasta que lo vea por escrito.

(La Vanguardia, http://www.lavanguardia.com/politica/20140211/54401050543/abogadourdangarin-desconfia-posible-peticion-fiscal.html)

(7) La sonda Planck, lanzada en 2009, continúa surcando el espacio.

(Abc, http://www.abc.es/ciencia/20130321/abci-imagen-detallada-restosbang-201303211258.html)

La unión de dos nombres, uno de los cuales realiza función de aposición, es otro de los segmentos que están presentes en el corpus, generalmente sin resalte del determinante, como en (8):

(8) (...). La pena específica a reclamar dependerá de si el yerno del Rey abona antes, junto a su exsocio Diego Torres, los cerca de seis millones de euros de los que se apoderaron de las Administraciones públicas.

(...) 
En cuanto a Diego Torres, la pena que la acusación incluirá en su escrito de calificación provisional, que presentará en unos meses, oscilaría entre los diez y los 15 años, puesto que en su caso le será atribuido un solo delito fiscal. En relación con Urdangarin, el Ministerio Público apunta a que el duque defraudó al IRPF más de 120.000 euros tanto en 2007 como en 2008 a través de la empresa Aizoon, cuya titularidad comparte al 50\% con la infanta Cristina.

(Público, http://www.publico.es/politica/501030/ la-fiscalia-pedira-de-10-a-19-anos-de-carcel-para-inaki-urdangarin)

Se han documentado también abundantes casos de nombre + adjetivo y de nombre + SP, resaltados igualmente sin determinante. Así se observa en (9) en los segmentos delito fiscal, blanqueo de capitales, gastos fraudulentos y Estado de derecho:

(9) El juez José Castro ha imputado este martes a la infanta Cristina por delito fiscal y blanqueo de capitales en el 'caso Noos'. En un extenso auto de 227 folios, el titular del juzgado de instrucción número 3 de Palma concluye que hay indicios delictivos suficientes en el comportamiento de la hija del Rey y le cita a declarar el próximo 8 de marzo, a las 10 horas.

Tres años después de iniciar la investigación del 'caso Noos', una pieza separada de la macrocausa del Palma Arena, y ocho meses después de rastrear la actividad económica de la infanta Cristina, el juez vuelve a encausarla. Según detalla en su auto, existen indicios de que la hija del Rey se prestó a que Aizoon, la sociedad que comparte al 50\% con su marido, Iñaki Urdangarin, "sirviera de andamiaje imprescindible para la comisión de delitos fiscales" y realizó gastos fraudulentos con fondos de la empresa.

(..)

Asimismo, considera que el hecho de citar a Cristina para que explique las supuestas irregularidades no hará "tambalear los pilares del Estado de derecho, más bien todo lo contrario".

(El Periódico, http://www.elperiodico.com/es/noticias/politica/juez-castro-imputa-infantacristina-delito-fiscal-blanqueo-capitales-caso-noos-2988109) ${ }^{6}$

Asimismo, se identifican casos de sintagmas nominales completos resaltados en negrita, con inclusión del determinante, como en (10):

(10) Fue el 23 de enero del pasado año cuando el Parlament dictó una primera declaración soberanista que no contó con el apoyo del PSC y sí recabó el aval de CiU, ERC e ICV. En esta primera declaración, el Parlament defendía que Cataluña es «sujeto jurídico y político soberano». Posteriormente, el 13 de marzo, el Parlament aprobó por una amplia mayoría, más de dos tercios de la Cámara (104 votos), una resolución en la que se instó al Gobierno de la Generalitat a «iniciar un diálogo» con el Ejecutivo central para celebrar una consulta de autodeterminación en Cataluña. Esta iniciativa fue votada a favor por CiU, ERC, ICV-EUiA y PSC.

$(A b c$, http://www.abc.es/espana/20140214/abci-constitucional-catalua-201402140151.html)

6 Para mayor claridad, hemos eliminado del ejemplo la negrita original de los siguientes nombres propios y nombres comunes: José Castro, infanta Cristina, caso Noos, Palma Arena, Aizoon, Iñaki Urdangarín, andamiaje. 
Aproximadamente el 65\% de los segmentos resaltados en negrita del corpus corresponden a elementos nominales y el $50 \%$ de ellos son solo nombres. No se han documentado, en cambio, verbos resaltados en negrita. Sí constan en el corpus segmentos de verbo + argumento, de verbo + CC o sintagmas verbales completos como en (11):

(11) La ley de 1985, que se mantuvo intacta hasta 2010 con dos legislaturas populares en medio, despenalizaba el aborto en tres supuestos y en dos tiempos. Si había violación, era legal hasta las 12 semanas de gestación. Y si había malformación del feto, hasta las 22.

Pero el llamado tercer supuesto tenía que ver con el "grave riesgo" para la salud "física o psíquica" de la mujer. Y no establecía ningún límite en el tiempo.

La ley de 2010 sacó al aborto del Código Penal (excepto en alguna circunstancia) y lo convirtió en un derecho de la mujer. Aquel texto, que desaparece hoy, facilitaba las cosas a la mujer durante las primeras semanas, pero se las complicaba a partir de la semana 22, cuando sólo una circunstancia extrema del feto y no de ella justificaran la interrupción del embarazo.

(El Mundo, http://www.elmundo.es/espana/2013/12/20/52b34702268e3e70218b4573.html)

El corpus contiene también ejemplos de realce de cláusulas, como en (12), donde se destaca en negrita incluso la conjunción, que, en otros casos, no se incluye en el segmento marcado:

(12) El magistrado atribuye además a la Infanta Cristina la contratación "en negro" de su servicio doméstico y destaca que ella misma participaba en la selección del personal: "Si hemos de creer a los testigos, empleados del hogar familiar del matrimonio, y no hay de momento razón alguna para no hacerlo, en su contratación intervino personalmente Doña Cristina de Borbón y Grecia anunciando a los aspirantes, cuya situación irregular en España conocía aquélla, que de ser contratados se les abonarían sus salarios en 'negro' accediendo a documentar las relaciones sólo cuando, tras su verbal y efectiva contratación, los empleados se lo pidieron para obtener el permiso de residencia pero haciendo figurar entonces como empresa contratante a Aizoon S. L. cuando los empleados nunca prestaron sus servicios para tal entidad".

(El Mundo, http://www.elmundo.es/espana/2014/01/07/52cbcbe9268e3e91448b456f.htmll)

No son infrecuentes los casos en que el periodista opta por realzar oraciones completas, como puede advertirse en (13):

(13) No obstante, los argumentos de Asúa han generado un profundo malestar entre la mayoría del TC, cuyo presidente, Francisco Pérez de los Cobos, aspiraba a ofrecer una imagen de unidad jurídica frente al desafío secesionista planteado por la Generalitat catalana.

De momento, el acuerdo del Parlament se encuentra suspendido desde el 8 de marzo de 2013, día en el que el Gobierno impugnó el acuerdo, una suspensión ratificada «a posteriori» tras el recurso del Parlament.

(Abc, http://www.abc.es/espana/20140214/abci-constitucional-catalua-201402140151.html)

Tal y como ponen de manifiesto los ejemplos incluidos en las líneas precedentes, en muchos casos, los periodistas resaltan, mediante el recurso tipográfico del que nos ocupamos, unidades gramaticales completas. Sin embargo, no son infrecuentes los segmentos inconsistentes desde el punto de vista de la segmentación. En algunos casos, la inconsistencia parece 
deberse a falta de atención, tal vez a causa del apremio con que llevan a cabo su tarea los profesionales del periodismo, como en los ejemplos (14) y (15):

(14) El explorador lunar «quedó desactivado cuando mostraba un estatus anormal», explicó Pei. (Abc, http://www.abc.es/ciencia/20140213/abci-yutu-robot-despierta-201402130914.html)

(15) Holanda y Suecia tienen las legislaciones más permisivas de la Unión Europea, con aborto libre durante las primeras 24 y 18 semanas de gestación, respectivamente. Fuera de Europa, naciones como Canadá, EEUU, Australia, Rusia o China disponen igualmente de legislaciones permisivas, mientras que en América Latina y África la norma general son leyes restrictivas que penalizan el aborto.

(Público, http://www.publico.es/actualidad/491870/

la-reforma-de-la-ley-del-aborto-mas-cerca-de-latinoamerica-que-de-la-ue)

Se trata de pequeñas inconsistencias formales que apenas afectan a la lectura de las piezas informativas. Pero, en algunos casos, como los que pueden observarse en (16), constituyen imprecisiones que podrían evitarse acordando y respetando un criterio claro; en este caso, precisamente, la decisión acerca de si se realza la conjunción entre dos nombres coordinados marcados en negrita. En (16), el periodista incluye la conjunción en el primer caso y no en el siguiente:

(16) (...) los dos instructores del caso Palau, Juli Solaz y Josep Maria Pijuan, jueces de instrucción como Josep Maria Miquel Porres y Josep Niubó, y el magistrado de la Audiencia de Barcelona Santiago Vidal.

(Abc, http://www.abc.es/catalunya/politica/20140213/abci-jueces-catalanes-firmanmanifiesto-201402131849.html)

Del mismo modo, en el ejemplo (17), se trata de ser consecuente en el realce de la preposición:

(17) Los magistrados también apelan a «la voluntad del pueblo» como «base de la autoridad del poder público» recogida en Declaración Universal de Derechos Humanos y «al derecho de los pueblos a su libre determinación», incluido en el Pacto Internacional de Derechos Económicos, Sociales y Culturales.

(Abc, http://www.abc.es/catalunya/politica/20140213/abci-jueces-catalanesfirman-manifiesto-201402131849.html

Hay en el corpus otros casos de marcación inconsistente desde el punto de vista formal. Un ejemplo puede verse en (5). En el primer párrafo del fragmento, el periodista marca tres segmentos de la misma frase: "el Gobierno ha aprobado la ley del aborto más restrictiva de la democracia." Los tres segmentos señalan los elementos gramaticales correspondientes a cuatro funciones gramaticales distintas, pues el segundo incluye el elemento léxico de una forma verbal compuesta con su argumento, que aparece resaltado con el determinante incluido. Los determinantes de los nombres realzados en el primer y el tercer segmento no están en negrita, así como tampoco el polo gramatical de la forma verbal compuesta. Por otro lado, desde el punto de vista del contenido, no se puede afirmar que el concepto "democracia" resulte más relevante para la comprensión de la frase que el expresado mediante el 
modificador "más restrictiva". En definitiva, se podría suponer que el redactor de la noticia evita realzar la frase completa, tal vez siguiendo una norma de estilo del medio; con todo, el corpus que hemos estudiado incluye oraciones marcadas en negrita extraídas de piezas informativas de $A b c$, como el ejemplo reproducido en (13), de modo que es lícito plantearse si, en el caso que analizamos, no hubiera sido recomendable realzar toda la frase.

No son escasos, pues, en el corpus, los ejemplos de marcación formalmente inconsistente de los segmentos realzados. Incluimos a continuación un fragmento que contiene dos ejemplos más:

(18) La ignorancia era aún más profunda en el proceder de Cristina, puesto que el puro desconocimiento ha sido su respuesta ante el interés de Castro por conocer a quién pertenecía la filiación laboral de los empleados domésticos de la residencia de los Urdangarin-Borbón en Barcelona. Unos empleados extranjeros que, ilegales y pagados en negro según el juez instructor, había seleccionado ella misma. Cristina Federica de Borbón y Grecia no sabía que esos empleados eran de Aizoon S.L. Una vez más, unos gastos privados cargados como gastos de la empresa común. Un hecho que Castro considera probado, y que conllevaría delito fiscal en el caso de superar los 120.000 euros en el monto de la defraudación a la Hacienda pública.

La ignorancia también ha servido como argumento para despachar el asunto del origen del dinero de Aizoon S.L. La infanta Cristina jamás supo, así lo ha declarado, que ese dinero provenía de Nóos, punto central sobre el que Castro basa sus indicios sobre el delito de blanqueo de dinero que pesa sobre la imputada. Todo lo que Cristina de Borbón sabía cuando firmó lo que firmó en Aizoon S.L. es que confiaba en su marido, la "teoría del amor" como la ha bautizado la abogada Negrete.

(Público, http://www.publico.es/politica/500860/la-infanta-declaraal-juez-que-no-sabia-ni-lo-que-firmaba)

Para concluir este apartado de nuestro trabajo, cabe ilustrar, a través de un mismo fragmento que comparten dos noticias del corpus, que las inconsistencias en el uso de la negrita se producen en un mismo medio:

(19a) El juez José Castro ha imputado a la Infanta Cristina por un delito de blanqueo de capitales y otro fiscal presuntamente cometidos por la hija del Rey en su condición de copropietaria de Aizoon, empresa familiar a la que se desviaron más de un millón de euros públicos desde el Instituto Nóos.

(El Mundo, http://www.elmundo.es/espana/2014/01/07/52cbcbe9268e3e91448b456f.html)

(19b) El juez José Castro ha imputado a la Infanta Cristina por un delito de blanqueo de capitales y otro fiscal presuntamente cometidos por la hija del Rey en su condición de copropietaria de Aizoon, empresa familiar a la que se desviaron más de un millón de euros públicos desde el Instituto Nóos.

(El Mundo, http://www.elmundo.es/espana/2014/01/07/52cba147268e3ea3448b456a. html?cid=MNOT23801\&s_kw=la_infanta_cristina_imputada_ por_blanqueo_y_delito_fiscal)

En suma, el análisis de los elementos resaltados en negrita en las piezas informativas de los distintos periódicos revela un uso asistemático de este recurso desde el punto de vista formal, incluso por parte de los profesionales de un mismo medio informativo. Así, pese a 
que, como se subrayará en este trabajo, la negrita cumple una función relevante en la lectura e interpretación de los textos digitales, el resalte aleatorio de los segmentos lingüísticos refleja la escasa atención que los trabajos normativos han prestado a los aspectos tipográficos de la lengua escrita, en general, y de los textos en soporte digital, en particular.

\subsection{Descripción funcional}

La negrita, como apuntábamos en el apartado 3, se ha descrito generalmente como un recurso tipográfico orientado, fundamentalmente, a la focalización de la información. El aumento del grosor de la letra aumenta consecuentemente el grado de prominencia -esto es, de saliencia- del elemento resaltado (Van Leeuwen, 2006: 148), de modo que se llama la atención del lector sobre dicho elemento, que cobra mayor relevancia en el contexto y genera una expectativa acerca de su importancia potencial. En este sentido, la negrita, en tanto que rasgo tipográfico, resalta elementos informativos del texto (función de resalte informativo), centrando la atención del lector sobre ellos. Esta función de resalte (informativo) representa una función genérica o macrofunción del uso de la negrita que suele materializarse contextualmente en usos más concretos que encajan dentro de alguna de las tres metafunciones comunicativas de Halliday (1978) aludidas anteriormente: ideacional, interpersonal y textual. En lo que sigue, presentamos una descripción de los usos de la negrita que hemos encontrado en el corpus analizado, asociando cada uno de ellos con su correspondiente metafunción comunicativa.

\subsubsection{Negrita y cohesión: la metafunción textual}

Como apuntábamos más arriba (ver $\S 4$ ), una de las metafunciones comunicativas más destacadas del rasgo tipográfico "grosor del tipo de letra", esto es, de la negrita, es la metafunción textual. En nuestro corpus, esta metafunción se concreta en las funciones siguientes ${ }^{7}$ :

- Localizar palabras y conceptos relevantes del texto

- Resaltar contenidos del texto

- Crear itinerarios de lectura rápida

Todas estas funciones sirven para cohesionar y estructurar el discurso, dotando de relevancia visual (saliencia) ciertos elementos sobre los que se requiere la atención del receptor/ lector; constituyen, pues, focos de atención. La focalización de estos elementos ayuda, por un lado, al lector a localizar palabras y contenidos clave en el texto, resaltándolos como elementos informativos o sugiriendo itinerarios de lectura rápida; y, por otro, al redactor a cohesionar y estructurar el contenido.

La tabla 3 muestra el reparto de las funciones anteriores en función del periódico y de la sección en que aparecen.

7 En este trabajo, no consideramos el uso de la negrita para optimizar la búsqueda automática de contenidos, ya que esta función excede el interés de este estudio. 


\begin{tabular}{|c|c|c|c|c|}
\hline & & $\begin{array}{c}\text { Localizar } \\
\text { palabras clave }\end{array}$ & $\begin{array}{c}\text { Resaltar } \\
\text { contenidos }\end{array}$ & $\begin{array}{c}\text { Itinerario de } \\
\text { lectura }\end{array}$ \\
\hline \multirow[b]{2}{*}{ El País } & $\mathrm{J}$ & 0 & 0 & 0 \\
\hline & $\mathrm{C}$ & 0 & 0 & 0 \\
\hline \multirow{2}{*}{ La Vanguardia } & $\mathrm{J}$ & 5 & 0 & 0 \\
\hline & $\mathrm{C}$ & 3 & 1 & 0 \\
\hline \multirow{2}{*}{ Público } & $\mathrm{J}$ & 2 & 3 & 1 \\
\hline & $\mathrm{C}$ & 0 & 1 & 2 \\
\hline \multirow{2}{*}{ El Periódico } & $\mathrm{J}$ & 4 & 0 & 0 \\
\hline & $\mathrm{C}$ & 3 & 0 & 0 \\
\hline \multirow{2}{*}{$A B C$} & $\mathrm{~J}$ & 1 & 3 & 2 \\
\hline & $\mathrm{C}$ & 0 & 3 & 1 \\
\hline \multirow[b]{2}{*}{ El Mundo } & $\mathrm{J}$ & 3 & 5 & 1 \\
\hline & $\mathrm{C}$ & 0 & 2 & 1 \\
\hline \multicolumn{2}{|c|}{$\begin{array}{l}\mathrm{N}^{\circ} \text { total por } \\
\text { función }\end{array}$} & 21 & 18 & 8 \\
\hline
\end{tabular}

Tabla 3. Número de piezas informativas según medio y función predominante.

\subsubsection{Localizar palabras y conceptos relevantes}

El uso más frecuente de la negrita en las piezas informativas que se han analizado (ver tabla 3) es el de llamar la atención del lector sobre determinados nombres y sintagmas nominales que hacen referencia a personajes e instituciones (nombres propios) o conceptos clave del hecho noticiado.

Con esta función de localización de palabras clave, se han documentado ejemplos en todas las piezas informativas de los periódicos analizados, a excepción de El País, que no utiliza la negrita en el cuerpo del texto (ver §6.1). Llama la atención que es mayor el empleo de la negrita con esta función en las noticias y crónicas de contenido jurídico que en las de tema científico: 15 piezas informativas en el primer caso, frente a 6 en el segundo (ver tabla 3). Como señalábamos en el apartado 4, es posible que la mayor incidencia del uso de la negrita con esta función en el subcorpus legal se deba a una mayor necesidad informativa de señalar determinados segmentos de información con fuerza argumentativa o carga significativa clave, generalmente personajes involucrados en los hechos noticiados y determinados conceptos relevantes para comprender el alcance o la gravedad del asunto narrado (a menudo términos especializados de diversas disciplinas científicas, médicas o judiciales).

Por lo general, como muestran los ejemplos (20) y (21), se trata de fragmentos de información inconexos entre sí que no conforman una estructura coherente per se (no permiten una lectura rápida de la noticia que la "resuma"), sino que han de contextualizarse dentro del texto; esto es, ponerse en relación con la información circundante para aprehender su alcance dentro de la noticia o crónica.

(20) Barcelona. (Agencias). El fiscal Anticorrupción Pedro Horrach puede pedir hasta 17 años de prisión para el duque de Palma, Iñaki Urdangarin. En cambio, de no encausar a la 
Infanta, confirmando así una postura alejada de la mantenida en su imputación por el juez José Castro, Doña Cristina debería pagar un monto de 600.000 euros por responsabilidad civil.

Cuando se encara el tramo final del caso Nóos, y considerando los diferentes delitos de malversación, falsedad y otros fiscalesque se juzgan en los juzgados de Palma de Mallorca, Horrach podría reclamar al Duque de Palma hasta 17 años de cárcel y considerar hasta 15 para su exsocio Diego Torres.

(La Vanguardia, http://www.lavanguardia.com/politica/20140210/54400110142/ fiscalia-carcel-urdangarin.html)

(21) Gran paso para la fusión nuclear. Investigadores estadounidenses han logrado por primera vez que un experimento de fusión nuclear produjera más energía que la necesaria para ponerlo en marcha, un paso prometedor hacia el desarrollo de una nueva fuente energética limpia, ya que no genera residuos, e ilimitada, pues su combustible es el hidrógeno, uno de los componentes del agua.

El experimento, extraordinariamente fugaz, se realizó el pasado noviembre en la National Ignition Faciliity (NIF), una infraestructura de investigación del Gobierno de Estados Unidos con grandes aplicaciones en el sector militar, pero no se ha dado a conocer hasta comprobar la exactitud de los datos. Los detalles de la investigación se han publicado en la revista 'Nature'.

(El Periódico, http://www.elperiodico.com/es/noticias/ciencia/gran-paso-para-fusionnuclear-rentable-3096656)

\subsubsection{Resaltar contenidos}

Otra de las subfunciones metatextuales de la negrita que presenta un índice de uso elevado en el corpus analizado es la de resaltar segmentos de información que se consideran relevantes para la comprensión de la noticia. Como ocurría con la función descrita en el apartado anterior, el resalte de contenidos tiene mayor presencia en las noticias y crónicas de contenido legal (11 piezas informativas) que en las de tema científico (7 piezas informativas). Por su parte, si se compara el uso de la negrita como recurso para localizar palabras y conceptos con el uso que estamos describiendo ahora, la diferencia en cada subcorpus no resulta muy significativa. Hay un ligero descenso en el corpus legal: $15 / 11$, y un pequeño aumento en el científico: 6 / 7 (ver tabla 3).

Con esta función, los segmentos marcados en negrita exceden el límite gramatical del nombre sin determinación o el SN simple $(\mathrm{N}+$ adj), como muestra la siguiente pieza informativa (22a), que copiamos íntegra: estos fragmentos no aluden a personajes o conceptos clave de la noticia, sino a información más compleja.

(22a) Las 6 horas y media que la infanta Cristina ha estado [declarando como imputada ante el juez Castro] ${ }_{1}$ han servido para dos cosas. (1er párrafo)

Sino por el [reguero de interrogantes que no han sido despejados] ${ }_{2}$ por su declaración; ( $2^{\circ}$ párrafo)

(...) han consistido en mostrar un gran número de pruebas de gasto, facturas y comprobantes de compras que José Castro ha ido acumulando en la instrucción del sumario (...). (3er párrafo) 
Las respuestas que ha conseguido hilvanar la hija del rey (cuya efigie presidía la sala de juicios) [han llegado a merecer el calificativo de "vergüenza ajena" $]_{3}$ oído en las voces de los abogados Manuel Delgado y Virginia Negrete, representantes de las acusaciones populares del Frente Cívico Julio Anguita y de Manos Limpias, respectivamente. ( $4^{\circ}$ párrafo) $\mathrm{La}$ [ignorancia era aún más profunda en el proceder de Cristina] ${ }_{4}$, puesto que el puro desconocimiento ha sido su respuesta ante el interés de Castro por conocer a quién pertenecía la filiación laboral de los empleados domésticos de la residencia de los UrdangarinBorbón en Barcelona. (...). ( $5^{\circ}$ párrafo)

(...)Todo lo que Cristina de Borbón sabía cuando firmó lo que firmó en Aizoon S.L. es que [confiaba en su marido, la "teoría del amor" $]_{5}$ como la ha bautizado la abogada Negrete. (...) ( $6^{\circ}$ párrafo)

(...)"Ha colaborado con la justicia sin privilegios" se vanagloriaba el abogado catalán, minutos después que el vehículo que transportaba a la hija del rey hubiera abandonado el patio del juzgado, como medida de especial y excepcional seguridad, inédita para el resto de imputados de la causa, incluido su consorte. (...) ( $7^{\circ}$ párrafo)

El juez Castro, que ha evitado el tratamiento de alteza para la imputada (se ha dirigido a ella como señora todo el interrogatorio), [ha empleado las 5 horas de la sesión matinal de la citación $]_{6}$ para plantear más de 400 cuestiones diferentes a Cristina de Borbón. (...) ( $8^{\circ}$ párrafo)

El instructor de la causa, que por la mañana ha escuchado [vítores y gritos en su favor de los ciudadanos $]_{7}$ concentrados ante el juzgado, (...). ( $9^{\circ}$ párrafo)

A diferencia de los casos anteriores, en que la negrita marca palabras o combinaciones sintagmáticas simples que no guardan entre sí una relación cohesiva, los fragmentos de mayor contenido señalados en negrita sí presentan un grado mayor de cohesión y permiten un escaneo rápido del contenido, tal como puede comprobarse en (22b), donde se han aislado los segmentos informativos destacados en negrita:

(22b) declarando como imputada ante el juez Castro reguero de interrogantes que no han sido despejados pruebas de gasto, facturas y comprobantes de compras han llegado a merecer el calificativo de "vergüenza ajena ignorancia era aún más profunda en el proceder de Cristina confiaba en su marido, la "teoría del amor medida de especial y excepcional seguridad ha empleado las 5 horas de la sesión matinal de la citación vítores y gritos en su favor de los ciudadanos

Casos como el anterior denotan un cierto esfuerzo del periodista por sintetizar estratégicamente fragmentos relevantes de la información global de la noticia o crónica. No obstante, la inconsistencia formal de los segmentos marcados (no se marcan elementos referenciales necesarios para comprender el segmento marcado de un solo vistazo) conlleva también inconsistencias semánticas, lo cual provoca que el escaneo resulte incompleto e infructuoso.

Aunque los ejemplos anteriores responden a casos prototípicos del uso de la negrita para localizar palabras y conceptos relevantes $(20$ y 21$)$ y resaltar contenidos del texto (22a y $22 \mathrm{~b}$ ), no es infrecuente que ambos usos coaparezcan en una misma pieza informativa: 
(23) En el vídeo, grabado con la cámara ladeada y la imagen vibrando, se aprecia a la infanta Cristina por detrás, respondiendo a las preguntas del juez, mientras que se escuchan silbidos y protestas en la calle.

El juez Castro pregunta sobre las actividades del Instituto Nóos mientras muestra en una pantalla documentos y correos electrónicos relacionados con esas actividades, (...).

(...). Para ello, estableció la obligación de que todas las personas que accedieron a la sala, unas cuarenta entre abogados defensores, fiscales, representantes de la acusación y funcionarios, depositaran bajo custodia policial antes de entrar sus teléfonos móviles, tabletas, ordenadores portátiles o cualquier otro dispositivo que pudiera grabar imágenes o sonido.

(Público, http://www.publico.es/500997/no-lo-se-y-no-me-acuerdolas-respuestas-tipo-de-la-infanta)

\subsubsection{Crear itinerarios de lectura rápida}

En algunos casos, además de una localización rápida de información clave, el resalte de fragmentos relevantes del texto permite también establecer un itinerario de lectura rápida que funciona a modo de resumen del contenido principal de la noticia. Tal como muestran los ejemplos (24) y (25), los segmentos resaltados en negrita guardan entre sí una relación de coherencia y conforman una microtexto que recoge la información esencial de la pieza informativa. De este modo, la negrita establece un primer plano de lectura que permite al lector llevar a cabo un escaneo rápido sobre pantalla y decidir si le interesa profundizar en la noticia, accediendo a un plano de lectura más profundo.

En el ejemplo (24), la pieza informativa original, que trata sobre la implicación del ministro Gallardón en el extravío de la solicitud de indulto del juez Garzón, consta de 468 palabras. Sin embargo, la selección estratégica de determinados fragmentos informativos más el titular, que supone información determinante para la comprensión de la noticia abreviada, permite condensar la información clave en 110 palabras:

(24) Gallardón no asume ninguna culpa por el extravío de la solicitud de indulto a Baltasar Garzón

su actuación una vez que se conoció la pérdida del expediente ha sido "ágil y legal"

no fue hasta el pasado verano cuando el Gobierno se enteró por la prensa del extravío de la petición

El Alto Tribunal dijo que no había recibido la solicitud de indulto para Garzón, y eso que sí le llegaron otras seis peticiones

Justicia "asumió con normalidad el retraso en la recepción de los informes

"hay 35 peticiones de informes pendientes de respuesta cuyo oficio de remisión a los tribunales se envió en el mes de junio de 2012

(Público, http://www.publico.es/politica/500144/gallardon-no-asume-ninguna-culpapor-el-extravio-de-la-solicitud-de-indulto-a-baltasar-garzon) 
Lo mismo puede observarse en el ejemplo (25). Se trata de una noticia sobre el descubrimiento de un agujero negro y su estrella, cuyo contenido se extiende a lo largo de 37 líneas y 399 palabras. Igual que en el caso anterior, el texto original se resume mediante cuatro fragmentos marcados en negrita, dos al principio y dos al final de la noticia, que constituyen un minitexto de 42 palabras:

(25) una estrella y un agujero negro orbitan entre sí a un ritmo de locos, una vez cada 2,4 horas, a una velocidad vertiginosa de dos millones de kilómetros por hora casi 20 veces más rápido que la Tierra gira alrededor del Sol.

( $A B C$, http://www.abc.es/ciencia/20130320/abci-descubren-desbocados-agujero-negro-201303201116.html)

Un caso tal vez extremo, pero excelente desde el punto de vista estratégico, es el que muestra el ejemplo (26), en que la selección de un breve fragmento de información (7 palabras) condensa el contenido informativo clave de la noticia (308 palabras) y responde a la pregunta implícita en el titular: «La NASA pone fin al misterio del "donut" aparecido en Marte»:

(26) un pedazo desprendido de una roca mayor

(Público, http://www.publico.es/502148/la-nasa-pone-fin-al-misteriodel-donut-aparecido-en-marte)

Tal como muestran los ejemplos anteriores, se observa que el uso de la negrita puede orientarse estratégicamente hacia funciones textuales que permitan un acceso fácil y rápido a la información; asimismo, este uso denota también un mayor grado de conciencia por parte del periodista respecto de su tarea de planificar y diseñar itinerarios de lectura.

\subsubsection{Intensificación del contenido: la metafunción interpersonal}

Otra de las funciones que puede desempeñar la negrita en las piezas informativas analizadas es la metafunción interpersonal. Con este uso de la negrita, se intensifican contenidos para guiar al lector hacia determinadas actitudes respecto del hecho noticiado, tales como (des)afección, empatía, etc.

En todas las piezas informativas analizadas, el resalte de la información cumple fundamentalmente una función textual relacionada con la localización de palabras y contenidos clave que ayudan al lector a retener información relevante para comprender el alcance de la noticia. No obstante, en algunos casos, este resalte de información va más allá de la mera función textual.

Así, por ejemplo, en la siguiente pieza informativa la negrita llama la atención no solo sobre determinadas palabras clave del texto, sino también sobre aspectos valorativos del segmento en cuestión que se interpretan contextualmente. De este modo, se lleva a cabo una intensificación del valor conceptual del término o del fragmento resaltado en negrita, cuyo valor semántico se incrementa con valores connotativos que sugieren en el lector un cierto juicio de valor sobre el hecho noticiado. Así, en el ejemplo (27), los segmentos destacados en negrita crean una imagen negativa de la protagonista principal de la noticia, la infanta 
Cristina, y sugieren en el lector una lectura de condena sobre la actuación de los imputados y de aplauso hacia la actuación del juez instructor:

\section{(27) titular La infanta declara al juez que no sabía ni lo que firmaba}

(1er párrafo) Las 6 horas y media que la ha estado declarando como imputada ante el juez Castro han servido para dos cosas.

Si es cierto que el desconocimiento de la ley no es un eximente para su cumplimiento, y que su aplicación a la luz de los hechos y sus consecuencias iguala a todos los ciudadanos, entonces se puede colegir que la infanta ha salido de los juzgados de Vía Alemania en Palma de Mallorca peor de lo que

$\left(2^{\circ}\right.$ párrafo) ha entrado. Y no por haber pisado la manida rampa, que ha atravesado en la butaca trasera de un coche oficial. Sino por el reguero de interrogantes que no han sido despejados por su declaración;

Gran parte de la batería de preguntas que el juez instructor ha ido planteando a Cristina, en un interrogatorio que ha sido alabado sin ambages por la acusación popular y tildado de muy correcto por parte de la defensa, han consistido en mostrar un gran número de pruebas de gasto, facturas y comprobantes de

(3er párrafo) compras que José Castro ha ido acumulando en la instrucción del sumario gracias a los informes de la Agencia Tributaria, y de cuya existencia ya se había dado cuenta en el escrito de imputación de la infanta del pasado 8 de enero.

Las respuestas que ha conseguido hilvanar la hija del rey (cuya efigie presidía la sala de juicios) han llegado a merecer el calificativo de "vergüenza ajena"

( $4^{\circ}$ párrafo) oído en las voces de los abogados Manuel Delgado y Virginia Negrete, (...).

La ignorancia era aún más profunda en el proceder de Cristina, puesto que el puro desconocimiento ha sido su respuesta ante el interés de Castro por

( $5^{\circ}$ párrafo) conocer a quién pertenecía la filiación laboral de los empleados domésticos de la residencia de los Urdangarin-Borbón en Barcelona.

(....).Todo lo que Cristina de Borbón sabía cuando firmó lo que firmó en Aizoon S.L. es que confiaba en su marido, la "teoría del amor"como la ha bautizado

( $6^{\circ}$ párrafo) la abogada Negrete. (...).

(...).”Ha colaborado con la justicia sin privilegios" se vanagloriaba el abogado catalán, minutos después que el vehículo que transportaba a la hija

( $7^{\circ}$ párrafo) del rey hubiera abandonado el patio del juzgado, como medida de especial y excepcional seguridad, inédita para el resto de imputados de la causa, incluido su consorte. (...). ( $7^{\circ}$ párrafo)

( $8^{\circ}$ párrafo) El juez Castro, que ha evitado el tratamiento de alteza para la imputada (se ha dirigido a ella como señora durante todo el interrogatorio), ha empleado las 5 horas de la sesión matinal de la citación para plantear más de 400 cuestiones diferentes a Cristina de Borbón. (...).

( $9^{\circ}$ párrafo, El instructor de la causa, que por la mañana ha escuchado vítores y gritos en último) su favor de los ciudadanos concentrados ante el juzgado, y que a su salida ha sido aplaudido por algunos curiosos que se apostaban al borde de la rampa, (...).

(Público, http://www.publico.es/politica/500860/la-infanta-declara-al-juez-que-no-sabia-ni-loque-firmaba) 
Este valor añadido de la negrita puede captarse mejor comparando el tratamiento que confieren otros periódicos a la misma noticia. En todos los periódicos analizados (a excepción de El País, que, reiteramos, no utiliza la negrita en el cuerpo de la noticia), se marcan los nombres de personajes relevantes de la noticia. Sin embargo, no todos los medios ponen el foco de atención sobre las causas de la imputación, esto es, sobre los delitos de los que se acusa a los imputados de la noticia. Un ejemplo de ello puede observarse en la siguiente pieza informativa del periódico $A b c$, del mismo día que la noticia del ejemplo (27), que informa sobre el mismo suceso (la comparecencia de la infanta Cristina ante el juez Castro):

\section{(28) Iñaki Urdangarín}

Pedro Horrach

ha abandonado los juzgados de Palma a las 18.12 horas

se despidió con un saludo general a los periodistas

utilizó la tarjeta de Aizoon para gastos personales

Doña Cristina no ha incurrido en ninguna contradicción y se ha mostrado muy tranquila en todo momento

Desconocer las actividades que allí se llevaban a cabo

La infanta ha señalado que "tenía mucha confianza" en su marido

El magistrado ha preguntado factura por factura por los gastos de Aizoon

Jesús Silva

Manuel Delgado

Virginia López Negrete

saludó tres veces con un "buenos días".

Acompañaba a la infanta su abogado, Miquel Roca.

Jesús Silva

ni los gritos ni los pitidos de los manifestantes

(Abc, http://www.abc.es/espana/20140208/abci-infanta-llegada-201402080953.html)

La diferencia en el uso de la negrita no parece responder solo a una distinta orientación del foco de atención, sino que podría deberse también a la intención del periodista (o de la línea editorial del periódico) de intensificar determinadas relaciones causales entre el delito y la imputación, así como de crear una determinada imagen del protagonista de la noticia. Dado que los términos resaltados en negrita son datos marcados que presumiblemente retendrá el lector en la memoria, la marcación parece orientarse a crear en el lector una predisposición (des)favorable hacia dicha relación causal y hacia el personaje noticiado.

Así, en (27), Público incide en las acciones presuntamente delictivas por las que debe responder la infanta ante el juez instructor y en en la actuación de la infanta durante la comparecencia. De esta forma, aunque la información resaltada es información factual clave para entender la noticia, orienta al lector hacia la construcción de una determinada imagen desfavorable del protagonista de los hechos:

(27 bis) La infanta declara al juez que no sabía ni lo que firmaba declarando como imputada ante el juez Castro el reguero de interrogantes que no han sido despejados por su declaración Las respuestas que ha conseguido hilvanar la hija del rey (cuya efigie presidía la sala de juicios) han llegado a merecer el calificativo de "vergüenza ajena" La ignorancia era aún más profunda en el proceder de Cristina confiaba en su marido, la "teoría del amor" 
En cambio, los fragmentos destacados por el diario $A b c$ crean una imagen más "amable", colaborativa, de la infanta:

(28bis) se despidió con un saludo general a los periodistas

Doña Cristina no ha incurrido en ninguna contradicción y se ha mostrado muy tranquila en todo momento

Desconocer las actividades que allí se llevaban a cabo

La infanta ha señalado que "tenía mucha confianza" en su marido

El magistrado ha preguntado factura por factura por los gastos de Aizoon saludó tres veces con un "buenos días".

Una lectura comparada de las negritas de las dos piezas informativas ilustra la diferente orientación interpretativa del mismo hecho noticiable que se propone al lector. Compárense, a tal efecto, el contraste entre los siguientes destacados en ambos periódicos:

\section{Público}

$A b c$

Las respuestas que ha conseguido hilvanar la hija del rey (cuya efigie presidía la sala de juicios) han llegado a merecer el calificativo de "vergüenza ajena"

La ignorancia era aún más profunda en el proceder de Cristina
Doña Cristina no ha incurrido en ninguna contradicción y se ha mostrado muy tranquila en todo momento

La hija del rey ha dicho desconocer las actividades que allí se llevaban a cabo

La infanta ha señalado que "tenía mucha confianza" en su marido

\subsubsection{Negrita, connotación y metáfora: la metafunción ideacional}

Según Kress y Van Leeuwen (2002) y Van Leeuwen (2005a; 2005 b), la connotación y la metáfora son los dos principios semióticos que explican cómo aportan los rasgos tipográficos su potencial de significado. Insistimos en que, a través de la connotación, se construye significado potencial por la traslación discursiva de asociaciones desde las ideas y los valores asociados a la letra en el contexto de origen hacia el contexto de destino. Por su parte, la metáfora tipográfica (Van Leeuwen 2005b: 29-36; Van Leeuwen 2006:146-147) se basa en el principio de similitud. Así, el fragmento destacado en negrita puede motivar en su interpretación, mediante una traslación metafórica o un reflejo icónico (Peirce, apud Norgaard 2009: 147-154), conceptos asociados como fuerza, solidez o asertividad. En efecto, los objetos cotidianos de un grosor o de una anchura manifiesta suelen ser sólidos, fuertes, difíciles de romper; igualmente, el "grosor", prosódico o gráfico, de un enunciado le confiere fuerza, solidez argumentativa y manifiesta un mayor compromiso del emisor, cargándose, de este modo, con un valor añadido de solidez o asertividad.

La metafunción ideacional de la negrita aparece principalmente en los titulares, ladillos y destacados de las piezas informativas, que suelen presentar un cuerpo, grosor y tipo de letra distintos del cuerpo del texto. Esta combinación de rasgos tipográficos confieren al fragmento informativo mayor relevancia contextual: llama la atención del lector y crea una 
expectativa sobre su potencial significatividad. Pero, al mismo tiempo, como muestra la figura 3, transmiten también valores ideacionales connotativos relacionados con la solidez de esa información y, por tanto, con un mayor compromiso del emisor respecto de esta: solidez informativa, fuerza argumentativa, aserción.

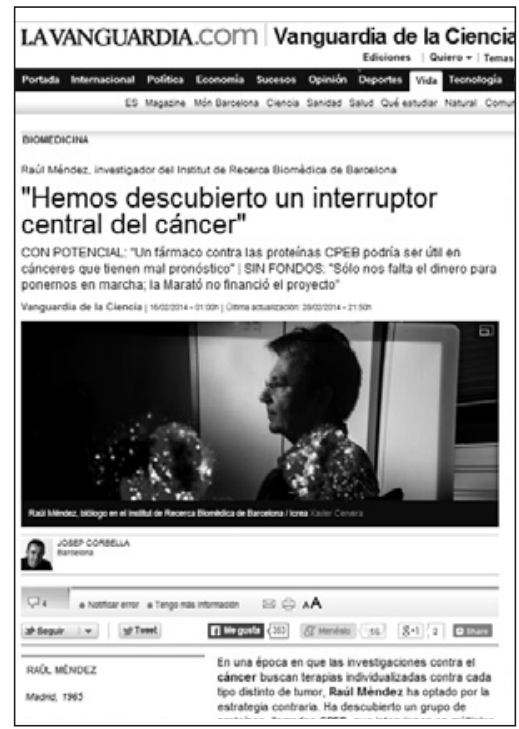

Figura 3. Combinación de rasgos tipográficos con función ideacional en una pieza informativa ${ }^{8}$

Con todo, la función ideacional también puede interpretarse en los casos comentados anteriormente, en que la negrita destaca palabras y contenidos relevantes de la información o establece itinerarios de lectura rápida. En todos ellos, en los que el grosor de la letra dota al elemento destacado de prominencia visual y genera una interpretación por defecto de relevancia informativa, puede interpretarse también un valor metafórico de solidez transmitido por la relación icónica entre el grosor de la letra y el grosor de una estructura física. Este valor conceptual de solidez se reinterpreta discursivamente como fuerza argumentativa (la solidez física del fragmento destacado en negrita implica en el discurso mayor relevancia informativa en relación con el resto de elementos no marcados) y, en buena medida, como un determinado grado de compromiso del emisor respecto de la importancia de la información que resalta (si el periodista destaca un elemento del discurso es porque cree que merece la pena llamar mi atención sobre él).

\section{Conclusiones}

Como apuntábamos en el apartado 4, uno de los objetivos de este trabajo consistía en confirmar los usos descritos por los teóricos del periodismo sobre la negrita. En efecto, la macrofunción de resalte de información de la negrita se manifiesta, especialmente, a través de la metafunción textual, orientada a la cohesión y coherencia informativas: señalar pala-

8 Fuente de la captura de pantalla: La Vanguardia.com (http://www.lavanguardia.com/vanguardia-de-la-ciencia/20140216/54401318691/hemos-descubierto-interruptor-central-cancer.html\#ixzz2xiQe8t) 
bras y conceptos clave, resaltar contenidos y crear itinerarios de lectura rápida. Con todo, la metafunción textual coactúa con las otras dos metafunciones, la ideacional y la interpersonal. Así, por el hecho de distinguirse por un mayor grosor de letra, la negrita satisface una función ideacional relacionada con la solidez de la información destacada; también, en algunos casos, además de señalar palabras clave y contenidos relevantes o crear itinerarios de lectura rápida que cobran relieve argumentativo dentro del cuerpo de la noticia, el resalte de información puede, asimismo, connotar el contenido y orientar al lector hacia determinadas actitudes e interpretaciones en clave ideológica respecto del hecho noticiado.

A modo de resumen, la figura 4 sintetiza los valores funcionales que se han comentado en los apartados anteriores.

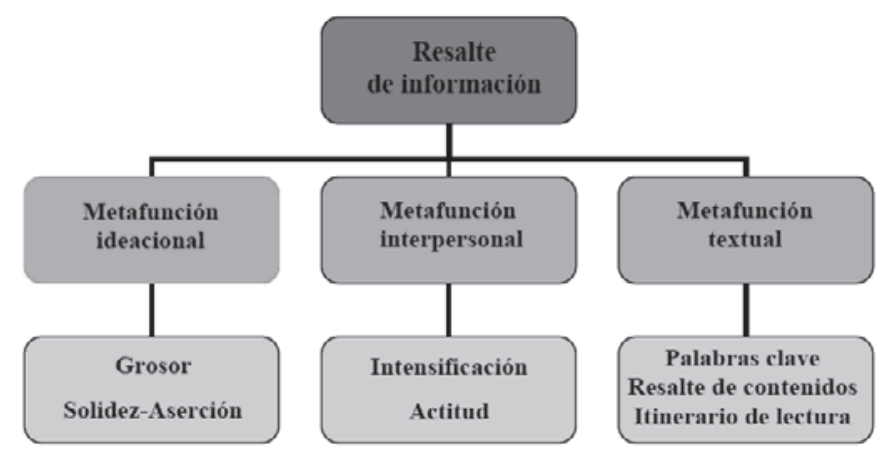

Figura 4: Red funcional de la negrita.

En cuanto a los segmentos textuales que se resaltan en negrita, su tipología y extensión es variable entre periódicos o incluso dentro de un mismo periódico. Esta variabilidad depende, principalmente, del tipo de información que se está destacando. Así, el resalte de palabras y conceptos clave suele corresponderse formalmente con nombres comunes, nombres propios o sintagmas nominales. Por su parte, el resalte de contenidos abarca unidades lingüísticas mayores de límites diversos, dado que la información destacada es más compleja: no se señalan simplemente los protagonistas, los conceptos o las acciones que constituyen las piezas fundamentales de la noticia, sino que se resaltan aspectos de la información que permiten al lector construirse una representación más completa de los hechos noticiados.

Con todo, la marcación de los segmentos presenta, con frecuencia, inconsistencias desde el punto de vista formal. En este sentido, en la mayoría de los casos el segmento destacado en negrita no coincide formalmente con una unidad sintáctica completa. Es frecuente, por ejemplo, que los nombres comunes y los sintagmas nominales en negrita dejen fuera del marcaje el determinante, o que se deje sin marcar la preposición que introduce el complemento nominal.

En este sentido, resulta más llamativo aún que se marquen aleatoriamente segmentos de una unidad sintáctica e informativa mayor, generalmente una oración, fraccionándola de manera que los segmentos destacados no resulten significativos por sí mismos, como muestra este extracto del ejemplo (5):"(...) el Gobierno ha aprobado la ley del aborto más restrictiva de la democracia". En casos como este resultaría más rentable desde el punto de vista informativo destacar en negrita toda la oración (esto es, toda la unidad informativa), sobre todo cuando parte de la información que no queda resaltada es especialmente relevante para entender el 
alcance del hecho noticiado: en el caso particular del extracto del ejemplo (5), que la ley del aborto que aprueba el Gobierno no es una más, sino la más restrictiva de la democracia.

Cabe añadir, por último, que el empleo de la negrita según el subcorpus analizado, científico o jurídico, muestra también diferencias significativas en lo que se refiere al resalte de palabras y conceptos clave, y al resalte de contenidos. Con la primera función, resalte de palabras clave, la negrita se usa en 15 piezas informativas de contenido jurídico, frente a su uso en 6 de contenido científico. Con la segunda función, resalte de contenidos, la negrita tiene mayor presencia en las noticias y crónicas de contenido legal (11 piezas informativas) que en las de tema científico ( 7 piezas informativas). Hemos apuntado a que la mayor incidencia del uso de la negrita con estas funciones en el subcorpus legal se debe, posiblemente, a una mayor necesidad informativa de señalar determinados segmentos clave con fuerza argumentativa o carga significativa que atañen, especialmente, a la identificación de personajes involucrados en los hechos noticiados.

De hecho, solo la función metatextual de la negrita en la creación de itinerarios de lectura rápida presenta la misma proporción de aparición en los subcorpus científico y jurídico. Este uso de la negrita se orienta estratégicamente hacia funciones textuales que permiten un acceso fácil y rápido a la información al establecer un itinerario de lectura rápida que funciona a modo de resumen del contenido principal de la noticia. Revela, asimismo, un mayor grado de conciencia por parte del periodista respecto de su tarea de planificar el texto y diseñar itinerarios de lectura.

En suma, este trabajo propone una reflexión sobre el uso de la negrita para satisfacer metafunciones derivadas de la macrofunción de resalte o focalización. De lo aquí desarrollado se deriva el interés de un futuro análisis sobre la copresencia de la negrita con otros recursos de resalte, en sincretismo multimodal, en la prensa digital, como el cambio del color de la tinta en los hipervínculos o el recurso a letras cursivas.

Asimismo, se ha puesto de relieve la conveniencia de optimizar el uso de la negrita por parte de los profesionales de la prensa digital para lograr una consistencia formal en la delimitación de los elementos destacados que favorezca la legibilidad de la pieza informativa. Del mismo modo, resulta recomendable progresar hacia el desarrollo de itinerarios de lectura abreviada que satisfagan las necesidades de barrido (skimming) y exploración (scanning) de los lectores de prensa en pantalla.

\section{Referencias bibliográficas}

Cassany, D. (2011): En_línia. Llegir i escriure a la xarxa. Barcelona: Graó.

García, M. Á. y Palomeque, C. (2012): "El blog multimodal: la potencialidad comunicativa y de representación de la imagen en interacción con sonidos y texto", Tonos. Revista electrónica de estudios filológicos, 22. [En línea]. Disponible en: https://www.um.es/tonosdigital/ znum22/secciones/estudios-12-el_blog_multimodal_garciaasensio_palomeque.htm

Grice, P. H. (1975): "Logic and Conversation", en Grice, P. (1989): Studies in the Way of Words. Harvard University Press, 22-40.

Halliday, M.A.K. (1978): Language as social semiotic: The social interpretation of language and meaning. London: Edward Arnold.

Jewit, C. (2009): "Different approaches to multimodality", en C. Jewit (ed.) (2009): The Routledge Handbook of Multimodal Analysis. London: Routledge Taylor \& Francis Group.

Kress, G. (2003). Literacy in the new media age. London: Routledge. 
Kress, G. y Van Leeuwen, T. (1992): "Structures of visual representations", Journal of Literay Semantics, 21 (2), 91-117.

Kress, G. y Van Leeuwen, T. (1996): A grammar of visual imagery. London: Routledge.

Kress, G. y Van Leeuwen, T. (2001): Multimodal Discourse. London: Routlege.

Kress, G. y Van Leeuwen, T. (2002): "Colour as a semiotic mode: notes for a grammar of colour", Visual Communication, 1 (3): 343-369.

Kress, G., Leite-García y Van Leeuwen, T. (2000): "Semiótica discursiva”, en T. A. van Dijk (comp.): El discurso como estructura y proceso. Barcelona: Gedisa, 2000, p. 373-416.

Machin, D. (2007): Introduction to Multimodal Analysis. Hodder Arnold: London.

Martínez Albertos, J. L. (1997): Curso de redacción periodística. Madrid: Paraninfo.

Nogaard, N. (2009): “The Semiotics of Typography in Literary Texts. A Multimodal Approach", Orbis Litterarum 64(2), 141-160. [En línea] Disponible en: http://www.sheltonography.com/resources/Articles/SemioticsofTypography.pdf

O’Halloran, K. (2008): "Systemic functional-multimodal discourse analysis (SF-MDA): Constructing ideational meaning using language and visual imagery", Visual Communication, 7(4), 443-474.

Pajares Tosa, S. (2004): Literatura digital: el paradigma hipertextual, Cáceres: Universidad de Extremadura.

Palomo, M. B. (2005): “Estructura editorial. Diseño, navegación y usabilidad”, en R. Salaverría (coord.): Cibermedios. El impacto de internet en los medios de comunicación en España. Sevilla: Comunicación Social, 186-222.

Parodi, J. (2010): "Multisemiosis y lingüística de corpus: artefactos (multi)semióticos en los textos de seis disciplinas en el corpus PUCV-2010, Revista de Lingüística Teórica y Aplicada, 48 (2), II Sem., 33-70. [En línea]. Disponible en: http://www.scielo.cl/scielo. php?pid=S0718-48832010000200003\&script=sci_arttext]

Salaverría, R. (2006): “Técnicas de redacción ciberperiodística”, en R. Salaverría: Redacción periodística en Internet. Pamplona: Universidad de Navarra, 67-139.

Salaverría, R.; Sancho, F. (2007): Diseño periodístico en internet. Donostia-San Sebastián: Editorial de la Universidad del País Vasco.

Serafini, F. y Clausen, J. (2012): “Typography as Semiotic Resource”, Journal of Visual Literacy, 31(2) [En línea]. Disponible en: http:/www.frankserafini.com/publications/serafini-typography.pdf

Steen, M. (2009): "Extensión, formato de párrafo y separaciones", en M. Tascón (2009): Escribir en internet. Guía para los nuevos medios y las redes sociales. Barcelona: Galaxia Gutemberg. Círculo de lectores, 298-299.

Tascón, M. (dir.) (2012): Escribir en internet. Guía para los nuevos medios y las redes sociales. Barcelona: Galaxia Gutemberg. Círculo de lectores.

Yúfera, I., García, M. Á. y Polanco, F (2014): "El léxico jurídico en el periodismo digital: mecanismos de clarificación”, Lingüística Española Actual, XXXV/2, 181-208.

Van Dijk, T. (1988): La noticia como discurso. Comprensión, estructura y producción de la información. Barcelona: Paidós Comunicación, 1990.

Van Leeuwen, T. (2005a): “Typographic meaning”, Visual Communication, 4 (2). [En línea]. Disponible en: http://vcj.sagepub.com/content/4/2/137.extract

Van Leeuwen, T. (2005b): Introducing Social Semiotics. Routledge: London \& New York.

Van Leeuwen, T. (2006): "Towards a semiotics of typografy", Information Design Journal 14(2), 139-155. 


\title{
LA MOTIVACIÓN LÉXICA EN EL ÁMBITO DE LA GLOSODIDÁCTICA
}

\author{
Juan Manuel García Platero \\ Universidad de Sevilla \\ jugarcia@us.es
}

Recibido: $15 / 12 / 2014$

Aceptado: 13/04/2015

\begin{abstract}
Resumen
En la enseñanza y aprendizaje del léxico de una segunda lengua están presentes factores muy diversos, por lo que se requiere de un tratamiento específico y complementario. En este trabajo se analizan los mecanismos de motivación relativa de las palabras, tanto desde la perspectiva intralingüística como atendiendo a las relaciones de semejanza y contigüidad. Se trata de intentar, en la medida de lo posible, aminorar de la opacidad léxica alentando una reflexión metalingüística, de especial interés para los aprendices de la lengua meta.

PALABRAS CLAVE: Glosodidáctica, léxico, lexicogénesis, metáfora, metonimia.
\end{abstract}

\begin{abstract}
Teaching and learning second language lexicon requires a specific and complementary treatment due to the different factors involved. In this paper, specific mechanisms of relative motivation for words are analysed. With this aim in mind the intralingual viewpoint and similarity and contiguity relationships will be taken into account. The main goal is to reduce lexical opacity encouraging students to accomplish metalinguistic reflections which are of particular interest to students of the target language.

KEY WORDS: Language methodology, lexicon, word formation, metaphor, metonymy.
\end{abstract}

\section{Introducción}

No son pocos los trabajos en los que se ponen de manifiesto las dificultades del docente para conseguir un objetivo determinado en la enseñanza de una segunda lengua (Benítez Pérez, 1994; Baralo, 2003; Santamaría Pérez, 2006) sobre todo en el nivel léxico. Aún más numerosas son las propuestas, con frecuencia imaginativas y no siempre pertinentes (visibles en congresos o revistas especializadas en el ámbito glosodidáctico), que, desde diferentes enfoques, pretenden incidir en ciertos aspectos lingüísticos y culturales y subsanar carencias. En todo caso, existe una realidad fácilmente verificable, al margen de las muy diversas circunstancias espaciotemporales: la clasificación por niveles de conocimiento no refleja con veracidad el dominio léxico. Se trata de un problema al que los docentes especializados en la adquisición de vocabulario se enfrentan con más frecuencia de la deseable.

No es este el lugar adecuado para poner en entredicho las sutiles descripciones que impone el establecimiento de compartimentos estancos en el continuo léxico, pero lo cierto es que las discreciones morfosintácticas, e incluso fonéticas, no guardan parangón con el complejo universo de la adquisición de vocabulario. Es habitual encontrarnos con disparidades dentro de un mismo estatuto de dominio lingüístico, pues en los procesos de enseñanza y aprendizaje los distintos enfoques hacen hincapié, marcados por inevitables urgencias, en la adquisición 
de competencias gramaticales y en un léxico instrumental, al que se adicionan paulatinamente unidades derivadas de necesidades genéricas o específicas. Y aunque es una obviedad que la enseñanza y aprendizaje no se circunscriben a los niveles iniciales, con frecuencia se desdeña el manejo de algunas voces, e incluso de procedimientos lexicogenésicos, al no incluirse entre las herramientas esenciales de comunicación, tal vez por una identificación basada en la frecuente demanda de un tipo determinado de alumnado. Pero el problema radica en la necesidad de abarcar realidades más complejas. Si a esto le añadimos que se trabaja con ejercicios orientados preferentemente al manejo morfosintáctico, por lo que de forma colateral se incluyen en los textos correspondientes unidades circunscritas a registros o niveles lingüísticos heterogéneos (con los correspondientes problemas de inflación o déficit léxicos, según los casos, sin olvidar las confusiones dentro del continuo diastrático-diafásico), se concluye que el aprendizaje de vocabulario carece de una adecuada sistematización ${ }^{1}$.

No se trata de suposiciones, sino de datos extraídos del quehacer cotidiano, ya que no resulta raro que se detecten contradicciones en la etiquetación del nivel de conocimiento del discente. De hecho, desde la perspectiva de la disponibilidad, aunque se observe, obviamente, que un mayor nivel de aprendizaje implica un conocimiento de vocabulario más amplio, no se reconoce homogeneidad de crecimiento en la adquisición de unidades léxicas, dado que la proporción entre los ciclos iniciales e intermedios no se corresponde con lo aprendido en el avanzado (Sánchez-Saus Laserna, 2010). De ahí que alumno muestre impotencia al enfrentarse a las lagunas léxicas, sin olvidar las irregularidades en determinados actos discursivos ${ }^{2}$. En ese sentido, es habitual que el aprendiz ubicado en un conocimiento idiomático medio, e incluso alto, tienda al recurso hiperonímico. Sin negar la plurivalidez referencial de las unidades archilexemáticas, básica para los primeros ciclos de formativos, es obvio que resultan insuficientes para grados superiores, pues el hablante muestra pobreza expresiva al ignorar elementos sustitutivos parasinonímicos. No hay que olvidar que las tareas orientadas al aprendizaje de sustituciones estilísticas no son nada desdeñables, en la medida en que se consigue la consolidación de dominio léxico, por lo que están generalmente presentes en gran parte de los métodos de idiomas. Y no cabe duda de que el escaso dominio discursivo del vocabulario ocasiona no pocas inadecuaciones ante determinadas sinfasías, por lo que el docente ha de suplir las lógicas carencias de un material didáctico que no puede abarcar dimensiones pragmáticas heterogéneas. En este, como en otros casos, las dificultades en el manejo léxico pueden mitigarse con la elaboración de actividades que complementen los estándares inicialmente propuestos, ya que, como suele suceder la mayoría de las veces, se parte de métodos idiomáticos de amplio espectro en los que se vislumbra un aprendizaje implícito de vocabulario, sin la sistematicidad y adecuación pragmáticas ${ }^{3}$, que únicamente se consiguen con una selección pertinente de las unidades (Bartol Hernández, 2010).

1 Con respecto a los ejemplos de inadecuación léxica en los manuales de aprendizaje, cfr. Benítez Pérez (1994). Para la multiplicidad de factores que entran en juego en la competencia léxica, debe verse el trabajo de Santamaría Pérez (2006).

2 No me refiero únicamente a la tradicional didáctica en el aula, pues la experiencia de llevar a cabo iniciativas de asesoramiento para el aprendizaje de lenguas con metodología tándem evidencia problemas en el adecuado intercambio léxico entre los participantes. Para esta perspectiva de enseñanza, cfr. Morán Manso (1998).

3 Es innegable que las situaciones pueden ser muy diversas, tanto para el docente como para el aprendiz, ya que, al margen, evidentemente, del grado de conocimiento idiomático de este último, los resultados dependerán de si ambos están ubicados o no en el espacio geográfico donde se habla la lengua meta. Una vez más el nivel léxico será el más condicionado por la realidad del aula. 
Conviene subrayar que no me refiero a carencias de una obra concreta, sino a un hábito consagrado. En ese sentido, se han consultado para la elaboración de este trabajo los manuales de aprendizaje de mayor difusión, en los diferentes niveles de adquisición lingüística. No es mi propósito reseñarlos, dado que, en la medida de sus posibilidades, cumplen una función de acuerdo con los parámetros trazados para una adquisición genérica de los resortes descodificadores. Y pese a que dichas obras puedan complementarse con otras que incluyan tareas orientadas específicamente al conocimiento de vocabulario, el problema radica en que se necesita una intervención más directa y concienciada del docente con la finalidad de paliar lo que, de forma inevitable, conllevan estos instrumentos de aprendizaje: carencias codificadoras derivadas del alejamiento discursivo. Esto también ocurre, salvando las distancias, con los repertorios lexicográficos monolingües, pensados para los alumnos que aprenden, en el nivel de conocimiento propicio, una segunda lengua, aunque no se pongan en duda sus indiscutibles ventajas (Martín García, 1999; Alvar Ezquerra, 2003; García Platero, 2010). Es lógico pensar que toda etiquetación léxica es meramente aproximativa, dada la adiscursividad de lo catalogado. Incluso si hablamos de aprendizaje con fines específicos, podemos caer en excesivas simplificaciones que no tienen en cuenta que las circunstancias comunicativas son muy variables y no han de reducirse a una sinstratía desnaturalizada. Es decir, nos encontramos con generalizaciones de empleo que constriñen una realidad compleja por heterogénea. En la medida en que en la enseñanza de las unidades léxicas se parte, de forma inevitable, de elementos deshabitados, al margen de su veracidad discursiva, por mucho que se intente paliar con propuestas muy diversas, el problema se acrecienta cuando las intercomunicaciones se extienden más allá del ámbito de una unidad didáctica ${ }^{4}$.

Pese a estas dificultades, nacidas de la preeminencia incidental en el aprendizaje del vocabulario, si entendemos que toda discreción teórica, dentro de la continuidad léxica que manifiesta la observación cotidiana de la interacción comunicativa, ocasiona una actuación consciente restitutiva, es pertinente establecer las relaciones léxicas necesarias (tanto en su organización horizontal, el universo fraseológico, incluida la coaparición de unidades léxi$\mathrm{cas}^{5}$, como en la verticalidad paradigmática ${ }^{6}$ y buscar contextualizaciones fidedignas ${ }^{7}$. Y es que la construcción de redes relaciones y su ulterior estabilización es el fundamento del aprendizaje léxico propio del hablante nativo (Escandell Vidal, 2007: 165-183).

4 De hecho, se detectan no pocas dificultades de manejo discursivo en alumnos de nivel, como apunté antes, avanzado, que, tras varios años de aprendizaje en su propio país, pretenden completar sus conocimientos fuera de su lugar de origen. Y no hablo de conjeturas, sino de la experiencia compartida con otros docentes.

5 Sin embargo, en el caso de las colocaciones la opacidad es manifiesta, dado que la elección del colocativo por parte de la base léxica deviene en seudodesemantización, en la medida en que, en no pocas ocasiones, salvo la tipicidad léxica, adquiere una función meramente intensificadora del contenido de la unidad seleccionadora (García Platero, 2002). Esta característica implica que las colocaciones entren a formar parte como esfera en el universo fraseológico, por más que se haya puesto en duda en alguna ocasión. Resulta innegable que el aprendiz, tal y como reflejan los distintos análisis de errores, se enfrenta a no pocos problemas de codificación en el caso de las unidades léxicas que coaparecen. Para la visión glosodidáctica, cfr. Castillo Carballo (2004), Higueras García (2006) y Alba Quiñones (2014). De la combinatoria léxica aplicada a fines específicos se han ocupado, entre otros, Vidal y Cabré (2005).

6 De hecho se ha defendido la reutilización de la teoría de los campos semánticos en el aprendizaje de lenguas (López Morales, 1992).

7 Incluso la multiplicidad significativa en el fenómeno polisémico implica la interrelación de contenidos, según la perspectiva baldingeriana, por más que este proceder implique no pocas subjetividades, por lo que la diferenciación entre variante e invariante significativas arroja más luz a la posible solución del problema. 
Este trabajo pretende centrarse en un aspecto concreto de la didáctica léxica, a sabiendas de que son muchas las propuestas que deben tenerse en cuenta para subsanar las carencias referidas. El análisis de la motivación léxica, entendida en el entorno sintagmático y asociativo del signo (Díaz Hormigo, 2009), resulta de interés en el ámbito en el que nos movemos, pues en circunstancias no propicias para la inmersión lingüística (desde los primeros años de formación) la adquisición de mecanismos que conforman la analogía sistemática, que tiende a reivindicarse como método de dominio de vocabulario para primera o segunda lengua (Martín Camacho, 2007), conlleva una minoración de la opacidad de las voces, especialmente eficaz para una retentiva lógicamente más limitada y urgente que la visible en el aprendizaje de lenguas nativas ${ }^{8}$. Se trata de la llamada "motivación intralingüística de carácter morfológico" (Penadés Martínez y Díaz Hormigo, 2008), por más que, en todo caso, la transparencia léxica siempre será, como bien sabemos, relativa. En este análisis, sin descartar otros estudios posteriores, fijo mi interés en la seudomotivación morfológica, los mecanismos intralingüísticos, aunque no pueden obviarse los casos de similitud y desplazamiento de tipo referencial ${ }^{9}$. Se defiende, en este sentido, un proceso de reflexión metalingüística en el aula, entendido como elemento mitigador del problema del déficit léxico ${ }^{10}$, aunque evidentemente no es el único ${ }^{11}$.

Conviene, finalmente, resaltar que no hay que entender estas reflexiones como una crítica a un método específico de aplicación en el aula. No son pocas las voces que, a la vez que lamentan el desinterés por el desarrollo de destrezas léxicas complementarias, defienden un eclepticismo metodológico paliativo de las carencias señaladas (Soler Albiñala, 2008).

8 Entre hablantes nativos, y al margen, obviamente, de contextos de aprendizaje, son numerosos los ejemplos de uso de la etimología popular, precisamente por la eterna búsqueda de la relación natural entre los componentes del signo (Méndez García de Paredes, 1993). La physis cratilense, frente a la dificultosa realidad de las relaciones por convención, puede, en un acto generalmente inconsciente de rebeldía lingüística ante lo opaco, ocasionar el consenso, visible en la sanción lexicográfica correspondiente (piénsese en olor de multitudes).

9 Obviamente el concepto de motivación presupone unos conocimientos y vivencias no necesariamente compartibles entre los individuos de una sociedad, por lo que no resulta objetivable, sobre todo cuando nos encontramos con determinadas sintopías (Jiménez Cuenca, 1999), y en especial en el universo fraseológico, con lógicos problemas, en este último caso, de transcodificación (Negro Alousque, 2010). Cabe señalar, incluso, que la perspectiva evolutiva, en los niveles de conocimiento pertinentes, resulta inevitable en el tratamiento de los dobletes léxicos cuando el contraste significativo de las unidades no se capta con facilidad (si la oposición entre el alcance de contenido literal y traslaticio no es sistematizable, en relación con el carácter popular o culto del vocablo). En estos casos, las adecuadas aclaraciones de tipo enciclopédico, con la consiguiente reflexión metalingüística, contrastiva o no, van orientadas a la minoración de la opacidad (Calví y Martinell, 1998)

10 De hecho, no es extraño que se hable, aunque desde una perspectiva esencialmente instrumental, de la necesidad del conocimiento metalingüístico en la clase de ELE, básica para el manejo idiomático en el aula, sobre todo cuando se aborda la interacción entre alumnos y profesores, el dominio de la terminología gramatical y la descodificación de las tareas de aprendizaje (Izquierdo Gil, 2005: 64-68). Para la importancia de las modificaciones interactivas en el contexto institucional del aula, cfr. Alcón Soler (2001).

11 En la Universidad de Sevilla imparto la asignatura "Competencias léxicas y terminológicas en español" a una treintena de alumnos de nivel B2. En la encuesta inicial les pido una autoevaluación de sus destrezas léxicas y que hagan hincapié en sus carencias y posibles causas. La mayor parte reconoce una disociación de conocimientos entre esta materia y otras relacionadas con la fonética o la gramática, pues los aprendientes no han recibido un tratamiento autónomo del vocabulario. Sin embargo, al finalizar el curso (un cuatrimestre) reconocen que su nivel de confianza en el empleo léxico ha aumentado y valoran positivamente la importancia codificadora de la reflexión metalingüística. Estos datos se repiten año tras año. 


\section{La relativización de lo motivado en la lexicogénesis}

Qué duda cabe de que el manejo de los diversos mecanismos lexicogenésicos resulta especialmente rentable, al ser las unidades derivadas los ejemplos más palpables de la llamada arbitrariedad relativa de los signos lingüísticos. De hecho, cuando se trabaja en el aula con corpus que priorizan los medios de comunicación, por su especial capacidad creativa (además de la lógica relación con la realidad cultural y política de la sociedad en la que se habla la lengua meta), más que la voz neológica en sí misma es relevante la captación del proceso formativo. Es decir, al margen de la importancia de las palabras testigo (que, obviamente, han considerarse en el nivel de conocimiento léxico requerido), lo esencial es adquirir las herramientas constitutivas necesarias para descifrar y codificar unidades. Por ello, los ejercicios de orientación onomasiológica a partir de los valores sémicos primarios o secundarios de los constituyentes lexicogenésicos ${ }^{12}$ conllevan innegables ventajas en la fijación de los contenidos significativos ${ }^{13}$. En estos últimos casos se perciben en los constituyentes usos polivalentes bien diferenciados desde el punto de vista de la no discreción sinstrática-sinfásica, aunque escasamente visibles en los repertorios lexicográficos (García Platero, 2000). Piénsese en el formante -itis en ejemplos como amigdalitis, frente a titulitis, con el consiguiente valor disfemístico del segundo sentido del afijo, al igual que ocurre con -oide en romboide, frente a sentimentaolide. En el primer caso, del valor de 'inflamación' se pasa al de 'afición desmesurada o excesivo apego a algo o alguien', por lo que a la motivación morfológica hay que añadir en la noción peyorativa un empleo traslaticio. Por otra parte, este último afijo entra en clara competencia con el constituyente antepuesto (p)seudo- (seudointelectual), puesto que la acepción no especializada desarrolla un sentido de no veracidad, desde el momento en que la semejanza objetivable deviene en valor depreciativo, al no alcanzar el límite exigible de aceptación social. Se trata, como se verá, de un mecanismo similar al que se percibe en los sufijos diminutivos, en especial -illo, cuando se combinan con bases léxicas tanto de estimación inicial positiva como negativa, con una finalidad pragmática disfemística.

En algunos casos de aspectualidad sufijal polisémica al no estar presente la noción devaluativa, ya que se parte de un contenido a priori ortofemístico (al margen, obviamente de consideraciones discursivas pragmáticamente pertinentes), la relación entre sentidos resulta más opaca (como ocurre, por ejemplo, con -ero, dado que al valor de 'receptáculo de objetos' hay que añadir, entre otros, el agentivo). Esto no sucede, precisamente por el desarrollo peyorativo, con - $a d a^{14}$, en el que a partir de la idea de 'acción repentina', presente en voces como estocada, se percibe el carácter disfemístico de gamberrada o gansada (Lang, 1992: 175-178). Del mismo modo, no es extraño encontrarnos en los medios de comunicación, sobre todo en las columnas periodísticas, ejemplos como aznarada o zapaterada.

En la verbalización sabemos que, exceptuando los usos parasintéticos o las voces neonímicas, en las que efectivamente entra el sufijo - ar (al igual que ocurre con -ificar, pero sin tendencia a la parasíntesis), la mayor parte de las creaciones se obtienen con -izar y, sobre

12 En el sentido de desarrollos no etimológicos, esencialmente en los llamados elementos compositivos, que, en el fondo, dada su iteratividad y dispersión discursivas (pues traspasan lo estrictamente neonímico), adquieren suficiente vitalidad morfológica.

13 Por su productividad, también cabría destacar la importancia de la composición deverbal (Liceras, 2009).

14 Para un estudio exhaustivo del sufijo, cfr. Pujol (2009). 
todo, -ear, pues con -ecer únicamente nos encontramos con lexicalizaciones de sentido incoativo (como florecer). Pero lo que nos interesa, desde la perspectiva de este trabajo, es la tendencia a combinarse con nombres propios, puesto que uno de los valores de -ear es el iterativo, con una clara connotación disfemística ${ }^{15}$. En efecto, la creación léxica verbal a partir de nombres propios adquiere en español un contenido devaluativo, en la medida en que se resalta la habitualización de determinados actos generalmente vituperables de personajes públicos o privados, también visible en -izar (Martínez Linares, 2012). Es decir, el hablante subraya un rasgo negativo característico y descarta cualquier mención a otras cualidades. De ahí el valor peyorativo de creaciones, generalmente presentes en los medios de comunicación, independientemente de que sean o no esporádicas, como ocurre con $a z$ narear, pujolear, etc.

Subrayo estos casos porque los alumnos presentan problemas de identificación de los sentidos devaluativos de las unidades. Es preciso, por lo tanto, incidir en consideraciones de este tipo, válidas para reducir la opacidad léxica. Especialmente interesantes resultan, desde este enfoque, los vocablos formados por sufijación estrictamente no aspectual, aunque no hablemos con exactitud de discreciones, como hemos observado en los valores secundarios de los llamados elementos compositivos o en determinados empleos contextualmente disfemísticos de constituyentes no apreciativos. En efecto, el carácter potestativo de algunos formantes lexicogenésicos, dejando a un lado, lógicamente, las lexicalizaciones (por más que la perspectiva diacrónica arroje transparencia ${ }^{16}$ ), implica una inevitable carga de subjetividad en un continuo eufemístico-disfemístico ${ }^{17}$. En los constituyentes aumentativos y diminutivos comprobamos que se aminora la opacidad léxica al partirse de la idea de lo dimensional objetivo, únicamente por la coincidencia de múltiples subjetividades, a lo que se agregan sentidos meliorativos o peyorativos ${ }^{18}$. En general, lo dimensional, en su vertiente aumentativa o diminutiva, comporta connotaciones bien diferenciadas. Así, tradicionalmente se relaciona lo pequeño con lo positivo, al contrario que lo grande, lo que no impide que se intercambien las percepciones, en relación, generalmente, con las valoraciones de las bases léxicas con las que se combinan los formantes no aspectuales, como sucede con regalazo. La vitalidad de este último sufijo se percibe en la evolución del tradicional valor

15 Lang (1992: 215) cita ejemplos de empleos iterativos en voces verbalizadas como parpadear, relampaguear y chinchinear y esencialmente disfemísticos en discursear, fanfarronear y hombrear. Junto con la actualización del sema iterativo se ha hablado del carácter diminutivo (en el que puede entrar la dimensión subjetiva de valor disfemístico), como sucede con canturrear, pues la disminución léxica va más allá de lo nominal (Monterrubio Prieto, 1990).

16 En vocablos lexicalizados con sufijos no aspectuales, como molinillo, almohadón, telón o madrastra, se conservan rasgos dimensionales o estrictamente peyorativos que aminoran la opacidad, aunque se produzca la desparagramaticalización a la que se refería Lüdtke (1996: 83-84): "A funciones como predicado, sujeto o diminutividad, en la formación de palabras, las llamamos "paragramaticales" y a la formación de palabras "paragramática" o "gramática del léxico", porque el término de formación de palabras no permite ni siquiera la acuñación de un adjetivo de relación, menos aún la creación de términos para denominar procesos de cambios [...]. Se han desparagramaticalizado, por ejemplo, casi enteramente las funciones diminutiva y aumentativa en francés. Maisonnette no es sencillamente una maison diminutiva".

17 Si entendemos que el eufemismo y el disfemismo no son productos léxicos, sino procesos de actualización de recursos que pretenden minorar el referente interdicto o intensificarlo, según la realidad discursiva (Casas Gómez, 2009), se puede explicar que los problemas de descodificación o de adecuación contextual aparezcan al margen de catalogaciones apriorísticas.

18 Aunque algunos formantes se agrupen tradicionalmente dentro de los despectivos propiamente dichos, como ocurre con casucha. 
de 'golpe' (Monge, 1972), hasta llegar a creaciones disfemística, algunas más vinculadas que otras al contexto inmediato (decretazo, medicamentazo, tarjetazo, etc.), que ya vimos con la variante apreciativa del sufijo aspectual -ada. En el caso de -ón, por las mencionadas asociaciones dimensionales, los ejemplos de usos devaluativos no escasean, dando lugar a insultos que dejan, obviamente, de ser tales en la complicidad discursiva. Menos numerosas son las atenuaciones opacas, que se actualizan generalmente con la variante alomórfica del aumentativo (tontorrón).

En cuanto a los diminutivos, lo frecuente es el valor de atenuación (diablillo), más marcado en el caso de -ito, en el que la carga afectiva se intensifica (lo que encuentra parangón con la tendencia al empleo de abreviamientos en situaciones de informalidad, como cole, pelu, uni), con todos los matices pragmáticos de cortesía o modestia que podamos considerar (piénsese en el caso de regalito), por lo que en ciertas situaciones comunicativas lo minorativo puede interpretarse o no en su visión objetiva. Sin embargo, en más de una ocasión lo dimensional se concibe desde una óptica distinta, pues los referentes que se someten a juicio han de superar la aceptabilidad social, como se vio más arriba. De lo contrario, el vocablo pertinente que se adjunta con el afijo adquiere una dimensión disfemística. Así se percibe en politiquillo, curilla, jefecillo, mediquillo, etc. Esta posibilidad puede extenderse, incluso, a bases léxicas consideradas peyorativas, según la perspectiva cultural o ideológica de un número considerable de hablantes, por lo que cuando se añade el constituyente diminutivo se intensifica el valor apriorístico. La razón estriba en que, conviene reiterarlo, la dimensión minorativa juega en contra, en la medida en que, dentro del consenso devaluativo, no se alcanza, con matices, cierta respetabilidad. Esto sucede, desde las correspondientes ópticas ideológicas, con voces como como rojillo o fachilla (García Platero, 1997). En relación con lo señalado, podría entenderse que el continuo eufemístico-disfemístico, considerado como proceso de actualización de mecanismos, constituye un obstáculo insalvable en la búsqueda de la relativización de la arbitrariedad. Sin embargo, en lexicogénesis, incluso en las voces derivadas con constituyentes no aspectuales, donde el continuo dimensional implica rasgos no necesariamente objetivables, se evidencia la actualización de lo cuantitativo en función de determinadas realidades asumidas por la mayor parte de los hablantes. Es decir, en los vocablos en los que entran consideraciones de índole pragmática de cierta complejidad para la correcta descodificación resulta posible la minoración de la opacidad léxica atendiendo a una motivación que tenga en cuenta el conocimiento de las valoraciones socioculturales. El problema radica, en muchas ocasiones, en el tratamiento, en gran parte comprensible, tanto de los manuales como de los repertorios lexicográficos, al no poder abarcar la multiplicidad de sentidos de la apreciación y obviar las contextualizaciones pertinentes (Castillo Carballo y García Platero, 2006). Por ello, el docente debe recurrir a ejemplos más acordes con la perspectiva pragmática, a partir de corpus escritos y orales que muestren la no aspectualidad lexicogenésica en toda su amplitud ${ }^{19}$.

Por lo que respecta a la afijación antepuesta, la existencia de varios constituyentes que comparten identidad significativa implica, obviamente, una mayor dificultad, especialmente destacable con los formantes que denotan negación de la base léxica ${ }^{20}$ (no ocurre así en la polivalencia de extra-, al percibirse con facilidad el continuo entre el carácter locativo,

19 En relación con lo señalado, los enfoques por tareas, en sus diversas líneas de investigación (Ortega, 2004), poseen un interés indudable.

20 Para este tipo de prefijación debe verse Serrano-Dolader (2006). 
negativo e intensificador, por lo que el grado de relativa motivación es lógicamente mayor). Nos encontramos en esta, como en otras ocasiones, con una oposición entre la inteligibilidad estigmatizada, derivada de la aplicación analógica, entendida como el desarrollo de la capacidad generalizadora, sin tener en cuenta lo consuetudinario (a partir, por ejemplo, de la elección de un único formante para todo el paradigma ${ }^{21}$ ), y la no estigmatizada, que implica el conocimiento, sin demasiadas fisuras, de los empleos normativos. Hablamos de inteligibilidad, pues el destinatario del mensaje que domina la lengua meta no tiene problemas al descifrarlo, aunque la elección lexicogenésica no sea la convenida socialmente, al igual que ocurre con las irregularidades verbales, incluso entre nativos. Sin embargo, el conocimiento léxico del emisor queda en evidencia, frente a las situaciones que no conllevan una elección léxica arbitraria. De hecho, el propio hablante no foráneo se topa con motivaciones contextuales en el ámbito lexicogenésico, por diferentes razones ${ }^{22}$, por más que distinga la transgresión leve de las violentas, como ocurre, por ejemplo, con los adverbios en -mente (García Page, 1991). En todo caso, al margen de la anteposición o posposición del constituyente, como bien señala Serrano-Dolader (2005: 12), la sobregeneralización a la que tiende el aprendiz no es un problema esencial, pues el uso discursivo cotidiano subsana los posibles empleos no consensuados ${ }^{23}$, dado que "la enseñanza-aprendizaje de léxico no es en realidad un fin en sí mismo, ya que el léxico no es sino un medio para comunicarse y mejorar la competencia comunicativa".

En definitiva, en el ámbito de la formación de palabras cabe distinguir, desde la finalidad glosodidáctica, entre la no apreciación y apreciación lexicogenésica. Si en el primer caso, no nos encontramos con especiales problemas de opacidad, aunque sí con obstáculos normativos subsanables con el tiempo ${ }^{24}$, en el segundo las dificultades de descodificación y codificación se acentúan desde el momento en que son necesarios conocimientos de índole pragmática. Sin embargo la continuidad entre lo dimensional y determinadas connotaciones meliorativas o peyorativas, según los casos, pueden evidenciarse, por lo que la opacidad léxica se aminora. De ahí que se haya prestado especial atención a la no aspectualidad afijal.

21 Lo que demuestra que el discente ha interiorizado los mecanismos lexicogenésicos (Fernández López, 1992; Gómez Molina, 1997).

22 No hay que olvidar que el proceso de aprendizaje del léxico es gradual, por lo que determinados aspectos pueden no estar necesariamente cubiertos en un nivel determinado, tanto en los discentes foráneos como en los escolares nativos (Baralo, 2003), por lo que resultan lógicas las reanalizaciones de vocablos (Martín Vegas, 20032004; 2005). Los paralelismos entre el proceso de aprendizaje de la morfología compleja y la sintaxis son indudables, como señala (Varela 2003: 577-578): "Es plausible suponer que, en un sentido, la adquisición del léxico por parte del no-nativo se distancia del modo en que adquiere la sintaxis y que se asemeja mucho más al proceso que sigue el propio hablante nativo. En lo que se refiere al léxico derivado, el no-nativo desarrollaría presuntamente estrategias semejantes a las del nativo, basadas por lo pronto en su capacidad de segmentar o parcelar la palabra y de dotarla de significado a partir del de sus partes. De hecho, aún sin la base de investigaciones sólidas sobre el proceso de adquisición de la morfología léxica en L2, es práctica usual que las gramáticas pedagógicas planteen tareas de reconocimiento y producción del léxico complejo que en poco difieren de las que podemos encontrar en libros escolares destinados a que los hablantes nativos enriquezcan su vocabulario".

23 En muchas ocasiones, en las que no entran variaciones apreciativas, resulta ciertamente complejo encontrar una sistematización que implique transparencia entre los componentes del signo sin entrar en contradicción con los empleos consensuados. Así sucede con ciertos adjetivos denominales en -ble, como saludable (Gil Giménez, 1998).

24 Al margen de las contextualizaciones continuas, sin duda lo más rentable, algunas propuestas de ejercicios que inciden en la perspectiva onomasiológica pueden ser de ayuda (piénsese en las paráfrasis definitorias de profesiones que el aprendiz ha de adivinar utilizando el constituyente adecuado, como -ero o -ista). En cuanto a la anteposición lexicogenésica de valor negativo, son de utilidad los ejercicios referentes a la antonimia morfológica (posible, real, politico). 


\section{Las relaciones de semejanza y contigüidad}

La concepción tradicional de la metáfora (Ullmann, 1962) en la que se distinguían, entre otros, los empleos traslaticios antropomórficos (las manecillas del reloj), de los animalísticos (paso de cebra) y de los sinestésicos (voz cálida), ya poseía interés glosodidáctico, por la minoración de la opacidad léxica. Especial valor tienen los usos traslaticios cuando en el proceso de selección sémica metafórica se destaca una serie de comportamientos de animales para compararlos con los de las personas, no siempre visualizados en todas las culturas. Además, la recurrencia a la diminutividad en algunos casos (por ejemplo, hormiguita) ahonda en el continuo dimensional-afectivo ${ }^{25}$. En ese sentido, la reflexión metalingüística, cuando el nivel del discente lo permite, opera en beneficio del aprendizaje, rompe creencias etnocéntricas y consigue una empatía con la realidad léxica.

Por otra parte, es sabido que gracias a las aportaciones del cognitivismo la metáfora ha dejado de concebirse como una anomalía o desvío léxico, pues se enfatiza el conocimiento que el hablante posee de la realidad circundante ${ }^{26}$. De hecho, los procesos de pensamiento se consideran, en gran medida, metafóricos ${ }^{27}$. Es decir, se parte de la idea de que estamos ante una característica definidora de nuestro sistema mental, por más que se valga de la lengua y se refleje en ella ${ }^{28}$. De ahí la habitual diferenciación entre los esquemas abstractos que permiten la agrupación de expresiones traslaticias y sus correspondientes actualizaciones (Lakoff y Johson, 1980), de especial interés en el ámbito de la enseñanza de lenguas (Beréndi, Csábi y Kövecses, 2008). La perspectiva cognitivista toma en consideración experiencias humanas compartidas por culturas muy diversas ${ }^{29}$, por lo que se incrementa el nivel de transparencia. Los esquemas abstractos que se tienen en cuenta, por ejemplo la concepción cuantitativa en términos de verticalidad ("Ha subido la leche") o las ideas compartidas de que la vida es un viaje ("Juan nos ha dejado"), el amor es una guerra ("Lo conquisté con la mirada"), la mente es un recipiente ("No me cabe en la cabeza lo que vas a hacer"), las teorías son edificios ("Tiene argumentos poco sólidos") o las tareas son cargas ("Debes descargarte de trabajo"), dan lugar a que expresiones cotidianas sean fruto de la señalada reflexión. En cuanto al lenguaje político y al periodístico, nada desdeñables para nuestros fines (Romero Gualda, 2008: 235-237), con una clara

25 En relación con lo señalado, cabe resaltar la importancia de los culturemas (Luque Durán, 2007; Pamies Bertrán, 2009), entendidos como como símbolos culturales de especial importancia en el uso traslaticio del vocabulario, por lo que muestran hábitos y prejuicios reflejados en frases estereotipadas.

26 Cfr. el esclarecedor trabajo de Arribas Esteras (2009). Para una visión general de los usos metafóricos coloquiales, véase Fernández Colomer (2003).

27 Llamas Saíz (2005: 238) se refirió, con acierto, a la relativa motivación de las creaciones metafóricas, a partir de la visión cognitivista: "[...] el conocimiento del mundo que el hablante posee y sus ideas acerca de las cosas intervienen en la conformación del significado a partir de metáfora de un modo regular que puede sistematizarse mediante una serie de proyecciones que permiten hablar de una cierta coherencia metafórica. En este sentido, puede decirse que la ampliación del significado mediante metáfora está motivado, si bien no es posible saber el porqué de unas expresiones frente a otras".

28 Se ha dicho que esta perspectiva implica que nos encontremos ante una metalingüística que pretende explicar el lenguaje real (Martínez del Castillo, 2008: 188-195). Es decir, nos enfrentamos, una vez más, con expresiones acontextuales. En todo caso, conviene insistir en que la reflexión a la que aludimos, dejando a un lado estas observaciones, resulta de especial interés en el dominio del aprendizaje de lenguas.

29 Al margen del ámbito estrictamente traslaticio, pero en relación con las interrelaciones culturales, algunos estudios centrados en los aspectos contrastivos paremiológicos llegan a considerar, pese a las divergencias, importantes paralelismos interlingüísticos, como ocurre, por ejemplo, entre el español y el alemán (Zurdo, 1993). 
tendencia retroalimentativa, no son pocos los casos que pueden enumerarse a partir de los presupuestos cognitivistas. Resulta, de este modo, de interés la presencia de esquemas conceptuales y sus correspondientes expresiones traslaticias en el discurso parlamentario, analizadas con acierto por Sánchez García (2009): la política es una batalla ("Hay que luchar contra el paro"), la política es una mercancía ("Ya sabemos lo que vale su palabra"), el gobierno es un barco ("Es necesario enderezar el rumbo de la economía"), etc.

Incluso desde métodos de enseñanza y aprendizaje estrictamente inmersivos, son útiles los contrastes entre sistemas lingüísticos, el nativo y el correspondiente a la lengua meta, pues se aprovechan las ventajas de una concepción no anómala de los usos traslaticios y se aminoran, como se dijo más arriba, etnocentrismos, al evidenciarse identidades interculturales más intensas que las esperadas. Además, la consideración del no desvío del empleo metafórico consigue que el aprendiente entienda los procesos creativos de muchas unidades fraseológicas, caracterizadas precisamente por su idiomaticidad. Desde esta visión, conviene recordar que el ser humano parte del conocimiento de lo más inmediato, su propio cuerpo, sus necesidades primarias y los esfuerzos para alcanzarlas. Es un fenómeno de evolución semántica consabido que para nombrar lo nuevo se recurre intralingüísticamente a lo ya conocido. Del mismo modo, es connatural al hablante que acuda a lo tangible para designar conceptos y sentimientos. Casos como "Se cree el ombligo del mundo", "Es mi ojito derecho" o "Me saca las castañas del fuego" obedecen a esta necesidad de trasladar lo material cotidiano a sensaciones o comportamientos que, sin este proceder, eran inicialmente inefables. Si la adición significativa de los componentes de una unidad fraseológica no comporta su correcta descodificación, por su estructura metafórica unipolar, la minoración de la opacidad se consigue, precisamente, gracias al reconocimiento de experiencias con las que se visualizan nuestras raíces más profundas, al margen de las inevitables distancias culturales. Obviamente el grado de transparencia dependerá de los aspectos idiosincrásicos (Liceras y Carter, 2008: 388-390).

No cabe, por lo tanto, duda de que la conjunción entre la óptica cognitiva y la visión pragmática es esencial para un acercamiento al fenómeno glosodidáctico (Cepello Moreno y García Manga, 2012: 185):

En la actualidad se trata de explicar la naturaleza expresiva de la metáfora a partir de una aproximación conjunta desde la perspectiva pragmático-comunicativa y cognitiva. La pragmática inferencialista, en tanto que guía en el procesamiento lingüístico, encaja perfectamente en la perspectiva cognitiva del lenguaje, pues la pragmática ha de acudir a modelos cognitivos idealizados (aspectos del conocimiento del mundo sistematizados) para resolver los procesos de producción e interpretación de mensajes.

En la tarea de búsqueda de motivaciones relativas de las unidades léxicas en un sentido amplio, ocupan un lugar destacado los desplazamientos referenciales. De nuevo nos encontramos, a partir de los presupuestos señalados, con la adquisición de mecanismos que ayudan a la retención de determinados vocablos, tanto en el proceso codificador como descodificador. Así, la contigüidad presente en la designación del contenido con el significante del continente ("Se bebió la botella de vino"), en la de un producto con la expresión del lugar de procedencia ("Está muy bueno este jerez") o en la de un objeto con la mención al material con el que está hecho ("Compro oro"), junto con los habituales esquemas 
del todo por la parte ("Tiene muchas bocas que alimentar") o viceversa ("España ganó la Eurocopa"), debe tenerse muy en cuenta en el proceso de aprendizaje léxico. Incluso, en los niveles superiores, no son en absoluto desdeñables los fenómenos de antonomasias de cierta complejidad, en la medida en que dan lugar, incluso, a formas derivadas, lógicamente circunscritas a un determinado continuo sinstrático-sinfásico, como sucede con perogrullada, salomónico, platónico o rocambolesco. En estos ejemplos la motivación morfológica se une a la relación de contigüidad, lo que conlleva que el grado de opacidad quede aminorado, aunque se exijan los correspondientes datos históricos o culturales. De esta manera, especialmente productivas, en el nivel del conocimiento al que se hace referencia, son las tareas que animan al aprendiz a buscar las fuentes pertinentes y exponer en el aula el conocimiento enciclopédico adquirido, ya que, sin lugar a dudas, ayudan a la retención de este tipo de creaciones.

En trabajos clásicos como el de Le Guern (1973) se aludía a la experiencia extralingüística común entre los hablantes como resorte fundamental para entender estos desplazamientos. Es lógico suponer que la disminución motivadora es proporcional al estatuto lexicalizador de la unidad que ha experimentado el proceso de contigüidad, al igual que ocurre con los fenómenos metafóricos. Es decir, cuando se produce una verdadera alteración de la sustancia semántica (Sánchez Manzanares: 2007-2008). Por otra parte, es obvio que la descodificación metonímica dependerá de conocimientos referenciales, incluso para hablantes nativos. Sin embargo, la captación del proceso de contigüidad se evidencia en no pocos empleos (Sánchez Manzanares, 2009: 199):

Por otra parte, el desconocimiento de referentes de tipo cultural hace que no sean comprensibles metonimias como las de lugar por producto, o de autor por obra. Así, cuando se dice un Velázquez por un cuadro de Velázquez, la restitución de un cuadro no es clara para todo hablante de español, sino para un grupo social con un determinado nivel cultural, aunque se supone que la mayoría de los españoles ha accedido a un nivel educativo medio. Sin embargo, un hablante que desconozca que Velázquez es un pintor, no tiene por qué restituir un cuadro. Como nombre propio, puede identificar Velázquez con un antropónimo o un topónimo. Lo mismo sucede con la metonimia de lugar un Rioja, puesto que un hablante que ignore que la Rioja es una comarca en la que se elabora un vino con denominación de origen La Rioja no podrá identificarlo. No obstante, tanto en uno como en otro caso, los hablantes captan una relación de contigüidad que les lleva a interpretar la elipsis relacional, bien de lugar, bien de autor. Esto sucede porque el hablante es competente en la estructuración de los contenidos semánticos de su lengua -aunque ni siquiera para los especialistas sea posible describir la estructuración semántica del léxico-, y percibe una traslación referencial, un cambio denominativo. La determinación referencial por el artículo no llega a realizarse porque hay un desconocimiento del entorno semiótico de Velázquez o de Rioja, pero el hablante capta que hay una denotación oblicua porque hay una sustitución en el plano paradigmático que, en el caso de la metonimia, ocurre por una alteración en el nivel pre-sintagmático.

La captación de contigüidad, al margen del desconocimiento referencial, evidente en la lengua nativa, resulta lógicamente extensible, con las complejidades añadidas, a la lengua meta. Sin embargo hay que hacer hincapié cuando hablamos de aprendizaje léxico, por motivos lógicos, en la restitución de la unidad elidida. 


\section{Conclusiones}

Tanto la motivación relativa intralingüística como la que se basa en relaciones de semejanza o contigüidad con otras unidades tienen especial importancia en la glosodidáctica. Se ha subrayado que en el aprendizaje del vocabulario se observan no pocos desequilibrios, pues el discente presenta lagunas e inadecuaciones discursivas que persisten, pese a que se encuadre académicamente en un nivel global de conocimiento medio o alto. Las causas deficitarias se deben a que los métodos de enseñanza y aprendizaje no pueden, por las limitaciones de formato, abarcar la especificidad del léxico, por lo que no se plantean tareas adecuadas a la realidad inmediata. De ahí la necesidad de conjugar la adquisición incidental con la explícita para aumentar el lexicón del aprendiz. De esta manera, se huye de aproximaciones asistemáticas y se atiende a una adquisición gradual. En esta deseable complementariedad se ubican las reflexiones metalingüísticas, que entrañan el planteamiento de mecanismos minorativos de la opacidad léxica, especialmente útiles para quien pretende dominar una segunda lengua.

El aprendizaje de inmersión total no rivaliza con problemas de adecuación discursiva, ya que las unidades se manejan en su hábitat, con toda la plurivalidez comunicativa que esto implica. Sin embargo, cuando esto no es posible las carencias pueden paliarse con métodos que no necesariamente resultan pertinentes para hablantes nativos, pero sí para los que adquieren una lengua meta en circunstancias mucho menos propicias. En ese sentido, la recurrencia a textos mediáticos, caracterizados por la búsqueda de la expresividad léxica, es de especial interés, aunque hay de resaltar que lo básico no es el vocablo creado, no necesariamente perdurable, sino la aprehensión del mecanismo lexicogenésico y su valor pragmático.

En el acercamiento a la motivación intralingüística no hay que obviar los usos meliorativos y disfemísticos, de innegable relevancia pragmática, especialmente cuando nos situamos en la no aspectualidad afijal, dentro de un continuo dimensional-apreciativo. Y aunque se evidencie la idea, como se dijo más arriba, del eufemismo como proceso y no como producto, las catalogaciones léxicas tienden a marginar la incidencia pragmática al abordar los contenidos de los constituyentes, sobre todo los aumentativos y diminutivos. La mayor parte de los materiales didácticos olvidan la premisa de adecuación discursiva, tal vez por el escaso interés que el MCER ha mostrado ante el fenómeno, sobre todo cuando abordamos la no aspectualidad afijal. Es reseñable, en todo caso, que la sufijación ofrece más posibilidades de análisis que la prefijación, donde, por regla general, se atiende a la motivación morfológica que condiciona la adición de una base léxica a un constituyente antepuesto, aunque es frecuente que las restricciones normativas adquieran en la anteposición del formante lexicogenésico cierta relevancia.

Finalmente, conviene subrayar que los empleos traslaticios, junto con los antes aludidos ejemplos de contigüidad, son de especial interés, pues evidencian que no nos encontramos, sobre todo en el primer caso, únicamente con anomalías lingüísticas justificadas por los anhelos creativos del escritor, sino que son reflejo de esquemas derivados del conocimiento que los hablantes tienen de la realidad circundante, como bien se ha ocupado de defender la perspectiva cognitiva. Todo ello da lugar a la reflexión metalingüística, de indudable validez en el aprendizaje léxico, en el nivel de conocimiento pertinente, lo que contrasta con las necesidades, querencias y actos discursivos, tan rutinarios como libres, de quien maneja su lengua materna. 


\section{Referencias bibliográficas}

Alba Quiñones, V. de (2014): “Sobre diccionarios monolingües de aprendizaje de español y colocaciones léxicas. Estudio e implicaciones didácticas". En Garcés Gómez, M. ${ }^{\mathrm{a}}$ P. (ed.): Lexicografía teórica y aplicada. A Coruña, Universidade da Coruña, Anexos de Revista de Lexicografía, 26, págs. 119-133.

Alcón Soler, E. (2001): "Interacción y aprendizaje de segundas lenguas en el contexto institucional del aula". En Pastor Cesteros, S. y Ventura García Salazar (eds.): Tendencias y líneas de investigación en adquisición de segundas lenguas. Alicante, ELUA, Anexo 1, págs. 271-287.

Alvar Ezquerra, M. (2003): La enseñanza del léxico y el uso del diccionario. Madrid, Arco Libros.

Arribas Esteras, M. ${ }^{a}$ N. (2009): "Historias de las palabras: una propuesta antropológica y etnolingüística para el aprendizaje del léxico en ELE”. En Barrientos Clavero, A. (coord.): El profesor de español LE-L2. Actas del XIX Congreso Internacional de la Asociación para la Enseñanza del Español como Lengua Extranjera (ASELE). Cáceres, Universidad de Extremadura, págs. 185-202.

Baralo, M. (2003): "Lingüística aplicada: aprendizaje y enseñanza de español/LE", Interlingüística, 14, págs. 31-44.

Bartol Hernández, J. A. (2010): “Disponibilidad léxica y selección del vocabulario". En Castañer Martín, R. M. ${ }^{a}$ y V. Lagüéns Gracia (coords.): De moneda nunca usada. Estudios dedicados a José M. ${ }^{a}$ Enguita Utrilla. Zaragoza, Instituto Fernando El Católico, CSIC, págs. 85-107.

Benítez Pérez, Pedro (1994): "Léxico real/léxico irreal en los manuales de español para extranjeros". En Montesa Peydró, S. y A. M. Garrido Moraga (coords.): Actas del Segundo Congreso Nacional de ASELE. Madrid, ASELE, págs. 325-334.

Beréndi, M. , S. Csábi y Z. Kövecses (2008): “Using conceptual metaphors and metonymies in vocabulary teaching". En Boers, F. y S. Lindstromberg (eds.): Cognitive Linguistic Approaches to Teaching Vocabulary and Phraseology. Berlin, Mouton de Gruyter, págs. 65-100.

Calví, M. a V. y E. Martinell, (1998): "Los dobletes léxicos en la enseñanza del español a extranjeros". En Alonso, K; F. Moreno Fernández y M. ${ }^{a}$ Gil Bürmann (dirs.): El español como lengua extranjera: del pasado al futuro. Actas del VIII Congreso Internacional de ASELE. Madrid, Universidad de Alcalá de Henares, págs. 227-240.

Casas Gómez, M. (2009): "Hacia una nueva perspectiva de enfoque en la definición lingüística el eufemismo". En Fuentes Rodríguez, C. y E. R. Alcaide Lara (eds.): Manifestaciones textuales de la descortesía y agresividad verbal en diversos ámbitos comunicativos. Sevilla, Universidad Internacional de Andalucía, págs. 11-29.

Castillo Carballo, M. ${ }^{\text {a }}$ A. y J. M. García Platero (2006): "Valor pragmático de la apreciación en español". En Álvarez, A. et alii (eds.): La competencia pragmática y la enseñanza del español como lengua extranjera. Actas del XVI Congreso Internacional de ASELE. Oviedo, Universidad de Oviedo, págs. 208-212.

Castillo Carballo, M. A A. (2004): "La información colocacional en los diccionarios para L2". En Galloso Camacho, M. ${ }^{\mathrm{a}}$ V. y J. Prado Aragonés (eds.): Diccionario, léxico y cultura. Huelva, Universidad de Huelva, págs. 71-83. 
Cepedello Moreno, M. ${ }^{a}$ P. y M. C. García Manga (2012): “La motivación metafórica en el lenguaje: hacia una concepción cognitiva". En Calero Vaquera, M. ${ }^{a}$ L. y M. ${ }^{a}$ A. Hermosilla Álvarez (eds.): Lenguaje, Literatura y Cognición. Córdoba, Universidad de Córdoba, págs. 167-188.

Díaz Hormigo, M. ${ }^{a}$ T. (2009): "En torno a la teoría saussureana de la motivación lingüística”, ELUA, 23, págs. 73-98.

Escandell Vidal, M. ${ }^{\mathrm{a}}$ V. (2007): Apuntes de Semántica léxica. Madrid, UNED.

Fernández Colomer (2003): "La metáfora en español coloquial”, Interlingüística, 14, págs. 359-374.

Fernández López, S. (1992): "Formación de palabras y adquisición de la lengua". En Vázquez, C. y J. R. Losada (eds.): Actas del VIII Congreso Nacional de AESLA. Vigo, Universidad de Vigo, págs. 255-265.

García-Page, M. (1991): "El adverbio en -mente. Motivación contextual en formaciones léxicas “anómalas”, Anuario de estudios filológicos, 14, págs. 149-182.

García Platero, J. M. (1997): "Sufijación apreciativa y prefijación intensiva en español actual”, $L E A, 19,1$, págs. 51-62.

García Platero, J. M. (2000): "Presencia de las voces seudosufijadas en los diccionarios del español”. En Ruhstaller, S. y J. Prado Aragonés (eds.): Tendencias en la investigación lexicográfica del español. El diccionario como objeto de estudio lingüístico y didáctico. Huelva, Universidad de Huelva, págs. 425-432.

García Platero, J. M. (2002): “Aspectos semánticos de las colocaciones”, LEA, 24, 1, págs. 25-34.

García Platero, J. M. (2010): “La información semántica en los diccionarios de aprendizaje”. En Ruhstaller, S. y M. ${ }^{a}$ D. Gordón Peral (eds.): Diccionario y aprendizaje del español. Bern, Peter Lang, págs. 171-184.

Gil Jiménez, G. (1988): Aspectos gramaticales de la motivación lingüística. Málaga, Imprenta Montes.

Gómez Molina, J. R. (1997): “El léxico y su didáctica: una propuesta metodológica”, REA$L E$, 7, págs. 69-93.

Higueras García, M. (2006): Estudio de las colocaciones léxicas y su enseñanza en español como lengua extranjera. Málaga, ASELE.

Izquierdo Gil, M. ${ }^{a}$ del C. (2005): La selección del léxico en la enseñanza del español como lengua extranjera. Málaga, ASELE.

Jiménez Cuenca, M. A. (1999): “Consideraciones sobre creación y motivación en el léxico del español de Andalucía”. En Samper Padilla, J. A. y M. Troya Déniz (coords.): Actas del XI Congreso Internacional de la Asociación de Lingüística y Filología de la América Latina. Las Palmas de Gran Canaria, Universidad de Las Palmas de Gran Canaria, Librería Nogal, págs. 289-295.

Lakoff, G. y M. Johnson (1980): Metáforas de la vida cotidiana. Madrid, Cátedra.

Lang, Mervyn F. (1992): Formación de palabras en español. Morfología derivativa productiva en el léxico moderno. Madrid, Catedra.

Le Guern, M. (1973): Sémantique de la métaphore et de la métonymie. París, Larousse.

Liceras, J. M. y D. Carter (2008): "La adquisición del léxico". En De Miguel, E. (ed.): Panorama de la lexicología. Barcelona, Ariel, págs. 371-404.

Llamas Saíz, C. (2005): Metáfora y creación léxica. Navarra, Universidad de Navarra. 
López Morales, H. (1992): “En torno al aprendizaje del léxico. Bases psicolingüísticas de la planificación curricular”, RLA: Revista de lingüistica teórica y aplicada, 30, págs. 39-50.

Lüdtke, J. (1996): “La diacronía en la semántica de la formación de palabras”. En Henríquez Salido, M. ${ }^{\text {a }}$ do C. y A. Rifón (eds.): Estudios de morfología. A Coruña, Universidade de Vigo, págs. 77-90.

Luque Durán, J. D. (2007): “La codificación de la investigación lingüístico-cultural en los diccionarios interculturales". En Luque Durán, J. D. y A. Pamies (eds.): Interculturalidad y Lenguaje: El significado como corolario cultural. Granada, Método Ediciones, págs. 329-374.

Martín Camacho, J. C. (2007): “Observaciones sobre el papel de la analogía en los procesos morfológicos”, Revista de investigación Lingüística, 10, págs. 173-191.

Martín García, J. (1999): El diccionario en la enseñanza del español. Madrid, Arco Libros.

Martín Vegas, R. A. (2003-2004): "Evolución de la lingüística como ciencia cognitiva", Anuario de lingüística hispánica, 19-20, págs. 227-244.

Martín Vegas, R. A. (2005): “¿Segmentación morfemática o reanálisis? Formaciones con el sufijo -idad o *-abilidad, *-icidad, *-eidad”, Moenia, 11, págs. 269-281.

Martínez del Castillo, J. (2008): La lingüística cognitiva. Análisis y revisión. Madrid, Biblioteca Nueva.

Martínez Linares, M. ${ }^{\text {a }}$ A. (2012): “Aznarizar, zapaterizar... En torno a verbos forma sobre nombres propios con el sufijo -izar", LEA, XXXIV/2, págs. 247-275.

Méndez García de Paredes, E. (1993): "Valores asociados en la creación léxica". En Alcaide Lara, E. R.; M. ${ }^{a}$ del M. Ramos y F. J. Salguero (eds.): Estudios lingüísticos en torno a la palabra. Sevilla, Universidad de Sevilla, págs. 143-160.

Monge, F. (1972): "Sufijos españoles para la designación de golpe". En Homenaje a Francisco Ynduráin. Zaragoza, Facultad de Filosofía y Letras, págs. 229-247.

Monterrubio Prieto, J. M. (1990): “La disminución léxica, ¿un concepto exclusivamente nominal?", Verba, 17, págs. 77-92.

Morán Manso, M. (1999): "La enseñanza de E/LE con la metodología “Tandem”. En Losada Aldrey, M. ${ }^{\text {a }}$ C. y J. F. Márquez (coords.): Español como lengua extranjera, enfoque comunicativo y gramática: actas del IX congreso internacional de ASELE. Santiago de Compostela, Universidad de Santiago de Compostela, págs. 411-418.

Muñoz Liceras, J. (2009): "La morfología léxica del español y el llamado problema de la adquisición del lenguaje no nativo". En Serrano-Dolader, D.; M. 'A. Martín Zorraquino y J. F. Val Álvaro (eds.): Morfología y español como lengua extranjera. Zaragoza, Prensas Universitarias de Zaragoza, págs. 21-66.

Negro Alousque, I. (2010): "La traducción de las expresiones idiomáticas marcadas culturalmente”, Revista de lingüística y lenguas aplicadas, 5, págs. 133-140.

Ortega, L. (2004): “Aproximaciones cognitivo-interaccionistas al aprendizaje de segundas lenguas mediante tareas", Estudios de lingüística inglesa aplicada (ELIA), 5, págs. 15 40.

Pamies Bertrán, A. (2009): "Metáforas libres y metáforas lexicalizadas". En Luque Toro, L. (ed.): Léxico español actual II. Venezia, Università Ca’ Foscari Venezia, págs. 229-238.

Penadés Martínez, I. y M. ${ }^{a}$ T. Díaz Hormigo (2008): "Hacia la noción lingüística de motivación”. En Álvarez de la Granja, M. (ed.): Lenguaje figurado y motivación. Frankfurt am Main, Peter Lang, págs. 51-68. 
Pujol, I. (2009): “A propósito de los sustantivos en -ada: una reflexión metodológica del análisis de la formación de palabras en diacronía”, Cuadernos del Instituto Historia de la Lengua, 2, págs. 53-79.

Romero Gualda, M. ${ }^{a}$ V. (2008): Léxico del español como segunda lengua: aprendizaje y enseñanza. Madrid, Arco Libros.

Sánchez García, F. (2009): “Usos metafóricos del lenguaje político español. La metáfora estructural en los debates sobre el estado de la nación”. En Campos Gómez, P. y A. Sánchez Pérez (eds.): A Survey of Corpus-based Research. Panorama de investigaciones basadas en corpus. Murcia, AELINCO, págs. 1191-1207.

Sánchez Manzanares, M. C. (2007-2008): "Precisiones conceptuales en la definición de la sinécdoque como tropo metonímico", Pragmalingüística, 15-16, págs. 200-214.

Sánchez Manzanares, M. C. (2009): "Léxico y metonimia”. En Reyes, M. a J. (coord.): Léxicoy cultura.Badajoz,@becedario,págs.173-204.

Sánchez-Saus Laserna, M. (2010): “La variable 'nivel de español’ en el léxico disponible de los estudiantes de español como lengua extranjera", Pragmalingüística, 17, págs. 140-153.

Santamaría Pérez, M. ${ }^{a}$ I. (2006): La enseñanza del léxico en español como lengua extranjera. Alicante, Universidad de Alicante.

Serrano-Dolader, D. (2005): “La formación de palabras en español como lengua extranjera: reflexión y aplicación", Frecuencia L (Revista de Didáctica Español Lengua Extranjera), 28, págs. 11-15.

Serrando-Dolader, D. (2006): "La prefijación en la clase de ELE: los prefijos de valores negativos", Frecuencia L (Revista de Didáctica Español Lengua Extranjera), 32, págs. 11-15.

Soler Albiñana, M. ${ }^{a}$ (2008): “Aspectos relacionados con la enseñanza del léxico de E/ LE”. En Martí Contreras, J.; E. Peláez; A. Ortega y E. Lara (coords.): Teoría y práctica docente. Actas del II Congreso Internacional de Lengua, Literatura y Cultura de E/LE. University of Virginia, Món Editorial, Valencia, págs. 339-350.

Ullmann, S. (1962): Semántica. Introducción a la ciencia del lenguaje. Madrid, Taurus.

Varela Ortega, S. (2003): “Léxico, morfología y gramática en la enseñanza de español como lengua extranjera”, ELUA, 17, págs. 571-588.

Vidal, V. y M. ${ }^{\text {a }}$ T. Cabré (2005): "La combinatoria léxica en la enseñanza y aprendizaje de lenguas para propósitos específicos”. En Castillo Carballo, M. ${ }^{a}$ A.; O. Cruz Moya, J. M. García Platero y J. P. Mora Gutiérrez (coords.): Las gramáticas y los diccionarios en la enseñanza del español como segunda lengua: deseo y realidad. Sevilla, ASELE, Universidad de Sevilla, Universidad Pablo de Olavide, págs. 896-902.

Zurdo, M. ${ }^{a}$ T. (1993): "Motivación situacional del léxico de los Refranes/Sprichwörter. Contribución a un análisis intercultural”, Revista de Filología Alemana, 1, págs. 197-215. 


\title{
BLACK WOMEN THROUGH ALICE WALKER'S POETRY (A CHARACTERIZATION OF THE VALUATING SUBJECTS OF HER POEMS)
}

\author{
Yeni Hechavarría Urquiaga and Yadelys Garriga Cruz \\ Equipo de Servicios de Traductores e Intérpretes (ESTI) \\ Group of Semantic, Ideographic and Discourse Studies of the School of Foreign \\ Languages of the University of Havana \\ yeni.hechavarria@esti.cu; yeni.urquiaga@gmail.com \\ yadelys.garriga@esti.cu; marcosalicia2014@gmail.com
}

Recibido: $15 / 05 / 2015$

Aceptado: 03/06/2015

\section{Resumen}

Indudablemente, el discurso literario, particularmente la poesía, es algo bello y placentero para los ojos y los oídos; es también una herramienta poderosa para expresar ideas de carácter social, cultural y político. Este trabajo en particular se centra en la obra poética de Alice Walker y está dirigido a identificar aspectos de la ideología de la mujer afro-estadounidense como grupo en la poesía de esta autora. Como miembros del Grupo de Estudios Semánticos, Ideográficos y del Discurso de la Facultad de Lenguas Extranjeras de la Universidad de La Habana (FLEX), las autoras del trabajo decidieron acudir al análisis de discurso dimensional para llevar a cabo su investigación, y para ello se basaron en la teoría del doctor Leandro Caballero Díaz sobre las dimensiones del significado y las macrocategorías semánticas modales redefinidas por la doctora Ana María Galbán Pozo en su tesis doctoral. Este fue el primer acercamiento del grupo al discurso poético, centrando el análisis en los enunciados valorativos implícitos con contenido ideológico.

PALABRAS CLAVES: discurso, ideología, macrocategorías semánticas, dimensiones modales.

\begin{abstract}
No doubt, literary discourse- particularly poetry - is a beautiful thing, pleasant for eyes and ears. We shouldn't doubt either that it is a powerful means used to convey social, cultural and political ideas. This work is focused on Alice Walker's poetry. It is aimed to find aspects of the ideology of the African-American women as a group in the poetry of this author. As members of the Group of Semantic, Ideographic and Discourse Studies of the School of Foreign Languages of the University of Havana (FLEX), the authors of this paper decided to make use of the dimensional discourse analysis to carry out their research. Thus, the work has followed the theory on the meaning dimensions and the modal semantic macrocategories introduced by Leandro Caballero Díaz, later on redefined by Ana María Galbán Pozo. Ours was the first approach to poetic discourse in our group, centering our analyses on the implicit valuating utterances with ideological content.
\end{abstract}

KEYWORDS: discourse, ideology, semantic macrocategories, modal dimensions.

\section{Introduction}

Literature is not only pieces of writing having excellence of form and expression. As a matter of fact, it is one of the most important sources of knowledge humanity can count on. Literature helps us travel back and forth in time, providing us with valuable elements of our 
present and past history, including that of our ancestors, their ways of thinking, their lifestyles, their luck and misfortune. Thus, the new generations begin to forge their own destiny.

Literature is not exclusive of any given community or culture; it actually embraces uncountable cultures with different characteristics. In our paper we are going to deal with African-American literature, especially that of black women. In order to accomplish our goal, we will focus on the work of one of those authors who has devoted a considerable part of her life to writing about her origins, beliefs and sufferings. An incredible woman who has gained world recognition due to her unique way of writing and her constant battle against black women's discrimination: Alice Walker.

According to the sources we have consulted, there have been plenty of works concerning Alice Walker's prose, especially her novel The Color Purple (1983). However, in terms of Walker's poetry, it has been difficult for us to find information. In addition, no previous reseach about Walker's poetry has been carried out in our Group of Semantic Studies, and that is one of the reasons why we have felt motivated towards this subject.

As literature is one of the written representations of language in which communicative intentions, ideologies and emotions of the authors are present, discourse is a relevant aspect to be taken into consideration when approaching it. That is why we have decided to use discourse analysis as a tool to analyze Walker's poems from her work Her Blue Body: Everything We Know Earthling Poems (1992) which is a compilation of six books.

The problem of this research was how to establish the ideological intentionality of the African American valuating subject in Alice Walker's poems. The main objective was to demonstrate through discourse analysis of the valuating subject in Alice Walker's poems, some aspects of the ideology of African American women as a group. Therefore, the object of study of the paper is the ideology of African American women as a group reflected in Alice Walker's poetry.

Before beginning the analysis of the poems selected, we will make reference to the biography of the author and the history of the Black Feminist Movement. In like manner, we'll address different criteria of discourse analysis, ideology and society, and the link among them. Likewise, we are going to refer to the Valuation Theory.

\section{Alice Walker}

Alice Walker is a relevant African-American writer who has devoted her entire life to women's defence. She was born in Eatonton, Georgia, on February 9, 1944. It is through her prose, both fiction and non-fiction, that Walker has found her most faithful audience and has established the subject matter of her work, which consistantly reflects her concern about racial, sexual, and political issues, mainly related to black women's struggle for survival. Among her prose we can find: In love and Trouble: Stories of Black women (1973), You Can't Keep a Good Woman Down(1981), and The Color Purple (1983), her most famous work and winner of both an American Book Award and a Pulitzer Prize for fiction.

However, despite the fact that she is worldwide known as a prolific novelist, she is also an accomplished poet. She began her professional career as a poet, and has continued, though less prolifically, to publish volumes of verse, among which we can mention Once (1968), Revolutionary Petunians and Other Poems (1973), Good Night Willy Lee, I'll See You in the Morning (1984), and Horses Make a Landscape Look More Beautiful (1984). Her work is 
deeply rooted in the oral tradition.

\section{Black Feminism: Womanism}

Black Feminism essentially argues that sexism and racism are inextricable from one another. Forms of feminism that strive to overcome sexism and class oppression, but ignore or minimize race, can perpetuate racism and thereby contribute to the oppression of many people, including women. Black feminists argue that the liberation of Black women entails freedom for all people, since it would require the end of racism, sexism, and class oppression.

The current incarnation of Black Feminism is a political/social movement that grew out of a sense of feelings of discontent with both the Civil Rights Movement and the Feminist Movement of the 1970s. Not only did the Civil Rights Movement primarily focus only on the oppression of black men, but many black women faced severe sexism within Civil Rights groups such as the Student Nonviolent Coordinating Committee. Besides, The Feminist Movement focused on the problems faced by white women who advocated social changes such as woman's suffrage. This movement focused largely on oppressions based on sexism, but it ignored oppression based on racism and classism. Neither movement confronted the issues that concerned black women specifically. Because of their intersectional position, black women were being systematically disappeared by both movements. Thus, the need of the term womanism arose.

The word womanism was adapted from Pulitzer Prize winning author, Alice Walker. In her book In Search of Our Mothers' Gardens: Womanist Prose, Walker used the word to describe the perspective and experiences of African American women who descended from Africa.

In this same book, she defines a womanist as:

1. From womanish (Opp. of "girlish," i.e., frivolous, irresponsible, not serious) A black feminist or feminist of color. From the black folk expression of mothers to children, "you acting womanish," i.e., like a woman. Usually referring to outrageous, audacious, courageous or willful behavior. Wanting to know more and in greater depth than is considered "good" for one. Interested in grown-up doings. Acting grown-up. Being grown up. Interchangeable with another black folk expression: "you trying to be grown." Responsible. In charge. Serious.

2. Also: A woman who loves other women, sexually and / or nonsexually. Appreciates and prefers women's culture, women's emotional flexibility (values tears as natural counter balance of laughter), and women's strength. Sometimes loves individual men, sexually and / or nonsexually. Committed to survival and wholeness of entire people, male and female. Not a separatist, except periodically, for health. Traditionally Universalist, as in: "Mama, why are we brown, pink, and yellow, and our cousins are white, beige, and black?" Ans.: "Well, you know that colored race is just like a flower garden, with every color flower represented". Traditionally capable, as in: "Mama, I am walking to Canada and I am talking you and a bunch of other slaves with me." Reply: "It wouldn't be the first time"

3. Loves music. Loves dance. Loves the moon. Loves the spirit. Loves love and food and roundness. Loves struggle. Loves the Folk. Loves herself. Regardless

4. Womanist is to feminist as purple is to lavender. 
The roots of theological womanism grew out of the theology of James Hal Cone, Jacquelyn Grant, and Delores Williams. The latter suggested that womanists theologians need to "search for the voices, actions, opinions, experience, and faith" of black women in order to experience the God who "makes a way out of no way." In her book Sisters in the Wilderness (1995), she defines womanism in the following way:

Womanist theology is a prophetic voice concerned about the well-being of the entire
African American community, male and female, adults and children. Womanist theology
attempts to help black women see, affirm, and have confidence in the importance of their
experience and faith for determining the character of the Christian religion in the African
American community. Womanist theology challenges all oppressive forces impeding black
women's struggle for survival and for the development of a positive, productive quality of
life conducive to women's and the family's freedom and well-being. Womanist theology
opposes all oppression based on race, sex, class, sexual preference, physical ability, and
caste.

With the increasing use of the term in Master of Divinity, African American Studies, and Women's Studies, programs have clearly began to incorporate womanism into university and seminary courses. One example of an educational institution that incorperates womanism in their graduate coursework is Eden Theological Seminary in Saint Louis, Missouri.

Professionals such as historians are regarded as "womanist" historians if they have incorporated the views and experiences of African American women in their accounts of history.

\section{Discourse Analysis}

Providing a comprehensive definition for discourse is a difficult task since numerous authors and linguists have referred to it. One starting point was the definitions provided by the Encarta Dictionary 2007 and the Webster's Dictionary ( $7^{\text {th }}$ new collegiate edition: 238). We found that those definitions were mostly terminological; meanwhile, there were others referring to the social aspect of discourse. For instance, Toril Moi ${ }^{1}$ provided a different definition of discourse in her book Sexual and Textual Politics. Feminist Literary Theory; in which she describes discourse as:

"[...]the social activity of making meanings with language and other symbolic systems in some particular kind of situation or setting." (1985:6)

In this book, the author also refers to the importance the participants have in this activity regarding the role they may play, whether they may speak or write, or only listen or read, and whether they are considered actually present in or only potentially relevant to the situation.

In addition, other linguists have highlighted the importance of the participants in this process of production of discourse. For example, Hatim and Mason refer to discourse as "modes of speaking and writing which involve participants in adopting a particular attitude towards areas of socio-cultural activity" (2013: 240).

1 Toril Moi is Professor of Literature and Romance Studies at Duke University. She works on feminist theory and women's writing; on the intersections of literature, philosophy and aesthetics; on finding ways of reading literature with philosophy and philosophy with literature without reducing the one to the other. 
After having analyzed all the concepts previously presented, we have reached at the following conclusion:

\section{Discourse is the production of meanings in the process of communication. It is condi- tioned by the ideologies, the personal experiences and the communicative intentions of the participants in a given socio-cultural context.}

We consider that it is important to point out that discourse is not only oral, there is also written discourse (as there are oral texts). In fact, discourse and text are two different concepts, although undoubtfully linked. Referring to this aspect, R. Fowler expresses in his book "Linguistic Criticism" that:

To look at language as text entails the study of whole units of communication seen as coherent syntactic and semantic structures which can be spoken or written down. Discourse is the whole complicated process of linguistic interaction between people uttering and comprehending texts. (1996:111)

Consequently, it is necessary to take different criteria or methods into consideration when analyzing text or discourse.

Professor Patrick Charaudeau (1998) proposed three ways for analyzing discourse:

1. The study of discourse as a production mechanism inherent to texts resulting from the process of enunciation.

2. The study of discourse as an empirical object which allows us to determine the different types of discourse (politic, didactic, scientific, etc).

3. The study of discourse as social representation, as manifestation of ideological positions, power relations, etc.

The criterium we have selected to carry out our analysis is the one concerning the study of discourse as social representation, due to the fact that our work is going to be focused on the ideology of a specific social group, and how it is reflected through the discourse of one of its members: Alice Walker. Referring to the importance of discourse analysis, Ana Curbeira expresses that it "highlights the fact that the use of language and thinking are typically and functionally expressed in the social discursive interaction" (2003:167) (translated) ${ }^{2}$. On the other hand, Van Dijk considers discourse analysis is:

An autonomous discipline capable of providing the most efficient way to study the langua-
ge, analyze cognition, study the interaction and social structures not as different things, but
as different aspects of a single and more complex scientific venture: discourse's description
and explanation. (2003: 167)

For us, discourse analysis is of great importance because it is a way to analyze not only how the author expressed their ideas, but also what is between the lines, that is, the speaker/ author's intentionality.

2 All translations in the paper have been made by the authors. 
All this analysis is done through utterances which are communicative units made up of one or more speech acts (considered to be dynamic units of discourse) that as a whole convey a given meaning.

The production of a speech act is conditioned by different factors:

- The person that emits discourse and the receiver, who have a common cultural background.

- The psychological and illocutionary positions of both participants.

- The production conditions of the discursive activity.

- The reality that serves as element of communication.

There are two types of speech acts: direct and indirect.

Direct speech acts are those in which the communicative intention is explicitly stated. On the contrary, in indirect speech acts the communicative intention of the person that produces discourse is implicit.

There are different authors who have proposed diverse criteria of classification of speech acts. For example, Austin (1962) and Searle (1969) introduced different taxonomies to classify speech acts such as: the locutionary, illocutionary and perlocutionary speech acts, which are directed to the analysis of the intention of what is being said and the effect it has upon the receptor.

In later studies, the illocutionary speech acts (which express the intentionality in discourse) have received most detailed attention, and there have been many attempts towards creating an effective and comprehensive typology. Austin suggests a model of analysis where the illocutionary acts are distinguished according to the illocutionary force (which lies in the intention of the person that produces discourse and the interpretation of the receiver) associated with each class. These speech acts are denominated: verdictives, exercitives, commissives, behaviotives, and expositives. Following Austin`s studies, Searle basically uses the same model of analysis and improves it in a more reasonable and methodic way. He named the speech acts as follows:

- Assertive: the function of these speech acts is the one of representing a state of present, past, future or hypothetical events.(Austin`s expositive, and verdictive)

- Directive: they are used to have the receiver do what the agent is saying. (Austin's exercitive)

- Commissive: they commit the receivers to do something. (Austin`s commissive)

- Expressive: they only express the psychological state of the agent. (Austin`s behaviotive)

- Declarations: they are used to put into practice the agent's authority. (Austin`s exercitive).

Furthermore, Austin also reached crucial conclusions when approaching the study of speech acts. They were related to some necessary conditions for the optimum realization of speech acts, which he named felicity conditions, later modified by some other authors as appropriateness conditions, stating that the term used by Austin was more connected to 
philosophic studies. These conditions were analyzed in detailed by Searle (1969:123-124) who divided them into three major groups:

- Preparatory conditions: in which the person that produces the speech act must have the authority to do it. Besides, it must be the appropriate situation to do so. These are typical conditions of evaluative speech acts in which the valuating subject must have a social status that confirms them as a person capable of evaluating.

- Sincerity conditions: in which the person that produces the illocutionary speech act should do it by his own will. If it is not so, the person could be lying. These conditions are manifested in the modal dimension through the modal attributes of the valuating subject, which are present in the theory of the valuative speech acts. These conditions are tightly bound to the modal semantic category of loyalty.

- Essential conditions: in which the person that produces the speech act is conditioned by some beliefs or intentions. In this case, the conditions are also manifested in the modal dimension of the category of valuation through the attributive aspect. Here, the valuating subject assumes a certain position, which is referred to as an appraisal in the illocutionary dimension.

We are going to analyze the modality of speech acts within the most significant utterances to reveal their intentionality, therefore revealing the ideological dimension in a given poem.

Carrying out discourse analysis in poetry is complex because utterances and speech acts are shorter and more concise in a poem; therefore, a lot is said in few words. For this reason, we think it is better and reasonable to analyze what is implicit in the utterances of the poems. For this task, we need to bear in mind three important concepts: Proposition, Presupposition, and Implication (Lyons, 1977).

Proposition:

"Every statement that can be made by uttering a simple sentence expressed a proposition, which, if it is informative, provides the answer to either an explicit or an implicit question" (Lyons, 1977:503)

Presupposition:

What can be logically deduced from what is being said (proposition).

"Eg: In asking What happened? We presuppose minimally that some event or process occurred." (Lyons, 1977: 504)

Implication:

Implication is the message that can be understood although it is not explicitly stated. According to Lyons, "The notion of implicature rests upon a distintion between what is actually said and what is implied in saying what is said" (Lyons, 1977: 592)

\subsection{Ideology, Society and Discourse}

It has been proved that a person's ideology can be perceived through their discourse. According to Van Dijk's approach on ideology and discourse, the study of the ideological 
components of discourse is an attempt towards establishing some kind of relation between discourse and society. He states that:

Ideologies are not merely sets of beliefs, but socially shared beliefs of groups. These beliefs are acquired, used and changed in social situations, and on the basis of social interest of groups and social relations between groups in complex social structures. (1998)

In this concept Van Dijk highlights the fact that ideologies exist within society, expressed by those social groups with shared goals and interests, which are the basis of their actions and thinking, and what make them react, behave and face reality in a particular manner.

Although discourse is conditioned, first by socio-political ideologies, and then by ideological groups, it is important to point out that neither institutions nor organizations emit discourse, but the people who conform them. This way, their discourse will depend on their own way of seeing reality, but always keeping the "essential or core ideological propositions [...] those that are the specific, defying or prototypical fundamental beliefs of a group" (Van Dijk, 1998). In addition, people may be part of different ideological groups during their lives and thus, they may share different ideologies, which, of course, are going to be conveyed, shared, and legitimated through their discourse.

At this point, an important question arises: Can only one group member's discourse represent the ideology of the whole group? In this regard, Van Dijk (1998) expressed that: "A group has an ideology if most of its members share most of the propositions that define such ideology."

Therefore, we assume that despite the fact that an individual may have personal opinions, different from some other members of the group, they still have the basics or the essence of their beliefs as a commonality.

In our intention to demonstrate how the ideology of African-American women as a group is reflected through Alice Walker's poetry, we follow Curbeira's idea that "Ideologies are the bases of the different types of valuation human beings carry out through discourse."(2003) (translated)

However, we have to take into consideration the words of Curbeira when she states that even though ideologies are expressed through discourse, "it does not mean that we can "read" ideologies in discourse". It is deduced from her words that it is important to carry out a semantic analysis to better understand the underlying meaning of an utterance. That is the reason why we are going to use discourse analysis as a tool to achieve our purpose.

\subsection{Valuation in Discourse}

Leandro Caballero in his unpublished monograph "Semiótica y Diccionario" (Semiotics and Dictionary) deals with the caraterization of valuative speech acts. In his theory, modal values have to be precised in research intended to establish the semantic dimensions of subjectivity.

When studying modality, Caballero (2002) states that in order to establish the senses of discourse and the components of the system of language, which can be assumed as modal for its clear basis on the psychological attitudes of the producers of signs and messages, it is necessary to state that the nature of modality is semantic. That is to say, that modality is in 
the meaning of those signs and messages in contrast to others valid modalities in the logical and grammatical dimensions. In like manner, he explained that there is a broad group of modal phenomena. However, we have to deal just with those that are rooted in the semantic content of language as reflection of the subjective position of speakers in language.

Caballero (2002) proposed a conception of meaning in which it is considered as an entity where there are modal, interactive and referential contents inextricably linked that are carried out thanks to grammatical constructive values or resources.

Taking this as starting point, Galbán Pozo (2006) develops four meaning dimensions: modal, illocutionary, referential and grammatical, defining each of the four as follows.

- Modal dimension reflects the noetic features that have to do with the psychological position assumed before what is said in discourse. They materialize in language, which serves as material and semantic support to convey subjectivity in the socialized communicative activity.

- Illocutionary dimension reflects the features transmitting the intentional interactive contents of speech acts.

- Referential dimension frames up the referent features considered by the agents of dictum, that are characterized by a set of features, namely, constitutive, relational, dominion based and taxonomist.

- Constructive-Grammatical dimension explains the morphologic and syntactic rules intervening in the formularization of statements taking the semantic features as a starting point.

In our paper we are going to focus on the modal and the illocutionary dimensions for they are the most useful to our work since this paper is aimed at characterizing the discourse of the valuating subjects in the poems selected according to the intentionality and the modality of discourse. The modal semantic macrocategories we are going to work with are those proposed by the Group of Semantic, Ideographic and Discourse Studies of FLEX: Valuation, Loyalty, Certainty, Expressiveness, Affectivity and Interest.

\section{Valuation:}

It is a modal semantic macrocategory expressing the subjective position of the speaker before what is said on the basis of social standards in which the pragmatic value of objects and phenomena is taken into account. These two final elements classify in a range of axiological values. It can be perceived that the valuation is characterized by the presence of an illocutionary agent that intends to carry out different sorts of valuations that take place in different kinds of valuating speech acts (Galbán, 2006).

The modal semantic macrocategory of valuation is the basic modal category (Galbán 2006) because valuation involves certain grammatical semantic and social values. Valuation reflects the intention of the speaker in saying a particular thing towards the object in question in the process of valuation. That is, any time valuations are carried out; they are going to be conditioned by the perception of the world as well as the social and cultural values of the speaker. 
In terms of the illocutionary dimension, Galbán (2006) speaks about a valuating illocutionary agent (that we are going to identify with the valuating subject, this being the voice of the poem, which in literary terms would be referred to as the poetic persona). The valuating subject is defined as the producer of discourse expressing a communicative intention in which their subjective position with respect to the object under consideration is revealed so as to acknowledge on it a value of a range or socialized standard.

Considering that there are three types of valuating speech acts, Galbán (2006) has defined three types of valuating subjects:

- Evaluator: A discourse producer that, taking as a basis a status people recognize in them, expresses a communicative intention. Here, they expose their subjective position with respect to an object under consideration to emit a valuation in which the value of a range of standard or parametric values (previously established, socialized and linguistically structured) is attributed on it. This way the emitted valuation has a conclusive, transcendent and closed character since this valuation may have certain consequences for the valuated object.

- Appreciator: A discourse producer that does not take into account aspects related to social status. Taking a socialized defused standard as basis, the appreciator expresses a communicative intention in which their subjective position towards the object in question is revealed. The object is intentionally under consideration in order to emit an open and socially inoffensive valuation. So, the attribution or acknowledgement does not have transcendental consequences for the object.

- Hierarchizer: A discourse producer that expresses a communicative intention in which their subjective position towards the object in question is revealed. The object is intentionally under consideration in order to emit a valuation that is carried out establishing a hierarchic order of the object regarding another object or group of objects. These are taken as point of reference to carry out a valuation that will be distinguished by its relative character.

In terms of the axiological aspect, Galbán (2006) recognizes four values: good (favorable), bad (unfavorable), ambivalent (both good and bad), and ambiguous (neither good nor bad).

Loyalty is defined as a modal semantic macrocategory expressing the subjective position of the speaker before what is said in three perspectives depending on the aspect focused. These are: the discursive perspective (referring to the correspondence feeling-discourse), the ethical-intentional perspective (referring to the ethical-intentional aspect), and the cognitiveintellectual perspective (addressing the cognitive-intellectual aspect).

The discursive perspective focuses on the psychological position of the speaker in correspondence to their discourse. This perspective shows two contraries: sincerity vs. insincerity. These two notions are going to be exposed by speakers who express their subjective position towards them, by means of discourse. Under this perspective the valuating subject is going to be either sincere or insincere. We are not going to find contradictories, in part, due to the fact that there are no middle terms in being sincere or insincere.

The ethical-intentional perspective refers to the ethical valuation of the intention expressed by the speaker in their discourse. This perspective states two contraries: good intention vs. bad intention and two contradictories: non-bad intention vs. non-good intention. The 
first pair shows a semiotic balance in which the notion of intentional ambivalence appears. In the case of the second pair, a balance can also be produced; this is shown in the notion of intentional ambiguity.

The cognitive-intellectual perspective reflects the means used by the speaker (valuating subject) in his interaction with other speakers so as to achieve certain purposes. This perspective shows two contraries: astuteness vs. naiveness.

Regarding the illocutionary dimension, there are no specific valuating subjects for this category.

Certainty is defined as a modal semantic category expressing the subjective position of the speaker before what is said on the basis of sureness as a pragmatic value. In the cognitive-discursive perspective, that is translated into sure, clear and evident knowledge of things. On the other hand, in the volitive perspective, that is reflected in the firmness or determination as pragmatic values. The volitive aspect of the subject actions are based on those values.

Under the cognitive-discursive perspective there are two contraries: sureness vs. unsureness and two contradictories: non-sureness vs. non-unsureness. The first pair is going to be expressed in modal attributes of a range of degrees going from a high level of sureness (sure) to the lowest level unsureness (unsure). There is a middle term in between which is ambiguous security. This is going to be determined by a series of hints available for the speaker that make them think of the possibility that something has a certain state although it has not yet been corroborated.

Under the volitive perspective there are two contraries: decision vs. indecision. They reflect the character of individual attitudes (definite vs. indefinite) towards a certain stance to assume. There are no contradictories in this perspective.

With regards to the illocutionary dimension, Galbán (2006) only speaks of valuating subject in the case of inquiring (speech) acts in which, by means of inquiry, the speaker tries to change from an unsureness state to sureness.

The macrocategory of Expressiveness is defined as that expressing the subjective position of the speaker before what is said about objects and phenomena of the reality. This position reveals the emotional state of the speaker in two perspectives: mode of expression and expressed emotional tone.

The mode of expression perspective states two contraries: containment vs. gush and the contradictories: non-gush vs. non-containment. They show the link between the mode of emotion expressions and the socio-cultural models of valuation. Consequently, it is necessary to pay attention to the socio-cultural models established by the different social groups for they play an important role when exteriorizing discourse.

In addition to the notions including this perspective there is a semic balance between non-gush and non-containment which is denominated calm. Here we talk about speakers showing no emotional tension, a neutral position instead. This is a state in which expressiveness is not revealed at all.

Under the expressed emotional tone perspective, Galbán (2006) proposes two contraries: satisfaction vs. dissatisfaction. These replace the ones of laughing and crying established by Caballero (2002) for they are more inclusive as far as position assumed by the speaker on the basis of feelings, emotions, and moods, is concerned. As reflect of the semic balance between contraries, a sentimental ambivalence in which there is a mix of joy and grief. 
This perspective includes two contradictories: non-dissatisfaction vs. non-satisfaction. This time a balance is also produced: indifference. It reflects the combination between the two contradictories in terms of experienced feelings.

With regards to the illocutionary dimension, there is no specific valuating subject or illocutionary agent for this modal semantic macrocategory.

Affectivity is defined as a modal semantic macrocategory expressing the subjective position of the speaker towards what is said on the basis of the affective feelings that objects and phenomena of reality evoke in them.

Here Galbán (2006) includes in a gradual structure three levels of intensity (maximum tension, middle tension and minimum tension) containing three pairs of contraries. They will reflect different levels of tension of affective feelings expressed by speakers: from the most intense tension or level of intensity, love vs. hate, passing by affection vs. disaffection, to the less intense way of tension, pleasure vs. displeasure. In like manner, we are going to find three pairs of contradictories respectively: non-hate vs. nonlove, non-affection vs. non-disaffection, and non-pleasure vs. non-displeasure.

There is no specific valuating subject for this macrocategory. However, illocutionary agents producing different types of speech display some of the modal attributes related to the category of affectivity.

Galbán (2006) defines interest as the expression of the subjective position of the speaker before what is said. This position reveals how reality objects and phenomena cause concentration of attention, expression of mood towards the object or not. All this may constitute an incentive to carry out a conscious act. This macrocategory shows two perspectives: the volitive-actional perspective and the attention perspective.

In the case of the volitive perspective, it is manifested in the degree of volition, whether an action is carried out at will or not. In this perspective, a contrary relation between the two notions of interest and obligation is produced. This combination results in commitment. On the other hand, the relation of contradiction between the notions of non-obligation and non-interest results in the exclusion of interest.

There is also a relation established among contraries and contradictories. On the positive side, when there is interest and non-obligation, the outcome is desire. On the negative side, when there is obligation and non-interest, the outcome is compulsion. Under these relations set out by contraries and contradictories, the interest gradation of human beings is revealed.

The attention perspective refers to the degree of attention towards what is said. In this perspective there is a pair of contraries, interest vs. lack of interest and a pair of contradictories, non-lack of interest vs. non-interest. The relation between the contradictories leads to the notion of indifference.

Regarding the illocutionary dimension, there are not specific illocutionary values assigned to this macrocategory.

\section{Analysis of the Poems}

\subsection{Poem: SONG}

As we all know African - American women have been discriminated against not only for being females, but also for their skin color. Racism is a curse that has affected many 
people in general and black people in particular throughout history. They have been treated as savages, as working animals, as objects whose only purpose in life was serving the white people and making them happy.

There have been plenty of ways of discrimination: hard work, segregation and even the discourse used to address black people. First, they were referred to as negroes and afterwards colored which had a very negative connotation. Then, after the achievements of the Civil Rights Movement, the public opinion started to call the black population People of color. Obviously, this term far from being neutral is rather excluding because it does not include people from other nationalities or other races who evidently have a certain skin color.

This is precisely the main topic of the poem "Song" in which the author uses a sarcastic tone to address this polemic issue.

The author uses this poem to express her concern, and maybe her anger concerning the terms used to denominate black people; that is the reason why she begins the poem with the next utterance that is composed of two speech acts:

\section{Utterance $\mathrm{I}^{3}$}

1. The world is full of colored people

2. People of color

This utterance is a positive valuation, and according to the illocutionary dimension, it is a categorical, physical, and ideological appraisal. We all know that people of color and colored people are excluding terms, only used to refer to blacks, in this poem the valuating subject uses them in an including way instead. That is to say that when she states: the world is full of colored people people of color; she includes people from other races, which is something positive. In this utterance, one of the main aspects of the womanist ideology is present: antiracism.

This time, the valuating subject is sure because she could have used expressions like $a$ lot of, plenty of, a great deal of etc.; however, she uses the categorical adjective full to indicate that every single person on earth has a particular skin color. In addition, another modal attribute accompanying the appraisal inherent to the valuating subject is interest, as to the subjective position of the speaker towards what is being said in the attention perspective. Here, the valuating subject manifests her interest in calling the readers' attention to the issue being raised in the poem by using two terms with a different sense. Likewise, the valuating subject is sincere and expressive, a macrocategory inherent to poetic discourse due to great deal of literary resources used.

In order to support her idea, the valuating subject bases the next utterances on physical traits that characterize people from all races, stating no valuation. We must clear up that we will analyze only the utterances and speech acts we consider relevant to achieve the objective of the work.

Utterance II

1. They have black hair and black and brown eyes.

3 Roman numerals for utterances and cardinal numbers for speech acts. 
Utterance III

1. Their skins are pink and yellow and brown

Utterance IV

1. Some have full lips

2. Some have thin

What she wants to highlight with these three utterances is that we can find different skin colors and physical traits that belong to all races around the world.

Finally, the author uses the phrase Colorful people (utterance V) which is actually the most important utterance of the poem. Even though this phrase may seem to be another variant of the previously analyzed expressions, there is a positive approach in it, because the author wants to convey the idea that all skin colors are equally beautiful and important, and that we should not find in color a way to discriminate others against. Color is what provides the world with variety and people, far from being embarrassed, should be proud of their skin color and should have others feel the same.

That is why we consider this is a positive valuation and the appraisal is physical and ideological. Furthermore, the valuating subject is sure, categorical, expressive, sincere, and well-intended, since with the expression colorful people, she is trying to erase discourse discrimination when addressing black people.

\subsection{Poem: Torture}

Throughout the history of human kind there have been people who have devoted their lives to causing harm to others, whereas there have been others who have always worked hard for the sake of a better society. Destruction, pain, and suffering have been the main goals of a minority who believe themselves to be superior, and thus, discriminate against and sometimes exterminate a big sector of society whose only sin has been the fact of being poor, black, woman or child. Fortunately, there has always been a response: endurance. That is precisely the main topic of this poem since the author is encouraging the oppressed to resist and never give up trying as far as their rights are concerned.

The poem is divided into six utterances and thirteen speech acts, one of which is repeated five times through the poems.

Utterance I.

1. When they torture your mother

2. Plant a tree.

Utterance II.

1. When they torture your father

2. Plant a tree.

Utterance III

1. When they torture your brother and your sister

2. Plant a tree 


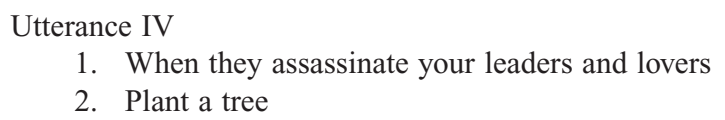

Utterance $\mathrm{V}$

1. When they torture you too bad to talk

2. Plant a tree

Utterance VI

1. When they begin to torture the trees

2. and cut down the forest they have made

3. start another

The six utterances of the poem are divided into two different kinds of speech acts. The first ones are assertive, and the valuating subject is addressing an adverse reality in which negative actions are raised. Thus, these valuations are generally negative, categorical and physical appraisals.

In the first five utterances, the valuating subject introduces words like mother, father, brother, sister, leaders, and lovers, in an attempt to point out relevant symbols in people's life; leaving the final spot to the personal approach. If we address the poem as a whole without splitting the analysis, we can evidence the use of these elements in a multiple consecutive hierarchical fashion, narrowing the field of action until there is nothing else left to torture.

Meanwhile, the second speech act in utterances I to V, and the third one in utterance VI are directive ones, calling the target reader to react positively in response to the aggression stated in the previous speech acts. The valuating subject uses the phrase plant a tree as a symbol, meaning carrying out good and pacific actions. Trees, as part of nature, are associated with strength, long life and hope. In addition, the final speech act of the poem: Start another, reinforces the idea of endurance, thus introducing the aspect of the womanist ideology present in the poem.

These speech acts are positive and ideological appraisals being modalized by the presence of modal macrocategories as in the case of certainty, for the valuating subject is sure of the issues she is stating in a categorical and factual way. Likewise, she is optimist and determined to never give up no matter how difficult the situation may be, well-intended and interested in having readers resist.

Furthermore, the macrocategory of expressiveness is a central element to be taken into consideration when approaching poetry, since the word choice is really detailed and most of the times combined with the implicit messages the author wants to convey, bringing a great deal of subjectivity into the discourse and allowing the readers to come up with their own interpretations. In the case of the first speech act in utterance number $\mathrm{V}$, the valuating subject uses the word too which besides having negative semes like: in excess; to such a degree as to be regrettable, also entails a certain degree of gushing.

\subsection{Poem: A woman is not a potted plant}

Sexism is another issue African - American women have faced throughout history. Black women have been doubly discriminated against, for being women and for being black. This 
issue has made black women's struggle harsher. Men have always treated women as the weak sex; moreover, black women have been tacitly confined to "ladies' work", and they have usually played that role restrained and fearful of fighting for their rights.

That is precisely what Alice Walker conveys through the poem's valuating subject.

\section{Utterance I}

1. a woman is not a potted plant

In spite of the fact that it is a negative, assertive speech act, this is a positive valuation where the valuating subject refuses to acknowledge a negative characteristic attributed to women. This is a moral and ideological appraisal since the valuating subject is implying that women are not only pretty faces that may be used to decorate places, unable to speak and come up with reasonable arguments; instead, they also have values, wishes, opinions and concerns.

Concerning the valuating subject, we could say that she is appraiser, sure, interested, expressive, and well-intended. Sure because she states the utterance as a fact, interested because she explicitly wants others to realize what women actually are by showing what they are not, repeating the utterance three times along the poem. Finally, there is expressiveness since the valuating subject could have used expressions like decorative object or ornament, but instead she uses potted plant to make the identification more vivid and also to activate semes like being ordinary and dependent on others' care.

In the following utterances, the speaker establishes a comparison based on the similarities potted plants and women may have:

\section{Utterance II}

1. her roots bound to the confines of her house

In this utterance, the speaker uses the word bound, which implies tied, fastened, fixed, and joined, giving the message that women are supposed to be attached to their houses as plants to their pots.

Utterance IV

1. her leaves trimmed to the contours of her sex

In this case, the speaker uses the verb to trim to imply that women are kept from performing multiple activities due to their female condition. However, at the same time, society obliges them to carry out other functions like raising their children and taking care of their house as if other members of the family did not have the same amount of responsibility.

Utterance VI

1. her branches espaliered against the fences of her race her country her mother her men

In this utterance, the speaker is trying to convey the idea that black women's world is composed and ruled by everything that implies being black, living in such a country like the United States, and always bearing in mind the submissive, male-centered education they received from their mothers. 


\section{Utterance VII}

1. her trained blossom turning this way \& that to follow the sun of whoever feeds and waters her

This time, the speaker is trying to imply that submissive women, like plants, try to be always attached to those who support them, as if they were incapable of standing up for themselves.

These four utterances are made of assertive, negative speech acts since the valuating subject is giving different characteristics potted plants and women may have in common in order to highlight the negative aspects that others (usually men) use to minimize women's values. In addition, the appraisal is moral, and ideological. Moral, because they refer to the negative moral values certain sectors of society embrace. Ideological, for it portrays the male-chauvinist ideology still vivid in the minds of a great deal of the society.

The valuating subject is appraiser, sure, expressive, interested, and well-intended. Sure, because the valuating subject is very aware of what she is saying. Expressiveness is evidenced in the metaphors used to refer to women and their situation. Besides, the valuating subject shows interest in having readers reflect on the fact she is introducing. Finally, the valuating subject is well-intended for she is criticizing the state of affairs and drawing people's attention towards the fact.

Hence, the last utterance is of a great importance since it specifies the valuating subject's position concerning the main topic of the poem.

Utterance VIII

1. a woman is wilderness unbounded

2. holding the future between each breath

3. walking the earth only because she is free and not creepervine or tree. Nor even honeysuckle or bee.

Here, the valuating subject finally introduces her moral and ideological position towards the issue. Anti-sexism is evidently one of the banners held by the Womanist Movement along the years. This final utterance clearly states the idea of women being able to think by themselves, to make decisions, to walk the earth with their own feet. Besides, they are the sources of life; that is why they deserve respect, affection and wings to fly.

These final speech acts are assertive, positive appraisals. They are moral, categorical and ideological. The valuating subject is also appraiser, sure, well - intended, interested, and gushing marked by the use of the adjective unbounded (having or appearing to have no limits).

\section{Conclusions}

In this Paper, we have tried to identify the presence of the womanist ideology in Alice Walker's poems by analyzing the discourse of the valuating subject. This research has been a big challenge since there was no antecedent with this approach, combining the ideological discourse analysis to the modal semantic macrocategories using poetry as the object of study. Contrary to what some people might believe, analyzing poetry is not an easy task, let alone when you have to identify the implicit information in discourse to describe the valuating subject. 
After having analyzed three poems of the book Her blue body Everything we know, we were able to describe the different positions assumed by the valuating subjects, which we assume were African Americans for the correlation established between the author, the message, the content of the poems and the audience being targeted. The ideological aspects of the Womanist Movement identified in the three poems by Alice Walker are: antiracism, endurance, and antisexism; which are some of the foundations of this movement.

The analysis yielded that concerning the illocutionary dimension no evaluations were identified. Most of the valuations were appraisals, and there was only one multiple-consecutive hierarchization. Additionally, the valuations were generally positive and the appraisals were mostly moral, physical and ideological. Concerning the modal dimension, the valuating subjects were mostly appraiser, expressive, interested, sure and well-intended. Concerning the semantic category of interest, we arrived at the conclusion that in Alice Walker's poems the valuating subject is most of the times interested for there is a marked intention to have readers reflect on the ideological message she is conveying. We know that it is very difficult to find interest in poetry. However, if we follow the principle of analyzing the implicit ideological message being conveyed in the poems, based on the presuppositions and implications of the utterances, it is not difficult to identify the underlying interest of the valuating subject in drawing the readers' attention towards the message of the poem. That is why we consider that the semantic category of interest should be taken into account when analyzing poems that convey ideological messages.

\section{Bibliography}

Austin, J.L. (1962): How to Do Things with Words. Oxford, Clarendon Press.

Caballero Díaz, Leandro (2002): Modalidades Semánticas del Lenguaje. (Monografía inédita) Facultad de Lenguas Extranjeras, Universidad de la Habana.

Chafe, William H. (1977): Women and Equality. Oxford, Oxford University Press

Charaudeau, Patrick. (1998): “Las grandes problemáticas del análisis de discurso”. México, Revista: Estudios de Lingüistica Aplicada, Núm. 27.

Curbeira Cancela, Ana (2003): Lecturas de Semántica. La Habana, Félix Varela.

Curbeira Cancela, Ana (2007): Introducción a la Teoría del Lenguaje. La Habana, Félix Varela.

Eliot, Samuel y Stele, Henry (1951): Historia de Estados Unidos de Norteamérica. México, Fondo de Cultura Económico Panuco.

Fernández Gayol, Manuel (1945): Teoría Literaria. La Habana, El siglo XX.

Fowler, Roger (1996): Linguistic Criticism. USA, Oxford University Press.

Frazier, Thomas R. (1971): Afro-American History: Primary Sources, Harcourt Brace Jovanovich. Galbán Pozo, Ana María (2007): Categorías Semánticas Valorativas. (Tesis doctoral inédita)

Facultad de Lenguas Extranjeras, Universidad de la Habana.

Hatim, Basil and Mason, Ian (2013): Discourse and the Translator. New York, Routledge. Ivanov, R. (1979): La Historia de Estados Unidos y el Problema Negro. La Habana, Ciencias Sociales.

Lions, John (1977): Semantics 2. Cambridge, Cambridge University Press.

Meyer, Michael (1993): The Bedford Introduction to Literature II. Third edition. Bedford, Saint Martins. 
Moi, Toril (1985): Sexual and Textual Politics. Feminist Literary Theory. London \& New York, Loulettge.

O’Relly, Richard (1984): El Pueblo Negro de Estados Unidos: Raíces Históricas de su Lucha Actual. La Habana, Ciencias Sociales.

Parrilo, Vincent N. (1990): Strangers to these shores. New York: McMillan.

Rowbothom, Sheila (1972): Women, Resistance and Revolution. New York, Random House, Inc.

Schneir, Miriam (1994): Feminism: The essential Historical writings. New York, Vintage Books.

Searle, J. (1969): Speech Acts. Cambridge, C.U.P.

Van Dijk, T. (1998): A Multidisciplinary Approach. Great Britain, The Cromwell Press

Walker, Alice (1974): In Search of our Mothers' Gardens: Womanist Prose. Florida, HBJ.

Walker, Alice (1993): Her Blue Body Everything We Know: Earthling poems. USA, Harcourt Brace and Company.

Webster's Dictionary Seventh New Collegiate Edition (2003). La Habana, Felix Varela.

Zinn, Howard (2004): La otra cara de los Estados Unidos. La Habana, Ciencias Sociales.

\section{Internet Sites:}

Alice Walker Poetry: American Poets Analysis: http://www.enotes.com/topics/alice-walker/ critical-essays/analysis-3 (04-11-2006)

But Some of Us Are Brave: A History of Black Feminism in the United States. http://www. mit.edu/ thistle/v9/9.01/6blackf.html (05-01-2006)

Civil Rights Movement. http://www.history.com/topics/black-history/civil-rights-movement (01-11-2006)

Thomas E. Linda: Womanist Theology, Epistemology, and a New Anthropological Paradigm. http://www.crosscurrents.org/thomas.htm (04-12-2006)

Women's History in America. http://www.wic.org/misc/history.htm (01-11-2006) 


\section{Song}

The world is full of colored

People

People of color

Tra - la -la

The world is full of

Colored people

Tra - la - la -la - la

They have black hair

And black and brown

Eyes

The world is full of

Colored people

Tra - la - la

The world is full of colored

People

People of color

Tra - la - la

The world is full of colored

People

Tra - la - la - la - la

Their skins are pink and yellow and brown

all colored people

people of color

colored people

tra - la-la

Some have full lips

Some have thin

Full of colored people

People of color

Colored lips

Tra - la - la

The world is full of

Colored people

People of color

Colorful people

Tra - la - la!

\section{Torture}

When they torture your mother

Plant a tree

When they torture your father

Plant a tree

When they torture your brother

And your sister

Plant a tree

When they assassinate

your leaders

and lovers

plant tree

when they torture you

too bad

to talk

plant a tree

when they begin to torture

the trees

and cut down the forest

they have made

start another
A women is not a potted plant

her roots bound

to the confines

of her house

a women is not

a potted plant

her leaves trimmed

to the contours

of her sex

a woman is not

a potted plant

her branches

espaliered

against the fences

of her race

her country

her mother

her men

her trained blossom

turning

this way

\& that

to follow

the sun

of whoever feeds

and waters

her

a woman

is wilderness

unbounded

holding the future

between each breath

walking the earth

only because

she is free

and not creepervine

or tree.

Nor even honeysuckle

or bee. 


\title{
EL DISCO ESTÁ BESADO POR JUSTIN, LA NOVELA YA ESTÁ LEÍDA: A PROPÓSITO DE LAS CONSTRUCCIONES RESULTATIVAS CON ESTAR
}

\author{
Ma Antonia Martínez Linares \\ Universidad de Alicante \\ Grupo EPA \\ antonia.martinez@ua.es
}

Recibido: 16/06/2015

Aceptado: 02/09/2015

\begin{abstract}
Resumen
Este trabajo tiene por objeto indagar sobre dos aspectos de las construcciones resultativas formadas por un participio y el verbo estar: por un lado, la vinculación de estas construcciones con el concepto de 'estado resultante'; por otro lado, la existencia de construcciones resultativas de sentido atributivo que incorporan complementos referidos al agente y/o no están formadas por verbos que incluyan en su estructura léxica un estado resultante. El examen muestra que "estado resultante" se usa al menos con dos sentidos que se relacionan asimismo con dos tipos de construcciones resultativas: unas de sentido atributivo o cualitativo, más comúnmente reconocido, otras con un sentido "de fase" más temporal, asociado a la interpretación del "aspecto perfecto". Muestra igualmente que las complementaciones agentivas contribuyen a formar el sentido cualitativo propio de las construcciones atributivas y que ninguna de estas dos clases de construcciones se restringe a verbos que incluyan en su estructura léxica un "estado resultante" ni su formación puede explicarse tomando como base las clases léxico-aspectuales de predicados o rasgos exclusivamente gramaticales sin tomar en consideración aspectos contextuales y pragmáticos.

PALABRAS CLAVE: Estado resultante, construcción resultativa, aspecto perfecto, complementaciones agentivas, adverbio de fase.
\end{abstract}

\begin{abstract}
This study focuses on two aspects of estar+past participle resultative constructions. On the one hand, the paper analyses the concept of 'resultant state' and its relevance to the analysis of these constructions. On the other hand, this work examines estartpast participle constructions that have an attributive meaning but are not built with a change of state verb and/or include an agentive $b y$-phrase. The study shows that there are at least two senses in which the term "resultant state" is used and that those senses are also related to two types of resultative constructions: one of them has an attributive or qualitative meaning, the other one has a more temporal "phasal" sense, related to the meaning of "perfect aspect". The study also reveals that none of these two types of constructions is restricted to verbs that lexicalize a "resultant state" and cannot be explained by using exclusively grammatical features or aspectual classes; it is also necessary to take contextual and pragmatic factors into account.
\end{abstract}

KEY WORDS: Resultant state, estar+Pparticiple resultative construction, perfect aspect, agentive complements, phasal adverb.

\section{Introducción}

Tanto la posibilidad de que un verbo admita una construcción de participio con estar como las peculiaridades semánticas y sintácticas de estas construcciones se han venido explicando, fundamentalmente, tomando como base las propiedades léxico-aspectuales de los verbos. 
La anomalía de *Mi hijo está amado, por ejemplo, se ha justificado por el carácter estativo, imperfectivo, no acotado de amar (Marín, 2004: 26; De Miguel, 2001; Fernández et al., 2002: 392). En cambio, la buena formación de La ciudad está destruida o La puerta está abierta se debería a que destruir y abrir son verbos que denotan un cambio e incluyen en su estructura léxica un estado resultado. Asimismo, se han vinculado a distinciones de índole aspectual las diferencias entre construcciones como La ciudad está destruida, que rechazaría un complemento agente con por (*por los romanos), y El garaje está vigilado por un guarda, que sí admitiría una complementación agentiva y que, frente a la anterior, estaría formada por un verbo "imperfectivo" (Gómez Torrego, 1988: 188), "atélico" (Jurado, 2000: 186), de "actividad" (Yllera, 1999: 3430), un verbo que, en definitiva, ni exige "conceptualmente un principio y un fin" (Bosque, 1999: 292) ni codifica un cambio.

No obstante, también se ha señalado que aún quedan muchas cuestiones por resolver en torno a estas construcciones; que no todo parece explicarse de forma satisfactoria partiendo de propiedades aspectuales, a menudo, por lo demás, difícilmente acotables. Y, en efecto, conforme se va profundizando en el análisis de las construcciones de participio con el verbo estar, no solo parece necesario matizar las clases que se distinguen en este grupo y las características que se les atribuyen, sino también considerar entre los condicionantes de la formación de determinadas construcciones factores que no son estrictamente de índole léxico-aspectual.

Este trabajo tiene por objeto indagar algo más en las propiedades y los condicionamientos de algunas de estas construcciones; en particular de las que, para diferenciarlas de las "inversiones de locación" - como La ciudad está rodeada por montañas- y de las "pasivas no resultativas" (Jurado, 2000) ${ }^{1}$-como El garaje está vigilado (por un guarda)-, suelen catalogarse como "(estativas) resultativas" (Fernández et al., 2002: 391), "pasivas de resultado o resultante" (Mendikoetxea, 1999: 1623; Jurado, 2000), "resultativas no pasivas" o "resultativas puntuales" (Conti, 2004), "pasivas de carácter perfectivo-estativo" (Gómez Torrego, 1988: 188) o "pasivas adjetivas"2; en definitiva, las del tipo La ciudad está destruida, que vienen a coincidir con las construcciones a las que Kratzer (2000) o Maienborn (2009) entre otros atribuyen una lectura "target state" y a las que en adelante me referiré simplemente como "resultativas". Con ese fin, se recordarán en primer lugar las características semánticas y los condicionamientos que, de forma más general, se les han venido asociando para, posteriormente, analizar dos aspectos que se han ido revelando como especialmente problemáticos ${ }^{3}$ en el análisis de estas construcciones: por un lado su vinculación con el concepto de 'estado resultante' y los sentidos que explícita o implícitamente se asocian al término; por otro lado, la existencia de construcciones resultativas que incluyen complementos relacionados con el "agente" y/o se forman con verbos que no incorporan en su estructura léxica un estado resultante. El análisis permitirá, en primer lugar, mostrar los varios sentidos que

1 También llamadas "pasivas imperfectivas" (Gómez Torrego, 1988: 188) o "pasivas de estado" (Conti, 2004: 27). Se consideran formadas con verbos de "actividad", con una estructura eventiva simple, que no incorpora un cambio de estado o un estado resultado; por lo que respecta al significado, se les atribuye la denotación de un presente extendido (alguien vigila el garaje, Dios gobierna el mundo), de una acción que se presenta como coexistente con el estado descrito por el participio (Bosque, 1999: 292) y requiere la actuación continua del agente para seguir manteniendo el estado.

2 Poniéndolas así en relación, al menos en parte, con las pasivas adjetivas del inglés o del alemán.

3 Omito las discusiones en torno a la pasividad de estas construcciones, cuyo carácter problemático queda ya patente en las denominaciones que se utilizan para identificarlas. 
subyacen a "estado resultante" y los diferentes tipos de construcción, vinculados con esos sentidos, que se han mezclado a menudo como si formaran una sola clase: las construcciones que configuran una interpretación atributiva y las que tienen un sentido de "fase". En segundo lugar, pondrá de manifiesto la relevancia que adquieren en la viabilidad de las construcciones resultativas de sentido atributivo tanto las complementaciones referidas al agente -compárese, por ejemplo, ¿?El edificio está construido y El edificio está construido por Мoneo- como, en general, factores que no son estrictamente aspectuales.

\section{Sobre las construcciones resultativas}

Las construcciones resultativas del tipo Las puertas están cerradas, La ciudad está destruida, se han descrito, al igual que sus equivalentes en otras lenguas ${ }^{4}$, como construcciones "estativas", de "caracterización", en cuanto que denotan una propiedad o estado 5 del sujeto resultante del evento designado por el verbo; así, las oraciones antes mencionadas expresarían que el sujeto se encuentra en el estado descrito por el participio como consecuencia de haberse realizado previamente la acción de destruir o cerrar; estarían pues, de conformidad con la Academia, "en correspondencia con" (RAE, 2009: 2215) La ciudad ha sido destruida, Las puertas han sido cerradas, pero, mientras estos tiempos compuestos de la pasiva con ser focalizarían la acción que da lugar al estado, en la construcción resultativa la actividad previa estaría totalmente "ausente en la interpretación" (Fernández et al., 2002: 391), habría sido "desfocalizada por completo" (Conti, 2004: 38), de manera que, "according to the traditional view" (Gehrke y Sánchez, 2014: 188), también el "argumento externo", el "actor", vinculado a esa actividad anterior, "is truly missing" (Kratzer, 2000: 391), estaría "completely absent" (Gehrke, 2012: 187); por tanto, esta construcción resultativa de carácter atributivo no admitiría, o al menos "resistiría", "tendería a rechazar" (Mendikoetxea, 1999: 1624; Bosque, 1999: 292), la expresión de un complemento agentivo con por, que se asocia a la acción, o la incorporación de complementos de finalidad o adverbios de manera que impliquen la existencia de un agente vinculado a la acción anterior: * La ciudad está destruida por los romanos, *La casa está construida por los albañiles/por los hermanos/por obreros mexicanos, *La cena ya está preparada por un cocinero profesional se han considerado anómalas por incluir complementos agentivos (Mendikoetxea, 1999: 1624; Conti, 2004: 28; Hengelved, 1986: 411; Bruhn de Garavito y Valenzuela, 2008: 329), igual que *El cuadro está pintado por Leonardo para agradar al marido de Mona Lisa por dar cabida a un complemento de finalidad (De Miguel, 2001), o *Emilio estaba atado violentamente al árbol (Conti, 2004: 38) por expresar un complemento de "manera" relacionado con la existencia de un "Actor". En definitiva, estas construcciones de participio con estar se han caracterizado como las oraciones copulativas con adjetivos perfectivos, de las que también se ha dicho que

\footnotetext{
4 Como las pasivas estativas o resultativas en alemán, que, a diferencia de las pasivas eventivas, no se combinan con el auxiliar werden sino con sein (Bosque, 2014: 42; Gehrke, 2012: 185; Maienborn, 2009: 38; Kratzer, 2000: 385).

5 No entro en la especificación de los conceptos de 'estado', 'cualidad', 'propiedad', que a veces se utilizan como si fueran equivalentes. Como indica Bosque (1990: 185), "es razonable afirmar que los adjetivos perfectivos representan estados alcanzados por las entidades de las que se predican, pero es discutible que representen cualidades suyas", esto es "características o rasgos definitorios". Sin embargo, para Conti (2004: 39) en Este cuadro está pintado por Velázquez el predicado expresa una propiedad inherente del sujeto paciente.
} 
expresan "el estado subsecuente al término de las acciones que las producen" (Fernández Leborans, 1999: 2430), pero sin pensar necesariamente en los procesos que lo llevan a cabo (Bosque, 1990: 186). De hecho, para Vázquez et al. (2000: 136) o Fernández et al. (2002: 392), por ejemplo, están contentos, están limpias, serían construcciones resultativas, alternativas a están limpiadas, están contentados $^{6}$; Conti (2004: 39) cataloga La casa ya está limpia como "resultativa puntual" que "focaliza la fase de estado asociada al Paciente", al igual que Emilio estaba atado al árbol; para Jiménez Peña y Rodriguez Sellés (2002: 227) El sofá está sucio sería una variante resultativa de Josep ha ensuciado el sofá, del mismo modo que La puerta está abierta o Las coles de Bruselas están congeladas lo serían de Josep ha abierto la puerta/ha congelado las coles de Bruselas; en opinión de Mendikoetxea (1999: 1624), La ciudad está destruida tendría un significado equivalente al de "construcciones copulativas <estar+adjetivo perfectivo>" como estar limpio, estar seco. Para De Miguel (2001), por último, tanto en el caso del enunciado La puerta está abierta como en el de Este cuadro está pintado en la pared fpor Leonardo "ci troviamo di fronte ad una struttura attributiva che esprime un risultato".

En lo que atañe a los condicionamientos, el rasgo más reiterado como requisito para la formación de estas construcciones ha sido, sin duda, que el verbo base del participio incluya como parte de su contenido léxico la denotación de un "estado resultante" o "estado resultado". La Real Academia (2009: 2215-6) subraya a este respecto que la construcción "estar+participio" se forma con verbos que "denotan estado resultante de una acción o de un proceso" - como Las puertas están cerradas-; por consiguiente, la admitirían, a su juicio, los verbos transitivos que expresan "creación, destrucción o modificación de algo". Mendikoetxea (1999: 1623) la relaciona con verbos bieventivos, como destruir, a los que se atribuye una estructura compuesta por un evento causativo de acción y un evento resultativo de estado; desde el punto de vista de Fernández et al. (2002: 392), los verbos que posibilitan estas construcciones han de contener en su significado un "límite que coincide con el estado resultado" consecuencia del proceso de cambio designado por el verbo. En opinión de Jurado (2000: 185) la construcción requiere verbos télicos (logros y realizaciones), que denotan eventos con un final inherente y dan lugar a un "estado resultante" del cambio que se produce cuando el evento ha llegado a su culminación; de ahí, a su juicio, la gramaticalidad de La cima está alcanzada, La lección está explicada o El patio (ya) está barrido7. En términos de Gehrke (2012: 189), por citar una opinión más, "accomplishment and achievement verbs, whose internal argument undergoes a change of state and as a result is the bearer of a consequent state, are good inputs" para las construcciones equivalentes en alemán; en definitiva, como resume Bruening (2012: 10), si describen estados de las entidades, parece lógico que "a general felicity condition on their use, then, is that the semantics of the base verb be compatible with a (result) state". Por el contrario, quedarían excluidos de esta construcción, por ejemplo, los verbos que expresan "actividades en el sentido de acciones no delimitadas" (RAE, 2009: 2216) como empujar, acariciar, besar ${ }^{8}$, que no dan

6 Indican al respecto que "aunque el estado resultado suele expresarse mediante un participio, en algunos casos se requiere un adverbio o bien un adjetivo": Las habitaciones están limpias (*limpiadas) (2002: 392).

7 En este caso, comenta, la telicidad vendría dada por el patio, aunque barrer sea un verbo de actividad (Jurado, 2000: 188).

8 Besar para unos sería "semelfactivo", para otros de "actividad" o un tipo particular de verbo de "actividad" (RAE, 2009: 1700). 
lugar a un estado resultante, que no aluden a "acciones que conllevan procesos o que se caractericen por desembocar en estadios episódicos" (Bosque, 1999: 288).

Pero si bien buena parte de los textos consultados destacan como requisito habilitador el concepto de 'estado resultante' y subrayan como propiedad de la construcción resultativa la "focalización" de ese estado en detrimento del proceso que lo ha originado, lo cierto es que también llaman la atención las discrepancias sobre el sentido y la gramaticalidad de determinados enunciados, discrepancias que parecen tener su base ya en la clase aspectual del verbo y su capacidad para denotar un estado resultante, ya en la presencia o ausencia de complementos vinculados a la acción, como los de naturaleza agentiva encabezados con por $^{9}$.

\section{Sobre la telicidad, el estado resultante y la lectura resultativa}

Por lo que concierne a las diferencias de opinión relacionadas con la estructura léxicoaspectual del verbo, se ha de subrayar que, junto a construcciones resultativas prototípicas, indiscutidas, con verbos de cambio, como La ciudad está destruida, en los estudios sobre las construcciones de participio con estar se han presentado como ejemplares de este tipo otros enunciados que, cuando menos, parecen discutidos en lo que concierne a su contenido "de caracterización", atributivo, o a su "gramaticalidad" (o "aceptabilidad"); así La casa está construida ${ }^{10}$, con un verbo de creación, o El piso ya está comprado, El patio (ya) ${ }^{11}$ está barrido, La cima (ya) está alcanzada, La lección (ya) está explicada ${ }^{12}$, Las solicitudes están revisadas, con verbos que no lexicalizan un cambio, se catalogan en algunos estudios como construcciones resultativas (Jurado Salinas, 2000: 185; Gómez Torrego, 1988: 189; Conti, 2004: 38; Mendikoetxea, 1999: 1623) que atribuyen al sujeto un "estado"; otros, por el contrario, o no las interpretan como resultativas, como construcciones que predican del sujeto una característica resultante de un evento previo (Fernández et al., 2002: 392; Vázquez y Fernández, 2003: 160), o ni siquiera las consideran aceptables salvo que incluyan elementos como el adverbio modal bien o como el adverbio aspectual ya, llamativamente recurrente en los enunciados con que se ilustran las peculiaridades de las construcciones de participio con estar. Para Marín (2004: 28), por ejemplo, son "perfectamente gramaticales" El cuadro está bien pintado, La casa ya está construida, pero cataloga como "de dudosa aceptabilidad" El cuadro está pintado, La casa está construida; Jiménez Peña y Rodríguez Sellés (2002: 220) consideran "agramatical" Los platos están fregados, con un verbo que, al igual que barrer, suele catalogarse como de "actividad", pero añaden que sí resultaría aceptable con ya: Los platos ya están fregados. Desde el punto de vista de Vázquez y Fernández (2003: 160) y Fernández et al. (2002: 392), tampoco sería válida como construcción resultativa, “de

9 Sí se consideran válidos en cambio enunciados como El cuadro está pintado por Leonardo (De Miguel, 2001); El documento está firmado por Cervantes (Conti, 2004: 39) o El libro está publicado por la mejor editorial del pais (RAE, 2009: 289).

10 Para Conti (2004: 27) no resulta una construcción extraña; es una construcción aspectual de valor resultativo que no tiene sentido pasivo.

11 Incluyo ya entre paréntesis porque las mismas combinaciones aparecen con o sin ese adverbio, a menudo sin que se llame la atención sobre su incorporación al enunciado. Conti (2004: 27, 30), por ejemplo, ilustra las características de las construcciones de participio con estar utilizando enunciados como El piso ya está comprado *por mis hijos, El pastel ya está hecho.

12 Jurado las utiliza sin ya (La lección está explicada, La cima está alcanzada), pero también con ya: La cima ya está alcanzada. Parece considerar del mismo tipo El patio ya está barrido y El patio está barrido. 
caracterización", la formada con un verbo "atélico" "agentivo" como revisar: Estos aparatos están revisados, Las solicitudes están revisadas serían construcciones correctas y semejantes formalmente a las resultativas, pero no tendrían el sentido atributivo que se considera propio de las resultativas, y otro tanto afirman de La casa ya está vendida.

Hay pues discrepancias sobre la gramaticalidad de determinados enunciados originadas por los verbos que unos y otros consideran habilitados para formar una construcción resultativa, aun cuando, según se habrá podido apreciar en el anterior apartado, a todas las unidades verbales mencionadas se les haya asociado la denotación de un estado resultante; es lógico pensar que pueden ser muchas y de diversa índole las cuestiones imbricadas ${ }^{13}$ en estas discrepancias, pero considero relevante destacar que al menos parte de ellas parecen tener su origen en las interpretaciones de que es susceptible el término "estado resultante" y la imprecisión ${ }^{14}$ o la falta de definición de que adolece con frecuencia su empleo, pese al papel relevante que se le otorga en la explicación de estas -y no solo de estas- construcciones sintácticas.

\subsection{Sobre los sentidos de "estado resultante"}

"Estado resultante" (o "resultado") no es, en efecto, un término unívoco. De los estudios que se han venido citando se infiere la existencia de, cuando menos, dos sentidos que no suelen estar suficientemente diferenciados, si bien de cada uno de ellos se podrían derivar no solo condiciones distintas sobre la formación de las construcciones resultativas, sino también diferentes interpretaciones "resultativas".

El concepto de estado resultante que se desprende de los planteamientos más restricti$\operatorname{vos}^{15}$ sobre las construcciones resultativas y sus condicionamientos está relacionado ${ }^{16}$ con la noción de cambio de estado: alude a las propiedades adquiridas por una entidad como consecuencia del cambio significado por el predicado. En consecuencia, la construcción resultativa que focaliza ese tipo de estado resultante se considera propia de verbos como destruir, cortar, cerrar, que, además de denotar eventos temporalmente delimitados, implican un "argumento afectado", cambiado, y tienen, efectivamente, esa estructura léxico-aspectual bieventina integrada por un evento de cambio que afecta a los atributos de una entidad y un estado resultante de ese cambio. De conformidad con Marín (2004: 28), por ejemplo, la afectación, la modificación del objeto léxicamente especificada, resulta crucial en las construcciones de participio con estar; no solo exigirían un predicado delimitado temporalmente, sino, según sus términos, "un resultado o, cuando menos, un cambio de estado" asociado a un "argumento afectado". Igualmente para Jiménez Peña y Rodríguez Sellés (2002: 218) o para Fernández et al. (2002: 391), la viabilidad de la construcción se asocia exclusivamente a verbos como romper o cortar que denotan un cambio de propiedades que afecta a una entidad. De tal supuesto se seguiría que, por ejemplo, no se podría formar un enunciado

13 Entre ellas, las que refieren al aspecto "perfecto" y las mejoras con ya.

14 Bosque advertía hace un tiempo (1999: 288-289) que el concepto "resultado" se maneja en estas construcciones de participio "como si se tratase de una información evidente que proporciona automáticamente cada noción verbal" cuando en realidad el concepto "encierra una considerable complejidad". También Marín (2004: 18) 1lamaba la atención sobre la vaguedad que rodea al término; a su juicio resulta difícil saber exactamente qué significa.

15 Según Bosque (2014: 67) sería básicamente la interpretación de Levin y Rappaport.

16 Como ha señalado Bosque (2014: 41) a propósito de los significados de los participios. 
resultativo a partir de fregar los platos, puesto que no contiene un verbo de cambio, ni a partir de leer un libro ya que, si bien la acción que denota implica un final, ese final no tiene "como consecuencia un determinado resultado" (Bosque, 1990: 181). La condición de que el verbo denote un estado resultado de un cambio explicaría asimismo para algunos investigadores la anomalía de *Una canción está cantada ${ }^{17}$-"es difícil determinar si una canción ve alteradas sus propiedades al ser cantada" (Fernández et al., 2003: 11)- o de El río está cruzado: cruzar un río configura una situación acotada temporalmente, pero de ella no se deriva ningún resultado, no supone que el río se vea afectado "de la misma forma que una puerta al ser abierta o una barra al ser doblada" (Marín, 2004: 28).

Así pues, ni leer la novela, ni cantar la canción o cruzar el río implicarían un estado resultante en este sentido ni, en consecuencia, los predicados se considerarían, según este planteamiento más restrictivo, habilitados para formar construcciones resultativas que atribuyan al sujeto un estado.

No obstante, las referencias a los condicionamientos antes recogidas sugieren que para otros estudiosos no es la denotación del cambio, sino la telicidad del verbo o del predicado -es decir, el hecho de que aluda a un evento delimitado, con "culminación"- el rasgo que se destaca como condicionante de la construcción resultativa y de la configuración de un estado resultante. En opinión de Conti (2004: 24), por ejemplo, se halla limitada, al igual que la pasiva con ser, a lexemas verbales que denotan un cambio de estado o "un evento susceptible de ser interpretado télicamente". Para Jurado, según se reflejaba en algunas citas anteriormente incluidas, la viabilidad de La lección está explicada, La cima está alcanzada o El patio está barrido, que no están formadas por verbos de cambio, se basa en la telicidad de estos predicados: todos tienen un final "más allá del cual no pueden continuar y en el cual dan origen a algunos estados resultantes" (2000: 184), que son, a su juicio, los estados destacados mediante la construcción con estar. También la Academia (2009: 2214-5) hace extensiva la construcción "con participios que designan el estado resultante de una acción o proceso" a los verbos transitivos de "realización o consecución" que "poseen término", entre los que incluye, por ejemplo, ganar la carrera, alcanzar la cima o leer un diario (2009: 1692), que no expresan ni creación, ni destrucción ni modificación de algo; así, señala al respecto que el hecho de leer un libro "no afecta al libro", pero si alguien puede decir de una novela que "ya está leída", es "natural interpretar la novela como objeto afectado", pues lo que resulta relevante "es la existencia o la presencia de un límite como componente natural del proceso" (2009: 1700).

Esta relación entre las nociones de 'cambio', 'telicidad' ('culminación', 'delimitación') y 'estado resultante' no es, desde luego, inusual en los estudios sobre la semántica de las unidades verbales. Para Pustejovsky (1991: 51), por ejemplo, el estado resultante es una propiedad de los eventos télicos; todos, desde su punto de vista, son complejos, con dos subeventos, un proceso y una transición a "some sort of resultant state"; Tenny (1987: 75) enlaza culminación del evento con la afectación del objeto ${ }^{18}$ y el subsiguiente estado resultado, de ahí que, en su opinión, read the novel, climb the mountain, cross the dessert configurarían eventos con un argumento afectado y un estado resultante. En esa misma línea De Miguel (2001, 2004: 189) afirma que verbos o predicados como leer un libro, ver la

17 No obstante, el uso de "una" en lugar de "la" contribuye a la "anomalía" de la construcción

18 La afectación sería, desde su punto de vista, una propiedad aspectual dependiente de que "the direct argument of the verb" delimite el evento (Tenny, 1987: 75). 
película denotan eventos complejos que incorporan actividades o procesos que desembocan en un punto seguido de un "cambio de estado", igual que pintar un cuadro. En definitiva, desde esta perspectiva todos los eventos télicos "involve a TRANSITION from one event to a second, often from an atelic process to a result state" (Levin, 2009: 16). Por tanto, puesto que cruzar el río, leer la novela, cantar la canción denotan eventos télicos, con un argumento de trayectoria (Morimoto, 1998: 45; Marín, 2004: 28) cuya extensión delimita el evento y lo dota de una culminación natural (Bosque, 1990: 181), también darían lugar, desde esta perspectiva, a un estado resultante.

Queda pues patente que de leer la novela, cantar la canción o cruzar el río se ha podido justificar tanto que dan lugar a un estado resultante como todo lo contrario ${ }^{19}$; de alcanzar la cima, fregar los platos o barrer el patio se ha dicho que permiten ${ }^{20}$ la formación de construcciones resultativas que enfocan el estado originado por el predicado, pero también que la rechazan porque los verbos no incluyen un estado resultante en su significado; las construcciones que integran El piso está vendido/comprado, Las solicitudes están revisadas se han catalogado bien como resultativas que atribuyen al sujeto un estado, bien como construcciones que son semejantes en la forma a esas resultativas, pero que solo serían gramaticales con otra interpretación, precisamente porque en ellas "no se asocia ninguna propiedad al sujeto" que resulte del evento y "nos permita caracterizarlo" (Fernández et al., 2002: 391; Vázquez y Fernández, 2003: 13). Es lógico concluir, por tanto, que, aun cuando "estado resultante" se emplee frecuentemente como si fuera un término unívoco y no se considere necesario definir con qué sentido específico se está utilizando, la noción que le subyace no puede ser la misma en todos los casos.

No sería posible tratar ahora con profundidad cuestiones tan largamente discutidas en la investigación lingüística como la afectación, la telicidad, el cambio, que están implicadas en los sentidos de "estado resultante". Pero, de cara a clarificar las lecturas y los condicionamientos de las construcciones catalogadas como resultativas, estimo pertinente destacar en primer lugar que, como indican Levin y Rappaport (2005: 93), un evento télico, con culminación, no implica necesariamente un estado resultante en el sentido más restrictivo anteriormente comentado; según sus términos "an event can have a culmination without defining an obvious result state", un cambio en las propiedades de una entidad que pueda ser interpretado a partir del significado básico codificado por el verbo; por ejemplo, memorizar el discurso es un predicado télico, tiene "a natural culmination" (Levin y Rappaport, 2005: 93), pero, desde su punto de vista, "it is difficult to characterize accurately what the result state is". El evento de alcanzar la cima, por poner otro ejemplo, sería "verdad", siguiendo a Rappaport (2008: 20) "just in case we went from not being at the summit to being at the summit"; estaríamos hablando, por tanto, de un cambio en la ubicación del sujeto, de un

19 No son desde luego inusuales las diferencias de opinión respecto al contenido léxico-aspectual de los verbos y respecto a la denotación de un "resultado" en particular. Del verbo vigilar, frecuentemente citado en los trabajos sobre las construcciones de participio con estar, se ha dicho, por ejemplo, que es un verbo de actividad, que no forma predicados que den lugar a un estado resultante (véase Jurado, 2000: 187), pero también se ha dicho que incorpora un estado resultado de un evento de transición previo, que ha alcanzado su final y da lugar a un "estado nuevo" (De Miguel, 2001, 2004). Frente a ambos supuestos, Fábregas y Marín (2012: 13) afirman que las predicaciones del tipo alguien vigila el garaje no configuran ni una actividad ni una transición; antes bien, las consideran predicaciones estativas que denotan una relación entre dos entidades.

20 Por ejemplo, el concepto de estado resultado asociado a los verbos de cambio, puede predecir "that verbal PPrts denoting no result will be excluded" de las construcciones con estar (Bosque, 2014: 67). 
sujeto "being at the summit”, pero ¿cuáles son las propiedades de la cima que cambian al realizarse el evento? Si leer el periódico, a diferencia de escribir la novela, no indica, como afirma Bosque (1990: 181), un determinado resultado, no se entiende muy bien que sea natural interpretar que en La novela ya está leída el sujeto representa al objeto afectado, si ha de entenderse como tal una entidad que ha experimentado un cambio en sus propiedades como resultado de la lectura ${ }^{21}$; afirmar que el cambio sufrido por la novela "is that of "becoming read"" no puede entenderse como una justificación de que las propiedades de la novela se hayan visto alteradas; de conformidad con Rappaport (2008: 34), la misma afirmación se podría aplicar al objeto de cualquier verbo de actividad: “ if I tickle my daughter, we can say that my daughter has 'become tickled"" aunque tickle no se clasificaría "as a [+change] verb". En realidad, mediante justificaciones de este tipo el concepto acabaría siendo tan vago que, como indicaba Marín (2004: 18), casi “cualquier cosa" podría ser concebida "como resultado de un cambio".

En segundo lugar, de aceptar que también La novela ya está leida, La cima ya está alcanzada designan un "estado resultante" porque perfilan el "estado" que tiene lugar cuando las acciones que configuran leer la novela, alcanzar la cima finalizan -llegan a su término, a su culminación natural- habrá de admitirse asimismo que el término "estado resultante" no puede tener en estos casos el mismo sentido cualitativo, intensional, alusivo a propiedades, que se asocia a los enunciados formados por verbos de cambio ${ }^{22}$. Antes bien, el concepto que puede inferirse se habría de definir, al igual que el "resultant state" que Parsons (1990: 234) delimita como interpretación del "perfecto"23 (apud Kratzer, 2000: 386), en un eje meramente temporal, como "the state of the base eventuality having ocurred" (Nishiyama y Koening, 2010: 618); en términos de Parsons, se trataría simplemente de "the state of e's having culminated", que sigue indefectiblemente a "every event e that culminates" 24 (apud Kratzer, 2000: 386, 387); el "estado resultante" en este sentido no denotaría, pues, propiedades atribuibles a una entidad; solo vendría a designar la situación, el estado de cosas, que sigue a la conclusión del evento. Utilizando un ejemplo de Maienborn (2009: 37), si se considera que en The manuscript is submitted, let's turn to the project proposal now la "pasiva adjetiva" expresa un estado resultante, el término habría de entenderse, en ese sentido temporal -o temporal-aspectual ${ }^{25}$, no cualitativo, que se ha destacado: no incluiría al manuscrito en "the class of submitted papers, rather tan being, e.g., accepted or published of rejected"26 (Maienborn, 2009: 37); referiría simplemente a "the post state of a submitting

21 Según Rappaport (2008: 25), "read not entail a change in the denotee of its direct object, but rather in that of its subject. If you want to know if a road sign was read by someone, you don't check anything about the road sing, but you do check something about the reader". Señala asimismo que "verbs like read even on their telic reading, are not associated with a result state (...) verbs such as read and other information ingestion verbs, such as study and peruse, do not pass any of the test which have been offered to probe the existence of a state predicate" (2008: 33). Bosque (2014: 61), por su parte, afirma que "reading something is not 'causing it to be read' but being involved in a process of following something along a course".

22 De ahí quizá el recurso a expresiones del tipo "some sort of resultant state" (Pustejovsky, 1991: 51), "cierto estado resultante" (RAE, 2009: 1820), cuando se analizan estos casos.

23 Un sentido “conditioned by an implicit HAVE” según Bosque (2014: 68).

24 Con palabras de Nishiyama y Koening (2010: 617-618) el estado resultante se caracterizaría en este caso "by his following the base eventuality" a lo que añaden que "introducing such states unduly populates de space of states".

25 Véase Bosque, 2014.

26 Esa lectura cualitativa sería la que se desprendería de The manuscript is submitted, but not accepted/published.... (Maienborn, 2009: 37). 
event" (ibid.), a la situación subsiguiente a la conclusión del evento en la que la tarea de enviar el artículo ya se ha llevado a cabo, en contraste con el espacio temporal previo en el que la acción no se había realizado ${ }^{27}$.

\section{A propósito de la interpretación de las construcciones resultativas: el sentido atri- butivo y el sentido de fase}

De lo tratado anteriormente se puede colegir que, si bien construcciones del tipo La novela ya está leida se han mezclado frecuentemente con las del tipo La novela está bien escrita o La ciudad está destruida, como si formaran una sola categoría "resultativa", tienen en realidad interpretaciones distintas, paralelas a los dos sentidos de "estado resultante" que se han diferenciado.

Considérese, por ejemplo, el sentido de ya está leída/o en los siguientes enunciados tomados de Internet ${ }^{28}$ :

1. Sus novelas anteriores me encantaron y tenía muchas ganas de leer esta por lo que en cuanto cayó en mis manos me puse con ella. Ya está leída y me ha encantado aunque disfruté más con las anteriores.

2. [El libro] me lo envía Punto de lectura. ¡Mil gracias! Ya está leído; lo terminé anoche.

No predican de la novela o de el libro una propiedad que hayan adquirido como resultado de la acción de leer y que los diferencie en un plano cualitativo de una novela o de un libro "no leídos"; no tienen, pues, la interpretación cualitativa, de caracterización, que sí tendría La novela está bien escrita. La lectura que configura la construcción se relaciona, por el contrario, con ese sentido más temporal, vinculado al "aspecto perfecto" que también se ha asociado a "estado resultante": perfilaría el estado de cosas que sigue de manera inmediata a la culminación del evento -la lectura de la novela o del libro-, a su terminación, en contraste con el estadio temporal previo en el que no se daba esa situación ${ }^{29}$.

Además, frente al carácter estativo que se considera propio de los enunciados resultativos, no parece que el evento ${ }^{30}$, la actividad previa denotada por el verbo, esté "totalmente ausente" en la interpretación de este tipo de enunciados, según puede deducirse del contraste entre, por ejemplo, El armario está vacio y El armario ya está vaciado.

27 Para Kratzer (2000: 395), por poner otro ejemplo, si el enunciado The building is evacuated fuera emitido por un policía que informa a su supervisor de que la acción de evacuar el edificio ya se ha llevado a cabo, tendría una interpretación temporal, no atributiva.

28 Los enunciados que se utilizan como ejemplos proceden de textos obtenidos a través de Internet. Al final se incluye un apéndice con las páginas de donde se han extraído.

29 Como de "evento finalizado" catalogan Vázquez y Fernández (2003: 160) las construcciones del tipo El piso ya está vendido porque no denotan una propiedad que haya adquirido el sujeto sino una "propiedad del evento", en concreto que este "ha finalizado" y "como resultado se enuncia la oración del ejemplo". Escandell y Leonetti (2002: 169) describen como "the end of the process reading", diferente de la meramente estativa la interpretación de las construcciones absolutas. Se ha de subrayar, sin embargo, que no es tanto la finalización en sí lo que focaliza la construcción como la situación, el estadio, inmediatamente posterior a la finalización.

30 Bosque (2014: 46) indica al respecto que llenado, secado, son participios eventivos, a diferencia de lleno, seco que serían "R-PPrts", es decir, participios resultativos. Véase también Alexiadou (2005: 18). 
Según se dijo anteriormente, está limpio, está seco, está vacio, que incluyen participios truncos o adjetivos perfectivos, se han considerado construcciones resultativas -alternativas a las que podrían formarse con los correspondientes participios regulares- porque, al igual que las formadas con participios como está cerrado, está destruido, atribuyen un estado interpretable "como resultado de una acción o proceso" (Bosque, 1990: 178); no obstante también se ha señalado que, cuando existe el participio regular junto al participio trunco, no vehiculan el mismo tipo de significado ${ }^{31}$. Con el participio trunco el estado denotado puede concebirse sin pensar necesariamente en los procesos ${ }^{32}$ que lo llevan a cabo porque la naturaleza eventiva del verbo "habría desaparecido para dejar solo el significado correspondiente al estado final” (Bosque, 1999: 279). Así, como indica Bosque (1990: 186), de una habitación puede decirse que "está vacía" sin que previamente se haya vaciado. Con el participio regular está vaciada, en cambio, "es preciso tener en cuenta el proceso" por el que se obtiene el estado resultado ${ }^{33}$ (Bosque, 1999; 285; RAE 2009: 2093); por consiguiente, las construcciones de participio con estar que se incluyen más abajo no son equivalentes a las construcciones atributivas, “de caracterización”, La pista está seca, El buzón está vacío, El sendero está limpio ${ }^{34}$, puesto que en su interpretación sí estarían presentes las acciones a las que aluden los participios, sí obligan a interpretar que alguien ha llevado a cabo esas acciones de secar, limpiar, vaciar, que ya han terminado:

3. La pista ya está secada [...] en 15 min. empieza esto.

4. El sendero esta limpiado recientemente, porque yo lo recordaba muy dejado y difícil de seguir.

5. No me había dado cuenta de que tenía el buzón 1leno, pero ya está vaciado.

Habida cuenta de la eventividad y de la denotación del estado de cosas inmediatamente posterior a la finalización, se podría catalogar esta clase de construcción como una "perífrasis de fase", es decir, como una de las perífrasis que focalizan una de las "etapas ordenadas cronológicamente de un evento" 35 , una característica que, según recoge la gramática de la Academia $^{36}$ (2009: 2215), algunos investigadores atribuyen a las construcciones de participio con estar, pero de dudosa aplicación a las "otras" construcciones resultativas, a las "de caracterización".

Ese sentido "de fase" relacionado con el aspecto perfecto explicaría las "mejoras" que, según los estudios que se han ido citando, experimentan determinadas predicaciones si incluyen $y a$, así como la frecuente presencia de este adverbio en los enunciados con que se ilustra la combinación de los participios con estar. Al fin y al cabo, a diferencia de bien, ya es un adverbio "de fase", "aspectual”37, que según García Fernández (1999: 3155; 1995:

31 Véase asimismo Embick (2009: 12-13; 2004: 357, 361).

32 Aun cuando los procesos puedan entenderse como implicados.

33 Asimismo, según Hengelved (1986: 413), la diferencia entre "está entristecido" y "está triste” es que la primera presenta el estado como resultado de un proceso y la segunda no.

34 Considérese que La pista está seca, pero nadie la ha secado no implica contradicción, pero no se puede decir lo mismo de La pistada está secada, pero nadie la ha secado.

35 Así describe la gramática de la Academia "las fases de una situación” (RAE, 2008: 2331).

36 La Academia no se pronuncia claramente al respecto, pero parece sugerir alguna objeción a que se pueda hacer extensiva esa condición de "perífrasis fasal" a las construcciones de participio con estar.

37 En palabras de Bosque (1990: 194), ya es un adverbio aspectual que denota "el estado inmediatamente posterior al obtenido cuando se ha llegado al resultado del proceso significado por el predicado". 
366), discrimina la lectura del aspecto perfecto ${ }^{38}$ porque permite referir a un momento posterior a la realización del evento, un momento "en el que se considera el estado de cosas" que es su consecuencia o resultado.

Ahora bien, a la presencia del evento y a ese sentido "más temporal" de estas construcciones, habría que añadir otro rasgo al que también apunta el recurso a ya. Este adverbio de fase, aspectual, no solo incide en la situación posterior a la terminación del evento; se le atribuye, además, la confirmación de "expected situations" (Bosque, 2014: 69), o la "inducción de una expectativa" (RAE, 2009: 2336; Girón, 1991: 13): que la situación descrita por el predicado no se daba en una fase anterior, pero que se esperaba que se diera; por tanto, las "mejoras" de las construcciones con $y a$, su inclusión habitual en enunciados con este sentido de fase, temporal, vendrían a poner de relieve, de conformidad con Delbecque (2006), que hay algo más que esa incidencia en la fase posterior a la terminación ${ }^{39}$ : la implicación de que el evento denotado forma parte de un guion, de cierto tipo de programación más amplia, compuesta de fases que se conciben como tareas que han de ser superadas y cuya secuenciación puede venir dada "por el orden de las cosas, las costumbres, las convenciones culturalmente arraigadas" (Delbecque, 2006: 47).

En el siguiente enunciado, por ejemplo, la combinación de la construcción de participio con el adverbio ya lleva a interpretar que la consecución del primer objetivo se inserta en una serie de objetivos escalonados que han de cumplirse para la adecuada andadura del máster:

6. ¿Qué objetivos quieren alcanzar en este primer año del máster? V T: El primer objetivo ya está alcanzado: conseguir la acreditación nacional oficial del título y despertar el interés de los alumnos.

En este otro el logro de "ese peldaño" ha de entenderse asimismo como el cumplimiento de una de las fases que han de superarse en el marco de "la campaña":

7. Finalmente, señaló que él y sus pupilos irán paso a paso en la campaña y por lo pronto este peldaño ya está escalado.

En el fragmento que se incluye más abajo la construcción de participio con ya destaca la situación posterior al término de cada una de tres fases ordenadas que forman parte del proceso de ingestión:

8. [Ese postre] lo hice el año pasado así que ya está comido, digerido y metabolizado.

38 Según García Fernández (1995: 367), en A las tres Juan ya había escrito la carta la presencia de ya conlleva que el complemento temporal no incide en el evento sino en la situación posterior, como considera propio del aspecto perfecto, de ahí que, según sus términos, sea parafraseable por la "perífrasis resultativa pasiva" "estar+participio" que perfila el valor "perfecto": A las tres la carta ya estaba escrita (García Fernández, 1995: 367). Es también de destacar que casi todos los ejemplos con que García Fernández $(1999,1995)$ ilustra la noción de 'aspecto perfecto' incluyen $y a$.

39 Así, desde el punto de vista de Delbecque, Ya he comprado los ingredientes no solo indica que la acción de comprar los ingredientes ya ha finalizado, sino también que forma parte de un plan, como puede ser la ejecución de una receta; igualmente, en Ya han asentado la cerradura la inclusión de ya posibilita "la impresión de estar a la altura de los procedimientos habituales" (2006: 63), cosa que no ocurre en Han asentado la cerradura pese a su perfectividad. 
En el siguiente, por último, se hace patente que los participios combinados con estar no solo aluden a una fase subsiguiente a la finalización de las acciones designadas por los verbos; también llevan a interpretar que esas acciones formaban parte de un plan, de una serie de tareas escalonadas que el que emite el enunciado se había impuesto realizar:

9. Ya está examinado, valorado, criticado y sufrido hasta límites de insoportable minuciosidad.

En suma, la combinación del participio con estar configuraría en estos casos un sentido equiparable al que Maienborn (2009) y Gehrke (2012) por ejemplo, tomando como base a Kratzer (2000), identifican como lectura "post state"40 con el matiz "the job is done" para las construcciones equivalentes en alemán.

Queda fuera de los objetivos de este trabajo tratar de forma pormenorizada las peculiaridades de las construcciones del tipo La cima ya está alcanzada o La novela ya está leída. Pero puesto que sí se ha planteado la relación entre los varios sentidos que pueden subyacer al término "estado resultante", la mezcla de construcciones con sentidos distintos como si formaran una sola clase y las diferencias de opinión sobre la gramaticalidad o aceptabilidad de determinadas construcciones, debe subrayarse asimismo que esas dos "interpretaciones" que se han diferenciado no tienen que estar sometidas a los mismos condicionantes ni tienen por qué implicar los mismos procesos sintácticos ${ }^{41}$.

De entrada, parece claro que las construcciones con ese sentido temporal, de fase, no tienen por qué estar restringidas a verbos que incluyan un estado resultante en su estructura léxica. Así, La canción está cantada, El río está cruzado serán anómalas si se proyecta sobre ellas una interpretación cualitativa, atributiva o de caracterización; pero no lo serían como construcciones de "fase posterior", vinculadas a ese sentido de "estado resultante" no atributivo, más temporal, como ponen de manifiesto los siguientes enunciados tomados de Internet:

10. Ya está cruzado el enésimo puente, el último de la carrera; [ahora] giro a la izquierda y a tirar hacia el Paseo Echegaray.

11. Hay que entender que la canción ya está cantada, grabada y lo que sea.

Igualmente, de conformidad con Bosque (1999: 288) El libro está sacado de la estantería puede ser anómala con una lectura atributiva, de propiedad, porque el verbo sacar no alude a una actividad "cuyo resultado se pueda medir o evaluar", pero no parece que haya ninguna anomalía en este otro enunciado con el verbo sacar del que se deduce esa interpretación de fase subrayada por ya:

40 Se trata de la lectura que Kratzer (2000) identifica específicamente como "resultant state" para diferenciarla de la interpretación "target state".

41 Según Kratzer (2000: 395) estás construcciones en las que el participio tiene un sentido temporal "are more widely available tan target state participles". Los procesos sintácticos que intervienen en la formación de estas construcciones plantean también cuestiones controvertidas. Así, según señala Bosque, resulta especialmente problemático "what specific layers are involved" en las lecturas de los participios o de las construcciones resultativas, si están "related to aspect, voice, the event itself of its result". Para Kratzer (2000: 395), por ejemplo, el participio con esa lectura temporal eventiva "involves an aspectual operator". Desde el punto de vista de Maienborn (2009: 35) las dos lecturas se derivan "from a semantically underspecified representation that requires the pragmatic machinery to infer a suitable contextual instantiation". 
12. No me esperaba que fueran tan malas [...] de todas maneras, ya están sacadas de la bolsa, conque no las puedo cambiar.

Es más, en la medida en que el guion, el marco en el que se sitúan las fases, pone en juego "una base de conocimientos enciclopédicos o experiencias compartidas por el enunciador y el receptor" (Wilk- Racieska, 2012: 38) y viene dado por factores no estrictamente gramaticales, es de esperar que tampoco las condiciones para esta clase de construcciones se ciñan a cuestiones aspectuales o de índole gramatical. Las posibilidades de formación se abren incluso a los verbos de actividad (Kratzer, 2000: 388, Embick, 2004: 361) siempre que se den "certain contextual conditions" que permitan proyectar esa base programática que "defines the fulfillment of the activity as a contextually salient target that has to be achieved" (Gese, Stolterfoth y Maienborn, 2009: 136). Así, por ejemplo, los siguientes enunciados, que tienen esa interpretación "post state"+"job is done"42, están formados por verbos normalmente señalados, por su clase léxico-aspectual ${ }^{43}$, como inhabilitados para formar construcciones resultativas con estar:

13. El chucho ya está paseado y aseado y la menda es requerida por los bancos, a ver si hoy por fin me ponen la alfombra roja como a "la Pé".

14. - Mándales un beso y un abrazote grande de parte de la peña del pedal.

- Gracias José. Ya están besadas y abrazadas todas de tu parte.

Sin embargo, las construcciones de sentido atributivo, como El vaso está roto, La puerta está abierta o La ciudad está destruida ni requieren o implican ${ }^{44}$ ya ni precisan o suponen un "programa" en el que se inserte el evento significado por el verbo base como tarea que ha de ser realizada. Así cuando la gramática académica (2009: 2215) afirma que la construcción de participio con estar -sin más especificaciones- se ve favorecida si el hablante asocia los procesos "con tareas que han de ser superadas" como La casa (ya) ya está vendida y la deuda está pagada, parece estar refiriéndose a las construcciones con sentido de fase, pero habría que matizar que tal requisito no parece hacerse extensivo a "todas" las construcciones resultativas formadas con un participio y el verbo estar.

\section{La clase léxico aspectual y los complementos relacionados con la actividad en las construcciones resultativas de carácter atributivo}

La "anomalía" que se percibe en El río está cruzado, La canción está cantada o El libro está sacado de la estantería si se proyecta en ellas una lectura atributiva pone de manifiesto que ni la telicidad está necesariamente asociada a un estado resultante en el sentido más restrictivo ni garantiza por sí sola la viabilidad de una construcción resultativa con un sentido cualitativo.

42 Son enunciados semejantes a, por ejemplo, Anna has done her neighborly duties: the mailbox is emptied, the flowers are watered and the cat is petted, que Maienborn (2009: 36) utiliza para ilustrar la lectura "the job is done". 43 Anteriormente ya se hizo referencia a besar. En cuanto a pasear, expresa una acción no delimitada, una "actividad".

44 De conformidad con la Academia (2009: 1820-1821) hay construcciones con lectura perfectiva en las que se sobreentiende ya aunque no esté expresado. Bosque (2014: 70) afirma al respecto que "the adverb ya may be omitted if we know, from extralinguistic evidence, that a certain task is expected after others", a lo que añade: "this entailment, clearly triggered by the phasal adverb, is also associated to resultative perfects inside the (so-called) "extended now"'. 
Por el contrario, puesto que los verbos bieventivos, de cambio, como abrir, cerrar, sí incorporan un estado resultante en esa acepción más restrictiva, sí codifican un cambio en las propiedades del argumento afectado, parece claro que han de posibilitar una construcción resultativa en la que el participio asigna al sujeto una propiedad especificada por el verbo y que, por tanto, puede ser interpretada sin necesidad de otros elementos y sin requerir "esfuerzo pragmático" (Maienborn, 2009: 45).

Es evidente asimismo que enunciados como La casa está construida por los albañiles, Este cuadro está pintado por el niño (Conti, 2004: 40), El Quijote está escrito por Cervantes (Bosque, 1999: 293), que incluyen complementos agentivos con la preposición por $^{45}$, resultan en mayor o menor medida anómalos o extraños, según se ha subrayado para justificar el rechazo de las construcciones resultativas a las complementaciones referidas a la acción y no a su resultado.

Sin embargo, como han ido poniendo de manifiesto los estudios sobre este tipo de construcciones en español y en otras lenguas, no se puede concluir que las combinaciones de sentido atributivo estén limitadas a los verbos que lexicalizan un estado resultado ${ }^{46}$ ni que la inclusión de complementos relacionados con el "agente" convierta en anómalos este tipo de enunciados, sin que ello obste para que la combinación "estar+participio" sitúe en primer plano no el proceso, sino su resultado.

Por lo que respecta a la clase léxico-aspectual del verbo, los datos que proporcionan enunciados obtenidos de Internet ponen claramente de manifiesto que también con verbos que no son de cambio ni incorporan un estado resultado léxicamente especificado se forman construcciones con esa lectura "de caracterización", de contenido atributivo, consistente en adscribir al sujeto "a complex property which has to be derived from the verbal base of the participle" (Gese, 2011: 260).

Por ejemplo, más arriba se dijo que memorizar el discurso no lleva aparejado un estado resultante, pero es evidente que en el siguiente enunciado se atribuyen "al discurso", mediante la construcción de participio, ciertos rasgos que, tal como se infiere de las especificaciones contextuales, contrastan en una dimensión cualitativa con, por ejemplo, los que pueda tener un discurso espontáneo:

15. Cuando un discurso está memorizado, pierde calor y fuerza: y suena más a una recitación que a algo que sale desde dentro.

Es asimismo evidente, sin embargo, que esos rasgos que lo pueden oponer al discurso espontáneo no están codificados por memorizar ni pueden interpretarse solo a partir de su significado "retener en la memoria algo".

Diversos estudios han constatado que, en realidad, se puede obtener esta lectura atributiva con otras clases de verbos; que, aunque dar lugar a un estado resultante no forme parte de su significado básico, de alguna manera permiten configurar una propiedad atribuible al sujeto. Como señalan Bosque (1999: 288) o la Academia (RAE, 2009: 2216) no es

45 Igual que Der Brief ist ¿?? von Gabi / von einem Experten geschrieben (Gese, 2011: 260) o *Der Wein ist vom kellner eingeschecnkt=the wine is by-the waiter poured (Rapp, 2001: 396).

46 Como señala Bosque (2014: 67), la interpretación restrictiva de "estado resultado" que adopta Marín (2000; 2004), por ejemplo, llevaría a formular predicciones incorrectas sobre la agramaticalidad de combinaciones de estar con participios de verbos que no incorporan un estado resultante de un cambio. 
sencillo determinar cómo se obtiene esa interpretación con esos otros grupos semánticos de verbos, pero sí parece claro que no depende de la clase léxico-aspectual o del significado lexicalizado.

Por lo que atañe a la insuficiencia de la clase aspectual y de ese significado mínimo lexicalizado al que algunos han constreñido los aspectos relevantes para el análisis lingüístico, ha de subrayarse que uno de los factores que más comúnmente se ha destacado cuando se trata de explicar la posibilidad de formar construcciones resultativas con verbos que no conllevan un estado resultante es el "efecto" causado" en el objeto (RAE, 2009: 2216) -en particular, su "visibilidad" o "perceptibilidad" 47 , aunque ese efecto no esté codificado, no forme parte de su significado básico. Así, por ejemplo, según Hengelved (1986: 412), la anomalía de *La chica está besada se debería a que besada no denota un estado visible y ello limita su combinación con estar. Y, en efecto, participan de esta construcción verbos que, si bien no incluyen un cambio de estado en su significado básico, aluden a acciones que tienen efectos "perceptibles" 48 típicamente asociados. Por ejemplo, los verbos barrer y fregar son, según se dijo anteriormente, verbos de actividad ${ }^{49}$, que incorporan la manera de actuar el sujeto, no el resultado, pero sí pueden asociarse a efectos que se producen normalmente en el objeto afectado y que pueden inferirse de otros rasgos más específicos de su significado ${ }^{50}$ : arrastrar basura con una escoba para limpiar, limpiar una cosa con agua...

Así, los siguientes enunciados con el verbo fregar, que ni incorporan ni implican $y a^{51}$, son gramaticales y atribuyen al sujeto un estado convencionalmente asociado a la acción de fregar como pueden ser "estar mojado" (16) o "estar resbaladizo" (17), por el hecho de estar mojado:

16. No podía pisar en la cocina porque el suelo estaba fregado.

17. El pasado 29 de Febrero iba caminando por la planta baja de El Corte Inglés de la Calle Preciados (Madrid) y tuve una caída un tanto aparatosa por culpa de que el suelo estaba fregado y sin indicación.

Está barrida en este otro enunciado tiene el sentido de "está limpia" puesto que el hecho de que el objeto "barrido" quede limpio es un resultado deseable, y perceptible, de la acción de barrer:

18. De modo que regresa y encuentra que su antigua casa está barrida y en orden.

47 Jurado Salinas (2000: 185) afirma que "describen estados visualmente perceptibles"; Fernández Ramírez (1986: 414) hace hincapié en un "resultado que imprime en el objeto un sello o marca visible".

48 Según Levin y Rappaport (2005: 233), "when verbs with manner roots are found in a complex event structure, the type of result must be one that can be naturally obtained given the type of manner".

49 Siguiendo a Levin y Rappaport (véase, por ejemplo, Levin y Rappaport, 1991; Levin y Rappaport, 2013), barrer y fregar serían verbos de actividad que describen un proceso que puede llevarse a cabo indefinidamente y que no codifican alcanzar ningún resultado.

50 Cito a continuación las definiciones que da el DUE (Moliner, M., Diccionario de uso del español, Madrid, Gredos, 1971) de barrer y de fregar:

Barrer: Arrastrar con una escoba o utensilio que haga el mismo efecto basura, desperdicios, etc., para limpiar de ellos el suelo.

Fregar: Limpiar una cosa como los cacharros sucios de comida, el suelo, las puertas... restregándolos con un estropajo, una bayeta, etc., con agua y alguna sustancia adecuada.

51 Es decir, no tiene la interpretación de fase, temporal, alusiva a la realización de una tarea programada. 
Asimismo, mordisquear, por poner otro ejemplo, no es télico ni codifica un cambio en su objeto; es un verbo de actividad que refiere a una manera de actuar del sujeto. Y, sin embargo, no resultan anómalos los siguientes enunciados en los que se atribuye al sujeto un estado que puede entenderse como un efecto visible típico de la acción de mordisquear ${ }^{52}$ -que le falten pequeños trozos o tenga marcas visibles de dientes- aun cuando ese efecto no forme parte de su significado básico:

19. El $40 \%$ restante [de los cuerpos] está mordisqueado por depredadores y carroñeros como prueban las innumerables marcas de colmillos halladas sobre los huesos humanos.

20. Ésta fotografía pretende simbolizar un síntoma de ansiedad. Podemos intuir que el lápiz está mordisqueado por efectos del nerviosismo.

No obstante, como señala la Academia (RAE, 2009: 2216) los efectos pueden ser "inmateriales", no aparecen "gravitando sobre la sustancia como una marca recognoscible" (Fernández Ramírez, 1986: 414); de conformidad con Bosque (2014: 62), la interpretación de esos estados resultantes no codificados por el verbo "might involve more subtle notions" y frecuentemente implican un componente evaluativo, valorativo ${ }^{53}$, que, como se sugirió anteriormente, ni depende solo del verbo -aun tomando en consideración esos otros rasgos más "enciclopédicos"- ni queda constreñido por factores gramaticales.

Por un lado, según plantea Kratzer (2000: 394), es posible que ese componente valorativo no esté proporcionado por el verbo ${ }^{54}$ "but by other material within the VP, a manner adverb, for example". Así ocurre, por ejemplo, en el siguiente enunciado, en el que lo relevante no es el estado subsiguiente al evento de construir sino el componente valorativo aportado por el adverbio cuidadosamente y, de modo más indirecto, por a mano:

21. El sello independiente de joyas Nylon Sky nació del amor por la forma geométrica y los cortes a láser. Habiendo comenzado la etiqueta en Londres, está actualmente radicada en España, donde todo está cuidadosamente construido a mano en su estudio de Barcelona.

También las complementaciones con para pueden proporcionar los datos para inferir la calidad del objeto y configurar ese componente evaluativo, como muestra, por ejemplo, el enunciado que se incluye a continuación:

22. Nuestras bombas están construidas para operar en las condiciones más difíciles del yacimiento petrolífero.

Entre ese "material" que permite moldear el sentido cualitativo asociado a la evaluación es preciso incluir las complementaciones de carácter agentivo introducidas con por, mucho más habituales ${ }^{55}$ de lo que sugiere "the traditional view" sobre estas construcciones que

52 Mordisquear: Morder algo repetidamente y con poca fuerza (DUE).

53 Bosque (1999: 288) plantea que los resultados de la acción se han de poder medir o evaluar. Jurado (2000: 185) habla de un "marco de referencia individualizado" que implica la valoración de un hablante que percibe un estado de cosas y lo compara con un estándar.

54 A juicio de Kratzer (2000: 392), la gramaticalidad de The hair was still combed sloppily "shows that stativization operation that created the target state participle (...) must have affected a phrase, rather than a mere lexical item. Véase también Maienborn (2009: 40).

55 Según Rapp (2001: 396), “von-phrases which seem to refer to the verb's subject argument are often posible 
se mencionó al principio, sin que su presencia suponga en realidad la "instanciación” del evento denotado por el verbo en la interpretación del enunciado.

Así, por ejemplo, citar no sería, según Gehrke (2012: 188), un buen candidato para una construcción resultativa porque no da lugar a una estructura eventiva con un componente estativo. Sin embargo, El texto está citado por Chomsky no solo es una construcción estativa, de caracterización, aceptable, sino que nos dice algo sobre la calidad del texto que lo hace recomendable en la comunidad académica; le atribuye, por tanto, una cualidad que no depende del significado de citar; viene dada por el complemento que permitiría establecer una oposición cualitativa entre "estar citado por Chomsky" y, pongamos por caso, "estar solo citado por un recientemente graduado".

Bruhn de Garavito y Valenzuela (2008: 329) consideran que *La cena ya está preparada por un cocinero profesional resultaría anómala debido a la complementación agentiva, pero, en realidad, la anomalía no parece provenir del complemento "por un cocinero profesional" sino, en todo caso, de $y a$, que, como se dijo anteriormente, se vincula a otro tipo de lectura, más "temporal". De hecho, no se pueden considerar anómalos los siguientes enunciados, formados igualmente con el verbo preparar:

23. La comida está preparada por verdaderos expertos y se nota la calidad en los productos.

24. He estado yendo a este restaurante desde que abrió sus puertas, y me encanta la comida. Está preparada por chefs tailandeses y siempre sabe delicioso.

25. La comida está preparada por nuestro chef Andrew Kelso y su equipo, proporcionando un menú variado, mezcla de la cocina tradicional y la moderna, usando los mejores productos locales.

26. Si te gusta la comida árabe podéis ir los viernes a la noche al Colegio armenio MARIE MANOUKIAN (Armenia al 1300, Palermo), te atienden los alumnos de quinto año y la comida está preparada por las madres, lo que te garantiza su "caserismo".

Pero no focalizan la atribución al sujeto del estado configurado por preparada como opuesto a "no preparada"; atribuyen a la comida una propiedad con un componente evaluativo - la calidad, la excelencia, en 23-25, la condición, asimismo valorativa, con un componente afectivo "maternal", de "casera" en 26- que viene dado por las complementaciones "agentivas" -por verdaderos expertos, por chefs tailandeses, nuestro chef Andrew Kelso, por las madres- y no solo por preparar.

Algo similar se puede decir de los siguientes enunciados en los que las construcciones están formadas a partir del verbo cocinar; no establecen un contraste entre el "estado" resultante de cocinar y el previo que corresponde al evento no realizado ${ }^{56}$. La propiedad que atribuyen al sujeto tiene que ver no ya con el hecho de "estar cocinado" - es decir, no se oponen "platos sin cocinar" a "platos cocinados"-, sino con la "calidad" que se infiere del complemento introducido con por:

with the adjectival passive (...) The adjectival passive allows for von-phrases that are characteristic of the result state, but not for those that just describe de event proper"; véase asimismo Gehrke y Sánchez Marco (2014). 56 De conformidad con Gehrke (2012: 204) El pollo está cocinado puede tener dos lecturas, igual que The meat is cooked: una lectura "post" -El pollo (ya) está cocinado. Podemos comerlo- y una lectura "cualitativa" o "de caracterización”: El pollo está cocinado, no precocinado, por ejemplo. 
27. Si lo que tienen que ingerir no está cocinado por un chef desconocido, no tiene un nombre larguísimo y complicado y no presenta un aspecto psicodélico y nunca visto, ni se dignan a metérselo en la boca.

28. Carnes y pescados a la brasa, cocido madrileño, gachas o migas. Cualquiera de estos platos te va a parecer que está cocinado por un ser superior, ¡sólo te faltará pedirle un autógrafo!

29. Una tortilla de patatas no es una lata de caviar y sin embargo, si está cocinada por un maestro como Mundi, no solo se le puede igualar... es que la sobrepasa de largo.

30. Empezando por el trato, que es de lo más amable y cercano posible, hasta los platos, que se nota que están cocinados por alguien con muchos años en la cocina y siempre de forma casera.

Igualmente en los siguientes enunciados se atribuye a los "artículos" y al "material" una calidad que no está especificada en el significado léxico de "revisar" ni puede depender solo de su interpretación. Es nuevamente la complementación el elemento que permite establecer un contraste cualitativo con otros artículos o materiales no sujetos a ese tipo de revisión:

31. Cada serie de libros se ha elaborado por encargo especial, y cada artículo de las publicaciones está revisado por colegas profesionales para asegurar la presentación de investigaciones de alta calidad por su aplicación práctica y relevancia en el terreno.

32. Todo el material que se introduce en NiceTales está revisado por un equipo de educadores y especialistas en edición que leen y consideran los cuentos para establecer unos estándares de calidad lo más altos posibles.

Tampoco en estos otros se atribuye al sujeto una cualidad codificada únicamente por el participio; son nuevamente los complementos los que nos dicen algo sobre la "calidad" del sujeto:

33. El piso piloto está amueblado por Nusco Mobiliario.

34. Este apartamento de Madrid está decorado por uno de los diseñadores de interiores más importantes de nuestro país: Tomás Alía.

La relevancia de esas complementaciones referidas al agente queda claramente de manifiesto en las construcciones con verbos de creación, como construir, pintar, muy utilizados para ilustrar la "resistencia" de las construcciones resultativas a los complementos relacionados con la actividad, pero también muy discutidos por lo que atañe a la gramaticalidad de las construcciones que forman con estar.

Se dijo al principio que los verbos de creación se consideran habilitados, por su estructura léxica, para formar construcciones resultativas de sentido atributivo y se dijo asimismo que en algún estudio se citan como ejemplo de esta clase enunciados con verbos de creación del tipo La casa está construida. Pero no es menos cierto que estas combinaciones se han considerado anómalas -con ese sentido atributivo, no con interpretación de fase que implica $y a$ - debido a la escasa "informatividad" del estado resultante descrito por el verbo. De conformidad con Batiukova (2006: 232) o Marín (2004: 28-29), por ejemplo, Esta casa está construida, Este cuadro está pintado, Esta novela está escrita no serían aceptables porque la información que transmitiríamos sería simplemente que la casa, el cuadro, la novela existen (estado resultante) y que se crearon "in specific ways" (Goldberg y Ackerman, 2001: 803) -construyendo, pintando o escribiendo-, pero el artículo definido ya implica la existencia 
del objeto y la información de que han sido creados mediante un cierto tipo de proceso ${ }^{57}$ estaría asimismo contenida "a nivel subléxico" en casa, cuadro, novela; de ahí que resultaría "informativamente vacío" atribuirles simplemente como "estado" la llegada a la existencia mediante este tipo característico de proceso ${ }^{58}$; como indican Goldberg y Ackerman (2001: 803), "an utterance asserting that a house was built simply states what is already known to competent participants in a conversation"; sin embargo, La casa está bien construida, La novela está escrita con mucha sensibilidad sí atribuirían al sujeto, mediante los complementos, propiedades informativamente relevantes, al igual que sucede con el complemento "agentivo" en El cuadro está pintado por Velázquez. En los siguientes enunciados, la propiedad "cualitativa", la "evaluación" del sujeto, viene dada por las complementaciones "de manera":

35. Está redactada en bonito y todo.

36. Nuestras pólizas están redactadas de forma clara y transparente.

En estos otros la incorporación de complementos agentivos con por no solo no convierten en agramatical la construcción, sino que también son los elementos que confieren ese componente valorativo, evaluativo, que la hace "aceptable" y que, evidentemente, no se desprende solo del estado alusivo a la llegada a la existencia codificado por el verbo de creación:

37. Todas las guitarras a partir del $8 \mathrm{P}$ están construidas por un pequeño grupo de experimentados artesanos.

38. El cartel de la II Fira d'Art está diseñado por Josep Serra del estudio Ménsula.

39. La música está compuesta por el ganador del Premios de la Academia Hans Zimmer ("El Rey León").

En realidad, incluso los estudios que destacan la tendencia de estas construcciones a rechazar las complementaciones agentivas acaban admitiendo la existencia de combinaciones de este tipo perfectamente gramaticales. Bosque (1999: 293), por ejemplo, tras afirmar que los participios adjetivales de los verbos transitivos que denotan acción anterior al resultado observado tienden a rechazar el complemento agente cuando se construyen con estar, advertía de "cierta inestabilidad", "que requiere un estudio más pormenorizado", en el caso de los verbos de creación; a este respecto subrayaba el contraste entre Este cuadro está firmado por Salvador Dalí y el enunciado El Quijote ¿?está escrito por Cervantes, dudosamente aceptable. También Conti (2004: 39-40), una vez establecido que "las construcciones resultativas puntuales" "no admiten la aparición del SP-por referido al actor", señalaba la existencia de "casos esporádicos", como El cuadro está pintado por Velázquez, que requerían una explicación. Pero no parece que esa explicación pueda basarse exclusivamente en factores de índole gramatical.

57 Sería distinto si el método de creación fuera inusual (Goldberg y Ackerman, 2001: 804).

58 Como señala Gehrke (2012: 195), "it is somewhat odd to talk about a letter in a state of being written (8.23a) or a plank being sawn (8.24a), given these are the normal states for letters or planks to be in, i.e. letters are usually written and planks are usually sawn. Under the current account, we can explain the improvement of the examples because adding the modifiers here creates a subkind, such as written with red ink or cut in two pieces, and thus attributing such a property to letters and planks becomes informative again". 
Para dar razón de estos casos "esporádicos" se ha apelado a la relevancia cultural de la entidad $^{59}$ aludida por el sintagma introducido mediante por-como Velázquez o Chomsky- o a su alta "informatividad". Desde el punto de vista de Conti (2004: 40), por ejemplo, la relevancia de Velázquez según "nuestro conocimiento del mundo" -que no es, obviamente, un rasgo gramatical-, justificaría la buena formación de Este cuadro está pintado por Velázquez frente a El cuadro está pintado por el niño, cuyo complemento agentivo, además de no denotar una "entidad relevante", está formado por un sintagma definido de baja informatividad" Sin embargo, desde mi punto de vista también sería aceptable, y tendría un componente valorativo, No pienso quitar este cuadro. Está pintado por mi niño, pese a que la entidad denotada "mi niño" solo sea relevante para el que habla y esté también representada por un SN definido. Razones puramente informativas, y no gramaticales, podrían igualmente justificar la anomalía, señalada por Bosque, de El Quijote está escrito por Cervantes; por tratarse de un dato sobradamente conocido puede resultar redundante desde el punto de vista informativo; pero no hay anomalía en Este libro debe valer una millonada. Los expertos piensan que está escrito por Cervantes, un enunciado en el que la complementación no solo aporta información, sino que dota de ese componente valorativo que hace aceptable la construcción.

Se ha subrayado asimismo la pertinencia de la "visibilidad" del agente en el estado resultante, quizá uno de los factores más repetidos cuando se trata de justificar la presencia de ese tipo de complementaciones, en teoría descartadas de las construcciones resultativas con estar: el hecho de que "el agente sea reconocible en el estado", que sea "visible" de forma relevante, explicaría, a juicio de Hengelved (1986: 416), que tanto El escrito está firmado por el embajador como Este artículo está escrito por una persona indocta sean construcciones aceptables. Gehrke (2012: 190) destaca igualmente que esa complementación ha de aludir a un participante en el evento cuya participación ha de tener algún impacto o ser visible durante el estado subsiguiente; así El dibujo está hecho por un niño "still display an impact" del actor que ha creado el dibujo; se ha de admitir, sin embargo, que al igual que el efecto causado por el verbo, la huella del "actor", la impronta de su participación, puede ser "indirecta", no perceptible físicamente, inmaterial, como sucede cuando lo que aporta es fama o prestigio en un ámbito determinado que repercute en la valoración del objeto afectado; así, el hecho de que Chomsky cite un artículo, pongamos por caso, tiene un impacto en la valoración de ese artículo, pero no se puede hablar en sentido estricto de su huella física, de su "visibilidad". Recuérdese a este respecto que, por ejemplo, La chica está besada se ha catalogado como anómala porque besar no desemboca en un estado "visible"; difícilmente pues el agente podría dejar un "impacto visible" en el estado del argumento objeto de besar. Pero que participe un "agente" al que nuestro conocimiento del mundo otorga relevancia sí puede tener un "impacto" en la valoración del objeto, como ponen de manifiesto los siguientes enunciados formados con el participio de besar y un complemento alusivo al "actor" que aporta un componente evaluativo y posibilita la lectura atributiva, de caracterización:

59 Según Gehrke y Sánchez (1914: 202), "the respective person has to be somewhat 'famous enough"”.

60 Conti (2004: 40) trata de delimitar factores relacionados con la "alta informatividad" del complemento. En ese sentido, además de la "relevancia" de la entidad, apunta a que se trate de un sintagma indefinido (El cuadro está pintado por un niño/*el niño) o que sea un complemento contrastivo (Este cuadro está pintado por mi amigo, no por el tuyo). 
40. Me dijo Ud. que este Rosario está besado por la Santísima Virgen de Garabandal.

41. Consíganlos. Yo ya tengo el mío. Está buenísimo. Además, [los discos] están besados por Justin.

42. Esta medalla está besada por el Papa Pío X o Pío Xl (no recuerdo bien).

Los datos muestran, pues, que no solo son admisibles en las construcciones resultativas complementos de carácter agentivo introducidos mediante por, sino que en muchos enunciados la aceptabilidad viene dada por su inclusión en cuanto que permite inferir un contenido cualitativo que no depende solo del participio, que tampoco se explica por rasgos estrictamente gramaticales y que no existiría sin esa complementación.

Como sucede con tantas otras cuestiones lingüísticas, las peculiaridades de este tipo de complementaciones comparadas con las que se incluyen en las pasivas perifrásticas -las pasivas consideradas "eventivas"- suscitan interrogantes que dan lugar a controversias. Se ha planteado si estos complementos agentivos son diferentes de los que forman parte de las pasivas $^{61}$, si inciden sobre el evento o solo sobre el resultado (Rapp, 2001: 396; Alexiadou, 2005: 18), si están habilitadas "by the causative (or argentive) semantics associated with the underlying verb, rather than voice" (Gehrke y Sánchez Marco, 2014: 190). No obstante, para los objetivos de este trabajo puede ser suficiente señalar que ni estos complementos "agentivos" suponen que el evento denotado por la base verbal no esté desfocalizado, ni hay en realidad razones gramaticales para establecer un vínculo necesario entre la desaparición "total" del agente y el hecho de que la construcción no incida sobre la acción sino sobre su resultado. Sin entrar en otras consideraciones, baste subrayar que, al fin y al cabo, los participios que forman parte de estas combinaciones no se han "adjetivado" ${ }^{2}$, no han perdido su carácter verbal ni, por tanto, tienen por qué haber "olvidado" que los procesos que describen implican que un agente -en sentido amplio- los origine o los lleve a cabo. Así, por ejemplo, en Este candidato incluye en su currículum un artículo citado por Chomsky, Un material revisado por especialistas ofrece más garantías, citado por Chomsky, revisado por especialistas aportan una cualidad del artículo o del material, no focalizan un evento de citar o revisar ${ }^{63}$. Ha de destacarse asimismo que ni la existencia de una complementación agentiva garantiza, según la Academia ${ }^{64}$ (RAE, 2009: 2896), que la construcción en que se incluye tenga una interpretación oracional ni, desde luego, estos complementos "agentivos" serían los únicos que no "instancian" un evento ubicado en el espacio y en el tiempo; así ocurre con los sintagmas "agentivos" de las nominalizaciones o de los adjetivos formados con el sufijo -ble (Alexiadou, 2005: 19; RAE, 2009: 2896; Bosque, 2014: 54).

En definitiva, en Este rosario está besado por la Santísima Virgen de Garabandal, Todo el material que se introduce en NiceTales está revisado por un equipo de educadores y especialistas en edición no están perfilados los eventos de besar o revisar; atribuyen a este

61 Como explican Gehrke y Marco (2014), el estatus de estos complementos en relación con los que se incluyen en las pasivas es una cuestión discutida. Desde su punto de vista, son diferentes; mientras los de las pasivas se relacionan con "event tokens", los de las resultativas modificarían "event kinds" (2014: 190).

62 De conformidad con Bosque (2014: 44), las pasivas resultativas en inglés se consideran adjetivas por muchos autores, pero en español, a su juicio, los participios derivados de verbos transitivos pertenecen a categorías verbales, no adjetivas.

63 Tampoco, como evidencian las construcciones pasivo-reflejas, la eventividad, la implicación de un agente, garantiza que se pueda incluir un complemento agentivo. Todo depende de los aspectos que perfile la construcción. 64 Así lo afirma a propósito de las complementaciones agentivas en las construcciones absolutas. 
rosario, a todo el material una cualidades - grosso modo, propiedades divinas, calidad- no codificadas por el participio, sino deducibles de besado por la Santísima Virgen de Garabandal, revisado por un equipo de educadores y especialistas, que permiten establecer un contraste, en una dimensión cualitativa, con otros rosarios sin las propiedades atribuidas a los besados por la Santísima Virgen y con otro material sin la calidad que cabe deducir de su revisión por parte de especialistas.

Según lo visto, se podría afirmar, por tanto, en primer lugar, que como sugiere Maienborn (2009: 39-41) la lectura atributiva, de caracterización o propiedad, está mucho más extendida de lo que puede predecir la mera consideración de la clase léxico aspectual, puesto que la admiten verbos, como besar, en teoría descartados para formar una construcción resultativa con estar. Incluso se puede dar con un verbo como vigilar habitualmente utilizado para ejemplificar la lectura "pasiva no resultativa" por tratarse de un verbo de 'actividad'. Obsérvense, por ejemplo, los siguientes enunciados:

43. Nuestro funcionamiento está vigilado por la DGT y las autoridades sanitarias. Desconfíe, por tanto, de aquellos Centros que hacen "grandes descuentos". Los Centros de Conductores tenemos un compromiso con la Seguridad Vial.

44. Este servicio obtuvo en 2001 la Certificación de Calidad según la Norma EN-ISO 9002: 1994; y las cocinas la acreditación ISO 9001:2000. El comedor está vigilado por profesores del colegio, como parte del Programa de Acción Tutorial "Aprender a ser".

45. El aparcamiento de este establecimiento no está vigilado, por lo que LA CASONA DE LA REINA BERTA no responde de los objetos dejados en el interior de los vehículos, ni de los daños que pudieran sufrir estos.

Desde mi punto de vista al menos, estas construcciones con vigilar no denotan, como se considera propio de las "pasivas no resultativas" un "presente extendido" (alguien vigila X), una acción que se presenta como coexistente con el estado descrito por el participio (Bosque, 1999: 292) "che si mantiene stabile" "perché qualcuno continua ad operare su qualcosa" (De Miguel, 2001). Son construcciones que atribuyen al sujeto un rasgo valorativo que no procede solo del significado del verbo, sino que se puede inferir de nuestro conocimiento del mundo, y que establece un contraste evaluativo con otras entidades cuyo funcionamiento no ofrece las garantías que implica la propiedad de "estar vigilado por la DGT y las autoridades sanitarias", con otros comedores que "no están vigilados por profesores del colegio" o con otros aparcamientos que no se encuadran la categoría de los "no vigilados" con las diferencias respecto a la seguridad que se pueden inferir de ello.

En segundo lugar, si bien en las construcciones con verbos "bieventivos", de cambio, se atribuye, según se reconoce generalmente, una característica especificada por el verbo cuya interpretación no necesita "esfuerzo pragmático", con otros verbos -como sucedía con barrer, fregar, mordisquear - la propiedad no está reflejada en el significado mínimo asociado a la clase aspectual, sino que depende de otros componentes de significado más específicos y seguramente menos formalizados ${ }^{65}$; con otros, por último, la interpretación sí demanda "esfuerzo pragmático" en mayor o menor grado, en cuanto que la propiedad que

65 Ya en otros trabajos se ha hablado de la importancia que tienen en muchas parcelas del análisis lingüístico propiedades subléxicas específicas que algunos considerarían más enciclopédicas que lingüísticas, como las que en los planteamientos procedentes de Pustejovsky (1995) se incluyen en las estructuras de qualia o las que FrameNet incorpora a los marcos. Véase, por ejemplo, Martínez Linares $(2011,2012)$. 
atribuye al sujeto ni está especificada mediante algún tipo de rasgo subléxico, ni depende necesariamente del verbo; puede ser "activada" por los complementos y/o requerir ciertas inferencias que "may vary considerably and depend largely on our particular background knowledge and attitude" (Maienborn, 2009: 40-41).

Se podría concluir, pues, que, como afirma Maienborn (2009: 37) respecto de la "pasiva adjetiva" en alemán, la construcción de participio con estar ${ }^{66}$ es "a flexible gramatical means of creating a potentially new ad hoc property based on the verbal event"; pero cuál sea propiedad ${ }^{67}$, la relevancia del "estado" configurado por la construcción "can be provided by the participle itself, or it can be triggered by the inner- or extrasentential context" (Gese et al., 2009: 135), de manera que su "exact import, and therefore the place they occupy in the subject referent's property space, is more or less shaped by the context and by our contextually available world knowledge" (Maienborn, 2009: 41).

\section{Para finalizar}

De conformidad con los objetivos inicialmente planteados, a lo largo de este trabajo se han tratado algunos aspectos de las construcciones de sentido "resultativo" formadas por el verbo estar y un participio que cabe considerar problemáticos, según sugieren ya las diferencias de opinión sobre los rasgos que condicionan la viabilidad de estas construcciones o sobre la gramaticalidad de determinados enunciados.

Partiendo de las características "clásicas" atribuidas a las combinaciones "estar + participio" que se consideran "resultativas", se ha examinado, en primer lugar, el concepto de "estado resultante', clave en el análisis de estas construcciones; se ha mostrado que el término se usa frecuentemente de un modo impreciso y que de su empleo se infieren al menos dos sentidos relacionados a su vez con dos tipos de construcciones "resultativas" que, si bien pueden estar vinculadas $^{68}$, difieren en su interpretación y en sus condicionamientos.

Así se ha visto que los rasgos atributivos, "de caracterización”, que se asignan a construcciones "resultativas" como La barra está doblada, La ciudad está destruida, descansan en un concepto de "estado resultante" cualitativo, intensional, según el cual denota propiedades producto del proceso al que alude el verbo base del predicado.

Pero también se ha mostrado que, aunque algunos estudios han incluido en la misma clase enunciados del tipo La novela ya está leída, La cima ya está alcanzada, Los platos ya están fregados, asumiendo que denotan igualmente un "estado resultante", en realidad esta clase de construcciones no vehiculan el mismo significado atributivo, ni responden a los mismos condicionamientos, ni se les puede aplicar ese mismo sentido cualitativo, intensional, de "estado resultante". Antes bien, les subyace otro sentido más "temporal", asociado a la interpretación del "perfecto", que permite conceptuarlas como perífrasis de "fase": focalizan el estadio, la fase, subsiguiente a la conclusión del evento denotado por

66 La Academia (2009: 2215) también viene a reconocer que mediante la construcción "estar+participio" se crea sintácticamente la propiedad a partir del efecto causado por el proceso.

67 De hecho, como destaca Maienborn (2009: 41), un manuscrito al que se le atribuye estar escrito en una noche, como un cuadro del que se predique estar pintado por un niño, puede ser "either ingenious or awfully sloppy". 68 Véanse, entre otros, Gehrke (2012) y Maienborn (2009), a propósito de la relación entre ambas. Según Maienborn, por ejemplo, el participio estaría infraespecificado para una u otra lectura; correspondería a la pragmática proporcionar el valor "contextually suitable" que orientaría la lectura en una u otra dirección (2009: 44-46). 
el verbo- es decir, un 'estado resultante' en otro sentido del término-, que, además, suele encuadrarse en un marco de tareas que han de ser superadas; de ahí la frecuente presencia en este tipo de enunciados del adverbio de fase ya asociado tanto a la lectura del aspecto perfecto como a la expectativa que crea ese marco de tareas; las resultativas atributivas, por el contrario, ni requieren o implican ya, ni tampoco un guion "contextual" que proyecte una serie de fases que se han de culminar.

Se ha puesto de relieve, asimismo, que estas combinaciones de sentido más temporal no se hallan circunscritas a verbos que incorporan en su estructura léxica un "estado resultante" en su sentido más restrictivo; se construyen de hecho con verbos de clases distintas, incluso con verbos como besar, cantar, cruzar, frecuentemente señalados como inadecuados para las formaciones resultativas por su significado; solo se necesitan condiciones contextuales que permitan incluir el evento denotado en "some implicit frame concerning one or more supposed or scheduled tasks" (Bosque, 2014: 69).

En cuanto a las atributivas - como La puerta está abierta, La casa está bien construida-, no se pone en tela de juicio la desfocalización del evento en que se sustenta su condición estativa, ni tampoco el hecho de que los verbos bieventivos de cambio, con un evento causativo de acción y un evento resultativo de estado, sean los más capacitados para formar construcciones que asignan al sujeto propiedades interpretables sin "esfuerzo pragmático". Pero sí se ha hecho hincapié en que la interpretación "cualitativa” propia de esta clase de construcción está mucho más extendida de lo que podrían predecir las explicaciones clásicas basadas en rasgos aspectuales. Según se ha visto, la propiedad atribuida no solo puede provenir del significado lexicalizado por el verbo; puede derivar de otras facetas más enciclopédicas del contenido de las unidades verbales que permiten construir un "efecto" más o menos perceptible en la entidad afectada por el proceso -como El piso está fregado-, o puede ser una propiedad no perceptible, más sutil, inmaterial, con un componente evaluativo o valorativo configurado a partir de inferencias dependientes del conocimiento del mundo "contextually available" y/o de "otros materiales", como los complementos con por alusivos a un agente que o bien deja una "huella" visible de su participación o bien tiene un "impacto" valorativo que aporta ese componente cualitativo requerido por la construcción: La comida está preparada por verdaderos expertos, El material está revisado por especialistas, La medalla está besada por el Papa.

Como se admitía al principio, aún queda mucho por analizar en el campo de las construcciones grosso modo resultativas formadas mediante un participio y el verbo estar. Bosque (2014: 69), por ejemplo, señalaba recientemente que no había podido encontrar en la bibliografía sobre estas construcciones muchas referencias al factor "efecto fasal" tan vinculado al uso de ya; en cuanto a las atributivas, si bien se admite que el evento denotado por el predicado ha de tener un efecto que se pueda medir o evaluar, no parece fácil sistematizar cuándo y cómo se configura un efecto que se pueda medir o evaluar. Pero sí se habrá comprobado que ninguna de las dos lecturas que se pueden diferenciar en el grupo de las construcciones resultativas relacionadas con dos sentidos de "estado resultante" se hallan constreñidas a verbos que lexicalizan un estado resultante ni pueden explicarse partiendo solo de clases aspectuales o de factores estrictamente gramaticales, sin tomar en consideración aspectos pragmáticos y contextuales ${ }^{69}$.

69 De hecho, como sugería recientemente Levin (2015), la relevancia de esos aspectos pragmáticos y contextuales va dejando su impacto en la evolución de las investigaciones sobre materias circunscritas inicialmente al dominio sintáctico. 


\section{Referencias bibliográficas}

Alexiadou, A. (2005): "A note on non-canonical passives: the case of the get passive", en Broekouis, H. et al. (eds.): Organizing Grammar: Linguistic Studies in Honor of Henk van Riemsdijk, Berlin, Mouton de Gruyter, pp. 13-21.

Batiukova, O. (2006): "Las oraciones medias como proyección de estructuras subléxica", en Villayandre Llamazares, M. (ed.): Actas del XXXV Simposio Internacional de la Sociedad Española de Lingüística, León, Universidad de León, pp. 221-241. http://www3. unileon.es/dp/dfh/SEL/actas.htm

Bosque, I. (1990): "Sobre el aspecto en los adjetivos y en los participios", en Bosque, I. (ed.): Tiempo y aspecto en español, Madrid, Cátedra, pp. 177-211.

Bosque, I. (1999): "El sintagma adjetival. Modificadores y complementos del adjetivo", en Bosque, I. y V. Demonte (dirs.): Gramática descriptiva de la lengua española, Madrid, Espasa, pp.217-310.

Bosque, I. (2014): “On Resultative Past Participles in Spanish”, Catalan Journal of Linguistics, Vol. 13, pp. 41-77 http://revistes.uab.cat/catJL/article/view/v13-bosque/155-pdf-en [21-03-2015].

Bruening, B. (2012): "Word Formation is Syntactic: Adjectival Passives in English" http:// udel.edu/ bruening/Downloads/AdjectivalPass3.pdf [15-12-2014]

Bruhn de Garavito, J. y E. Valenzuela (2008): "Eventive and stative passives in Spanish L2 acquisition: A matter of aspect", Bilingualism: Language and Cognition, 11, 3, pp. 323-336.

Conti, C. (2004): “Construcciones pasivas con estar”, Estudios de Lingüística, 18, págs. 21-44.

Delbecque, N. (2006): “Ya: Aclaración cognitiva de su uso y función”, Revista Española de Lingüística,36, pp. 43-71.

De Miguel, E. (2001): "Relazioni tra il lessico e la sintassi: classi aspettuali di verbi ed il passivo spagnolo", Círculo de Lingüistica Aplicada a la Comunicación, 8. Publicado en Simone, R. (ed), Studi Italiani di Linguistica Teorica e Applicata, 2000, 29.2, 201-217. http://www.ucm.es./info/circulo/no8/demiguel.htm

De Miguel, E. (2004): “Qué significan aspectualmente algunos verbos y qué pueden llegar a significar”, en Cifuentes Honrubia, J. L. y C. Marimón Llorca (eds.): Estudios de Lingüística: el verbo, Alicante, Universidad de Alicante, pp. 167-206.

Embick, D. (2004): "On the Structure of Resultative Participles in English", Linguistic Inquiry, VOL. 35, No 3, PP. 355-392.

Embick, D. (2009): Roots, states, stative passives. Handout for Roots workshop; Stuttgart, Universidad de Stuttgart, http://www.ling.upenn.edu/ embick/stut.pdf [12-01-2015]

Escandell, M. V. y M. Leonetti (2002): “Coercion and the Stage/Individual Distinction”, en Gutiérrez Rexach, J. (ed.), From words to discourse, Amsterdam, Nueva York, Elsevier, pp. 159-179.

Fábregas, A. y R. Martín (2012): "Syntactic and semantic properties of Davidsonian state verbs “, 42 Linguistic Symposium Romance Languages, University of SouthernUTAH.

https://www.academia.edu/1722270/Syntactic_and_semantic_properties_of_Davidsonian_ state_verbs [15-10-2014]

Fernández, A., Vázquez, G. y Martí, M.A. (2002): “Alternancias diatéticas relacionadas con el aspecto", Verba, 29, pp. 389-402. 
Fernández Leborans, M. J. (1999): “La predicación. Las oraciones copulativas”, en Bosque, I. y V. Demonte (dirs.): Gramática descriptiva de la lengua española, Madrid, Espasa, pp. 2357-2460.

Fernández Ramírez, S. (1986): Gramática española. 4. El verbo y la oración, vol. ordenado por I. Bosque, Madrid, Arco Libros.

García Fernández, L. (1995): "La interpretación temporal de los tiempos compuestos", Verba, 22, pp. 363-396.

García Fernández, L. (1999): “Los complementos adverbiales temporales. La subordinación temporal", en Bosque, I. y V. Demonte (dirs.): Gramática descriptiva de la lengua espanola, Madrid, Espasa, pp. 3129-3208.

Gehrke, B. (2012): "Passive states", en Demonte, V. y L. McNally (eds.): Telicity, Change and State. A Cross-Categorial Viev of Event Structure, Oxford, Oxford University Press, pp. 185-211.

Gehrke, B.y C. Marco (2014): "Different by-phrases with adjectival and verbal passives: Evidence from Spanish corpus data", Lingua, 149, pp. 188-214: https:/www.academia.edu/8682251/Different_by-phrases_with_adjectival_and_verbal_passives_Evidence_from_Spanish_corpus_data (03-03-2015).

Gese, H. (2011): "Events in adjectival passives", en Reich, I., E. Horch y D. Pauly (eds.): Proceedings of Sinn un Bedeutung 15, Saarbrucken, Universaar-Saarland University Press, pp. 259-273.

Gese, H., B. Stolterfoht, C. Maienborn (2009): "Context Effects in the Formation of Adjectival Resultatives”, en Winkler, S. y S. Featherston (eds.): The Fruits of Empirical Linguistic: Vol 2, Berlin, De Gruyter, pp. 125-155.

Girón Alconchel, J. L. (1991): Tiempo, modalidad y adverbio, Salamanca, Universidad de Salamanca.

Goldberg, A. y F. Ackerman (2001): "The pragmatics of obligatory adjuncts", Language, 77, no 4, pp. 798-814.

Gómez Torrego, L. (1988): Perifrasis verbales, Madrid, Arco Libros.

Hengelved, K. (1986): “Copular verbs in a functional grammar of Spanish", Linguistics, 24, pp. 393-420.

Jiménez Peña, S. y y Rodríguez Sellés (2002): “AAgentes causantes?”, en González Pereira, M. Souto Gómez y A. Veiga Rodríguez (coords.): Léxico y gramática [Selección de ponencias e comunicación presentadas no Congreso Internaciona de Lingüística "Léxico \& Gramática" celebrado na Facultade de Humanidades de Lugo do 25 ó 28 de setembro de 2000], pp. 215-224.

Jurado Salinas, M. (2000): "Las construcciones pasivas con ser y estar", Número Especial. Ed. R. Maldonado Soto. Revista Española de Lingüística Aplicada, pp. 175-191.

Kratzer, A. (2000): "Building statives", Proceedings of the Twenty-Sixth Annual Meeting of the Berkeley Linguistic Society: General Session and Parasession on Aspect, Vol $26 \mathrm{n}^{\circ}$ 1, pp. 385-399. http://elanguage.net/journals/bls/article/view/3344/3331

Levin, B. (2009): "Lexical Semantics of Verbs IV; Aspectual Approaches to Lexical Semantics Representation", Course LSA 116. http://web.stanford.edu/ bclevin/lsa09aspapp.pdf [23-03-2014]

Levin, B. (2015): "Semantics and Pragmatics of Argument Alternations", Annual Review of Linguistics, 1, pp. 63-83. 
Levin, B. y M. Rappaport Hovav (1991): "Wiping the slate clean: A lexical semantic exploration”, en Levin, B. y S. Pinker, (eds.) (1991): Lexical and Conceptual Structure, Oxford, Blackwell, págs.123-151

Levin, B. y M. Rappaport Hovav (2005): Argument Realization, Cambridge, Cambridge University Press.

Levin, B. y M. Rappaport Hovav (2013): "Lexicalized meaning and manner/result complementariry", en Arsenijevic, B., B. Gehrke y R. Marín (eds.); Studies in the composition and decomposition of event predicates, Springer, Dordrecht, pp. 49-70.

Maienborn, C. (2009): "Building Event-Based Ad Hoc Properties: On the Interpretation of Adjectival Passives”, en Riester, A. y T. Solstad (eds.): Proceedings of Sinn und Bedeutung, 13, Stuttgart, University of Stuttgart, pp. 35-49.

Marín, R. (2000): El componente aspectual de la predicación, Tesis doctoral, Departament de Filologia Espanyola, Universitat Autònoma de Barcelona.

Marín, R. (2004): Entre ser y estar, Madrid, Arco Libros.

Martínez Linares, M. A. (2011): “On protagonizar 'an event' and the scope of the concept of light verb”, en Cifuentes Honrubia, J. L. y S. Rodríguez Rosique, Spanish Word Formation and Lexical Creation, Amsterdam/Philadelpia, John Benjamins, pp. 185-216.

Martínez Linares, M. A. (2012): “Aznarizar, zapaterizar... En torno a verbos formados sobre nombres propios con el sufijo -izar”, LEA, XXXIV/2, pp. 247-274.

Mendikoetxea, A. (1999): “Construcciones inacusativas y pasivas", en Bosque, I. y V. Demonte (dirs.), Gramática descriptiva de la lengua española, Madrid, Espasa, pp. 15751629.

Morimoto, Y. (1998): El aspecto léxico: delimitación, Madrid, Arco Libros.

Nishiyama, A. y J. P. Koening (2010): "What is a perfect state", Language, 86, n 3, pp. 611-646.

Parsons, T. (1990): Events in the Semantics of English. A Study of Subatomic Semantics, Cambridge,Mass., MIT Press.

Pustejovsky, J. (1991): “The syntax of event structure”, en Levin, B. y S Pinker (eds.): Lexical and Conceptual Structures, Oxford, Blackwell, pp. 47-81.

Pustejovsky, J. (1995): The Generative Lexicon, Cambridge, Mass., MIT Press

Rapp, I. (2001): "The attributive past participle. Structure and temporal interpretation", en Féry, C. y W. Sternefeld (eds.): Audiatur Voz Sapientiae. A Festschrift for Arnim von Stechow, Berlín, Academie-Verlag, pp. 392-409.

Rappaport, M. (2008): "Lexicalized meaning and the internal temporal structura of events", en Rothstein. S. (ed.): Theoretical and crosslinguistics approaches to the semantic of aspect, Amsterdam, John Benajmins, pp. 13-42.

Real Academia Española (2009): Nueva gramática de la lengua española, 2 vols., Madrid, Espasa.

Tenny, C. L. (1987): Grammaticalizing aspect and affectedness, Tesis doctoral, Department of Linguistics and Philosophy, MIT.

Vázquez, G., A. Fernández y M. A. Martí (2000): Clasificación verbal. Alternancias de diátesis, Lleida, Universitat de Lleida.

Vázquez, G. y A. Fernández (2003): “Interpretación semántica de esquemas sintácticos”, $R L A, 41$, pp. 143-169.

Wilk-Racieska, J. (2012): "Esbozo del estudio de las funciones semántico-pragmáticas de ya", ELUA, 26, pp. 383-404. 
Yllera, A. (1999): "Las perífrasis verbales de gerundio y participio", en Bosque, I. y V. Demonte (dirs.): Gramática descriptiva de la lengua española, Madrid, Espasa, pp. 3391-3443.

\section{Anexo}

1. http://www.eluniversodeloslibros.com/2013/10/nuevas-lecturas-septiembre.html

2. http://archivosdelvalhalla.blogspot.com.es/2012/11/imm-noviembre.html

3. http://www.mediavida.com/foro/32/us-open-2010-393924/42

4. http://davidmalabarista.blogspot.com.es/2012/11/mondarruego-por-la-faja-de-la-escuzana.html

5. http://www.gsmspain.com/foros/su3488652_u66622_p3_mensajes-usuario-aristos.html

6. http://www.diarioinformacion.com/universitarios/2011/10/18/formamos-profesionalescontexto-sociedad-digital/1179944.html

7. http://www.desdelasgradas.com.mx/imprimir.php?id_n=1110

8. http://www.experimentosconazucar.com/2011/11/poniendo-el-pino.html

9. http://boscodigresiones.blogspot.com.es/2008/09/amanece-lloviscando-fotografas-delotoo.html

10. http://torreschava.blogspot.com.es/2010/11/domingo-7-de-noviembre-dia-d.html

11. http://www.panageos.es/gente-grabada-sin-saberlo

12. http://unosetentaydos.mforos.com/1631430/10149309-infanteria-alemana-1-72-hasegawa/

13. http://www.rankia.com/foros/bolsa/temas/1078368-encuesta-margrave-cuanto-dineronecesitas-para-vivir-trabajar-ser-feliz?page $=1402$

14. http://www.foromtb.com/showthread.php/646673-Quebrantahuesos-2011/page41

15. https://books.google.es/books?id=zahkJUpUOqoC\&pg=PA197\&lpg=PA197\&dq=\%2 2 cuando + un + discurso + est $\% \mathrm{C} 3 \% \mathrm{~A} 1+$ memorizado $\% 22 \&$ source $=$ bl\&ots $=$ fTiHIIwEW A\&sig=ZBUYRExhK_-7picyZGVis8MtZRw\&hl=es\&sa=X\&ei=ECNsVeHZAYrzUO $7 \mathrm{Ig}-\mathrm{gO} \& \mathrm{ved}=0 \mathrm{CCEQ} 6 \mathrm{AEwAA} \# \mathrm{v}=$ onepage $\& \mathrm{q}=\% 22$ cuando $\% 20 \mathrm{un} \% 20$ discurso $\% 20$ est $\% \mathrm{C} 3 \% \mathrm{~A} 1 \% 20$ memorizado $\% 22 \& \mathrm{f}=$ false

16. http://in-a-words.blogspot.com.es/2012/01/no-podia-pisar-en-la-cocina.html

17. http://www.indemnizacionaccidentes.org/Indemnizacion-por-caida./9

18. ht tp://www.biblegateway.com/pas sage/? search=Lucas $+11 \% 3 \mathrm{~A} 14$ 28\&version=RVR1960;LBLA;NTV;NVI;TLA

19. http://drabada.blogspot.com.es/2012/03/atapuerca-mentiras-y-evolucion-humana.html

20. http://www.es.scribd.com/doc/86143747/Comunicacion-en-imagenes

21. http://mutuocentro.com/molecula-producto/

22. http://www.pioneerpump.co.uk/es/markets/oil-gas.htm

23. http://www.tripadvisor.es/ShowUserReviews-g198524-d1597128-r181115459-Hotel_ Imbery-Hinterzarten_Black_Forest_Baden_Wurttemberg.html

24. http://www.tripadvisor.es/ShowUserReviews-g186258-d1128719-r124146855-Thai_in_ the_Park-Plymouth_Devon_England.html

25. http://www.tripadvisor.es/SimilarHotelsPopunder?MTPU_RULE=287\&onclick=1

26. http://www.patagonia4x4.com.ar/phpbb3/viewtopic.php?t=42509\&p=447110

27. http:/eljuntaletrascom.wordpress.com/2012/09/04/fauna-humana-26-el-modenno/

28. http://elcamionerorecomienda.blogspot.com.es/2010/02/ciudad-real.html 
29. http://www.unblogparacomerselo.com/?p=1677

30. http://www.minube.com/rincon/la-eritana-a690681

31. http://www.emeraldinsight.com/portal/es/products/collections.htm

32. http://www.nicetales.com/preguntas-frecuentes

33. http://www.gartoo.es/fotos-piso-piloto-amueblado

34. http://mundojardin.portalmundos.com/un-apartamento-en-madrid-decorado-por-tomasalia

35. http://valdeperrillos.com/book/export/html/4354

36.http://www2.pelayo.com/opinion/noticias.htm

37. http://www.alhambrasl.com/index.php?option=com_content...

38. http://www.lavanguardia.com/fotos/20120420/54284654092/el-cartel-de-la-ii-fira-d-artesta-disenado-por-josep-serra-del-estudio-mensula-es-un-homenaje-al.html

39. https://fr33ky.wordpress.com/2012/07/25/disfruta-del-batimovil-y-el-batpod-en-vivo-ya-todo-color/

40. http://www.stjosephpublications.com/book_manuscripts_pages/testimonies/113\%20 -\%20Lucio\%20Rodrigo, \%20S.J.\%27s\%20Story\%20Following\%20the $\% 20$ Letters $\% 20$ from $\% 20 J a n u a r y \% 2018, \% 201967 . h$ tm

41.http://es-la.facebook.com/permalink.php?story_fbid=190670287684356\& $\mathrm{id}=23858888287188$

42. http://www.terra.es/personal5/felix.pascual/Pag.28.htm

43. http://www.renovarcarnetdeconducir.com/nuestra-garantia/

44. http://www.sek.es/index.php?section=colegios/santa-isabel/servicios

45. http://www.lacasonadelareinaberta.com/tarifas-y-reservas.html 


\title{
FRASEOLOGÍA Y LINGÜÍSTICA COGNITIVA. ESTUDIO INTERDISCIPLINAR DE LA FRASEOLOGIZACIÓN DE LA LOCUCIÓN SOMÁTICA DE BOCA EN BOCA
}

\author{
Alicia Merino GonZÁlez \\ Universidad de Valencia \\ aliciamerinogonzalez@gmail.com
}

Recibido: 03/06/2015

Aceptado: 02/09/2015

\begin{abstract}
Resumen
En este artículo se analiza la fraseologización de la locución somática (LS) de boca en boca. Para ello, se abordará el objeto de estudio mediante la imbricación de la fraseología y la cognición, pues la lingüística cognitiva puede arrojar luz al estudio de la aparición, fijación e idiomaticidad del fraseologismo mediante los mecanismos figurativos. El proceso de fraseologización requiere la documentación de la locución en corpus diacrónicos y sincrónicos para trazar el proceso evolutivo de la unidad fraseológica (UF). La LS que se estudiará se encuentra en las obras lexicográficas actuales, no obstante, solo mediante el estudio diacrónico se logrará averiguar qué variantes o variaciones han dado lugar a esta combinación fija de palabras que conocemos hoy en día.

PALABRAS CLAVE: Fraseología, fraseologización, lingüística cognitiva, mecanismos figurativos.
\end{abstract}

\begin{abstract}
In this article is analyzed the phraseologization of the somatic locution (SL) de boca en boca. To do this, the object of study is discussed by the imbrication between the phraseology and the cognicion, then, the cognitive linguistic can give off light on the study of the appearance, fixation and idiomatic of the phraseologies though the figurative mechanisms. The phraseologication's process requires the documentation of the locution in diachronic and synchronous corpus in order to draw the evolutionary process of phraseological unit (PU). The SL that is studied is in the actual lexic, however, only with the diachronic study is found out which variants and variations grow this fixed combination of know today.

KEYWORDS: Phraseology, phraseologization, cognitive linguistic, figurative mechanism.
\end{abstract}

\section{Introducción}

En el presente trabajo se presentará un estudio diacrónico de una unidad fraseológica somática (UFS). En concreto, se trata de la locución somática de boca en boca, locución que presenta como núcleo el somatismo boca. En primer lugar, se debe destacar la hegemonía de los estudios sincrónicos de los fraseologismos y la escasez de investigaciones desde la perspectiva diacrónica. Así pues, se pretende contribuir a la profundización y desarrollo de dicha perspectiva histórica con la finalidad de mostrar la importancia de esta para comprender las unidades fraseológicas actuales. Asimismo, presentamos la perspectiva diacrónica y sincrónica como complementarias y constituyentes de un continuo; por lo que se aboga por la realización de estudios que abarquen tanto la perspectiva diacrónica como la sincrónica.

En segundo lugar, se debe destacar la interdisciplinaridad que caracteriza a la fraseología como disciplina, hecho que permite llevar a cabo estudios en los cuales se imbrica con otra 
disciplina. El estudio llevado a cabo por Ruiz (2001) muestra la posibilidad de complementar la fraseología y lingüística cognitiva desde una perspectiva sincrónica. Este trabajo es clave para esta investigación, pues se pretende analizar desde las perspectivas diacrónica y sincrónica la aparición, fijación y consolidación de la LS; para ello, el estudio se sustentará en la interdisciplinaridad que presentan tanto la fraseología como la lingüística cognitiva. De este modo, el estudio fraseológico y cognitivo nos permite dar cuenta de la aparición, creación y fijación de la combinación fija de palabras a través de los mecanismos figurativos, en concreto, de la metáfora y la metonimia (Lakoff y Johnson, 1980; Cuenca y Hilferty, 2013).

En tercer lugar, al tratarse de una locución somática se cree oportuna la imbricación de la fraseología y la lingüística cognitiva, ya que los hechos físicos del cuerpo humano pueden posibilitar la motivación o creación de significados figurados. Asimismo, las características, propiedades y funciones de la boca pueden influir en la aparición del fraseologismo de boca en boca, así como de sus variantes y variaciones.

De las apreciaciones presentadas se desprende el principal objetivo de este trabajo que es analizar desde las perspectivas diacrónica y sincrónica la creación, evolución y consolidación del fraseologismo somático de boca en boca. Para ello, se imbrica la fraseología y la lingüística cognitiva, ya que esta última puede arrojar luz al estudio de la aparición y fijación de la unidad fraseológica que nos ocupa, así como de las variantes y variaciones que se articulan en torno a esta.

\section{Estado de la cuestión}

La delimitación del objeto de estudio como locución somática y la restricción de los mecanismos figurativos a la metáfora y la metonimia presentan como ineludibles los estudios cognitivos para dar cuenta de la intersección que se produce entre la fraseología y la lingüística cognitiva. Así pues, en los siguientes apartados se presenta el origen y recorrido de la fraseología como disciplina, una aproximación al cognitivismo, los estudios diacrónicos que se han realizado y las contribuciones en el terreno somático. Además, se tendrá en cuenta los diferentes postulados respecto a la metáfora y la metonimia, así como los estudios que plantean la imbricación entre fraseología y cognición.

\subsection{La fraseología como disciplina}

El origen de la fraseología como disciplina se halla en los lingüistas soviéticos, pues estos fueron los que consideraron dicha disciplina como autónoma al resto de ramas de la lingüística. No obstante, esta concepción ha evolucionado hasta contemplarse como una rama interdisciplinar, tal y como sustenta Ruiz (1998). El objeto de estudio de esta disciplina ha pasado por diferentes estadios y denominaciones, pues a pesar de consolidarse el término unidad fraseológica o fraseologismo (Zuluaga, 1980), se propusieron otros que no se llegaron a consolidar: expresión pluriverbal (Casares, 1992 [1950]) y expresión fija (Zuluaga, 1980).

La aportación llevada a cabo por Casares (1992[1950]) consiste en distinguir locuciones y fórmulas pluriverbales, caracterizándose las primeras por ser una combinación estable de dos o más términos que funciona como un elemento oracional y presenta sentido. Respecto a las fórmulas pluriverbales, se debe tener en cuenta que este autor las presenta como autónomas y sin función oracional. La clasificación elaborada por Casares es continuada por 
Zuluaga (1980), quien no contempla las colocaciones y presenta como objeto de estudio las combinaciones de al menos dos palabras e incluso de aquellas que conforman un enunciado.

Corpas (1997) combina el criterio de enunciado (acto de habla) con el de fijación que generan el primer nivel de clasificación donde se distinguen UF en tres esferas. A partir del concepto de enunciado presenta dos grupos de UF que son las que no constituyen un enunciado completo y las que sí lo conforman. En el primer grupo se halla los fraseologismos que no constituyen actos de habla ni enunciado (son los equivalentes a un sintagma) y este grupo, a su vez se subdivide en dos esferas que son la I (formada por UF que se fijan en la norma, es decir, las colocaciones) y la esfera II (constituida por UF pertenecientes al sistema, es decir, las locuciones). Por otro lado, en el segundo grupo están las UF que pertenecen al acervo sociocultural, por lo que la esfera III está formada por unidades del habla: enunciados fraseológicos, es decir, unidades fijadas en el habla constituyentes de actos de habla independientes. En el segundo nivel de la clasificación se presentan las divisiones de las tres esferas y en este se especifica qué tipos de colocaciones, locuciones y enunciados fraseológicos hay.

De la contribución de Ruiz se debe destacar el trabajo llevado a cabo en torno a las locuciones adverbiales, pues esta autora clasifica estas locuciones con esquema Prep $C$ en tres grupos: a) Los sintagmas prepositivos propiamente dichos; b) las unidades fraseológicas verbales en las que aparece un verbo y un complemento precedido por una preposición; y c) fraseologismos con formas diferentes a los sintagmas prepositivos, como por ejemplo, cara a cara. Además de esta clasificación, presenta las diferentes funciones que dichas locuciones adverbiales pueden desempeñar: modificadores del verbo, modificadores del predicado sin presentar relación sintáctico-semántica con él y modificadores oracionales (1997: 33).

Para finalizar con el recorrido histórico de la formación de la fraseología como disciplina, así como la delimitación y clasificación de sus objetos de estudio, se debe tener en cuenta la aportación de García-Page (2008). Este autor refleja la diversidad de locuciones y añade las oracionales a las clasificaciones realizadas por las autoras mencionadas en párrafos anteriores. Asimismo, da cuenta en profundidad de las características de los fraseologismos en los diferentes niveles y muestra la heterogeneidad del universo fraseológico.

\subsection{La perspectiva diacrónica}

Los estudios sincrónicos predominan sobre los diacrónicos, hecho que se puede constatar al observar el elevado número de contribuciones desde la perspectiva sincrónica y el reducido número de estudios diacrónicos. A este aspecto hacen referencias autoras como Pérez-Salazar (2007) y Echenique (2011), quienes abordan los fraseologismos desde la perspectiva diacrónica e inciden en su importancia para el conocimiento tanto de la fraseologización como de la comprensión de la unidad fraseológica actual. Se deben tener en cuenta estudios fraseológicos tales como los de Martí (2004) y Pérez-Salazar (2007), ya que en el primero se lleva a cabo la investigación de fraseologismos en el siglo XVIII, y en el segundo se presenta la evolución de las UF a lo largo de los siglos. De dichas aportaciones, debemos destacar la de Pérez-Salazar (2007), pues guarda cierta similitud con el estudio que se llevará a cabo en esta contribución. En "Unidades fraseológicas y diacronía. Sobre las fórmulas negativas de ninguna manera y en absoluto" observamos la documentación de los fraseologismos y variantes en los corpus de referencia, por lo que se traza la fraseologización y productividad de dichos fraseologismos. 
Por último, destacar la afirmación de Pérez-Salazar (2007), pues prevé un aumento progresivo de estudios históricos. Asimismo, en el presente artículo se contribuirá a la aproximación de las UF desde la perspectiva diacrónica a través de la investigación de la fraseologización de la locución de boca en boca.

\subsection{Aproximación a la lingüística cognitiva}

La lingüística cognitiva se caracteriza por ser un movimiento lingüístico que en palabras de Ibarretxe-Antuñano y Valenzuela "concibe el lenguaje como un fenómeno integrado dentro de las capacidades cognitivas humanas" (2012: 13). De hecho, uno de los rasgos definitorios es la corporeización (embodiment), la cual describe Johnson (1987) como la motivación más o menos directa del lenguaje mediante la experiencia corpórea, física, social y cultural.

El germen de la lingüística cognitiva se halla en la obra de Chomsky (1957) debido a que esta supone una revolución para la concepción del lenguaje y las ciencias cognitivas. No obstante, no fue hasta el 1980, cuando con la obra Metaphors we live by (Lakoff y Johnson, 1980) se marcase el inicio de la lingüística cognitiva y el declive del generativismo. Estos autores mediante su obra presentaron la metáfora y la metonimia como mecanismos cognitivos utilizados en la vida cotidiana, y por lo tanto, no exclusivos de la literatura. Cabe destacar la contribución de Fillmore (1985) al basarse en la psicología cognitiva para formular las bases de la semántica de marcos. Esta semántica se caracteriza por ofrecer una perspectiva novedosa para el estudio de la creación tanto de nuevas palabras y sintagmas, como de nuevos significados. En dicha propuesta se tiene en cuenta la organización en marcos o esquemas de las unidades lingüísticas y las unidades semánticas del texto.

Otro de los pioneros de la lingüística cognitiva es Langacker, creador de la gramática cognitiva de tendencia radicalmente opuesta a la gramática de corte generativista. Este autor la define como: "diverges from standard assumptions in two fundamental respects: (i) its claim that grammar is symbolic in nature; and (ii) its focus on constructions (rather than "rules") as the primary objects of description" (2009: 1). Así pues, la gramática cognitiva presenta el lexicón, la morfología y la sintaxis como un continuo que se dividen únicamente de manera arbitraria en componentes discretos y contempla como objetos de estudio entidades abstractas tales como los conceptos (1999; 2009). La aportación de Langacker no se reduce a la gramática cognitiva, sino que va más allá y presenta el término dominio cognitivo como: "is convenciently used for either a basic domain (as defined above) or a conceptualization of any kind of degree of complixity. We can saw, then, that a lexical item evokes a set of cognitive domains as the basis for its meaning, and exhibits considerable flexibility in the regard" (Langacker, 1999: 4).

Tras la presentación de algunas de las contribuciones que han marcado la historia de la lingüística cognitiva, debido a que el estudio que se presentará adopta la perspectiva diacrónica, se debe tener en cuenta la gramaticalización, concepto clave y en cierto modo relacionado con la fraseologización. La gramaticalización surge de las ideas neogramáticas y entre los diversos estudios que presentan dicho proceso, merecen mención especial Grammaticalization (Hopper y Traugott, 2003) y Regularity in semantic change (Traugott y Dasher, 2002). A continuación se presenta la concepción de gramaticalización que Hopper y Traugott postulan:

[...] Has two meanings, one to do with a research framework within which to account for language phenomena, the other with the phenomena themselves. In this respect the term 
"grammaticalization" resembles not only other terms in linguistics such as "grammar", "syntax", and "phonology", but the terminology of all higher, level concepts in scholarly disciplines. As a term referring to a research framework, "grammaticalization" refers to that part of the study of language change that is concerned with such questions as how lexical items and constructions come in certain linguistic contexts to serve grammatical functions or how grammatical items develop new grammatical functions. This research framework is also concerned with characterizing the subset of cross-linguistically recurring correlations across time among semantic-pragmatic, morphosyntactic, and (sometimes) phonological changes (Hopper y Trougott, 2003: 1).

De las palabras de Hopper y Traugott se desprende la caracterización minuciosa de qué se entiende por gramaticalización, no obstante, además de definir el proceso y sus características, estos autores presentan dos perspectivas desde las cuales se puede abordar la gramaticalización. La perspectiva diacrónica estudia los cambios que se producen, así como los diferentes pasos y estadios que explican la consolidación de una unidad. En cuanto a la segunda perspectiva, la sincrónica, estos autores resaltan el estudio de la sintaxis y del discurso pragmático.

La contribución de Heine y Kuteva no se puede obviar, pues tienen en cuenta la gramaticalización en lenguas de contacto e introducen el término "contact-induced grammaticalization" como "a grammaticalization process that is due to the influence of one language on other. We will distinguish two main types of contact-there exists already a model source-totarget grammaticalization process to be replicated" (2005: 80). Los cambios que caracterizan la gramaticalización son presentados por Heine y Kuteva (2005) como parámetros de gramaticalización y se distinguen cuatro: extensión, desemantización, descategorización y erosión. Así pues, un elemento se ha gramaticalizado cuando "a content word assumes the gramatical characteristics of a función word” (Hopper y Trougott, 2005: 4).

Para finalizar con la presentación grosso modo de la lingüística cognitiva, cabe destacar los mecanismos figurativos tales como la metáfora y la metonimia, objeto de estudio y mención en las obras de corte cognitivo desde el surgimiento de este movimiento (Lakoff y Johnson, 1980) hasta la actualidad. En el apartado siguiente se abordarán estos mecanismos, no obstante, se considera oportuno mencionar la metáfora y metonimia como integradoras del proceso de gramaticalización al que hemos aludido por contemplarse estrategias metafóricas para regular y negociar la comunicación entre hablantes y oyentes (Hopper y Traugott, 2003: 92-93).

\subsection{Los mecanismos figurativos. Cognición y fraseologización}

La metáfora como mecanismo cognitivo ha sido tratada por diferentes autores y estos han coincidido en la contemplación de dos dominios (Lakoff y Johnson, 1980; Croft y Cruce, 2004; Geeraerts, 2010; Cuenca y Hilferty, 2013). No obstante, la concepción tradicional de las figuras retóricas las vinculaba con la literatura, pues se concebían como el resultado de la creación artística de escritores. Esta es refutada por Lakoff y Johnson (1980) al plantear la metáfora como un mecanismo, en ocasiones convencionalizado, mediante el cual se procesa la información abstracta a partir de conceptos más simples y concretos. La teoría de la metáfora conceptual caracteriza este mecanismo cognitivo como un fenómeno en el que el dominio origen (DO) se representa conceptualmente en términos de otro (dominio destino). Así pues, se acerca la realidad al hablante mediante la presentación de lo abstracto en términos de lo concreto o corpóreo. Las metáforas conceptuales se hallan jerarquizadas y por ello, no es de 
extrañar que de una metáfora subyazga otra. Finalmente, en cuanto a este tipo de metáfora, cabe destacar que la proyección es parcial, pues son determinadas propiedades las que se proyectan de un dominio a otro. Además de la metáfora conceptual, Lakoff y Johnson (1980) distinguen la de imagen, división que postulan y desarrollan Cuenca y Hilferty (2013).

Asimismo, para Cuenca y Hilferty la metáfora conceptual proporciona un patrón para un sistema determinado de expresiones metafóricas, frente a la metáfora de imagen que se constituye a partir de la relación que se produce entre la imagen esquemática del dominio origen (DO) y el dominio destino (DD). A continuación se mostrarán metáforas conceptuales y de imagen con la finalidad de apreciar en casos particulares las características descritas (Cuenca y Hilferty, 2013: 101, 104):

(1) DO: LOS ALIMENTOS, DD: LAS IDEAS

¿Y eso cómo se come?

No me trago lo que me estás diciendo

Algo se está cociendo en la Moncloa

Me cuesta digerir tanta información

Italia es una bota

La proyección puede ser ontológica o epistémica, la primera vincula subestructuras entre los dos dominios, a diferencia de la epistémica que no presenta conexiones entre las subestructuras de los dominios, sino que representan el conocimiento importado del DO al DD. En (2) y (3) se muestran algunos de los ejemplos que estos autores presentan de la proyección ontológica y epistémica, respectivamente (2013: 102):

(2) Las ideas corresponden a los alimentos

La persona que come los alimentos corresponde a la persona que acepta la idea

Cocinar el alimento corresponde a concebir la idea

Digerir el alimento corresponde a comprender la idea

(3) Dominio origen: los alimentos sustentan el cuerpo

Dominio destino: las ideas sustentan la mente

Los casos (2) y (3) presentan los dos tipos de proyección, en (2) se produce la relación analógica entre las partes más relevantes de cada dominio, mientras que en (3) se ponen de manifiesto las intuiciones extraídas del DO.

La metonimia, al igual que la metáfora, se concibe como un fenómeno conceptual y en este mecanismo aparece el término punto de acceso mental, a través del cual se accede a la información y comprensión del domino (Langacker, 1999). Son varias las concepciones que de esta se tiene; por un lado, hallamos la consideración de que toda metonimia es necesariamente referencial (Croft y Cruce, 2004), y por otro, la concepción de que dicho mecanismos suele ser referencial pero también cabe la posibilidad de que no lo sea. En los primeros estudios metonímicos, Lakoff y Johnson (1980) la dotan de referencialidad, pero, además, la muestran como fundamental para la representación y comprensión de la realidad.

La metonimia opera en un solo dominio, en concreto, en un dominio funcional. No basta con que la fuente y la meta se hallen en el mismo dominio, sino que según Fauconnier 
(1994), deben estar conectadas mediante proyecciones con función pragmática. Peirsman y Geeraerts (2006) presentan los diferentes tipos de metonimia en función de la prototipicidad de estas. De este modo, las más prototípicas son aquellas que operan en el domino espacial y material, mientras que en la periferia se hallan las que actúan en el dominio de los "grupos y colecciones" de entidades.

Con anterioridad se mencionó la adopción de la obra de Cuenca y Hilferty como pilar para comprender la metaforización de de boca en boca. Asimismo, a continuación se presentará la metonimia desde la concepción de estos autores, debido a que será la que se tenga en cuenta para el análisis metonímico de la unidad fraseológica. Así pues, la metonimia es la referencia indirecta que alude a la entidad implícita a través de otra explícita, es decir, asocia dos entidades que conceptualmente son contiguas y pertenecen al mismo dominio. Al respecto, cabe destacar dos conceptos clave: el punto de referencia (PR) y la zona activa (ZA). A continuación se muestra la clasificación de las principales metonimias llevada a cabo por Cuenca y Hilferty (2013: 112):

1. La parte por el todo

2. El todo por la parte

3. El contenido por el continente

4. La persona por su nombre

5. El lugar físico por la institución situada en ese lugar

6. La institución por las personas responsables

7. El productor por el producto

8. El controlador por sus subordinados

Expuestas las diferentes concepciones de la metáfora y la metonimia, se cree oportuno hacer referencia al papel que los factores culturales pueden desempeñar en la aparición y creación de nuevas metáforas y metonimias. Asimismo, es importante tener presente que los mecanismos cognitivos presentados y descritos no son excluyentes, de hecho, en numerosas ocasiones la metáfora surgen a raíz de una metonimia, por lo que se observa la complementación y sucesión de estos mecanismos (Geeraerts, 2010).

Una vez se ha dado cuenta de las contribuciones sobre las metáforas y metonimias, se debe abordar la presencia de estos mecanismos figurativos en los estudios fraseológicos. Son ineludibles autores como Ruiz (2000; 2001), Adam (2007) y Olza (2011a; 2011b), entre otros, no obstante, antes de presentar los trabajos señalados, se debe hacer mención especial a la obra de Álvarez de la Granja Lenguaje figurado y motivación: una perspectiva desde la fraseología (2008) debido a la contemplación que en esta se hace de los mecanismos figurativos como procedimientos de creación de los fraseologismos, y por lo tanto, posibles procedimientos motivadores del sentido figurado de algunas UF. Esta obra es un pilar imprescindible para la realización de estudios que den cuenta de dichos mecanismos, pero, sobre todo si el estudio se realiza desde la perspectiva diacrónica. Expuesta la relevancia de la obra de Álvarez de la Granja (2008), se procede a la contemplación de estudios específicos donde se conjugan fraseología y mecanismos figurativos. Ruiz en "Las metáforas de un día en los medios de comunicación españoles" (2000) lleva a cabo el análisis de las metáforas en los medios de comunicación, y en concreto, se centra en la ruptura de la tregua de la banda terrorista ETA y cómo la prensa escrita y de radio cubren dicha noticia. Dichas metáforas convencionalizadas forman parte del universo fraseológico, pues aparecen fraseologismos como ponerse los pelos de punta (locución verbal coloquial). 
Las UF con núcleo somático o nombre de animal conllevan, además de cierta transparencia, la actuación de los procedimientos figurativos en su formación. Debemos centrarnos en las unidades fraseológicas somáticas (UFS) y los estudios que se han llevado a cabo por autores como Adam (2007) y Olza (2011a; 2011b), en los cuales se presenta como objeto de estudio las UFS y los mecanismos figurativos tales como la metáfora y la metonimia. Adam estudia los fraseologismos somáticos cuyo núcleo es boca, cara, mano, ojo o pie y se documentan en corpus españoles y polacos. Este trabajo es un claro ejemplo de fraseología contrastiva. Por otro lado, Olza (2011a) lleva a cabo la clasificación de las locuciones somáticas ${ }^{1}$ mediante el núcleo de las mismas. Se presentó con anterioridad la estrecha relación que poseen los mecanismos figurativos y la motivación de las UF, pero también se debe tener en cuenta que tal y como Olza (2011b) manifiesta, estos procedimientos están relacionados con la idiomaticidad de los fraseologismos. De hecho, en numerosas ocasiones los fraseologismos con un alto grado de idiomaticidad deben este rasgo al significado figurado adquirido mediante la intervención de mecanismos como la metáfora o la metonimia.

\section{Metodología}

Las UFS, al igual que el resto de fraseologismos, se adquieren en bloque a lo largo de nuestra vida y conforman nuestro saber enciclopédico. Son varios los estudios que versan sobre los FS (Ruiz, 2001; Olza, 2011a, 2011b), sin embargo, estos plantean un análisis sincrónico. Mediante el estudio sincrónico y diacrónico de la locución adverbial de boca en boca se pretende llevar a cabo una aproximación al estudio del fraseologismo y su fraseologización. En el proceso de fraseologización intervienen distintos mecanismos que ayudan a consolidar y fijar una expresión, se trata de los procedimientos figurativos y por ello, la base del análisis estriba en la intersección entre cognitivismo y fraseología. Sin duda, el estudio diacrónico de una UF fijada en la lengua no es tarea fácil y para obtener datos objetivos que permitan observar la fraseologización se recurrirá a tres corpus de referencia (CORDE, CREA y CORPES XXI).

\subsection{Definición funcional de la UF}

Conviene presentar las principales características de las UF para consolidar la base metodológica de nuestro análisis, pues el paso previo al análisis es plantear qué se entenderá por UF y qué características se deben tener en cuenta para abordar su estudio. Las propiedades por excelencia de los fraseologismos son la idiomaticidad y la fijación (Ruiz, 1997, 1998, 2001; López, 2002); no obstante, se debe tener en cuenta la aportación de Ruiz al respecto, pues esta autora presenta la fijación como propiedad necesaria y la idiomaticidad como subsidiaria y jerarquizada en grados (2001: 125-126). En el proceso de fraseologización tiene especial importancia la repetición de la combinación de palabras, pues mediante su reproducción esta se fija y se convierte en una unidad. Asimismo, "la reproducibilidad debe ser entendida en estos dos sentidos por un lado, como la causa de la formación de una UF y, por otro, como la consecuencia de otra de sus propiedades, la fijación" (López, 2002: 40); por lo que la idiomaticidad, la fijación y la reproducibilidad están interrelacionadas.

1 En dicho estudio se tiene en cuenta solo los fraseologismos considerados locuciones. 


\subsubsection{Idiomaticidad y motivación}

La idiomaticidad es una propiedad no necesaria y consiste en la no deducibilidad del significado global a raíz de la suma del significado de sus componentes (Corpas, 1996; Ruiz, 1998; López, 2002). Dicha propiedad está relacionada con el grado de motivación, tal y como manifiesta Olza:

El nivel de idiomaticidad de una UF se halla relacionado inversamente con el grado de motivación semántica que puede asociársele, esto es, con la transparencia que pueden ser percibidos los distintos mecanismos [...] responsables de su significado no composicional; por otro lado, la complejidad del entramado de esquemas figurativos en que se basa cada significado fraseológico es normalmente responsable de un grado mayor de idiomaticidad (Olza, 2011a: 112).

Esta característica es potencial y no esencial, por lo que en función de esta y de la motivación se pueden distinguir dos tipos de fraseologismos: los prototípicos y los periféricos (Ruiz, 2001; López, 2002). Respecto a la motivación, Álvarez de la Granja (2008) contempla dos tipos de motivación: la externa se basa en la relación entre el significado y la forma significante; y la interna que se origina en el interior del sistema de la lengua y presenta dos tipos (motivación morfológica y paronímica). Otro tipo de motivación es la semántica y para el análisis deberemos tener en cuenta la motivación paronímica y la semántica, pues la primera contempla la homonimia y la segunda, en palabras de Álvarez de la Granja, “designa en la realidad un objeto o concepto con el que lo designado por el primero presenta o una relación de analogía o semejanza, o una relación de carácter extralingüístico [...] basada en asociaciones entre signos que designan objetos o conceptos que están relacionados de alguna manera en la realidad" (Álvarez de la Granja, 2008: 65).

La idiomaticidad puede estar ligada a los mecanismos figurativos y en el análisis de las locuciones somáticas se pretende comprobar cómo mediante determinados tropos se confecciona la UFS de boca en boca. Al respecto se debe tener en cuenta la aportación de Cuenca y Hilferty sobre la idiomaticidad:

En el fondo, la idiomaticidad se basa en la posibilidad de sacar provecho de facetas asociativas de nuestro conocimiento del mundo con el fin de proyectar la situación que éstas representan sobre otra de índole análoga. En muchas ocasiones, estas asociaciones se derivan de nuestros modelos cognitivos, cuya naturaleza idealizada nos permite sacar el sentido pertinente de la expresión en cuestión (Cuenca y Hilferty, 2013: 119).

Los mecanismos figurativos más productivos son la metáfora y la metonimia y estos se tendrán en cuenta en la realización del análisis, asimismo, es posible su complementación y sucesión. De hecho, la metonimia se llega a concebir como la motivadora de las metáforas, es decir, el mecanismo desencadenante de otro mecanismo figurativo, como es el caso de la metáfora. Esta concatenación se podrá comprobar a lo largo del estudio que se lleva a cabo, pues en numerosas ocasiones la variación de una variante de la UF de boca en boca se explica mediante la sucesión de estos mecanismos. 


\subsubsection{Fijación y reproducibilidad}

La fraseologización se suele definir como el proceso mediante el cual se constituye una UF y en este intervienen la idiomaticidad, la fijación y la reproducibilidad. Las UF nacen del uso y repetición de estructuras formadas por varias palabras (combinación libre) y a raíz del uso en contextos determinados se llega a la estabilidad y fijación tanto estructural como semántica. Así pues, nos encontramos ante una combinación fija con significado figurado y con cierto grado de idiomaticidad. Se debe destacar la importancia que tiene el respaldo de la sociedad mediante la repetición de la estructura, pues así es como se fija, mediante la memorización y repetición en bloque.

\subsubsection{Significado literal y significado figurado}

Es conveniente delimitar los dos significados que pueden presentar los fraseologismos, y por ello, en este apartado se pretende dar cuenta de qué se entenderá por significado literal y qué por figurado. Estos no se extrapolan, pues, pueden darse durante el proceso de fraseologización al convertirse una combinación libre de palabras (significado literal) en una unidad fija y estable debido a su significado no deducible de la suma de los significados de sus componentes. De ahí surge la idiomaticidad entendida como la superación del significado literal y conformación de combinaciones fijas de palabras (Ruiz, 2001), en ocasiones, producto de los procedimientos figurativos que crean y consolidan la UF.

Una vez planteados los dos significados y la relación que existe entre estos, debemos tener en cuenta el lexema boca y las acepciones que presenta como lema. Son varias las obras lexicográficas que se han consultado ${ }^{2}$, no obstante, se seguirá el Diccionario del español actual (DEA) debido a que los autores de este también lo son del Diccionario fraseológico documentado del español actual (DFDEA), diccionario que se tendrá en cuenta a la hora de discernir el significado fraseológico de la locución. Mediante esta decisión se pretende dotar al estudio de coherencia y evitar controversias en torno a las diferentes entradas lexicográficas que presentan los diversos diccionarios. A continuación se muestran las acepciones correspondientes al lema boca que se tendrán en cuenta para nuestro estudio, así como la clasificación de estas en significado literal o figurado:

\begin{tabular}{|l|l|}
\hline \multicolumn{1}{|c|}{ Significado literal } & \multicolumn{1}{c|}{ Significado figurado } \\
\hline Órgano del habla. & $\begin{array}{l}\text { Loc adj } \sim \text { a } \sim: \text { :Respiración] provocada en una } \\
\text { persona accidentada, consistente en aplicar la } \\
\text { boca a la de esa persona para insuflarle aire } \\
\text { con un ritmo determinado. }\end{array}$ \\
\hline $\begin{array}{l}\text { Entrada o salida [de un lugar más o menos } \\
\text { estrecho o de una cavidad]. }\end{array}$ & $\begin{array}{l}\text { De } \sim \text { en } \sim: \text { Divulgándose en conversaciones } \\
\text { o comentarios, o en transmisión oral. Frec } \\
\text { con } v s \text { como ANDAR o CORRER. Tb adj. }\end{array}$ \\
\hline$\sim$ a $\sim$ : relación o transmisión oral directa. & \\
\hline
\end{tabular}

Figura 1: Boca y sus significados.

2 Los diccionarios generales que se han tenido en cuenta además del DEA son el Diccionario de la Real Academia Española (DRAE) y el Diccionario de uso del español (DUE). 
A pesar de que el lema boca ofrece 58 acepciones, en la figura 1 se presentan aquellas que podrían aparecer al estudiar la locución de boca en boca. Esta delimitación es el primer paso hacia la pavimentación del objeto de estudio y el segundo paso se llevará a cabo en el apartado 3.4., donde se abordará la problemática existente en torno a los límites entre locución adverbial y locución verbal.

\subsection{Variantes y variaciones: definiciones y clasificaciones}

En torno a la variante y la variación se observa homogeneidad entre varios autores, pues contemplan la variante como un fraseologismo que se halla en la misma lengua funcional, sin diferencia de significado y con una estructura y componentes semejantes a la UF; en cuanto a la variación, esta se presenta como el cambio de significado de una estructura semejante al fraseologismo (Zuluaga, 1980; Corpas, 1996; Mena y Corpas, 2003; Montoro del Arco, 2006).

Las variantes y variaciones han sido clasificadas por dos autores: García-Page $(2008)^{3}$ y Montoro del Arco (2006). La clasificación que se seguirá es la llevada a cabo por Montoro del Arco (2006) ya que este clasifica tanto las variantes como las variaciones. Es imprescindible mostrar qué entiende este autor por variante y variación antes de tratar su clasificación. Según Montoro del Arco, las variantes se dan en la misma lengua funcional que la UF, no presenta diferencia de sentido y son idénticas en su estructura y componentes. En cuanto a las variaciones, de la aportación de dicho autor cabe destacar el cambio de sentido que presentan. A continuación se ofrece grosso modo la clasificación de Montoro del Arco, pues debido a su complejidad es oportuno mostrar el esqueleto que vertebra su clasificación antes de proceder a la explicación de la misma:

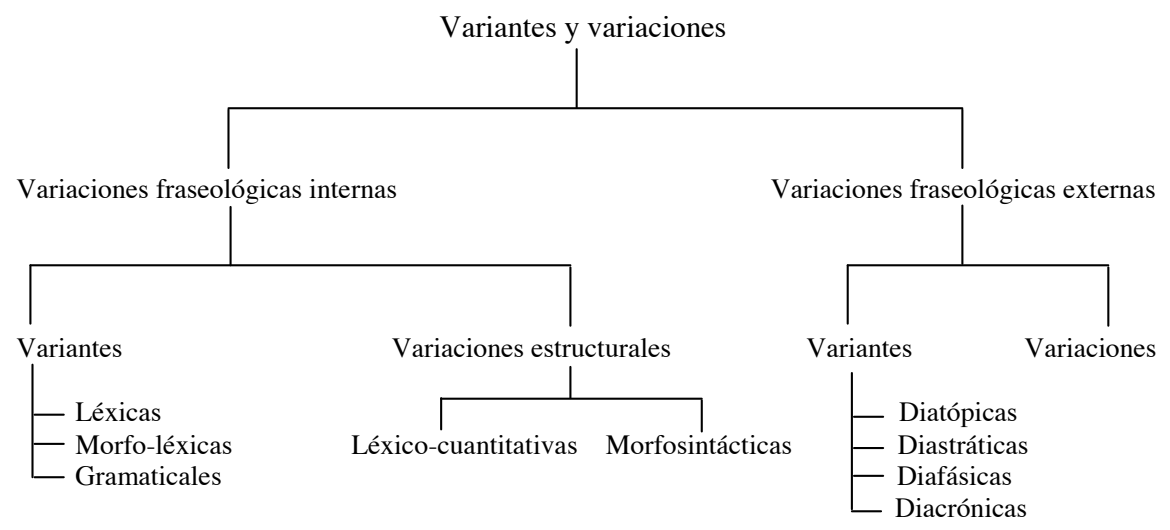

Figura 2: Clasificación de variantes y variaciones (Montoro del Arco, 2006).

La primera distinción que se lleva a cabo es clasificar las variaciones fraseológicas en internas y externas, así pues, debido a la envergadura de la clasificación, en primer lugar se presentarán las variaciones fraseológicas internas y los tipos de variantes y variaciones que hallamos en esta, y finalmente las variaciones fraseológicas externas y sus variantes y variaciones.

3 Este autor distingue tres variantes: variante gramatical, variante léxica y variante sintáctica. 
En las variaciones fraseológicas internas se distinguen tres tipos de variantes (variantes léxicas, morfo-léxicas y gramaticales) en función de la morfología presentada por el elemento sustituido:

Variantes léxicas: alteración de uno o varios componentes de la locución mediante la sustitución ya sea por un lexema o un sintagma. A su vez, dependiendo de la función que desempeña el elemento modificado se distinguen tres tipos de alteración: alteración del núcleo verbal, del núcleo nominal y de ambos núcleos.

Variantes morfo-léxicas: estos cambios se producen en la morfología derivativa o léxica al emplear sufijos o prefijos para crear superlativos, diminutivos o aumentativos.

Variantes gramaticales: es el tercer tipo y a pesar de la similitud que presenta con las variantes léxicas, la diferencia reside en que el componente estructural que se modifica es gramatical. Estas variantes gramaticales se pueden dar mediante dos procedimientos: la sustitución de la categoría morfológica de un segmento léxico (no pegar un ojo > no pegar los ojos), o bien mediante la sustitución de un elemento cuya función sea gramatical ${ }^{4}$.

Las variaciones estructurales articuladas bajo las variaciones fraseológicas internas son dos y estas a su vez se subdividen:

Variaciones léxico-cuantitativas: fraseologismos que admiten la reducción o el incremento de su estructura en función de la fijación y el inventario fraseológico que posea. Hallamos tres tipos de variaciones léxico-cuantitativas que son a) el incremento, sustracción y complementación (hilar [muy] fino); b) sintetización o variación gráfica (a bocajarro y a boca de jarro); y c) las citas interrumpidas fijadas, es decir, aquellos enunciados fraseológicos que no se enuncian al completo y su significado no se ve afectado debido a que el fraseologismo forma parte del conocimiento compartido de los hablantes (ojo por ojo...).

Variaciones morfosintácticas: Modificaciones producidas por la verificación de parte de los comportamientos libres de algún elemento del fraseologismo y estas modificaciones pueden ser a) cambios de género y número; b) alteración del orden y nominalización; y c) UF con casillas vacías que se rellenan con un elemento perteneciente a su paradigma (a mis/tus/sus anchas).

Las variaciones fraseológicas externas, al igual que ocurría con las internas, se dividen en variantes y variaciones. Las variantes que hallamos son léxicas y pueden ser a) diatópicas; b) diastráticas; c) diafásicas; y d) diacrónica. De estas cuatro la que más nos puede ayudar a lo largo del análisis es la cuarta, pues la lengua está en continuo cambio y puede haber variantes pertenecientes a distintas épocas que convivan durante una etapa de la evolución y consolidación del fraseologismo. En cuanto a las variaciones estructurales, estas se caracterizan por implicar varias lenguas funcionales y sería el caso de fraseologismos que están compuestos por lexemas pertenecientes al español peninsular y al hispanoamericano.

Al comienzo de este apartado se proporcionó la definición de variación propuesta por Montoro del Arco y tras presentar y desglosar su clasificación debemos realizar una anotación al respecto, pues algunas de las variaciones estructurales que este autor propone no afectan semánticamente al fraseologismo, como puede ser la variación léxico-cuantitativa. Incluso en

4 Se trata de las tradicionalmente llamadas partículas que abarca artículos, pronombres, preposiciones, etc. 
el ejemplo proporcionado por el propio autor (hilar [muy] fino) se observa que el cambio semántico es prácticamente inexistente. Al respecto, se debe tener en cuenta que los corpus nos proporcionarán casos en los que la variante se haya formado mediante un procedimiento considerado por Montoro del Arco como variación. De este modo, se producirá un choque entre la clasificación elegida y las ocurrencias que manifiestan los corpus, por lo que en dicho caso se optará por entender la variación como un procedimiento que en ocasiones complementa la formación de variantes y no siempre variación va ligada a cambio semántico.

\subsection{Corpus}

\subsubsection{Descripción}

Las UF, al igual que el resto de unidades que conforman el léxico del español, han evolucionado, pues la estructura y el significado actual pueden no coincidir con la primera datación de dicha unidad. La lengua no es estable, al menos en su totalidad, y por ello se recurre a la perspectiva diacrónica para trazar la fraseologización de la locución somática. El análisis debe sustentarse en datos objetivos de la evolución histórica del fraseologismo a lo largo de las distintas épocas y para ello se han utilizado tres corpus (CORDE, CREA y CORPES XXI) mediante los cuales se ha trazado la evolución de de boca en boca. No obstante, cada uno de estos corpus posee unas características determinadas que de una forma $\mathrm{u}$ otra han repercutido en la recopilación de datos.

La principal base de datos que proporciona una perspectiva diacrónica es el CORDE, pues a pesar de que se complementa con el CREA, esta última estaría a caballo entre la diacronía y la sincronía. Estos dos corpus plantean una serie de características que pueden favorecer la documentación de la locución o condicionar el planteamiento del estudio. Ambos poseen un motor de búsqueda que permite delimitar el período histórico, el país e incluso la autoría (para estudios de índole idiolectal). Estas son propiedades que favorecen la búsqueda, sin embargo, en ocasiones no se proporciona una fecha exacta, sino que se baraja un período temporal que en algunos casos puede abarcar dos siglos, pues este hecho se ha producido en varias ocasiones durante la extracción de casos. Esto nos obliga a tomar una decisión acerca de la datación en estos casos y por lo tanto, cuando un caso de de boca en boca se halle entre varios años se tendrá en cuenta la fecha más antigua.

El CORPES XXI complementa los datos del CREA y no es de extrañar que algunos casos extraídos del CREA aparezcan en el CORPES XXI al realizar la misma búsqueda, pues el CREA abarca años contemplados por el CORPES XXI (2001-2004); por ello, cuando suceda se tendrá en cuenta los casos del CREA. El CORPES XXI ofrece fechas exactas y un motor de búsqueda avanzado, no obstante, presenta un contexto reducido que en ocasiones dificulta la comprensión del fraseologismo.

Los tres corpus de referencia mostrados poseen representatividad en cuanto a la variedad geográfica, sin embargo, debido a la importancia del cognitivismo en los fraseologismos y las diferencias cognitivas que pueden presentar los hablantes de español de un lado del charco y del otro, se opta por delimitar el objeto de estudio a la variedad peninsular. Los corpus sincrónicos poseen documentación de la oralidad de los fraseologismos, sin embargo, nuestro estudio versará en torno a las ocurrencias registradas a lo largo de la historia mediante la escritura. 


\subsubsection{Obtención y filtración de datos}

Las características de los corpus que sustentan este trabajo ya han sido expuestas y a continuación se tratará el procedimiento que seguiremos tras la búsqueda de los fraseologismos en los corpus. Se contemplan diversas variables, sin embargo, antes de tratarlas una a una debemos tener en cuenta el cuadro que se presenta a continuación:

\begin{tabular}{|c|c|c|c|c|}
\hline Período de tiempo & Casos & Significado & Valor & Verbo \\
\hline \multicolumn{5}{|l|}{$1201-1250$} \\
\hline \multicolumn{5}{|l|}{$1251-1300$} \\
\hline \multicolumn{5}{|l|}{$1301-1350$} \\
\hline \multicolumn{5}{|l|}{$1351-1400$} \\
\hline \multicolumn{5}{|l|}{$1401-1450$} \\
\hline \multicolumn{5}{|l|}{$1451-1500$} \\
\hline \multicolumn{5}{|l|}{$1501-1550$} \\
\hline \multicolumn{5}{|l|}{$1551-1600$} \\
\hline \multicolumn{5}{|l|}{$1601-1650$} \\
\hline \multicolumn{5}{|l|}{$1651-1700$} \\
\hline \multicolumn{5}{|l|}{$1701-1750$} \\
\hline \multicolumn{5}{|l|}{$1751-1800$} \\
\hline \multicolumn{5}{|l|}{$1801-1850$} \\
\hline \multicolumn{5}{|l|}{$1851-1900$} \\
\hline \multicolumn{5}{|l|}{$1901-1950$} \\
\hline \multicolumn{5}{|l|}{$1951-2000$} \\
\hline 2001-2014 & & & & \\
\hline
\end{tabular}

Figura 3: Tabla para los casos de de boca en boca.

Esta tabla reúne las variables que pueden sintetizar aquellos aspectos más relevantes para la primera aproximación al estudio fraseológico de de boca en boca. La figura 3 corresponde a boca a boca, y las minidiacronías comienzan en el siglo XIII debido a que su primera aparición se registra en la segunda mitad de dicho siglo. Dichas minidiacronías pueden variar en función de la fecha de aparición de cada variante.

Es conveniente llevar a cabo la distinción operativa entre significado y valor con la finalidad de evitar posibles conflictos entre dichos términos. La variable valor es abierta, no se trata de un inventario cerrado debido a que se entenderá por valor aquellos significados (figurados o literales) que en función del contexto pueden presentar un contenido semántico u otro. De este modo, los valores corresponden a las diferentes acepciones que las obras lexicográficas 
presentan (DFDEA y $D E A$ ). El siguiente cuadro (figura 4) se corresponde con la figura 3, no obstante, en este aparece la recopilación y clasificación de los casos de boca a boca:

\begin{tabular}{|c|c|c|c|c|}
\hline $\begin{array}{l}\text { Período de } \\
\text { tiempo }\end{array}$ & Casos & Significado & Valor & Verbo \\
\hline $1201-1250$ & - & - & - & - \\
\hline $1251-1300$ & 2 & $\begin{array}{l}\text { Literal }(0) \\
\text { Figurado (2) }\end{array}$ & Relación o transmisión oral directa & Fablare \\
\hline $1301-1350$ & - & - & - & - \\
\hline $1351-1400$ & 1 & $\begin{array}{l}\text { Literal }(0) \\
\text { Figurado (1) }\end{array}$ & Relación o transmisión oral directa & Fablare \\
\hline $1401-1450$ & 1 & $\begin{array}{l}\text { Literal }(0) \\
\text { Figurado (1) }\end{array}$ & $\begin{array}{l}\text { Divulgándose en conversaciones o comentarios, } \\
\text { o en transmisión oral }\end{array}$ & Recibir \\
\hline $1451-1500$ & - & - & - & - \\
\hline $1501-1550$ & 1 & $\begin{array}{l}\text { Literal }(0) \\
\text { Figurado (1) }\end{array}$ & $\begin{array}{l}\text { Divulgándose en conversaciones o comentarios, } \\
\text { o en transmisión oral }\end{array}$ & Oír \\
\hline $1551-1600$ & 4 & $\begin{array}{l}\text { Literal (0) } \\
\text { Figurado (4) }\end{array}$ & Relación o transmisión oral directa (4) & Hablar (2) \\
\hline $1601-1650$ & $\begin{array}{l}6 \\
4\end{array}$ & $\begin{array}{l}\text { Literal (2) } \\
\text { Figurado (2) }\end{array}$ & $\begin{array}{l}\text { Relación o transmisión oral directa (2) } \\
\text { Contacto de una boca con la otra(2) }\end{array}$ & $\begin{array}{l}\text { Hablar } \\
\text { Juntar } \\
\text { Informar } \\
\text { Atar }\end{array}$ \\
\hline $1651-1700$ & 1 & $\begin{array}{l}\text { Literal (0) } \\
\text { Figurado (1) }\end{array}$ & Relación o transmisión oral directa & $\varnothing$ \\
\hline $1701-1750$ & - & - & - & - \\
\hline $1751-1800$ & - & - & - & - \\
\hline $1801-1850$ & - & - & - & - \\
\hline $1851-1900$ & - & - & - & - \\
\hline $1901-1950$ & 7 & $\begin{array}{l}\text { Literal (3) } \\
\text { Figurado (4) }\end{array}$ & $\begin{array}{l}\text { Relación o transmisión oral directa (4) } \\
\text { Contacto de una cavidad bucal con otra (3) }\end{array}$ & $\begin{array}{l}\text { Unir (1) } \\
\text { Hablar (4) } \\
\varnothing\end{array}$ \\
\hline $1951-2000$ & 64 & $\begin{array}{l}\text { Literal (37) } \\
\text { Figurado (27) }\end{array}$ & $\begin{array}{l}\text { Divulgándose en conversaciones o comentarios, } \\
\text { o en transmisión oral (24) } \\
\text { Relación o transmisión oral directa (1) } \\
\text { [Respiración] provocada en una persona } \\
\text { accidentada, consistente en aplicar la boca a la } \\
\text { de esa persona para insuflarle aire con un ritmo } \\
\text { determinado } \\
(35)\end{array}$ & $\begin{array}{l}\text { Comunicar (1) } \\
\text { Enviar }(1) \\
\text { Hacer }(16) \\
\text { Practicar }(7) \\
\text { Recorrer }(1) \\
\text { Iniciar }(1) \\
\text { Reanimar }(1) \\
\text { Saber }(1) \\
\text { Ser }(1) \\
\text { Pasar }(1) \\
\varnothing(1) \\
\varnothing(13)\end{array}$ \\
\hline
\end{tabular}




\begin{tabular}{|c|c|c|c|c|}
\hline & & & $\begin{array}{l}\text { Saludo oral (1) } \\
\text { Personas que reciben información de manera } \\
\text { oral (1) } \\
\begin{array}{l}\text { Transmisión de un líquido u objeto de una } \\
\text { cavidad bucal a otra (2) }\end{array}\end{array}$ & $\begin{array}{l}\varnothing(8) \\
\text { Difundir (1) } \\
\text { Aplicar (1) } \\
\text { Funcionar (2) } \\
\text { Salvar (1) } \\
\text { Generar (1) } \\
\text { Transmitir (1) } \\
\text { Aprobar (1) } \\
\text { Usar (1) } \\
\text { Correr } \\
\text { Ser }\end{array}$ \\
\hline 2001-2014 & 16 & $\begin{array}{l}\text { Literal (0) } \\
\text { Figurado (16) }\end{array}$ & $\begin{array}{l}\text { Divulgándose en conversaciones o comentarios, } \\
\text { o en transmisión oral (11) } \\
\text { [Respiración] provocada en una persona acci- } \\
\text { dentada, consistente en aplicar la boca a la de } \\
\text { esa persona para insuflarle aire con un ritmo } \\
\text { determinado (5) }\end{array}$ & $\begin{array}{l}\text { Funcionar (1) } \\
\text { Resucitar (1) } \\
\text { Hacer }(2) \\
\varnothing(2) \\
\varnothing(5) \\
\text { Hacer }(1) \\
\varnothing(2) \\
\text { Existir (1) } \\
\text { Correr(1) }\end{array}$ \\
\hline
\end{tabular}

Figura 4: Casos de boca a boca.

Observamos cómo el significado de boca a boca solo puede ser literal o figurado, mientras que en la columna valor se presenta disparidad de acepciones. Los datos obtenidos se han almacenado en un documento de Access y en este se contemplan diversas variables que pueden resultar de gran utilidad para el análisis de los casos y el trazado de la fraseologización. A las variables que los corpus CORDE y CREA presentan como predeterminadas (siglo, año, tema y autor) se le añaden en el documento de Access otros campos como son: a) corpus; b) UF, variante, variación o combinación libre; c) forma/estructura; d) contexto; e) observaciones; y f) palabras clave.

\subsection{La unidad de análisis: delimitación y procedimiento de análisis}

A lo largo de los apartados anteriores se ha proporcionado información sobre aspectos relacionados con el objeto de estudio y su investigación. En el presente apartado se delimitará la locución somática, la problemática en torno a su catalogación como locución adverbial o verbal y su perspectiva de análisis.

De boca en boca es un binomio prepositivo formado por la estructura PREP $+\mathrm{N}+$ PREP +N y al respecto García-Page (2008: 123) presenta dos correlaciones prepositivas con carácter fijo y cuyos huecos léxicos son cubiertos por sustantivos escuetos; las más frecuentes son: $d e \sim e n \sim$ y de $\sim a \sim$. La primera de ellas es la que se observa en de boca en boca, no obstante, no se debe pasar por alto la segunda estructura, pues la alternancia entre la preposición en y $a$ es habitual en diferentes épocas y puede haberse producido dicha conmutación en la evolución del fraseologismo. El esquema de $\sim$ en presenta el significado 'con una determinada frecuencia' y $d e \sim a \sim$ como 'totalidad espacial o temporal' por lo que 
nuestra UFS presenta en cierto modo el significado que García-Page plantea al producirse en de boca en boca una repetición o divulgación de información que conlleva la realización de dicha acción en varias ocasiones.

Para discernir qué tipo de locución es de boca en boca se debe tener en cuenta si en los corpus esta UF aparece con verbo y qué tipo de verbo. Para ello resulta imprescindible acudir a los diccionarios fraseológicos, pues deben ser estos los que mediante la institucionalización del fraseologismo arrojen luz a esta cuestión. A pesar de que parece una tarea fácil, al consultar las obras lexicográficas de carácter específico (diccionarios fraseológicos tales como el DELE, DFDEA, DFEM y DFSO) no se obtuvo la unanimidad que se esperaba:

\begin{tabular}{|l|l|l|}
\hline DFSO (1921) & \multicolumn{1}{|c|}{ Locución adverbial } & \multicolumn{1}{c|}{ Locución verbal } \\
\hline DFEM (1996) & \multicolumn{1}{|c|}{-} \\
\hline DFDEA (2004) & $\begin{array}{l}\text { De boca en boca: } \\
\text { adv Divulgándose en } \\
\text { conversaciones o comentarios, } \\
\text { o en transmisión oral. Frec con } \\
\text { vs como andar o correr. }\end{array}$ & $\begin{array}{l}\text { Andar u.c. de boca en boca (f.). Ser } \\
\text { de dominio público, propagarse. } \\
\text { Andar/estar u.p./u.c. en boca(s) de } \\
\text { alguien (inf.). Ser objeto de la mur- } \\
\text { muración de alguien. }\end{array}$ \\
\hline DELE (2009) & \multicolumn{1}{|c|}{$\begin{array}{l}\text { De boca en boca: } \\
\text { andar/correr/propagarse [algo] de } \\
\text { boca en boca; [loc. verb.] (col) (f). } \\
\text { propagarse/andar/ correr de persona } \\
\text { a persona, oralmente. }\end{array}$} \\
\hline
\end{tabular}

Figura 5: De boca en boca en las obras lexicográficas.

De las tres obras lexicográficas que recogen la locución que nos ocupa, se seguirá el $D F D E A$ puesto que son los autores que confeccionaron el diccionario general que se tuvo en cuenta para la obtención y clasificación de los significados de boca. Asimismo, se deben tener en cuenta los datos proporcionados por los corpus y si de boca en boca aparece con o sin verbo, ya que el uso registrado del fraseologismo muestra cómo se contempla esta locución, si como adverbial o como verbal. En la base de datos realizada se presentan los casos obtenidos y no hay unanimidad, puesto que hay casos en los que la locución no aparece con un verbo, aparece con los verbos mencionados en las obras lexicográficas o con otros verbos que no se tienen en cuenta en dichas obras.

No es de extrañar que en las diversas etapas de la lengua la UF que nos ocupa conviva con otras formas, ya sean variantes o variaciones de una variante de la UF. Los corpus sincrónicos muestran que hay varias estructuras coetáneas a de boca en boca en la actualidad y estas se 
registran en los diccionarios actuales como fraseologismos o variantes. Esta contemporaneidad nos da pie a realizar el análisis partiendo de la sincronía, por lo que de boca en boca en nuestro estudio se contemplará como UF y en función de si hay cambio semántico o no se articularán las variaciones y variantes. Independientemente de la perspectiva que se postule a la hora de abordar la locución, se parte de la primera aparición de esta para observar los posibles cambios semánticos y variaciones estructurales. Debido al número de casos que presenta de boca en boca (438) en el siguiente apartado se analizarán varios casos por siglo.

Con este trabajo se pretende realizar un acercamiento diacrónico y sincrónico a la locución somática mediante la complementación entre fraseología y cognitivismo, por ello, se realizará el análisis desde la perspectiva fraseológica (variaciones y variantes estructurales) y simultáneamente se adoptará la perspectiva cognitiva para arrojar luz a la aparición y fijación de las combinaciones de palabras. De este modo, el análisis propiamente fraseológico se llevará a cabo bajo las directrices de Montoro del Arco (2006) y su clasificación; mientras que para abordar la fraseologización desde la perspectiva cognitiva se seguirá a Cuenca y Hilferty (2013).

\section{Análisis: hacia la fraseologización de de boca en boca}

Tras la recopilación de datos se procede a la realización del análisis cuantitativo y cualitativo de las ocurrencias del fraseologismo, sus variantes, sus variaciones y sus combinaciones libres. Para realizar el análisis se dividirá este en varios siglos con la finalidad de observar detenidamente el proceso de fraseologización. Dicho análisis se llevará a cabo mediante la contemplación de varios aspectos: se trazará el proceso evolutivo mediante la contemplación de las diferentes estructuras y simultáneamente se abordará la locución desde la perspectiva cognitivista, mediante las asociaciones lingüísticas y extralingüísticas.

El FS de boca en boca presenta un total de 438 casos entre UF, variantes, variaciones y combinaciones libres; el número elevado de casos propicia la contemplación del análisis mediante la división y agrupación de siglos en función de los casos y los cambios semánticos y estructurales que se produzcan. A lo largo de la historia del fraseologismo este ha coexistido con diversas formas y se debe tener en cuenta las obras lexicográficas sincrónicas para observar qué fraseologismos en la actualidad podrían ser considerados como variantes de de boca en boca. A continuación se muestran algunas de las UF que el DFDEA presenta en la entrada correspondiente a boca y que pueden ser o pudieron ser variantes de nuestro objeto de estudio:

De boca a boca $\rightarrow$ BOCA A BOCA [3]

Correr de boca en boca $\rightarrow$ DE BOCA EN BOCA

De boca en boca. $a d v$ Divulgándose en conversaciones o comentarios, o en transmisión oral. Frec con vs como andar o correr. Tb adj. \| Mas-Matute Literatura 47: Existen dos clases de fábulas, las milesias... y aquellas que corren de boca en boca, llamadas apólogas. D Plaja Literatura 99: El trasiego de boca en boca origina que de cada romance se encuentren infinidad de versiones (Seco, 2004: 191).

Boca a boca. adj [Respiración] provocada en una persona accidentada, consistente en aplicarle aire con un ritmo determinado. \| Gac 11.5.69, 74: Se arrodillaron y en un instante comenzaron a aplicar la respiración boca a boca. 2 boca a boca. $m$ Respiración boca a boca $\|$ Yo le hubiera hecho con gusto el boca a boca..., todo menos dejarle ir así. 3 boca a boca (o, más raro, de boca a boca). $a d v$ En conversaciones o comentarios, o en transmisión oral. Tb adj. \|A.R. Sánchez Ver 23.2.21 (In): El buen hacer que se transmite boca 
a boca será tu mejor publicidad. Alegre Locus 75 (C): dice que las mujeres van a sentirse ofendidas, y eso es bueno, porque hoy por hoy siguen siendo la mejor propaganda boca a boca de un producto. M. Gómez SEIM 9.5.99 (In): La publicidad boca a boca es lo que mejor funciona en estas situaciones. Matute Gadú 680: Terroríficas leyendas propagadas boca a boca. 4 boca a boca. $m$ Relación o transmisión oral directall C. Santos D16 1.5.83,8: Antonio Garrígues sigue haciendo la campaña en la calle. Cada día dedica siete u ocho horas al "boca a boca", el contacto directo con los electores (Seco, 2004: 190).

De boca a boca presenta el mismo valor que boca a boca en su tercera acepción ('en conversaciones o comentarios, o en transmisión oral') por lo que en algún momento de la historia de la lengua estos dos fraseologismos han convergido. La información obtenida del DFDEA nos muestra que boca a boca y de boca a boca se asemejan a la locución somática de boca en boca en la forma y el significado. En la siguiente tabla se muestran los casos por siglo de UF, variantes, variaciones y combinaciones libres de de boca en boca:

\begin{tabular}{|c|c|}
\hline Siglo & Casos \\
\hline XIII & 2 \\
\hline XIV & 1 \\
\hline XV & 3 \\
\hline XVI & 21 \\
\hline XVII & 22 \\
\hline XVIII & 10 \\
\hline XIX & 107 \\
\hline XX & 241 \\
\hline XXI & 31 \\
\hline $\mathbf{4 3 8}$ & \\
\hline
\end{tabular}

Figura 6: Casos por siglo.

Tal y como se mencionó con anterioridad, el análisis se llevará a cabo mediante la división en subapartados que comprendan varios siglos. Así pues, una vez mostrados los casos agrupados en siglos y las posibles variantes, se procede a la realización del análisis.

\subsection{Siglos XIII, XIV, XV, XVI y XVII}

A lo largo de los siglos XIII, XIV, XV, XVI y XVII hallamos 49 casos que aparecen entre el 1260 y 1698 . En el siglo XIII se registran dos casos de boca a boca cuyo valor dista del actual significado:

$(4)^{5}$ Muchas cosas uos ouiera a escreuir, mas no quis con tinta ni con pennola, ca te cuedo ueer ayna, e fablaremos boca a boca. Paz sea contigo. Saludan te los amigos. Saluda tu a nuestros amigos, a cada uno por si.

5 Los ejemplos que se mostrarán y analizarán en este apartado han sido extraídos de los corpus de referencia diacrónicos y sincrónicos. 
(5) Mas el mi sieruo

moysen no es tal car en toda mi casa es muy

fiel. [8] Car boca a boca fablo con el \&

paladino \& non por espeios vee el

adios nin por figuras. Pues porque non

temiestes dezir mal del mi sieruo moysen.

Los casos (4) y (5) presentan una variación de la variante boca a boca al manifestarse un significado figurado distinto al de la variante: 'relación o transmisión oral directa'. La estructura boca a boca presenta un significado global que en principio no se podría discernir del significado de cada componente; no obstante, el hecho de que este fraseologismo posea un homónimo literal ayuda a intuir su significado figurado. Dicho significado figurado se ha formado a raíz de la intervención de mecanismos figurativos (Cuenca y Hilferty, 2013), por lo que se procederá al análisis de dichos mecanismos que han dado como resultado el significado figurado de boca a boca con el valor 'relación o transmisión oral directa'. En el proceso de creación del significado figurado que presentan los casos (4) y (5) en boca a boca se produce dos procesos metonímicos y uno metafórico cuyo resultado es la acepción 'relación o transmisión oral directa', a continuación se muestran y explican dichos mecanismos figurativos:

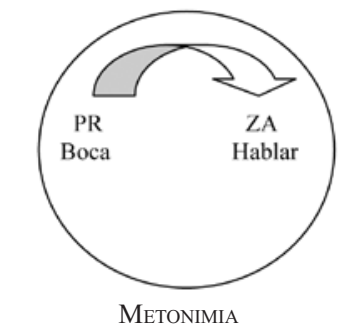

EL ÓRGANO POR LA FUNCIÓN
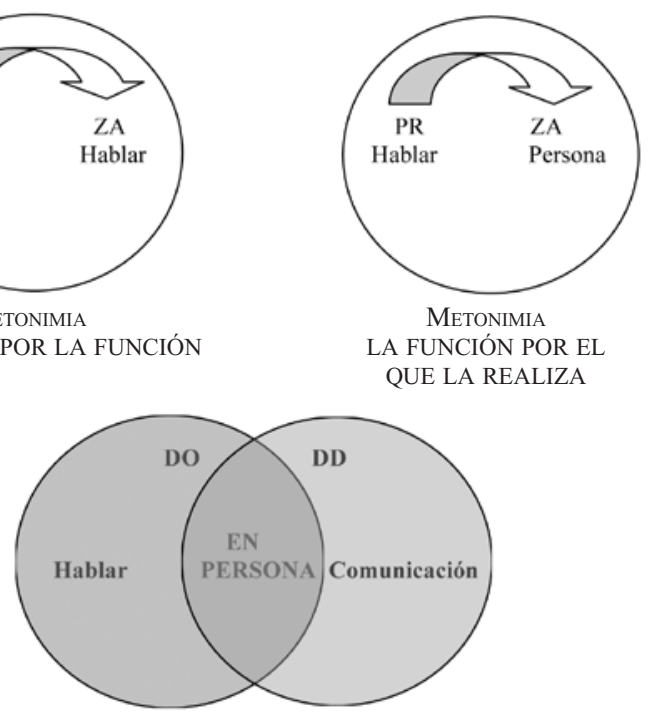

METÁForiZACIÓN DE LA RELACIÓN ENTRE LA COMUNICACIÓN VERBAL Y LA PRESENCIA

Figura 7: Procesos metonímicos y metafóricos de boca a boca.

En la figura 7 se presentan los tres procedimientos figurativos, dos metonimias y una metáfora. En cuanto a las primeras, se caracterizan por referirse a una estructura implícita (ZA) a través de otra explícita (PR), en concreto hallamos en a) EL ÓRGANO POR LA FUNCIÓN y en b) LA FUNCIÓN POR EL QUE LA REALIZA. La metáfora, al contrario que la metonimia, asocia entidades pertenecientes a dominios distintos (DO-DD) y de dicha proyección subyace una entidad, en este caso de la asociación hablar-comunicación obtenemos 'en persona', 
pues en el siglo XIII las conversaciones solo podían realizarse en presencia del otro. En cuanto al papel que esta locución desempeña, se puede observar en los ejemplos que el fraseologismo se presenta como una forma concreta de hablar y equivalente a una conversación presencial.

Esta variación manifiesta supremacía hasta el siglo XIV, pues no será hasta el siglo XV cuando dicha variación coexista con otras formas como la UF y las variantes boca a boca y de boca a boca. La variante gramatical boca a boca aparece en el 1450 con el significado figurado 'en conversaciones o comentarios, o en transmisión oral'. Esta variante es gramatical debido a la sustitución de la preposición en por $a(e n>a)^{6}$ y también se produce una variación estructural léxico-cuantitativa por reducción al desaparecer la preposición de sin que el significado global varíe:

(6) Y las partes que son escriptas de fuera de vna manera y dentro de otra, que es vn secreto diuino que ynporta grande misterio, y otras cosas del rresçebimiento i que son entregadas solamente a la Ley rresçebida boca a boca?, Así es dicho sobre los versos, que dize: "A mis leies guardaredes, $i$ la Ley escripta y la Ley del rresçebimiento" lo qual es allende de la escriptura fasta que fizieron saber en el Maçoret que la Vaf de Gahon es la meytad de la cuenta de la Ley, letra por letra, para enseñar el estudio que touieron en las cosas rresçebidas y la vnidat del misterio postrimero de la cuenta de las letras todas juntas, el qual non se conternía en ellos sy vna sola fallesçiese u ouiese sobrada otra.

El caso (6) es una variante gramatical y presenta una variación léxico-cuantitativa por reducción sin que esta repercuta en el significado del fraseologismo, pues Montoro del Arco presenta este tipo de variación como producto de la fijación del inventario de constituyentes y por ello, el significado no ha variado. La variante que se muestra en el ejemplo hace referencia al modo de recibir información de manera indirecta, pues la noticia se expande y comparte de manera oral y de unos a otros (ver apartado 4.4.).

La última ocurrencia que hallamos en este siglo se documenta a finales (c 1499-1502) y esta representa la primera documentación de la unidad fraseológica de boca en boca cuyo significado figurado es 'divulgándose en conversaciones o comentarios, o en transmisión oral':

(7) Pues yo bien siento mi honra. Pluguiera a Dios que fuera yo ellos y perdiera la vida, y no la honra y no la esperanza de conseguir mi comenzado propósito, que es lo que más en este caso desastrado siento. ¡Oh mi triste nombre y fama, cómo andas al tablero de boca en boca! ¡Oh mis secretos más secretos, cuán públicos andarés por las plazas y mercados!

El mecanismo figurativo que interviene en la UF y las variantes no se ha expuesto con anterioridad por resultar más adecuado realizarlo una vez se hayan visto las variantes que coexisten con la UF. De este modo, a continuación se presenta un ejemplo de la variante de boca a boca:

(8) $[\ldots] \&$ asi convjene que de entonçes fasta oy non se çeso de se rresçbir de boca a boca sin se escreujr jamas en libro.

6 Esta conmutación es habitual, pues así lo manifiesta Coromines (1980-1991) al hacer hincapié en la alternancia que se produce entre estas dos preposiciones utilizadas indistintamente. 
De boca a boca, al igual que la variante, boca a boca (6), hace referencia al modo de recibir una información de manera oral. Las preposiciones de y a que aparecen en la variante (8) manifiestan la circulación de la información que estaba en un punto inicial y se dirige hacia otro punto, otro destinatario. La LS de boca a boca se conforma y fija mediante la metonimia LA PARTE POR EL TODO y la metaforización de la oralidad conjugada entre el DO boca y el DD comunicación:
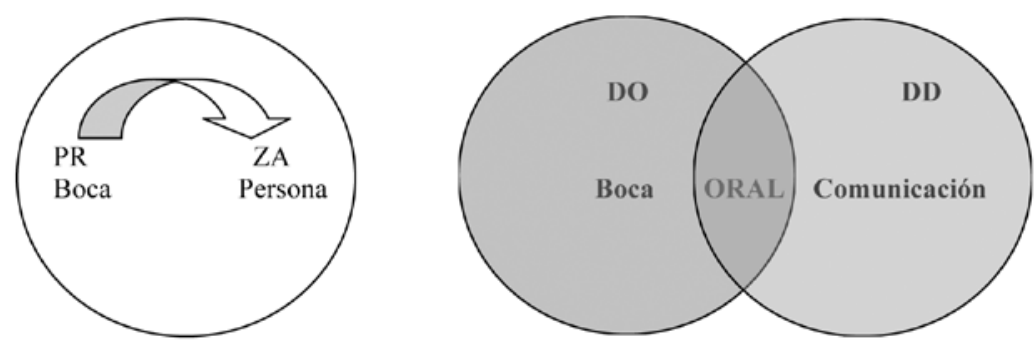

Figura 8: Metonimización y metaforización de de boca a boca.

En los esquemas anteriores se puede apreciar el proceso metonímico mediante el cual aparece el órgano en vez de la persona que lo posee, por lo que tras de boca a boca subyace la acción de una persona a otra. Dicha acción llevada a cabo por el órgano es el resultado de la asociación del DO y el DD, se trata de la oralidad, de la transmisión oral de una persona a otra.

A partir del siglo XVI el número de casos aumenta de manera considerable, pues hallamos 21 casos frente a los 2 o 3 que se manifestaban en los siglos anteriores. En este siglo coexiste la UF con diversas variaciones (de boca a boca, de boca en boca y boca a boca) y con la variante de boca a boca. En la década de los treinta hay un par de casos de la UFS junto a boca a boca (variación) y de boca a boca como combinación libre. La primera combinación libre de de boca a boca presenta el significado literal 'de una cavidad a otra':

(9) Asi que, resumiendo este camino, digo que desde el estrecho de Magallanes, costa a costa, hasta la Equinocial y cabo Blanco (por donde de ella pasa en la Tierra Firme en la parte oriental), hay, contando asimesmo las ciento e diez leguas del mesmo Estrecho (de boca a boca en su longitud), mill e seiscientas e cuatro leguas. Pero más de dos mill serán de navegar para lo andar.

En el 1549 aparece la primera variación de de boca en boca cuyo significado figurado dista del proporcionado por la UF, tan solo conserva la direccionalidad proporcionada por las preposiciones:

(10) Anda la cabra de roca en roca, como el bostezo de boca en boca.

La ocurrencia (10) es una variación de la UF cuyo significado es 'contagiar', pero este contagio no se realiza mediante el contacto de una cavidad con otra, sino que se lleva a cabo 
por el aire. Esta variación es producto de la metonimia EL ÓRGANO POR LA PERSONA QUE REALIZA LA ACCIÓN, pues el contagio del bostezo se realiza de persona en persona sin que haya contacto entre estas:

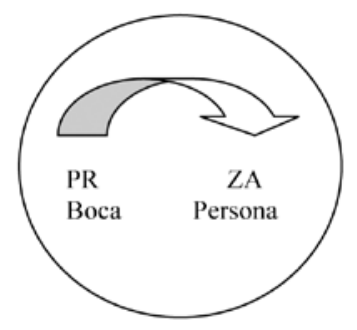

Figura 9: Metonimia de de boca en boca ('contagiar').

A mediados de siglo aparecen varios casos de la UF y será a finales cuando además de observar casos de la variación boca a boca (ver figura 7) vuelva a aparecer la variante gramatical por permutación de boca a boca. En el siglo XVI aparecen diversas estructuras coexistentes (las variaciones boca a boca, de boca a boca y de boca en boca, y la variante de boca a boca) y esta disparidad de estructuras se prolongará hasta el XVII. A pesar de que en el siglo XVII no aparecen las variantes, por el contrario, se muestra la hegemonía de la UF, pues más de la mitad de las ocurrencias son de de boca en boca. Este siglo presenta dos novedades, en primer lugar, el aumento de combinaciones libres con la estructura boca a boca y de boca a boca; y por otro lado, la aparición de la variación de la variante diacrónica voca a voca:

\section{(11) Que me digas pluma a pluma, por no poder voca a voca, que tienes otro devoto.}

En (11) voca a voca es una variación al tratarse de una acción llevada a cabo de manera presencial, pero, esta variación ya se produjo en el siglo XIII con la variación de la variante boca a boca. Boca a boca y voca a voca están relacionadas, pues esta última podría ser una variante fraseológica externa diacrónica de la primera al presentar cambios ortográficos propios de la época y la coexistencia de estas dos variantes en la diacronía.

\subsection{Siglos XVIII y XIX}

En el siglo XVIII el número de casos se reduce por primera vez mientras que el siglo XIX es un siglo prolífico en cuanto al número de ocurrencias, pues dicha cifra supera la centena. De los casos registrados en el siglo XVIII, el 90\% pertenecen a la UF (aparecen en la década de los treinta y setenta) y el $10 \%$ restante corresponde a una combinación libre cuya estructura es de boca a boca. A partir del siglo XIX se observa un notable incremento de ocurrencias al superar el centenar de casos proporcionados por el corpus diacrónico de referencia. En este período coexisten variantes, variaciones, combinaciones libres y la UF, no obstante, es digna de resalte la abundancia de ocurrencias de la UF por conformar casi un $94 \%$ de los casos con un total de 100 casos frente a las combinaciones libres de palabras 
(4 casos), dos ocurrencia de las variantes de boca en boca y de boca a boca, y una variación de la UF. A continuación se mostrará un caso de combinación libre, pues el número de ocurrencias de estas ha aumentado considerablemente en este siglo:

\section{(12) El estrecho les pareció que tenia cien leguas de boca á boca.}

Este es el primer caso de combinación libre registrado en este siglo y se diferencia del resto de combinaciones libres con las que coexiste en la segunda preposición, ya que $a$ indica la distancia que hay de una cavidad a otra, mientras que con la preposición en se hace referencia a la situación de transito. Se apuntó con anterioridad el incremento de casos de la UFS y su hegemonía, este hecho nos permite realizar un acercamiento a los verbos que aparecen junto al fraseologismo. El verbo correr aparece en la mayoría de los casos documentados en el CORDE, ya que supone 45 casos de los 100 que se dan en este siglo. La combinación con este verbo se manifiesta en los diccionarios fraseológicos, no obstante, otro verbo que según las obras lexicográficas suele aparecer con la UFS es andar. Este solo aparece en dos ocurrencias de la UF, hecho que llama la atención al no corroborarse los datos aportados por las obras lexicográficas y en su lugar destacan verbos como circular, repetirse y volar.

\subsection{De la diacronía a la sincronía: siglos XX y XXI}

Los datos del siglo XX se extrajeron del corpus diacrónico de referencia y del sincrónico de referencia (CORDE y CREA), pues el primero de ellos da cuenta de prácticamente la totalidad de los siglos y las décadas que faltan para completar el siglo se obtuvieron del CREA. Las ocurrencias extraídas de estos dos corpus son más del doble presentadas en el siglo anterior, con un total de 241 casos. Por ello, es conveniente exponer qué tipo de estructuras nos vamos a encontrar en los más de doscientos casos obtenidos del CORDE y CREA:

\begin{tabular}{|c|c|}
\hline Tipo de estructura & Casos \\
\hline Unidad fraseológica & 151 \\
\hline \multirow{4}{*}{ Variantes (32) } & boca a boca (13) \\
\cline { 2 - 2 } & el boca a boca (9) \\
\cline { 2 - 2 } & un boca a boca (2) \\
\cline { 2 - 2 } & de boca a boca (2) \\
\cline { 2 - 2 } & del boca a boca $(6)$ \\
\hline \multirow{4}{*}{ Variaciones (35) } & boca a boca (24) \\
\cline { 2 - 2 } & el boca a boca (14) \\
\cline { 2 - 2 } & un boca a boca (3) \\
\cline { 2 - 2 } & de boca a boca (4) \\
\hline \multirow{4}{*}{ Combinación libre de palabras (13) } & del boca a boca $(\varnothing)$ \\
\cline { 2 - 2 } & boca a boca $(5)$ \\
\hline \multirow{2}{*}{$\mathbf{2 4 1}$} & de boca en boca $(5)$ \\
\hline
\end{tabular}

Figura 10: Ocurrencias del siglo XX. 
La prolijidad del siglo XX se manifiesta desde un principio, pues el primer caso data del 1902 y es una combinación libre (boca a boca). Tras esta ocurrencia se sucederán más de 15 casos de la UF en seis años, cuyos verbos son de movimiento y predomina correr:

(13) Corrieron alli de boca en boca noticias referentes al duelo del día anterior.

A finales de la primera década del siglo hallamos cuatro variaciones de la variante diacrónica boca á boca que aparecen con el mismo valor y verbo que los casos de boca a boca (XIII). En estas aparece el verbo hablar y la variación posee el significado 'relación o transmisión oral directa', variación formada y consolidada mediante la complementación de dos metonimias y una metáfora (ver figura 7). El predominio de la UF es incuestionable, esta unidad se ha fijado y muestra de ello son los numerosos casos que presenta frente a las otras formas. A finales de los treinta y principios de los cuarenta aparecen dos variaciones de la variante de boca a boca cuyo significado figurado es 'contagiar' y el procedimiento figurativo que se produce en la creación de esta variación es la metonimia (ver figura 9). Desde el 1941 hasta el 1961 los casos registrados pertenecen únicamente a la LS de boca en boca, son 20 años en los que no hay productividad de variaciones y variantes, tan solo hallamos la aparición de tres combinaciones libres (dos con la estructura de boca a boca y una de de boca en boca). Los casos del 1951 presentan la estructura de boca a boca y el significado literal 'transmisión de un líquido u objeto de una cavidad bucal a otra'.

En 1962 aparece la variación de la variante boca a boca cuyo significado figurado es 'relación o transmisión oral directa', sin embargo, es digno de mayor resalte la aparición de una nueva variación de dicha variante con la estructura el boca a boca:

(14) Para mí que le estuvo haciendo el boca a boca, tú me dirás.

\section{(15) Estuvo haciendo el boca a boca.}

En (14) y (15) aparece una variación de la variante boca a boca formada mediante la variación estructural morfosintáctica por nominalización, y el significado que presenta es '[respiración] provocada en una persona accidentada, consistente en aplicar la boca a la de esa persona para insuflarle aire con un ritmo determinado'. Esta variación posee un homónimo literal que es 'pasar algo de una cavidad bucal a otra' y en cierto modo es el significado que tiene la variación, con la diferencia de que se pasa aire en unas determinadas circunstancias.

Entre 1966 y 1983 las estructuras que coexisten son la UFS y la variación de la variante boca a boca con el significado '[respiración] provocada en una persona accidentada, consistente en aplicar la boca a la de esa persona para insuflarle aire con un ritmo determinado'. Esta variación además de presentar la forma nominalizada el boca a boca, aparece con la misma estructura que su variante boca a boca. La variante boca a boca hasta este momento es la más productiva en este siglo, pues ha dado lugar a la variación (el) boca a boca y también en 1983 aparecerá otra variación, se trata del siguiente caso:

(16) Aquel Welch me envía un boca a boca; esto es, un saludo verbal, no teman. 
En el caso (16) hallamos una variación estructural morfosintáctica por nominalización al aparecer el artículo indefinido un. El procedimiento figurativo que interviene en la formación de esta variación es la metonimia EL TODO POR LA PARTE, pues se asocian dos entidades conceptuales contiguas que pertenecen al mismo dominio y en él hallamos un PR y una ZA:

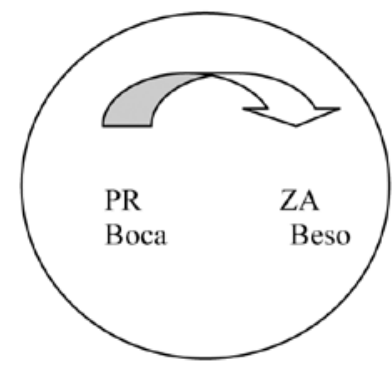

Figura 11: Procedimiento metonímico de un boca a boca con el significado de 'saludo'.

Nos hallamos ante una metonimia conceptual en la que el PR hace referencia de manera implícita a la zona activa (beso), de este modo enviar un boca a boca equivale a "enviar un beso', y por lo tanto, es un tipo de saludo.

En el 1985 aparece de nuevo la variante de boca a boca, sin embargo, dicha variante no tendrá prácticamente peso, ya que se produce la coexistencia de la UF con la variación el boca a boca de la variante boca a boca y se producirá una novedad, la aparición de dos variantes nuevas:

(17) Al menos una vez al año, la Golden Line anunciaba drásticos cambios en la empresa: ascensos, descensos, promociones, nombramientos y despidos. La noticia recorría vertiginosamente la agencia en un boca a boca extraoficial, y durante algunas semanas el personal se esforzaba más que nunca en hacer méritos.

(18) Al margen de los comunicados, los socios de Cartera Central propalan por el método del boca a boca algunos asuntos de mayor gravedad: Mario Conde no está interesado en la gestión.

El (17) es una variante gramatical al sustituirse $e n>a$ y también se lleva a cabo otro procedimiento, una variación estructural léxico-cuantitativa por reducción al desaparecer la preposición de y otra por incremento de la estructura mediante el artículo un que nominaliza la estructura (variación estructural morfosintáctica por nominalización). El caso (18) representa una nueva variante fruto de de boca a boca, se trata de del boca a boca y de esta cabe destacar que en el ejemplo se presenta como un método de comunicación y divulgación de información. Por otro lado, nos hallamos ante una variante de la UF, ya que posee el mismo significado que esta y en concreto, nos hallamos ante una variante gramatical al sustituirse $e n>a$. Otro procedimiento que se lleva a cabo y altera la estructura pero no el significado de esta es la variación estructural léxico-cuantitativa por incremento, pues entre la preposición de y el núcleo somático aparece el artículo definido el. 
Los últimos años del siglo XX presentan un abanico de estructuras ya sea por las diversas variaciones, las variantes (el) boca a boca y de boca a boca, o de boca en boca como UF. De los últimos casos que manifiesta este siglo se debe destacar un rasgo que subyace a las variantes del boca a boca y boca a boca, se trata de un contexto de uso que solo presentan estas dos variantes y que se anticipó en el análisis de la ocurrencia (18):

(19) Por otro lado, cuatro ministros daban mitines en cines y locales cerrados siguiendo con la campaña del boca a boca.

En este caso el fraseologismo hace referencia a realizar propaganda o publicidad, por lo que en este contexto de uso el fraseologismo se muestra como un sistema de promoción. Este contexto de uso se puede considerar integrado en la acepción de de boca en boca y de boca a boca [3], no obstante, se debe tener en cuenta que no es lo mismo saber de un rumor o noticia mediante la transmisión oral en conversaciones que realizar la promoción de un producto o programa mediante un sistema llamado "boca a boca". Casos como el (18) y el (19) se producen a finales del siglo XX y el hecho de que se revise este significado y se contemple como una acepción distinta o incluida en la proporcionada por el DFDEA depende de la trascendencia que este uso presente en el siglo XXI. El siglo XX presenta numerosas variaciones, la variante (el) boca a boca y la unidad fraseológica, panorama que se prolonga hasta el siglo XXI, tal y como se expondrá a continuación.

El hecho de que en los primeros años del siglo XXI ya haya casos deja entrever que no hay ruptura entre un siglo y otro, sino que se continúa con los casos de el boca a boca y del boca a boca que clausuraron el siglo anterior. Un dato a tener en cuenta es que en el siglo XXI hay casos de (el) boca a boca en un contexto de uso determinado que presentan esta estructura como un sistema de propaganda y realización de publicidad.

Las aportaciones que se pueden realizar en torno al siglo XXI son conjeturas que se constatarán o refutarán. La primera conjetura tiene que ver con el análisis cuantitativo, se ha observado que a partir del siglo XIX el número de casos (tanto de la UFS como de sus variantes y variaciones) ha incrementado cada siglo de manera considerable, y a pesar de tener 32 casos, estos se han registrado en un periodo de 14 años (los años que ya han transcurrido del siglo XXI). No obstante, si tomamos la primera década observamos que son 30 los casos que se producen, por lo que si se mantiene este número de ocurrencias por década la UF consolidada en el siglo XX podrá incluso presentar y fijar nuevas variantes o variaciones que en el siglo XX no se han consolidado, como es el caso de un boca a boca.

La segunda conjetura se expuso al final del análisis del siglo XX y es el hecho de que si se sigue utilizando del boca a boca y el boca a boca como sistema publicitario los diccionarios deberán tener en cuenta este contexto de uso y barajar la posibilidad de incluirlo en la entrada de de boca a boca o de boca a boca; o bien contemplarlo como un contexto de uso.

\subsection{Verbos y evidencialidad}

La locución somática analizada en los apartados anteriores presenta el significado actual 'divulgándose en conversaciones o comentarios, o en transmisión oral' y de este se desprende indicadores de la fuente y modo de adquisición de la información. A través del 
verbo que acompaña a la locución se puede observar el aspecto evidencial que aporta, no obstante, en primer lugar se debe indagar en el concepto de evidencialdad que propone Aikhenvald (2011):

Is a grammatical category with source of information as its primary meaning -whether the speaker saw the event happen (known as visual evidential), or hear it but didn't see it (non-visual evidential), or made an inference based on general knowledge or visual traces (assumed evidential and inferential evidential respectively), or was told about it (known as reported, second hand, or hearsay evidential) (Aikhenvald, 2011: 602).

Esta autora, además de distinguir diferentes tipos de información en función de la obtención de la misma, realiza diferentes clasificaciones de la evidencialidad en categorías gramaticales como deícticos, sustantivos y verbos (Aikhenvald, 2004; 2011). De la aportación de Aikhenvald, nos interesa especialmente la clasificación de los diferentes verbos, ya que "different evidential specifications come from (A) verb of speech, (B) verbs of perception, and, less frequently, (C) verbs of other semantic group" (Aikhenvald, 2011: 604). Asimismo, también se debe tener en cuenta la clasificación que realiza esta autora en función de cómo se adquiere la información: I. Visual, II. No visual, III. Inferencia, IV. Supuestos, V. Rumor, y VI. Citas (Aikhenvald, 2004: 63-64).

La locución somática, tal y como se ha mostrado a lo largo del análisis de su fraseologización, puede aparecer tanto con verbo como sin él. Con la finalidad de indagar en la evidencialidad de las diferentes variantes y variaciones, se realizará una aproximación a los verbos que aparecen junto a las construcciones fijas de palabras. De los datos obtenidos en los corpus se extrae el predomino de verbos de movimiento como correr, ir o saltar. Frente a dicha hegemonía hallamos verbos de lengua que apenas aparecen en 15 ocasiones, de las cuales 10 pertenecen a boca a boca. Esto se debe al significado de la variación ('relación o transmisión oral directa') ya que se hace referencia a la fuente primaria de la información, así como al modo en que ha sido adquirida (mediante la audición de la información). La obtención de la información se realiza de manera presencial, y muestra de ellos se da a través de verbos como hablar o comunicar. Además, si tenemos en cuenta la clasificación llevada a cabo por Aikhenvald (2004: 63), la evidencialidad que se muestra en boca a boca pertenece al segundo grupo que distingue: información no visual. Llama poderosamente la atención que a diferencia de boca a boca, en los casos de de boca a boca y de boca en boca no se han obtenido ocurrencias con el verbo hablar, y la mayoría de los casos presentan un verbo de movimiento como saltar, ir o volar.

Inherente a la definición de de boca en boca es la intervención de la audición, y si en el párrafo anterior se ha planteado los verbos de lengua mediante los cuales se presentaba la situación $X$ dice/habla $A$, a continuación se presentará la situación $X$ oye/ve $A$. De este modo, los casos correspondientes a los verbos de percepción (segundo tipo de verbo en la clasificación de Ankhenvald) se reducen a oir. No es de extrañar que aparezca dicho verbo, pues la locución hace referencia a la transmisión oral y esta solo se percibe mediante la audición. Por ello, nos encontramos ante el segundo tipo de obtención de información (al igual que ocurría con boca a boca), debido a que esta se obtiene a través del sentido auditivo. Sin embargo, se debe destacar que no aparecen verbos semejantes a oir como escuchar y tan solo se produce una ocurrencia con este verbo a lo largo del proceso de fraseologización. 
Por último, se debe destacar la escasez de verbos que conlleven evidencialidad, ya que en primer lugar, numeras ocurrencias se presentan sin verbo y en el caso de que la UF o sus variantes aparezcan junto a un verbo, en la mayoría de estas se trata de verbos de movimiento. Así pues, se debe destacar la aparición relativamente abundante de verbos de habla en los casos de boca a boca en contraposición con las combinaciones de boca a boca y de boca en boca.

\section{Conclusiones}

La intersección entre la fraseología y la lingüística cognitiva ha dado como resultado el estudio de la locución somática de boca en boca desde las perspectivas diacrónica y sincrónica. Se debe tener en cuenta la aportación del cognitivismo no solo en el estudio de la fijación y consolidación del fraseologismo, sino el papel que los mecanismos como la metáfora y la metonimia han desempeñado en el análisis semántico de de boca en boca. A través de la complementación de metáforas y metonimias se ha demostrado que la corporeidad se presenta como fundamental para expresar y entender el mundo que nos rodea. Cuenta de ello se ha dado en el apartado correspondiente al análisis, pues los diferentes mecanismos figurativos muestran la implicación de las funciones y propiedades del órgano boca en la creación de nuevos significados.

El análisis diacrónico hacia las raíces de la LS de boca en boca pone de manifiesto la importancia de la diacronía para entender la sincronía, pues se ha podido observar su productividad mediante las numerosas variantes y variaciones que se han creado en torno a esta unidad fraseológica. La mayoría de las variantes se han consolidado y hoy en día aparecen en las obras lexicográficas, no obstante, se debe destacar del boca a boca y (el) boca a boca. Estas combinaciones fijas de palabras aparecen a finales del siglo XX y desde su aparición se observa la tendencia ascendente del número de ocurrencias en un contexto determinado en el que el significado se concreta al contemplarse como un método o sistema de divulgación con fines comerciales y publicitarios. Debido al número de casos de estos fraseologismos, se prevé que en las próximas obras lexicográficas se tengan en cuenta y por lo tanto, estas construcciones sean incluidas como un contexto de uso, o bien se cree una entrada lexicográfica nueva.

Debido a la profundidad histórica que presenta la unidad fraseológica y a su prolijidad, se ha podido llevar a cabo una aproximación a los verbos que aparecen junto a estas construcciones. En concreto, se ha indagado en la evidencialdiad que el componente verbal puede aportar y es digno de reseñar el contraste que se observa entre la variación boca a boca (siglo XIII) y las demás variantes, ya que la primera se combina con verbos de habla, frente al resto de construcciones que aparecen con verbos de movimiento.

De la interdisciplinaridad de la fraseología subyace un amplio abanico vías y perspectivas de análisis desde las cuales se puede abordar una unidad fraseológica. En el presente trabajo se optó por la adopción de las perspectivas diacrónica y sincrónica, con la finalidad de contribuir a los estudios diacrónicos de los fraseologismos. Asimismo, se ha mostrado el grado de convencionalización que tanto de boca en boca como las variantes y variaciones presentan, ya que los hablantes las utilizan sin percibir los mecanismos cognitivos que las vertebran. Del estudio llevado a cabo se desprende la rentabilidad de la complementación de la fraseología y la cognición, así pues, debido a los resultados obtenidos se indagará en 
otros fraseologismos con el núcleo somático boca adoptando la metodología de este artículo. Así pues, en futuras investigaciones se abordará el estudio de la locución somática punto en boca y su posible vinculación al ámbito costurero u ortográfico, incógnita que se despejará a través de las metáforas y metonimias.

\section{Referencias bibliográficas}

Aikhenvald, A. Y. (2004): Evidentiality, Oxford/New York, Oxford University Press.

Aikhenvald, A. Y. (2011): "The grammaticalization of evidentiality". En Heine, H. y H. Narrog, págs. 602-610.

Adam Stepién, M. (2007): "Metáfora y metonimia conceptual en la fraseología de cinco partes del cuerpo humano en español y polaco", Anuario de Estudios Filológicos, $\mathrm{n}^{\mathrm{o}}$ 30, págs. 391-409: http://dehesa.unex.es:8080/xmlui/bitstream/handle/10662/913/0210-8178_30_391.pdf?sequence=4 (05-05-2014).

Álvarez de la Granja, M. (2008): Lenguaje figurado y motivación: una perspectiva desde la fraseología, Frankfurt, Peter Lang.

Carneado, Z y A. M. Tristá (1980): Estudios de fraseología, La Habana, Instituto de Literatura y Lingüística.

Casares, J. (1992[1950]): Introducción a la lexicografía moderna, Madrid, Consejo Superior de Investigaciones Científicas.

Chomsky, N. (1957): Syntactic structures, La Haya, Mouton de Gruyter.

Coromines, J. y J. A. Pascual (1980-1991): Diccionario crítico etimológico de la lengua castellana, Madrid, Gredos.

Corpas Pastor, G. (1997): Manual de fraseología española, Madrid, Gredos.

Croft, W. y D. A. Cruse (2004): Cognitive Linguistics, Cambridge, Cambridge University Press.

Cuenca, J. M. y J. Hilferty (2013): Introducción a la lingüistica cognitiva, Barcelona, Ariel Lingüística.

Díaz-Vera, J. E. (ed.) (2015): Metaphor and metonymy across time and cultures: Perspectives on the sociohistorical linguistics of figurative language, Berlin/Munich/Boston, Walter de Gruyter GmbH.

Echenique Elizondo, M. T. y M. J. Martínez Alcalde (2011): Diacronía y gramática histórica de la lengua española, Valencia, Tirant Humanidades.

Fauconnier, G. (1994): Mental spaces: aspects of meaning construction in natural language, Cambridge, Cambridge University Press.

Fillmore, C. (1985): "Frame and the semantics of understanding", Quaderni di Semantica, 6, págs. 222-254.

García-Page, M. (2008): Introducción a la fraseología española: estudio de las locuciones, Barcelona, Anthropos.

Geeraerts, D. (ed.) (2006): Cognitive Linguistics: Basic Readings, Berlin/New York, Mouton de Gruyter.

Geeraerts, D. (2010): Theories of Lexical Semantics, Oxford, Oxford University Press.

Heine, B. y T. Kuteva (2005): Language Contact and Grammatical Change, Cambridge, Cambridge University Press.

Heine, B. y H. Narrog (2011): The Oxford Handbook of Grammaticalization, Cambridge, Cambridge University Press. 
Hopper, P. J. y E. C. Traugott (2003): Grammaticalization, Cambridge, Cambridge University Press.

Ibarretxe-Antuñano, I. y J. Valenzuela (dirs.) (2012): Lingüística Cognitiva, Barcelona, Anthropos Editorial.

Johnson, M. (1987): The body in the mind. The bodily basic of meaning, imagination and reason, Chicago, University of Chicago Press.

Lakoff, G. y M. Johnson (1980): Metaphors we live by, Chicago, The University of Chicago Press.

Langacker, R. W. (1999): Grammar and conceptualization, Berlin/New York, Mouton de Gruyter.

Langacker, R. W. (2009): Investigations in Cognitive Grammar, Berlin/New York, Mouton de Gruyter.

López, C. (2002): Aspectos de fraseología contrastiva (alemán-español) en el sistema y en el texto, Frankfurt, Peter Lang.

Martí Contreras, J. (2004): "Introducción a proyectos fraseológicos en el siglo XVIII”, Res Diachronicae, 3, págs. 67-71: https://resdiachronicae.files.wordpress.com/2013/12/volumen-3-08_67_72_martinez_contreras_jorge.pdf (14-07.2015).

Martínez López, J. A. y A. Myre Jorgensen (2009): Diccionario de expresiones y locuciones del español, Madrid, Ediciones de la Torre.

Mena Martínez, F. y G. Corpas Pastor (2003): “Aproximación a la variabilidad fraseológica de las lenguas alemana, inglesa y española”, Estudios de Lingüística de la Universidad de Alicante, 17, págs. 181-202.

Moliner, M. (2007): Diccionario de uso del español, Madrid, Gredos.

Montoro del Arco, E. T. (2006): Teoría fraseológica de las locuciones particulares: las locuciones prepositivas, conjuntivas y marcadoras en español, Frankfurt, Peter Lang.

Olza Moreno, I. (2011a): Corporalidad y lenguaje: la fraseología somática metalingüistica del español, Frankfurt, Peter Lang.

Olza Moreno, I. (2011b): “Aspectos sobre la relación de idiomaticidad, metáfora y metonimia”. En Santibáñez, C. y J. Osorio, págs. 167-216.

Peirsman, Y. y D. Geeraerts (2006): "Metonymy as a prototypical category", Cognitive Linguistics, 17 (3), págs. 269-316.

Pérez-Salazar Resano, C. (2007): “Unidades fraseológicas y diacronía. Sobre las fórmulas negativas de ninguna manera y en absoluto", Estudios Humanísticos. Filología, 29, págs. 253-281: file://C:/Users/Alicia/Downloads/Dialnet-UnidadesFraseologicasYDiacronia-2339406\%20(2).pdf (12-07-2015).

Ruiz Gurillo. L. (1997): Aspectos de fraseología teórica española, Valencia, Universidad, Anejo XXIV de Cuadernos de Filología.

Ruiz Gurillo, L. (1998): La fraseología del español coloquial, Barcelona, Ariel.

Ruiz Gurillo, L. (2000): "Las metáforas de un día en los medios de comunicación españoles", Estudios de Lingüistica de la Universidad de Alicante, 14, págs. 199-215.

Ruiz Gurillo, L. (2001): "La fraseología como cognición: vías de análisis”, Lingüistica Española Actual, XXIII, págs. 107-132.

Santibáñez, C. y J. Osorio (2011): Recorridos de la metáfora: cuerpo, espacio y diálogo, Concepción (Chile), Cosmigonon Editorial.

Seco, M. (dir.) (2004): Diccionario fraseológico documentado del español actual: locuciones y modismos españoles, Madrid, Aguilar lexicografía. 
Seco, M., O. Andrés y G. Ramos (2011): Diccionario del español actual, Madrid, Aguilar lexicografía.

Traugott, E. C. y R. B. Dasher (2002): Regularity in semantic change, Cambridge, Cambridge University Press.

Varela, F. y H. Kubath (1996): Diccionario fraseológico del español moderno, Madrid, Gredos.

Real Academia Española: Banco de datos CORDE: Corpus diacrónico del español. Disponible en http://www.rae.es (04/06/2014).

Real Academia Española: Banco de datos CREA: Corpus de referencia del español actual. Disponible en http://www.rae.es (04/06/2014).

Real Academia Española: Banco de datos CORPES XXI: Corpus del español del siglo XXI. Disponible en http://www.rae.es (04/06/2014).

Zuluaga, A. (1980): Introducción al estudio de las expresiones fijas, Berne, Peter Lang. 


\title{
IMPLICACIONES DE LA FRECUENCIA DE USO DE LAS LOCUCIONES EN LA ELABORACIÓN DE UN DICCIONARIO ${ }^{1}$
}

\author{
InMaculada Penadés Martínez \\ Universidad de Alcalá \\ inmaculada.penades@uah.es
}

Recibido: $26 / 05 / 2015$

Aceptado: 03/06/2015

\begin{abstract}
Resumen
En este artículo se reflexiona, en primer lugar, sobre la frecuencia de las locuciones en relación con los límites que los investigadores establecen para el periodo de tiempo calificado como actual. En segundo lugar, se muestra cómo, aun limitándose a un corpus determinado, la situación de los estudios en fraseología, a día de hoy, vuelve extremadamente compleja la tarea de indicar la frecuencia absoluta de una locución concreta respecto a un conjunto de locuciones o la relativa en función de la distribución de las locuciones en clases o en relación con las unidades léxicas simples con las que la locución se vincula. En tercer lugar, el análisis de un amplio conjunto de locuciones ya llevado a cabo ha mostrado que, en la frecuencia de uso de una locución, influye su pertenencia a un determinado estado de lengua, la existencia de variantes no marcadas de la locución en cuestión y la posibilidad de que se dé una combinación de palabras homónima de la locución, pero de naturaleza no fraseológica. Los tres puntos mencionados se examinan para establecer sus implicaciones en la redacción de un diccionario de locuciones idiomáticas del español.

PALABRAS CLAVE: fraseología, lexicografía, locuciones, frecuencia.
\end{abstract}

\begin{abstract}
In the first place, this article is a reflexion on the frequency of idioms in relation to the limits established by researchers for the period of time which can be defined as the present. Secondly, we have shown how, despite having restricted the study to a specific corpus, the situation of phraseology studies today makes it extremely difficult to indicate the absolute frequency of a certain idiom with regard to a set of idioms or its relative frequency according to the distribution of idioms in classes or in relation to the simple lexical units with which the idiom is linked. Thirdly, the previous analysis of a broad set of idioms has shown that the frequency of use of an idiom is influenced by its belonging to a certain period of the language and also by the existence of unmarked variants of the idiom in question and the possible existence of a group of words that is homonymous with the idiom but not phraseological. The three points mentioned have been examined in order to establish their implication in the compilation of a dictionary of Spanish idiomatic expressions.
\end{abstract}

KEYWORDS: phraseology, lexicography, idioms, frequency.

\section{Introducción}

La elaboración de un diccionario de locuciones ${ }^{2}$ idiomáticas del español ${ }^{3}$ ha conducido a plantearse cuáles deben formar parte de su macroestructura y cuáles deben excluirse de ella, en

1 Una primera versión muy reducida de este trabajo se presentó, bajo el título «Factores que influyen en la frecuencia de uso de las locuciones», en el XI Congreso Internacional de Lingüística General, celebrado en Pamplona del 21 al 23 de mayo de 2014.

2 Por locución se entiende la «combinación fija de palabras que funciona como elemento de la oración y cuyo significado no se corresponde con la suma del significado de sus componentes» (Penadés Martínez, 2012b: 23).

3 El DILEA (Penadés Martínez, 2008; Penadés Martínez, 2010). 
función de su carácter de actuales o no actuales. Por otra parte, se ha hecho evidente, asimismo, la necesidad de marcar aquellas que presentan tanto un alto grado de frecuencia como un bajo grado de esta misma particularidad en relación con el estado de lengua presente. Desde este punto de partida, la búsqueda y el registro de ejemplos de uso para varios miles de locuciones han puesto de manifiesto diversas cuestiones que constituyen el objeto de estudio de este artículo. En primer lugar, se reflexiona (apartado 2.) sobre la relación entre la frecuencia de las locuciones y la periodización que se establece para la lengua, pues los límites que los investigadores fijan para el estado de lengua actual no son homogéneos ni fruto de un acuerdo consensuado. Esta situación conlleva la posibilidad de extender la sincronía presente más allá de los últimos cincuenta años, y de ahí la justificación del registro de locuciones arcaicas o antiguas en un diccionario fraseológico del español correspondiente al periodo actual, pero, al mismo tiempo, surge la obligación de marcarlas en relación con su baja utilización.

En segundo lugar, se muestra (apartado 3.) cómo la marcación de la frecuencia de las locuciones en un diccionario se ve dificultada por cuestiones todavía pendientes de resolución en fraseología, como la pertenencia de determinadas unidades fraseológicas a una u otra clase, pues son muchos todavía los desacuerdos existentes en relación con unidades concretas, de manera que las de clasificación dudosa no pueden ponerse en relación de frecuencia con las de una clase específica ni con las unidades léxicas simples de la clase correspondiente. Por otra parte, la naturaleza polisémica u homonímica de las locuciones, per se o en relación con una combinación de palabras no fraseológica, impide apoyarse de manera absoluta en los instrumentos que facilitan las nuevas tecnologías de la información para alcanzar resultados completamente satisfactorios en el estudio de su frecuencia.

En tercer lugar, el examen de numerosísimos ejemplos de uso de locuciones ha puesto en evidencia (apartado 4.) que la baja frecuencia de muchas de ellas va acompañada de la presencia de variantes no marcadas y de la existencia de combinaciones de palabras no fraseológicas homónimas. De este modo, cuando una locución cuenta con dos variantes no marcadas, es muy habitual que una de ellas sea más frecuente que la otra; de manera semejante, ha podido comprobarse que la colisión homonímica entre una locución y una combinación de palabras no fraseológica, ambas con idéntico significante, repercute en la baja frecuencia del fraseologismo.

Las implicaciones lexicográficas que todas estas cuestiones suponen para la elaboración de un diccionario de locuciones son presentadas en el apartado 5., en el que, de manera específica, se ofrecen las claves para determinar el umbral a partir del cual se puede empezar a fijar la frecuencia de una locución y para diferenciar si aquella es baja o elevada.

La naturaleza de este estudio, el examen de la frecuencia de las locuciones a partir del rastreo y registro de sus ocurrencias en los corpus académicos y en la red, impide la presentación de una hipótesis de trabajo que deba ser probada. El planteamiento adoptado es otro: el análisis de múltiples ejemplos de uso, es decir, la asunción de una metodología inductiva, permite demostrar las tesis de que la frecuencia de las locuciones está condicionada por la concepción que se mantenga del concepto estado de lengua actual, por la decisión que se tome en relación con la clasificación de estas unidades y por las características que de las locuciones muestren los datos examinados: locuciones con variantes y locuciones homónimas de combinaciones de palabras no fraseológicas.

La adopción de una metodología inductiva en una investigación concreta no entra en contradicción, claro está, con su fundamentación teórica. En este trabajo, se parte del estructuralismo y funcionalismo europeos representados por los trabajos de Saussure, Hjem- 
slev, Trubetzkoy y Coseriu citados en las referencias bibliográficas, más los ya clásicos de semántica de Ullmann, así como de las aportaciones que enmarcadas en una fraseología claramente descriptiva ofrecen las obras mencionadas de Zuluaga, Corpas Pastor, Ruiz Gurillo, Mellado Blanco o Penadés Martínez.

\section{La frecuencia de las locuciones en relación con la periodización de la lengua ${ }^{4}$}

Si se vincula el concepto de frecuencia con el de actualidad no se origina una relación biunívoca, pues si bien es cierto que podría considerarse que una locución frecuente es actual, no ocurre lo contrario, es decir, puede darse el caso de que una locución actual no sea frecuente, y ello por su escasa presencia en corpus lingüísticos que la documenten para este periodo. Así, por ejemplo, no puede afirmarse que mandar a hacer gárgaras sea muy frecuente si se tiene en cuenta que el CREA solo registra dos ejemplos, el primero de 1987 y el segundo de 1995:

(1) Sus diferencias databan de 1985, cuando Hussein y Arafat no pudieron coordinar sus puntos de vista sobre negociaciones de paz con Israel. Entonces, el Monarca hachemita mandó a Yasser a hacer gárgaras.

(2) Un día le pregunté a mi madre que Rosa de quién era hija, para ser prima nuestra. Mi madre estuvo a punto de mandarme como siempre a hacer gárgaras, pero luego, no sé por qué, se lo pensó mejor y me dijo lo que Rosa ya me había dicho.

Además, las ocurrencias que figuran en las diez primeras páginas de la red $^{5}$ no pueden considerarse usos reales, pues corresponden a ejemplos inventados para ilustrar repertorios lexicográficos, o, al menos, parecen serlo. Análoga es la situación de llamar Dios a su santo seno, el CREA solo documenta el primero de los siguientes ejemplos y la red, el segundo:

(3) a tu papá lo ahorcaron en Pitiquito pero murió con mucha dignidad y decencia, un hombre debe ser digno y decente hasta que Dios le llame a su santo seno.

4 El análisis de la cuestión enunciada en el título de este apartado va a ceñirse al periodo de tiempo relativo a la actualidad, pues el diccionario de locuciones mencionado, el DILEA, corresponde al estado de lengua ahora vigente. 5 La búsqueda de ejemplos de uso en la red para este artículo se ha llevado a cabo, en los meses de noviembre y diciembre de 2013, y en enero de 2014 mediante el buscador Google y limitándola siempre a las diez primeras páginas de España y en español ofrecidas por el buscador. Esto significa que los textos de donde se han obtenido los ejemplos pertenecen a la modalidad escrita y oral de la lengua, pues el buscador ofrece indistintamente páginas de medios de comunicación, de blogs, de chats, de foros, etc. Los ejemplos de los corpus académicos también han sido extraídos en el mismo periodo de tiempo; por otra parte, aunque el corpus oral académico constituye aproximadamente un $10 \%$ de los últimos períodos del CREA, es posible acceder a través de él a casi 9 millones de formas procedentes de trascripciones de la lengua hablada, con más de 1600 textos encuadrados en dos grandes grupos: textos procedentes de grabaciones de radio o de televisión que han sido transcritos y codificados siguiendo el sistema de codificación de la parte oral de CREA, y textos ya transcritos procedentes de otros corpus orales que, tras la revisión del texto y/o del audio, se han convertido al sistema de transcripción y codificación del CREA oral (Real Academia Española, <http://www.rae.es/recursos/banco-de-datos/crea-oral >. De ahí que, al hablar de la frecuencia de una locución concreta a partir de los datos obtenidos en la red y en los corpus académicos, se trate de su frecuencia absoluta, es decir, independientemente de si es mayor su aparición en textos orales que escritos, por ejemplo, pues no se busca la frecuencia en relación con el tipo de texto en que la locución pueda ser más habitual, dado que tal proceder no sería acorde con un diccionario que pretende recoger locuciones idiomáticas del español actual (lo que supone una limitación diacrónica), peninsular (lo que implica una limitación diatópica), pero pertenecientes a las distintas modalidades de lengua (oral, escrita), propias de diferentes situaciones de habla (formal, informal) o específicas de los varios registros (vulgar, neutro), sin limitaciones diafásicas, por tanto. 
(4) Ahora nos enteramos que, según la forense, el enfermo tiene leves síntomas y que todavía le queda un tirón para que Dios lo llame a su santo seno.

Como se verá en el apartado 4., la baja frecuencia de una locución en un estado de lengua puede estar relacionada con factores relativos a la propia unidad: la existencia de variantes no marcadas o su colisión con homónimos no fraseológicos. Pero también se podría explicar por los desajustes que se dan en el establecimiento de los límites para los periodos o estados por los que ha pasado una lengua. Quiere decirse con ello que, en función de la amplitud o reducción con que se tome el término actual, una locución puede presentar distinta frecuencia.

En efecto, la situación con que nos encontramos en relación con la lengua española, al delimitar el estado de lengua presente, no es uniforme. El calificativo actual, usado sobre todo en diccionarios generales de lengua y específicos de fraseologismos, no es resultado de aplicar una periodización homogénea y consensuada. Así, los autores del DEA, para ceñirse al léxico contemporáneo, establecieron su propio catálogo léxico creando una base documental constituida por textos reales de lengua española no anteriores a la segunda mitad del siglo XX, de este modo se puede afirmar que el adjetivo actual, cuando se publicó el diccionario, hacía referencia a las palabras usadas por los españoles a lo largo de los cincuenta últimos años del siglo anterior (Seco, Andrés y Ramos, 1999: XIII).

No siempre los redactores de diccionarios son tan precisos en sus explicaciones sobre la vigencia temporal del léxico recopilado. Así, por ejemplo, en la «Introducción» al GDUEA, que salió a la luz en 2001, los límites del término actual son más difusos, pues se habla de la lengua «usada en nuestros días», «en el presente histórico en que nos toca vivir», «en los últimos años del siglo XX, uso que ciertamente se prolongará en los inicios del siglo XXI» (Sánchez, 2001: 7 y 9).

Los mismos compiladores del DEA, a principios de este siglo, concretamente en 2004, publicaron una nueva obra lexicográfica, esta vez limitada a unidades fraseológicas, en cuyo título, Diccionario fraseológico documentado del español actual, también aparece el término de la compilación anterior y casi con la misma extensión, aunque no exactamente, pues las unidades registradas pertenecen al español contemporáneo -hasta el 2004, no hasta el fin del XX- y su existencia real está acreditada con testimonios escritos de los últimos cincuenta años. El DFDEA es, en palabras de sus autores (Seco, Andrés y Ramos, 2004: XII y $\mathrm{XV}$ ), un diccionario sincrónico cuya documentación está integrada por citas procedentes de textos publicados entre 1955 y 2004, es decir, el último medio siglo en relación con la fecha de aparición de la obra, periodo en el que viven los hablantes de español de ese momento, tanto los más viejos como los más jóvenes ${ }^{6}$.

6 No siempre el ámbito temporal de un diccionario queda claro desde el propio título, pues, en otros casos, aparecen denominaciones como moderno, en el DFEM, o usual, en el DFE, término este último que obliga a ampliar el análisis a los diccionarios calificados como de uso, ya sean de lengua (DUE) o fraseológicos (JAM). No obstante, este trabajo no va a abordar estas obras, baste con indicar que moderno queda sin precisar en el DFEM, pues sus autores solo indican que recogen las unidades fraseológicas que «proceden de la moderna lengua hablada del español de España» (sic.) (DFEM, 1994: X), mientras que los compiladores del DFE, sin explicar explícitamente que entienden por usual, afirman que el diccionario recoge numerosas locuciones y expresiones de uso normal y frecuente en español, expresiones de la lengua de todos los días (DFE, 2007: 8), lo que no ha sido obstáculo para incluir locuciones como descubrirse la hilaza, 'Aparecer o ponerse de manifiesto un defecto que se procuraba ocultar o disimular', no recogida en el DFEM ni en el DFDEA, aunque sí existe una ocurrencia de esta locución 
Fuera del campo de la lexicografía, actual califica el que, posiblemente, es el mejor corpus del español, el CREA de la Real Academia Española, compuesto, como es de sobra conocido, de una amplia variedad de textos escritos y orales, producidos en todos los países de habla hispana desde 1975 hasta 2004, y estructurado en períodos de cinco años: 19751979; 1980-1984; 1985-1989; 1990-1994; 1995-1999; y 2000-2004. Por su parte, el CORPES XXI (Corpus del Español del Siglo XXI) se solapará parcialmente con el CREA, pues, cuando finalice la primera parte del proyecto en diciembre de 2014, los textos procederán del periodo comprendido entre 2001 y $2012^{7}$, además de originarse la paradoja de restringir la denominación actual al siglo pasado al no utilizarse para los textos de este.

Según lo que se acaba de indicar, los límites para incluir o excluir de un diccionario las locuciones que presenten el carácter de actuales o carezcan de él varían en función de la posición metodológica adoptada, dando lugar, a partir de los datos anteriores, a un periodo fluctuante que comprende desde el 1950 al 1974. En consecuencia, locuciones que se documenten solo en ese espacio temporal -no resulta ahora de interés que también se registren en otros anteriores a él- podrán ser caracterizadas como actuales o no, y, por tanto, recogidas o desechadas para un diccionario, en función de la perspectiva adoptada por el lexicógrafo.

Más todavía, y enlazando ahora el factor de actualidad con el de frecuencia, si una locución es frecuente en el tercer cuarto del siglo XX, el que va de 1950 a 1974, pero se documenta con una baja frecuencia o no se documenta del 1975 hasta el día de hoy, cabría plantearse la posibilidad de excluirla de un diccionario cuya macroestructura esté constituida por locuciones actuales, siempre y cuando el inicio del estado de lengua contemporáneo se fije en el 1975. Unos ejemplos servirán para concretar más la cuestión. La consulta del DFDEA indica que forman parte de su macroestructura locuciones con ocurrencias en textos cuya publicación se sitúa en los años comprendidos entre 1950-1974. Así, el uso de la locución estar hecho con rabos de lagartija, clasificada en el DFDEA (2004: 860) como locución verbal que 'Se emplea, referido a pers, para ponderar su rápido y continuo movimiento o su inquietud"8, está documentado en una obra publicada en 1963; pero hay que tener en cuenta que de esta locución no existen ejemplos de uso en el CREA ni el CORDE, tampoco se encuentra ninguno en las diez primeras páginas de la red; cabría cuestionarse, pues, su carácter actual. Algo semejante ocurre con echar lumbre, 'Dar muestras de mucho enfado' (DILEA), pues el ejemplo del DFDEA es también de 1963, el CREA no registra ninguno y los más modernos del CORDE son de 1909, documentados en dos obras de Benito Pérez Galdós:

(5) No te quiero decir cómo se puso el hombre al ver la profanía... Su cara echaba lumbre, rediós; le tembló la papada, apretó los puños...

(6) En Calatañazor había gran escándalo, y los Gaitines de Soria echaban lumbre, abrasados de ira y furor de venganza.

Por supuesto, no habría que percibir como actual una locución documentada solo con anterioridad al 1950, si ahí se fija el límite de inicio de este periodo de la lengua. Aunque no tengamos la certeza de que no se ha respetado este límite inferior, podría pensarse que no ha

en el CREA, en un texto de Fernando Arrabal: Tarsis considera la red que le tiende su adversario como un arte que descubre la hilaza, le da carrete y toma el peón 19... Db2xa2.

$7<$ http://rae.es/recursos/banco-de-datos/crea >; <http://rae.es/recursos/banco-de-datos/corpes-xxi>.

8 Cuando se proporciona el significado de una locución, se indica el diccionario del que se toma. 
sido una práctica inusual en el DFDEA por los ejemplos que en este diccionario figuran con un asterisco que les precede, indicando que la falta de testimonio escrito se ha suplido por uno oral (DFDEA, 2004: XXVI). Por ejemplo, dar el estallido, con el significado 'Morir por exceso de presión o de fatiga' (DFDEA), viene documentada de ese modo, con un enunciado que parece construido ad hoc:

(7) *Un día darás el estallido si no dejas de trabajar a ese ritmo.

Ni el CORDE ni el CREA registran usos de esta locución y en la red, buscándola con el verbo conjugado en distintas formas, solo se encuentra la siguiente ocurrencia de Fortunata y Jacinta, novela de Pérez Galdós con fecha de publicación 1886-87:

(8) Para que lo sepas; tu mujer te ha faltado con aquel señor de Moreno, que se murió de repente, una noche. La suerte tuya fue que dio el estallido; y es que los corazones revientan, de la fuerza del querer.

Aunque la locución forma parte de la macroestructura del DFDEA, bien podría pensarse que no es actual, en este caso por no estar fehacientemente documentada en textos de la segunda parte del siglo XX.

Como se habrá ido intuyendo esta situación problemática tiene que ver con el concepto de estado de lengua o sincronía, y con varias cuestiones relacionadas con él. Situándose en la perspectiva saussureana, la lingüística sincrónica se ocupa, como se sabe, «de las relaciones lógicas y psicológicas que unen términos coexistentes y que forman sistema, tal como aparecen a la conciencia colectiva» (Saussure, 1945: 174). No obstante, el establecimiento de los principios generales de un sistema o de los factores constitutivos de un estado de lengua no deja de suponer una complejidad reconocida por el propio maestro ginebrino, por cuanto que un estado de lengua no es un punto, sino una extensión más o menos larga, de diez años, de una generación, de un siglo o incluso mayor. De este modo, se comprende su reconocimiento explícito de que la limitación en el tiempo es una de las dificultades que se encuentran en la definición de un estado de lengua (Saussure, 1945: 175-177). Por eso el adjetivo actual para referirse al estado presente de la lengua española puede abarcar desde el 1950 hasta el último año del siglo XX, según la percepción del DEA, desde el 1955 hasta el 2004, desde la concepción del DFDEA, desde el 1975 hasta el 2004, según el punto de vista de la Real Academia Española al confeccionar el CREA, o incluso todo el siglo XX y lo que llevamos del XXI, si aceptamos que un hablante relativamente culto del español actual es capaz de comprender las obras literarias escritas en torno al 1900, porque tiene, si bien parcialmente, una conciencia, con otro término: una competencia, de la lengua de aquella época, aunque sea pasiva.

Más todavía, aunque Coseriu (1978) se mostró fuertemente crítico con la concepción de Saussure sobre sincronía / diacronía, acabó reconociendo el relativismo en la noción de estado de lengua, pues no de otro modo cabe interpretar sus afirmaciones acerca de que 1) en un estado de lengua pueden comprobarse arcaísmos, que, en cuanto existen y funcionan, son elementos actuales; 2) los hablantes tienen la conciencia de que ciertos elementos son más viejos o más nuevos; 3) la lengua sincrónica es un sistema actual de tradiciones lingüísticas antiguas y recientes; y 4) en la lengua conviven durante largo tiempo lo viejo y lo nuevo (Coseriu, 1978: 18, 17, 61 y 128). 
En consecuencia, la imposibilidad de establecer claramente los límites de un estado de lengua y la existencia en él de unidades -en el caso que aquí interesa fraseológicas- que para la conciencia de los hablantes, y como fruto de su reflexión metalingüística, pueden calificarse de arcaicas, antiguas o viejas conduce a afirmar que locuciones como echar lumbre o dar el estallido pueden verse, sí, como actuales, si se amplía esta sincronía hasta principios del siglo $\mathrm{XX}$, y de ahí la justificación de su registro en un diccionario fraseológico del español correspondiente al periodo actual, pero, al mismo tiempo, como no frecuentes, y su escasa frecuencia de uso obliga a plantearse también la posibilidad de su exclusión en un diccionario calificado de actual, o, al menos, a marcarlas en relación con su baja utilización.

Por otra parte, visto que actualidad no implica frecuencia, surge la necesidad de examinar esta última característica de las locuciones per se, sin establecer relación alguna con aquella, tan solo acotando el número de veces que se presenta una locución en conjuntos de textos más o menos extensos. Ahora bien, la determinación de la frecuencia de las locuciones tampoco es una cuestión libre de dificultades, como se muestra en el siguiente apartado.

\section{Dificultades en el análisis de la frecuencia de las locuciones}

$\mathrm{Al}$ observar la situación de otras lenguas, se comprueba que para el inglés se cuenta con datos sobre la frecuencia de las locuciones en corpus de la magnitud del COBUILD, analizado por Moon (1997) ${ }^{9}$, y, como explica Corpas Pastor (2013), se pueden obtener, igualmente, en el corpus BYC-BNC; asimismo, para el alemán existen proyectos de bases de datos que ofrecen información acerca del nivel de la frecuencia de uso de los fraseologismos (Mellado Blanco, 2012: 150). Sin embargo, en el caso del español, los estudios que arrojen luz sobre esta cuestión en corpus de extensión similar son prácticamente inexistentes exceptuando la investigación de Boers y Stengers (2008), quienes han analizado la frecuencia de aparición de 500 locuciones del inglés y del español en el Collins Cobuidl Online Wordbanks de ambas lenguas; no obstante, es necesario indicar que las unidades contabilizadas fueron previamente extraídas, para el caso del español, de dos diccionarios: el de Buitrago Jiménez, Diccionario Espasa de dichos y frases hechas, y el de Giménez, Del dicho al hecho. Por otra parte, las locuciones estaban agrupadas según distintos dominios fuente tales como juegos y deportes, fauna y flora, guerra y agresión, vehículos y transportes o religión y superstición; en este sentido, los tantos por ciento que se ofrecen corresponden a los grupos de locuciones, no a unidades particulares.

Disponemos, en cambio, de análisis sobre conjuntos de textos relativamente reducidos (Penadés Martínez, 2004; Penádes Martínez, 2012a), concretamente sobre dieciocho conversaciones y dieciséis entrevistas, ambas calificables como conversaciones coloquiales periféricas, que ocupan unas veintisiete horas de grabación y contienen una suma aproximada de 322000 palabras, y, por otra, sobre treinta y seis entrevistas que constituyen el corpus PRESEEA-Madrid (Barrio de Salamanca), que comprenden unas treinta y seis horas de grabación $^{10}$.

9 Esta investigadora comprobó (Moon, 1997: 52) respecto a 4000 locuciones que un 30\% aparece menos de una vez por diez millones de palabras; el 35\% aparece entre una y tres veces por diez millones de palabras, y el $20 \%$ tiene una frecuencia de, al menos, un ejemplo por dos millones de palabras.

10 Contamos, además, con las investigaciones de Corpas Pastor (1998) sobre la frecuencia de las paremias en el corpus Vox-Biblograf. Junto a ello Ruiz Gurillo (1998) ofrece porcentajes de los sintagmas prepositivos fraseo- 
Los distintos objetivos de los estudios citados en el párrafo anterior, tanto en el cuerpo del texto como en la nota a pie de página, hacen difícil establecer vinculaciones entre ellos para obtener datos concretos sobre la frecuencia de las locuciones. Aun así, limitándose a Penadés Martínez (2004), se desprende, en primer lugar, que las 10 locuciones verbales más frecuentes del total de 515 emitidas son, con sus respectivos porcentajes: darse cuenta $(12,2 \%)$, hacer falta $(10,8 \%)$, llevarse bien (6,9\%), dar igual $(5,6 \%)$, tener en cuenta $(3,3 \%)$, tener que ver $(3,3 \%)$, dar lo mismo $(2,7 \%)$, echar de menos $(2,3 \%)$, querer decir $(1,9 \%)$ y darse bien $(1,7 \%)^{11} ; \mathrm{y}$, en segundo lugar, que son muy numerosas las que tienen la menor frecuencia relativa hallada, $0,1 \%$, concretamente 103 locuciones verbales de un total de 158 distintas registradas.

Independientemente de los datos reales obtenidos en los estudios que se acaban de citar, lo que encontramos sobre esta cuestión son referencias bibliográficas en las que se comenta la posibilidad de estudiar la frecuencia de las locuciones 1) en bases de datos con determinadas características (Mogorrón Huerta, 2012; Ghezzi, 2012), 2) apoyándose en la lingüística de corpus (Mellado Blanco, 2012) y 3) incluso mediante la utilización del buscador Google (Sevilla Muñoz, 2012). Es previsible que esta deficiencia de investigaciones sobre la frecuencia de uso de las locuciones en español se subsane con el tiempo. Con todo, hay una serie de cuestiones que afectan al estudio de las locuciones en esta lengua desde la situación actual de la fraseología y que vuelven extremadamente compleja la tarea de indicar la frecuencia absoluta y relativa de una locución concreta aun limitándose a un corpus determinado.

\footnotetext{
lógicos, de las unidades fraseológicas verbales y de los esquemas fraseológicos documentados en un corpus de español oral. Castillo Carballo (2000), por su parte, apunta, como resultado del estudio de su corpus, que la base de datos recoge un total de mil seiscientos treinta y cinco registros de unidades pluriverbales, de las que cuatrocientas siete se catalogan como locuciones verbales. Por último, el trabajo de Sosiński (2010) presenta los resultados de un análisis cuantitativo de las unidades fraseológicas empleadas por cuatro inmigrantes marroquíes residentes en Granada y por un hablante nativo de español entrevistado como parte del corpus PRESEEA-Granada.

11 Obsérvese que la mayor parte de ellas no presenta la característica de la idiomaticidad. En efecto, la locución hacer falta significa 'Ser necesario' (DFDEA, 2004: 452), y el verbo faltar, que tiene el mismo significado léxico que el elemento falta de la locución, en su acepción 3, es 'Hacer falta o ser necesario' (DEA, 1999: 2117); por su parte, llevarse bien significa 'Tener buena relación' (DFDEA, 2004: 590) y el verbo llevarse, en la acepción 22, significa, según el DSLE (1996: 953), 'Mantener < una persona > [buenas o malas relaciones con una o varias personas]'; la locución dar igual significa, según el DFDEA (2004: 545), 'Ser indiferente', y el elemento igual de la locución, en su acepción 1: '[Pers. o cosa] de las mismas características externas o internas [que otra [...]], en todo o en el aspecto que se considera' (DEA, 1994: 2550); tener en cuenta significa 'Tener presente o en consideración' (DFDEA, 2004: 345) y contar, verbo con el mismo significado léxico que el elemento cuenta de la locución, en su acepción 10, quiere decir 'Tener presente [...] para algo que se proyecta' (DEA, 1999: 1217); dar lo mismo tiene como significado, según el DFDEA (2004: 653), 'Ser indiferente', y el elemento mismo de la locución, en su acepción 5, se define así: 'Precediendo o siguiendo al $n$, o siguiendo a un pron, indica que se elige una entre varias posibilidades sin que haya motivo de preferencia' (DEA, 1999: 3090); por último, darse bien tiene como significado 'Tener buenas condiciones para actuar' (DFDEA, 2004: 362), mientras que el verbo darse, según el DUE (1966: 859), en su acepción 5, significa 'Resultar fácil para alguien una cosa por tener habilidad o aptitud para hacerla o aprenderla'. Por otra parte, casi todas ellas muestran una fijación formal relativa: darse (perfecta) cuenta, hacer (mucha / poca) falta, llevarse (bastante / muy) bien; dar (exactamente) igual, tener (muy) en cuenta, tener (mucho / poco) que ver, dar (exactamente) lo mismo, echar (mucho / tanto) de menos y darse (bastante / muy) bien. Significa esto que prácticamente todas las locuciones verbales que aparecen con mayor frecuencia están situadas en la periferia, no en el centro, de la clase de las locuciones.
} 
En primer lugar, no son pocas las locuciones sobre las que recaen dudas acerca de su ubicación en una u otra clase. Como se ha indicado en Penadés Martínez (2006), el fin del mundo, moco de pavo, plato de gusto, trigo limpio, agua pasada, el espíritu de la golosina, el pan nuestro de cada día y muchas más son nominales, tal como las recoge el DFDEA, no verbales, $\mathrm{y}$, consecuentemente, pese a su inclusión en esta clase por parte del DSLE, su forma no corresponde a no ser el fin del mundo, no ser moco de pavo, no ser plato de gusto, no ser trigo limpio, ser agua pasada, ser el espíritu de la golosina, ser el pan nuestro de cada día. También para las clases de las verbales y las adverbiales hay unidades que, según la obra lexicográfica tomada como referencia, quedan encuadradas entre las de la primera clase o las de la segunda. Así, las siguientes, por ejemplo: andar/estar a dos velas, andar/ estar como el perro y el gato, andar de boca en boca, andar/estar de uñas, andar/estar ojo avizor, anunciar/gritar/pregonar/publicar a los cuatro vientos, son verbales para el DFEM, si nos atenemos a la paráfrasis definitoria, ya que en este diccionario no se marcan gramaticalmente de manera explícita; sin embargo, la consulta del CREA muestra que está más acertado el DFDEA al considerarlas adverbiales, pues, a dos velas se combina con dejar, estar y quedar; como el perro y el gato, con andar, estar y llevarse; de boca en boca, con una amplia variedad de verbos: andar, circular, correr, extenderse, ir, trasmitirse, etc.; igual que de uñas, que modifica a esperar, estar, poner, recibir, etc.; ojo avizor, por su parte, lo hace sobre andar, estar, mantenerse, pasear; y a los cuatro vientos aparece también con una extensa serie de verbos, como, además, paradójicamente, muestra el propio lema del DFEM: airear, anunciar, clamar, contar, pregonar, proclamar, propagar, repetir, vocear, etc.

Los ejemplos están puestos para hacer ver que, en tanto no tengamos establecida sin discusión la clasificación de una locución dudosa, no tendrá mucho sentido analizar su frecuencia, pues no podrá ponerse en relación con la de las otras locuciones de su clase, ni con la de las locuciones de clases distintas ni con la de las unidades léxicas simples de la clase correspondiente. $\mathrm{Y}$, si se hace, los datos estarán sujetos a una provisionalidad tal que se convertirán en poco fiables para marcar las locuciones en un diccionario en relación con su frecuencia de uso.

En segundo lugar, de manera análoga a como ocurre con las unidades léxicas simples, existen locuciones que cuentan con la particularidad de la polisemia u homonimia ${ }^{12}$, es decir, que presentan más de un significado. No existe acuerdo entre los fraseólogos a la hora de considerar si es un fenómeno que se da en las locuciones de manera usual o no ${ }^{13}$. En cualquier caso, su existencia es innegable, y también lo es la dificultad añadida que supone para contabilizar la frecuencia de uso de estas unidades fraseológicas, pues no basta con su simple registro en un conjunto de textos, es necesario, asimismo, que el propio investigador discrimine si una ocurrencia concreta se refiere a uno u otro significado de una misma cadena formal, de un único significante ${ }^{14}$. Piénsese, por ejemplo, en locuciones como meter caña, para la que pueden establecerse seis significados distintos a tenor de sus ejemplos

12 Para las razones que conducen a no diferenciar entre los fenómenos de la polisemia y la homonimia véase Penadés Martínez (2012b: 267-277).

13 Así, para Corpas Pastor (1996: 115) y Mogorrón Huerta (2012: 71) la polisemia en las locuciones es un fenómeno frecuente, mientras que Larreta Zulategui (2001: 199) y Mellado Blanco (2004: 75) ponen en duda esta particularidad.

14 No proceden así, sin embargo, Boers y Stengers (2008), que hacen caso omiso de los distintos significados de una locución sumando simplemente las distintas ocurrencias de ambos; igual actúan con aquellas locuciones que son parcialmente homófonas: por los pelos y traer por los pelos, no se computan de manera separada. 
de uso, exactamente 'Golpear', 'Atacar criticando', 'Tratar con dureza y con exigencias', 'Provocar', 'Hacer que un vehículo aumente de velocidad' y 'Actuar con fuerza o con agresividad' (DILEA):

(9) Los Domecq, Alfonso Domecq senior y Alfonso Domecq junior, armaron la trapatiesta en la corrida goyesca de Ronda, el año 75, y parece que le metieron caña a un modesto representante de la autoridad.

(10) Ten en cuenta que a Guardiola le metieron caña después de dos partidos empatados. Si lo hicieron con él, que es considerado un icono allí, lo hacen con Vilanova seguro.

(11) Iñaki les mete caña. El técnico sigue aumentando la intensidad de los entrenamientos, en el segundo día, con doble sesión de trabajo.

(12) El líder del PP utilizó con «los mayores» un lenguaje diferente al que suele utilizar en sus mitines normales, intentando dar a los jubilados mensajes positivos y de confianza, de forma que, aunque habló de escándalos y corrupción, sin citar para nada a Roldán u otros casos, fueron los propios asistentes los que «metieron caña» y en cuanto hablaba de austeridad, los jubilados pedian «que devuelvan el dinero que han robado», «Felipe a la cárcel».

(13) he metido caña a la moto para tratar de ganar una etapa. Finalmente no ha sido posible, pero estoy contento porque ayer me encontraba mal fisicamente mientras que hoy me siento muchísimo mejor.

(14) El disco lo hicimos a lo grande y ahi está la gracia del directo. El disco suena con gracia, muy pulido, pero en directo, como somos diez y no treinta, metemos más caña.

En el CREA se recogen solo siete ocurrencias de meter caña, por lo que su análisis no resulta complejo, pero contabilizarlas simplemente y ponerlas en relación, de manera conjunta, con las de otra locución monosémica carece de sentido, ya que uno de los significados anteriores no está registrado en el CREA ('Golpear') y otros lo están aunque con una mínima presencia; de 'Atacar criticando' solo hay dos ejemplos, igual número tiene 'Actuar con fuerza o con agresividad', mientras que se encuentra un registro de cada uno de estos significados 'Tratar con dureza y con exigencias', 'Provocar' y 'Hacer que un vehículo aumente de velocidad'. Los datos de meter caña en conjunto contrastan con los de la variante dar caña, de la que el CREA contiene cincuenta y seis ocurrencias, que deberían ser distinguidas de acuerdo con su significado para, posteriormente, estudiar la frecuencia de las muestras de lengua de cada significado en relación con las correspondientes a la variante meter caña y en relación, asimismo, con las locuciones de la clase verbo, sean monosémicas o tengan más de un significado.

Lo que se quiere indicar con estos datos es la necesidad de una revisión individual, locución por locución, por parte del investigador, pues, a partir de ellos, no existe una locución meter caña, sino seis. Para determinar las locuciones más frecuentes de un determinado corpus, no basta entonces con el simple recuento de una cadena de significantes en una base de datos -efectuado, si así se desea, mediante programas informáticos procesadores de textos-, lo impide el fenómeno de la polisemia u homonimia de las locuciones, y también la homonimia entre una locución y una combinación de palabras que no es fraseológica, tercera cuestión que afecta al establecimiento de la frecuencia de las locuciones dificultándola.

En efecto, junto al caso de meter caña o dar caña, locuciones polisémicas u homonímicas, existen también situaciones como las ilustradas en los siguientes ejemplos, uno de la locución abrir la puerta, con el significado de 'Hacer posible una cosa o hacer que ocurra' 
(DILEA) bajo la forma abre la puerta, y el otro de la combinación de palabras abre la puerta, literal, no fraseológica a partir de la acepción 2. de abrir en el DRAE ${ }^{15}$ :

(15) La ciencia nos abre la puerta al pensamiento crítico, y este nos da libertad, autonomía y control sobre el propio destino.

(16) Mientras nos abre la puerta de su casa, nos habla de otra de sus aficiones: la recogida de fósiles por los distintos andurriales.

El hecho de que existan locuciones que se relacionan con combinaciones no fijas de palabras homónimas ha sido explicado por algún autor considerando que los fraseologismos se caracterizan por poseer, junto a su significado literal, deducible de los significados de cada uno de sus componentes, un significado global en su conjunto, el significado fraseológico (López Roig, 2002: 33-34). Ahora bien, considerar que una unidad fraseológica cuenta con un significado literal, «resultante de la suma de los significados de los componentes que forman la UF tomando ésta como combinación libre de palabras» (Lopez Roig, 2002: 114), conduce a eliminar su condición intrínseca de unidad fraseológica, para asignarle la naturaleza de combinación no fija de palabras, con lo que deja de ser un fraseologismo. No es posible, por lo tanto, hablar de significado literal y fraseológico de locuciones como abrir la puerta, ir arreglado ('Estar equivocado'), llamar a la puerta ('Pedir ayuda'), marcar un gol ('Sorprender') (DILEA), etc., etc. ${ }^{16}$. Lo que la realidad de la lengua muestra es la existencia de combinaciones de palabras homónimas: una no fijada y otra fijada en su forma y en su significado, esta última, pues, fraseológica.

Los casos en que la lengua dispone de una locución homónima de una combinación no fija de palabras no son infrecuentes, al contrario, y su existencia tiene el mismo efecto que la polisemia u homonimia en una misma unidad fraseológica: la necesidad de que el investigador examine ocurrencia por ocurrencia para deslindar la que corresponde a la locución y la que constituye una combinación de palabras no fraseológica, de modo que los recuentos estadísticos de las locuciones no queden falseados ${ }^{17}$, pues, como afirma Corpas Pastor

15 'Separar del marco la hoja o las hojas de una puerta o ventana, haciéndolas girar sobre sus goznes, o quitar o separar cualquier otra cosa con que esté cerrada una abertura, para que deje de estarlo'.

16 Véanse los siguientes pares de ejemplos, el primero de cada par es de la locución y el segundo, de la combinación no fraseológica de palabras:

a) No hay reforma que valga, y Rajoy si cree que ya en la Moncloa va a poder hacer algo por lo suavín va arreglado.

b) ¿Con vaqueros no se va arreglado acaso? ¿Qué puede pasar si no vas arreglado?

a) Su lema es que «sin riesgo no hay éxito» y que lo justo es «dar oportunidades a la gente que llama a la puerta».

b) Alguien dice: «Podríamos pedir unas pizzas y unas cervezas». Aprobación inmediata. Al cabo de veinte minutos, un chico con un casco, que ha dejado la moto en la acera, llama a la puerta y reparte la cena.

a) ¿Que interpretáis de la jugada de Mou? ¿Es un estrechamiento de manos entre entrenador-capitán? ¿Han sido todas las movidas una estrategia para despistar? ¿Qué opináis? Yo reconozco que Mou me ha marcado un gol en esa acción.

b) Leandro - Delantero (fichado por una pasta sólo me ha marcado un gol en 5 partidos, poca titularidad así...). 17 Así, en Mogorrón Huerta (2012: 78-79), se muestra un ejemplo de la aplicación del programa Unitex a un conjunto de textos con la finalidad de obtener las expresiones que contienen el verbo abrir. Una de ellas está registrada en el siguiente fragmento: «[...] Antes de que nadie intentara abrir la puerta, un juez ha suspendido el desalojo y ha [...]», fragmento que, a su vez, forma parte de este otro:

«Todo eso hizo que hoy activistas y vecinos se acantonaran en el lugar preparándose para una defensa numantina. Una joven ha llegado a encadenarse por el cuello a una de las puertas de entrada al recinto. Un cartel 
(2013: 351), actualmente los sistemas de identificación de las expresiones multiverbales (y las unidades fraseológicas lo son) no disponen de las técnicas necesarias para poder procesarlas ni interpretarlas contextualmente de manera adecuada.

El análisis de la frecuencia de las locuciones a partir de los instrumentos que facilitan las nuevas tecnologías de la información es una realidad que cada vez se va haciendo más presente en el quehacer de la investigación fraseológica ${ }^{18}$, pero las posibilidades de ahí derivadas no deben ocultar las dificultades que giran en torno a él por estar todavía pendientes de resolución en fraseología cuestiones que afectan a la esencia de las unidades fraseológicas, como es el hecho de su pertenencia a una u otra clase y su naturaleza polisémica u homonímica per se o en relación con una combinación de palabras no fraseológica. Conviene, pues, que desde la fraseología queden bien delimitadas estas cuestiones antes de abordar el estudio de la frecuencia de unidades fraseológicas concretas.

\section{La frecuencia en locuciones con variantes no marcadas y en locuciones homónimas de una combinación no fija de palabras}

La redacción del DILEA, iniciada por las locuciones pertenecientes a la clase de las verbales, ha evidenciado que, en no pocos casos, la frecuencia de uso de una locución determinada es distinta para sus diferentes variantes no marcadas y se reduce al mínimo cuando existe una combinación no fija de palabras homónima de la locución. Estos dos casos, que son explicados en los siguientes apartados, obligan a tomar decisiones acerca de la inclusión o no, en el diccionario, de una variante y de una locución homónima de una combinación no fija de palabras, o, al menos, acerca de la necesidad de marcar de algún modo su baja frecuencia.

\subsection{La distinta frecuencia de variantes no marcadas}

Antes de abordar esta cuestión, conviene indicar lo que se entiende por variante y por variación no marcada y variación marcada en las unidades fraseológicas. Siguiendo a Zuluaga (1980: 109): «Las variantes fraseológicas son parcialmente idénticas en su estructura y en sus componentes», o a Mellado Blanco (2004: 91): «las variantes fraseológicas se reconocen porque el número de elementos que no varían en ellas supera al de elementos que varían», se considera que llevarse el demonio, por ejemplo, debe analizarse como una variante léxica en relación con llevarse el diablo. Por su parte, no marcado se utiliza para indicar un uso neutro de una variante de una locución; con un ejemplo, las variantes esconder la cabeza bajo el ala meter la cabeza bajo el ala pueden aparecer indistintamente en

advertía: «Peligro de muerte. Detrás de esta puerta una mujer está encadenada por el cuello. Si intentan abrir esta puerta la matarán a ella». Antes de que nadie intentara abrir la puerta, un juez ha suspendido el desalojo y ha ordenado al ayuntamiento que informara a los vecinos de sus planes de desalojo parcela a parcela».

La contextualización de la supuesta locución abrir la puerta indica a las claras que se trata de una combinación no fraseológica que no debe contabilizarse para obtener la frecuencia de la locución homónima. Téngase en cuenta que el contexto constituye una de las salvaguardas contra cualquier posibilidad de confusión provocada por dos homónimos (Ullmann, 1983: 181-182; Ullmann, 1986: 297-298).

18 Ya indica Corpas Pastor (2013: 368): «Quizá en un futuro no muy lejano podamos disponer de los corpus necesarios y las herramientas adecuadas para detectar, extraer, interpretar, representar y traducir todo tipo de unidades fraseológicas»». 
diferentes contextos, hecho que queda representado por la ausencia de una marca que las caracterice en los diccionarios, de ahí su carácter de variantes no marcadas de la invariante de contenido 'No querer ver la realidad' (DILEA) ${ }^{19}$. Por el contrario, marcado señala que una variante fraseológica es propia de alguna sincronía o estado de lengua, de una determinada diatopía, específica de hablantes caracterizados por alguna variante social o particular de alguna situación comunicativa o de una modalidad de lengua; en este sentido, mandar a paseo y mandar a la mierda, la una informal por la imagen mental de acción cotidiana que provoca y la otra vulgar por el elemento mierda que la forma (Penadés Martínez, 2013), constituyen dos variantes marcadas de la invariante de contenido 'Echar o rechazar a una persona o una cosa' (DILEA).

Aunque el estudio de la frecuencia de las variantes de las locuciones puede llevarse a cabo tanto para las que son marcadas como para las no marcadas, aquí va ceñirse el análisis a estas últimas, pues la ausencia de un valor diatópico, diastrático o diafásico ${ }^{20}$ en el uso de una u otra posible variante permite que su comparación se lleve a cabo en relación con la propia locución. Si contaran para el análisis los factores lugar, característica social y situación comunicativa (formal, informal), registro (neutro, vulgar) o modalidad (oral, escrita), las distintas frecuencias de las variantes deberían vincularse a estos factores y no a las distintas formas de una misma locución ${ }^{21}$.

Pues bien, no resulta difícil encontrar ejemplos de locuciones con variantes no marcadas de distinta frecuencia para cada una de estas. Por ejemplo, examinando el caso de cerrarse a la banda / cerrarse en banda, se comprueba que la primera variante está documentada solo en el CORDE en cuatro textos que, para el siglo XX, van de 1916 (uno de Unamuno) hasta el 1951 (uno de Guerra Navarro y dos de Cela); por el contrario cerrarse en banda tiene cuarenta y cuatro ocurrencias en el CREA, la distinta frecuencia de una y otra variante es, pues, notable. En cuanto a pagar con la misma moneda / pagar en la misma moneda, la situación no es la misma, pero el resultado sí: una variante es más frecuente en la actualidad que la otra; la prueba nos la ofrecen, de nuevo, los corpus académicos: en el CREA hay diecisiete ocurrencias de pagar con la misma moneda, frente a cinco de la otra variante; el CORDE, por su parte, recoge este mismo número de ejemplos para esta variante y cuatro para pagar con la misma moneda, lo que significa que el uso de esta última se va incrementando frente a la obsolescencia de la otra.

19 Como se habrá deducido, esta concepción de invariante y variante está, asimismo, vinculada al estructuralismo europeo, sobre todo al praguense y al danés, más en concreto a las reglas de Trubetzkoy (1987: 41-46) para diferenciar sonidos de fonemas y al interés de Hjemslev (1974: 90-108) por establecer las invariantes de un sistema lingüístico.

20 Como viene siendo habitual en los estudios sobre la variación (Casas Gómez y Escoriza Morera, 2009; Kabatek, 2002), no hay obstáculo alguno para que la diafásica incluya la llamada variación diamésica, es decir, la determinada por el medio de realización, gráfico o fónico, de un texto.

21 Obsérvese que no se menciona el valor diacrónico, relativo al factor tiempo, porque, justamente, la mayor o menor frecuencia de una variante respecto de otra puede llevar a la conclusión de que la menos frecuente pertenece a un estado de lengua anterior, con lo que entraría en juego la variación marcada diacrónicamente. Aunque, como esa interpretación no tiene por qué ser la única posible, puesto que una variante no frecuente no ha de serlo necesariamente por ser de una sincronía precedente, el factor tiempo no va a tenerse en cuenta en el análisis de la frecuencia que se presenta a continuación. Dicho de otra manera, cuando se indique de los ejemplos que se van a estudiar que una de las variantes no es frecuente, no se da por hecho que sea más usada en el estado de lengua inmediatamente anterior, puede que sea así o puede que no; la certeza solo podría obtenerse tras un análisis específico con el punto de mira puesto en la variación diacrónica. 
En ocasiones, el DFDEA se hace eco del distinto comportamiento de dos variantes, aunque no siempre; así, de cerrarse a la banda indica que es más raro, pero en la entrada correspondiente a pagar con/en la misma moneda no aparece ninguna marcación, al igual que en otras locuciones ninguna de cuyas dos variantes es frecuente, como levantar de cascos / levantar los cascos; en efecto, en el CREA no hay ningún ejemplo de levantar de cascos que corresponda a la acepción definida por Seco: 'Alborotar[le] o inquietar[le] por la atracción sexual', mientras que en el CORDE se encuentran tres, el último de 1927; por lo que respecta a levantar los cascos, no hay ningún registro en ninguno de los dos corpus de la Academia; los datos son suficientes para considerarla poco frecuente, aunque no presenta la marca raro en el DFDEA.

Los ejemplos sobre esta cuestión podrían multiplicarse, de ahí la necesidad de estar alerta acerca de la posibilidad de que dos variantes no marcadas de una locución tengan distinta frecuencia y, por supuesto, de emprender análisis que la certifiquen, pues es muy probable que una de ellas, al no tener valor distintivo por ser ambas variantes no marcadas, quede abandonada. La explicación puede encontrarse en las causas del cambio lingüístico tal como las entiende Coseriu (1978: 203-204): la libertad lingüística de los hablantes abandona aquello que resulta prácticamente inútil desde el punto de vista funcional. De este modo, un significante de una locución (una variante no marcada) que no sirve para distinguir, que resulta inútil, se abandona.

\subsection{La colisión homonímica entre una locución y una combinación no fraseológica de palabras}

El interés por estudiar la homonimia y, especialmente, las colisiones homonímicas entre unidades léxicas simples se hace patente ya en la semántica tradicional, que se ocupó, de manera hasta cierto punto extensa, de esta cuestión (Ullmann, 1983: 176-192; Ullmann, 1986: 295-317). Pero la vinculación de la ciencia que estudia el significado al nivel de la palabra, con exclusión de los otros niveles lingüísticos y de las unidades fraseológicas equivalentes a las palabras, también, claro está, el retraso en la constitución de la fraseología como disciplina lingüística independiente, impidieron que las unidades fraseológicas, al menos las locuciones, fueran examinadas en relación con las posibles colisiones homonímicas que presentan, no ya entre dos unidades fraseológicas que coinciden en la forma y difieren en el significado, sino entre una combinación de palabras no fraseológica y otra que lo es. Sin embargo, el fenómeno se da, y con repercusiones en la frecuencia de uso de las locuciones, como se mostrará a lo largo de este apartado. Pero antes va a presentarse el fenómeno de la homonimia entre dos combinaciones de palabras, una fraseológica y la otra no, en los términos en que la semántica tradicional lo ha hecho para las palabras.

Reconocida la existencia de la homonimia como una forma de ambigüedad, se hace necesario indicar que los homónimos relativos a combinaciones de palabras, al igual que los homónimos léxicos, no causan problemas en el uso de la lengua al menos por la existencia de dos salvaguardas que limitan las posibilidades de confusión: el contexto y la pertenencia a clases distintas, entre las distintas salvaguardas o soluciones terapéuticas delimitadas por Ullmann (Ullmann, 1983: 181-185; Ullmann, 1986: 296-302) para diferenciar las palabras homónimas. En el caso que aquí se está analizando, puede entenderse por contexto la distinta valencia que una locución y una combinación de palabras no fraseológica presentan, es decir, el distinto número de actantes y su diferente valor sintáctico-semántico. Esta 
salvaguarda tiene especial incidencia sobre las locuciones verbales, pues con excepción de las avalentes, el resto de clases, como los verbos, presentan la particularidad de la valencia. Así, la locución abrir la puerta, citada anteriormente, exige los actantes alguien / algo abre la puerta a algo, frente a la combinación homónima no fraseológica, que, aunque puede construirse con un actante sujeto correspondiente a un alguien o a un algo, no exige el complemento a algo: alguien / algo abre la puerta:

(17) a EI PSOE, junto a un plan completo, con nuevos impuestos y una optimista previsión de lucha contra el fraude, abre la puerta a una bajada de impuestos a las clases más desfavorecidas y a los parados.

(17) b Letona recoge sus cosas, se levanta, abre la puerta y se va.

Igual ocurre con otras locuciones como cubrir la espalda, darse patadas o echar gasolina $a^{22}$ en relación con su correspondiente combinación de palabras homónima no fraseológica. Los actantes de unas y otras son: alguien cubre la espalda a alguien / algo cubre la espalda de alguien o algo cubre la espalda a alguien, dos cosas se dan patadas o una cosa se da patadas con otra / dos personas se dan patadas, alguien echa gasolina / alguien echa gasolina a algo:

(18) a Nadie le cubre la espalda cuando sale a marcar y ya hay un jugador, el checo Poborsky, que puede decir que lo superó ampliamente.

(18) b El impresionante tatuaje que cubre la espalda de Rajon Rondo. El base de los Boston Celtics Rajon Rondo ha decido cubrir su espalda con este llamativo tatuaje con su logo: una erre montada sobre otra.

(18) c Una larga capa sostenida por un collar de plumas y cadenas plateadas le cubre la espalda.

(19) a Espejos granadinos y sillones Luis XV talaveranos convivían dándose patadas ${ }^{23}$.

(19) b Recuerdo que, en la hora del patio, había niños que estaban todo el rato dándose patadas.

(20) a cuando lleguen a la Campana aprovecharán para salir a «echar gasolina», beber un trago en cualquier bar ${ }^{24}$.

(20) $\mathrm{b}$ ¿Es bueno echarle gasolina o aceite al gasoil cuando hace frio?

Lo que no significa que en todos los casos la valencia actúe como elemento que desambigua una locución frente a una combinación de palabras homónima no fraseológica, pues también existen ejemplos en que el número y la naturaleza de los actantes son los mismos en ambas: alguien da en la cabeza a alguien, alguien da una charla a alguien, alguien mete en la cama a alguien ${ }^{25}$.

(21) a hay que seguir y seguiremos dándoles en la cabeza; $y$ hay que combatirlos hasta acabar con ellos.

22 Los significados de las locuciones son, respectivamente, 'Proteger a una persona contra un riesgo o una eventualidad' (DILEA), 'Combinar muy mal' (DFDEA) y 'Echar un trago (tomar bebidas alcohólicas)' (DFDEA).

23 Ejemplo tomado del DFDEA (2004: 753).

24 El ejemplo procede del DFDEA (2004: 490).

25 Los significados de las locuciones en el DILEA son, respectivamente: 'Contrariar las pretensiones de una persona, procurar que no se cumplan', 'Reprender a una persona' y 'Hacer que realice el acto sexual'. 
(21) b uno de los hombres lo sujetó por el cuello, y otro, con la tranca, le dio en la cabeza, y lo golpeó de tal modo, que lo dejó muerto.

(22) a «La segunda operación coincidió con un Everton-Chelsea», recuerda, «al despertarme tenía al lado en la sala de recuperación a un aficionado del Everton. Él tenía la radio puesta y me iba dando el resultado. Luego otro me dio una charla por los pasillos: 'El otro día aposté por vosotros y perdí dinero'. ¡Y yo allí medio mareado!».

(22) b Me pidió que si iba hacia Cibeles le dejara en el Gijón. No pude negarme. Por el camino me dio una charla interminable sobre la libertad.

(23) a El marido dice: «yo, cuando la veo triste, lo que le digo es «ven aquí, cariño» y la meto en la cama».

(23) b A esta edad tu pequeño será más reacio a irse a la cama, y la clave aquí radica en ser firme, coherente y seguir siempre el horario y el ritual de cada día [...] Mételo en la cama cuando esté despierto, evita que se duerma en el salón o en otra cama.

En cuanto a la pertenencia a clases de palabras distintas como salvaguarda contra la homonimia según Ullmann (Ullmann, 1983: 182-183; Ullmann, 1986: 303-304), si, en principio, evita el riesgo de confusión entre homónimos léxicos, pues resulta muy improbable que un verbo (bajo) ocupe la misma posición que una preposición (bajo) o un adjetivo (bajo), en ocasiones puede dejar de funcionar, como ejemplifica este autor para el sustantivo francés part y la preposición par de la misma lengua. También una locución verbal y una combinación de palabras no fraseológica homónima de aquella, cuyo elemento nuclear sea un verbo, son, de hecho, unidades de clases distintas: sintagma fijo / sintagma no fijo, pero su equivalencia funcional en una oración: ser el predicado, contrarresta esta potencial salvaguarda, de manera que solo queda la interpretación del enunciado para dilucidar si se está ante un significado idiomático, el de la locución, o uno literal, el de la combinación de palabras no fraseológica. En consecuencia, cabría añadir el tipo de significado: fraseológico / literal, a la relación de salvaguardas enunciadas por el semantista citado.

Si aun a pesar de las salvaguardas, se produce una colisión homonímica, la consecuencia en los homónimos léxicos es la desaparición de uno de ellos y su sustitución por otro elemento, efectuada de múltiples maneras. Conocer hasta qué punto los modos de llenar el vacío creado por la desaparición de una palabra homónima son aplicables a las locuciones exige unos análisis diacrónicos de estas unidades de los que, por el momento, carecemos. Por otra parte, aquí no interesa averiguar si una locución verbal, homónima de una combinación no fraseológica de palabras, ha desaparecido del uso lingüístico en un estado de lengua, sino constatar su baja frecuencia, que puede estar determinada, justamente, por la existencia de la combinación de palabras no fraseológica.

En efecto, en los siguientes pares de ejemplos, están documentadas una combinación de palabras que no corresponde a una locución y una unidad fraseológica de esta clase, en concreto irse al agua, 'Fracasar' (DILEA), llevar la cesta, 'Acompañar a una pareja de enamorados, esp. cuando se muestran afecto' (DFDEA), colocar el disco, 'Exponer un tema conocido y que resulta pesado, esp. por su reiteración' (DFDEA), y meter las manos, 'Intervenir' (DILEA):

(24) a Krieger la cogió en brazos y se fueron al agua.

(24) b Sentía que éramos [...] bastante felices, pero nuestro amor se fue al agua.

(25) a De pronto, mi hermano se volvió para ofrecerse a llevar la cesta de la merienda, como si hasta aquel momento no hubiera reparado en ella. 
(25) b ¡Llevar la cesta! Eso ya no se estila. Era de nuestros tiempos, cuando un beso era pecado.

(26) a Coloque el disco en su caja protectora, si la tiene, e insértelo en la unidad.

(26) b -De este permiso no pasa el que la coloque el disco - decía un combatiente enamorado mientras trazaba sus planes respecto a la señora de sus pensamientos ${ }^{26}$.

(27) a Cuando volví a meter las manos en el agua, el extraño ser dio un salto hacia atrás y estuvo a punto de perder el equilibrio.

(27) b No puedo dejar de responder a todo, a toda cosa en la que se pueda meter las manos. $Y$ no es deseo de mangonear, no, es que esa emoción, ese arrebato que me produce la perfección -la vista o la imaginada-lo sufro por las cosas más increíbles.

De ninguno de los casos anteriores puede afirmarse, con absoluta seguridad, que se ha producido la desaparición del homónimo fraseológico ni que esta se haya compensado de las maneras que se ha visto para las palabras (Ullmann, 1983: 186-188; Ullmann, 1986: 309-313), pero sí es posible considerar que la colisión homonímica repercute en la baja frecuencia de uso de las locuciones, y existen muchos más casos, de manera que no parece cumplirse la afirmación de Martinet (1955: 183) acerca de que los conflictos homonímicos reales son mucho más raros que los teóricos, aunque este lingüista se esté refiriendo al francés. Así, la consulta del CREA muestra que de la combinación literal irse al agua o ir al agua hay cinco ocurrencias, frente a las tres de la locución homónima. Lo cual, sin embargo, no supone ninguna merma en las posibilidades de expresión para los hablantes, dado el amplio número de locuciones sinónimas y de variantes con las que se puede expresar el significado de 'Fracasar'27. No se ha llegado, pues, a producir la desaparición de la locución homónima irse al agua, pero su lugar está siendo ocupado por un amplio conjunto de sinónimos y variantes, lo que repercute en su baja frecuencia, tres ocurrencias en un corpus de 160 millones de formas frente a cinco de la combinación de palabras no fraseológica.

En cuanto a la locución llevar la cesta, en el CREA no se encuentra ningún ejemplo que la documente, las seis ocurrencias que aparecen son de la combinación de palabras homónima no fraseológica, igual que en la red, donde, no obstante, buscando con el verbo en infinitivo, se encuentra el ejemplo anotado anteriormente. El DFDEA, que sí registra la locución, la marca indicando hoy raro; por otra parte, está recogida en el DRAE, pero no en el DUE ni en el GDUEA, y tampoco en diccionarios fraseológicos como el DFEM o el $\mathrm{DDEE}^{28}$. Posiblemente, la baja frecuencia de uso de esta locución encuentre su razón de ser, no tanto en la colisión homonímica con la combinación de palabras no fraseológica, cuanto en los cambios producidos en la sociedad en relación con los usos y comportamientos en las relaciones amorosas, que ya no exigen la presencia de una carabina que lleve la cesta. En cualquier caso, resulta probada su baja frecuencia de uso.

26 El ejemplo está tomado del DFDEA (2004: 403).

27 Véase este listado: dar el gatillazo, dar gatillazo, hacer agua, hacer aguas, irse a freír espárragos, irse a freir monas, irse a hacer gárgaras, irse a hacer puñetas, irse a la eme, irse a la m, irse a la mierda, irse a la porra, irse a paseo, irse a tomar por culo, irse a tomar por el culo, irse a tomar viento, irse al carajo, irse al cuerno, irse al demonio, irse al diablo, irse al garete.

$28 \mathrm{El}$ autor de este último es, a la vez, coautor del DFE, que, en cambio, sí incluye la locución llevar la cesta. 
Peor es la situación de la locución colocar el disco. El CREA tampoco registra de ella ninguna ocurrencia, y las cuatro que existen corresponden a la combinación de palabras homónima de la locución, combinación que no es fraseológica, pues tiene un significado literal a partir del verbo colocar y del sustantivo disco. Por otra parte, la búsqueda a través de Google, con distintas formas verbales de colocar, tampoco ofrece resultados positivos. Además, la lengua no dispone de sinónimos de la locución que puedan compensar la colisión homonímica con la combinación no fraseológica. Todo esto explicaría que distintos diccionarios del español, generales y fraseológicos, no la recojan $^{29}$. Sin tener ningún afán adivinatorio, se podría prever la desaparición de esta unidad fraseológica.

El caso de meter las manos presenta particularidades distintas a las de las locuciones anteriores, pues junto a ella está la variante no marcada meter mano. La búsqueda en el CREA de la cadena meter las manos, en infinitivo, para facilitar la localización de ocurrencias, ofrece solo una de esta locución, la que figura en (27), frente a ocho de la combinación homónima no fraseológica. Por su parte, de la otra variante, meter mano, consultándola también en infinitivo, se encuentran nueve ejemplos. Debe pensarse, pues, que esta última variante le está ganando terreno a meter las manos, y la explicación puede estar en la homonimia de esta última con la combinación de palabras no fraseológica.

De lo expuesto en este apartado no cabe concluir, necesariamente, una relación de causa-efecto entre la colisión homonímica de locuciones y combinaciones no fraseológicas de palabras, y la baja frecuencia de las locuciones; en otras palabras, no se está afirmando aquí que la colisión homonímica sea la causa que provoca el efecto del escaso uso de determinadas locuciones, aunque desde un punto de vista teórico nada obsta para que así sea, pues, como apunta Coseriu en el análisis de las causas del cambio lingüístico, si un significante no se distingue de otro con significado distinto (aquí una unidad fraseológica homónima de una combinación no fija de palabras) se modifica o se sustituye. La existencia de variantes de las locuciones irse al agua y meter las manos, que también son poco frecuentes, son prueba de que estas locuciones se están modificando; por su parte, la baja frecuencia de colocar el disco y llevar la cesta indican que pueden encontrarse en un proceso de sustitución que, claro está, no es puntual sino gradual.

En cualquier caso, lo que se ha intentado mostrar, simplemente, es que la baja frecuencia en la utilización de ciertas locuciones va acompañada, para muchas de ellas, de la existencia de combinaciones de palabras no fraseológicas, homónimas de las locuciones. Que la relación entre colisión homonímica y baja frecuencia sea casual o causal no tiene interés desde el punto de vista aquí adoptado, el lexicográfico. Sí tiene, sin embargo, implicaciones para la labor lexicográfica, pues la cuestión examinada en este apartado y las presentadas en los anteriores repercuten en la confección de un diccionario de locuciones.

\section{Implicaciones lexicográficas}

En efecto, del apartado 2. se deduce que existen locuciones actuales, es decir, pertenecientes a un estado de lengua de límites difusos para la teoría lingüística, desde la

29 Es el caso, por ejemplo, del DRAE, del DUE, del GDUEA, del DFEM o del DFE. 
perspectiva de los investigadores y desde la percepción de los hablantes, las cuales, no obstante, deben marcarse como poco frecuentes en un diccionario que las recoja por su escasa representación en corpus de textos del periodo considerado. La marcación sería inexcusable realizarla si se opta por la inclusión de estas locuciones en la macroestructura del diccionario, pero también cabe su exclusión. En uno y otro caso se plantea el problema de qué criterio o criterios seguir para marcar como poco frecuentes o excluir determinadas locuciones. ¿Es suficiente su no documentación en el CREA? ¿Debe acompañarse este criterio del examen del CORDE, al menos desde 1900 hacia delante? ¿Cuántos ejemplos de una locución en el CREA y en el CORDE determinan su baja frecuencia o su exclusión? ¿Qué peso debería darse a las ocurrencias de una locución en relación con la cronología de los documentos que la registran? ¿Qué número de registros de la locución debería documentarse en la red para considerarla de baja frecuencia, en caso de no estar en los corpus de la Academia?

Es fácil imaginar la complejidad de dar respuesta exacta a estas interrogantes y la amplia casuística que se puede derivar de su aplicación potencial al conjunto de locuciones de una lengua. La tarea de su resolución parece titánica y el esfuerzo que conlleva puede ser descorazonador. De ahí la necesidad de tomar unas decisiones que, aunque provisionales y discutibles, faciliten la labor de redacción de un diccionario, la cual nunca se llevaría a cabo si hubiera que esperar a tener todas las locuciones completamente analizadas.

Partiendo de que el CREA es un corpus de 160 millones de formas, el CORDE cuenta con 250 millones de registros y la red, aunque limitada al español de España, es un universo, un mundo lingüístico, cabe pensar que encontrar menos de tres ocurrencias de una locución tras la consulta de los dos corpus académicos y de la red ${ }^{30}$ es indicio de una baja frecuencia. Aunque no disponemos de datos para fijar el umbral a partir del cual se puede empezar a considerar la frecuencia de una locución. Piénsese que el GDUEA, uno de los pocos diccionarios de la lengua española que ofrecen información relativa a la frecuencia de uso de las voces registradas, ha fijado el valor para acceder al nivel más bajo de frecuencia en cinco ocurrencias sobre el total del corpus Cumbre utilizado para elaborar el diccionario: 20 millones de palabras (GDUEA, 2001: 10). Pero debe quedar claro que se trata de la frecuencia de uso de las unidades léxicas simples, no de las locuciones registradas en él.

En consecuencia, la locución para la que no se hayan obtenido tres ejemplos podría o bien ser excluida de un diccionario de locuciones del español actual o bien ser marcada como poco frecuente. Las que se corresponden con esta situación, a tenor de lo observado tras el vaciado del DFDEA, son numerosas, pero baste este pequeño conjunto para probarlo; todas van en la forma y con el significado que proporciona el DFDEA: no caber la menor ('No caber la menor duda'), no descubrir la pólvora ('Se usa para ponderar la falta de inteligencia o perspicacia'), no echarse nada en el bolsillo ('No obtener ningún beneficio económico'), no haber cosa con cosa ('No existir relación entre una cosa y otra de las mencionadas'), no haber (ni) para un diente ('Ser muy escasa o insuficiente'), no oírse más allá del cuello de la (o su) camisa ('Hablar en voz muy baja'), no poner los pies en el suelo ('Correr o caminar muy rápidamente'), no quedar ni el apuntador ('Producirse

30 Recuérdese que la consulta de la red se limita a las diez primeras páginas que ofrece de la cadena objeto de búsqueda. 
muchas muertes') y no tener más que pellejo ('Estar sumamente delgado o consumido') ${ }^{31}$. No deja de ser curioso, sin embargo, que solo una: no haber cosa con cosa, se marca como raro en el DFDEA.

Por el contrario, tener ampliamente documentada una locución en relación con otras, después del vaciado de un conjunto de textos orales y escritos tomados como fuentes lingüísticas, puede ser criterio para marcarla como muy frecuente. En este sentido, aunque las fuentes utilizadas para el DILEA no están cerradas, pues se van incrementando paulatinamente ${ }^{32}$, es posible afirmar que, frente a otras locuciones todavía no documentadas a partir de tales fuentes, se cuenta ya con un conjunto de ejemplos relativamente amplio para locuciones nominales como callejón sin salida, canto de sirena, el más allá, idas y venidas o ir y venir; adjetivas como de carne y hueso, de derechas, de mala muerte o de medio pelo; verbales como darse cuenta, echar de menos, echar una mano, sacar pecho o salirse con la suya; y adverbiales como a bocajarro, a cal y canto, a estas alturas, contra viento y marea, de buenas a primeras o de vez en cuando.

Lo expuesto incide sobre la necesidad de marcar las locuciones en un diccionario en relación con su frecuencia de uso, si no la elevada -que puede tener interés en relación con cuestiones más específicas como la enseñanza de la lengua-, sí la baja, para que el usuario del diccionario sea consciente de esta particularidad que condiciona, al menos, la comprensión de muchas locuciones. En general, los diccionarios específicos de esta clase de unidades fraseológicas no establecen ni utilizan marcas para la frecuencia. Una excepción la

31 Como se ha indicado, todas ellas están registradas en el DFDEA, aunque ilustran distintas situaciones. En cuanto a no caber la menor, solo se documenta en el CORDE en dos ejemplos de 1927; en la red, mediante la búsqueda de la cadena «no cabe la menor», no se encuentra ningún ejemplo en que no aparezca el sustantivo $d u d a$; téngase en cuenta que esta locución parece haberse formado por la elipsis de duda en no caber la menor $d u d a$. En los corpus académicos solo se registra un ejemplo, en el CREA, de no descubrir la pólvora; en la red no se encuentra ninguno; por otra parte, no la recoge el DUE, el GDUEA ni el DFEM. Los corpus de la Academia no documentan ningún ejemplo que se corresponda con el lema no echarse nada en el bolsillo; la búsqueda en la red solo ofrece una ocurrencia de esta locución. De no haber cosa con cosa se documentan diez ejemplos en el CORDE, aunque todos de Delibes y de la misma obra, Diario de un emigrante (1958); en la red no se encuentra ningún ejemplo adecuado; no la registran el DUE, el GDUEA ni el DFEM. La Academia no documenta ningún ejemplo de no haber (ni) para un diente; en la red se obtiene una ocurrencia buscando la cadena «ni para un diente»; el ejemplo del DFDEA va precedido de un asterisco, lo que significa que la falta de testimonio escrito se ha suplido por uno oral. Los corpus académicos no proporcionan ningún ejemplo de no oírse más allá del cuello de la (o su) camisa y la red no ofrece ningún ejemplo adecuado. La locución no poner los pies en el suelo no está documentada ni en el CREA ni en el CORDE; en la red aparece una ocurrencia y, además, ejemplos de esta locución en El Quijote, más otros correspondientes a la combinación de palabras homónima no fraseológica; por otra parte, el ejemplo del DFDEA no corresponde a ningún documento escrito al ir precedido de un asterisco. Tampoco existen ocurrencias de no quedar ni el apuntador en la Academia; la búsqueda en la red solo proporciona dos ejemplos. Por último, en el CREA y el CORDE no se encuentran ocurrencias de no tener más que pellejo; los ejemplos que se obtienen usando Google corresponden a la combinación de palabras homónima no fraseológica; y, como en otros casos, el ejemplo de uso del DFDEA no ha sido extraído de ningún documento escrito, parece, más bien, creado ad hoc: «*Esta niña no tiene más que pellejo».

32 En estos momentos están constituidas por cuarenta y ocho textos escritos de distinta extensión, correspondientes a novelas y ensayos, que han sido vaciados al completo en relación con las locuciones nominales, adjetivas, pronominales, verbales y adverbiales que contienen; los periódicos EL PAÍS y EL MUNDO, pues su lectura ocasional pero frecuente es aprovechada para vaciar todas las locuciones de las clases anteriores de cada ejemplar leído; y seis corpus de textos orales (los recopilados para las investigaciones expuestas en Cestero Mancera (2000), Blanco Canales (2004) y Ruiz Martínez (2003); el de Briz y Grupo Val.Es.Co (2002); y los del PRESEEA publicados en Cestero Mancera, Molina Martos y Paredes García (2012), y Moreno Fernández, Cestero Mancera, Molina Martos y Paredes García (2002)), asimismo vaciados. 
constituye el DFDEA, que usa frec (frecuente o frecuentemente) para señalar construcciones frecuentes en las que aparece la unidad fraseológica de la que se aporta esta información, no para referirse a la propia frecuencia de esta, y raro u hoy raro para indicar la cuestión que se analiza en este artículo, pues se entiende que la unidad fraseológica que se marca así es una «Expresión infrecuente; en especial, expresión anticuada empleada hoy solo de manera ocasional» (DFDEA, 2004: XXXI), pero ya se ha visto a lo largo de todo el trabajo la necesidad no tanto de revisar las así marcadas, cuanto de asignar la marca a muchas que no la presentan.

También REDES, aunque no es un diccionario de unidades fraseológicas, sino de combinaciones, proporciona marcas de frecuencia no tanto de las locuciones que registra cuanto de la combinación de una locución con determinadas palabras, pero, vaciando las locuciones contenidas en este diccionario, se obtendría un conjunto de locuciones y de combinaciones frecuentes de ellas que, de manera indirecta, mostraría que aquellas no tienen una baja frecuencia de uso. Por ejemplo, caer en saco roto es una locución verbal registrada en REDES que presenta una combinación sumamente frecuente con los sustantivos consejo, advertencia y palabra, y bastante frecuente con propuesta, iniciativa, petición, demanda, denuncia, promesa, idea, reflexión y esfuerzo. De estos datos cabría inferir que la locución verbal caer en saco roto es, al menos, frecuente.

Por último, el DELE ha hecho un uso completamente sistemático de marcas como pf (poco frecuente), f (frecuente) y $\mathrm{mf}$ (muy frecuente), hasta el punto de que todas las locuciones recogidas aparecen con alguna de las tres marcas indicadas, pero desconocemos los criterios que han llevado a sus autores a asignarlas a locuciones como dar/meter caña, que tiene la marca (mf); hacer sus primeras armas, con la marca (pf); tragárselas dobladas, marcada como (f); (un) animal de bellota(s), cuya marca es también (mf) ${ }^{33}$, además de la falta de información acerca de los datos que les han conducido a considerar una locución frecuente en vez de muy frecuente, o al revés, y otra frecuente, pero no poco frecuente, o lo contrario ${ }^{34}$.

\section{Conclusiones}

De este trabajo se desprenden una serie de conclusiones que se desglosan a continuación. 1. $\left.{ }^{a}\right)$ El término actual no se restringe necesariamente a los últimos cincuenta o veinticinco

33 Téngase en cuenta, sin embargo, que, como ya se ha indicado, las ocurrencias de dar/meter caña difieren mucho en el CREA, de la primera variante de esta locución, que tiene seis acepciones distintas, hay un total de cincuenta y seis, mientras que de la segunda solo hay siete, no se puede, en consecuencia, asignar la misma marca de frecuencia a las dos variantes; de hacer sus primeras armas existen doce registros en el CORDE y diez en el CREA, lo que incide en la necesidad de tener establecido un criterio para determinar qué locuciones son poco frecuentes; tragárselas dobladas, a pesar de su marca de frecuente en el DELE, solo tiene un registro en el CORDE y otro en el CREA; (un) animal de bellota(s) está documentada en el CORDE, ya sea bajo la forma animal de bellota o un animal de bellota, con siete ocurrencias y en el CREA, bajo esas mismas formas, con cinco ejemplos, pero en ninguno de los dos corpus se registra animal de bellotas o un animal de bellotas, lo que prueba lo indicado en este trabajo: que no todas las variantes de una locución tienen la misma frecuencia, de manera que no se puede marcar (un) animal de bellotas como muy frecuente sin más. Puesto que es relativamente fácil obtener ejemplos del DELE de locuciones cuya marca de frecuencia contrasta con su documentación en los corpus académicos, baste, pues, con los presentados.

34 Añádase a todo esto que tampoco los diccionarios generales de lengua dan un tratamiento sistemático y coherente a este aspecto de las locuciones. 
años, pues los límites de un estado de lengua no son fáciles de fijar, además de estar sometidos a modificación continua, por el paso del tiempo, cuando el estado de lengua es el actual. La imposibilidad de establecer claramente los límites de un estado de lengua y la existencia en él de unidades -en el caso que aquí interesa fraseológicas- que para la conciencia de los hablantes, y como fruto de su reflexión metalingüística, pueden calificarse de arcaicas, antiguas o viejas conduce a considerar que determinadas locuciones pueden verse como actuales, si se amplía esta sincronía hasta principios del siglo XX.

2. $\left.{ }^{a}\right)$ El análisis de la frecuencia de las locuciones se ve dificultado por cuestiones todavía pendientes de resolución en fraseología, tales como la pertenencia de las unidades fraseológicas a una u otra clase y su naturaleza polisémica u homonímica per se o en relación con una combinación de palabras no fraseológica. Sería necesario, pues, que desde la fraseología quedaran bien delimitadas estos aspectos de los fraseologismos para alcanzar resultados completamente satisfactorios en el estudio de su frecuencia, el cual, además, todavía no puede apoyarse de manera absoluta en los instrumentos que facilitan las nuevas tecnologías de la información.

3. a) Al analizar la frecuencia de las locuciones, el investigador debe prestar especial atención a aquellas que cuentan con variantes, pues existe la posibilidad de que dos variantes no marcadas de una locución tengan distinta frecuencia. Es altamente probable que una de ellas, al no tener valor distintivo por ser ambas variantes no marcadas, quede abandonada, sea muy poco frecuente. La libertad lingüística de los hablantes deja de lado aquello que resulta prácticamente inútil desde el punto de vista funcional. De este modo, un significante de una locución (una variante no marcada) que no sirve para distinguir, que resulta inútil, acaba por no ser usado.

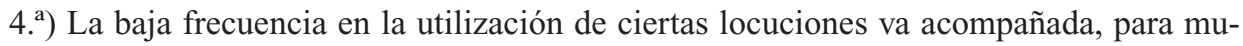
chas de ellas, de la existencia de combinaciones de palabras no fraseológicas, homónimas de las locuciones. Este hecho no implica una relación de causa-efecto entre la colisión homonímica de locuciones y combinaciones no fraseológicas de palabras, y la baja frecuencia de las locuciones. Dicho de otro modo, no se debe concluir que la colisión homonímica sea la causa que provoca el efecto del escaso uso de determinadas locuciones, aunque desde un punto de vista teórico nada obsta para que así sea, pues en el análisis de las causas del cambio lingüístico está comprobado que, si un significante no se distingue de otro con significado distinto (aquí una unidad fraseológica homónima de una combinación no fija de palabras), se modifica o se sustituye. Lo que sí cabe deducir, simplemente, es que el estudio de numerosos ejemplos muestra una relación entre la baja frecuencia de una locución y la existencia de una combinación de palabras no fraseológica homónima de la unidad fraseológica.

5. a) Desde la perspectiva lexicográfica, hay una serie de puntos que deben tenerse en cuenta en la redacción de diccionarios de locuciones y en el tratamiento lexicográfico de las locuciones en diccionarios generales de lengua, todos ellos relativos a la frecuencia de uso de estas unidades fraseológicas: a) un diccionario de locuciones calificado de actual obliga a plantearse la posibilidad de excluir aquellas que presenten una baja frecuencia de uso; b) no obstante, una obra lexicográfica de tal naturaleza puede incluir locuciones anticuadas siempre que sean convenientemente marcadas en relación con su escaso uso; c) es necesaria, pues, una marca (rara, poco frecuente) para señalar esta particularidad de las locuciones que están escasamente documentadas; y c) la marcación de frecuencia tendrá que llevarse a cabo a partir de unos criterios previamente fijados y sistemáticamente aplicados tanto para establecer el umbral a partir del cual se puede empezar a determinar la frecuencia de una locución, como para diferenciar si aquella es baja o elevada. 


\section{Referencias bibliográficas}

Blanco Canales, A. (2004): Estudio sociolingüístico de Alcalá de Henares. Alcalá de Henares, Servicio de Publicaciones de la Universidad de Alcalá.

Boers, F. y Stengers, H. (2008): «A Quantitative Comparison of the English and Spanish Repertoires of Figurative Idioms». En F. Boers y S. Lindstromberg (eds.): Cognitive Linguistic Approaches to Teaching Vocabulary and Phraseology. Berlin / New York, Mouton de Gruyter, págs. 355-374.

Briz, A. y Grupo Val.Es.Co (2002): Corpus de conversaciones coloquiales. Madrid, Arco/Libros.

Casas Gómez, M. y Escoriza Morera, L. (2009): «Los conceptos de diastratía y diafasía desde la Teoría Lingüística y la Sociolingüística Variacionista». En M. V. Camacho Taboada, J. J. Rodríguez Toro y J. Santana Marrero (eds.): Estudios de lengua española: descripción, variación y uso. Homenaje a Humberto López Morales. Madrid / Frankfurt am Main, Iberoamericana / Vervuert, págs. 151-178.

Castillo Carballo, M. ${ }^{a}$ A. (2000): «Lingüística de corpus y fraseología: algunas consideraciones sobre las locuciones verbales». En G. Corpas Pastor (ed.): Las lenguas de Europa: estudios de fraseología, fraseografía y traducción. Granada, Comares, págs. 95-126.

Cestero Mancera, A. M. (2000): El intercambio de turno de habla en la conversación (análisis sociolingüístico). Alcalá de Henares, Servicio de Publicaciones de la Universidad de Alcalá.

Cestero Mancera, A. M. ${ }^{a}$, Molina Martos, I. y Paredes García, F. (2012): La lengua hablada en Madrid. Corpus PRESEEA-Madrid (distrito de Salamanca), Volumen I. Hablantes de instrucción superior. Alcalá de Henares, Universidad de Alcalá.

Corpas Pastor, G. (1996): Manual de fraseología española. Madrid, Gredos.

Corpas Pastor, G. (1998): «El uso de paremias en un corpus del español peninsular actual». En G. Wotjak (ed.): Estudios de fraseología y fraseografía del español actual. Frankfurt am Main / Madrid, Vervuert / Iberoamericana, págs. 365-390.

Corpas Pastor, G. (2013): «Detección, descripción y contraste de las unidades fraseológicas mediante tecnologías lingüísticas». En I. Olza y E. Manero Richard (eds.): Fraseopragmática. Berlin, Frank \& Timme, págs. 335-373.

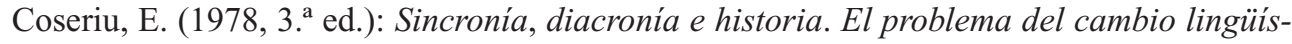
tico. Madrid, Gredos.

Ghezzi, M. (2012): «Creación de una base de datos para el estudio de las comparaciones estereotipadas y su explotación en la enseñanza de ELE». En M. ${ }^{a}$ I. González Rey (ed.): Unidades fraseológicas y TIC. Madrid, Instituto Cervantes, págs. 203-216.

Hjemslev, L. (1974): Prolegómenos a una teoría del lenguaje. Madrid, Gredos.

Kabatek, J. (2002): «Oralidad, proceso y estructura», Pandora, 2, 2, págs. 37-54.

Larreta Zulategui, J. P. (2001): Fraseología contrastiva del alemán y el español. Frankfurt am Main, Peter Lang.

López Roig, C. (2002): Aspectos de fraseología contrastiva (alemán-español) en el sistema $y$ en el texto. Frankfurt am Main, Peter Lang.

Martinet, A. (1955): Économie de changements phonétiques. Traité de phonologie diachronique. Berne, A. Francke.

Mellado Blanco, C. (2004): Fraseologismos somáticos del alemán. Frankfurt am Main, Peter Lang. 
Mellado Blanco, C. (2012): «Optimización de los recursos TIC en la fraseografía del par de lenguas alemán-español». En M. ${ }^{a}$ I. González Rey (ed.): Unidades fraseológicas y TIC. Madrid, Instituto Cervantes, págs. 147-166.

Mogorrón Huerta, P. (2012): «Explotación informática de una base de datos multilingüe de unidades fraseológicas». En M. ${ }^{\mathrm{a}}$ I. González Rey (ed.): Unidades fraseológicas y TIC. Madrid, Instituto Cervantes, págs. 63-81.

Moreno Fernández, F., Cestero Mancera, A. M. ${ }^{\text {a, }}$ Molina Martos, I. y Paredes García, F. (2002): La lengua hablada en Alcalá de Henares. Corpus PRESEEA - ALCALÁ. I. Hablantes de instrucción superior. Alcalá de Henares, Servicio de Publicaciones de la Universidad de Alcalá.

Moon, R. (1997): «Vocabulary Connections: Multi-word Items in English». En N. Schmitt y M. McCarthy (eds.): Vocabulary: Description, Acquisition and Pedagogy. Cambridge, Cambridge University Press, págs. 40-63.

Penadés Martínez, I. (2004): «Caracterizan las locuciones el registro coloquial?». En M. Villayandre Llamazares (ed.): Actas del V Congreso de Lingüistica General, León, 5-8 de marzo de 2002, III. Madrid, Arco/Libros, págs. 2225-2235.

Penadés Martínez, I. (2006): «La información gramatical sobre la clasificación de las locuciones en los diccionarios». En M. Alonso Ramos (ed.): Diccionarios y fraseología. A Coruña, Universidade da Coruña, Servizo de Publicacións, págs 249-259.

Penadés Martínez, I. (2008): «Proyecto para la redacción de un diccionario de locuciones del español». En E. Bernal y J. DeCesaris (eds.): Proceedings of the XIII EURALEX International Congress (Barcelona, 15-19 July 2008). Barcelona, IULA, Universitat Pompeu Fabra, págs. 1379-1384.

Penadés Martínez, I. (2010): «El Diccionario de locuciones del español actual (DILEA)». En C. Mellado, P. Buján, C. Herrero, N. Iglesias y A. Mansilla (eds.): La fraseografía del S. XXI. Nuevas propuestas para el español y el alemán. Berlin, Frank \& Timme, págs. 191-210.

Penadés Martínez, I. (2012a): «La variación en las locuciones a partir de materiales del PRESEEA (Barrio de Salamanca, Madrid)». En A. M. Cestero, I. Molina y F. Paredes (eds.): La lengua, lugar de encuentro. Actas del XVI Congreso Internacional de la ALFAL (Alcalá de Henares, 6-9 de junio de 2011). Alcalá de Henares, Universidad de Alcalá, págs. 2081-2091.

Penadés Martínez, I. (2012b): Gramática y semántica de las locuciones. Alcalá de Henares, Servicio de Publicaciones de la Universidad de Alcalá.

Penadés Martínez, I. (2013): «La imagen subyacente a las locuciones como criterio de marcación». En I. Olza y E. Manero Richard (eds.): Fraseopragmática. Berlin, Frank \& Timme, págs. 23-47.

Ruiz Gurillo, L. (1998): La fraseología del español coloquial. Barcelona, Ariel.

Ruiz Martínez, A. M. (2003): Estudio fonético del nordeste de la Comunidad de Madrid. Alcalá de Henares, Servicio de Publicaciones de la Universidad de Alcalá.

Saussure, F. de (1945): Curso de lingüística general. Publicado por Ch. Bally y A. Sechehaye con la colaboración de A. Riedlinger. Traducción, prólogo y notas de A. Alonso. Buenos Aires, Losada.

Sevilla Muñoz, M. (2012): «Utilización de recursos en línea en la enseñanza/aprendizaje de traducción de unidades fraseológicas». En M. ${ }^{a}$ I. González Rey (ed.): Unidades fraseológicas y TIC. Madrid, Instituto Cervantes, págs. 283-298. 
Sosiński, M. (2010): «Aproximación a la fraseología de los inmigrantes (comparación de los materiales del corpus ISPIE y del corpus PRESEEA-Granada)», Lengua y Migración / Language and Migration, 2, 2, págs. 113-125.

Trubetzkoy, N. S. (1987): Principios de fonología. Madrid, Cincel.

Ullmann, S. (1983, reimp.): Semantics. An Introduction of the Science of Meaning. Oxford, Basil Blackwell

Ullmann, S. (1986, 2. ${ }^{\mathrm{a}}$ reimp.): Introducción a la semántica francesa. Traducción y anotación por Eugenio de Bustos Tovar. Madrid, C.S.I.C.

Zuluaga, A. (1980): Introducción al estudio de las expresiones fijas. Frankfurt am Main, Peter D. Lang.

\section{Diccionarios}

DDEE: Cantera Ortiz de Urbina, J. (2011): Diccionario de dichos y expresiones del español. Su interpretación al alcance de todos. Madrid, Abada Editores.

DEA: Seco, M., Andrés, O. y Ramos, G. (1999): Diccionario del español actual. Madrid, Aguilar.

DELE: Martínez López, J. A. y Jørgensen, A. M. (2009): Diccionario de expresiones y locuciones del español. Madrid, Ediciones de la Torre.

DFDEA: Seco, M., Andrés, O. y Ramos, G. (2004): Diccionario fraseológico documentado del español actual. Locuciones y modismos españoles. Madrid, Aguilar.

DFE: Cantera Ortiz de Urbina, J. y Gomis Blanco, P. (2007): Diccionario de fraseología española: locuciones, idiotismos, modismos y frases hechas usuales en español [su interpretación]. Madrid, Abada Editores.

DFEM: Varela, F. y Kubarth, H. (1994): Diccionario fraseológico del español moderno. Madrid, Gredos.

DILEA: Penadés Martínez, I. (en preparación): Diccionario de locuciones idiomáticas del español actual.

DRAE: Real Academia Española (2001, 22. ${ }^{\text {a }}$ ed.): Diccionario de la lengua española. Madrid, Espasa Calpe.

DSLE: Gutiérrez Cuadrado, J. (dir.) (1996): Diccionario Salamanca de la lengua española. Barcelona, Círculo de Lectores.

DUE: Moliner, M. (1984, reimp.): Diccionario de uso del español. Madrid, Gredos.

GDUEA: Sánchez, A. (dir.) (2001): Gran diccionario de uso del español actual. Alcobendas, Sociedad General Española de Librería.

JAM: Calles Vales, J. y Bermejo Meléndez, B. (2001): Jergas, argot y modismos. Recopilación de palabras y expresiones de uso cotidiano que no suelen aparecer en los diccionarios. Alcobendas, Libsa.

REDES: Bosque, I. (dir.) (2004): Las palabras en su contexto. REDES. Diccionario combinatorio del español contemporáneo. Madrid, Ediciones SM. 



\title{
ENUNCIADOS FIGURADOS EN TEXTOS TURÍSTICOS DEL ÁMBITO INSTITUCIONAL: ANÁLISIS SEMÁNTICO- PRAGMÁTICO EN FOLLETOS Y ANUNCIOS DE LA CAMPAÑA REGIÓN DE MURCIA NO-TYPICAL
}

\author{
Carmen Sánchez Manzanares \\ Universidad de Murcia \\ carmensm@um.es
}

Recibido: $19 / 05 / 2015$

Aceptado: 08/09/2015

\section{Resumen}

El propósito de este artículo es el análisis de la funcionalidad en textos turísticos de enunciados de sentido figurado. Para ello hemos seleccionado un conjunto de textos emitidos por la Comunidad Autónoma de la Región de Murcia en el marco de una campaña para la promoción de la Región como destino turístico. La marca del destino en dicha campaña es Región de Murcia no-typical y en torno a ella se articulan una serie de textos en los que se tienen enunciados que cumplen con la finalidad propia de un eslogan publicitario. Nos centramos principalmente en la función comunicativa de metáfora y metonimia para la construcción del sentido figurado, por lo cual realizamos un análisis tanto semántico como pragmático de estos enunciados. Nuestra hipótesis de partida es que mediante estos procedimientos se proyecta una imagen del destino turístico que implica para su interpretación la activación de procesos cognitivos y de valores afectivos del destinatario. Con ello se guía la elección del producto que se promociona, pues la imagen así creada conecta los llamados atractivos turísticos del lugar con las expectativas personales del turista potencial, tanto en lo cognitivo como en lo afectivo.

PALABRAS CLAVE: enunciado figurado, texto turístico, metáfora, metonimia, función comunicativa
\end{abstract}

\begin{abstract}
The purpose of this article is to analyze functionality in statements with a figurative meaning in tourist texts. In order to do so, we have selected a group of texts published by the Region of Murcia as part of a campaign to promote the region as a tourist destination. The motto in this campaign is Region of Murcia no-typical, and around it a number of texts are articulated- all of which fulfill the expected aim of a marketing slogan. We mainly focus on the communicative function of metaphors and metonymies to construct a figurative meaning, so we carry out both a semantic and pragmatic analysis of the selected statements. Our hypothesis considers that these procedures project an image of the tourist destination that relies on the recipients cognitive processes and emotional values for its interpretation. These techniques therefore lead the choice of the marketed product, as the constructed image links the tourist appeals of the region with the expectations of the future tourist, both in cognitive and emotional areas.
\end{abstract}

KEYWORDS: figurative statement, tourist text, metaphor, metonymy, communicative function

\section{Introducción}

En este artículo nos proponemos abordar cómo se configuran los enunciados de sentido figurado, principalmente metafóricos y metonímicos, en el discurso para la promoción de un destino turístico emitido en el ámbito institucional y analizar cuál es la finalidad 
de estos enunciados, qué función cumplen con respecto a la finalidad global del discurso turístico. El concepto de turismo ha evolucionado y la publicidad de un lugar se centra actualmente en las vivencias y emociones que puede ofrecer al potencial turista. Metáfora y metonimia posibilitan una imagen del destino turístico original y subjetiva, a la vez que conforman un enunciado atractivo y sorprendente. Mediante estos procedimientos se consigue la adhesión o captación de la voluntad del destinatario del texto, tanto a nivel intelectual como a nivel afectivo, pues se crean o refuerzan expectativas sobre el destino turístico y se cambian creencias o actitudes frente al producto que se promociona. La construcción del sentido figurado, en general, responde en estos enunciados a una estrategia discursiva persuasiva, propia del texto publicitario, orientada a intervenir sobre la elección del turista y a determinar su actuación. Sin embargo, lo llamativo es cómo se liga esta orientación a la práctica descriptiva natural del texto turístico mediante los procesos metafóricos y metonímicos.

Nuestro análisis del sentido figurado de un enunciado integra la perspectiva tanto de la semántica como de la pragmática ${ }^{1}$, pues consideramos tanto la semanticidad como la intención comunicativa y los factores contextuales. La conjunción de los distintos enfoques nos proporciona un marco teórico y herramientas metodológicas para el análisis de los procedimientos y para la determinación de la funcionalidad de los enunciados figurados en los textos turísticos. De esta manera, nos proponemos obtener resultados clarificadores sobre la producción e interpretación de sentido en este tipo de textos.

En el ámbito de la promoción institucional turística se ha producido, como en otros ámbitos, una apuesta por la difusión de textos en Internet, pues es incuestionable el mayor alcance de la difusión, sobre todo si se piensa en destinatarios internacionales. Por esta razón, hemos seleccionado para el análisis documentos emitidos durante una campaña turística de la Región de Murcia publicados en la web de la Consejería de Cultura y Turismo de esta Región (http://goo.gl/al1KCk). También analizamos otros textos que formaban parte de la campaña, como los que se difundían en grandes lonas que se exhibían en fachadas de edificios principales y los anuncios que se distribuían en prensa.

El tipo textual que seleccionamos para la constitución de nuestro corpus es el que se enmarca en las producciones textuales para la descripción y promoción del destino turístico; dentro de estas producciones, los textos seleccionados son folletos y anuncios. Mientras que el folleto constituye un macrogénero del turismo, el anuncio es un género del ámbito de la publicidad con características específicas cuando se insertan en el ámbito del turismo. Todos ellos pertenecen a la familia de los géneros institucionales. Nos basamos para esta caracterización tipológica en la agrupación que presenta Calvi (2010) de producciones textuales del turismo, correspondientes a las distintas prácticas sociales, y en su clasificación de géneros textuales ${ }^{2}$.

1 El enfoque de la lingüística cognitiva es también rentable, como muestran Barcelona y Rocamora en su trabajo: "El argot turístico y la teoría cognitiva de la metáfora y la metonimia" (2000).

2 Como señala Calvi (2010: 10), el turismo como actividad profesional ha promovido el desarrollo de géneros textuales específicos. 
La campaña turística a la que nos referimos, de tres años de duración, desde enero de 2009 a enero de $2012^{3}$, se concibió de una forma inusual contando para su desarrollo, aparentemente, con la colaboración ciudadana. Daremos cuenta de la idea matriz de la campaña que motivó esta participación y dio lugar al lema Región de Murcia no-typical para situar los textos seleccionados, todos ellos interrelacionados y vertebrados por esta idea.

\section{Presentación del corpus, hipótesis y objetivos}

\subsection{Corpus}

Hemos constituido nuestro corpus seleccionando de la campaña Región de Murcia no-typical dos tipos de textos promocionales que nos interesan por su proximidad al texto publicitario:

- los folletos que se presentan en la web de la Consejería, que pertenecen a una categoría superior dentro de los géneros del turismo y que, de acuerdo con Calvi (2010: 23), se caracterizan por un lenguaje muy cercano al publicitario;

- los anuncios que se distribuyen en prensa y los carteles en la vía pública, que se categorizan como textos publicitarios que, como hace notar Calvi (2010: 25), se recontextualizan en el ámbito turístico adquiriendo rasgos específicos, especialmente cuando están promovidos por las instituciones.

En estos tipos es ostensible la intención persuasiva, como en los textos publicitarios, y, como en ellos también, la metáfora y otros usos figurados involucran una representación imaginativa de atributos del producto que se promociona. La actual tendencia de la publicidad al sentido figurado se debe, además, a la implicación cognitiva y afectiva del receptor y ello es visible también en estos textos seleccionados. Como observa Calvi (2010: 19), la peculiaridad del producto requiere unos modelos textuales propios, que entroncan con distintas tradiciones discursivas.

El primer conjunto de documentos, los folletos, se disponían en una sección de la web titulada Qué hacer, en la que se tenía acceso a quince enlaces para la promoción de distintas categorías turísticas (Sol y Playa, Rural, Cultura, etc.). Como observa González (2012: 21), la hipertextualidad da coherencia a estos distintos enlaces de la sección y, por otra parte facilita que la web funcione como repositorio de documentos de interés. Estos folletos, bastante extensos y de algún modo similares a pequeñas guías turísticas, se presentaban con una titulación siempre encabezada por Hoy en la que se condensaba el aspecto que se privilegiaba del producto turístico que se promocionaba; así, para Murcia como destino de sol y playa, el título del folleto era: Hoy me siento pez. Se disponía así de varios accesos para conocer la oferta turística según la apetencia puntual del usuario. Además se contaba con un folleto de carácter general titulado: Hoy estás en la Región de Murcia.

3 Esta campaña se inicia en enero de 2009 y la siguiente se presenta públicamente en enero de 2012. No obstante, el portal de Internet no se renueva hasta dos años después de presentarse la nueva campaña, por lo que los documentos que analizamos han estado accesibles hasta febrero de 2014. Tenemos, por tanto, que señalar el desfase entre la recuperación de la información turística en el hipertexto por parte del usuario y la recepción del discurso promocional de la campaña vigente. 


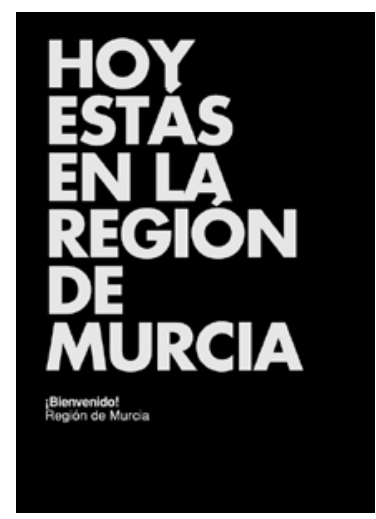

Imagen 1

Los folletos que seleccionamos forman parte, como antes señalamos, de las producciones textuales dedicadas a la descripción y promoción de lugares turísticos, en este caso emitidos por una institución pública ${ }^{4}$. En este bloque en el que se encuadran, se tienen las más peculiares formas textuales y aunque los términos que se usan en ellos proceden de otros ámbitos de especialidad, tales como el geográfico, el histórico, el gastronómico, etc., son destacables las recurrentes combinaciones de estos términos con adjetivos con valor ponderativo. Por nuestra parte, hacemos notar el sentido figurado de los títulos de estos folletos. A continuación los enumeramos indicando el tipo turístico que se promociona:

- Hoy me siento pez (Turismo de sol y playa)

- Hoy el gusto es mío (Turismo gastronómico)

- Hoy estoy curioso (Turismo cultural)

- Hoy estoy que no paro (Turismo activo y buceo)

- Hoy estoy rural (Turismo rural)

- Hoy me siento bien (Turismo de salud y belleza)

Los folletos se inscriben en el marco de una campaña que fue motivo de gran polémica, debatida incluso en un pleno de la Asamblea Regional de Murcia el 18 de febrero de 2009 (recogido el debate en el Diario de Sesiones de 2009, $n^{\circ} 40$ ), poco después de un mes de su comienzo. En esta campaña se encuentran también, junto a estos textos distribuidos a través de Internet, una serie de anuncios, algunos de ellos distribuidos en prensa y otros colocados en la vía pública en soporte cartel, que formaron parte de la campaña. En nuestra opinión, la recepción del anuncio incitaba al usuario a obtener mayor información del lugar en la red. Todos ellos nos muestran la estrategia institucional para la promoción del destino turístico, que tenemos que tener presente para comprender la funcionalidad de los enunciados figurados. Por esta razón, hemos seleccionado algunos anuncios y carteles para el análisis con el fin de mostrar su coherencia con la idea que guía la campaña.

4 Calvi (2010: 18) agrupa las prácticas sociales del turismo y sus correspondientes producciones textuales en tres bloques: 1) reflexión teórica sobre el turismo y sus características; 2) gestión; 3) descripción y promoción del destino turístico. 


\subsection{Hipótesis y objetivos}

Nuestra hipótesis de partida para el análisis es que los enunciados figurados presentes en los textos proyectan una imagen del destino turístico que implica para su interpretación la activación de procesos cognitivos y de valores afectivos del destinatario. La imagen de un destino "consiste en la interpretación subjetiva de la realidad realizada por el turista, interviniendo en su formación tanto elementos cognitivos como afectivos" (Bigné et alii 2007: 60). Como han señalado Hidalgo Alcázar et alii (2012: 367), el componente cognitivo de la imagen de un destino turístico está constituido por las creencias y conocimientos del individuo sobre los atributos de este destino, mientras que el componente afectivo lo conforman sus sentimientos hacia el lugar y sus motivaciones para su elección. Metáfora y metonimia, como procedimientos privilegiados del sentido figurado, guían un proceso de interpretación por parte del destinatario focalizando en los atributos del lugar que se promociona, por lo que se potencia su implicación cognitiva y afectiva. Como señalan Gallarza, Gil y Calderón (2002: 53), el primer factor que apoya la naturaleza múltiple de la imagen de un destino es la existencia de la multiplicidad de atributos sobre los que se basa. De este modo, la imagen del destino resultado de dicha interpretación conecta los llamados atractivos turísticos del lugar con las expectativas personales del turista potencial, lo que es determinante para la elección del producto.

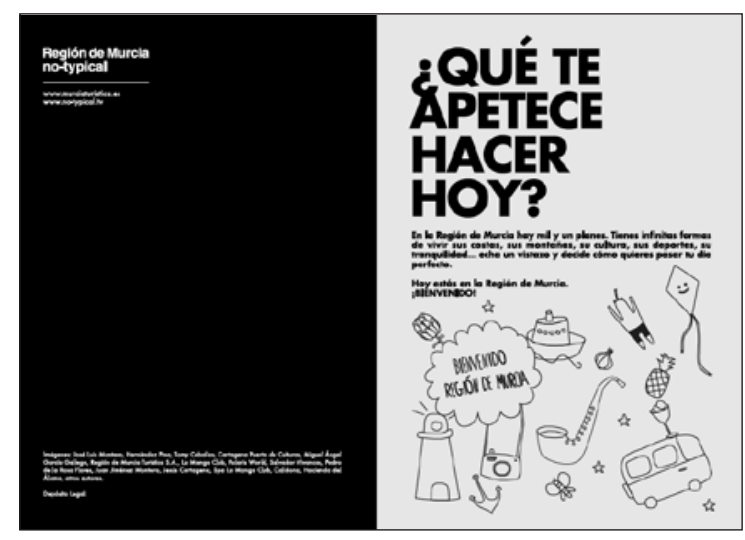

Imagen 2

Estos textos tienen una finalidad, evidentemente, persuasiva, puesto que están ligados a la actividad del marketing turístico, pero son textos híbridos, de tipo descriptivo y de tipo argumentativo al mismo tiempo. En cuanto a su función persuasiva, como sucede en el texto publicitario, se tienen distintas estrategias, compartiendo con el texto publicitario la presentación de un eslogan sugerente que activa múltiples interpretaciones, pero queremos subrayar la vinculación que se establece con la marca Región de Murcia no-typical. Para ello, en el siguiente apartado damos cuenta de la creación de esta marca, para centrarnos después en el análisis de eslóganes y anuncios.

El objetivo principal de nuestro trabajo es observar la activación del componente cognitivo y afectivo que tiene lugar en el proceso de interpretación de los enunciados figurados 
presentes en textos turísticos promocionales que se categorizan, por su configuración lingüística, como textos publicitarios. Secundariamente, veremos cómo se articula el racional creativo de la marca Región de Murcia no-typical en los distintos enunciados para lograr la finalidad comunicativa que se pretende por parte de la institución.

\section{Metodología}

Para mostrar la funcionalidad de los enunciados figurados en el texto turístico promocional que nos ocupa, realizamos un análisis semántico-pragmático de algunos casos presentes en nuestro corpus. No se pretende un análisis cuantitativo de usos figurados, sino mostrar cómo se conecta la configuración enunciativa a la función comunicativa que se quiere privilegiar. Metáfora y metonimia no pueden concebirse localmente, en una palabra, como se pretendía en el enfoque retórico, presente también en la teoría lingüística que definía la metáfora como sustitución, por lo que asumimos una teoría enunciativa del sentido figurado (Tamba-Mecz 1981). Por una parte, los trabajos de la semántica estructural nos proporcionan algunas herramientas teóricas y metodológicas para realizar el análisis semántico; así, tenemos presente el análisis del significado de Greimas (1966). Sin embargo, es fundamental en nuestra investigación la teoría de la metáfora y la metonimia desarrollada por Le Guern (1973), en la que, a partir de la nueva concepción de los tropos que se inaugura con Jakobson $(1956)^{5}$, se conjuga el análisis semántico estructural con los aspectos cognitivos de ambos procedimientos lingüísticos. Bonhomme $(1987,1998)$ sigue esta dirección, pero complementa su estudio focalizando en la intención comunicativa, lo nos que permite una aproximación pragmática. Introducimos también el enfoque pragmático de Sperber y Wilson (1986), considerando su concepto de inferencia contextual, y la revisión que de esta teoría hace Vega (2007) para explicar la interpretación del sentido figurado. En definitiva, aplicamos una metodología heterogénea, acorde con la complejidad del objeto de análisis, integrando las bases metodológicas de distintos modelos teóricos.

\section{La campaña del no-estereotipo}

En enero de 2009 el entonces Consejero de Cultura y Turismo de la Región de Murcia, Pedro Alberto Cruz, presenta la puesta en marcha de una nueva campaña impulsada por la Comunidad Autónoma para la promoción turística y cultural de la Región. En una primera fase de esta campaña, el objetivo es buscar estereotipos que identifiquen a la Región de Murcia, para lo cual se anuncia en todos los medios informativos ${ }^{6}$ que se ha contratado al reputado antropólogo Vladimir Karabatic, creador del eslogan typical spanish y responsable de convertir la paella en icono de Valencia, entre otros méritos. También se da noticia de que de forma inminente estará disponible la web www.murciaencuentrasuestereotipo. com (hoy ya no accesible), en la que se va a dar cuenta de todo el proceso de investigación de este científico de origen croata y en la que el ciudadano podrá participar en el estudio opinando y aportando ideas sobre los estereotipos de la Región. En palabras del Consejero,

5 La teoría de la metáfora y la metonimia desarrollada a partir de que Jakobson postula la estructuración del lenguaje en dos polos, el metafórico y el metonímico, vinculados, respectivamente, a los ejes paradigmático y sintagmático, redefine los tropos como procedimientos lingüísticos y no como meras operaciones retóricas.

6 Véase, por ejemplo, la noticia en el portal independiente Murcia.com: http://goo.gl/dh52Nv 
se trata de "un proceso de construcción colectiva en donde todos van a poder participar en la construcción real de una imagen real de la Región de Murcia", cuyo objetivo es generar una "expectación sin precedentes" tanto a nivel regional como nacional, a propósito de la imagen turística de la Región de Murcia. En FITUR 2009 se presenta esta campaña, con la presencia de Karabatic.

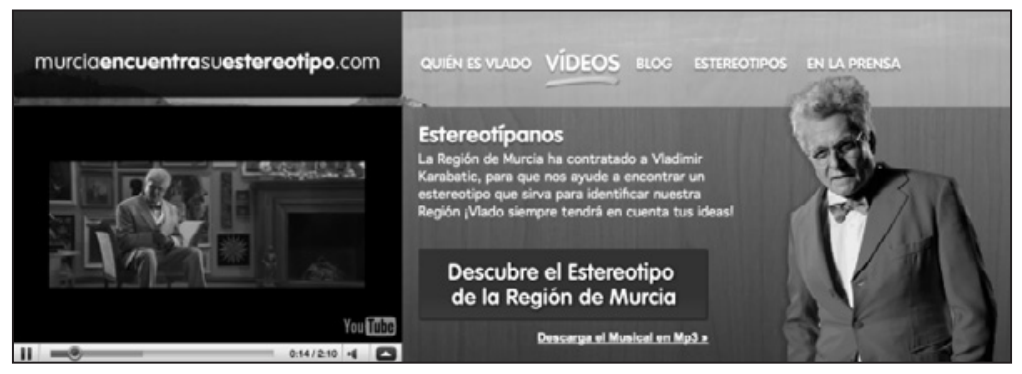

Imagen 3

$\mathrm{Al}$ poco tiempo, se descubre que es una estrategia de marketing viral, pues Karabatic es un personaje ficticio, interpretado por un actor. La farsa, apoyada institucionalmente, fue motivo de enfado tanto de políticos como de algunos medios de comunicación, que se sintieron manipulados y cuestionaron el engaño en tanto que afectaba a la imagen de Murcia y su credibilidad. A mediados de marzo de 2009, el Consejero, Pedro Alberto Cruz, presenta las conclusiones de la investigación de Karabatic: Murcia no tiene estereotipo y comienza la segunda fase de la promoción turística, si bien Karabatic continúa con su papel, aunque ya se ha descubierto su impostura y se ha borrado de Wikipedia el artículo fraudulento que sobre él se colgó el 30 de enero ${ }^{7}$. Se anuncia el certamen Región de Murcia: No-typical, organizado por la Consejería y Jameson Notodofilmest, para premiar los vídeos en los que se proyecte una imagen no estereotipada de la Región. Así, la primera fase de la campaña Murcia encuentra su estereotipo, da como resultado el eslogan Región de Murcia, no typical, que sustituye al anterior, Región de Murcia, donde vive el sol, pues Karavatic concluye que es tal la diversidad de la Región, que no puede reducirse a un cliché, a un estereotipo ${ }^{8}$. En un comunicado, la Consejería declaraba su apuesta por una Región "orgullosa de su diversidad y no reducida a un cliché, una Región No-Typical en cuanto a su gastronomía, socialmente, culturalmente y también en la forma de contarlo". La web, en esas fechas, había recibido más de 93.000 visitas $^{9}$.

\footnotetext{
7 http://goo.gl/1eD3Ff

8 En distintos medios, como La Razón, se publicó este resultado: http://goo.gl/UyrCsg

9 David Briones, creativo de la agencia murciana Germinal Comunicación, responsable de la campaña, nos ofrece en su página personal (http://goo.gl/qeeuLT) los siguientes datos: "251.000 visitas a la web; más de 300.000 visionados de los vídeos; 1.900 estereotipos propuestos; más de 8.000 referencias de Karabatic en internet y más de 10.000 de la web y la campaña. Karabatic apareció en cerca de una veintena de debates, coloquios y programas de televisión; se habló de la campaña en diarios nacionales y regionales de prensa escrita y digital, en cerca de 1.100 blogs y se creó un club de fans de Karabatic en Facebook. Por otro lado, instituciones como la Universidad de Murcia, la Universidad Rey Juan Carlos de Madrid o la Escuela de Negocios de Buenos Aires se han interesado por la campaña para utilizarla como caso de estudio".
} 


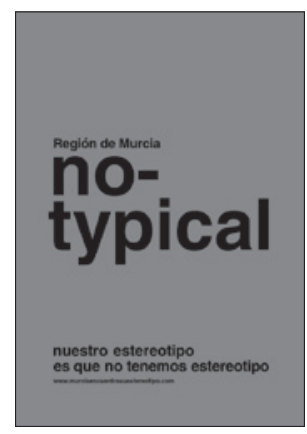

Imagen 4

En abril de 2009 el eslogan figuraba en una lona gigantesca que colgaba en la fachada de un edificio histórico de la Gran Vía en Madrid.

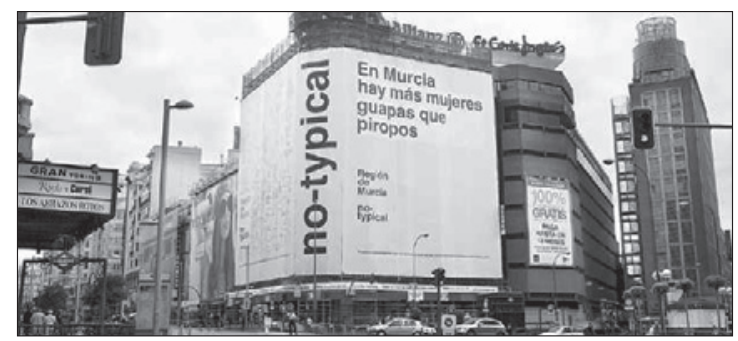

Imagen 5

El triunfo de un eslogan en el que se potencia la ausencia de tipicidades, dio ocasión para crear una serie de textos alusivos a estereotipos de otras comunidades ${ }^{10}$, como la fabada como estereotipo de Asturias, la Pilarica como estereotipo de Aragón, o el camino de Santiago como estereotipo de Galicia.

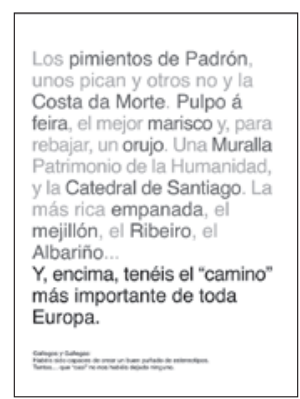

Imagen 6

10 La introducción en la campaña de una serie de textos simétricos mostrando los estereotipos de otras comunidades, fue motivo de disgusto entre las autoridades de dichas comunidades, como es el caso del alcalde de Toledo (http://goo.gl/oXlVW6). 
El 4 de enero de 2012, el Consejero anuncia la sustitución de la campaña no-typical por otra cuyo eslogan es: Destino Región de Murcia, donde operan los conceptos: destino, descubrir, relax, disfrutar, aprender y diversión. El 19 de febrero de 2014, presenta el nuevo portal www.murciaturistica.es, renovado después de diez años, con la marca Destino Región de Murcia, que sustituye a Región de Murcia no-typical, explicando: "Hemos pasado del cómo es al qué es; del adjetivo al sustantivo". Como señalan Aires Barroso y Nicolau Mota (2010: 246), la marca, como elemento destacado del marketing de un destino turístico, debe despertar el deseo del consumo.

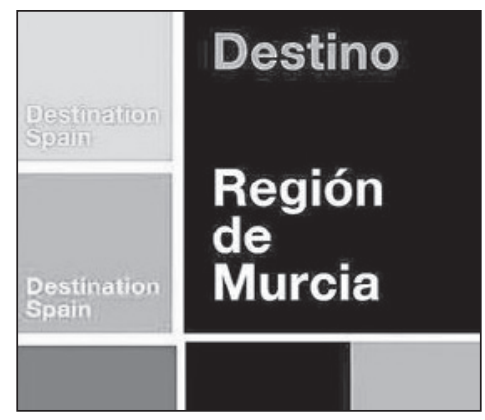

Imagen 7

Los documentos de nuestro corpus de partida se englobaron en la campaña anterior en la sección Qué hacer, mientras que en última los atributos que se promocionan aparecen en la sección Disfrutar.

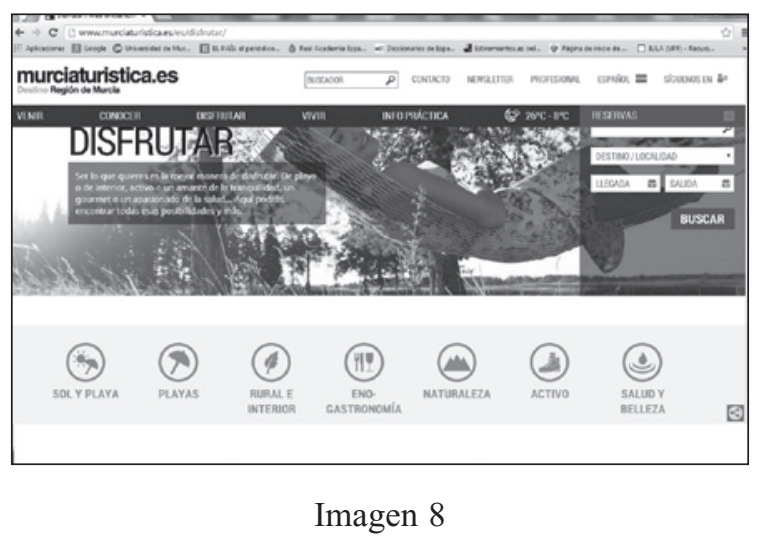

En este momento, cabe cuestionarse cuál es la concepción turística de Murcia en esta campaña, cuáles son los conceptos clave, qué se promociona y, sobre todo, cuál es la idea motor de los textos: frente al estereotipo, en la Región de Murcia está la variedad. Aunque el eslogan es Región de Murcia, no-typical, hay una serie de bienes del lugar y para cada uno tenemos un documento, como el que se titula Hoy me siento pez, un folleto que potencia el turismo de sol y playa, pero focalizando en el ahora. Es un enunciado atractivo y 
sorprendente, cumpliendo con el papel de gancho del eslogan publicitario, que se centra en las apetencias en el momento presente, del hoy. Estos folletos, presentados simultáneamente en la web, crean el efecto de diversidad que se pretende ofrecer y, al mismo tiempo, cada uno de ellos capta la atención de aquel turista que busque solo un determinado producto, sea turismo de sol y playa, turismo rural, turismo cultural, turismo gastronómico, etc. Se pretende comunicar que durante la estancia en Murcia, se tendrán posibilidades diversas, según diversas apetencias puntuales, y todas pueden verse cumplidas. Por esto se presenta la colección de folletos de forma separada, pero unidas por ese hoy, que actúa como nexo que nos invita a disfrutar cada una de las oportunidades de disfrute que ofrece esta tierra: Hoy me siento pez; Hoy estoy rural; Hoy el gusto es mío; etc. La organización del turismo ha variado y no se reduce a los períodos vacacionales, de modo que se propicia la promoción de viajes para distintos tiempos de ocio, como fines de semana. Por esta razón también se tiene en estos textos promocionales una apuesta por el hoy, que exige una menor inversión económica y de tiempo que las típicas vacaciones.

Aparentemente, la promoción turística en la actualidad no puede apostar por estereotipos, cuando el potencial turista busca nuevas experiencias y sensaciones, pero no se puede renunciar a una imagen de una Región que capte al usuario que decide un destino turístico focalizando en un bien o valor particular que identifica el lugar. La creación de la imagen de un lugar forma parte del marketing turístico, siendo el primer paso para la construcción de esta imagen la identificación de los atractivos turísticos (Aires Barroso y Nicolau Mota 2010: 250). En la campaña Región de Murcia no-typical, cada atractivo turístico se corresponde con las distintas categorías de la sección Qué hacer.

\section{Hoy me siento pez: análisis de enunciados metafóricos y metonímicos}

Si hemos de valorar la mayor o menor presencia de la metáfora en los textos turísticos institucionales, hemos de ser precavidos, pues son fundamentalmente descriptivos, si bien, como hemos dicho, también argumentativos, por la intención persuasiva dado el carácter promocional de los textos. Por ello hemos de advertir que encontramos el uso de metáforas principalmente en eslóganes y en textos concebidos como anuncios publicitarios, mientras que en el cuerpo de los folletos que analizamos se acude a otros recursos para causar impacto, principalmente la adjetivación valorativa ${ }^{11}$. La metonimia, en cambio, es más frecuente, por ser un procedimiento que incide sobre lo referencial, a diferencia de la metáfora, que incide sobre la sustancia semántica: "la metonimia completa la función referencial normal del lenguaje, superponiendo a la designación de la realidad descrita una información sobre la forma especial en que el hablante concibe esa realidad" (1980: 89). Es lo que sucede en la metonimia sol y playa que forma parte ya de la lengua del turismo (turismo de sol y playa, destino de sol y playa).

11 Esta adjetivación da lugar a la creación de nuevas denominaciones en la lengua del turismo, como hotel familiar, si bien estos nuevos términos representan conceptos que el hablante desconoce y que aún no se recogen en los repertorios lexicográficos, ni siquiera en los especializados (Sanmartín 2012: 90). A propósito de la praxis lexicográfica, apuntamos también, como señala Azorín (2015) que la selección de voces depende, entre otros factores, del criterio valorativo del lexicógrafo, de la idea de lengua que maneje, lo que es especialmente relevante en el caso de los neologismos. 
Ciertamente, en los folletos de la sección Qué hacer de la web, así como en los anuncios distribuidos en prensa, lo más destacable es la adjetivación; así, en el folleto Hoy me siento pez, solo en una de sus páginas, la subtitulada Hoy te bañas en la Costa Cálida, encontramos: extensas arenas claras, tranquilas aguas, paraísos casi inalterados, la costa más abrupta, calas vírgenes, puntas rocosas, excelentes playas de fin arena, suaves temperaturas, espacios increíbles. Sin embargo, como decíamos, en aquellas partes textuales que se identifican como propias de la argumentación, más que de la descripción (eslóganes y anuncios), se recurre a la producción de enunciados figurados, a veces complejos, con superposición de metáfora y metonimia. En el cuerpo de los folletos los usos creativos se introducen en menor medida, dado que, como hemos señalado, es predominante una adjetivación valorativa. Por tanto, en consonancia con su finalidad, estos textos integran una adjetivación apreciativa en el plano de la descripción y, al mismo tiempo, metáforas y metonimias, en el plano de la argumentación.

\subsection{Análisis de eslóganes en los folletos turísticos}

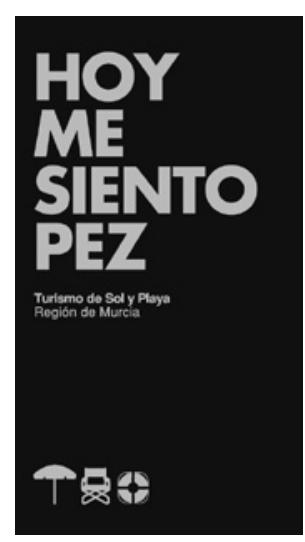

Imagen 9

Nos centramos en el análisis de dos de los títulos: Hoy me siento pez y Hoy el gusto es tuyo, que, a nuestro parecer, son los más sorpresivos, por lo que son ejemplos señeros para mostrar la implicación intelectual y afectiva del receptor para su interpretación.

El eslogan Hoy me siento pez aparece en la primera página del folleto; en la segunda página, cuando comienza el texto, se cambia a la segunda persona: Hoy te sientes pez. Del mismo modo sucede en los otros documentos: en el folleto Hoy el gusto es mío, dedicado al turismo gastronómico, se pasa a un discurso dirigido al tú, turista potencial: Hoy el gusto es tuyo. En el primero de los enunciados tenemos la metonimia pez por mar, pero se solapa con la imagen metafórica que subyace en la unidad fraseológica sentirse como pez en el agua. La metonimia aquí desempeña la función comunicativa que Bonhomme (1987: 127) denomina individualizadora: se denota el referente mar de forma oblicua, focalizando en uno de los polos denotativos que forma parte, por contigüidad, del dominio semiótico de mar. En el segundo enunciado tenemos también una metonimia: el sentido del gusto por el turismo gastronómico; en este caso, cumpliría con la función deceptiva que Bonhomme señala para 
este tropo (1987: 159), por cuanto que se tiene una incertidumbre referencial, una ambigüedad contextual, que después analizaremos. No obstante, el propósito es la focalización en lo sensitivo, lo que aparece explícitamente en el eslogan que encontramos en otro documento de interés de la web dedicado a las rutas enoturísticas: Una experiencia para los sentidos.

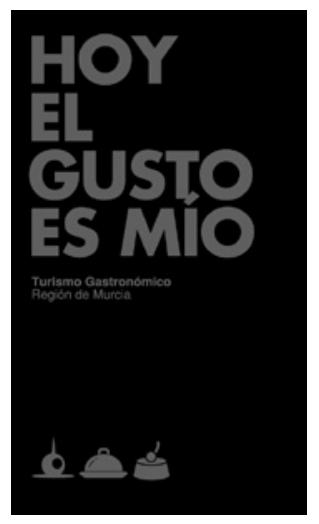

Imagen 10

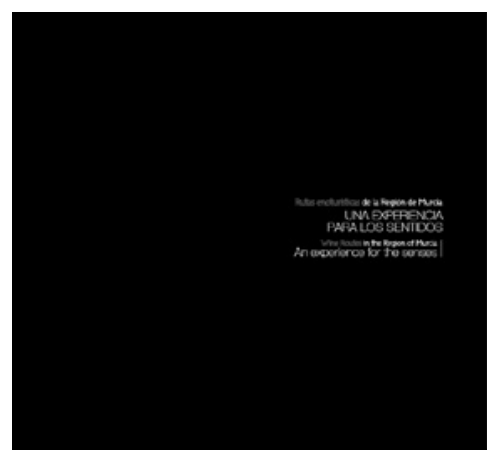

Imagen 11

Para examinar la funcionalidad de estos usos en el texto turístico conviene un análisis semántico y pragmático que integre los distintos aspectos que intervienen en la producción e interpretación del sentido figurado. Aunque en primer lugar, desde el punto de vista cognitivo, hemos considerado que el sentido figurado en el enunciado Hoy me siento pez sucede contextualmente por metonimia, también podemos interpretar el enunciado como una metáfora nominal del tipo N1 es un N2 en la medida que sentirse se considera un verbo semiatributivo. Este tipo de enunciados metafóricos, que Tamba-Mecz (1999) analiza ilustrando con une femme est une fleur, no constituyen enunciados clasificatorios basados en la inclusión o pertenencia a clases, sino que, por el contrario, bloquean propiedades de clase para remarcar una propiedad. En Hoy me siento pez, por otra parte, el complemento predicativo que aparece con este verbo semiatributivo es un sustantivo concreto, cuando al verbo sentir tendría que seguir un elemento léxico con el clasema [+abstracto]; además, aparece 
un sustantivo en lugar de un adjetivo, que sería lo esperable, puesto que, aunque es posible la construcción sentirse + [sustantivo], la construcción prototípica en español es sentirse + [adjetivo]. Lo anterior sería un índice discursivo en el plano gramatical de la presencia de una figura, que se suma al índice en el plano semántico que viene dado por la conexión de dos dominios conceptuales distintos: sentimiento (abstracto) y seres vivos (concreto). La ruptura clasémica que se produce en el enunciado por la presencia de pez en un contexto no habitual para esa ocurrencia léxica es lo que procura, según Moreno Villanueva (1993: 198), una gran fuerza expresiva, pues el oyente descubre contextos "imaginables" en lugar de los contextos "normales".

Por otra parte, en el enunciado Hoy me siento pez podemos interpretar una modificación de la unidad fraseológica sentirse como pez en el agua, si bien, como hemos visto, también puede concebirse como enunciado figurado al margen de esta expresión prefijada y convencional. El sentido figurado de sentirse como pez en el agua, y de su variante estar como pez en el agua, nos remite a una sensación de satisfacción o disfrute en algún medio o lugar, en alguna circunstancia o situación, que se asimila a nuestro medio natural ${ }^{12}$. Quizás esta asociación, que podría ser no consciente, hay que evaluarla como un valor connotativo que se suma al enunciado. Sin embargo, subyace la imagen, como lo corrobora el hecho de que en la actual campaña Destino Región de Murcia, la promoción de Murcia como destino de sol y playa se presenta como una reescritura de los textos de esta campaña anterior que estamos analizando. Presentamos los enunciados de una y otra campaña relacionados:

Campaña Región de Murcia no-typical: Hoy te bañas al sol. [...] Hoy descubres una cala y le pones tu nombre. [...] Cambia la sombrilla por el traje de neopreno y el flotador por alguna actividad acuática mucho más aerodinámica.

Campaña Destino Región de Murcia: Bañarse al sol en playas de arena, bautizar calas escondidas, desafiar al viento sobre una tabla o cambiar la sombrilla por el traje de neopreno son sólo algunas de las opciones que tenemos para que te sientas como pez en el agua.

Por tanto, además de la metonimia pez/mar (relación de contigüidad entre la entidad y su lugar, incluso metonimia del continente por el contenido), está la analogía entre el hábitat natural del pez, que es el mar, con el hábitat del individuo, que se construye en Hoy me siento pez como metáfora nominal a partir de la asociación con sentirse como pez en el agua (téngase presente la expresión antónima: estar/sentirse como pez en el agua). La metáfora nominal que interpretábamos anteriormente en Hoy me siento pez, se localiza en pez, sino en todo el enunciado, pues no estamos ante una sustitución, sino ante una imagen creada en virtud de una analogía que se desprende del contexto enunciativo en el que aparece pez y sumando la competencia fraseológica del hablante ${ }^{13}$. La complejidad, como vemos, es alta, lo que motiva la implicación del destinatario en el proceso de interpretación del sentido figurado. Ello es propio de los textos publicitarios, como ya hemos señalado en otra ocasión:

12 Otra unidad fraseológica que presenta la forma pez es estar pez (en alguna materia), pero no la consideramos porque no responde a la intención comunicativa del enunciado que analizamos.

13 El enfoque sustitutivo y comparativo en la teoría de la metáfora fue puesto en cuestión por Black, quien propone un enfoque interactivo inspirándose en Richards: “decir que la metáfora crea la semejanza sería mucho más esclarecedor que decir que formula una semejanza que existiera con anterioridad” (1966: 47). 
La elección, por parte del creativo publicitario, de un significante que no lleve directamente a la referencia -que es lo que sucede en los signos "automatizados", y que es lo que la publicidad quiere evitar a toda costa-, conduce, necesariamente, a un ejercicio interpretativo. Ayuda a que una construcción sea memorable el que se proponga un juego interpretativo, de tipo inferencial, que implique el razonamiento del destinatario. Ello es así porque ese juego forma parte de nuestros procesos cognitivos y por tanto es creador de conocimiento (Corrales, 1999: 120). Por otra parte, esta implicación, este juego, nos lleva a la dimensión lúdica del discurso publicitario, que estaría en relación -cómo no- con el delectare clásico, el combate contra el tedio. Es el placer del conocimiento (Sánchez Manzanares 2003: 746).

Los efectos cognitivos que resultan del uso figurado en el plano cognitivo son más claros o fuertes cuanto mayor sea la innovación, puesto que el proceso inferencial implica la reconstrucción de mayor número de elementos contextuales. En la perspectiva de la teoría pragmática de la relevancia de Sperber y Wilson (1986), se diría que en los enunciados figurados hay un conjunto de supuestos que están contextualmente débilmente implicados. No obstante, la comprensión no puede dificultarse en exceso en el texto turístico, puesto que se pretende motivar una determinada elección, por lo que se tendrá presente el conocimiento compartido. En este sentido, las locuciones, como cápsulas informativas del acervo cultural de una comunidad, resultan adecuadas, incluso cuando se modifican o cuando están solamente sugeridas, como en el caso de sentirse como pez en el agua; además, como señala Guiraud (1967: 57), en las locuciones se tienen empleos figurados a partir de observaciones cotidianas, lo que facilita la comprensión.

En el caso de Hoy el gusto es mío, se tiene también un juego interpretativo con la fórmula rutinaria para una presentación El gusto es mío, que forma parte de nuestro repertorio fraseológico. Como señalamos anteriormente, tenemos una metonimia (el sentido del gusto por el turismo gastronómico), pero, en este caso, la unidad fraseológica no favorece la interpretación del sentido figurado. El propósito del eslogan es, por el contrario, funcionar como gancho que golpea al destinatario para interesarlo por el sentido, que se resuelve en la leyenda situada bajo él, en caracteres bastante más pequeños: Turismo gastronómico. De la misma manera que en los textos humorísticos los indicadores que tienen que ver con la polisemia y la ambigüedad son los más rentables (Ruiz Gurillo 2014: 160), así sucede en los textos publicitarios, puesto que en ambos se pretende la sorpresa. Es la función deceptiva que mencionamos anteriormente para esta metonimia, cuyos indicadores son la polisemia de gusto y la ambigüedad contextual, más aún cuando se juega con una fórmula cuya ilocución está prefijada. Esta incertidumbre referencial incide en la "literariedad" del mensaje, en la atención a la misma constitución formal del mensaje, lo que es característico del eslogan publicitario. La función "poética" de la metonimia ha sido señalada, entre otros, por Le Guern (1980: 89) y es un efecto del desplazamiento referencial que se produce con este tropo, que conduce, en este caso, a una focalización sobre la materialidad de la propia lengua.

\subsection{Análisis de enunciados en anuncios}

\subsubsection{Anuncios en prensa}

Es necesario un conocimiento del contexto cultural para comprender la descripción que de la Semana Santa se hace en un texto como el que sigue: 


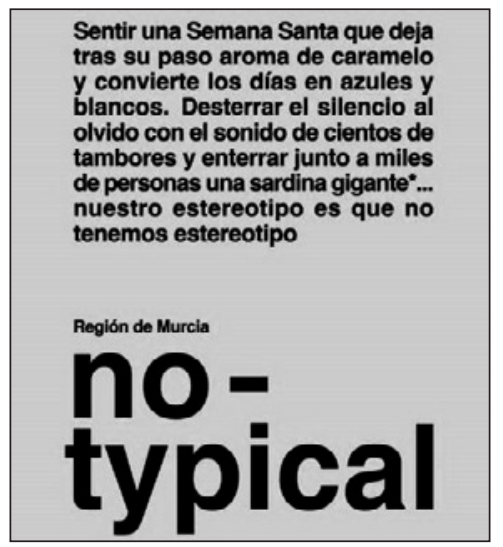

Imagen 12

En el primer enunciado, cuando se nos dice que la Semana Santa deja tras su paso aroma de caramelo, primeramente, tenemos el juego con la polisemia de paso, puesto que, además de su sentido en el seno de la construcción dejar tras su paso, también se actualiza el sentido de paso como el trono con las imágenes que se procesiona en Semana Santa. En segundo lugar, y aquí es donde cabe el conocimiento del contexto cultural para la comprensión del enunciado, aroma de caramelo alude al hecho de que en las procesiones de nuestra Región es típico que los que procesionan repartan caramelos al público espectador. En cuanto a los días que se convierten en azules y blancos, se hace referencia a las procesiones de Lorca, donde hay dos cofradías, la de los blancos y la de los azules -a su vez, metonimias por el color de la túnica de los penitentes-, que muestran su rivalidad efusivamente durante los actos de la Semana Santa. Es claro que sin estos datos contextuales, no se llegará a una interpretación completa del enunciado, pero para nuestro análisis, lo que nos interesa es que la Semana Santa (metonimia por los actos que tienen lugar en ese tiempo) se muestra con atributos materiales, como el aroma. Tenemos la representación de la Semana Santa como un bien tangible mediante un proceso metafórico tan natural como complejo. La metáfora hace sensible lo no perceptible y lo que se pretende es hacernos sentir la Semana Santa, como se nos dice explícitamente.

El enunciado resulta poético, por las imágenes que despierta la sugerencia del aroma de los caramelos y los días blancos y azules, incluso si se desconocen los elementos culturales. Ello tiene que ver, por una parte, con la selección léxica, que suma valores connotativos positivos: aroma, caramelo, blanco, azul, todos ellos añaden un valor subjetivo positivo que se suma al valor propiamente denotativo. Pero es en la configuración final del enunciado que se tiene una imagen sugerente, que transmite sensaciones incitantes, atractivas. Ese es uno de los objetivos del enunciado: promocionar sensaciones, vivencias, emociones, que satisfagan las expectativas del turista actual. El otro es la reformulación de estereotipos a base de la representación no convencional de los atractivos turísticos de la Región, de acuerdo con la marca no-typical.

La metáfora nos ofrece una visión diferente del producto, destaca un aspecto o atributo del mismo de un modo novedoso, procurando una impresión de frescura, una originalidad 
que es fruto de una aprehensión del mundo desde una óptica no convencional. Para Le Guern, la metáfora suspende la significación lógica y despierta en el receptor una imagen que lo implica en un proceso de interpretación en el que accede a una significación impuesta por el contexto, que priva a la imagen asociada de su carácter arbitrario. No obstante, no es preciso que el receptor sea consciente de esa imagen en el nivel de la inteligencia lógica:

Ahí se encuentra el carácter específico de la metáfora: al obligar a abstraer a nivel de la comunicación lógica cierto número de elementos de significación, ella permite poner de relieve los elementos mantenidos; a un nivel distinto del de la pura información, y por medio de la introducción de un término extraño a la isotopía del contexto, provoca la evocación de una imagen asociada que percibe la imaginación y que ejerce su impacto sobre la sensibilidad sin el control de la inteligencia lógica, pues la naturaleza de la imagen introducida por la metáfora le permite escapar a él (1980: 25).

Así, además, es más eficaz la persuasión (Le Guern 1980: 85), por cuanto no puede haber oposición desde la lógica intelectual.

Por otra parte, en el segundo enunciado del anuncio, la primera parte, Desterrar el silencio al olvido con el sonido de cientos de tambores ${ }^{14}$, el sentido figurado resulta de una personificación por metáfora del silencio. No obstante, lo usual es que lo personificado aparezca como sujeto de la acción relatada en el enunciado y tenemos este recurso de forma recurrente en enunciados que encontramos en el interior de los distintos folletos de la sección Qué hacer. Así, por ejemplo, podemos observarlo en el enunciado Hoy las olas te mecen con cariño y el viento te cuenta secretos al oído, presente en la siguiente página del folleto Hoy me siento pez:

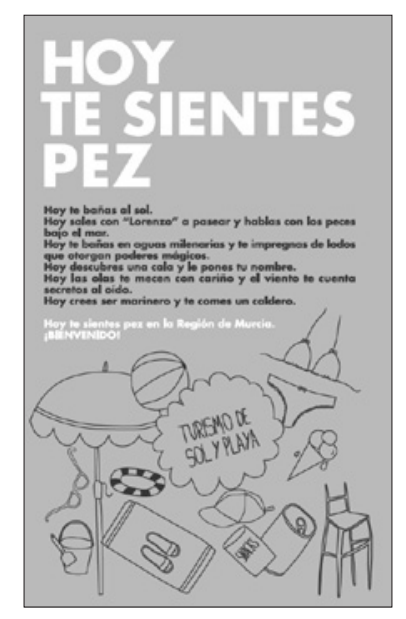

Imagen 13

14 La segunda parte del enunciado: enterrar junto a miles de personas una sardina gigante, motiva la interpretación de la participación del destinatario en un acto que es, en realidad, un acto simbólico: la celebración del entierro de la sardina tras la Semana Santa. 
Como nos dice Prandi, un verbo puede usarse metafóricacmente de dos formas: "pour opérer une classification conflictuelle d'un procès - par exemple, un acte de parole est catégorisé comme une instance de chant- ou pour entraîner des actants conflictuels dans un procès: des êtres inanimés comme les montagnes, par exemple, se voient attribuer le procès du sommeil" (Prandi 2002: 11). En el enunciado Dorment les sommets des montagnes, en el que se aplica al verbo un sujeto conflictual, observa Prandi que el sujeto virtual coherente con el verbo, el ser animado, se proyecta sobre el sujeto virtual, las montañas, como un sujeto subsidiario, de manera que los dos sujetos forman un paradigma interactivo, no sustitutivo. La única función admitida por este paradigma es, en la perspectiva de Prandi, enmarcar una proyección de los seres vivos sobre las montañas (Prandi 2002: 12). Del mismo modo, en nuestro enunciado se proyecta el ámbito de la acción humana sobre las olas y el viento.

Para Lausberg (1991: 64, § 559), esta figura es la "forma más penetrante de la metáfora sensibilizadora". La transferencia entre los rasgos semántico-referenciales inanimado/ animado se interpreta como una de las constantes psicolingüísticas del proceso metafórico. Estas metáforas para la personificación suponen una incompatibilidad combinatoria en el plano semántico y una proyección de atributos en el plano cognitivo.

\subsubsection{Carteles}

Por último, analicemos algunos enunciados comparativos que proyectan el sentido figurado presente en la metáfora sobre la que se construyen ${ }^{15}$. Se inscriben en los textos que se exhibieron en las lonas publicitarias que colgaron en fachadas de ciudades principales, como Madrid.

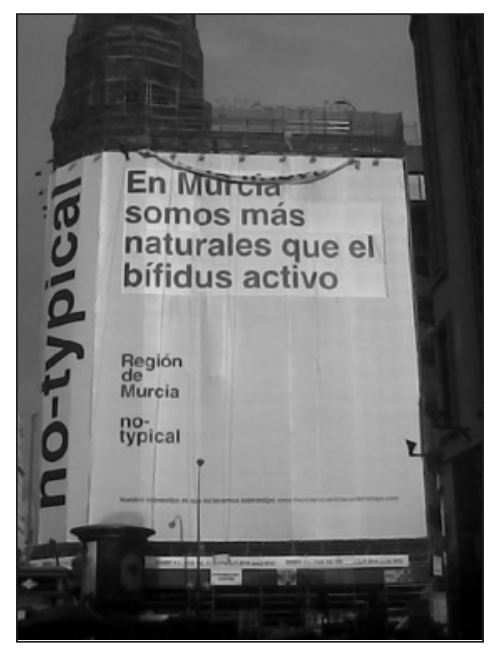

Imagen 14

15 Otras estructuras comparativas que encontramos en la campaña son hipérboles, como En Murcia hay más mujeres guapas que piropos. También tenemos una estructura comparativa que resulta de la modificación de un eslogan publicitario muy conocido en la comunidad española: En Murcia la primavera llega antes que al Corte Inglés, para significar el clima cálido de la Región. 
El enunciado En Murcia somos más naturales que el bífidus activo es una estructura comparativa que se sustenta en la metáfora: Murcia es un producto natural; esta metáfora sustenta una estructura comparativa mediante la cual se consigue una intensificación del atributo que se pretende potenciar. La finalidad de estas estructuras comparativas es focalizar la atención del receptor en aquello que se quiere hacer relevante y ello se consigue mediante la intensificación del atributo que se pretende potenciar. La metáfora, como nos dice Le Guern (1980: 47), pone de relieve el atributo dominante que, en la imaginación del hablante, comparten los "objetos" entre los que se establece la analogía, de manera que por la metáfora se consigue una sobresignificación cuyo efecto es una gran fuerza expresiva.

Si estas estructuras comparativas se fundamentan en estereotipos, como es el caso de más negro que el carbón, tendrán una base cultural (el carbón como prototipo cultural de la negrura) y una base semántica (presencia del sema 'negro' en el significado de carbón) (García Page 2008: 146). En nuestro caso, el atributo sobresaliente del bífidus activo de 'producto natural' es una creencia que se ha impuesto recientemente en nuestra cultura, por lo que la comparación resulta original y llamativa, al mismo tiempo que divertida. El carácter lúdico de estos textos para la promoción de la Región de Murcia es evidente; precisamente la función lúdica de la metáfora, por el juego interpretativo, es otra de las funciones de este procedimiento que se suele valorar en los textos creativos.

\section{Conclusión}

El concepto de turismo ha evolucionado, así como el concepto de imagen de destino (Andrade 2012: 478), centrándose la promoción de un destino en las vivencias y emociones del potencial turista. El análisis de enunciados figurados en distintos textos de corte publicitario de la campaña turística Región de Murcia no-typical, promovida institucionalmente, nos ha mostrado la intervención de metáfora y metonimia en la creación de la imagen del destino turístico. Las bases metodológicas que sustentan este análisis se fundamentan en modelos teóricos de la semántica y de la pragmática que están presentes en estudios como los de Le Guern (1973) o Vega (2007).

En el marco de una campaña cuya idea clave es la apuesta por la diversidad y lo no convencional, hemos seleccionado para el análisis semántico-pragmático una serie de enunciados figurados presentes en folletos y anuncios en los que se reformulan los estereotipos vinculados a los atractivos del lugar. Específicamente, se trata de los títulos de los folletos, que se asimilan a eslóganes publicitarios, y de las leyendas de anuncios, tanto distribuidos en prensa como en carteles al modo de vallas publicitarias. Para lograr la persuasión, finalidad propia de los textos promocionales que nos ocupan, se guía al destinatario mediante estos enunciados en la construcción de una imagen de destino que crea o refuerza sus expectativas, incluso cambia sus creencias o actitudes frente al producto. Los componentes cognitivo y afectivo del destinatario se ven afectados por estos procedimientos creativos, la metáfora y la metonimia, en la medida en que lo implican en la interpretación del enunciado y le conducen a una representación subjetiva del lugar que determinará su elección. Se consigue así su adhesión, tanto a nivel intelectual como a nivel emocional. 


\section{Referencias bibliográficas}

Aires Barroso, G. y Nicolau Mota, K. C. (2010): "Marketing turístico internacional. La Marca Brasil”, Estudios y Perspectivas en Turismo, vol. 19, 2, págs. 241-267.

Andrade Suárez, M. J. (2012). "La interpretación de la realidad del destino por parte de los turistas: evaluaciones cognitivas y afectivas". Pasos, 10 (5): 477-494.

Azorín Fernández, D. (2015): “Ideología y diccionario: aspectos de la neología léxica en los inicios de la lexicografía moderna del español". En Cunita, A. y C. Lupu (eds.): Neologie, neologisme. Concepte, analize. Bucarest, Universidad de Bucarest, págs. 7-22.

Barcelona, A. y R. Rocamora (2000): "El argot turístico y la teoría cognitiva de la metáfora y la metonimia", Cuadernos de Turismo, 5, págs. 19-34.

Bigné, E.; Sánchez, I. y R. Currás (2007): “El papel de la imagen del destino en la valoración y comportamiento postcompra del turista de sol y playa", Papers de turisme, 42, págs. 57-73.

Black, M. (1966): Modelos y metáforas. Madrid, Tecnos.

Bonhomme, M. (1987): Linguistique de la métonymie. Berna, Editions Peter Lang.

Bonhomme, M. (1998): Les figures clés du discours. Paris, Éditions du Seuil.

Calvi, Maria Vittoria (2010): "Los géneros discursivos en la lengua del turismo: una propuesta de clasificación”, Ibérica, 19, págs. 9-32.

Gallarza, M.; Gil, I. y H. Calderón (2002): "Imagen del destino. Hacia un marco conceptual”, Annals of Tourism Research en Español, vol. 4, 1, págs. 37-62.

García-Page, M. (2008): "La comparativa de intensidad: la función del estereotipo", Verba, vol. 35 , págs. $143-178$.

González García, V. (2012): "El discurso del turismo en Internet: hacia una caracterización de sus géneros”. En Sanmartín Sáez, J. (ed.), págs. 13-49.

Greimas (1971 [1966]): Semántica estructural. Madrid, Gredos.

Guiraud, P. (1967): Les locutions françaises. Paris, Presses Universitaires de France.

Hidalgo Alcázar, Mª del C.; Sicilia Piñero, M. y Ruiz de Maya, S. (2012): "La imagen de destino y el contenido generado por otros usuarios: el caso del turismo rural". En Guevara, A. et alii (eds.) Actas del IX Congreso Nacional "Turismo y Tecnologías de la Información y las Comunicaciones”, TURITEC 2012. Málaga, Facultad de Turismo, págs. 365-379: http://www.turitec.com/actas/2012/Actas_Turitec_2012_Completas.pdf (15/05/2015)

Jakobson, R. y M. Halle (1980 [1956]): Fundamentos del Lenguaje. Madrid, Ayuso-Pluma.

Le Guern, M. (1980 [1973]): La metáfora y la metonimia. Madrid, Cátedra.

Lausberg, H. (1991): Manual de Retórica Literaria. Madrid, Gredos.

Moreno Villanueva (1993): "La metáfora desde la perspectiva de la Pragmática", Universitas Tarraconensis. Filologia, XIV, Tarragona.

Prandi, Michèle (2002): "La métaphore: de la définition à la typologie", Langue française, 134 , págs. 6-20.

Ruiz Gurillo, L. (2014): "Infiriendo el humor. Un modelo de análisis para el español”, clac 59/2014, págs. 148-162: http://revistas.ucm.es/index.php/CLAC/article/ view/46712/43844 (15/05/2014)

Sánchez Manzanares, C. (2003): “La metáfora en la recepción del discurso publicitario”. En Almela Pérez, R. et alii (eds.) Homenaje al Profesor Estanislao Ramón Trives. Murcia, Servicio de Publicaciones de la Universidad de Murcia, págs. 745-760. 
Sanmartín Sáez, J. (ed.) (2012): Discurso turístico e internet. Madrid, Iberoamericana Vervuert.

Sanmartín Sáez, J. (ed.) (2012): “De las normativas turísticas a las páginas electrónicas de promoción de hoteles: la clasificación hotelera desde la perspectiva lingüística”. En Sanmartín Sáez, J. (ed.), págs. 81-124.

Sperber, D. y D. Wilson (1994 [1986]): La relevancia: comunicación y procesos cognitivos. Madrid, Visor.

Tamba-Mecz, I. (1999): "La femme est-elle une fleur comme le bleuet est une fleur? Métaphore et clasification : les structures en “'Le N1 est un N2'»", en Kleiber, G. y N. Charbonnel (eds.), La métaphore: entre philosophie et réthorique. Paris: PUF, págs. 207-235.

Tamba-Mecz, I. (1981) : Le sens figuré. Vers une théorie de l'énonciation figurative. Paris, Presses Universitaires de France.

Vega Moreno, R. E. (2007): Creativity and Convention. The Pragmatics of Everyday Figurative Speech. Amsterdam, John Benjamins. 


\title{
LOS SUFIJOS -DAD, -TAD, -ICIA, -EZA, -EZ, -TUD Y -DUMBRE EN VOCES NEOLÓGICAS DEL CASTELLANO ORIENTAL DEL SIGLO XV
}

\author{
MatThiAs RAAB \\ Universitat de Barcelona \\ mraabfil@gmail.com
}

Recibido: 30/01/2015

Aceptado: 15/04/2015

\begin{abstract}
Resumen
En el presente estudio, pretendemos arrojar luz sobre la interrelación e interdependencia entre la variación morfológica y la tipología textual a través del análisis de voces terminadas en uno de los siguientes alomorfos, -tad y -dad, -icia, -eza y -ez y -tud y -dumbre, en cuatro diferentes tipos textuales del castellano del siglo XV. Con tal fin, hemos partido de las unidades neológicas que recoge el Diccionario del castellano del siglo $X V$ de la Corona de Aragón, de las cuales hemos extraído aquellos términos acabados en uno de los alomorfos en cuestión. Hemos analizado, en un siguiente paso, dichos neologismos desde los puntos de vista semántico y morfológico, poniendo de relieve, sobre todo, los casos de competencia morfológica entre estos y otros morfemas. En todo momento, hemos tomado en consideración los tipos textuales en que se documentan las voces: textos jurídicos y administrativos; textos científicos, técnicos y doctrinales; textos históricos; y textos novelescos y poéticos. Destacan, en el análisis, la mayor productividad y estabilidad de lexemas acabadas en -dad, la presencia exclusiva de un gran número de términos en textos científicos, técnicos y doctrinales y las competencias morfológicas entre los derivativos patrimoniales analizados.

PALABRAS CLAVE: historia de la lengua, morfología, variación, tipología textual, siglo XV
\end{abstract}

\begin{abstract}
The aim of this paper is to analyze the interrelationship and interdependence between morphological variation and text types by analyzing Spanish items finished in one of the allomorphs -tad $\mathrm{y}-d a d$, -icia, -eza and -ez, and -tud and -dumbre, in four different text types from the $15^{\text {th }}$ century. Therefore, we have created a corpus of neological units with documentation in the Diccionario del castellano del siglo XV de la Corona de Aragón. We have analyzed, in a next step, the neologisms from both a semantic and morphological perspective, highlighting, in particular, cases of morphological competition between these and other morphemes. At all times, we have taken into account the text types in which the neological itmes are documented: legal and administrative texts, scientific, technical and doctrinal texts, historical texts; and romantic and poetic texts. We've highlighted, in the analysis, the higher productivity and stability of lexemes finished in $-d a d$, the exclusive presence of a large number of terms in scientific, technical and doctrinal texts and the morphological variation between the inherited morphemes.

KEY WORDS: history of Spanish language, morphology, variation, text typology, $15^{\text {th }}$ century
\end{abstract}

\section{Introducción}

En el presente trabajo ${ }^{1}$, nos proponemos analizar tanto las características semánticas y morfológicas como la interrelación e interdependencia entre algunos morfemas derivativos

1 Este estudio se desprende de la tesis doctoral Préstamo y derivación: neología y tipología textual en el castellano del siglo XV de la Corona de Aragón (Raab, 2014), dirigida por la Dra. Coloma Lleal Galceran. Además, queremos dar las gracias a los evaluadores de esta revista por sus sugerencias y propuestas de mejora tan acertadas. 
y las tipologías textuales en que ellos se documentan. Hemos escogido con tal fin, los alomorfos nominalizadores -tad y -dad, por un lado; -icia, -eza y -ez, por otro; y, finalmente, -tud y -dumbre, y hemos estudiado su papel en la formación de neologismos del siglo XV. El hecho de centrarnos en esta centuria se debe a la mayor importancia que los investigadores han otorgado a la Edad Media y los siglos XVI y XVII. En la selección de morfemas, hemos elegido tres grupos de alomorfos que suelen formar cualidades abstractas a partir de raíces adjetivas. Detallaremos, en las próximas páginas, en primer lugar, las obras más importantes que se ocupan de la morfología histórica (2). Seguidamente, justificaremos el uso del corpus del Diccionario del castellano del siglo XV en la Corona de Aragón (DICCA-XV) como base de nuestra investigación y explicaremos la metodología de estudio seguida (3). A continuación, describiremos brevemente las características generales de los morfemas en cuestión antes de proceder al análisis semántico, morfológico y textual de las unidades extraídas de nuestro corpus de estudio (4). Finalmente, resumiremos los resultados más sobresalientes (5).

\section{Breve estado de la cuestión}

Los trabajos que versan sobre morfología histórica, procesos derivativos y competencia morfológica son numerosísimos, hecho que demuestra el interés que esta disciplina suscita en los estudiosos de la historia de la lengua española ininterrumpidamente desde sus inicios. Ténganse en cuenta, por solo enumerar algunos de los manuales de morfología española de más impacto, las aportaciones de Meyer-Lübke (1895), Hanssen (1913), Alemany Bolufer (1920), García de Diego (1951) o las contribuciones más recientes de Messner (1979), Pena (1980), Alarcos Llorach (1983), Alvar y Pottier (1983), Fernández Ramírez (1986), Bauer (1988), Lang (1990), Penny (1991), Bajo Pérez (1993), Lüdtke (1996), Segura Munguía (2000), Varela Ortega (2005), Amador Rodríguez (2009) y, sobre todo, Pharies (2002). Otra publicación reciente contempla los afijos derivativos de manera detallada y rigurosa: la Nueva gramática de la lengua española (RAE, 2009-2011). La obra dedica más de 400 páginas a las derivaciones nominal, verbal, adjetival y adverbial ${ }^{2}$.

Aun así, el siglo XV, situado en una posición intermedia entre la época medieval, en la cual destacan, entre otros, las figuras de Alfonso X y Gonzalo de Berceo, y el Renacimiento con sus poetas que caracterizaron la producción literaria de los siglos XVI y XVII, no ha sido la época a la cual más atención se ha prestado. Los trabajos realizados sobre aspectos lingüísticos del castellano del siglo XV son escasos; los más destacados son los que recogen los múltiples manuales que se dedican a la historia de la lengua, como los de Lapesa (1981 ${ }^{8}$ [1942]), Cano (2004) o Echenique y Sánchez (2005). En ellos, podemos encontrar alusiones al fenómeno o bien descripciones parciales, pero en ningún caso hallamos un análisis de las unidades derivativas objeto de estudio que intervienen en los procesos de derivación de la centuria y la zona geográfica propuestas.

Y los estudios que se han realizado desde este punto de vista histórico se centran, como nosotros, en determinados derivativos, una obra, un autor, un registro textual particular o en otros siglos: de este modo, entre muchos otros, Bustos Tovar (1974) estudia cultismos medievales, Herrero Ingelmo (1994-95) analiza los cultismos léxicos y semánticos en la obra completa

2 Otros estudios de enfoque exclusivamente sincrónico son los de Alvar (1993), Miranda (1994), Thiele (1992), una parte del tercer tomo de Bosque y Demonte (1999), Varela (1993) o las partes dedicadas a la derivación en las gramáticas de De Bruyne (1995: 571-584) o Vera-Morales (1992: 774-788). 
de quince autores de los siglos XVI y XVII. Acero Durántez (1980-81) se ocupa, en su tesis doctoral, de la Reforma y modernización en el léxico español en los siglos XV y XVI; Azofra Sierra (2002), de latinismos artificiales en el siglo XV. Dworkin (1989, 1990, 2002a y 2002b) ha publicado una amplia serie de investigaciones acerca de la pérdida léxica, entre otros, acerca de derivados medievales acabados en -dad, -dumbre, -eza y -ura (1989). Mancho Duque se dedicó durante muchos años a la investigación de adjetivos neológicos en los siglos XV y XVI. Así, investiga adjetivos derivados en -al y -ar en varios trabajos (1985, 1986 y 1987a); o lexemas en -oso en dos estudios posteriores (1987b y 1989). García-Macho (1992) se centra en adjetivos acabados en -eo, -ico, -ero, -ble e -ivo en la obra de San Juan de la Cruz, tres años después de publicar un artículo sobre el léxico de la lengua literaria del siglo XV (1989). Batllori (1998) analiza los sufijos -icia, -eza, -ez, -dad (y todas sus variantes) y -tud desde el siglo XII al siglo $\mathrm{XV}$, con especial atención a la obra del Rey Sabio. A pesar del enfoque claramente medieval de este trabajo, no son de menor interés los resultados para el estudio del siglo XV:

Una vez examinados los datos diacrónicos, podemos concluir que -dad fue siempre el sufijo más utilizado, ya desde el latín, y que, a pesar de que en la obra de Alfonso X el Sabio las formaciones en -ez / -eza parecen ganar terreno en la derivación de los sustantivos que estudiamos, nunca llegan a rebasar la frecuencia de uso del anterior. [...] Los derivados en -tud, por otra parte, únicamente aumentan su número por la entrada de cultismos que se inicia a partir del siglo XV [...], pero la productividad de este sufijo es nula (Batllori 1998: 123).

A pesar del gran número de investigaciones que versan acerca del léxico y la derivación medieval y renacentista, los morfemas y las variantes diatópica y diafásica propuestos en la presente investigación carecen de un estudio pormenorizado.

\section{Corpus y metodología}

El DICCA-XV es una obra lexicográfica elaborada a partir de un corpus representativo de la variedad castellana del siglo XV en la Corona de Aragón que proporciona al investigador un conjunto equilibrado de muestras textuales correspondientes a la totalidad de registros tanto literarios como no literarios de la centuria en cuestión ${ }^{3}$. La selección de documentos que forman el corpus del DICCA-XV se llevó a cabo según dos criterios destacados. En primer lugar, se ha recurrido exclusivamente a manuscritos originales y procedentes del siglo XV del territorio de la antigua Corona de Aragón, o bien ediciones del mismo siglo XV. Por consiguiente, los textos en los que se basará el análisis que nos hemos propuesto no han "rebasado la frontera del medio siglo entre la composición de la obra y la transcripción del códice" (Fernández-Ordóñez, 2006: 1790-1791), requisito imprescindible para estudios diacrónicos que propone la filóloga después de haber estudiado las fuentes de cincuenta y ocho monografías de gramática histórica.

Los tipos textuales que recoge el DICCA-XV son los siguientes:

A: textos jurídicos y administrativos

B: textos científicos, técnicos y doctrinales

3 Léase, acerca de los detalles de la confección del diccionario y corpus, entre otros, Lleal (2006 y 2008) y Anglada y Lleal (2010). 
C: textos históricos

D: textos novelescos y poéticos

El apartado A recoge transcripciones directas de manuscritos aljamiados, todos datados entre 1400 y 1492, cien registros procedentes de la Cancillería de la Corona de Aragón, alrededor de cien pergaminos del Fondo Sástago (en castellano o castellano-aragonés), dos manuscritos de las Rentas del Real Patrimonio y manuscritos del Archivo Provincial de Protocolos de Zaragoza.

El subgrupo B del corpus recoge la cantidad de quince textos. Se trata de una traducción del catalán del Libro de Albeytería de Manuel Díez de Calatayud; tres obras de Enrique de Villena, el Tratado de aojamiento o facinación, el Arte cisoria o Tractado del arte de cortar el cuchillo y el Tratado de la Lepra; dos incunables de la Biblioteca del Monasterio de San Lorenzo del Escorial, el Arte de bien morir y el Breve confesionario; la traducción de Gonzalo García de Santamaría del anónimo Cordial de las cuatro cosas postrimeras; la traducción de la obra Flor de Virtudes de Simón de Casia; el anónimo Tractado de Moral, el Tractado de la Peste que ha sido atribuido a Velasco de Taranta; el Recetario de Gilberto; el anónimo Tractado de Rectórica; el Tractado de salud humana de Johannes de Ketham y las Epístolas morales de Seneca en castellano, un manuscrito de Göttingen.

El conjunto $\mathrm{C}$ recoge transcripciones paleográficas de tres incunables de la Biblioteca Nacional de Madrid, la Crónica de Aragón de Gauberto Fabrizio de Vagad, el Tractado de Roma de Martín Martínez de Ampiés y una traducción al castellano del Viaje a Tierra Santa de Benardo de Breidembach.

El subcorpus D de textos novelescos y poéticos, por último, se compone de once cancioneros y cinco textos novelescos. Los cancioneros son los siguientes: el Cancionero de Coimbra, el Cancionero del fondo Egerton, el Cancionero de Estúñiga, el Cancionero de Herberey des Essarts (compilación atribuida a Hugo de Urriés), el Cancionero de Ixar, el Jaridinet d'orats, el Cancionero de Montserrat o Cançoner del Marquès de Barberà, el Cancionero de Vindel y, por último, el Cancionero de Zaragoza. Entre los textos novelescos se hallan el Breve tractado de Grimalte y Gradissa, el Tractado de Grisel y Mirabella y el Triunfo de Amor (todos de Juan de Flores), Los doze trabajos de Hércules de Enrique de Villena, la anónima Triste Deleytación y el Ysopete historiado.

Los textos reflejan, por consiguiente, las observaciones sobre las tipologías textuales del siglo XV de Santiago Lacuesta (2004), que elabora la siguiente estratificación:

a. Textos jurídico-administrativos: Estos textos corresponden al bloque A del DICCA-XV.

b. Textos técnicos (tratados): El compendio B del DICCA-XV recoge semejantes tratados.

c. Prosa doctrinal y didáctica: El DICCA-Xv recoge textos de este tipo en B (tratados morales).

d. Historiografía y cronística: En el caso del DICCA-XV, el bloque correspondiente (C) incluye crónicas que se centran en narrar historias de reinados y de personajes notables.

e. Traducciones: aunque el DICCA-XV no incluye ningún bloque exclusivo de traducciones, cabe destacar que algunas de las obras contenidas en B, C y D son traducciones, principalmente del catalán y del latín al castellano ${ }^{4}$.

4 En concreto, se trata de las obras Libro de Albeytería de Manuel Díez de Calatayud (B), Viaje de la Tierra Santa de Bernardo de Breidembach (C) — traducción del latín_-, ambas obras traducidas por Manuel Martínez de Ampiés; Los doze trabajos de Hércules de Enrique de Villena (D), texto traducido por el propio autor de la versión 
El segundo criterio consiste en la distribución equilibrada de ocurrencias entre los cuatro tipos de registros a partir de los cuales se ha confeccionado el corpus. Como se puede apreciar en la figura 1, de las 1422376 ocurrencias que componen el corpus del DICCA-XV, 387627 pertenecen a los textos del tipo A y 313299 al tipo B. Por consiguiente, 700926 formas del corpus corresponden a textos de diferentes registros no literarios. El resto de ocurrencias, un número de 721 450, provienen de textos de registros literarios, 404663 pertenecen al subgrupo $\mathrm{C}$ y 316787 al subgrupo D. La distribución porcentual de textos no literarios y literarios del corpus es, con un $49,3 \%$ de textos del tipo A y un $50,70 \%$ de documentos del registro $\mathrm{B}$, muy homogénea.

\begin{tabular}{|c|c|}
\hline Textos jurídico-administrativos (A) & Textos técnicos, científicos y doctrinales (B) \\
\hline 387627 & 313299 \\
\hline Textos históricos (C) & Textos novelescos y poéticos (D) \\
\hline 404663 & 316787 \\
\hline
\end{tabular}

Cuadro 1: Ocurrencias por tipo de texto en números.

Por último, cabe señalar que el DICCA-XV cuenta con la cantidad de 14230 voces comunes y es, por tanto, una obra amplia y representativa que permite un análisis profundo y detallado tanto del léxico literario como no literario de la variante diacrónica y diatópica del castellano antiguo que nos hemos propuesto ${ }^{5}$.

Para extraer los neologismos del DICCA-XV, hemos partido del listado de neologismos del siglo XV que ofrece la obra. A partir de ahí, hemos seleccionado aquellos lexemas que presentan uno de los derivativos objetos de estudio.

De este modo, hemos encontrado las siguientes voces acabadas en uno de los morfemas -tad y -dad:

el catalanismo

auguxidad, 'Humor acuoso que segregan algunos tumores purulentos';

el germanismo

esquividad, 'Cualidad de lo que es desagradable o desapacible' y 'Cualidad de la persona o el animal que rehúye el trato con los demás o sus muestras de afecto’;

el vocablo de origen incierto (posiblemente celta)

terquedad, 'Cualidad de la persona que persevera en una actitud errónea';

previa en catalán; Cordial de las cuatro cosas postrimeras (D), las Epístolas morales de Seneca en castellano (B), Flor de Virtudes (D) y del Ysopete historiado (D).

5 El DCECH de Corominas presenta poco más de 9000 lemas (Torruella Casañas 2006: 78). 
los términos patrimoniales

carnosidad, 'Carne superflua que se forma en una llaga';

enteridad, 'Cualidad de lo que está completo, sin ninguna falta';

espumosidad, 'Acumulación de burbujas e impurezas';

incertenidad, 'Cualidad de lo que provoca duda o inseguridad';

minoridad, 'Cualidad de las cosas de escaso valor';

oquedad, 'Espacio vacío dentro de un cuerpo sólido';

penalidad, 'Dificultad que hay que vencer con esfuerzo y sufrimiento';

realidad, 'Conjunto de cualidades o de características propias de un rey;

venenosidad, 'Cualidad de las sustancias capaces de causar la muerte'.

Por último, hemos extraído las siguientes unidades de origen culto:

acetosidad, 'Cualidad de las cosas que tienen sabor ácido o agrio';

altividad, 'Sentimiento o manifestación de orgullo';

ambigüedad, 'Dicho o circunstancia que genera confusión';

assiduidad, 'Cualidad de las cosas que se realizan con frecuencia o constancia';

calamidad, 'Suceso que supone desgracia o infortunio colectivos';

capacidad, 'Cualidad de quien manifiesta talento o disposición para comprender bien las

cosas';

cavernosidad, 'Hueco que resulta en un tejido orgánico dañado';

cetrinidad, 'Cualidad de las cosas de color amarillo verdoso';

conformidad, 'Relación de correspondencia entre personas o cosas';

corporeidad, 'Cualidad de las cosas que tienen existencia material';

credulidad, 'Cualidad de quien cree con excesiva facilidad';

cupididad, 'Cualidad de quien manifiesta un deseo desordenado de obtener placer';

diformidad, 'Imperfección, desproporción o irregularidad en la forma';

diuturnidad, 'Cualidad de las cosas de larga duración';

enormidad, 'Cosa que excede la medida o la proporción debidas';

generosidad, 'Cualidad de quien manifiesta nobleza de linaje';

habilidad, 'Capacidad o aptitud para actuar u obrar bien';

incompatibilidad, 'Relación entre cosas que no pueden darse simultáneamente';

indemnidad, 'Acción y resultado de preservar a alguien o algo de un daño o perjuicio';

infidelidad, 'Cualidad de quien manifiesta ausencia de fe religiosa';

insensibilidad, 'Cualidad de quien manifiesta incapacidad para sentir o expresar afecto';

integridad, 'Cualidad de quien cumple sus deberes con rigor y rectitud' y 'Cualidad de la mujer que no ha mantenido relaciones sexuales';

mitridad, 'Sustancia de color ocre y consistencia gomosa usada en medicina contra la peste';

monstruosidad, 'Acción disparatada o abominable';

moralidad, 'Enseñanza sobre las buenas costumbres que se deduce de una narración';

perspicacidad, 'Cualidad de lo que denota agudez mental';

pravedad, 'Cualidad de quien actúa de forma viciosa o con maldad deliberada';

probidad, 'Cualidad de quien cumple sus deberes con rigor y rectitud';

prodigalidad, 'Cualidad de quien se desprende fácilmente y sin reservas de sus bienes';

propinqüidad, 'Cualidad de lo que está a poca distancia en el espacio, el tiempo o la relación';

rigoridad, 'Actitud severa y estricta con que alguien actúa o juzga a los demás'; 
rusticidad, 'Cualidad de quien actúa con simplicidad, sin refinamiento'; solididad, 'Cualidad de las cosas que se mantienen de forma estable'; superioridad, 'Conjunto de beneficios derivados del poder'; sutilidad, 'Cualidad de las cosas o de las acciones que reflejan delicadeza' y 'Cualidad de las cosas o de las acciones que reflejan agudeza e ingenio';

terrosidad, 'Cualidad de lo que es semejante a tierra';

tortuosidad, 'Cualidad de lo que está retorcido o que sigue una línea ondulada'; velocidad, 'Cualidad de lo que se mueve con rapidez'; viscosidad, 'Cualidad de las cosas de consistencia espesa y pegajosa'; y voluptad, 'Placer sensual intenso'.

Los neologismos del siglo XV que acaban en uno los morfemas -icia, -eza y -ez se caracterizan por sus distintas procedencias etimológicas, aunque sobresalen, claramente, los términos de origen latino y románico. En concreto, hemos hallado los términos

agusidez, 'Cualidad de las cosas que terminan en punta o que forman ángulos pronunciados'; bestieza, 'Cualidad de quien actúa de manera irracional o con falta de sensatez'; neteza, 'Cualidad de quien actúa con decencia, honestidad y pudor'; y solteza, 'Cualidad de quien actúa con agilidad o desenvoltura',

de origen catalán; los derivados de voces populares latinas

amarillez, 'Cualidad de lo que es de color parecido al del limón'; certeza, 'Conocimiento seguro y claro de una cosa'; desnudez, 'Cualidad de lo que no está cubierto o protegido'; desperteza, 'Cualidad de quien actúa con agilidad de entendimiento', y, por metonimia, 'Actitud precavida y vigilante ante una necesidad o un peligro'; doblez, 'Actitud fingida o encubierta para el logro de un fin'; dulceza/dulcez, 'Cualidad de las cosas que producen una sensación placentera o apacible' y 'Acción o dicho que produce una sensación placentera'; espessez, 'Cualidad de lo que tiene densidad o turbiedad'; fineza, 'Cualidad de lo que es de excelente calidad y pureza'; floxeza, 'Cualidad de quien manifiesta ausencia de vigor o de fuerza'; garrideza, 'Cualidad de lo que se manifiesta con elegancia o belleza'; lindeza, 'Cualidad de las personas o las cosas que presentan buena disposición o perfección física y cuya contemplación produce deleite';

llaneza, 'Cualidad de quien actúa de manera natural y sencilla' y 'Cualidad de un terreno que no tiene inclinación o pendiente';

polideza, 'Cualidad de lo que actúa o se manifiesta con esmero o pulcritud';

preñez, 'Estado de la hembra que ha concebido y va a tener un hijo';

sordez, 'Cualidad o estado de quien está privado del sentido del oído'; turbieza, 'Cualidad de lo que carece de transparencia o nitidez'; y viudez, 'Estado de la persona a quien se le ha muerte el cónyuge';

el vocablo de origen incierto

lerdez, 'Cualidad de quien carece de agilidad, destreza o ingenio'; 
y los cultismos

alopicia, 'Caída o pérdida del cabello';

avideza, 'Deseo vehemente o inmoderado de conseguir algo';

calidez, 'Cualidad de las cosas que tienen una temperatura elevada';

delicadez, 'Cualidad de lo que tiene fragilidad o extrema finura';

impericia, 'Ausencia de habilidad o de destreza para actuar';

presteza/prestez, 'Rapidez en la ejecución de una cosa'; y

terecia, 'Enfermedad que se caracteriza por la acumulación de pigmentos biliares en la sangre'.

En el caso de los morfemas -tud y -dumbre, hemos hallado un total de diez unidades, todas de origen latino:

prontitud, 'Cualidad de lo que actúa o se manifiesta con rapidez y diligencia';

quietud, 'Situación de tranquilidad, sin alteración';

rectitud, 'Cualidad de quien actúa con justicia e integridad';

valitud, 'Cualidad de lo que tiene capacidad para actuar adecuadamente';

prestedumbre, 'Rapidez en la ejecución de una cosa';

apetitud, 'Inclinación de una persona a obrar de determinada manera';

altitud, 'Excelencia en nobleza o dignidad';

torpitud, 'Cualidad de lo que carece de habilidad o de destreza';

salsedumbre, 'Cualidad de las cosas que tienen un exceso de sal'; y

soledumbre, 'Situación de quien está sin compañía de nadie', 'Lugar en el que no vive nadie'.

\section{Análisis}

Los cinco morfemas analizados se caracterizan por ser sufijos derivativos nominalizadores, es decir, unidades que modifican la categoría gramatical, en este caso, hacia los sustantivos. Según apunta Varela Ortega (2005: 41), "la derivación léxica mediante sufijación es el procedimiento de formación de palabras más productivo, general y variado de nuestra lengua". Entendemos por sufijos de modificación gramatical aquellos derivativos que unen todas las características prototípicas de la formación de palabras por derivación, ya que tienen la capacidad de cambiar la categoría funcional de la raíz, implican, por la tonicidad de la mayoría de los sufijos, un cambio de acento respecto a la base y eligen la raíz léxica dependiendo de la categoría funcional de esta última ( $c f r$. también Pilleux (1980), Bustos y Santiago Lacuesta (1999), Martín Zorraquino (1997) o Martínez Celdrán (1975)). Batllori (1998) describe, de manera detallada, la historia y las características más destacadas de los derivativos que tratamos, por lo que resumiremos, brevemente, las claves más importantes en los tres casos.

\subsection{Los morfemas -tad y -dad}

Los nombres derivados de adjetivos en -tad o - dad suelen ser, como sus antecesores latinos terminados en -TĀS -TĀTIS, nomina qualitatis (Pharies 2002: 163) ${ }^{6}$ y derivar de adje-

6 Léase, acerca de la pérdida de nombres abstractos antiguos terminados en -dad, Dworkin (1989). 
tivos. Según la RAE (2009-2011: 413), -dad presenta uno de los morfemas derivativos más productivos que forman nombres de cualidad, estado y condición y puede combinarse con adjetivos de muy diferente índole, por ejemplo, los acabados en -al, - ar, -il, -io, -ia, -ivo, -oso, -ico y -ble (ibid.: 414-417). Esta alta productividad se demuestra también en los textos analizados, donde se trata del grupo de sufijos que en la mayor cantidad de neologismos aparece.

Textos jurídicos y administrativos (A)

En concreto, hemos registrado nueve cultismos neológicos de estas características en textos jurídico-administrativos:

ambigüedad, conformidad (también en C y D), habilidad (también en D), incompatibilidad, indemnidad, integridad (también en D), pravedad, probidad y superioridad.

Todos los términos derivan directamente de raíces adjetivas. El lema conformidad aparece, además, en textos del tipo C (textos históricos) y D (novelescos y poéticos); habilidad, también en D (textos novelescos y poéticos); e integridad se documenta, asimismo, en textos del tipo B (científicos, técnicos y doctrinales). Existe una clara preferencia por la variante morfológica - $d a d$. En general, se pueden apreciar numerosos casos de variación fonética entre los dos morfos examinados. En cambio, no existen variantes morfológicas de estas unidades, lo cual podría ser causa de la influencia del latín medieval en textos de este género ${ }^{7}$.

Cinco de las nueve voces son, claramente, nomina qualitatis. La voz indemnidad, en cambio, es un nomen actionis. El término ambigüedad denomina un estado. La unidad léxica superioridad se ha especializado en el lenguaje jurídico-administrativo por metonimia. E integridad, por último, expresa la 'exactitud y rectitud en el cumplimento de un deber' en las cinco documentaciones de esta voz en textos jurídicos y, en un sentido metonímico y etimológico, la 'virginidad de una mujer' en los documentos científico-técnicos.

Textos científicos, técnicos y doctrinales (B)

El número de voces neológicas documentadas en textos científicos, técnicos y doctrinales es más alto. Se trata, además, del grupo más nutrido, por lo que a la distribución textual entre los cuatro tipos se refiere. En concreto, hemos encontrado las siguientes unidades:

auguxidad, acetosidad, altividad, calamidad (también en C y D), capacidad (también en C y D), carnosidad, cavernosidad, cetrinidad, credulidad, cupididad, enormidad (también en C y D), enteridad, espumosidad, infidelidad (también en C y D), insensibilidad, integridad, mitridad, oquedad, propinqüidad (también en C y D), solididad, sutilidad (también en C y D), terrosidad, tortuosidad, venenosidad y viscosidad.

7 De hecho, Du Cange (1883-1887) documenta los términos habilitas, incompabilitas, indemnitas, integritas, pravitas, probitas y superioritas. 
Las voces calamidad, capacidad, enormidad, infidelidad, propinqüidad y sutilidad se recogen, asimismo, tanto en textos históricos como novelescos y poéticos.

De especial interés nos parece la unidad auguxidad, un probable catalanismo tomado de la voz augositat, y esta por aiguositat, que designa el 'humor acuoso que segregan algunos tumores purulentos'. A pesar de esta particularidad semántica, sorprende la variante morfológica de esta voz en el DICCA-XV, la palabra aguaça. Destaca, además, la unidad mitridad, ya que, etimológicamente, proviene de un antiguo nombre neutro (MITRIDATHIUM). Suponemos, en este caso, que el presente sufijo es consecuencia de un proceso basado en la analogía. Los demás derivados se basan en formas adjetivas. El lema altividad compite con la variante morfológica altiveza en nuestro corpus; la voz sutilidad, con sutileza; cavernosidad, con caverna. No sorprende, dada la analogía atípica de la unidad mitridad, el hecho de que esta, en vez de expresar una cualidad, designe una sustancia medicinal. Entre los restantes lexemas, se hallan nomina qualitatis y un nombre, terminado en -ibilidad, que expresa — como los adjetivos correspondientes en -ble- una posibilidad pasiva.

\section{Textos históricos (C)}

Los siguientes neologismos se documentan en textos de índole histórica:

calamidad (también en B), capacidad (también en B), conformidad (también en A), corporeidad, diuturnidad, infidelidad (también en B), minoridad, propinqüidad (también en B), sutilidad (también en B) y terquedad (también en D).

Tales unidades suelen designar, como hemos detallado líneas arriba, nomina qualitatis. No obstante, los presentes lexemas expresan matices semánticos de diversos tipos: cualidades o el conjunto de estas. Un apunte semántico se merece la voz minoridad, puesto que, a primera vista, insinúa ser una variante del término actual minoría, pero, sorprendentemente, se refiere a la 'cualidad de las cosas de escaso valor'. La unidad terquedad, por último, se encuentra recogida, asimismo, en textos novelescos y poéticos, que analizaremos a continuación.

\section{Textos novelescos y poéticos (D)}

Del bloque textual de los documentos novelescos y poéticos, hemos extraído los siguientes neologismos:

assiduidad, conformidad (también en A y C), diformidad, esquividad, generosidad, habilidad (también en A), incertenidad, monstruosidad, moralidad, penalidad, perspicacidad, prodigalidad, realidad, rigoridad, rusticidad, sutilidad (también en B y C), terquedad (también en C), velocidad y voluptad.

Morfológicamente, llama la atención la unidad voluptad, la cual parece mantener el morfema culto -tad debido a su posición no intervocálica. Además, varios de estos términos disponen de una variante morfológica en nuestro corpus de estudio. Así, incertenidad compite con el derivado incertidumbre; penalidad, con la voz pena; y realidad, por último, 
con realeza. Y es que esta unidad se refiere, semánticamente, al 'conjunto de cualidades o de características propias de un rey'.

Las características semánticas de estas voces llaman la atención, ya que designan conceptos de diferentes tipos, y no exclusivamente cualidades inherentes. Entre los campos de significado encontramos, aparte de cualidades, estados, conjuntos y lugares.

\subsection{Los morfemas -icia, -eza y -ez}

El sufijo patrimonial -eza y el alomorfo culto -icia se remontan al morfema latino -ITIA -AE. Los tres se emplean para formar sustantivos sobre bases adjetivales (ADJ + SUF $=s$ ) (Pharies, 2002: 249). Semánticamente, tales derivados suelen expresar-como sus predecesores clásicos- cualidades. El sufijo nominal -ez, en cambio, procede del latín -ITIĒS -ĒI. Los vocablos terminados en este morfema derivativo suelen designar, como los vocablos latinos acabados en la misma terminación, nomina qualitatis. Acerca de la selección de los alomorfos -eza y -ez, la Nueva Gramática de la Lengua Española apunta que "casi la mitad de los derivados en -ez en la lengua medieval poseen variantes en -eza" (RAE, 2009-2011: 421). Además, “-ez se adjunta con preferencia a bases adjetivas de más de dos sílabas, [...], mientras que -eza lo hace con más frecuencia a bases bisílabas" (ibid.: 422). Por último, "la gran diferencia entre $-e z$ y $-e z a$ radica en que el primero sigue siendo productivo, mientras que el segundo ha dejado de serlo, con muy escasas excepciones" (ibid.: 421), en el español actual.

Textos jurídicos y administrativos (A)

El primer dato que llama la atención es la falta de unidades neológicas acabadas en uno de los alomorfos en cuestión en documentos de tipo administrativo y jurídico. Parece que la influencia de la Edad Media, en que tales textos se redactaban casi exclusivamente en latín, propicia la poca productividad de derivados acabados en uno de los morfemas románicos analizados.

En textos científicos, técnicos y doctrinales (B)

En textos científicos, técnicos y doctrinales, en cambio, tales lexemas abundan, ya que trece de las veintisiete voces se documentan en ellos; y de estos, once de manera exclusiva. Se trata de los siguientes términos: agusidez, amarillez, desnudez, espessez, fineza, preñez, sordez, alopicia, avideza, calidez y terecia. La voz dulceza/dulcez se recoge, además, en textos novelescos y poéticos; presteza, tanto en textos históricos como en tales novelescos y poéticos.

En cuanto al número de sílabas, el sufijo -ez se presenta en los derivados de bases de más de dos sílabas agusidez, amarillez, desnudez, espessez y calidez, pero, asimismo, se combina con bases de dos sílabas en los términos preñez y sordez. El alomorfo -eza, en cambio, se documenta tanto en las voces fineza, dulceza, que alterna con dulcez, y preste$z a$, que compite con prestez — de bases bisílabas - como en el término avideza, derivado de una raíz adjetiva de tres sílabas. Volviendo sobre las afirmaciones de arriba, parece que el castellano del siglo XV en la Corona de Aragón presenta, por un lado, menos variación morfológica entre los derivativos -ez y -eza que el castellano medieval (cfr. Batllori 1998: 
123) y, por otro, una mayor productividad del alomorfo $-e z$, frente al menor rendimiento de -eza, en el español actual casi sin productividad alguna ( $c f r$. RAE, 2009-2011: 421).

Por lo que se refiere a la distribución de los alomorfos, sobresalen, claramente, los dos préstamos alopicia y terecia, ambos de origen griego, puesto que, en este último caso, se trata de una aféresis del grecismo ictericia, con el que, además, compite en los documentos analizados. Cabe destacar el lema preñez por su carácter desustantivo. En el resto de casos, estamos ante derivados deadjetivales, la mayoría de ellos -excepto avideza y presteza/prestez- de raíz popular.

Semánticamente, se confirman los valores prototípicos expresados por los morfemas en cuestión, dado que las voces formadas a través del los derivativos -ez y -eza expresan cualidades designadas por la base adjetiva o estados que, por metonimia, derivan de esas cualidades. Ahora bien, destacan las dos unidades de origen griego que presentan las variantes -ecia e -icia, dado que son las únicas que se salen de este patrón y denominan patologías ${ }^{8}$.

De gran interés son las numerosas variantes morfológicas de las unidades, en muchas ocasiones seguramente consecuencia de la ausencia de un patrón latino: en esta línea, el lexema amarillez compite con la unidad amarillura; espessez, con espessedumbre y espessura; y terecia, como hemos afirmado líneas arriba, con ictericia. El caso de las voces dulceza y presteza llama aún más la atención. La voz polisémica dulcezaldulcez denomina una cualidad en textos científicos, técnicos y doctrinales y, por metonimia, una acción que deriva de esta cualidad en textos novelescos y poéticos. Aun así, las variantes halladas, dulcedumbre, dulçor y dulçura, se recogen, de manera exclusiva, en el primer tipo de textos mencionados. La voz monosémica presteza presenta la variante morfológica prestedumbre. Aunque se trate de una voz de alcance textual múltiple, la variante mencionada se documenta solo en textos de tipo científico. Un último apunte que cabe resaltar versa en torno a la unidad preñez. Esta designa un estado derivado de una cualidad y, como tal, presenta una variante léxica terminada en el sufijo participial -ado (preñado), cuya carga semántica prototípica es, de hecho, la de expresar estados pasivos derivados de la acción expresada por la base verbal.

\section{En textos históricos (C)}

La cuantía de lexemas documentados en textos históricos presenta menores cifras que la de los arriba descritos. Aun así, no son de menor interés. Las voces que aparecen, únicamente, en este tipo de textos son desperteza, doblez, floxeza, lerdez, impericia y turbiez. Estos seis vocablos van acompañados por las voces llaneza, que se documenta, asimismo, en textos novelescos y poéticos, y presteza/prestez, que ya hemos mencionado arriba.

Los términos desperteza, doblez, lerdez y turbiez no siguen el patrón silábico arriba descrito, ya que derivan de bases de más de dos sílabas en el caso de -eza; y de dos sílabas, en los casos de doblez, lerdez y turbiez. Asimismo, es en la presencia del morfema -icia en la voz culta impericia en que radica otro dato destacado, sobre todo, teniendo en cuenta que se trata del único lexema que denomina un estado. Las demás unidades, también el segundo vocablo culto de esta seria, presteza/prestez, designan cualidades expresadas por la base adjetiva de la que derivan.

8 Y ello no sorprende, dada la importancia del griego para la filosofía y ciencias medievales ( $c f r$. Lapesa, $1981^{8}$ [1942]: 63). 
Por lo que atañe a la variación morfológico-léxica de las voces, únicamente floxeza compite con otros lexemas; en concreto, floxedad y floxura. Recuérdese que la variante prestedumbre del vocablo presteza se recoge solo en textos científicos, técnicos y doctrinales.

En textos novelescos y poéticos (D)

Las voces que se documentan, exclusivamente, en textos novelescos y poéticos son los nombres de cualidad bestieza, neteza, solteza, garrideza, lindeza, polideza y viudez. Llama la atención, aunque sea un mero apunte anecdótico que tres de las siete unidades sean préstamos del catalán, lo cual puede atribuirse a la mayor oralidad de textos de tal índole o una simple y pura coincidencia. Además, se recogen las voces dulceza/dulcez (también en textos científicos, técnicos y doctrinales), llaneza (también en textos históricos) y presteza/prestez (también en textos científicos, técnicos y doctrinales como en textos históricos).

Por lo que atañe la estructura silábica, sorprende el derivado viudez, puesto que el sufijo -ez se combina con una base bisílaba. Estamos, exclusivamente, ante nomina qualitatis. Un último apunte digno de mencionar radica en los competidores morfológicos de las voces estudiadas. Y es que solteza compite con la variante soltura; lindeza, con lindor; y viudez, finalmente, con viudedad.

\subsection{Los morfemas -tud y -dumbre}

El sufijo nominalizador español -tud tiene doble origen: por un lado, puede remontarse al sufijo latino -TŪS -ŪTIS; por otro lado, a -TŪDō -INIS (Pharies 2002: 500). Los lexemas acabados en el presente morfema acostumbran a designar cualidades. El sufijo castellano -dumbre proviene, como su doblete culto -tud, del sufijo latino -TŪDō -INIS. La forma reconstruida *-TŪMINE, propia del latín hablado, sirve para explicar la epéntesis - $m b r$ - que se produjo después de la caída de la vocal postónica9. La RAE especifica que el sufijo culto "está presente en un notable número de sustantivos, casi todos latininismos" (2009-2011: 445), a la hora que la variante patrimonial "ha formado en español una corta serie de nombres de cualidad" (ibid.: 446). Y estas observaciones se confirman en nuestros textos. Además, los ejemplos que presentaremos a continuación, comparados con el estudio de Ridruejo Alonso (2002) sobre los derivados medievales acabados en -dumbre, otorgan una mayor productividad al sufijo patrimonial en la Edad Media que en el español preclásico.

En textos jurídicos y administrativos (A)

Las tres unidades en -tud extraídas de textos jurídicos y administrativos presentan una base y el alomorfo cultos. Se trata, en concreto, de las voces deadjetivales prestadas prontitud, quietud y rectitud. Como sus antecedentes etimológicos terminados en uno de los dos sufijos latinos detallados líneas arriba, los presentes lexemas expresan nomina qualitatis. De nuevo, la tradición latina de tales textos puede haber propiciado la falta de variantes morfológicas en los tres casos.

9 Véase, acerca de la hibridación de los dos morfemas -tudo y -umen, Pharies 2004: 166. 
En textos científicos, técnicos y doctrinales (B)

Repárese, a continuación, en los neologismos acabados en uno de los morfemas que se documentan, exclusivamente, en textos científicos, técnicos y doctrinales y expresan, sin excepción, cualidades: se trata del préstamo valitud, del derivado deverbal apetitud, de las formaciones deadjetivas prestedumbre y soledumbre y de la palabra denominal salsedumbre.

Merecen, claramente, especial atención las voces apetitud, prestedumbre y salsedumbre, por lo que a los procesos derivativos atañe. La voz apetitud es un derivado deverbal basado en el simple apetir, en prestedumbre se junta una raíz culta con el alomorfo patrimonial y salsedumbre deriva a partir del nombre salsa, aunque este, a su vez, se remonta al adjetivo latino SALSA(M), 'salada'. La efimeridad y el poco éxito, sobre todo, del primer y último vocablo en cuestión, no sorprenden, por consiguiente. Sí subrayan la conciencia lingüística aguda de los escritores del siglo XV, quienes, para enriquecer el lenguaje o para expresar connotados sin denotado lexicológico ya existentes, utilizan los mecanismos que nos permite el sistema lingüístico para formar palabras novedosas.

Para algunos de los vocablos documentamos competidores morfológicos. Así, prestedumbre compite con el doblete presteza/prestez (véase 4.2); y el lexema soledumbre, con las variantes solitud y soledad.

\section{En textos novelescos y poéticos (D)}

Los dos constituyentes del subcorpus de textos novelescos y poéticos ${ }^{10}$ son los latinismos altitud y torpitud, por un lado; y la voz soledumbre, que se documenta, véase arriba, asimismo en textos científicos, técnicos y doctrinales. La voz altitud compite con la variante alteza, que se mantiene en uso hasta hoy, aunque con diferente significado; torpitud, en segundo lugar, con torpedad y torpeza. La unidad soledumbre alterna, en este tipo de textos, únicamente con solitud, hecho que subraya la naturaleza literaria de esta última voz que se ha mantenido hasta hoy en día. Las voces designan o cualidades o bien estados.

\section{Conclusiones}

El grupo más nutrido de los tres conjuntos analizados es el de las unidades acabadas en -tad y - $d a d$, lo cual refleja la ya alta productividad del morfema latino -TĀS -TĀTIS heredada de la lengua madre. Se documentan neologismos terminados en uno de los alomorfos en todos los subcorpus examinados, siendo los textos científicos, técnicos y doctrinales el bloque en que mayor productividad neológica presentan. Por lo que atañe a la selección de una de las dos variantes morfológicas, existe una clara preferencia sobre el morfema patrimonial - $d a d$, seguramente debido a la posición intervocálica. Solo puntualmente hemos podido documentar variantes de los neologismos en -dad acabadas en -eza, -dumbre o -ça. Y es que muchos de los términos se documentan ya en latín, un hecho que parece disminuir la competencia morfológica. Este fenómeno cobra especial importancia en textos jurídicos y administrativos, cuya larga tradición de textos escritos casi exclusivamente en latín parece provocar un menor rendimiento de variantes morfológicas, frente a aquellos

10 No se ha encontrado ninguna unidad de estas características en textos históricos. 
términos que siguen el patrón pautado por el latín clásico y medieval. La variación de los términos examinados presenta, en cambio, mayor alternancia en el plano fónico-gráfico. Así, documentamos numerosas variantes acabadas en -tat, -dat y -tad, como propinqüidad / propinqüidat, sutilidad / sotilidat, habilidad / abilidat, o bien cupididad / cupididat. Tal alternancia no solo es propia de textos procedentes de la Corona de Aragón, sino que se puede hallar, asimismo, en textos castellanos, sobre todo, hasta la primera mitad del siglo XV. Semánticamente, sobresale el hecho de que los neologismos designan conjuntos y acciones en varias ocasiones, aunque la mayoría expresa los valores prototípicos de los vocablos en -tad y - $d a d$, es decir, cualidades.

El análisis de los morfemas -icia, -eza y -ez nos ha llevado a las siguientes conclusiones: hemos podido apreciar, claramente, que la variante culta -icia solo aparece en lexemas directamente prestados del latín o del griego. No se trata, por consiguiente, de un morfema derivativo productivo en los textos del siglo XV. El sufijo patrimonial -eza, en cambio, aparece únicamente en derivados, tanto de base culta como de raíz heredada, $\mathrm{y}$, en algunos casos, puede presentar alternancia formal entre los morfos -eza y -ez, confundidos en los textos como meras variantes de un único morfema (presteza/prestez, dulceza/dulcez). Llaman la atención las estructuras silábicas de los derivados, puesto que hemos hallado, en numerosos casos, unidades que se han formado fuera del patrón propuesto en la Nueva gramática de la lengua española. En esta línea, hemos constatado que el sufijo -ez se combina con raíces bisílabas en formaciones como preñez, lerdez o turbiez, mientras que su variante -eza se puede combinar con bases de más de dos sílabas, como en avideza. Aun así, existe menos variación morfológica entre los dos alomorfos que en el período medieval. Ambos morfos alternan, además, con otros morfemas de evolución hereditaria como -dumbre o -dad. Todas las variantes halladas están formadas, en resumen, a través de uno de los morfemas propensos a expresar nomina qualitatis o estados. Los rasgos semánticos de los neologismos en cuestión no presentan, por lo tanto, sorpresa alguna. Por lo que se refiere, en último lugar, al morfema derivativo $-e z$, destacan dos datos sorprendentes: sobresalen, por un lado, el número muy reducido de variantes morfológicas $\mathrm{y}$, por otro, la distribución de los lexemas. Y es que la mayoría de los vocablos neológicos documentados se recoge, exclusivamente, en textos científicos, técnicos y doctrinales. Debido a las bajas cifras, estamos ante una mera tendencia, pero, aun así, el dato llama la atención.

La distribución de los neologismos acabados en el tercer par de alomorfos por los diferentes registros textuales apunta, como en el caso de -icia, -ez y -eza, a que el derivativo -dumbre sea productivo, sobre todo, en textos científico-técnicos, ya que las tres voces acabadas en este morfema se documentan - con excepción de soledumbre, exclusivamente- en este género textual. Los neologismos que presentan el alomorfo culto, en cambio, aparecen en tres de las cuatro tipologías textuales examinadas. Morfológicamente, el fenómeno que sobresale radica en la generalización del sufijo latino -TŪs -ŪTIS, que es bien sabida. Además, destaca el número de variantes morfológicas en -dad y -eza. En cuanto a la semántica, todos los lexemas designan el valor prototípico, es decir, cualidades. Un último fenómeno digno de reseñar descansa en la aparente arbitrariedad individual de determinados autores por lo que a la selección de alomorfos se refiere. Y es que los derivados salsedumbre y apetitud se han formado a partir de raíces nominales y verbales, respectivamente, mientras que el término prestedumbre presenta una base culta que deriva a través del alomorfo patrimonial. 
En resumidas cuentas, los términos analizados son prueba de la conciencia lingüística de los escritores del siglo XV de la Corona de Aragón que utilizan todos los mecanismos conocidos para formar palabras novedosas e innovar y enriquecer, de esta manera, la lengua en la época intermedia entre el castellano medieval y renacentista. Sobresalen los siguientes fenómenos: en primer lugar, destaca, claramente, la alta productividad del morfema -dad en todos los tipos de textos analizados, hecho heredado del carácter abierto y productivo de este derivativo en textos latinos y durante la Edad Media (cfr. Batllori, 1998). El aumento de los sufijos -eza y -ez en el siglo XV y ya presente en la obra de Alfonso X el Sabio se plasma, sobre todo, en textos de índole científica, donde la productividad de los morfemas casi alcanza la del derivativo - dad. El morfema -tud se presenta tanto en préstamos del latín como en el derivado deverbal apetitud. Ahora bien, la productividad derivativa del morfema patrimonial -dumbre es claramente mayor, ya que no solo deriva neologismos a partir de raíces adjetivas, sino también de bases nominales. Seguidamente, la presencia de un patrón latino parece provocar la menor presencia de variantes morfológicas, sobre todo, en textos del tipo jurídico y administrativo. Por lo que se refiere a los demás tipos textuales, existe el mayor número de variantes morfológicas tanto en textos científicos, técnicos y doctrinales como en textos novelescos y poéticos, debido, sobre todo, a la mayor oralidad de tales textos por el público al que se dirigen, el pueblo común. Por último, hay que volver a poner de relieve el castellano del siglo XV en la Corona de Aragón como paso intermedio entre el castellano medieval y el castellano renacentista y moderno. Este se plasma, comparado con el castellano medieval, sobre todo, en la menor variación entre los derivativos -eza y -ez y la mayor productividad del morfema -ez, que también caracterizan el español actual.

\section{Referencias bibliográficas}

Acero Durántez, I. (1980-81): Reforma y modernización en el léxico español (siglos XV$X V I)$. Tesis Doctoral. Alicante, Universitat d'Alacant.

Alarcos Llorach, E. (1983): “Consideraciones sobre la formación léxica”. En Homenaje a Fernando Lázaro Carreter, I. Madrid, Cátedra, págs. 11-15.

Alemany Bolufer, J. (1920): Tratado de la formación de palabras en la lengua castellana. Madrid, Suarez.

Alvar, M. y B. Pottier (1983): Morfología histórica del español. Madrid, Gredos.

Alvar Ezquerra, M. (1993). La formación de palabras en español. Madrid, Arco/Libros.

Amador Rodríguez, L. A. (2009): La derivación nominal en español: nombres de agente, instrumento, lugar y acción. Frankfurt am Main, Peter Lang.

Anglada, E. y C. Lleal (2010): “¿Qué pueden esperar los filólogos del Diccionario del castellano del siglo XV en la Corona de Aragón?”. En Medina, A. Ma. y M. C. Concepción Ayala (eds.): Los diccionarios a través de la historia. Málaga/Universidad de Málaga, Servicio de Publicaciones, págs. 13-30.

Azofra Sierra, Mª. E. (2002): "Latinismos artificiales en el siglo XV", Boletín de la Real Academia Española, 82/285, págs. 47-57.

Bajo Pérez, E. (1997): La derivación nominal en español. Madrid, Arco/Libros.

Batllori, M. (1998): “Derivación y diacrónía”. Estudi general, 17, págs. 111-143.

Bauer, L. (1988): Introducing linguistic morphology. Edinburgo, Edinburgh University Press. 
Bosque, I. y V. Demonte (drs.) (1999): Gramática descriptiva de la lengua española. Madrid, Espasa-Calpe.

Bruyne, J. de (1995): A Comprehensive Spanish Grammar. Malden/Oxford/Carlton, Blackwell Publishing Ltd.

Bustos, E. de y R. Santiago Lacuesta (1999): “La derivación nominal”. En Bosque, I. y V. Demonte (drs.): Gramática descriptiva de la lengua española. Madrid, Espasa-Calpe, págs. 4505-4594.

Bustos, J. J. de (1974): Contribución al estudio del cultismo léxico medieval (1140-1252). Madrid, Boletín de la Real Academia Española, anejo XXVIII.

Butler, J. L. (1971): Latin -īnus, -inna, -inus and-ineus. From Proto-Indo-European to the Romance Languages. Berkeley/Los Angeles, University of California Press.

Cano Aguilar, R. (coord.) (2004): Historia de la lengua española. Barcelona, Ariel.

Conde, J. C. (1985): "El siglo XV castellano a la luz del diálogo "De Vita beata" de Juan de Lucena”. Dicenda, 4, págs. 11-34.

Craddock, J. R. (1969): Latin Legacy versus Substratum Residue. The Unstressed 'Derivational'Suffixes in the Romance Vernaculars of the Western Mediterranean. Berkeley/Los Angeles, University of California Press.

Delgado, I. (1987): El cultismo en la oratoria sagrada del Siglo de Oro (1580-1633). Tesis doctoral. Madrid, Universidad Complutense de Madrid.

Du Cange, C. et al. (1883-1887): Glossarium mediae et infimae Latinitatis. Niort: L. Favre.

Dworkin, S. (1989): "Studies in lexical loss. The fate of Old Spanish post-adjectival abstracts in '-dad, -dumbre, -eza' and '-ura'”. Bulletin of Hispanic Studies, 66/4, págs. 335-342.

Dworkin, S. (1990): "The role of near-homonomy in lexical loss: the demise of Old Spanish "laido" ('ugly, repugnant')". La Corónica, 19, págs. 32-48.

Dworkin, S. (2002a): "La introducción e incorporación de latinismos en el español medieval tardío: algunas cuestiones lingüísticas y metodológicas”. En Saralegui, C. y M. Casado (eds.): Pulchre, Bene, Recte. Estudios en homenaje al profesor Fernando González Ollé. Pamplona, EUNSA, págs. 421-433.

Dworkin, S. (2002b): "Pérdida e integración léxicas: “aína" vs. "rápido" en el español premoderno. En Pöll, B. y F. Rainer: Études de lexicologie et de (méta-)lexicographie romanes en l'honneur du 60e anniversaire de Dieter Messner. Frankfurt, Peter Lang, págs. 159-167.

Echenique, Ma . T. y J. Sánchez Méndez (2005): Las lenguas de un reino. Historia lingüística hispánica. Madrid, Gredos.

Fernández-Ordóñez, I. (2006): “La historiografía medieval como fuente de datos lingüísticos. Tradiciones consolidadas y rupturas necesarias". En Bustos, J. J. de y J. L. Girón Alconchel (eds.): Actas del VI Congreso Internacional de Historia de la Lengua Española. Madrid, Arco/Libros, págs. 1779-1807.

Fernández Ramírez, S.: (1986). La derivación nominal. Anejo XL del Boletín de la Real Academia Española, Madrid.

Fleischman, S. (1977): Cultural and Linguistic Factors in Word-Formation: An Integrated Approach to the Development of the Suffix “-age”. Berkeley/Los Angeles/Londres, University of California Press. 
Frago G., J. A. (1980): “El criterio de afijación como cuestión de método en la investigación dialectal". Estado actual de los estudios sobre Aragón. Huesca: Instituto de Ciencias de la Educación, págs. 433-439.

García de Diego, V. (1951): Gramática histórica española. Madrid, Gredos.

García-Macho, Ma . L. (1989): "Variedad léxica y cultismo en la lengua literaria del siglo XV. En Lorenzo, R. (ed.) (1992): Actas delXIX Congreso Internacional de Lingüística e Filoloxia Románicas. A Coruña, Fundación P. Barrié de la Maza, págs. 507-516.

García-Macho, Ma L. (1992): "Los adjetivos "-eo, -ico, -ero, -ble" e "-ivo" en San Juan de la Cruz”. Boletín de la Real Academia Española, 72, págs. 269-300.

Georges, E. S. (1970): Studies in Romance Nouns Extracted from Past Participles [revised by J. R. Craddock y Y. Malkiel]. Berkeley/Los Angeles, University of California Press.

González Ollé, F. (1962): Los sufijos diminutivos en castellano medieval. Madrid, CSIC.

Grup d'història i contacte de llengües (GHCL) (2012): Diccionario general y etimológico del castellano del siglo XV en la Corona de Aragón: ghcl.ub.edu/diccaxv (15-12-2014).

Hanssen, F. (1913): Gramática histórica de la lengua castellana. Halle, Niemeyer.

Hasselrot, B. (1957): Études sur la formation diminutive dans les langues romanes. Uppsala, Lundequistska Bokhandeln.

Herrero Ingelmo, J. L. (1994-95): “Cultismos renacentistas (cultismos léxicos y semánticos en la poesía del siglo XVI)". Boletín de la Real Academia Española, 74 y 75, págs. 173-224 у 293-394.

Karlsson, K. E. (1981): Syntax and Affixation. The Evolution of "-mente" in Latin and Romance. Tübingen, Max Niemeyer.

Lang, M. F. (1990): Spanish Word Formation: Productive Derivational Morphology in the Modern Lexis. Londres, Routledge.

Lapesa, R. (1981 ${ }^{8}$ [1942]): Historia de la lengua española (versión refundida y ampliada). Madrid, Gredos.

Lathrop, T. A. (1984 [1980]): Curso de gramática histórica española. Barcelona, Ariel.

Lleal, C. (2006): "Lematización y diccionarios electrónicos". Oihenart, 21 (Actas de las I Jornadas de Lingüística Vasco-Románica, celebradas en Bilbao, en octubre de 2004), págs. 331-343.

Lleal, C. (2008): “El diccionari del castellà del segle XV a la Corona d'Aragó del GHCL de la Universitat de Barcelona". Estudis Romànics, 30, págs. 241-247.

Lloyd, P. M. (1993 [1987]). Del latín al español. i. Fonología y morfología históricas de la lengua española. Madrid, Gredos.

López, Ma . I. (1977): “Cultismos, arcaísmos, elementos populares y lenguaje paremiológico en la obra del Marqués de Santillana”. Anuario de Filología, 3, págs. 279-313.

Lüdtke, J. (1996): "La diacronía en la semántica de la formación de palabras". En Henríquez, Ma . do C. y A. Rifón (eds.): Estudios de morfología. Vigo, Universidad de Vigo, págs. 77-90.

Mancho, Ma. J. (1985): "Los adjetivos en "-al, -ar" en tres tratados médicos del s. XV". Anuario de Estudios Filológicos, 8, págs. 167-179.

Mancho, Ma . J. (1986): "Formaciones adjetivas en "-al, -ar" en cinco prosistas del siglo XV. Studia Zamorensia, VII, págs. 141-161.

Mancho, Ma. J. (1987a): "Estudio de los adjetivos en "-al / -ar" en el "Tratado de las apostemas" de Diego El Covo". Cahiers de Linguistique Hispanique Médiévale, 12, págs. 27-47. 
Mancho, Ma . J. (1987b): "Formaciones adjetivas en "-oso" en cinco prosistas del siglo xv. Studia Zamorensia, viii, 35-49.

Mancho, Ma . J. (1989): "Las formaciones adjetivas en "-oso" en cuatro tratados médicos del s. xv". Borrego Nieto, Julio (ed.): Philologica. Homenaje a D. Antonio Llorente, II. Salamanca, Editorial Universitaria, págs. 321-332.

Martín, Ma . A. (1997): "Formación de palabras y lenguaje técnico". Revista Española de Lingüística, 27/2, págs. 317-339.

Martínez Celdrán, E. (1975): Sufijos nominalizadores del español con especial atención a su morfofonología. Barcelona, Universitat de Barcelona.

Menéndez Pidal, R. (1980 [1926]): Orígenes del español. Estado lingüístico de la Península Ibérica hasta el siglo XVI. Madrid, Espasa-Calpe.

Messner, D. (1979): Geschichte des spanischen Wortschatzes. Heidelberg, Carl Winter, Universitätsverlag.

Meyer-Lübke, W. (1895): Grammaire des langues romanes. Morphologie (Vol.2). Paris, Welter.

Miranda Pozas, J. A. (1994): La formación de palabras en español. Salamanca, Ediciones Colegio de España.

Morras, Ma . (1995): "Latinismos y literalidad en el origen del clasicismo vernáculo: Las ideas de Alfonso de Cartagena (ca. 1384-1456)". En Recio, R. (ed.): La traducción en España: siglos XIV-XVI. León, Anexos de Livius, Secretariado de Publicaciones de la Universidad de León, págs. 35-58.

Pattinson, D. G. (1975): Early Spanish suffixes. A functional study of the principal nominal suffixes of Spanish up to 1300. Publications of the Philological Society, 27. Oxford, Basil Blackwell.

Pena Seijas, J. (1980): La derivación en español. Verbos derivados y sustantivos deverbales. Anejos de Verba. Santiago de Compostela, Universidade de Santiago.

Penny, R. (1991): A History of the Spanish Language. Cambridge, University.

Pharies, D. (2002): Diccionario etimológico de los sufijos españoles (y de otros elementos finales). Madrid, Gredos.

Pilleux Dresdner, M. (1980): Análisis morfofonológico, funcional y semántico de los sufijos en español. Estudio sincrónico. Santiago de Chile, Universidad Austral de Chile.

Raab, M. (2014): Préstamo y derivación: neología y tipología textual en el castellano del siglo XV de la Corona de Aragón. Tesis doctoral. Universitat de Barcelona.

Real Academia Española (2009-2011): Nueva gramática de la lengua española. Madrid, Espasa.

Ridruejo Alonso, E. (1984): “Tres catalanismos (y aragonesismos) sintácticos en "Los doze trabajos de Hércules" del Marqués de Villena". Archivo de Filología Aragonesa, 34-35, págs. 273-290.

Ridruejo Alonso, E. (2002): "El sufijo “-dumbre” en español medieval”. En Saralegui, C. y M. Casado (eds.): Pulchre, bene, recte. Estudios en homenaje al profesor Fernando González Ollé. Pamplona, Eunsa, págs. 1161-1175.

Santiago Lacuesta, R. (1975): "Sobre el primer ensayo de una prosodia y una ortografía castellanas: el "Arte de Trovar" de Villena". Miscellanea Barcinonensia, 14, págs. 39-52.

Santiago Lacuesta, R. (2003): "La puntuación según Enrique de Villena. De la teoría del autor, la práctica de los copistas y la edición del texto". En Girón Alconchel, J. L. et al (eds.): Estudios ofrecidos al profesor José Jesús de Bustos Tovar. Madrid, Editorial Complutense, págs. 197-214. 
Santiago Lacuesta, R. (2004): "La historia textual. Textos literarios y no literarios". En Cano, R. (coord.): Historia de la lengua española. Barcelona, Ariel, págs. 533-554.

Segura Munguía, S. (2000): Lexicogénesis. Derivados y compuestos en la creación del vocabulario latino y castellano. Bilbao, Universidad de Deusto.

Thiele, J. (1992): Wortbildung der spanischen Gegenwartssprache. Leipzig/Berlín, Langenscheidt.

Torruella, J. (2006): "Las documentaciones en el dcech“. En Clavería, G. y M a. J. Mancho: Estudio del léxico y bases de datos. Bellaterra/Universitat Autònoma de Barcelona, Servei de Publicacions, págs. 77-102.

Tuttle, E. F. (1975): Studies in the Derivational Suffix-ACULUM: Its Latin Origin and its Romance Development. ZRPh Beiheft, 146. Tubinga, Niemeyer.

Varela Ortega, S. (ed.) (1993): La formación de palabras. Madrid, Taurus.

Varela Ortega, S. (2005): Morfología léxica: La formación de palabras. Madrid, Gredos.

Vera-Morales, J. (1992): Spanische Grammatik. Tubinga, Niemeyer. 


\title{
LAS FORMAS DE TRATAMIENTO EN UN CORPUS DE ENTREVISTAS SEMIDIRIGIDAS DE ESPAÑOL DE GALICIA
}

\author{
María SAmpedro Mella* \\ Universidad de Salamanca \\ maria.sm@usal.es
}

Recibido: 06/11/2014

Aceptado: 20/04/2015

\begin{abstract}
Resumen
Este trabajo comprende un estudio de las formas de tratamiento en el corpus de entrevistas semidirigidas perteneciente a PRESEEA - Santiago de Compostela - ES y a ESLORA. Tras una introducción de la muestra objeto de estudio seleccionada para esta investigación y una síntesis bibliográfica sobre el estado de las formas de tratamiento en el español, se incluyen los resultados de la revisión de los usos de tú/usted, según la incidencia de diferentes factores sociales (inherentes a los propios hablantes) y contextuales. A partir de los resultados obtenidos, una parte de este trabajo se centra en el estudio cualitativo de un aspecto de interés hallado en el análisis: la variación de tú/usted que se produce ante un mismo interlocutor a lo largo de la misma entrevista, debido a diferentes causas.

PALABRAS CLAVE: formas de tratamiento, ESLORA, PRESEEA, análisis de corpus, entrevista semidirigida.
\end{abstract}

\begin{abstract}
This work is a study of address forms in the semi directive interview corpus belonging to PRESEEA Santiago de Compostela - ES and to ESLORA. After an introduction regarding the sample of study selected for this research and a bibliographical synthesis about the status of address forms in Spanish, the results of the tú/usted uses are included, according to the influence of different social (inherent to the speakers) and contextual factors. From these results, a part of this work focuses on the qualitative study of an interesting aspect that was found in the analysis: the variation of tú/usted that happens in the presence of the same interlocutor along the same interview, due to different causes.
\end{abstract}

KEY WORDS: address forms, ESLORA, PRE$S E E A$, corpus analysis, semi directive interview.

\footnotetext{
* Este trabajo forma parte de la investigación de mi tesis doctoral, para la que cuento con una beca de Formación de Profesorado Universitario (FPU, referencia AP2010-5977). Se inició en 2010 como parte de un Trabajo Académicamente Dirigido bajo la tutela de la profesora Dra. Vázquez Rozas (Universidade de Santiago de Compostela) y en 2012 se incrementó dando lugar a un Trabajo Fin de Doctorado, dirigido por la profesora Dra. Fernández Juncal (Universidad de Salamanca).
} 


\section{Introducción}

El presente artículo sobre el uso de las formas de tratamiento se basa en el análisis de un conjunto de entrevistas semidirigidas pertenecientes al corpus PRESEEA - Santiago de Compostela - ES ${ }^{1}$ y que también forman parte de ESLORA (Corpus para el estudio del español oral $)^{2}$, realizadas en la ciudad de Santiago de Compostela. Las grabaciones tienen una duración de aproximadamente cuarenta y cinco minutos y los informantes se seleccionaron a partir de las indicaciones de PRESEEA (2003) sobre la muestra poblacional: varones y mujeres residentes en la ciudad como mínimo durante los últimos 20 años y pertenecientes a tres grupos generacionales, en los que el primero comprende edades desde los 20 años hasta los 34, el segundo abarca desde los 35 hasta los 54 años y el tercero reúne hablantes a partir de los 55 años en adelante. El grado de instrucción también se divide en tres niveles: el primero incluye individuos que carecen de estudios o únicamente disponen de enseñanza primaria, el segundo está integrado por hablantes con estudios primarios y secundarios completos, y el tercero engloba a aquellos con estudios universitarios o de enseñanza superior (Moreno Fernández, 2005: 127 y ss.). A continuación se presenta una tabla que resume el perfil social de la muestra de PRESEEA:

\begin{tabular}{|l|c|c|c|c|c|c|}
\cline { 2 - 7 } \multicolumn{1}{c|}{} & \multicolumn{2}{c|}{ Generación 1 } & \multicolumn{2}{c|}{ Generación 2 } & \multicolumn{2}{c|}{ Generación 3 } \\
\cline { 2 - 7 } \multicolumn{1}{c|}{} & $\mathrm{H}$ & $\mathrm{M}$ & $\mathrm{H}$ & $\mathrm{M}$ & $\mathrm{H}$ & $\mathrm{M}$ \\
\hline Grado de instrucción 1 & 3 & 3 & 3 & 3 & 3 & 3 \\
\hline Grado de instrucción 2 & 3 & 3 & 3 & 3 & 3 & 3 \\
\hline Grado de instrucción 3 & 3 & 3 & 3 & 3 & 3 & 3 \\
\hline
\end{tabular}

Tabla 1: Distribución de la muestra-tipo de PRESEEA ${ }^{3}$

Para este trabajo, se han analizado las 18 entrevistas semidirigidas pertenecientes al grupo de estudios superiores o de grado de instrucción 3, que incluyen representantes varones y mujeres de los tres grupos de edades. El objetivo es revisar las formas de tratamiento utilizadas por ambos interlocutores -entrevistador y entrevistado- y la variación de uso que presentan en algunos casos. Para ello, se ha escogido este género discursivo, la entrevista semidirigida -también denominada “conversación semidirigida" (Vázquez Veiga, 1995) o "conversación grabada" (Silva-Corvalán, 2001)-, porque es un género híbrido entre la

1 El Proyecto para el Estudio Sociolingüístico del Español de España y América (PRESEEA), en el que colaboran diferentes universidades de España e Hispanoamérica, tiene como objetivo reunir un macrocorpus oral representativo del mundo hispánico en su variedad geográfica y social, que posibilite su aplicación con fines educativos y tecnológicos. Para ello se utiliza la técnica de la entrevista semidirigida, que se aplica a una muestra poblacional sociolingüísticamente representativa de un gran número de ciudades de ámbito hispánico. Para más información, vid. http://preseea.linguas.net, Moreno Fernández (1996, 2005) y Cestero Mancera (2013).

2 Al presente, estas entrevistas semidirigidas solo están disponibles a través de ESLORA (http://galvan.usc.es/ eslora), un corpus informatizado que se desarrolla actualmente en la Universidade de Santiago de Compostela como parte del Proyecto para el Estudio Sociolingüístico del Español de Galicia (PRESEGAL). Contiene, además de entrevistas, conversaciones espontáneas registradas en Galicia entre 2007 y 2014 . Para más información, vid. http://gramatica.usc.es/proxectos/eslora/ y Vázquez Rozas (en prensa).

3 Fuente: http:// preseea.linguas.net/Metodolog\%C3\%ADa.aspx. 
conversación espontánea y la entrevista prototípica cuyo objetivo es registrar muestras de habla naturales, propias del estilo espontáneo o vernáculo (cf. Labov, 1966) y que ofrece al investigaror información relativa a los hablantes. Además, al contrario que otros corpus de lengua oral (CREA, Davies, 2002), PRESEEA ofrece acceso al texto completo y, por tanto, los datos extraídos se estudian en su contexto total.

\section{Las formas de tratamiento}

Las formas de tratamiento son un reflejo de cómo se sitúan los interlocutores en el discurso: el uso de un sistema simétrico revela igualdad y proximidad entre hablantes, mientras que el empleo de un sistema asimétrico indica un desequilibrio de la relación social, que exige la presencia de estrategias de cortesía (Calsamiglia y Tusón, 2007: 149). En la actualidad son numerosos los estudios llevados a cabo sobre el uso de las formas de tratamiento ${ }^{4}$, si bien no existe unanimidad en lo relativo a los factores que determinan la elección pronominal, dentro del español o en términos generales en aquellos códigos con una marca ${ }^{5}$, ya que "aunque se trata de una forma de comportamiento universal, existen grandes diferencias entre las lenguas, no s[o]lo en cuanto a la manifestación formal de la misma, sino también en cuanto al comportamiento interactivo" (Havertake, 1994: 12).

Como señala Fernández (2003), la mayoría de los trabajos sobre las formas de tratamiento publicados después de los años 60 están basados en la propuesta teórica de Brown y Gilman (1968) (Calderón y Medina Morales, 2010; Medina López, 2010, etc.). Estos autores distinguen un primer eje horizontal de solidaridad, correspondiente a la distancia y proximidad entre interactuantes, basado en su grado de conocimiento mutuo, la relación afectiva o el tipo de situación en la que se encuentran (formal, ceremonial o informal) y un segundo eje vertical de poder que surge a partir de ciertas diferencias: fuerza física, riqueza, edad, sexo, papel institucionalizado en la iglesia, en el estado, la armada o la familia (Brown y Gilman, 1968: 255) ${ }^{6}$. Blas Arroyo (1995: 231) cuestiona este modelo, puesto que

ni el poder ni la solidaridad son factores estáticos que determinan mecánicamente un tratamiento categórico (...) puede ocurrir perfectamente que un locutor que ocupa un nivel jerárquicamente superior al de otro $-\mathrm{y}$ del que recibe la forma $\mathrm{V}-(\ldots)$ devuelva esa misma forma de tratamiento y no $\mathrm{T}$.

Otra teoría ampliamente adoptada en los estudios sobre cortesía es la de Brown y Levinson (1987) (Blas Arroyo, 1995; Pedroviejo Esteruelas, 2003; Zambrano-Paff, 2006). Estos autores consideran que la cortesía es un fenómeno universal necesario para evitar el conflicto. Para

4 Una amplia selección bibliográfica se encuentra en Fernández (2006).

5 En Frías Conde (2011: 6 y ss.) se establece una triple distinción entre aquellas lenguas "sin marca", es decir, con un único pronombre de segunda persona, como el inglés; de aquellas "con una marca", caso del español, el italiano, el francés, el checo, el ruso o el chino, o con "doble marca", como el rumano.

6 En Medina López (1990) puede encontrarse una aplicación de los conceptos poder y solidaridad de estos autores específicamente en las formas de tratamiento del español. En una perspectiva más amplia, Weinerman (1976: 57 y ss.) recoge una visión de esta teoría a través de la recopilación de distintos estudios sobre la dualidad de segunda persona en varias lenguas, como el ruso, el guaraní, el inglés, el español, el francés, etc. 
exponer su teoría, reintroducen el concepto goffniano de imagen o $\mathrm{face}^{7}$, al que asocian la necesidad de mantener la propia imagen y la de los demás, hecho que exige, por tanto, suavizar los actos amenazantes a través de distintos procedimientos corteses. Por otra parte, el nivel de cortesía que se debe emplear depende de otros factores, como el poder relativo -relative power- de un hablante sobre otro, la distancia social-social distance- existente entre ellos y el nivel de imposición - ranking of the imposition- del acto amenazante (Brown y Levinson, 1987: 15). De este modo, las formas de tratamiento están destinadas a minimizar esa posible carga amenazante contra el destinatario, y el uso de la forma tú se relacionaría con la denominada cortesía positiva y el de la forma usted con la negativa ${ }^{8}$. Esta teoría presenta algunos inconvenientes, como la propia noción de face, demasiado abstracta, o la independencia entre la imagen positiva y la negativa, por ejemplo, con la que no todos están de acuerdo.

Conjugando ambas teorías, se puede ver una necesidad en los hablantes por mantener un equilibrio en la relación social y querer evitar cualquier tipo de conflicto. Autores como Cots (1998) o Escavy Zamora (2008), en la misma línea de Goffman (1970), consideran que la creación y definición del propio sujeto (own self) se produce a partir de las reacciones de los demás, ya que el individuo en sí mismo no posee una realidad propia, sino que esta se manifiesta a través de su interacción social; en otras palabras, las personas alcanzan una definición de sí mismas a través de las respuestas de otros. En consecuencia, el interés de los participantes en obtener el mayor grado posible de coordinación en la interacción discursiva se debe a una necesidad, no solo de comunicar cierta información, sino también de construir un "yo" deseable que se ajuste a sus aspiraciones (Cots, 1998: 93). En términos de Escavy Zamora (2008:157-158):

En las relaciones interpersonales, uno trata de acomodarse a las circunstancias para evitar un desequilibrio arriesgado de la imagen. El habla es el instrumento posiblemente más importante con el que uno cuenta para darse a conocer a los demás, a través del cual se lleva a cabo el proceso de valoración del interlocutor.

La actuación del individuo no responde únicamente a la proyección interesada de sus propios deseos de imagen, sino que debe, a su vez, satisfacer y ajustarse a las expectativas del otro (Hernández Flores, 2005: 100). Para ello se emplean una serie de estrategias lingüísticas, que responden en mayor o menor medida al tipo de relación que se establece entre ellos, de poder o de solidaridad, hecho que se traduce en el uso de un sistema de tratamientos simétrico o no simétrico. El problema, entonces, es determinar cuáles son los factores que disponen el tipo de relación, que no se ciñen a cuestiones normativas, sino al uso real (y variable) de los hablantes nativos "para expresar su identidad personal y grupal, además de para delimitar espacios situacionales e ideológicos” (Mas Álvarez, 2014: 10). A partir de la demarcación del tipo de relación entre hablantes parece, entonces, relativamente fácil intuir la forma de tratamiento que utilizarán en su discurso.

7 Para Goffman (1970), la imagen o face es el valor social positivo que un individuo reclama para sí a través de la valoración de otros en un contacto particular. Por consiguiente, las personas han de llevar a cabo trabajos de imagen (face work) en sus relaciones sociales, a fin de conseguir una imagen pública que se ajuste a sus expectativas $\mathrm{y}$ a las de su interlocutor, en su entorno social.

8 Carrasco Santana (1999) en un completo examen sobre el modelo de Brown y Levinson (1987) encuentra que los términos de cortesía positiva y negativa entrañan algunos problemas terminológicos, por lo que prefiere referirse a estas nociones como cortesía valorizante y mitigadora. 
A continuación se presentan algunas síntesis de los criterios que conforman una relación jerárquica, que han apuntado algunos autores en términos generales o específicamente sobre el uso de las formas de tratamiento: Solé (1978: 5), a propósito de la enseñanza de estas formas a extranjeros, resume en cinco los indicios que hacen presuponer el uso de tú o usted:

(1) the interpersonal relationship of the speakers; (2) the norms governing personal relationships within a given setting; (3) the personal characteristics of the speakers -country of origin, rural/urban procedence, level of education, sex and age; (4) the speech context in which the exchange occurs; and (5) the neutrality or affectivity of the speech event itself.

Escandell (1995: 31; 2006: 136) apunta la importancia de la identidad social del destinatario y factores sociales, como la edad, el sexo, el grado de conocimiento previo, la posición social, la autoridad, la jerarquía, etc. De manera análoga, Hernández Flores (2005: 100) afirma que el hablante confirma la imagen de su interlocutor en relación con el rol que representa ante esa situación, al tiempo que confirma la suya propia, de acuerdo también con su rol. Por otra parte, Bravo (2005: 25) prioriza el

contexto sociocultural que comparten los hablantes [...], redes sociales, la clase socioeconómica, factores culturales como el conocimiento compartido, las creencias y valores, factores demográficos y sociales como la edad, el sexo, la educación, la clase social y el lugar de residencia, la identidad étnica o nacional.

Rodríguez Mendoza (2003: 64 y ss.) destaca en su tesis doctoral que la forma tú suele emplearse en situaciones caracterizadas por la "intimidad psicológica o complacencia social", es decir, en situaciones de familiaridad o de formalidad baja, mientras que usted es la alternativa formal, también utilizada para marcar distancia social, respeto, deferencia, etc., y para tratar a personas desconocidas.

Por su parte, la $N G L E$ (2009: 16.15a.), en una línea similar, menciona los siguientes aspectos:

Intervienen en la elección de las formas pronominales de tratamiento la confianza que exista entre los interlocutores, la cercanía, la solidaridad, la intimidad, el respeto, el nivel del que recibe el trato en relación con el de quien lo otorga, la situación comunicativa y su grado de formalidad, además de otros factores similares.

Calderón Campos (2010: 233) prescinde de los conceptos de "respeto" y "deferencia", y alude también a la "solidaridad, confianza e intimidad" de ciertas situaciones:

El trato de tú o vos implica proximidad con el interlocutor en alguno de estos tres grados señalados. Por tanto, se pueden utilizar tú o vos si el hablante considera que le une con el interlocutor una relación de solidaridad, confianza o intimidad. Por el contrario, se elige usted para indicar distancia (jerárquica, social, etaria, etc.). Además, independientemente de este rasgo de proximidad apuntado, siempre es posible dirigirse al interlocutor de tú o vos cuando [e]ste es joven, especialmente cuando se trata de niños o adolescentes. Este es el único caso en que el uso de tú o vos no sirve para expresar cercanía, si no que viene exigido por la asimetría etaria. En todos los demás casos, la elección de usted o tú/vos viene determinada por el deseo, la conveniencia o la obligación del hablante de marcar más o menos la distancia. 
Como se puede observar, en conjunto tienden a distinguirse aquellas variables inherentes a la naturaleza social de los interlocutores de las que tienen que ver con la relación que se establece entre ellos, sin dar cuenta del orden en el que participan en la creación de una situación jerárquica o simétrica que condicionará la elección de una u otra forma pronominal. En relación con esto, algunos autores como Alba de Diego y Sánchez Lobato (1980), Blas Arroyo (1994a, 1995), Morín Rodríguez (1997), Aijón Oliva (2009), etc. constatan a partir de diferentes trabajos de campo (fundamentalmente encuestas y análisis de corpus) que suele ser la edad el factor más influyente, que da lugar a la elección de un sistema de tratamiento solidario o no solidario (cf. Alba de Diego y Sánchez Lobato) ${ }^{9}$.

Por último, hay que tener en cuenta que este cambio en el español es más acusado que en otras lenguas del entorno con una marca e incluso en algunas variedades del español se produce con mayor acentuación que en otras (Molina Martos, 2002: 98). Ridruejo (1989) considera que esto se debe a que los hablantes sienten una preferencia hacia el tuteo, porque indica igualdad, frente al ustedeo, muestra de distanciamiento y de desigualdad social, hecho que también constatan Blas Arroyo (1994a: 21 y ss.) o Garrido Medina (1992: 1063), quien defiende lo siguiente:

A medida que la movilidad social y la ideología igualitaria se extienden, el sistema de tratamiento se inclina hacia la dimensión de la igualdad (es decir, la expresión de la distancia o de la familiaridad), en detrimento de la dimensión de la desigualdad, es decir la expresión de las relaciones de inferioridad o superioridad sociales.

Molina Martos (2002: 100) señala directamente a los jóvenes universitarios como promotores de este cambio, debido a la influencia igualitaria de la universidad, afirmación que años atrás realizaron Borrego Nieto, Gómez Asencio y Pérez Bowie (1978) derivada de una investigación que se llevó a cabo con encuestas a alumnado universitario de distintas edades ${ }^{10}$.

\section{Las formas de tratamiento en el corpus de entrevistas semidirigidas}

El contexto que nos ocupa, la entrevista semidirigida, se regula por una serie de normas discursivas y también sociales: los roles de los participantes están determinados con anterioridad al encuentro, la toma de turno está predeterminada y el registro empleado acostumbra a ser semiformal de acuerdo con el contexto, por lo que debe "rebajarse". Sin embargo, la incorporación de nuevos temas o la formulación de las preguntas se aproximan más en estos casos al género conversacional que a la entrevista prototípica (Albelda Marco, 2005: 112). En consecuencia, las muestras evidencian un registro más formal por parte del entrevistado y un posible exceso de control sobre su habla (Recalde y Vázquez Rozas, 2009), lo que de-

9 A este respecto, Aijón Oliva (2009: 23), en un análisis de anuncios publicitarios, destaca la importancia de la imagen que quiere proyectar el emisor, con el fin de persuadir más sobre el posible comprador.

10 Otros trabajos más recientes sobre estudiantes universitarios y, también basados en la técnica de encuesta son: Aguado Candanedo (1981) en Bilbao, Blas Arroyo (1994b) en la Comunidad Valenciana, con informantes de distintas edades; Molina Martos (2002) en Madrid, Rodríguez Mendoza (2003) en San Sebastián de la Gomera, Pedroviejo Esteruelas (2006) en Valladolid, Montero Curiel (2011) en Extremadura y Sanromán (2013) en Santiago de Compostela y Coruxo (con el fin de comparar posibles diferencias de uso entre ámbito urbano y rural). 
bería también repercutir en un mayor empleo del pronombre usted, más formal. No obstante, Morín Rodríguez (1997), en un estudio basado en el uso de las formas de tratamiento en un contexto laboral, afirma lo siguiente:

El ámbito laboral, al igual que cualquier otro marco situacional comunicativo, determina "a priori" el uso de un específico registro lingüístico (familiar, formal...), aunque es en definitiva el contexto situacional concreto quien fija la elección lingüística. Actores como la 'edad' o el 'nivel sociocultural' del hablante, o bien el 'sexo' o el 'estatus' del destinario son, sin duda, marcadores relevantes (Morín Rodríguez, 1997: 287).

En las entrevistas, los interlocutores, salvo en uno de los casos estudiados, no se conocían hasta el momento del encuentro (vid. tabla 2). En lo relativo al entrevistador, en PRESEEA no se tiene en cuenta su perfil, si bien algunos autores (Labov, Silva-Corvalán) consideran de vital importancia sus características sociales en la interacción: "mientras más similares sean las características sociales del investigador y el hablante, mayores serán las posibilidades de obtener habla espontánea y no formal" (Silva-Corvalán, 2001: 56). En ESLORA sí aparece información relativa al perfil social del entrevistador y se especifica, además, si conocía previamente al informante, lo que permite estudiar con mayor profundidad el tipo de relación que se establece entre ellos -jerárquica o igualitaria-, a tenor de sus características sociales.

En casi el total de la muestra seleccionada para este trabajo los rasgos del entrevistador son los siguientes: mujer, menor de 30 años y con estudios universitarios; las excepciones son tres entrevistas realizadas por varones del mismo perfil social ${ }^{11} \mathrm{y}$ otras dos de mujeres del segundo grupo de edad, también de estudios universitarios ${ }^{12}$. Por tanto, interesa señalar que los interlocutores pertenecen, a priori, a la misma categoría social (estudios universitarios), por lo que los rasgos más destacables en la constitución de su relación son el contexto de la entrevista y las posibles diferencias de edad y sexo.

Del conjunto de las dieciocho entrevistas, en diez de ellas se produce un sistema simétrico de tuteo recíproco entre los interlocutores $(55,5 \%)$ y tan solo en una de ellas (SCOM M33_009) hay un sistema asimétrico en el que la informante trata de tú a la entrevistadora y esta de usted a la entrevistada, lo que representa un 5,5\% del total. En lo relativo a las restantes entrevistas (39\%), interesa destacar que todas presentan alguna variación en la forma de tratamiento seleccionada, que analizaremos en el apartado 5. Así, en cinco de ellas $(27,7 \%)$ el informante tutea al entrevistador, mientras que este utiliza ambas formas de tratamiento para dirigirse a él; en una $(5,5 \%)$ es el informante quien emplea las dos formas de apelativas con su entrevistador, quien, a su vez, lo trata de usted y, finalmente, también en una entrevista $(5,5 \%)$ ambos participantes utilizan los dos pronombres con su respectivo interlocutor.

11 SCOM_H23_003,SCOM_H23_006 y SCOM_M33_011.SCOM es el acrónimo que utiliza PRESEEA (2008) para identificar a la ciudad de Santiago de Compostela La descripción de las claves es la siguiente: "SCOM" es el acrónimo que utiliza PRESEEA (2008) para identificar a la ciudad de Santiago de Compostela , "M" o "H" representa el sexo del informante, el primer número que aparece señala el grupo de edad al que pertenece el entrevistado $(1,2$ o 3$)$ y el segundo se refiere al nivel de estudios (en este caso, el 3 indica que se trata de estudios superiores). Finalmente, los números restantes identifican específicamente a cada entrevista.

12 SCOM_H33_015 y SCOM_M13_010. 


\begin{tabular}{|c|c|c|c|c|c|c|c|c|}
\hline $\begin{array}{l}\text { Código } \\
\text { Entrevista }\end{array}$ & $\begin{array}{c}\operatorname{Sexo} \\
I^{13}\end{array}$ & $\begin{array}{c}\text { Edad } \\
\text { I }\end{array}$ & $\begin{array}{l}\text { Titulación/ } \\
\text { Profesión } \\
\text { I }\end{array}$ & $\begin{array}{c}\text { Sexo } \\
\mathbf{E}\end{array}$ & $\begin{array}{c}\text { Edad } \\
\mathbf{E}\end{array}$ & $\begin{array}{l}\text { Titulación/ } \\
\text { Profesión } \\
\text { E }\end{array}$ & $\begin{array}{l}\text { Con. } \\
\text { previo } \\
\text { I-E }\end{array}$ & $\begin{array}{c}\text { Tratamiento } \\
\text { utilizado }\end{array}$ \\
\hline SCOM_H13_012 & Varón & 21 & $\begin{array}{l}\text { Estudiante de } \\
\text { Periodismo }\end{array}$ & Mujer & 29 & Prof ${ }^{\mathrm{a}}$ instituto & No & $\begin{array}{l}\text { Tuteo } \\
\text { recíproco }\end{array}$ \\
\hline SCOM_H13_013 & Varón & 28 & Informático & Mujer & 24 & $\begin{array}{l}\text { Becaria de } \\
\text { investigación }\end{array}$ & No & $\begin{array}{l}\text { Tuteo } \\
\text { recíproco }\end{array}$ \\
\hline SCOM_H13_014 & Varón & 28 & $\begin{array}{c}\text { Productor y } \\
\text { realizador de vídeo }\end{array}$ & Mujer & 22 & $\begin{array}{c}\text { Estudiante } \\
\text { universitaria }\end{array}$ & No & $\begin{array}{c}\text { Tuteo } \\
\text { recíproco }\end{array}$ \\
\hline $\begin{array}{l}\text { SCOM_- } \\
\text { M13_016 }\end{array}$ & Mujer & 20 & $\begin{array}{c}\text { Estudiante de } \\
\text { Animación turística }\end{array}$ & Mujer & 20 & $\begin{array}{c}\text { Estudiante } \\
\text { universitaria }\end{array}$ & No & $\begin{array}{c}\text { Tuteo } \\
\text { Recíproco }\end{array}$ \\
\hline $\begin{array}{l}\text { SCOM_- } \\
\text { M13_010 }\end{array}$ & Mujer & 26 & $\begin{array}{l}\text { Lcda. en Psicología. } \\
\text { Becaria de aula de } \\
\text { informática }\end{array}$ & Mujer & 40 & $\begin{array}{c}\text { Prof }^{\mathrm{a}} \\
\text { universitaria }\end{array}$ & No & $\begin{array}{l}\text { Tuteo } \\
\text { Recíproco }\end{array}$ \\
\hline $\begin{array}{l}\text { SCOM_- } \\
\text { M13_008 }\end{array}$ & Mujer & 29 & Odontóloga & Mujer & 24 & $\begin{array}{l}\text { Becaria de } \\
\text { investigación }\end{array}$ & No & $\begin{array}{c}\text { Tuteo } \\
\text { Recíproco }\end{array}$ \\
\hline SCOM_H23_006 & Varón & 38 & Abogado & Varón & 25 & $\begin{array}{c}\text { Becario de } \\
\text { investigación }\end{array}$ & No & $\begin{array}{c}\text { Tuteo } \\
\text { Recíproco }\end{array}$ \\
\hline $\begin{array}{l}\text { SCOM_- } \\
\text { M23_018 }\end{array}$ & Mujer & 39 & $\begin{array}{l}\text { Profesora de } \\
\text { instituto }\end{array}$ & Mujer & 20 & $\begin{array}{c}\text { Estudiante } \\
\text { universitaria }\end{array}$ & No & $\begin{array}{c}\text { Tuteo } \\
\text { Recíproco }\end{array}$ \\
\hline $\begin{array}{l}\text { SCOM_- } \\
\text { M23_001 }\end{array}$ & Mujer & 50 & $\begin{array}{c}\text { Lcda. en } \\
\text { Magisterio. Admva. }\end{array}$ & Mujer & 24 & $\begin{array}{c}\text { Becaria de } \\
\text { investigación }\end{array}$ & No & $\begin{array}{c}\text { Tuteo } \\
\text { Recíproco }\end{array}$ \\
\hline SCOM_H33_015 & Varón & 74 & Sacerdote & Mujer & 47 & $\begin{array}{c}\text { Prof }^{\mathrm{a}} \\
\text { universitaria }\end{array}$ & Sí & $\begin{array}{c}\text { Tuteo } \\
\text { Recíproco }\end{array}$ \\
\hline $\begin{array}{l}\text { SCOM_- } \\
\text { M33_009 }\end{array}$ & Mujer & 74 & Maestra jubilada & Mujer & 19 & $\begin{array}{c}\text { Estudiante } \\
\text { universitaria }\end{array}$ & No & $\begin{aligned} \mathrm{I} & \rightarrow \mathrm{E} \text { tú } \\
\mathrm{E} & \rightarrow \mathrm{I} \mathrm{Vd} .\end{aligned}$ \\
\hline SCOM_H23_003 & Varón & 38 & $\begin{array}{c}\text { Lcdo. en } \\
\text { Filología Clásica. } \\
\text { Comerciante }\end{array}$ & Varón & 20 & $\begin{array}{c}\text { Estudiante } \\
\text { universitario }\end{array}$ & No & $\begin{array}{c}\mathrm{I} \rightarrow \mathrm{E} \text { tú } \\
\mathrm{E} \rightarrow \mathrm{I} \text { tú/Vd. }\end{array}$ \\
\hline SCOM_H23_017 & Varón & 47 & $\begin{array}{l}\text { Lcdo. en Derecho. } \\
\text { Funcionario }\end{array}$ & Mujer & 22 & $\begin{array}{c}\text { Estudiante } \\
\text { universitaria }\end{array}$ & No & $\begin{array}{c}\mathrm{I} \rightarrow \mathrm{E} \text { tú } \\
\mathrm{E} \rightarrow \mathrm{I} \text { tú/Vd. }\end{array}$ \\
\hline $\begin{array}{l}\text { SCOM_- } \\
\text { M23_004 }\end{array}$ & Mujer & 46 & Enfermera & Mujer & 23 & Prof ${ }^{a}$ instituto & No & $\begin{array}{c}\mathrm{I} \rightarrow \mathrm{E} \text { tú } \\
\mathrm{E} \rightarrow \mathrm{I} \text { tú/Vd. }\end{array}$ \\
\hline SCOM_H33_007 & Varón & 61 & Arquitecto & Mujer & 22 & $\begin{array}{c}\text { Estudiante } \\
\text { universitaria }\end{array}$ & No & $\begin{array}{c}\mathrm{I} \rightarrow \mathrm{E} \text { tú } \\
\mathrm{E} \rightarrow \mathrm{I} \text { tú/Vd. }\end{array}$ \\
\hline $\begin{array}{l}\mathrm{SCOM} \\
\mathrm{M} 23 \_005\end{array}$ & Mujer & 67 & $\begin{array}{c}\text { Farmacéutica } \\
\text { jubilada }\end{array}$ & Mujer & 22 & $\begin{array}{c}\text { Estudiante } \\
\text { universitaria }\end{array}$ & No & $\begin{array}{c}\mathrm{I} \rightarrow \mathrm{E} \text { tú } \\
\mathrm{E} \rightarrow \mathrm{I} \text { tú/Vd. }\end{array}$ \\
\hline SCOM_H33_002 & Varón & 61 & $\begin{array}{c}\text { Comerciante } \\
\text { jubilado }\end{array}$ & Mujer & 19 & $\begin{array}{c}\text { Estudiante } \\
\text { universitaria }\end{array}$ & No & $\begin{array}{c}\mathrm{I} \rightarrow \mathrm{E} \text { tú/Vd. } \\
\mathrm{E} \rightarrow \mathrm{I} \mathrm{Vd} .\end{array}$ \\
\hline $\begin{array}{l}\text { SCOM } \\
\text { M33_011 }\end{array}$ & Mujer & 75 & $\begin{array}{c}\text { Profesora } \\
\text { universitaria } \\
\text { jubilada }\end{array}$ & Varón & 25 & $\begin{array}{l}\text { Becario de } \\
\text { investigación }\end{array}$ & No & $\begin{array}{l}\mathrm{I} \rightarrow \mathrm{E} \text { tú/Vd. } \\
\mathrm{E} \rightarrow \mathrm{I} \text { tú/Vd. }\end{array}$ \\
\hline
\end{tabular}

Tabla (2) Síntesis de la muestra: perfil social de los interlocutores, relación entre ellos y tratamiento utilizado.

13 Cabe señalar que se han mantenido las abreviaturas de los participantes empleadas en este corpus, pero no en el conjunto de PRESEEA; así, 'E' equivale al entrevistador e 'I' al informante o entrevistado. 

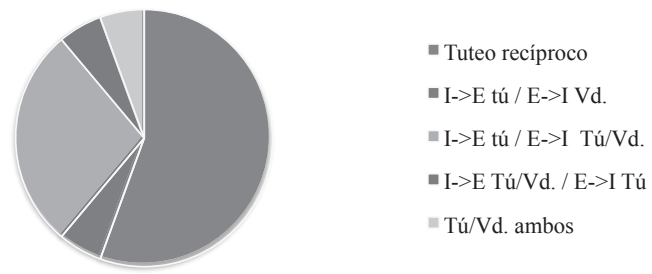

Gráfica 1: Número de entrevistas según el diferente tratamiento representado.

De acuerdo con los datos, el tuteo es la forma predominante, con un porcentaje superior a la mitad del conjunto; se observa, además, que se utiliza fundamentalmente en aquellos casos en los que los interlocutores son ambos jóvenes, menores de 40 años ${ }^{14}$-en su mayoría, de 30 años-. Tan solo hay dos casos de entrevistados de mayor edad a esta: la entrevista SCOM_M23_001, en la que la informante tiene 50 años y la entrevistadora 24, y la entrevista SCOM_H33_015, en la cual el informante tiene 74 años y la entrevistadora 47, si bien se conocían con anterioridad al encuentro. Estos datos se corresponden parcialmente con los de la bibliografía especializada (Alba de Diego y Sánchez Lobato, 1980: 98; Blas Arroyo, 1994a: 8; Matte Bon, 1995; Aijón Oliva, 2009), que indican que la edad y la pertenencia a una generación común dan lugar a una relación de solidaridad, traducida en el empleo común del mismo pronombre de segunda persona. Con todo, este factor no es exclusivo, ya que la afectuosidad o la cercanía de los entrevistados puede influir también en la forma adoptada por los entrevistadores. Por su parte, el sexo no parece ser un factor incidente en la elección tú/usted, puesto que en la totalidad de las situaciones de tuteo, son mujeres las entrevistadoras que en un $50 \%$ de estos casos entrevistan a varones y en el otro $50 \%$ a mujeres.

Tan solo hay un ejemplo de sistema asimétrico sin variación pronominal: la entrevistadora, mujer de 19 años, ustedea a la informante, mujer de 74 años y esta, en cambio, la trata de $t u ́$; esta diferencia de edad parece ser la razón del uso de un sistema no solidario (cf. Alba de Diego y Sánchez Lobato). Las restantes entrevistas también presentan este mismo sistema de tratamiento, aunque en todas ellas se registra algún tipo de alternancia en el uso de las formas de tratamiento empleadas, que se examinará en el apartado 5.

\section{Alusiones a las formas de tratamiento}

Para abordar el estudio de las formas de tratamiento, PRESEEA dispone de un cuestionario específico ${ }^{15}$ utilizado, por ejemplo, en la investigación de Molina Martos (2002), y cuyas ventajas metodológicas pueden consultarse en Paredes (2010). Sin embargo, esta herramienta no ha sido empleada en PRESEGAL, al considerar que no refleja los usos lingüísticos reales de los hablantes. La razón se debe a que se pregunta directamente, por ejemplo, la forma de tratamiento que se utiliza con interlocutores de distintas profesiones, sin tener en cuenta otros factores.

14 En Montero Curiel (2011: 113) se señala que el momento para ser tratado de usted comienza a los 40 años, edad con ciertas connotaciones sociales (veinteañero, treintañero vs. cuarentón) y marcada por el cambio a la madurez. En nuestro caso, representa el doble que tienen la mayoría de los entrevistadores.

15 Vid. http:// preseea.linguas.net/Portals/0/Metodologia/Cuestionario\%20FT.pdf 
En los módulos temáticos propuestos en PRESEEA (2003) para su aplicación en las entrevistas semidirigidas, aparece también la cuestión de los tratamientos en la sección dedicada a la presentación de los interlocutores, con la que se inicia el intercambio comunicativo:

¿Cómo quiere que le trate de tú o de usted? La verdad es que es un problema esto del tratamiento, nunca sabes c[ó]mo tratar a las personas ¿verdad? Por ejemplo, ¿tú cómo tratas a tus amigos de tú o de usted? ¿Y si son personas mayores? ¿Si se trata de alguien joven que no conoces? [...] ¿Si una persona más joven te/le trata de tú qué te/le parece? (Preguntar por si tratan de evitar el trato asimétrico o en qué situaciones les parece mejor). Es un problema, yo a veces no sé qué hacer. Bueno, a mí tráteme de tú ¿le/te parece?

En PRESEGAL, la utilización de estos módulos temáticos se ha limitado por los inconvenientes que conllevan las entrevistas estructuradas: excesivo control del entrevistador, rigidez del evento comunicativo, respuestas forzadas, etc. Así, con el fin de rebajar el nivel de formalidad y de obtener y registrar el habla espontánea, se ha procurado acomodar la entrevista a la personalidad de cada informante, a través de la introducción de temas que son de su agrado y que no necesariamente aparecen entre los recomendados por PRESEEA (2003) (vid. Fernández Sanmartín et alii, 2008; Vázquez Rozas, en prensa).

En el corpus analizado, las alusiones explícitas a las formas de trato son muy escasas (cuatro en total) y solo aparecen para establecer el tratamiento entre los participantes -aunque, como se verá en el siguiente apartado, no siempre se mantiene en toda la entrevista-. Las referencias al tratamiento tienen en común que se trata de peticiones o invitaciones de uno de los miembros para poder tutear al interlocutor o ser tuteado (no hay ningún caso en el que suceda hacia el usted). Por otro lado, la aparición explícita de estas formas se produce al comienzo del encuentro, cuando los interlocutores se reúnen por primera vez en persona, salvo en un caso (ejemplo 4) en el que ocurre en el minuto diecinueve. En todos estos ejemplos, además, los entrevistados tutean a los entrevistadores, por lo que el cambio al tú supone establecer un sistema solidario entre ambos interlocutores.

A diferencia de la propuesta incluida en los módulos temáticos de PRESEEA (2003), en los ejemplos de esta muestra la mención de las formas apelativas de segunda persona en la entrevista no se ha reutilizado para recabar datos sobre las creencias de uso de los tratamientos por parte de los informantes. Como se puede observar en los ejemplos (1) a (4), tras la referencia a dichas formas, se da comienzo a la entrevista (ejemplo 2) o se retoma el tema que se estaba tratando previamente: en (1) la explicación sobre el proyecto, en (3) el malentendido sobre el lugar de encuentro acordado por las interlocutoras y en (4) si es correcta la manera como está actuando la entrevistada en el intercambio comunicativo:

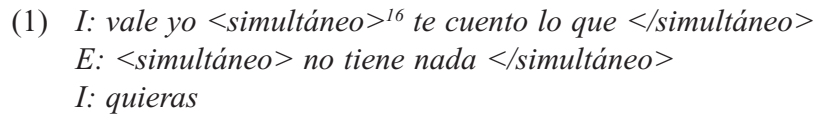

16 Se han mantenido las etiquetas en los ejemplos, tal y como aparecen en el corpus, puesto que aportan una mayor cantidad de información sobre el intercambio comunicativo. Las etiquetas representan elementos vocales y no vocales, como pausas, risas, estornudos, ruidos externos, etc. Turnos y solapamientos, fenómenos ininteligibles o de transcripción dudosa (cf. Llisterri, 1999). A esto hay que añadir algunos elementos léxicos, como alargamientos, citas, palabras cortadas, cambios de código, etc. En PRESEEA (2008) puede consultarse el listado de etiquetas mínimas obligatorias. 
E: después eeh ¿puedo tutearte?

I: sí / claro que sí <risas = "E"/> / yo también te he tuteado a ti / porque yo no estoy acostumbrada $<$ alargamiento/ $>$ /

E: no $<$ alargamiento/ $>$ / yo es que claro por $<$ simultáneo $>$ teléfono $<$ alargamiento/ $></$ simultáneo $>$

I: $<$ simultáneo $>$ ya $</$ simultáneo $>$ ya ya

E: no te conocía y tal / eemm / no mira / esto / aún están en clase <silencio/> pues eeh están $<$ alargamiento/> haciendo un estudio sobre <alargamiento/> la gente de Santiago / sus costumbres / modos de vida ... [SCOM_M23_018]

(2) E: ya encendí todas / todos los aparatos / bueno / eeh / usted se llama Marcos / yo me llamo Begoña

I: Marcos Budiño López /

E: vale / lo trataré de Marcos /

I: ¿eh?

E: ¿de usted o de tú?

I: de tú

E: vale

I: mis hijas me tratan de tú y tú no vas a ser menos/

E: no / porque soy igual <entre_risas> que su hija / más o menos </entre_risas > de la misma edad /

I: pues venga /

E: bueno / pues esto es un estudio <alargamiento/> sociológico que se está haciendo en la universidad de Santiago / y vamos a intentar estudiar los hábitos de vida que tienen las personas a las que entrevistamos / ¿me puede contar un poco a qué se dedica <alargamiento/> / en qué trabaja / en qué consiste su trabajo? / [SCOM_ H33_007]

(3) E: aunque no me acordé de pedirle el móvil

I: no no me trates de usted <risas = "E"/> pero bueno / tenías el de casa ¿o no?

E: sí el de casa <simultáneo > el fijo sí </simultáneo> [SCOM_M23_004]

(4) [...] yo no sé qué más quieres que te cuente / no sé si voy bien así contándote <simultáneo $>$ estas cosas o te estoy contando ¿qué? / bueno $</$ simultáneo $>$

E: <simultáneo > sí sí// o sea y / o sea </simultáneo> y usted se / <simultáneo>como / bueno como tú $</$ simultáneo $>$

I: $<$ simultáneo $>$ o o tú $<$ ininteligible $/>/$ bueno $</$ simultáneo $>$

E: $<$ simultáneo $>$ ¿de tú prefieres? $</$ simultáneo $>$

I: $<$ simultáneo $>$ de $<$ ininteligible $>$ sí $/</$ simultáneo $>$

E: $<$ simultáneo $>$ como prefieras $</$ simultáneo $>$

I: $<$ simultáneo $>$ sí prefiero de tú $/</$ simultáneo $>$

$E:<$ simultáneo $>$ bueno y cuando estabas $<$ risas $=" E " />/$ vale $</$ simultáneo $>$

I: $<$ simultáneo $>$ yo prefiero de $<$ ininteligible $><$ risas $=$ "I" $/></$ simultáneo $>$

E: $y$ cuando / eh

I: $<$ tiempo $=" 18.05 " />$ pregunta algo si quieres yo porque yo no estoy hablando pero no sé si estoy hablando bien <simultáneo $>$ o hablando mal </simultáneo $>$ [SCOM M33_011] 
En el ejemplo (1) la entrevistadora ha tratado de usted a la informante al concertar la cita telefónicamente y en la primera toma de contacto mantuvo el mismo tratamiento, pero tras comprobar que era mucho más joven de lo que pensaba decidió pedirle permiso para cambiar la forma de tratamiento. En (2) la entrevistadora pregunta al informante cómo prefiere ser tratado e ignora su respuesta tratándolo de usted; al preguntarle posteriormente el porqué de ese cambio afirmó no ser consciente de lo sucedido, y simplemente observó que era "más apropiada" la forma usted en el contexto en que se encontraba, lo que parece ser un indicio de la "naturalidad" en el uso de las formas de tratamiento también por parte de los entrevistadores; solo en una ocasión introduce una desinencia de segunda persona de singular, como veremos en el apartado 5.1.

En (3) es la entrevistada quien invita a la entrevistadora a tratarla de tú, por razones que se analizarán en el siguiente apartado $\mathrm{y}$, finalmente, en (4) se produce un pequeño malentendido fruto del continuo solapamiento entre ambos interlocutores en esta parte de la entrevista: la informante tutea al entrevistador, mientras que este la trata de usted, hasta que en este momento introduce el pronombre tú (hecho que repetirá en varias ocasiones, como se verá). La entrevistada pronuncia la siguiente secuencia solapada por varios turnos del entrevistador: no sé si voy bien así contándote estas cosas o te estoy contando ¿qué? / bueno o o tú <ininteligible/> / bueno. El entrevistador al oír la forma tú dirigida a él, parece que la interpreta como una invitación de la informante a tutearla, por lo que le pregunta directamente si quiere que la trate de tú, a lo que ella accede.

La mención directa de las formas de tratamiento es infrecuente, ya que podría constituir una amenaza a la imagen del interlocutor (cf. Goffman, 1970), quien se vería obligado a decidir con qué forma prefiere ser tratado. La utilización de un tratamiento simétrico de tuteo está relacionada con la cortesía positiva, pues se interpreta, en general, como un modo de vinculación y confianza mutua entre los interlocutores, mientras que el uso de usted recíproco representaría la cortesía negativa, a través de la idea de "no invadir" o "amenazar" la imagen del otro individuo ${ }^{17}$.

\section{Variación en el uso de las formas de tratamiento}

El fenómeno de la variación pronominal se produce con relativa frecuencia en la muestra estudiada; en concreto, dentro del conjunto de entrevistas analizadas (dieciocho) se observan cambios en ocho de ellas, lo que representa $39 \%$ del total ${ }^{18}$. De entre estos casos, interesa distinguir aquellos en los que en una ocasión puntual se produce un cambio pronominal y, automáticamente el interlocutor retoma la forma apelativa que había esco-

17 Blas Arroyo (1994a: 21) relaciona la elección del pronombre usted con el "mantenimiento de estrategias más conservadoras y tradicionalmente más prestigiosas", vinculadas a la cortesía negativa, y destaca el aumento del tuteo en las comunidades hispánicas como un reflejo de la modernización y "democratización" de las sociedades contemporáneas "que ha contribuido a una valoración crecientemente positiva del tuteo como forma de tratamiento adecuada".

18 En este apartado solo se han tenido en cuenta los casos de variación en el uso de las formas de tratamiento sin mención explícita al respecto. Por tanto, no se han incluido como tal los ejemplos (1) a (4) ni en el cómputo, ni en el análisis. Algunas de estas entrevistas sí aparecerán recogidas de nuevo, porque a lo largo del encuentro se producirá algún cambio en el tratamiento no señalado de manera directa por los participantes. 
gido inicialmente, de aquellos en los que esto ocurre de manera continua. A continuación se presenta una gráfica que resume esta tendencia y, seguidamente, se incluye un estudio de corte cualitativo al respecto:

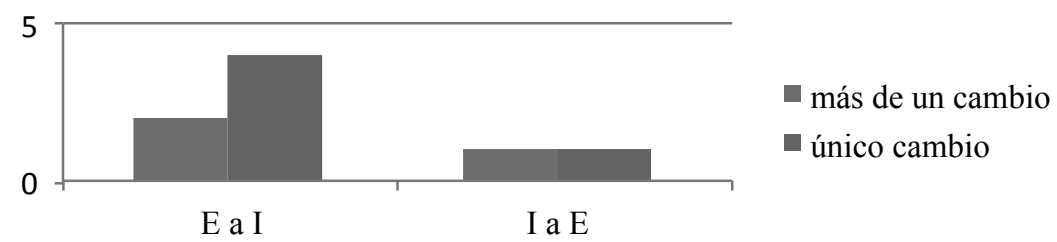

Gráfica 2: Variación tú/ Vd.

\subsection{Variación puntual}

Comenzando por los casos de variación puntual en las formas apelativas, interesa destacar que este hecho se produce en cinco entrevistas de la muestra analizada, lo que supone un $27,7 \%$ del total y, exceptuando un caso, en todos ellos tienen lugar del usted al tú y también en cuatro de ellos es la entrevistadora quien modifica la forma apelativa.

En lo relativo a los cambios de entrevistador a informante, tres de ellos se producen en sistemas de tratamiento asimétricos pertenecientes a las muestras SCOM_M23_005 (5), SCOM_H23_017 (6) y SCOM_H33_007 (7), respectivamente. Las tres entrevistadoras utilizan el pronombre usted y otros deícticos asociados a la misma forma, pero en un momento dado de la entrevista usan un pronombre posesivo, una desinencia verbal y un deíctico unido a una desinencia (respectivamente) asociadas al tuteo:

(5) E: ¿es tu nieta?

(6) $E$ : <ruido = "teléfono" $>$ coja no te preocupes

(7) E: y seguro que les tenías / en aquellos tiempos / miedo

En (5) el cambio se produce a los dieciséis minutos de comenzar la entrevista y coincide con un momento de distracción, en el que la nieta de la informante entra en la sala e interrumpe el desarrollo de la interacción, y da lugar a una pequeña conversación entre las tres. Es un uso espontáneo asociado a un contexto de los que Labov consideraba más pertinentes para obtener vernáculo: la entrada de terceras personas cercanas al entrevistado. La entrevistadora como hablante es sensible a la diferencia de contexto, lo que se refleja en su comportamiento lingüístico, aunque enseguida retoma el usted que había utilizado hasta el momento y que empleará hasta el final, aun viéndose interrumpida en otras dos ocasiones por la misma y por otras personas. En (6) el cambio también coincide con un momento de distracción debido a una llamada telefónica dirigida al informante que interrumpe la entrevista; tiene lugar a los veintinueve minutos de la grabación $\mathrm{y}$, tras producirse, la entrevistadora retoma la forma usted que había empleado hasta el momento. Por último, en (7) la modificación de la forma de tratamiento sucede a los treinta y seis minutos de la entrevista. Este cambio ocurre en una parte en la que el informante está narrando extensamente algunas experiencias desagradables que vivió con los médicos, los hospitales y su miedo hacia las inyecciones, y la entrevistadora participa en varias ocasiones; salvo en este caso en el 
que están abordando un tema que podría provocar cierto malestar o incomodidad, emplea siempre deícticos que corresponden al pronombre usted, a pesar de "olvidar" la invitación al tuteo (ejemplo 2).

Cabe señalar nuevamente que los interlocutores no se conocían hasta el momento de la entrevista y que el cambio se produce del usted que empleaban al tú. Las entrevistadoras comparten idénticos rasgos sociales: mujeres, estudiantes universitarias de $2^{\circ}$ o $3^{\circ}$ ciclo y menores de 25 años. Por su parte, los informantes son una mujer licenciada en Farmacia ya jubilada de 68 años (5), un varón funcionario licenciado en Derecho de 47 años (6) y un varón licenciado en Arquitectura de 62 años (7). Por tanto, parece que la variable edad, unida al nivel sociocultural de los entrevistados indujo a las tres entrevistadoras a decantarse por tratar de usted a sus respectivos interlocutores, si bien el cambio de planos discursivos o la temática de la entrevista motivaron la aparición espontánea de una forma de tuteo.

La última muestra de variación pronominal por parte del entrevistador se produce al comienzo de la entrevista SCOM_M23_004, que anticipamos en el apartado 4 (ejemplo 3): debido a un malentendido en el concierto de la cita, la entrevistadora está esperando más tiempo del previsto a que llegue la informante (mujer de 46 años). Cuando la recibe comienza tuteándola, tal vez por su aspecto joven ${ }^{19}$ o por el malestar producido por la dilatada espera (Placencia 2010: 367). No obstante, en el turno siguiente cambia al usted, que mantiene hasta que la entrevistada le pide que la trate de tú y a partir de ahí, la entrevista se desarrolla con un sistema de tuteo recíproco hasta el final:

(8) E: y estaba aquí esperándote

I: dije bueno <cita> entonces quedamos a las y media y cuando llegues a la parada me das $</$ cita $>$

E: $<$ simultáneo $>$ ¿a cuál? $</$ simultáneo $>$

I: $<$ simultáneo $>$ a la iglesia $</$ simultáneo $><$ cita $>$ me das un toque y te voy yo a buscar

$</$ cita $>$ y ahora dije $<$ cita $>$ pues andará perdida por ahi $</$ cita $>$

E: pues nada yo lo / del lo / del toque <simultáneo $>$ no me enteré para nada $</$ simultáneo $>$

I: $<$ simultáneo $>$ de eso no te enteraste claro $</$ simultáneo $>$

E: $<$ simultáneo $>$ yo $</$ simultáneo $>$

I: $\langle$ simultáneo $>$ bueno $</$ simultáneo $>$

E: pensé que habiamos quedado a las $<$ simultáneo $>$ tres y media $</$ simultáneo $>$

I: $<$ simultáneo $>$ claro $</$ simultáneo $>$

E: tampoco pasa nada / yo de hecho<alargamiento/> un ratillo si no venía la iba a $<$ simultáneo $>$ llamar </simultáneo $>[. .$.$] aunque no me acordé de pedirle el móvil$

En lo relativo a los informantes, solo hay un caso de variación puntual en la entrevista SCOM_M33_011, en la que inicialmente se establece un sistema de tratamiento asimétrico (ejemplo 4): la entrevista arranca sin advertir a la entrevistada (mujer de 75 años), quien tutea al entrevistador en el contacto inicial, en el que le pregunta por la finalidad del proyecto, se interesa por su ortodoncia dental y le pide que se cambie a otra habitación para "estar más cómodos".

(9) I: [...] tú ponte ahí / estamos mucho más cómodos yo creo / <ininteligible/> E: $<$ simultáneo $>$ no / me da igual $</$ simultáneo $>$

19 Al contrario de lo que sucede en el ejemplo (1) perteneciente a la entrevista SCOM_M23_018. 


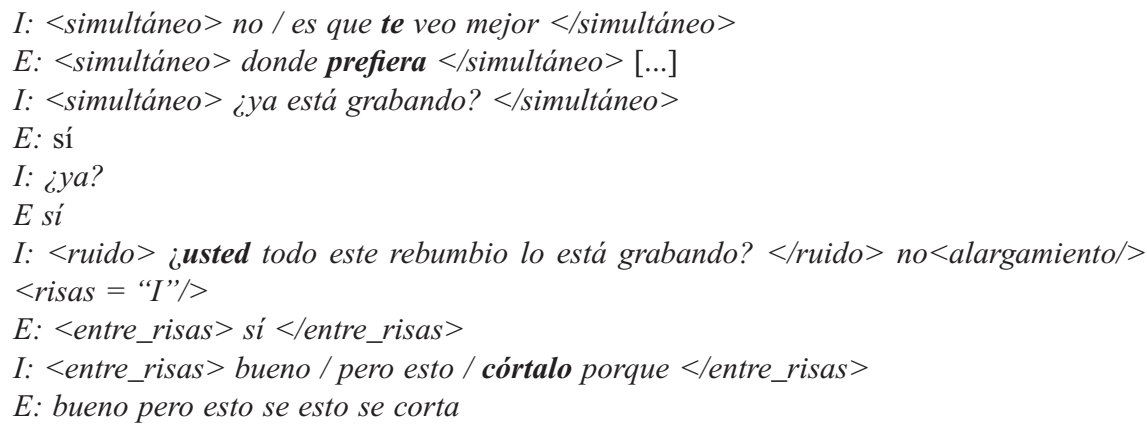

Cuando la entrevistada se percata de que la grabación ha comenzado sin previo aviso, le pregunta con la forma usted, la única que emplea en toda la entrevista, si efectivamente está grabando todo ese movimiento que no tiene que ver con la entrevista, tal y como ella la concibe. De este modo, parece querer distanciarse de su interlocutor de manera voluntaria, con objeto de hacerle notar que esa parte inicial que ha grabado no es apropiada, puesto que la entrevista propiamente no ha comenzado, está hablando de otros temas que considera no vinculantes para ese intercambio y ni siquiera han tomado asiento. Este uso de las formas de tratamiento con un fin distanciador aparece recogido por algunos autores (Rodríguez Mendoza, 2003; Kapovic, 2007), que indican que no acostumbra prolongarse en un extenso periodo de tiempo.

\subsection{Variación continua}

La variación constante en el uso de las formas de tratamiento es menos frecuente que la variación puntual y se produce en tres entrevistas del conjunto (16\%), en dos de ellas por parte del entrevistador y en una por el entrevistado.

Comenzando por la entrevista SCOM_H23_003, el entrevistador -varón de 20 añosopta por la forma usted para dirigirse a un interlocutor, también varón de 38 años, como señal de respeto y distancia. Sin embargo, a lo largo de la entrevista se producen cambios no consecutivos en la forma de tratamiento que utiliza. Así, hasta el minuto catorce, el entrevistador ustedea al informante y realiza preguntas y comentarios propios de una entrevista prototípica (10):

(10) a. E: [...] y llevar a cabo entrevista // bueno / pues $<$ alargamiento/> eeh / ¿a qué<alargamiento/> se dedica? / en la actualidad /

b. E: ¿o sea que trabaja de guía turístico?

c. E: eeh ¿ha perjudicado su<alargamiento/> / vamos / su trabajo / indirectamente con la ley antitabaco? /

Cuando el informante relata algunos aspectos anecdóticos de un viaje a Irlanda, como sus salidas nocturnas, el entrevistado muestra entonces una mayor cercanía con su interlocutor a través de risas, frases inconclusas y comentarios que buscan la complicidad de su oyente, y entonces cambia al tú, como una estrategia más de proximidad y de rebajar el nivel de formalidad del intercambio comunicativo: 
(11) a. E: <entre_risas> ¿qué te gusta más el ambiente de aquí o el de allá? </entre_risas> / b. E: y<alargamiento/> por ejemplo / cuando la gente se va a la calle / porque $s<$ palabra_cortada/ $>$ cierran locales $<$ fático $=$ "I" $/>/ \mathrm{mmm}$ yo no sé $/$ cuánto tiempo hace que / viniste para aqui pero $<$ alargamiento/ $>$ /

c. $E: i<$ sic $>$ conseguistes $</$ sic $>$ hacer amistades?

Sin embargo, al dejar el tema de Irlanda y otros secundarios derivados de este, el entrevistador retoma su rol y vuelve a la forma usted y a los enunciados de preguntas propios de una entrevista convencional:

(12) a. E: sí <risas = "E"/> de todas las fiestas que hay a lo largo del año <fático = "I"/> Semana Santa / Navidad / ¿con cuál se quedaría? / Carnavales

b. $E:<$ risas $=$ " $E$ "/> eeh cuando me dijo que estudió en la universidad <fático = "I"/> / le gustaba mucho leer /

c. E: <entre_risas> ¿que qué opina entonces del </entre_risas > de la programación de la televisión? /

Esta tendencia se repite sucesivamente a lo largo de todo el intercambio comunicativo y la alternancia de formas personales, en este caso, parece coincidir con la temática de la entrevista y otros aspectos vinculados a la formalidad del acto. La diferencia de edad entre interlocutores no es muy amplia y sus experiencias personales -estudios universitarios, estancias en el extranjero, salidas nocturnas, etc.- son similares, lo que también puede influir en que el entrevistador sienta una mayor proximidad con el entrevistado, y ello se manifieste en el cambio al tú. De acuerdo con Fontanella de Weinberg (1999), la forma tú se utiliza en situaciones de confianza, frente a usted, propio de situaciones de formalidad elevada, por lo que parece que en este caso el factor que determina la jerarquía es el nivel de formalidad de la situación comunicativa a tenor de la temática.

Otra muestra de variación continua en la elección de la forma de tratamiento, en este caso por parte del entrevistado, pertenece a la entrevista SCOM_H33_002: la entrevistadora -mujer de 19 años- selecciona de manera explícita el pronombre usted como forma en su primera intervención para dirigirse a su interlocutor, varón de 61 años:

(13) E: no sé / cuénteme <alargamiento/> // hábleme de usted // ¿es de aquí de toda la vida? <silencio/>

El entrevistado responde a la pregunta con una extensa narración sobre su infancia y llegada a la ciudad en la que no aparecen formas deícticas de segunda persona. Tras una interrupción externa, debida a una llamada al timbre, el informante le pide a la entrevistadora que detenga la grabación, y así utiliza por primera vez una forma desinencial asociada al usted:

(14) I: pare / pare si quiere <simultáneo/> / un mo <palabra_cortada/>

En cambio, tal vez desconcertado por la llamada, el entrevistado se dirige a la entrevistadora segundos después con el pronombre de segunda persona tú y seguidamente retoma la forma usted: 
(15) I: ¿tú venías con alguien? /

E: no < alargamiento/> /

I: es una llamada bastante extraña / es una voz una <alargamiento/> / mujer / dice que si podía hablar conmigo // <simultáneo $>$ sin más explicaciones $</$ simultáneo $>$

E: $<$ simultáneo $>$ no se preocupe o sea $</$ simultáneo $>$ si tiene que salir un $<$ simultáneo $>$ momento $</$ simultáneo $>$

I: <simultáneo > que no / </simultáneo > no / no / no / es que además ni sé de qué se $<$ simultáneo $>$ trata ¿no? $</$ simultáneo $>$

E: <simultáneo $>$ pues no / </simultáneo > para nada //

I: bueno / bueno pues le como le <transcripción_dudosa> iba diciendo </transcripción_dudosa $>/$ fue la única po <palabra_cortada $><$ ruido = "chasquido boca" $>>$ el el $<$ alargamiento/> o sea habia un cierto racismo

El informante trata de utilizar el pronombre usted como forma de tratamiento única, pero tutea a la entrevistadora en varias ocasiones. Así, en (16) al igual que ocurría en (5) y (6) el cambio de tratamiento coincide con diferentes planos discursivos: una interrupción externa y su contexto conversacional inmediato provoca un tú, y cuando el informante vuelve a situarse en el contexto de la entrevista regresa al usted, que utiliza además en una secuencia explícita de regreso (pues como le iba diciendo). Así, los diferentes planos discursivos marcan las distintas formas empleadas y, de acuerdo con los datos, el informante al situarse en su rol de "persona que está siendo entrevistada" utiliza la forma usted, mostrándose así solidario con su entrevistadora, que también lo emplea, y usa el tú en algunas partes de su discurso, por un cambio de plano discursivo o tal vez por la diferencia de edad que los separa, ya que generalmente los miembros mayores no suelen tratar de usted a los más jóvenes (Alba de Diego y Sánchez Lobato, 1980).

En los siguientes ejemplos (17) y (18) aparece otro caso de tuteo: el mismo entrevistado de (15) y (16) al abordar temas que pueden resultar controvertidos o incómodos para él, por tratar de su vida privada o de asuntos políticos que pueden generar confrontación utiliza el tuteo en ciertas ocasiones, como sucedía en (7) al introducir cuestiones como las enfermedades, hospitales, tratamientos médicos, etc. Así en (16) intenta justificar su situación personal y laboral presente; en definitiva, pretende aclarar que el hecho de estar jubilado no significa no desempeñar ningún tipo de actividad, como muchas veces se interpreta dicha situación:

(16) I: si // o <alargamiento/> me dedico<alargamiento/> pues ¿qué te diría yo? a jugar en la bolsa que no gano un duro <risas = "E"/> pero lo paso muy bien / <entre_risas $>$ o sea si </entre_risas > // si / realmente lo que he tratado es de no<alargamiento/> $<$ ruido = "chasquido boca" $>>$ o sea / a ver si me entiende / no ser un parado pasivo / en el sentido de decir <cita > bueno ¿y tú qué haces? </cita > / hombre si te refieres en<alargamiento/> el sentido de trabajos remunerados ninguno // pero procuras buscar cosas en las que<alargamiento/> estés ocupado //

En (17) el informante está hablando de asuntos políticos relacionados con las lenguas vernáculas de la península Ibérica e ideologías que considera extremas por parte de algunos partidos políticos que idolatran a Fidel Castro. Tras esta afirmación, trata de ilustrar con otro ejemplo de líder político que ninguno es ideal y, en medio de este controvertido discurso, de nuevo cambia la forma de tratamiento con la que se dirige a su interlocutora. 
(17) I: [...] te están hablando que sus ídolos pues son Fidel Castro no sé qué más < cita > <lengua $=$ "gallego" $>$ home </lengua $>$ no me fastidies oye / vamos a ser un poco congruentes $</$ cita> yo no te digo / que yo estoy de acuerdo que / que el Bush es un es es un carcamal o sea el Bush es una persona que no / pero bueno pero tampoco me vengas diciendo que Fidel Castro es un angelito hombre no vayamo <palabra_cortada/> vamos a irnos al<alargamiento/> sitio justo ¿no? / o sea por eso te digo que estamos hay veces en / hay cosas que $<$ alargamiento/> que que las ves y las oyes y las lees y tal <vacilación/> [...]

E: <simultáneo > aqui en Galicia es difícil / </simultáneo >

I: ¿entiende? y entonces pues eeh lo que pasa es que uno se calla ¿no?

En otra situación (18) comenta diversas actuaciones políticas y la entrevistadora se ríe, motivo por el que el informante le "reprocha" su actitud, de nuevo con una marca de tuteo. Este uso recuerda al de (9), en el que la entrevistada ustedea al entrevistador para preguntarle si está grabando la entrevista. En este caso, el cambio es del usted que utilizaba al tú, que parece emplear con el mismo fin:

(18) I: ¿y las otras qué pasa? o sea hay las de la <alargamiento $>$ vicepresidencia del gobierno y las otras que son de la Xunta son de segunda ¿no? / o sea <ruido = «chasquido boca»/>/ no sé / no te parece muy serio la cosa ¿no? I/

E: estuvieron en mi casa ayer hablando <entre_risas $>$ de eso </entre_risas $>/$

I: síl

E: por eso me río /

I: ya // sí / no / no sé es<alargamiento/> // yo hay cosas que no las ves o sea

Este mismo informante en algunas de sus narraciones se vale de consideraciones genéricas o impersonales, bien para apoyar sus afirmaciones o bien para no concretarlas, ya que no solo le atañen a él. Se trata de reflexiones genéricas en las que aparece un sujeto explícito (tú) o implícito con un valor no específico, cuyo referente es "uno", "la gente", "el mundo", etc. y no el destinatario presente en el acto comunicativo. En estos casos, la NGLE (2009: 16.2u) señala que

la interpretación genérica de la segunda persona se obtiene también en singular, sobre todo en contextos modales, irreales, y en general prospectivos. Se manifiesta este significado en la flexión verbal, como en Si quieres la paz, prepara la guerra (es decir, 'si uno quiere la paz...'); con los pronombres de segunda persona, sean átonos o tónicos y también con los posesivos.

Y, más adelante: “los posesivos tú y tus admiten un uso genérico o generalizados (a veces encubridor del hablante), en el que admiten la paráfrasis de 'uno cualquiera'. Comparten este rasgo con la flexión verbal de segunda persona y con los pronombres personales tú, te y $t i$ " (Ibid., 2009:18.2h).

Muestra de ello son los ejemplos (19) y (20) de la misma entrevista:

(19) I: $\mathrm{mmm} / /$ y<alargamiento/> o sea tenías además tenía que darte tu padre <fático = "E"> unos papel < palabra_cortada/> unas cartas autorizándote a viajar [...] y vas solo hasta allí o iba en avión por ejemplo ¿no? // y<alargamiento/> ento <palabra_cortada/ $>$ $y$ entonces a a te sorprende // sobre todo viviendo en aquella época $<$ fático $=$ " $E$ "/> // 
porque hoy en día la gente ya espabiló más pero en aquella época dices tú <cita > coño pues mira yo que me iba con catorce años hasta allá ¿eh? </cita> e iba // y bueno / y quieras que sí quieras que no pues te va<alargamiento/> condicionando ¿no? /

(20) I: teníamos en casa un<alargamiento/> comercio / de <alargamiento/ $>$ tejidos y de confección y todo eso $<$ silencio/ $>$ y $<$ alargamiento/ $>$ y ahi $/ /<$ ruido $=$ "chasquido boca" $/>$ porque en aquella época también te condicionaba mucho eso ¿no? [...] en el caso nuestro nos inclinaron más a a lo que era el comercio / por eso fue el hecho de mandarme a mí a Barcelona a estudiar Comercio / entonces <silencio/> bueno pues ya llega un momento en que<alargamiento/> mmm tú mismo te mentalizas en que $<$ alargamiento/> ese es $\boldsymbol{t} \boldsymbol{u}<$ alargamiento/ $>$ camino

Frente a estos casos de uso prototípico de formas no personales según la NGLE (2009), hay que mencionar otros en los que el informante pretende hacer una lectura genérica de una situación concreta y para ello emplea el pronombre usted e incluso utiliza ambas formas (usted y tú) dentro de una misma intervención:

(21) I: mire viajo mucho porque es que <alargamiento/> / <ruido = "chasquido boca"/> bueno viajo mucho / no / no viajo mucho / lo que ocurre es lo siguiente emmm // eh siempre<alargamiento/> basta que tengas una cosa para que te guste otra ¿no? o sea es que nosotros tenemos una casa en Ribeira // pero<alargamiento/> // en la playa ocurre una cosa que es que pasa como en el Antiguo Oeste // es decir / el el Oeste era tierras libres / tan pronto empezaron a poner alambradas y tal aquello se fastidió / bueno pues aqui pasa igual // usted en Ribeira tan pronto tenía una lancha y podía dejar la lancha donde te diera la gana no pasaba nada <silencio/> pero después empezaron a meterse y tal / y entonces ahora no $\boldsymbol{t}<$ palabra_cortada/> / tú una lancha tienes que tenerla con todos los papeles / no puedes apa < palabra_cortada/> dejarla en cualquier sitio / tienes que dejarla en un club náutico $<$ alargamiento/> o sea / te crea una serie de problemas ¿no?

(22) I: si si usted no tiene tradición o tiene costumbre a coger algo no <transcripción_dudosa $>$ pues </transcripción_dudosa> va usted a ir a<alargamiento/> / a repoblarlo ¿no? / entonces el único que puede repoblar es Medio Ambiente eso está clarísimo ¿no? / y si lo repuebla Medio Ambiente pues ya sabe que se va a cargar las especies autóctonas

(23) I: entonces usted claro si usted se imagina // eeh pues en Roma te sale pues un Quo Vadis o un<alargamiento/> / o el mismo Gladiador tal te salen unos palacios de los césares impresionantes ¿no?

Los ejemplos (21), (22) y (23) corresponden a fragmentos en los que se pone de manifiesto la variación existente en las formas de segunda persona, ya que parecen ser una muestra del intento del informante por ustedear a su interlocutora llevado al punto de variar la forma apelativa a la hora de generalizar. En estos casos, la interpretación particular no resulta coherente, porque el entrevistado desconoce si su interlocutora tenía una lancha en Ribeira (usted en Ribeira tenía una lancha) o si acostumbra ir de caza (si usted no tiene tradición). Solo podríamos aceptar esta interpretación para el ejemplo (23), ya que en este caso el informante no está presuponiendo cierta información, sino que está apuntando una hipótesis, correspondiente a la idea estereotipada que se tiene de la ciudad de Roma, hecho que se puede interpretar de manera genérica, pero también concreta. 
En todos estos casos la interpretación genérica del contenido parece la más adecuada, aunque la NGLE (2009 cf. 42) no menciona la posibilidad de usar la forma usted en este contexto. No obstante, autores como DeMello (2000) o León-Castro Gómez (2014), a partir de sendos análisis de corpus de la realidad hispánica sí ponen de manifiesto la utilización de esta forma genérica con el pronombre usted: "son muy escasos los ejemplos que hemos encontrado de hablantes que se dirijan a su interlocutor con la forma de tratamiento usted y empleen tú con un valor indefinido, donde el cambio de deíctico se debe a que el emisor se está refiriendo a sí mismo" (Ibid., 2014: 45). Otros autores también constatan este uso de la forma usted con valor generalizador que aparece cuando el hablante se dirige al interlocutor de usted, pero casi nunca cuando lo tutea (Fernández Ramírez, 1986). Por tanto, ante el desacuerdo bibliográfico, no queda claro si es la forma de ustedeo la que utiliza inadecuadamente y la de tuteo la que emplea de manera esperada en este contexto de impersonalización, de conformidad con la NGLE (2009) o, si por el contrario, la forma de tuteo es la inesperada en este caso, puesto que el interlocutor ustedea a la entrevistadora y, en consecuencia, la generalización tendría que hacerse bajo esa misma forma. En cualquier caso, la confluencia de ambas revela ciertas dudas en la elección pronominal.

En los casos registrados de variación entre las formas de tratamiento en esta entrevista, el informante comienza su intervención empleando el usted y posteriormente cambia al tú. La utilización en primer lugar de usted podría deberse a que es la forma con la que la entrevistadora lo trata, de modo que podría verse influido por ella, hasta que algún factor contextual o de otro tipo provoca un cambio en su tratamiento. Además, no hay que olvidar la naturaleza social de los interlocutores: el informante tiene 61 años y la entrevistadora 19, por lo que esa diferencia también es condicionante.

Finalmente, el último ejemplo de variación continua en el uso de las formas apelativas por parte del entrevistador es la entrevista SCOM_ M33_011, que vimos en (4), (8) y (9). El entrevistador ustedea a la informante, hasta que ella le permite tratarla de tú. Aunque inicialmente utiliza esa forma, acaba volviendo al usted seleccionado al comienzo y mezclando ambas formas, tal y como se puede ver en la formulación de distintas preguntas consecutivas:

(24) E: o sea que dio clases en primaria también

I: ¿qué? / en pri < palabra cortada/> sí en primaria en bachillerato

E: ah / pensaba que decía en / en el colegio

I: era secundaria / era secundaria [...]

E: ¿alguna vez te pasó algo así con un niño?

I: ¿qué? con niños no / con alumnos nunca me pasó nada ¿¿eh? / nunca [...]

E: <silencio> ¿y ya decidió irse?

I: ya / y no tenías nómina o sea te daba el dinero / y no tenías no figurabas en una nómina [...]

E: ¿y cómo recuerdas ese viaje?

I: mmm ese viaje muy bien fue un viaje muy bonito

La variación incluso se produce entre enunciados muy próximos, casi inmediatos:

(25) E: $<$ simultáneo $>$ ahora / que hablabas un poco de $<$ alargamiento/ $>$ de $</$ simultáneo $>$ I: $<$ simultáneo $>$ y de <palabra_cortada/ $>/ y$ después / y después de / </simultáneo $>$ de eso / mmm ya si quieres dejamos eso / si quieres te hablo ya un poco de <vacilación/> cuando ya paso a profesora si no te hablamos de otra cosa 
E: $<$ simultáneo $>$ de $<$ alargamiento/ $></$ simultáneo $>$

I: $<$ simultáneo $>$ de cla $<$ palabra_cortada $></$ simultáneo $>$ de la ciudad o de algo

E: hable de $<$ alargamiento/ $><$ simultáneo $>$ su vida familiar $</$ simultáneo $>$

I: $<$ simultáneo $>$;la ciudad? $</$ simultáneo $>$

E: $<$ simultáneo $>$ si $<$ alargamiento/ $>$ bueno $</$ simultáneo $>$

I: $<$ simultáneo $>$ ¿de la vida familiar mía? </simultáneo $>$

E: si le parece

I: $<$ simultáneo $>$ pues mira mi vi $<$ palabra_cortada $></$ simultáneo $>$

E: <simultáneo $>$ ¿cuándo conociste a tu marido? $</$ simultáneo $>$

I: pues mira mi vida familiar / mmm te voy a contar / vivíamos primero ahí /

A diferencia de los restantes casos estudiados en este trabajo, no se encuentran recurrencias en el análisis lingüístico que evidencien una distribución situacional de cada pronombre para determinar en qué contextos se utiliza una u otra forma apelativa. La razón de esta alternancia se puede justificar a partir de las diferencias sociales existentes entre interlocutores, tanto de edad como de categoría académica (becario frente a catedrática) que dificultan al entrevistado tutear a la informante, aunque ella le haya dicho que puede hacerlo al tratarse de una situación de una jerarquía social muy marcada. En este sentido, Hickey y Vázquez Horta (1990: 74) y Matte Bon (1995: 244) justifican el uso de usted en relaciones jerarquizadas y, sobre todo, al dirigirse a personas desconocidas o mayores con las que no se mantienen relaciones de confianza.

\section{Conclusiones}

El uso de las formas de tratamiento es un asunto de difícil interpretación. No existe unanimidad en cuanto al enfoque teórico más adecuado para su estudio ni en relación con los factores que señala la bibliografía especializada como determinantes en la elección de una u otra forma de tratamiento. El trabajo más aceptado es el de Brown y Gilman (1968), si bien, como se ha visto, no resuelve por completo la complejidad de la situación.

En este artículo se ha llevado a cabo un análisis cualitativo sobre la distribución de uso de las formas de tratamiento en el corpus de entrevistas semidirigidas de Santiago de Compostela. Para completarlo, se han aducido otros trabajos y otras teorías que mencionan diferentes factores que provocan un desequilibrio en la relación social entre hablantes. Dichos factores suelen dividirse entre los que tienen que ver con la naturaleza social de los individuos (edad, sexo, nivel sociocultural, etc.) y la relación que mantienen en una determinada situación (jerarquía, proximidad...). En este sentido, en diversas investigaciones, incluida esta, se constata que es la edad la variable que marca una mayor distancia social y, por ello, es la que más influye en los hablantes para seleccionar una forma apelativa u otra. Otros posibles parámetros como el nivel sociocultural, en este caso, a priori, son compartidos por los dos interlocutores y, en cuanto al sexo, no se han hallado evidencias en el análisis acerca de su posible influencia.

La alusión explícita al tratamiento y a un posible cambio no es muy habitual y, en la muestra estudiada, aparece fundamentalmente como una invitación al tuteo. Frente a estos casos, interesa señalar el elevado número de entrevistas en las que se registra algún tipo de variación en el uso de las formas de tratamiento. En conjunto, como se ha podido observar, los cambios se producen por distintas razones, que se resumen a continuación: 
1. De manera explícita, para introducir un sistema de tratamientos simétrico y establecer una situación solidaria. Ejemplos (2), (3) y (4).

2. Ante un cambio de planos discursivos por interrupciones externas. Ejemplos (5), (6) y (15).

3. Para manifestar un cierto reproche o marcar un distanciamiento voluntario. Ejemplos (9) y (18)

4. Para mantener la formalidad de la situación y situar el rol de entrevistador-ejemplos (10), (11) y (12)- y de entrevistado -ejemplo (14)-. En este último caso, además, para mostrarse solidario con el interlocutor utilizando la misma forma de tratamiento con la que está siendo tratado.

5. En el contacto inicial, debido a que el interlocutor tiene una edad que no se corresponde con la esperada (ejemplo 1, de forma directa) o porque ha causado algún malestar en el emisor. Ejemplo (8)

6. Por el tratamiento de temas incómodos. Ejemplos (7), (18) y (19).

7. Ante razones de diferencia social. Ejemplos (24) y (25).

8. En contextos impersonales o genéricos. Ejemplos (21), (22) y (23).

La variación de formas apelativas aparece en aquellos contextos en los que, al menos, uno de los interlocutores utiliza el pronombre usted como forma de tratamiento, lo que parece indicar que en las situaciones de relación solidaria es menos probable que se produzcan alternancias. Este fenómeno revela una falta de pericia en el uso de usted, ya que con una relativa facilidad los interlocutores pueden verse influidos por factores contextuales o externos para modificar el tratamiento que están utilizando, de manera que se puede confirmar que la forma no marcada en el español peninsular es tú (Hickey y Vázquez Horta, 1990: 75).

En suma, se ha comprobado que el uso de las formas de tratamiento no es algo estable y sujeto a reglas. Los hablantes seleccionan uno u otro pronombre dependiendo de dónde consideren que deben situarse respecto a su interlocutor, en función de diversos factores que, según los datos recogidos tienen que ver con la edad de los interlocutores y, en algunos casos también con la formalidad de la situación comunicativa.

\section{Referencias bibliográficas}

\section{Fuentes:}

ESLORA: Corpus para el estudio del español oral: http://galvan.usc.es/eslora (17-04-15).

PRESEEA: Proyecto para el estudio sociolingüistico del español de España y de América: http://preseea.linguas.net/ (17-04-15).

Aguado Candanedo, D. (1981): “Análisis sociolingüístico del uso de tú/ usted en los estudiantes universitarios de Bilbao", Letras de Deusto, 21, págs. 165-184.

Aijón Oliva, M. Á. (2009): “Tú y usted como estrategias de estilo y persuasión en la comunicación publicitaria”, Tonos, Revista electrónica de estudios filológicos, 18: http://www. um.es/tonosdigital/znum18/secciones/estudio-1-tu_y_usted.htm (12-11-14).

Alba de Diego, V. y J. Sánchez Lobato (1980): “Tratamiento y juventud en la lengua hablada. Aspectos sociolingüísticos", Boletín de la Real Academia Española, 21, págs. 165-184.

Albelda Marco, M. (2005): "Cortesía en diferentes situaciones comunicativas. La conversación coloquial y la entrevista sociológica semiformal”. En Bravo D. y A. Briz (coords.), págs. 109-134. 
Blas Arroyo, J. L. (1994a): "Los pronombres de tratamiento y la cortesía”, Revista de Filología de la Universidad de La Laguna, 10, págs. 7-36.

Blas Arroyo, J. L. (1994b): “Tú y Usted: dos pronombres de cortesía en el español peninsular actual. Datos de una comunidad peninsular", Estudios de Lingüística de la Universidad de Alicante (ELUA), 10, págs. 21-44.

Blas Arroyo, J. L. (1995): “Un ejercicio de sociolingüística interaccional: el caso de los pronombres de tratamiento en el español actual", Verba, 22, págs. 229-252.

Borrego, J.; J. J. Gómez Asencio y J. A. Pérez Bowie (1978): “Sobre el tú y el usted”, Studia Philologia Salamanticensia, 2, págs. 53-67.

Bravo, D. y A. Briz (coords.) (2005): Pragmática sociocultural. Estudios sobre el discurso de cortesía en español. Barcelona, Ariel.

Bravo, D. (2005): “Categorías, tipologías y aplicaciones. Hacia una redefinición de la cortesía comunicativa", en Bravo, D. y A. Briz (coords.), págs. 21-52.

Brown R. y A. Gilman (1968): "The pronouns of power and solidarity”, Semantic Aspects of style, págs. 253-276.

Brown, P. y S. Levinson ([1978] 1987): "Universals in Language Usage: Politeness Phenomena”. En Godoy, E. (ed.). Questions on Politeness. Cambridge, Cambridge University Press, págs. 56-289.

Calderón Campos, M. (2010): “Formas de Tratamiento". En Aleza Izquierdo, M. y J. M. Enguita Utrilla (coords.): La lengua española en América: normas y usos actuales, Valencia, Universidad de Valencia, págs. 225-236.

Calderón Campos M. y F. Medina Morales (2010): “La historia y situación actual de los pronombres de tratamiento en el español peninsular". En Hummel, M., B. Kluge y M. E. Vásquez Laslop (eds.), págs. 195-222.

Calsamiglia, H. y A. Tusón (2007 [1999]): Las cosas del decir. Barcelona, Ariel.

Carrasco Santana, A. (1999): "Revisión y evaluación del modelo de cortesía de Brown y Levinson”, Pragmalingüistica, 7, págs. 1-44.

Cestero Mancera, A. M. (2013): "El proyecto para el estudio sociolingüístico del español de España y América (PRESEEA)”, Español Actual, 98, págs. 227-234.

Cots, J. M. (1998): Teaching by chatting, a pragmatic analysis of instructor-student conversations at an American University. Lleida, Universitat de Lleida.

Davies, M. (2002): Un corpus anotado de 100.000.000 palabras del español histórico y moderno: www.corpusdelespanol.org (06-04-15).

DeMello, G. (2000): “Tú" impersonal en el habla culta", Nueva Revista de Filología Hispánica, 48: http://redalyc.org/articulo.oa?id=60248205 (06-04-15).

Escandell Vidal, V. (1995): "Cortesía, fórmulas convencionales y estrategias indirectas", Revista española de lingüística, 25/1, págs. 31-66.

Escandell Vidal, V. (2006): Introducción a la pragmática. Barcelona, Ariel.

Escavy Zamora, R. (2008): Pragmática y subjetividad lingüística. Murcia, Universidad de Murcia, Servicio de publicaciones.

Fernández, M. (2003): “Constitución del orden social y desasosiego: pronombres de segunda persona y formulas de tratamiento en español". Ponencia plenaria en el coloquio Pronoms de $2^{\circ}$ personne et formes d'adresse dans les langues d'Europe: http://cvc.cervantes. es/obref/coloquio_paris/indice.htm (06-04-15). 
Fernández, M. (2006): "Pronombres de segunda persona y fórmulas de tratamiento en español: una bibliografía", Linred: lingüistica en la red, 4: http://www.linred.es/informacion_pdf/informacion13_06072006.pdf (06-04-15).

Fernández Ramírez, S. (1986): Gramática española IV. El verbo y la oración. Madrid, Arco Libros.

Fernández Sanmartín, A.; M. García Salido, M. Recalde y V. Vázquez Rozas (2008): “Reflexiones metodológicas sobre la técnica de la entrevista semidirigida", Actas del XV Congreso Internacional de la ALFAL: http://alfal.easyplanners.info/programa/buscar. php?id_tl=886\# (06-04-15).

Fontanella de Weinberg, B. (1999): "Sistemas pronominales de tratamiento usados en el mundo hispánico". En Bosque, I. y V. Demonte (dirs.): Gramática descriptiva de la lengua española. Madrid, Espasa Calpe, págs. 1401-1425.

Frías Conde, X. (2011): “Los pronombres de cortesía. Entre la lingüística, la pragmática y la traductología", Seminario Ciencia del lenguaje y lingüística hispánica: http://uned. academia.edu/XavierFrias/Teaching/28902/Los_pronombres_de_cortesia (06-04-15).

Garrido Medina, J. C. (1992): "Semántica histórica del español: problemas y propuestas (a propósito de la evolución actual de las formas de tratamiento)". En Ariza Viguera, M. (coord.): Actas del II Congreso Internacional de Historia de la Lengua Española. Sevilla, Pabellón de España Editores, págs. 1055-166.

Goffman, E. (1970 [1967]): Ritual de la interacción. Buenos Aires, Tiempo Contemporáneo. Havertake, H. (1994): La cortesía verbal. Estudio pragma-lingüístico. Madrid, Gredos.

Hernández Flores, N. (2005): "La cortesía como búsqueda del equilibrio de la imagen social”. En Bravo, D. y A. Briz (coords.), págs. 95- 108.

Hickey, L. e I. Vázquez Orta (1990). "El empleo de tú y usted en el discurso publipropagandístico", Revista Española de Lingüística Aplicada, 6, págs. 73-82.

Hummel, M.; B. Kluge y M. E. Vásquez Laslop (eds.) (2010): Formas y fórmulas de tratamiento en el mundo hispánico. México D.F/ Graz, Universidad Karl Franzens de Graz /El Colegio de México.

Kapovic, M. (2007): "Fórmulas de tratamiento en dialectos de español; fenómenos de voseo y ustedeo", Hyeronimus, 1, págs. 65-87.

Labov, W. (1966): Principios del cambio lingüístico. Madrid, Gredos.

León-Castro Gómez, M. (2014): "Sobre el empleo de la segunda persona del singular como mecanismo de indefinición referencial en el habla culta. Diferencias entre las formas túl vos y usted", Lingüística y literatura, 65, págs. 37-63.

Llisterri, J. (1999): “Transcripción, etiquetado y codificación de corpus orales". En Gómez Guinovart, J.; A. M. Lorenzo Suárez, J. Pérez Guerra y A. Álvarez Lugrís (coords.): Panorama de la investigación en lingüística informática, Revista Española de Lingüistica Aplicada (volumen monográfico), págs. 53-82.

Mas Álvarez, I. (2014): "Formas de tratamiento y enseñanza del español como lengua extranjera", RedELE, 26: http://www.mecd.gob.es/dctm/redele/Material-RedEle/ Revista/2014_26/2014_redELE_26_06Inmaculada\%20Mas\%20\%C3\%81lvarez. pdf?document $\overline{\mathrm{Id}}=0901 \mathrm{e} \overline{\overline{2}} \mathrm{~b} 81946 \mathrm{da} 7$ (07-04-15).

Matte Bon, F. (1995): Gramática comunicativa del español. De la lengua a la idea. Madrid, Edelsa. 
Medina López, J. (1990): "Sobre los conceptos de «poder» y «solidaridad» en las formas de tratamiento". En Álvarez Martínez, Ma Á. (ed.): Actas del congreso de la Sociedad Española de Lingüística: XX aniversario, 2, Madrid, Gredos, págs. 630-638.

Molina Martos, I. (2002): "Evolución de las fórmulas de tratamiento en la juventud". En Rodríguez González, F. (coord.): El lenguaje de los jóvenes, Madrid, Ariel, págs. 97-121.

Moreno Fernández, F. (1996): "Metodología del 'Proyecto para el estudio sociolingüístico del Español de España y de América' (PRESEEA)”, Lingüística, 8, págs. 257-287.

Moreno Fernández, F. (2005): “Corpus para el estudio del español en su variación geográfica y social. El corpus PRESEEA”, Oralia, 8, págs. 123-139.

Montero Curiel, P. (2011): “Aproximación sociolingüística a las fórmulas pronominales de tratamiento en el habla juvenil”, Revista de estudios de juventud, 93, págs. 105-116.

Morín Rodríguez, A. (1997): "Independencia de variables en la investigación sociolingüística a través del análisis del tratamiento". En Almeida, M. y J. Dorta (coords.): Contribuciones al estudio de la lingüística hispánica. Homenaje al profesor Ramón Trujillo. Barcelona, Montesinos Editor, págs. 287-294.

Paredes, F. (2010): “¿Es factible un cuestionario estándar para el estudio del tratamiento? La experiencia del proyecto PRESEEA en Madrid y Alcalá de Henares". En Hummel, M.; B. Kluge y M. E. Vázquez Laslop (eds.), págs. 163-191.

Pedroviejo Esteruelas, J. M. (2003): "Formas de tratamiento pronominales y nominales en el siglo XX. Análisis de dos obras de teatro: Historia de una escalera y Bajarse al moro", Interlingüística, 14, págs. 388-397.

Pedroviejo Esteruelas, J. M. (2006): "Un estudio sociolingüístico. Sistemas de tratamiento de la Universidad de Valladolid", Tonos. Revista electrónica de estudios filológicos, 11: http://www.um.es/tonosdigital/znum11/estudios/20-tratamiento.htm (07-04-15).

PRESEEA (2003): Metodología del Proyecto para el estudio sociolingüístico del español de España y de América PRESEEA: http://preseea.linguas.net (17-04-15).

PRESEEA (2008): Marcas y etiquetas mínimas obligatorias, Versión 1.0.: http://preseea. linguas.net (17-04-15).

Real Academia Española y Asociación de Academias de la lengua española (2009): Nueva gramática de la lengua española. Madrid, Espasa.

Real Academia Española: Banco de datos (CREA) (en línea). Corpus de referencia del español actual: http://www.rae.es (07-04-15).

Recalde, M. y V. Vázquez Rozas (2009): "Problemas metodológicos en la formación de corpus orales”. En Cantos Gómez, P. y A. Sánchez Pérez (eds.): A Survey on Corpusbased Research / Panorama de investigaciones basadas en corpus. Murcia, AELINCO (Asociación Española de Lingüística de Corpus), págs. 37-49.

Ridruejo Alonso, E. (1989): Las estructuras gramaticales desde el punto de vista histórico. Madrid, Síntesis.

Rodríguez Mendoza, J. (2003): Lenguaje y sociedad. La alternativa tú/usted en San Sebastián de la Gomera. Tesis doctoral, Universidad de la Laguna: ftp://tesis.bbtk.ull.es/ ccssyhum/cs150.pdf. (06-04-15).

Sanromán, B. (2013): "Las formas de tratamiento del español peninsular actual. Los estudiantes de poblaciones gallegas", Représentations des formes d'adresse dans les langues romanes, 89: http://rudar.ruc.dk/handle/1800/8460. (07-04-15). 
Silva-Corvalán, C. (2001): Sociolingüistica y pragmática del español. Washington, Georgetown University Press.

Solé, Y. (1978): "Sociocultural determinants of symmetrical and asymmetrical address forms in Spanish”, Hispania, 61, págs. 940-949.

Vázquez Veiga, N. (1995): "Corpus de lengua hablada en la ciudad de A Coruña: El rol de entrevistador en la conversación semidirigida", Moenia, 1, págs. 181-202.

Vázquez Rozas, V. (en prensa): "ESLORA: Diseño, codificación y explotación de un corpus oral de español de Galicia": http://gramatica.usc.es/ vvazq/pdf_publ/corpus_eslora_pres.pdf (13-04-15).

Weinerman, C. (1976): Sociolingüística de la forma pronominal. México, Trillas.

Zambrano-Paff, M. (2006): “That Woman se convierte en Esa señora. El uso de marcadores de cortesía para proyectar una imagen más formal y salvaguardar la imagen de los interlocutores en los tribunales de inmigración”, III Coloquio Internacional Edice. Valencia, Sgel. 


\title{
UN MODELO PARA EL ANÁLISIS SEMÁNTICO-DISCURSIVO DE LA CAUSALIDAD
}

\author{
ERnesto Wong García \\ Facultad de Lenguas Extranjeras, Universidad de La Habana, Cuba \\ Grupo de Estudios Semánticos e Ideográficos \\ ewong@flex.uh.cu
}

Recibido: 23/03/2015

Aceptado: 02/09/2015

\begin{abstract}
Resumen
La teoría dimensional del significado, desarrollada por el Dr. Leandro Caballero, tiene algunas limitaciones en lo que respecta a la codificación, a nivel de rasgos semánticos, de las relaciones de causalidad. Utilizando principalmente los métodos de análisis componencial y dimensional del significado, de modelación sobre trapecios semióticos y de análisis comparativo de corpus, este trabajo propone un modelo de escenarios causales lingüísticamente estructurados, basado en la dinámica de fuerzas, que amplía considerablemente la expresividad de los rasgos relacionales de la dimensión referencial. Concluye además que es posible tratar la causalidad como una supra-categoría semántico-nocional para su estudio tanto en el sistema de la lengua como en el discurso.

PALABRAS CLAVE: causalidad, teoría dimensional del significado, semántica, análisis del discurso.
\end{abstract}

\begin{abstract}
The dimensional theory of meaning, developed by Leandro Caballero, has some limitations when it comes to encoding causal relationships in semantic features. Using mainly the methods of componential and dimensional analysis of meaning, modelling on semiotic trapezoids and comparative corpus analysis, this paper proposes a model of linguistically structured causal scenarios, based on force-dynamics, which substantially increases feature expressiveness. It furthermore proposes to treat causality as an independent semantic and notional supra-category for its study both within the language system and in discourse.
\end{abstract}

KEYWORDS: causality, dimensional theory of meaning, semantics, discourse analysis.

\section{Introducción}

La teoría dimensional del significado, propuesta y desarrollada por el Dr. Leandro Caballero para el estudio de la modalidad como supra-categoría semántica, ha sido el centro del trabajo del Grupo de Estudios Semánticos e Ideográficos de nuestra Facultad de Lenguas Extranjeras (FLEX) durante los últimos veinte años. Estos estudios se han dedicado a las seis macro-categorías semánticas modales (MSM) propuestas por Caballero — valoración, lealtad, certidumbre, interés, afectividad y expresividad-, y han producido resultados notables, tanto teóricos (como la tesis doctoral de la Dra. Ana Ma. Galbán Pozo, dedicada a la verificación del carácter universal de las MSM) como prácticos (varios diccionarios ideográficos y semánticos (DIS) publicados y por publicar). 
La teoría tiene, sin embargo, algunas limitaciones. Una de ellas, a la que está dedicada la investigación, todavía en curso, cuyos resultados preliminares se presentan aquí, tiene que ver con el análisis semántico de las relaciones de causalidad. Éstas se codifican en la dimensión referencial, por medio de un grupo de rasgos llamados relacionales. En este trabajo muestro cómo estos rasgos no son suficientes para capturar el espectro de relaciones causales que se expresan en el lenguaje (sección 2). Apoyándome en la dinámica de fuerzas (sección 3), propongo un modelo de relaciones causales lingüísticamente estructurado (sección 4), y considero además otros tres aspectos que los hablantes parecen tomar en cuenta al enmarcar escenarios causales en el discurso, todo lo cual me lleva a señalar lo conveniente de tratar la causalidad como una supra-categoría semántico-nocional (sección 5). Finalmente, presento y comento un ejemplo de análisis de corpus utilizando el modelo propuesto (sección 6).

Los métodos principales de esta investigación han sido los de análisis componencial y dimensional del significado, el de modelación sobre trapecios semióticos y el de análisis comparativo de corpora.

\section{La teoría dimensional del significado}

Caballero concibió el significado lingüístico como una entidad compleja en la que se vinculan distintos tipos de contenidos: modales, ilocutivos, referenciales y formales, que se corresponden con cuatro dimensiones del significado: modal, ilocutiva, referencial y constructivo-gramatical, y que se caracterizan por conjuntos de rasgos semánticos específicos. Al abordar la problemática de la causalidad, me he centrado sobre todo en la dimensión referencial.

En la dimensión referencial «se enmarcan los rasgos de los referentes [...] considerados por los agentes del decir y que se caracterizan por una serie de grupos de rasgos, a saber: constitutivos, relacionales, de dominio y taxonomizadores» ${ }^{1}$. Aquí, me ocuparé sobre todo de los rasgos relacionales, que codifican «los diferentes tipos de relaciones que se establecen entre los objetos del mundo sobre la base de una perspectiva antropocéntrica $»^{2}$. Es fundamental insistir en el hecho de que no se trata de las relaciones objetivas en el mundo, sino de la percepción subjetiva que de ellas tienen los emisores del discurso.

Los rasgos relacionales que en la teoría dimensional del significado (TDS) se utilizan para codificar relaciones causales son los siguientes: rasgos de participación operacional, que incluyen causación (cambios de cualidades, cantidades, estados o comportamientos; hacer-ser), manipulación (influencia de un actante manipulador sobre otro para que este último realice una acción; hacer-hacer), concesión (vinculado a las nociones de permisión y perdón) y control (externo o interno, para evitar determinados estados de cosas); y el rasgo de experimentación de la operación, como contracara de las participaciones operacionales anteriores.

Esto presenta varios problemas. Primeramente, es difícil ver exactamente cuál es la diferencia entre la causación de un comportamiento y la manipulación. Segundo, como cada uno de estos rasgos admite una marca $[+]$ o $[-]$ (así como también $[ \pm]$ ), no está clara la diferencia

1 A. Ma. Galbán Pozo: «Aproximación al estudio de las macrocategorías semánticas modales...», p. 27.

2 Ibídem, pp. 27-28. 
entre, por ejemplo, [+CONTROL] y [-CONCESIÓN] o viceversa; la elección de uno u otro se deja al analista, según éste "sienta" la variante léxico-semántica (VLS) en cuestión. Tercero, el rasgo de experimentación de la operación intenta ser un rasgo altamente generalizador, pero a menudo se convierte en un passe partout que carece de la expresividad que se espera de un clasificador semántico. Incluso cuando se llegue a niveles de discretización más específicos (experimentación de la causación, de la manipulación, etc.), esto no hace sino reproducir los problemas que señalé para los rasgos de participación operacional. Y cuarto, el lenguaje expresa otras relaciones causales, a parte de las anteriores, que no hay manera de capturar por medio de estos rasgos. Tal es el caso de la noción de ayuda, en la que dos actantes actúan en la misma dirección, y que se diferencia de concesión por el carácter pasivo de la no interferencia en ésta, contrastado con el carácter activo de la cooperación en la primera.

Para intentar resolver estos y otros problemas, o al menos aumentar la capacidad expresiva de los rasgos relacionales en la TDS, me pareció pertinente considerar los estudios sobre la percepción de las relaciones causales que se han realizado en ciencia cognitiva, principalmente los referenciados en Jackendoff (2002) y Pinker (2008).

\section{La causalidad como dinámica de fuerzas}

Inicialmente propuesta y desarrollada por Talmy (1985), la dinámica de fuerzas se entiende como una categoría semántico-nocional que describe las interacciones de entidades haciendo referencia a la noción de fuerza. Aunque éste es un concepto de la física, la dinámica de fuerzas no se aplica solamente al dominio físico, sino que, como muchas otras nociones que subyacen las llamadas metáforas conceptuales ${ }^{3}$, se aplica también a otros como el psicológico o el epistémico.

La dinámica de fuerzas describe lo que he elegido llamar escenarios, en los cuales participan dos entidades: un agonista, en el cual se percibe una tendencia intrínseca al movimiento o al reposo; y un antagonista, que ejerce una fuerza sobre el agonista, generalmente contraria a la tendencia percibida de éste, pero que puede también reforzarla. En este caso, el antagonista actúa en concierto con el agonista. En los demás, si la fuerza ejercida es mayor, el agonista pasará del movimiento al reposo o viceversa; si no, seguirá haciendo lo que normalmente hace.

Talmy distingue también entre dos variantes de la causalidad: una variante estática, que nos presenta una "foto" de la situación, en la que agonista y antagonista siempre han existido juntos; y una variante dinámica, que nos presenta el momento en que el antagonista entra al escenario o sale, o el momento en que se resuelve la tensión entre los dos. Esta distinción está estrechamente relacionada con la categoría de aspecto y opone, en principio, las clases aspectuales Evento (aspecto télico) y Actividad o Estado (aspecto atélico) ${ }^{4}$. Aquí, las tomo como oposiciones paralelas, aunque no descarto que en etapas futuras de la investigación sea necesario un análisis más matizado.

3 Ver Cuenca y Hilferty (1999), principalmente el capítulo 4, "Metáfora y metonimia".

4 J. Moeschler: Introduction à la linguistique contemporaine, pp. 133-136. Una manera posible de entender la contrariedad télico :: atélico es como la diferencia entre dos maneras de conceptualizar una situación, según ésta tenga comienzo y/o final. La primera (télico) se aplica a eventos, que tienen un principio y/o un final, así como a los eventos mismos de comenzar o terminar. La segunda (atélico) se aplica a actividades y estados, que no tienen principio ni final. Otra manera, que no necesariamente niega ésta, y que es la que asumiré aquí, es la propuesta por Krifka (1998). Ver sección 5, sobre los rasgos de aspecto. 
Otros escenarios son también posibles: por ejemplo, uno en el que el antagonista tiende en la misma dirección que el agonista, esto es, actúan ambos en concierto, o uno en el que el antagonista no ejerce fuerza alguna sobre el agonista, aunque esté presente.

Nótese que la dinámica de fuerzas no se basa en ninguna teoría física o filosófica de la causalidad. Por el contrario, está construida sobre lo que podríamos llamar una teoría ingenua de la causalidad, que tiene mucho más en común con la teoría medieval del ímpetu que con la mecánica clásica newtoniana, y que nace de las intuiciones en que confiaron los primeros seres humanos en el proceso del conocimiento, y que son al fin y al cabo las que quedaron cristalizadas en la cognición, en el significado lingüístico y en las prácticas discursivas. Es éste modelo ingenuo de la causalidad el que debe intentar reflejar la teoría semántica.

\section{Un modelo de escenarios causales}

Combinando los posibles escenarios anteriores, y apoyándome en la técnica del trapecio semiótico — según la propuesta de Galbán Pozo $(2003)^{5}$ — , propongo el siguiente modelo de escenarios causales, representado en la figura 1.

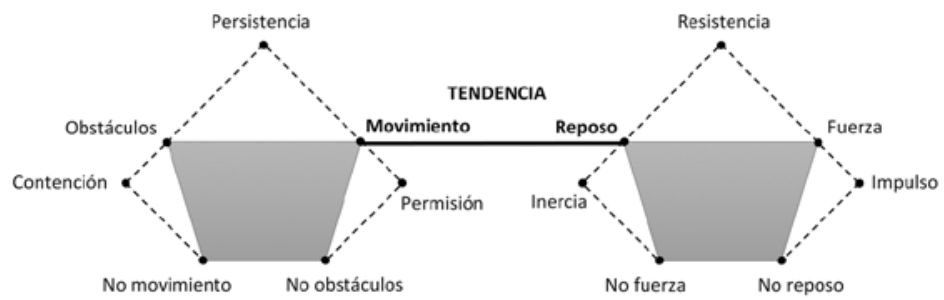

El modelo está construido sobre la oposición de los contrarios movimiento y reposo, que se refieren a la tendencia percibida del agonista. Cada uno de ellos genera a su vez su propio trapecio semiótico, al oponerse a otro contrario: movimiento :: obstáculos, y reposo :: fuerza, y al producir la oposición entre los correspondientes contradictorios no movimiento :: no obstáculos y no reposo :: no fuerza.

Ahora bien, es cierto que éstos no son contrarios en el sentido lexicológico de "antónimos". Sin embargo, es posible considerarlos contrarios semióticos en la medida en que se refieren a los comportamientos del agonista y del antagonista, respectivamente, en un escenario causal (EC), y en la medida en que, como se ve en la figura, sus conjunciones describen otros escenarios. Así, la conjunción de movimiento y obstáculos produce la noción de persistencia (movimiento a pesar de los obstáculos); la conjunción de fuerza y no reposo produce la noción de impulso (cambio hacia el movimiento); y, cruzando trapecios, la unión de movimiento y fuerza produce la noción de ayuda que resultaba imposible de representar en la dimensión referencial; entre otras.

5 Utilizar un trapecio, en lugar de la técnica tradicional del cuadrado semiótico creada por Greimas (1965) y adoptada por Caballero para el estudio de las MSM, permite, en caso de que lo doblásemos por la mitad de manera que contrarios y contradictorios quedaran sobre el mismo eje, reflejar el hecho de que la intensidad de la contradicción es menor que la intensidad de la contrariedad. En este caso, el uso del trapecio responde también a una necesidad lógica: no obstáculos no implica necesariamente movimiento, como no movimiento no implica necesariamente la presencia de obstáculos. Lo mismo se aplica al segundo trapecio. 
Aunque no estamos tratando con la mecánica clásica, inercia se refiere al concepto físico, tal como aparece enunciado en la Primera Ley de Newton, pero aplicado aquí solamente a un objeto cuya tendencia percibida es al reposo: Todo cuerpo persiste en su estado de reposo hasta que sea obligado a cambiar su estado por una fuerza ejercida sobre él. Se refiere entonces a un escenario en el que el antagonista "deja tranquilo" al agonista. Para los objetos cuya tendencia percibida es al movimiento, he preferido utilizar permisión.

Las conjunciones no movimiento :: no obstáculos y no reposo :: no fuerza no están marcadas porque producen, respectivamente, reposo y movimiento; volverlas a marcar sería redundante. Por otra parte, las conjunciones que no tienen opuestos - persistencia y resistencia - pueden marcarse en una matriz como $[+]$ o [-]. Además, como se demostrará en futuras etapas de esta investigación, todas estas conjunciones, contrarios y contradictorios pueden constituir la base de interacción con las MSM (ver además sección 6).

\section{La causalidad como supra-categoría semántico-nocional}

Incorporar las nociones de este modelo a la dimensión referencial como rasgos relacionales ya sería suficiente para aumentar de manera considerable su expresividad en cuanto a relaciones causales. Sin embargo, los hablantes parecen tomar en cuenta otros aspectos de estos escenarios a la hora de enmarcarlos en el discurso. Considérense los ejemplos siguientes:

(1) a. vencer a la resistencia b. resistir a toda costa

(2) el yugo imperial

(3) a. Estamos dispuestos a dialogar.

b. avenirse a razones

(4) a. ;No toleraremos otra derrota!

b. renunciar a sus principios

Los ejemplos en [1] nos presentan escenarios desde diferentes puntos de vista: [1a] desde el punto de vista del antagonista, y [1b] desde el del agonista. Además, [1a] nos presenta el momento en que se resuelve la tensión, mientras que [1b] nos presenta una imagen estática de la situación. El ejemplo en [2] nos presenta también una imagen estática, pero esta vez desde el punto de vista del antagonista. [3] nos muestra dos escenarios desde el punto de vista del agonista, pero [3a] es estático, mientras que [3b] es dinámico. Finalmente, [4a] y [4b] son ambos dinámicos, pero alternan entre los puntos de vista del antagonista y del agonista, respectivamente. Los ejemplos anteriores contienen además información sobre si el agonista logra o no realizar su tendencia intrínseca, y sobre si el antagonista logra o no alterar el comportamiento del agonista.

Tenemos entonces tres tipos de información que "delatan" la presencia de un hablante que enmarca los EC en el discurso desde su posición subjetiva: información sobre el actante categorial $^{6}$ focalizado (agonista o antagonista); sobre el aspecto del EC; y sobre el balance

6 Entiendo por actante categorial cada entidad "protagonista" de una supra-categoría semántico-nocional o de una macro-categoría semántica modal. En este caso, se refiere a las entidades participantes en un EC: agonista y antagonista. Para la MSM de valoración, serían el sujeto valorador y el objeto de la valoración; para interés, sería el sujeto interesado y el objeto de interés, etc. Los llamo actantes categoriales para distinguirlos de lo que 
final del EC. Toda esta información sugiere que estamos en presencia de algo mayor que un simple grupo de rasgos en la dimensión referencial.

La hipótesis que propongo considerar es la siguiente: La causalidad constituye una supra-categoría semántico-nocional (SSN).

Primeramente, es necesario explicar la terminología. ¿Por qué "semántico-nocional”? Porque estamos tratando con una región de la estructura conceptual que sirve para organizar tanto el contenido del pensamiento como el significado lingüístico. La problemática de la relación lenguaje-pensamiento-realidad se encuentra entonces en la base misma de esta investigación.

También debo explicitar qué entender por causalidad. De acuerdo con el modelo que propongo, y tratando de asegurarle la mayor aplicabilidad posible, entiendo por relación causal cualquier conceptualización lingüisticamente estructurada de una interacción entre dos entidades, de las cuales una exhiba un comportamiento en función de afectar la cualidad, cantidad / intensidad, comportamiento o estado de la otra (lo que en la TDS llamamos rasgos constitutivos).

La hipótesis anterior también tiene como consecuencia que las nociones que constituyen los nodos del modelo (Fig. 1) no sean atómicas, sino que tengan una estructura interna. Siguiendo a Talmy (1985), y luego a Jackendoff (2002), propongo estructurar los EC por medio de funciones de forma predicativo-argumental, que tomo como primitivas no descomponibles, y que divido en dos grupos: las funciones nucleares y las funciones complementarias.

Las funciones nucleares, como su nombre indica, estructuran el núcleo de la SSN de causalidad. Éstas son CAUS, LET y HELP.

- $\operatorname{CAUS}(\mathrm{x}, \mathrm{y})$ : El antagonista afecta al agonista. En la función, $\boldsymbol{x}$ es el antagonista, y $\boldsymbol{y}$ es una función complementaria.

- $\operatorname{LET}(\mathrm{x}, \mathrm{y})$ : El antagonista no se opone al agonista. Las variables toman los mismos valores que en $C A U S$.

- $\operatorname{HELP}(\mathrm{x}, \mathrm{y})$ : El antagonista refuerza la tendencia del agonista. Las variables toman los mismos valores que en CAUS y LET.

Las funciones complementarias ${ }^{7}$ son funciones básicas de la estructura conceptual que, en combinación con las funciones nucleares, permiten construir los EC. Las que propongo utilizar son BE, GO, STAY y CAMINO.

- $B E(\mathrm{x}, \mathrm{y})$ : (Categoría ontológica: Estado) Es la conceptualización de una configuración estática que se puede ubicar en un punto del tiempo o a lo largo de un período de tiempo.

- $G O(\mathrm{x}, \mathrm{y})$ : (Categoría ontológica: Evento) Es la conceptualización del evento en que $\boldsymbol{x}$ recorre $\boldsymbol{y}$. En la función, $\boldsymbol{x}$ toma los mismos valores que en $B E, \mathrm{y} \boldsymbol{y}$ es un Camino.

tradicionalmente se ha llamado actantes en las teorías de valencia. Estos actantes categoriales pueden realizarse como actantes (en el sentido tradicional), por ejemplo, como agentes, objetos, pacientes, experientivos, etc.

7 Esto no significa que las funciones en cuestión sean esencialmente complementarias, sólo que es ése su rol en este modelo. Es perfectamente posible, incluso probable, que funciones como GO, CAMINO y STAY sean funciones nucleares de una hipotética SSN de movimiento, por ejemplo, y que CAUS, LET y HELP tengan allí un rol complementario. El tratamiento de estas funciones ha sido tomado de Jackendoff (2002), pp. 394 en adelante. 
- $\operatorname{CAMINO}(\mathrm{w}, \mathrm{z})$ : (Categoría ontológica: Camino) En la versión de la función con la que estoy trabajando, $\boldsymbol{w}$ es el Origen y $\boldsymbol{z}$ es el Destino.

- $\operatorname{STAY}(\mathrm{x}, \mathrm{y})$ : (Categoría ontológica: Evento) Es la conceptualización de una configuración estática que se mantiene a lo largo de un período de tiempo. Las variables toman los mismos valores que en $B E$; de hecho, esta función es la "versión" eventiva de $B E$ (estativa).

A estos dos grupos de funciones es necesario también añadir operadores lógicos como NOT, que forman igualmente parte de la estructura conceptual, y que utilizamos aquí para modelar algunos EC.

$\mathrm{Al}$ relativizar, como hace Jackendoff, estas funciones complementarias por campo semántico (¿quizás "campo nocional” sería más apropiado?), se especifica el rango o tipo de valores que pueden tomar las variables (argumentos). Tomando como ejemplo la función $B E(\mathrm{x}, \mathrm{y})$, si la relativizamos al campo del espacio, $\boldsymbol{x}$ sería un Objeto, y $\boldsymbol{y}$ una Localización; en el campo de la posesión, $\boldsymbol{x}$ sería un Objeto, y $\boldsymbol{y}$ una persona que lo posee; en el campo de la atribución, $\boldsymbol{x}$ sería cualquier cosa, y $\boldsymbol{y}$ una Propiedad o Categoría a la que $\boldsymbol{x}$ pertenece.

Los principales EC del modelo quedarían entonces estructurados como sigue:

- Impulso: CAUS (Ant, GO (Ag, y))

- Contención: CAUS (Ant, STAY (Ag, y))

- Permisión: $L E T$ (Ant, GO (Ag, y))

- Inercia: NOT-CAUS (Ant, GO (Ag, y))

- Causación incoativa: CAUS (Ant, BE (Ag, y))

- Ayuda: HELP (Ant, GO (Ag, y)) - HELP (Ant, STAY (Ag, y))

- Persistencia: NOT-LET ( $\mathrm{Ag}_{\mathrm{i}}$, CAUS (Ant, STAY $\left.\left.\left(\mathrm{Ag}_{\mathrm{i}}, y\right)\right)\right)$

- Resistencia: NOT-LET (Ag,,$\left.C A U S\left(\mathrm{Ant}, G O\left(\mathrm{Ag}_{\mathrm{i}}, y\right)\right)\right)$

Nótese que he conservado el rasgo de causación que propone Caballero, pero aquí sólo se refiere a lo que he elegido llamar causación incoativa, esto es, de cambio de estado o, como lo llama Caballero, de hacer-ser. Los demás sustituyen y expanden el resto de las participaciones operacionales (manipulación, concesión, control, experimentación de la operación). Nótese también que, al contrario de los estudios tradicionales sobre la causalidad, en los que se habla de tipos de causalidad o de relaciones causales siempre en función del comportamiento del antagonista (causación, permisión, control, etc.), el modelo que propongo toma también en cuenta el comportamiento del agonista, y permite hablar de EC como persistencia o resistencia que, como lo veo yo, son también tipos de relaciones causales. Esto es precisamente lo que Caballero intentó hacer en la TDS con el rasgo relacional de experimentación de la operación.

También es conveniente contar con definiciones formales de los actantes categoriales de esta SSN. Podemos definir el agonista como una entidad participante en un escenario causal, que el emisor del discurso identifica como poseedora de una tendencia intrínseca al movimiento o al reposo. Por su parte, el antagonista sería una entidad participante en un escenario causal, que el emisor del discurso identifica como exhibidora de un comportamiento dirigido a afectar la cualidad, cantidad / intensidad, comportamiento o estado del agonista. 
La relación lógica entre ambas entidades es de presuposición. Agonista y antagonista sólo son tales en presencia uno del otro; es lógicamente imposible concebir un antagonista sin un agonista al que afectar, o un agonista sin un antagonista que lo afecte. Incluso en escenarios de inercia o de permisión, en los que el antagonista no afecta al agonista, el primero está presente y exhibe un comportamiento en función del segundo.

Más problemático es un enunciado como La revolución es imparable, en el que aparentemente se señala la ausencia de antagonista. Sin embargo, un análisis más detenido revela que, en la interpretación correcta (desde un punto de vista descriptivo, por supuesto, y no normativo), el antagonista se construye como una variable ligada por un cuantificador universal $(\forall x[\neg \diamond \text { parar }(x, r e v)])^{8}$, y cualquier entidad que satisfaga su valor participará como antagonista en un escenario de persistencia. El enunciado podría entonces parafrasearse como Nada de lo que existe es capaz de parar la revolución, o quizás de manera más precisa, Todo lo que existe es incapaz de parar la revolución. Vale señalar que, al parafrasear, hemos cambiado de actante categorial focalizado (del agonista al antagonista).

Según lo visto hasta ahora, tenemos cinco grupos de rasgos semánticos que son relevantes para el análisis de la SSN de causalidad, y que defino a continuación:

Rasgos de actante: Grupo de dos rasgos (agonista y antagonista) mutuamente excluyentes que reflejan el actante categorial que se focaliza en la VLS o en el enunciado para presentar el EC desde su punto de vista.

Rasgos de aspecto: Grupo de rasgos mutuamente excluyentes (aquí dos, télico y atélico, pero es posible concebir otras posibilidades como iterativo, por ejemplo) que reflejan la distribución en el tiempo del EC: atélico, si el EC se presenta como una situación, una configuración estática en la que el agonista y el antagonista siempre han existido juntos; o télico, si se presenta el momento en que el antagonista entra o sale del EC, o el momento en que se resuelve la tensión entre los dos.

Utilizo aquí los términos télico y atélico entendiéndolos según la propuesta, ya estándar, de Krifka (1998). Los EC atélicos serán aquellos para los que cualquier subparte de la eventualidad que describa el EC sea también una instancia del mismo EC (contribuir, intimidar, persistir, resistir). Por el contrario, los EC télicos sólo serán verdaderos de la eventualidad total que los describe, y no de ninguna de sus subpartes (ceder, claudicar, convencer, obligar). Como señalaba antes, esta concepción se corresponderá, en principio, con la oposición estático $: \because$ dinámico de Talmy (1985).

En dependencia del objeto del análisis (VLS aisladas o enunciados), debe cambiar el tipo de aspecto que se considera. Así, para las VLS aisladas estaremos hablando sobre todo de aspecto lexical, y de aspecto gramatical (composicional y morfológico) para los enunciados. De manera general, el tipo de aspecto a considerar dependerá de si el análisis semántico se circunscribe al sistema de la lengua (donde el aspecto está determinado por la naturaleza de la eventualidad) o al discurso (donde depende más de las elecciones del hablante).

8 Nótese el uso del operador para indicar la modalidad alética de imposibilidad, obtenida en este caso por la suma de los significados del sufijo - able y del prefijo -im. Esto es necesario para distinguir esta formulación de otra posible pero incorrecta, a saber, Nada de lo que existe está ahora parando la revolución. Estoy ignorando aquí la estructura del EC de contención que construye el verbo parar (pero ver anexo). 
Rasgos de balance final: Grupo de seis rasgos mutuamente excluyentes (éxito, fracaso, balance ambivalente, no éxito, no fracaso y balance ambiguo) que reflejan el balance final del EC: si el antagonista logra o no afectar al agonista, o si el agonista logra o no realizar su tendencia. Este grupo de rasgos se obtienen a partir de una modelación sobre trapecio semiótico, como muestra la figura 2.

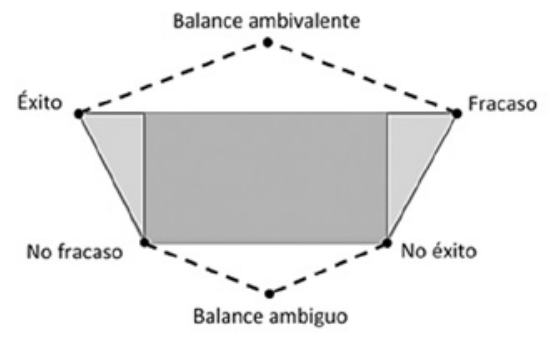

Es importante no axiologizar los contrarios y contradictorios, para no confundirnos con la MSM de valoración. Aunque los he llamado éxito y fracaso (o en el caso de cualquiera de los otros), estos nombres elegidos por conveniencia no deben interpretarse como portadores de una intención valorativa intrínseca: un éxito puede estar valorado como negativo ([2]), y un fracaso como positivo ([3a], [3b]).

No hay que confundir esta noción de balance final del EC con la de resultado del evento, utilizada en el análisis aspectual. Esta última se refiere a la relación que se establece entre un evento, el pre-estado que destruye, y el post-estado que crea9 ${ }^{9}$. La relación entre el evento y el post-estado es también causal, y se encuentra en la base de lo que aquí he llamado causación incoativa, o simplemente causación.

Rasgos de escenario: Grupo de doce rasgos (causación, movimiento, persistencia, obstáculos, contención, permisión, reposo, resistencia, fuerza, impulso, inercia y ayuda), no necesariamente excluyentes, que reflejan el EC en el que participa el actante focalizado, o el comportamiento de éste en un EC.

Rasgos de campo: Grupo de rasgos que relativizan los valores que pueden tomar los argumentos de las funciones que estructuran los EC. Constituyen un conjunto abierto, que podrá aumentarse según el nivel de discretización al que se aspire. Los principales serían espacio, tiempo, atribución, posesión, y psicológico. Este último es particularmente susceptible de subdividirse, ya que el valor que especifica para la variable $\boldsymbol{y}$ es uno de máxima generalidad, a saber, Estado Mental. Algunas subdivisiones posibles serían emocional, epistémico, volitivo, atencional, etc.

Estos cinco grupos de rasgos pueden sistematizarse en una matriz semántica, como en el análisis que se incluye en anexo, y que comento en la sección siguiente.

\section{Un ejemplo del modelo en uso}

A modo de ejemplo de la aplicación de este modelo, he querido incluir y comentar aquí un análisis de una pequeña muestra de 31 VLS aisladas que construyen EC, que deberá

9 J. Moeschler: op. cit., p. 135. 
servir para ilustrar las propuestas de este trabajo. Las definiciones lexicográficas con las que trabajé fueron tomadas del Diccionario de uso del español María Moliner (ver anexo 1).

Lo primero que hay que notar en este análisis es que muchas de las VLS consideradas son susceptibles de activar varios rasgos dentro de un mismo grupo. Tal es el caso, por ejemplo, de ceder $_{1}$, chantaje, convencer, exhortar, mover, prudente o testarudo. Esto se debe a que, en el sistema de la lengua, estas VLS están subespecificadas: poseen un rango de valores posibles, pero esa ambigüedad sólo se resuelve en el discurso. Cuando se realizan en enunciados completos, sí es posible determinar con exactitud los rasgos que se activan. Por ejemplo, convencer puede activar los rasgos de [+CONTENCIÓN] o [+IMPULSO] (entre otros); tomándola aislada, es imposible determinarlo. Sin embargo, si tomamos un enunciado como Lo convencí de que lo hiciera, se hace evidente que el EC que se construye es uno de impulso (mover a la acción, hacer-hacer).

Esta subespecificación también se refleja en los rasgos de campo. Para algunas VLS, la sección de rasgos de campo aparece sombreada. Esto significa que no es posible determinar cuál(es) de ellos se activan, pues la unidad aislada no lo especifica. Es así con contribuir, insuperable, irresistible, liberar, permitir o resistir. Otro caso es el de la VLS forzar ${ }_{2}$, que tampoco especifica un rasgo de campo, pero por razones distintas: en este caso, la VLS se refiere al comportamiento del antagonista (fuerza) en un EC, y no al EC completo. Como la variable $\boldsymbol{y}$ (cuyo valor debe relativizar el rasgo de campo) está en función del agonista, y al no considerarse aquí el agonista (aunque exista, recordemos que uno y otro se presuponen), tampoco es posible activar un rasgo de campo. En el caso de parar, el rasgo de campo podría ser [+ESPACIO], como en parar un tren, o [+TIEMPO], como en parar la huelga.

Las VLS ceder, y permitir ilustran el uso que hago de la noción de balance final y de los rasgos que le corresponden, así como también la diferencia entre ésta y la noción de resultado del evento, a la que hacía referencia arriba. En ceder ${ }_{l}$, lo que se focaliza es el fracaso del agonista al no realizar la tendencia intrínseca (reposo, entendido en el campo nocional psicológico o epistémico) que en él percibe el emisor de discurso. Independientemente del pre-estado que el evento de ceder, destruya y el post-estado que cree (que por demás no parecen evidentes), sigue siendo un hecho que el agonista de esta VLS no logra realizar su tendencia intrínseca. En el caso de permitir, se focaliza el fracaso, esta vez del antagonista, al no afectar la cualidad, cantidad / intensidad, comportamiento o estado del agonista. Aquí es también difícil ver cuáles serían el pre-estado y el post-estado del evento de permitir (¿agonista contenido y agonista libre?); sin embargo, el balance final del EC sí es determinable.

En otra línea, no muy alejada de ésta, las dos VLS anteriores contienen información sobre la intencionalidad (carácter deliberado) del comportamiento de los actantes categoriales: tanto ceder ${ }_{1}$ como permitir denotan acciones que, típicamente, se realizan de manera intencionada. Existen estudios ${ }^{10}$ sobre la construcción causativa en inglés que, tomando en cuenta la escala a la que se considera el evento, y los sub-eventos que se ignoran, sólo acepta verbos que se refieran a eventos causados de manera directa e intencionada. Lo que no queda claro es cómo esa intencionalidad se codifica en el significado del verbo y qué consecuencias tiene en la interpretación. Exactamente cuán relevante es esta información para el estudio de la SSN de causalidad en el sistema de la lengua (más allá de las restricciones de la construcción causativa) y en el discurso, es algo que habrá que determinar en futuras etapas de la investigación.

10 Por ejemplo, los de Wolff (2003), citados y comentados en Pinker (2008:107). 
También merecen comentario los pares de VLS prudente / cobarde y persistente / testarudo. En la matriz, estas VLS aparecen compuestas por los mismos rasgos (aunque testarudo puede, alternativamente, activar [+RESISTENCIA]), ya que denotan respectivamente los mismos comportamientos. La diferencia en la connotación (positiva para la primera VLS de cada par, negativa para la segunda) se resuelve al considerar la interacción de la SSN de causalidad y la MSM de valoración. Con las primeras VLS, el emisor de discurso hace una valoración apreciativa positiva del comportamiento de un agonista en un EC, mientras que con las segundas esta valoración es negativa ${ }^{11}$.

Otra interacción a considerar es la que se establece en la VLS convencer entre la SSN de causalidad y la MSM de certidumbre. Cuando esta VLS construye un EC de impulso, estructurado como CAUS (Ant, GO (AG, y)), y donde $\boldsymbol{y}$ es un Camino, las variables $\boldsymbol{w}$ y $\boldsymbol{z}$ (Origen y Destino) pueden corresponderse con las nociones contrarias que estructuran la MSM de certidumbre, a saber, los atributos modales indeciso y decidido para la perspectiva volitiva, e inseguro y seguro para la perspectiva cognoscitivo-discursiva ${ }^{12}$. El impulso puede entonces entenderse como "hacer ir de la indecisión a la decisión" (convencer a alguien de hacer algo) con un rasgo de campo [+PSICOLóGICo] (específicamente, [+volitivo]), o como "hacer ir de la inseguridad a la seguridad" (convencer a alguien de algo) con un rasgo de campo [+EPISTÉMICo]. La realización de la SSN de causalidad en las distintas MSM constituye el objeto de estudio principal de mi investigación actual.

Finalmente, la VLS liberar construye lo que he elegido llamar un escenario causal complejo (ECC), en el que un mismo actante categorial participa simultáneamente en dos EC. Como esta noción de ECC es también uno de los objetos de esta investigación en curso, el análisis que aparece en la matriz (dos filas, una para cada EC) es sólo tentativo.

\section{Conclusiones}

He señalado algunas limitaciones de la teoría dimensional del significado de L. Caballero, concretamente, limitaciones expresivas de los rasgos relacionales de la dimensión referencial, y he propuesto un modelo de escenarios causales, basado en la dinámica de fuerzas y modelado sobre trapecios semióticos. Además, he propuesto considerar la causalidad como una supra-categoría semántico-nocional, para la que he señalado tres aspectos que los hablantes toman en cuenta al enmarcar los escenarios causales en el discurso, y he incluido un ejemplo de análisis utilizando este modelo.

Éstos son sólo resultados preliminares de una investigación en curso que podría encontrar aplicaciones, por ejemplo, en el análisis del discurso político y/o periodístico — ¿qué nos dice la manera de construir y enmarcar un EC sobre la ideología del emisor?-, o en el análisis del discurso literario, en el que los EC pueden construir la estructura semántica narrativa.

11 Para un estudio más profundo de las MSM, y de valoración en específico, el lector interesado podrá consultar los trabajos referenciados del Dr. Leandro Caballero y de la Dra. Ana Ma. Galbán.

12 La perspectiva volitiva de la MSM de certidumbre refleja «el carácter de las actitudes (definidas vs indefinidas o dudosas) de los individuos en relación con los comportamientos a asumir» (Galbán Pozo, 2003:58). En la perspectiva cognoscitivo-discursiva «el hablante muestra en su discurso el grado de seguridad en relación con el conocimiento que tiene acerca de lo dicho» (Galbán Pozo, 2003:51). 


\section{Referencias bibliográficas}

Caballero, L. (2014): Semántica y diccionario. La Habana, Editorial de Ciencias Sociales.

- (2002): "Modalidades semánticas del lenguaje". En: Estudios lingüísticos cubanos (II) Homenaje a Leandro Caballero Díaz, Universitat de València, pp. 137-160.

Cuenca, M. J. y Hilferty, J. (1999): Introducción a la lingüística cognitiva, Barcelona, Editorial Ariel, S.A.

Galbán Pozo, A. Ma. (2003): “Aproximación al estudio de las macro-categorías semánticas modales (valoración, lealtad, certidumbre, interés, afectividad y expresividad) y su expresión a través de verbos de las lenguas española y alemana". Tesis de doctorado, La Habana.

Greimas, A. J. (1965): La sémantique structurale, París, Larousse.

Jackendoff, R. (2002): Foundations of Language, New York, Oxford University Press.

Krifka, M. (1998): “The Origins of Telicity". En: S. Rothstein (ed.): Events and grammar, Dordrecht, Kluwer Academic Press: http://amor.rz.hu-berlin.de/ h2816i3x/Publications/ TELICITY.pdf (06-06-2015).

María Moliner. Diccionario de uso del español. Edición electrónica, versión 3.0. Editorial Gredos, Madrid, 2008.

Moeschler, J. (2009): Introduction à la linguistique contemporaine, París, Armand Colin.

Pinker, S. (2008): The Stuff of Thought: Language as a Window into Human Nature, New York, Penguin Books.

Talmy, L. (1985): "Force-Dynamics in Language and Thought". Citado en Jackendoff (2002) y Pinker (2008).

Wolff, P. (2003): "Direct causation in the linguistic coding and individuation of causal events". En: Cognition, 88, pp. 1-48. Citado en Pinker (2008).

Wong, E. (2014): "Primer acercamiento al estudio de la macro-categoría semántica modal de interés en la lengua española". (Inédito) 


\section{Anexo 1: Muestra de variantes léxico-semánticas (VLS) aisladas \\ Fuente lexicográfica: María Moliner. Diccionario de uso del español.}

Boicotear: Privar a alguien, particularmente a una empresa industrial, de las relaciones o medios que necesita, para obligarle a ceder en cierta cosa.

Ceder ${ }_{1}$ : Cesar en una actitud de resistencia u oposición; por ejemplo, en una discusión o en una lucha.

Ceder $_{2}$ : Ponerse una cosa menos tensa o resistente. Romperse o soltarse algo sometido a una fuerza excesiva.

Chantaje: Procedimiento para conseguir algo que se pretende de una persona, amenazándola, particularmente con la difamación, si no accede a ello.

Claudicar: Ceder, rendirse o someterse; abandonar el esfuerzo o la resistencia en una empresa.

Coaccionar: Ejercer coacción sobre alguien para que haga cierta cosa.

Coacción: Cualquier procedimiento violento con que se obliga a alguien a hacer una cosa.

Cobarde: Se aplica a la persona que siente mucho miedo en los peligros o que no se atreve a exponerse a ellos, y, correspondientemente, a sus acciones, actitud, etc.

Coercer: Impedir a alguien que haga cierta cosa.

Coerción: Acción de reprimir por la fuerza.

Contribuir: Ser, junto con otras personas o cosas, causa de un suceso.

Convencer: Conseguir con razones que alguien se decida a hacer cierta cosa. Conseguir que alguien crea o piense cierta cosa.

Desistir: Abandonar cierta intención o proyecto, por necesidad, por convencerse de su imposibilidad o por cualquier consideración.

Exhortar: Inducir a alguien con palabras, razones o ruegos a que haga o deje de hacer una cosa.

Forzar $_{1}$ : Obligar a alguien, mediante la fuerza o cualquier clase de coacción, a que haga cosa contra su voluntad.

Forzar ${ }_{2}$ : Aplicar la fuerza a una cosa para hacer con ella cierta operación.

Forzar $_{3}$ : Esforzarse en que las cosas ocurran de manera distinta de como lo harían de manera natural, o más rápidamente.

Forzar $_{4}$ : Abrir algo, como una cerradura, una puerta o un cajón, por la fuerza.

Imparable: Que no se puede parar (ver infra).

Inamovible: No movible (ver mover).

Insuperable: No superable (ver superar).

Intimidar: Reducir a alguien a la acción por el temor.

Irresistible: Se aplica a lo que es imposible o inútil oponerle resistencia.

Liberar: Dejar libre algo o a alguien que estaba sujeto o preso.

Mover: Ser causa de que alguien haga cierta cosa, o contribuir a ello.

Obligar: Hacer que alguien realice cierta cosa usando para ello la fuerza o la autoridad o haciendo en cualquier forma que no tenga otro remedio que hacerla.

Parar: Hacer cesar un movimiento o una acción cualquiera. Detener una cosa oponiéndose a ella, antes de que llegue a su destino.

Permitir: No oponerse algo o alguien a que se realice u ocurra cierta cosa o a que alguien haga lo que se expresa.

Persistente: Que persiste.

Persistir: Seguir en cierta actitud u opinión.

Prudente: Aplicado a personas, a sus actos, palabras, se aplica al que obra con prudencia. Al que previene los peligros o los evita.

Prudencia: Moderación en el comportamiento para acomodarlo a lo que es sensato, discreto o exento de peligro.

Rendirse: Dejar de oponer resistencia en la guerra, en una lucha o en una discusión.

Resistir: No dejarse mover o influir por una fuerza u otra cosa.

Testarudo: Se aplica a la persona difícil de convencer, aun con razones convincentes, o a la que no se puede hacer desistir de cierta actitud. 


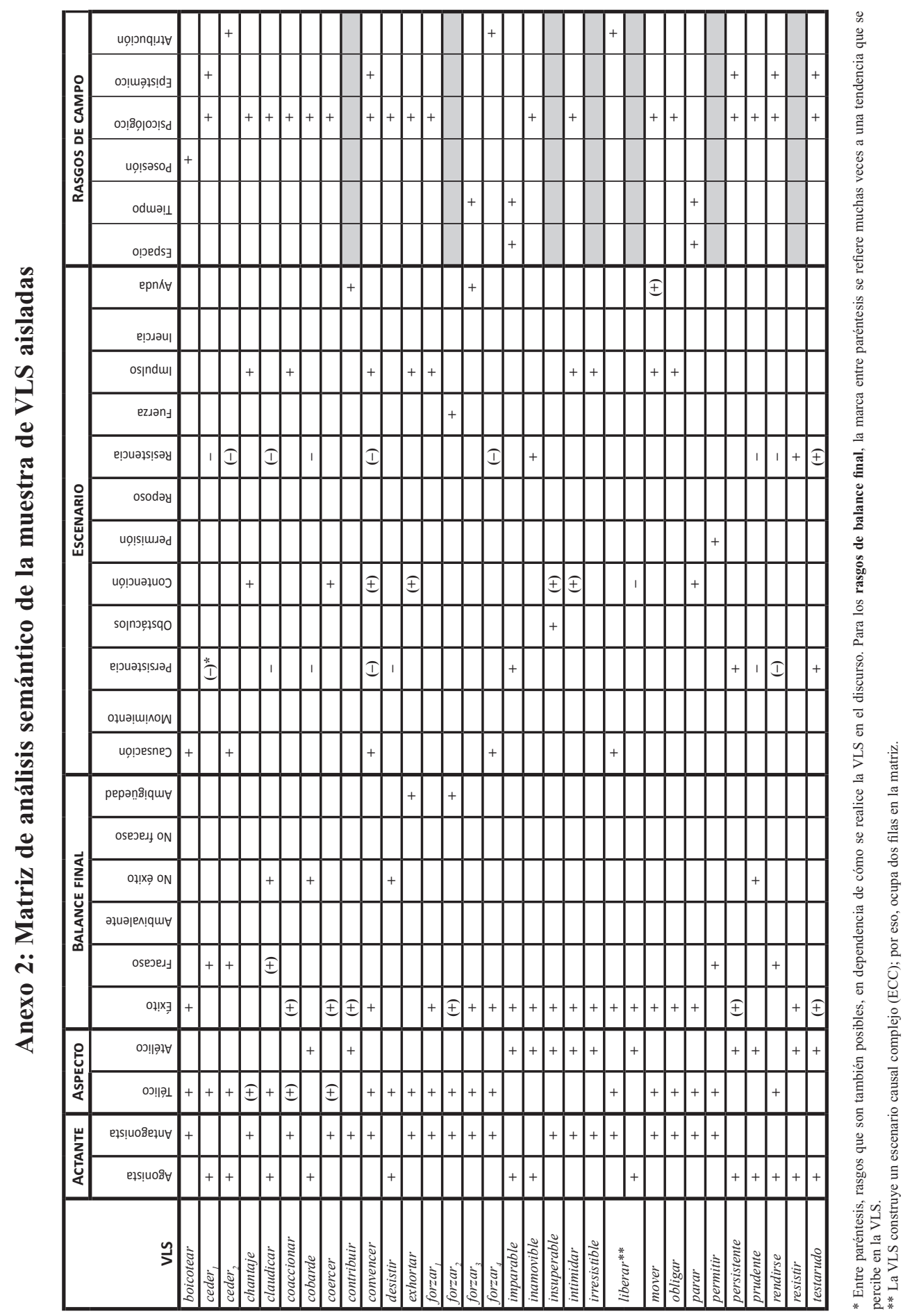




\title{
ANÁLISIS COMPARATIVO DE LA MANIPULACIÓN FRASEOLÓGICA EN LAS LENGUAS CHINA Y ESPAÑOLA
}

\author{
WU FAN \\ Guangdong University of Foreign Studies \\ patiwu@yahoo.com
}

Recibido: 27/04/2015

Aceptado: 02/09/2015

\begin{abstract}
Resumen
Las unidades fraseológicas tanto en chino como en español presentan diversos tipos de manipulación creativa en el discurso para conseguir determinados efectos expresivos. El presente trabajo pretende analizar los procedimientos frecuentes de la modificación fraseológica de la lengua china para comparar con la fraseología española, a fin de poner de manifiesto sus coincidencias y diferencias. Se distinguen dos grupos principales: las modificaciones formales que afectan a la estructura sintáctica de una unidad fraseológica, las cuales comprenden los procedimientos como la adición, reducción, sustitución, modificación gramatical, fusión y combinación de diferentes modificaciones; y las modificaciones semánticas que afectan al significado canónico de la unidad, que son la doble actualización y la literalización.

PALABRAS CLAVE: unidad fraseológica, manipulación creativa, modificación formal, modificación semántica, chino.
\end{abstract}

\begin{abstract}
Phraseological units both in Chinese and Spanish may appear with different kinds of speech in order to achieve specific expressive effects. In this paper we try to analyze frequent procedures of phraseological changes in Chinese so as to compare it with Spanish phraseology. We wish thus to discover their coincidence and difference. We have two main groups: the formal changes that influence the syntactic structure of a phraseological unit which include procedures such as addition, reduction, substitution, grammar changes, fusion and combination of different modifications, and the different semantic modifications which influence the canonic meaning of a unit, i.e. double actualization and literalization.
\end{abstract}

KEYWORDS: phraseological unit, creative manipulation, formal modification, semantic modification, Chinese

\section{Introducción}

Tanto en chino como en español las unidades fraseológicas (en adelante: UFs) se caracterizan por presentar distintos grados de fijación y estabilidad; no obstante, en aparente contradicción con lo anterior, dichas unidades permiten ciertas manipulaciones conscientes y voluntarias al ser insertadas en el discurso, a fin de conseguir determinados efectos expresivos (Wang, 1987; Sun, 1989; Corpas Pastor, 1996). Se trata de la manipulación o modificación creativa intencionada de una unidad fraseológica (en adelante: UF), por medio de la cual el hablante libera al lenguaje de su automatismo y con la que persigue conseguir determinados efectos discursivos, tales como el expresivo, sorpresivo, humorístico, etc. (Montoro del Arco, 2006: 43). El filólogo chino Wang (1987: 23), por su parte, señala que la 
manipulación creativa de las UFs en el discurso puede presentar diversos tipos (sustitución, adición, reducción, cambio de orden de los componentes, etc.); y, a través de los cuales se consiguen efectos expresivos, humorísticos, estilísticos, etc.

Esta variabilidad fraseológica ha sido identificada con diversos términos: modificación (Corpas Pastor, 1996), deslexicalización (García-Page, 1989), ruptura (Guerra Salas, 1997), manipulación (Corpas Pastor, 1996; Álvarez de la Granja, 1999; Montoro del Arco, 2003), desautomatización ${ }^{1}$ (Zuluaga, 1997; Ruiz Gurillo, 1997; Mena Martínez, 2003), etc. Pese a la confusión terminológica existente para referirse a esta variabilidad fraseológica, en adelante emplearemos indistintamente las denominaciones modificación, manipulación y desautomatización, puesto que son las más usadas por parte de la mayoría de los investigadores sobre la materia.

Por lo que concierne a la aplicación de la manipulación o modificación creativa, cabe señalar que muchos investigadores han destacado su existencia en las UFs de diferentes lenguas. Entre ellos, Tannen (1987) afirma que, en la lengua inglesa, es común la modificación de una UF en su forma canónica. De la misma manera, Corpas Pastor (1996) señala que estas modificaciones no son casos aislados y ocasionales, ni usos incorrectos, sino más bien constituyen una característica de las UFs, ya que muchas unidades manifiestan algún tipo de manipulación creativa en contexto.

Lo mismo ocurre en la fraseología china ${ }^{2}$, pues abundan los casos de las UFs modificadas creativamente en los textos publicitarios, literarios y periodísticos. Sin embargo, a pesar de su recurrencia en el discurso, cabe subrayar la escasez de trabajos sobre este tema, y entre los cuales, la mayoría se centra en los chengyu. Por otro lado, algunos investigadores consideran que se trata de un uso creativo de las UFs para fines expresivos, y otros lo critican señalando que estas manipulaciones, especialmente en textos publicitarios, no dejan de ser la contaminación o desviación ${ }^{3}$ de estas unidades.

Ahora bien, nos enfrentamos a dos cuestiones interesantes del tema: la que relaciona el tipo de UF con el grado de modificación y la que establece conexiones entre los géneros textuales y la frecuencia de aparición de la manipulación creativa.

Con respecto a la primera cuestión, en la lengua española, el texto periodístico es el género que más explota la potencialidad de los diferentes tipos de modificación fraseológica; también se dan modificaciones frecuentemente en los medios de comunicación de masas, en los textos

1 La desautomatización es un término rescatado por Zuluaga (2001: 76) de los formalistas rusos, quienes "hablan del arte como procedimiento o artificio que libere al lenguaje, y a los medios de expresión en general, de sus automatismos, de su cotidianidad monótona y refuerce la percepción”. Por su parte, Mena Martínez (2003: 5) la define como un "proceso que se desencadena en algunas UFs cuando se les ha aplicado de forma intencionada cualquier procedimiento de manipulación o modificación creativa".

2 La fraseología china (shuyu) distingue entre chengyu, guanyongyu, xiehouyu, yanyu y geyan. Chengyu es una combinación de palabras fijas, convencional, concisa y compendiosa y, en la mayoría de las ocasiones, de cuatro caracteres. Correspondería a "locución", "frase hecha" o "modismo" en español. Guanyongyu es una combinación de palabras fija y breve del lenguaje coloquial, y correspondería a "modismo" en español. Xiehouyu es un dicho alegórico compuesto de dos partes. La primera describe algo metafóricamente y la segunda es una explicación o declaración de la primera parte. Se trata de una forma especial de unidad fraseológica en chino, que no tiene correspondencia en la lengua española. Yanyu es un dicho breve, popular y significativo. Correspondería a "refrán", "dicho" o "proverbio" en español. Geyan es una sentencia concisa, con sentido amonestado y didáctico, y correspondería a "máxima", "aforismo" o "adagio" en español (véase Wu, 2014).

3 Estos dos términos hacen referencia a las realizaciones incorrectas que los hablantes producen por distintas causas, como el nerviosismo, o la inmediatez del discurso (Mena Martínez, 2003). 
argumentativos y en la publicidad (Corpas Pastor, 1996). De la misma manera, en chino también se encuentran muchos casos en textos literarios, en prensa y en publicidad, (Wu, 2014).

En cuanto a qué tipos de UFs afectan las modificaciones creativas, se puede decir que a todas. En la lengua española quizás destaquen las paremias (fundamentalmente refranes) y locuciones (Corpas Pastor, 1996). Mena Martínez (2003), por su parte, afirma que la mayor parte de los estudios que se han realizado sobre las modificaciones escogen como ejemplos las locuciones, por ejemplo, Barz (1986), Wotjak (1992), y también los refranes, caso de Corpas Pastor (1998) y Sabban (1998). En la lengua china, posiblemente sean los chengyu y guanyongyu las UFs más proclives a sufrir estas manipulaciones ${ }^{4}$. En cuanto a los enunciados fraseológicos, los xiehouyu y yanyu son más propensos a presentar esta modificación, mientras que los geyan cuentan con una mayor estabilidad tanto formal como semántica en contexto (Sun, 1989).

\section{Tipos de modificaciones fraseológicas}

Como hemos mencionado anteriormente, tanto en chino como en español abundan las modificaciones fraseológicas en el discurso, especialmente en textos literarios, periodísticos y publicitarios, donde se puede encontrar un variado abanico de procedimientos que ayuda a realzar la expresividad de las UFs. A continuación vamos a estudiar los principales tipos de manipulaciones creativas en ambas lenguas, siguiendo parcialmente los propuestos por Corpas Pastor (1996) para la lengua española.

Antes de empezar, entre diversos tipos de modificaciones fraseológicas efectuadas a las UFs chinas en el discurso, distinguiremos entre dos grupos generales: modificaciones creativas formales y modificaciones creativas semánticas. Las primeras afectan a la estructura formal de una UF con posibles consecuencias semánticas, y las segundas alteran el contenido semántico y no la estructura formal de una UF. Puesto que dicho tema ya ha sido investigado con detenimiento en diversos trabajos en la lengua española, en el presente trabajo solo citaremos ejemplos en chino. Aquí cabe mencionar que la traducción de las UFs y los fragmentos en chino es nuestra, excepto los textos extraídos de la obra Wei cheng ( $\mathrm{La}$ fortaleza asediada) traducida por Taciana Fisac (2009).

\subsection{Modificaciones formales}

Las modificaciones formales hacen referencia a aquellas manipulaciones intencionadas que se producen visiblemente en la estructura formal de la UFs, con posibles consecuencias semánticas.

Corpas Pastor (1996) afirma que en español predominan las modificaciones externas de carácter semántico. Sin embargo, en la lengua china los dos tipos de manipulación creativa se presentan como protagonistas según distintas clases de UFs; es decir, las modificaciones formales abundan en los guanyongyu y xiehouyu, y las semánticas suelen aparecer en los chengyu, yanyu y geyan.

4 Basándonos en la clasificación propuesta por Sun (1989) para la fraseología china y la propuesta por Corpas Pastor (1996) para la española, distinguimos las unidades fraseológicas chinas entre sintagmas fraseológicos (chengyu y guanyongyu) y enunciados fraseológicos (xiehouyu, yanyu y geyan), con el objetivo de facilitar la comparación fraseológica entre ambos idiomas (véase Wu, 2014). 
En cuanto a los tipos de modificaciones formales, se puede afirmar que presentan una amplia gama de posibilidades tanto en chino como en español. De acuerdo con Corpas Pastor (1996) y García-Page (2008), en la lengua española los procedimientos más importantes son la sustitución, la adición y la supresión e incluso la permutación de elementos; en el caso de la lengua china, las más empleadas son la adición, la reducción, la sustitución, la modificación gramatical y la combinación de distintos procedimientos.

\subsubsection{Adición}

La adición consiste en insertar uno o varios elementos externos a una UF sin alterar los componentes originales; mediante esta manipulación se aumenta el significado semántico, así como la expresividad de la unidad institucionalizada. En el siguiente fragmento, sobre la base de la UF 碰钉子 pèng dìngzi, se inserta el nuevo lexema 软 ruăn ('blando') en la unidad originaria para modificar el elemento 钉子 dingzi ('rechazo'), de forma que la unidad modificada软钉子 ruăn dīngzi ('rechazo suave e indirecto') adquiere una nueva información en cuanto al significado traslaticio:

(1) 碰钉子 $\rightarrow$ 碰了个软钉子 pèng dīngzi $\rightarrow$ pèng le ge ruăn dīngzi

[Darse con un clavo] $\rightarrow$ [Darse con un clavo blando]

Sfig.: Ser rechazado.

我停下来, 没有理她。她碰了个软钉子, 轻轻叹了口气。（《建国以来短篇小说 选》，第208页）

Traducción: Me detuve, sin hacerle caso. Al sentirse discretamente rechazada, ella lanzó un suave suspiro. (Antología de novelas cortas desde la fundación de la R. P. China, p. 208)

Lo mismo ocurre en el siguiente ejemplo, sobre la base de la UF 不打不相识 bù dă bù xiāngshí, que mediante la inserción del verbo 成 chéng ('convertirse; hacerse'), consigue precisar y enfatizar el significado de la UF originaria:

(2) 不打不相识 $\rightarrow$ 不打不成相识 bù dă bù xiāngshí $\rightarrow$ bù dă bù chéng xiāngshí

[Sin pelearse no se conocen bien entre sí]

咱们不打不成相识, 以后相处的日子正长, 要好好交个朋友。（《围城》第119页）

Traducción: En cualquier caso, si no hubiera sido por todo lo sucedido no nos hubiéramos conocido, y como en el futuro estaremos juntos, vamos a tener que ser buenos amigos. ( $L a$ fortaleza asediada, p. 193. Trad. Fisac)

En otras ocasiones se inserta un componente en una UF en virtud del cambio de afirmación a negación. En el siguiente fragmento sobre la base de la UF 旁观者清 pángguān zhě qīng, a la cual se añade 未必wèibì ('probablemente no'), se consigue de esta manera que la unidad modificada exprese una interpretación estándar opuesta:

(3) 旁观者清 $\rightarrow$ 旁观者未必清 pángguān zhě qīng $\rightarrow$ pángguān zhě wèibì qīng [Un espectador ve más claro]

Sfig.: Una tercera parte neutral ve el tema en cuestión con más claridad que los litigantes. 这是我作为一个外国人花了十年研究邓小平的一个看法, 旁观者未必请, 反正我是 这么看的。（凤凰网，2014-09-04） 
Traducción: Esta es mi opinión sobre Deng Xiaoping tras diez años de investigación como un extranjero. Aun siendo una persona desinteresada, probablemente no lo veo con más claridad que los demás, pero de todos modos, esta es mi opinión. (Ifeng, 04-09-2014)

\subsubsection{Reducción}

La reducción es el procedimiento opuesto a la adición. Consiste en suprimir algún o algunos componentes de una UF, bien por acortamiento, bien por alusión. Cabe mencionar que esta manipulación creativa es el procedimiento más corriente que usan muchas paremias en ambos idiomas, ya que con solo mencionar una parte se evoca a la unidad entera (Sun, 1989; Corpas Pastor, 1996). Por ello, se pueden encontrar muchas UFs chinas, especialmente los xiehouyu, de los que se suelen enunciar solamente la primera parte y se deja sobrentendida la segunda, como atestigua el siguiente ejemplo:

(4) 泥菩萨过河, 自身难保 $\rightarrow$ 泥菩萨过河 Ní púsà guò hé, zì shēn nán băo $\rightarrow$ Ní púsà guò hé

[El Buda de arcilla vadea el río - es incapaz de salvarse a sí mismo]

此外，英国政府负债率在欧盟主要国家中最高，英国房价下跌速度”欧洲第一”。他 的结论是：英国自身泥菩萨过河，英国媒体还为韩国操心？（《北京周报》200810-29第七版）

Traducción: Además, el gobierno británico tiene el ratio de endeudamiento más elevada entre los principales países de la Unión Europa, y además, las viviendas británicas sufren la mayor caída de precio de toda Europa; por lo cual se ha llegado a la conclusión de que el Reino Unido es incapaz de salvarse a sí mismo, y aun así, ¿sus medios de comunicación pueden preocuparse por Corea del Sur? (Beijing Review, 29-10-2008, 7).

Sin embargo, hemos de tener en cuenta que muchos xiehouyu pueden contar con una variante reducida institucionalizada. En este caso, ya no se trata de una manipulación creativa, tal como ilustran los dos siguientes ejemplos, cuyas formas suprimidas se han institucionalizado y registrado como sintagmas fraseológicos:

(5) a. 空穴来风, 未必无因 $\rightarrow$ 空穴来风 kōng xué lái fēng, wèi bì wú yīn $\rightarrow$ kōng xué lái fèng

[(Si) el viento se cuela por un agujero, tendrá una razón] $\rightarrow$ [por el agujero se cuela el viento]

Equi.: No hay humo sin fuego.

(5) b. 猫哭老鼠假慈悲 $\rightarrow$ 猫哭老鼠 māo kū lăoshǔ jiă cíbēi $\rightarrow$ māo kū lăoshǔ

[El gato llora la muerte del ratón fingiendo tener piedad] $\rightarrow$ [el gato llora por la muerte del ratón]

Equi.: Lágrimas de cocodrilo.

Por otra parte, la reducción por acortamiento no solo es típica de los enunciados fraseológicos, sino que también aparece con frecuencia en otros tipos de UFs, con el fin de revitalizar la imagen y, a la vez, enfatizar la expresividad de dichas unidades. Por ejemplo, en el siguiente fragmento sobre la base de la UF 囫囵吞菄 húlún tūn zăo, se suprime el objeto del verbo杳 zăo ('dátil') y se combina con otro objeto de la cláusula 整块痛苦 ('toda 
la amargura'); y así se resalta que el protagonista se había tragado de golpe toda la amargura sin poder asimilarla:

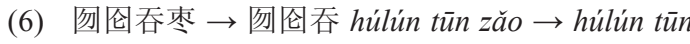

[Tragarse el dátil entero sin masticarlo]

Sfig.: Aceptar o tragar algo sin pensar o reflexionar.

昨天囫囵吞地忍受的整块痛苦, 当时没工夫辨别滋味, 现在, 牛反刍似的, 零星断 续, 细嚼出深深没底的回味。(《围城》第105页)

Traducción: El día anterior se había tragado de golpe toda la amargura, pero en realidad no había tenido tiempo de digerirla, y ahora, como una vaca rumiante, volvía a masticar aquellos pedazos interminables de regusto desagradable. (La fortaleza asediada, p. 168. Trad. Fisac)

Finalmente, la reducción por alusión se puede conseguir manteniendo el significado literal en un primer plano, mientras que la homonimia parcial con la UF y ciertos elementos contextuales permiten la activación simultánea del significado unitario de tal unidad (Corpas Pastor, 1996: 242). Por ejemplo, el siguiente fragmento ilustra el empleo de la UF滥竽充 数 làn yú chōng shù reducida a la secuencia “滥笔 làn yú”, que evoca la unidad completa:

(7) 滥笔充数 $\rightarrow$ 滥笔 làn yú chōng shù $\rightarrow$ làn yú

[Fingir saber tocar el yu para completar el número de un grupo musical]

Sfig.: Persona incompetente que se hace pasar por un experto; o cosa de mala calidad que se hace pasar por algo de buena calidad.

在文学界混了几年之后, 方知道自己并不会写小说, 不过滥竽其间而已。（《北京 晚报》1986-02-23第三版）

Traducción: Justamente después de meterme en el mundo literario durante varios años, me he dado cuenta de que no sé escribir novelas, solo ocupo indignamente un puesto en él. (Beijing Evening News, 23-02-1986, 3)

\subsubsection{Sustitución}

La sustitución consiste en reemplazar algún o algunos componentes de una UF por otra u otras unidades léxicas, sin afectar su estructura ni las relaciones sintácticas que se dan entre ellos. A través de este procedimiento creativo, las UFs modificadas presentan cambios semánticos, o bien consiguen determinados efectos que ocasionan estas unidades en el discurso.

Corpas Pastor y Mena Martínez (2003: 194) señalan que la sustitución semántica, denominada por Barz (1986) "paradigmática", utiliza el significado de los elementos integrantes de la UF institucionalizada para lograr sus objetivos, y que las relaciones que se establecen entre el componente sustituido y el sustituyente suelen ser la sinonimia, la antonimia, la hiperonimia, la hiponimia y la cohiponimia, entre otras. Lo mismo ocurre en la lengua china, puesto que se encuentran muchas UFs modificadas donde los elementos en cuestión son sinónimos, cohipónimos, antónimos, etc.

En el siguiente ejemplo que procede del título de una noticia digital publicada en la página web de la Agencia de Noticias Xinhua, se da cuenta de los accidentes que han ocurrido en los campus universitarios para resaltar los riesgos y peligros ocultos que puede haber por la falta de conocimientos e instalaciones de seguridad y mantenimiento. En este título 
se utiliza una UF modificada que presenta sustitución antonímica, pues, se reemplaza el elemento 未 wèi ('no') de la unidad institucionalizada por uno nuevo 已 y̌̀ ('ya'), de forma que se expresa una interpretación estándar opuesta a la de la UF originaria para resaltar las pérdidas irreversibles:

(8) 亡羊补牢, 为时未晚 $\rightarrow$ 亡羊补牢, 为时已晚 wáng yáng bǔ láo, wéi shi wèi wăn $\rightarrow$ wáng yáng bǔ láo, wéi shí y̌̌ wăn [Cuando una oveja se ha perdido, todavía no es demasiado tarde para reparar el redil] Equi.: Más vale tarde que nunca. “亡羊补牢”为时已晚 (新华网 2012-10-09)

Traducción: Cuando una oveja se ha perdido, ya es tarde para reparar el redil. (Noticias Xinhua, 9/10/2012)

En el siguiente ejemplo el componente sustituido y el sustituyente pertenecen al mismo campo semántico. El escritor cambia el verbo 吃 $c h \bar{\imath}$ ('comer') de la forma canónica de la UF por otro verbo 喝 hē ('beber'), debido a que este encaja más con el personaje, quien se emborracha todos los días:

（9）好吃懒做 $\rightarrow$ 好“喝”懒做 hào chī lăn zuò $\rightarrow$ hào “hē” lăn zuò

[Ser aficionado a comer y reacio a trabajar]

Sfig.: Ser glotón y perezoso.

可惜他又有一样坏脾气, 便是好“喝”懒做。（《鲁迅选集》第22页）

Traducción: Por desgracia, se ha enganchado a otro vicio, que es ser aficionado a beber y reacio a trabajar. (Antología de Lu Xun, p. 22)

Otro tipo de sustitución es la paronímica, que se apoya en la similitud fonético-fonológica para construir la modificación (Corpas Pastor y Mena Martínez, 2003). Teniendo en cuenta las características particulares de la lengua china, se dan casos en los que el componente sustituido y el sustituyente son homófonos, es decir, los dos elementos coinciden en la pronunciación ${ }^{5}$, pero no en su escritura. Veamos el siguiente fragmento sobre la base de la UF 人穷志短 rén qióng zhì duăn, donde se remplaza el sustantivo 志 zhì ('aspiración') por su homófono 智zhì ('inteligencia'), mediante lo cual se observa lo irónico y sarcástico que es el lenguaje empleado en la obra:

(10) 人穷志短 $\rightarrow$ 人穷“智”短 rén qióng zhì duăn $\rightarrow$ rén qióng “zhì” duăn

[Cuando una persona es pobre, no tendrá altas aspiraciones]

Sfig.: La pobreza ahoga la ambición.

真到忧患穷困的时候, 人穷“智”短, 谎话都讲不好的。（钱钟书《围城》第195页）

Traducción: Pero si llegaban momentos difíciles y angustiosos, la tensión limitaba la inteligencia, uno no era capaz ni de mentir. (La fortaleza asediada, p. 317. Trad. Fisac)

Por último, no todos los tipos de sustitución se realizan basados en relaciones semánticas o paronímicas entre los constituyentes implicados, también se encuentran casos en que se rompe la imagen de la UF institucionalizada, así se establece una relación contextual entre el nuevo lexema y el contexto en el que se produce la modificación. Por ejemplo, en el

5 Antiguo instrumento musical chino de viento. 
fragmento que sigue a continuación, el autor sustituye el verbo 死 š̌ ('muerte; morir') por el verbo 睡 shuì ('dormir'); mediante esta manipulación creativa, la UF modificada describe con viveza la prisa que tiene ella de meterse en la cama por el frío:

(11) 视死如归 $\rightarrow$ 视“睡”如归 shì sì rú guī $\rightarrow$ shì shuì rú guī

[Tomar la muerte como volver a casa]

Sfig.: Enfrentarse a la muerte sin ningún temor.

有一天夜里非常的寒冷。急急地要往床里钻的时候, 她说: “视睡如归。”(《张爱 玲文集》第240页)

Traducción: Una noche de mucho frío, ella se metió en la cama apresuradamente y dijo:

"Tomo el dormir como volver a casa". (Obras completas de Zhang Ailing, p. 240)

\subsubsection{Modificación gramatical}

Corpas Pastor (1996: 246) señala que la modificación gramatical consiste en los cambios oracionales relacionados a los aspectos morfológicos de los componentes de una UF, o bien a las relaciones sintácticas entre los mismos.

Se puede afirmar que este tipo de procedimiento afecta a las UFs de ambas lenguas. Sin embargo, teniendo en cuenta que la lengua china es altamente aislante, esta modificación solo se refleja en las relaciones sintácticas entre los componentes; es decir, una UF china sufre alguna manipulación formal para incorporarse a la cláusula como elemento oracional a fin de conseguir efectos expresivos. Por ejemplo, en el siguiente fragmento la unidad 指点迷津 zhǐdiăn míjīn se divide en dos partes, las cuales se alteran en orden y se insertan separadamente en dos cláusulas, al tiempo que se mantiene la cohesión semántica y estilística:

(12) 指点迷津 zhǐdiăn mijīn

[Dar consejos e instrucciones sobre los errores y confusiones]

可是群众对于这教育是否感到兴趣，制片人似乎很抱怀疑，因此不得不妥协一下， 将“迷津”夸张起来，将“指点”一节竭力的简单化。（《张爱玲文集》，第184页）

Traducción: Sin embargo, los productores de cine dudan si las masas están interesadas por este tipo de educación, así que no les queda más remedio que ceder, exagerando "los errores y confusiones" e intentando simplificar en la medida de lo posible en "dar los consejos e instrucciones". (Obras completas de Zhang Ailing, p. 184)

\subsubsection{Fusión}

La fusión consiste en unir dos o más UFs, o bien una UF y una combinación libre de palabras para formar una sola unidad en el discurso.

Aunque este tipo de manipulación se emplea en ambas lenguas, presenta cierta diferencia. En la lengua española, Corpas Pastor (1996) señala que se trata de un tipo especial de combinación de procedimientos, pues se unen varias UFs o bien sus acortamientos correspondientes a partir de un elemento en común; mientras que, en el caso de la lengua china, la forma más frecuente es la combinación de una UF con otra combinación libre de palabras, sin tener que compartir un elemento formalmente idéntico entre ambas unidades. Por ejemplo, en el lenguaje coloquial, se suele combinar la UF 嫁鸡随鸡, 嫁狗随狗 jià ji 
suí jī, jià gǒu suí gǒu con la cláusula 嫁个猴子满山走 jià gè hóuzi măn shān zǒu, y esta cuenta con la misma estructura sintáctica que las dos ramas de la unidad originaria, y al mismo tiempo, rima con ellas; de esta manera, la unidad modificada consigue un tono más jocoso y presenta una imagen más vívida:

(13) 嫁鸡随鸡, 嫁狗随狗 jià jī suí jī, jià gǒu suí gǒu

[Si se casa con un pollo, seguirá al pollo; si se casa con un perro, seguirá al perro]

嫁鸡随鸡, 嫁狗随狗, 嫁个猴子满山走。（《语文学习》第71页）

Traducción: Si uno se casa con un pollo, seguirá al pollo; si uno se casa con un perro, seguirá al perro; y si uno se casa con un mono, correrá con él por las colinas. (Chinese Language Learning, p. 71)

\subsubsection{Combinación de diferentes modificaciones}

Cabe mencionar que, tanto en chino como en español, las manipulaciones fraseológicas creativas no aparecen en estado "puro", ya que suelen combinarse con otro(s) procedimiento(s). Así, en ambas lenguas se dan muchos casos en los que las UFs emplean conjuntamente diferentes procedimientos de modificación, con el fin de conseguir efectos expresivos. En el siguiente fragmento, se inserta 毕竟 bijìng ('a fin de cuentas') en la UF 胳膊拧不过大腿 gēbo nǐng bú guo dàtuľ, y, a la vez, se reemplaza 拧 nǐng ('torcer') por su sinónimo 扭 ň̆u, de esta manera dicha unidad muestra simultáneamente la sustitución sinonímica y la adición:

(14) 胳膊拧不过大腿 gēbo nǐng bú guo dàtuľ

[El brazo no puede torcer la pierna]

Sfig.: Los débiles no pueden abatir a los poderosos.

对于事故之后的赔偿情况，东街居民更是觉得太不公平，只能不停地重复：“胳膊 毕竟扭不过大腿。”(中国新闻网，2002年11月20日）

Traducción: Con respecto a las condiciones de la indemnización por el accidente, los vecinos de la calle Este consideraban que era una injusticia, y no paraban de decir: "Los débiles, a fin de cuentas, no podrán abatir a los poderosos". (China News, 20-11-2002)

Por otra parte, la adición o la reducción suelen unirse con cambios de orden de los elementos conservados, como se observa en el siguiente fragmento sobre la base de la UF 挖 墙脚 wā qiáng jiăo, que, además de manifestar los procedimientos mencionados, pasa de voz activa a voz pasiva por la inserción de la preposición 被 $b$ è $i^{6}$ :

(15) 挖墙脚 wā qiáng jiăo

[Excavar los rincones de las paredes]

Sfig.: Socavar los cimientos.

民主政策开始了......他的公司的墙角被挖掉了。(《建国以来短篇小说选》第35页)

Traducción: Empezaba la política de la democracia..., y los fundamentos de su empresa han sido socavados. (Antología de novelas cortas desde la fundación de la R. P. China, p. 35)

6 Aquí la pronunciación se refiere tanto a la transcripción fonética como al tono. 
Finalmente, hemos de mencionar que, en ocasiones, se emplean simultáneamente más de tres procedimientos en una misma UF. Por ejemplo, en el siguiente fragmento, la paremia 寸金难买寸光阴 cùn jīn nán măi cùn guāngyīn se divide en dos partes, las cuales muestran adición de nuevos elementos, además de reducción, sustitución y cambio de orden de los elementos conservados:

(16) 寸金难买寸光阴 cùn jīn nán măi cùn guāngyīn

[Con una pulgada de oro no pueden comprar una pulgada de tiempo]

Sfig.: El tiempo vale más que el oro.

时间与空间一样，也有它的值钱地段，也有大片的荒芜。不要说“寸金难买”了，多 少人想为一口苦饭卖掉一生的光阴还没人要。( 《张爱玲文集》第245页)

Traducción: Al igual que el espacio, el tiempo también tiene su zona valiosa y gran extensión de terreno yermo. Por no hablar de "no poder comprar con una pulgada de oro", cuántas personas, para sobrevivir, incluso estarían dispuestas a vender el tiempo de toda su vida, pero nadie se lo comprará. (Obras completas de Zhang Ailing, p. 245)

\subsection{Modificaciones semánticas}

Como hemos expuesto anteriormente, las modificaciones formales pueden afectar tanto a la estabilidad como a la estructura de los componentes de una UF; en cambio, las manipulaciones semánticas no afectan a la estructura interna y formal de la UF originaria, sino a su contenido semántico.

En la lengua española, a este tipo de mecanismo Corpas Pastor (1996) lo denomina como "modificaciones externas". La misma autora señala que se trata de la interpretación unitaria y global de una determinada UF, acompañada de la activación simultánea del significado compositivo, y por tanto, independientemente de uno o alguno de sus componentes individuales o de la unidad entera por efecto de algún elemento del contexto.

Al igual que las manipulaciones formales, las semánticas también pueden presentar varias clases de procedimientos. A continuación vamos a analizar los dos principales procedimientos que tienen en común las UFs de las lenguas china y española: la doble actualización y la literalización.

\subsubsection{Doble actualización}

La doble actualización consiste en la simultánea activación del significado figurado y del significado literal de una UF en el discurso. Este procedimiento es lo que Corpas Pastor (1996: 236) denomina "prominencia del significado unitario", que hace referencia a la interpretación unitaria y global de una determinada UF, acompañada de la activación simultánea del significado compositivo de uno de los componentes o de la unidad entera por efecto de algún elemento del contexto. Este tipo de modificación semántica es una de las más frecuentes tanto en chino como en español, ya que se encuentran muchos casos de este procedimiento.

De los distintos procedimientos aplicados a este tipo de manipulación, abundan en ambas lenguas los casos en los que se repite uno de los componentes individuales de una UF, tomado en su significado independiente; y de esta manera se revitaliza el significado traslaticio de dicha unidad por remisión al significado de la misma como combinación libre de 
palabras (Corpas Pastor, 1996: 237). Por ejemplo, en el siguiente fragmento se reliteraliza la UF 司马昭之心, 路人皆知 Sìmă Zhāo zhī xīn, lùrén jiē zhī sobre la base del componente 路人 lùrén ('hombre de la calle; gente común y corriente'):

(17) 司马昭之心, 路人皆知 Sìmă Zhāo zhī xīn, lùrén jiē zhī

[Todos los hombres de la calle son conscientes de la intención de Sima Zhao]

Sfig.: Se dice de una conspiración conocida por todo el mundo.

“司马昭之心，路人皆知”......新闻记者鼓吹什么, 攻击什么的时候, 动轩抬出“路 人”来: “连路人也知道...”“路人所知道的”往往是路人做梦也没想到的。（《张爱玲 文集》第46页)

Traducción: Hay un refrán que dice "Todos los hombres de la calle son conscientes de la intención de Sima Zhao". [...] Los periodistas emplean a menudo este término para pregonar o criticar: "Los hombres de la calle son conscientes de..." De hecho, 'lo que los hombres de la calle conocen' suele ser lo que ellos no han soñado nunca en su vida. (Obras completas de Zhang Ailing, p. 46)

En el segundo fragmento sobre la base de la UF 唾珠咳玉 tuò zhū ké yù, se repiten los componentes 珠 $z h \bar{u}$ ('perla') y 玉 ỳ̀ ('jade'), que se interpretan literalmente, sin hacer referencia al sentido figurado de 珠玉 zhūyù ('palabras sublimes y hermosas'), de forma que se ofrece una viva descripción sobre cómo da el discurso aquel hombre tímido, la cual es completamente contraria a lo que expresa la unidad originaria:

(18) 唾珠咳玉 tuò zhū ké yù

[Escupir perla y toser jade]

Sfig.: Anunciar palabras sublimes y hermosas; o expresarse en términos adecuados y elegantes. 她批评一个胆小的人吃吃艾艾的演讲说: “人家唾珠咳玉，他是珠玉卡住了喉咙 了。”(《张爱玲文集》第241页)

Traducción: Ella critica así el discurso torpe de una persona tímida: "Otros anuncian palabras tan sublimes y hermosas como la perla y el jade, pero él habla como si tuviera perla y jade atascados en la garganta". (Obras completas de Zhang Ailing, p. 241)

En otras ocasiones, se repite algún componente o toda la UF, pero con un cambio de orden de los elementos constitutivos, $\mathrm{y}$, a la vez, se juega con el doble plano semántico de la unidad originaria; de esta manera se genera una mayor expresividad, tal como se observa en el siguiente fragmento:

(19) 狗尾续貂 gǒu wěi xù diāo

[Poner una cola de perro unida a la piel de visón]

Sfig.: Hacer un final indigno de un gran trabajo.

狗尾续貂的事情, 靠的是手艺, 能把貂的后半部分接上去; 而貂尾续狗, 靠的是创 意, 这活可不是一般的人都能做的。（《青年时报》，2008-03-11）

Traducción: "Poner una cola de perro unida a la piel de visón" requiere habilidad; sin embargo, poner una cola de visón unida a la piel de un perro hace falta la creatividad, ya que no todos son capaces de emprender este tipo de trabajo. (Youth Times, 11-03-2008)

Además, se encuentran en ambas lenguas muchos casos de componentes repetidos, que solamente guardan relaciones de identidad parcial con sus respectivas bases en el discurso, como atestigua el siguiente ejemplo: 
(21) 对牛弹琴 duì niú tán qín

[Tocar el laúd a una vaca]

Sfig.: Tener o elegir la audiencia equivocada (para burlarse de la persona que no entiende lo que le dicen, o de la persona que habla con personas equivocadas).

而要让外行人听懂, 自然不能采取凯恩斯那样“对牛弹琴”的做法, 对牛弹琴不是牛 的错, 而是弹琴的人搞错了对象。(《中国出版传媒商报》, 2005-2-25)

Traducción: Sin embargo, para hacer entender a los profanos, no conviene, naturalmente, adoptar la manera de Keynes de "tocar el laúd a una vaca"; y, esto no es culpa de la vaca, sino más bien de la persona que toca el laúd, por haberse equivocado de audiencia. (China Publishing \& Media Journal, 25-02-2005)

Por último, cabe mencionar que en la lengua china, a veces se emplea una combinación libre de palabras para interpretar literalmente una UF en el discurso, de forma parcial o completa, sin que aparezca la unidad originaria; y al mismo tiempo se activa simultáneamente el significado literal y el traslaticio de dicha UF. Se trata de un juego de la imagen que sirve de base a la unidad. Por ejemplo, en el siguiente fragmento, en vez de emplear la UF en su forma canónica 落井下石 luò jǐng xià shí, el escritor prefiere usar una cláusula no lexicalizada para expresar el significado compositivo de esta unidad, de forma que el texto adquiere un tono coloquial y sarcástico:

(20) 落井下石 luò jǐng xià shí

[empujar a una persona al pozo y tirarle piedras]

Sfig.: Añadir más desventuras a una persona que de por sí ya es lamentable.

虽然不见有人出来承认对什么错误应当负责，但我向着井口投掷石块就没有自己的 一份责任? (《巴金散文》第233页)

Traducción: Aunque nadie ha admitido ser responsable de algún error, ¿acaso no tengo alguna culpabilidad por tirar piedras al pozo? (La prosa de Ba Jin, p. 233)

\subsubsection{Literalización}

Este procedimiento consiste en la activación del significado literal y no el traslaticio de una UF en el discurso, sin alterar la estructura sintáctica de dicha unidad, con el fin de conseguir determinados efectos expresivos. Se trata de la prominencia del significado compositivo de Corpas Pastor (1996: 239), quien señala que este mecanismo se basa en la interpretación unitaria de la UF institucionalizada, aunque en el texto está empleada en su significado compositivo.

Por ejemplo, en el siguiente fragmento muestra la UF体无完肤 $t \grave{~ w u ́ ~ w a ́ n ~ f u ̈, ~ q u e, ~ e n ~}$ vez de presentar su significado canónico, se interpreta literalmente para dar una descripción viva de la cantidad de pulgas y piojos que le picaron hasta que no le quedó ninguna parte del cuerpo sin picadura, lo que genera más expresividad y mayor impacto:

(22) 体无完肤 tǐ wú wán fü

[Tener el cuerpo lleno de heridas]

Sfig.: Ser fuertemente criticado o completamente refutado.

鸿渐上床, 好一会没有什么, 正放心要睡去, 忽然发痒, 不能忽略的痒, 一处痒, 两处痒, 满身痒, .......咬得体无完肤, 抓得指无余力。(《围城》第151页)

Traducción: Hongjian se acostó. Durante un buen rato no sintió nada, pero cuando ya estaba tranquilo y se iba a dormir, empezó a sentir un extraño escozor en el pecho y un picor insoportable. Primero en un sitio, luego en dos, y al final en todo el cuerpo [...] Le devoraron todo el cuerpo y se rascó hasta quedarse sin fuerzas. (La fortaleza asediada, p. 243. Trad. Fisac) 
En el siguiente ejemplo, se activa el significado literal de la UF 千方百计 qiān fāng băi ji para resaltar que la chica a quien se refiere es una mujer con mucha trastienda:

(23) 千方百计 qiān fāng băi jì

[Mil medios y cien estratagemas]

Sfig.: Por todos los medios posibles.

鸿渐笑说: “你真是“千方百计”，足智多谋，层出不穷。幸而他是个男人，假使他是 个女人, 我想不出你更怎样吃醋? ” (《围城》第325页)

Traducción: -No sólo conoces todas las artimañas sino que lo sabes todo -dijo Hongjian con una sonrisa-. Menos mal que se trata de un hombre, si fuera una mujer no puedo imaginarme lo celosa que te hubieras puesto. (La fortaleza asediada, p. 529. Trad. Fisac)

\section{Conclusión}

Según hemos visto a lo largo de este trabajo, las modificaciones creativas constituyen una característica inherente y propia de las UFs tanto del chino como del español. Además, los diferentes mecanismos empleados en las UFs suelen presentarse en los textos literarios, periodísticos y publicitarios. Se trata de un proceso de relexicalización de los componentes de las UFs bastante recurrente para fines discursivos. Pese a la gran diferencia existente entre ambas lenguas, hemos encontrado muchas similitudes en cuanto a los tipos de procedimientos, puesto que las UFs de ambos idiomas han coincidido en la mayoría de las modificaciones tanto formales como semánticas a las que suelen recurrir estas unidades. Por ello, podemos considerar que la manipulación creativa es un universal fraseológico que no solo ha sido probado a través de los trabajos realizados en diversas lenguas europeas, sino también demostrado en el caso de la lengua china.

Sin embargo, mediante esta comparación también hemos revelado cierta diferencia. La mayor divergencia se refleja en los cambios ocasionales relacionados a los aspectos morfológicos de los componentes de las UFs. El chino es un idioma aislante y emplea palabras separadas para expresar morfemas gramaticales, por lo que las UFs en español pueden manifestar más variedad en cuanto a la modificación gramatical. Asimismo, hemos encontrado dos tipos de modificación que solo se dan en la lengua china: la sustitución homófona y la interpretación equivalente a la traducción literal de las UFs.

Finalmente, cabe subrayar que las UFs desautomatizadas suponen un gran esfuerzo para quien no está familiarizado con su forma o significado canónicos y, evidentemente, son uno de los grandes escollos en la didáctica de las lenguas extranjeras, así como en la traducción interlingüística de la fraseología.

\section{Referencias bibliográficas}

Álvarez de la Granja, M. (1999): "La manipulación de las unidades fraseológicas", Madrigal. Revista de Estudios Gallegos, 2, págs. 31-40.

Corpas Pastor, G. (1996): Manual de fraseología española. Madrid, Gredos.

Corpas Pastor, G. y Mena Martínez, F. (2003): “Aproximación a la variabilidad fraseológica de las lenguas alemana, inglesa y española”, Estudios de lingüística, 17, págs. 181-202.

García-Page Sánchez, M. (1989): "Sobre los procesos de deslexicalización en las expresiones fijas”, Español Actual, 52, págs. 59-79. 
García-Page Sánchez, M. (2008): Introducción a la fraseología española: estudio de las locuciones. Barcelona, Anthropos.

Guerra Salas, L. (1997): "La ruptura de la frase hecha en el lenguaje periodístico y publicitario”, Paremia, 6, págs. 301- 306.

Mena Martínez, F. (2003): "En torno al concepto de desautomatización fraseológica: aspectos básicos", Tono. Revista electrónica de estudios filológicos, 5: https:/www.um.es/ tonosdigital/znum5/estudios/H-Edesautomatizacion.htm (20-03-2012).

Montoro del Arco, E. T. (2003): "La manipulación humorística de las expresiones fijas como medio para la enseñanza de la fraseología del español”, J. A. Moya Corral y M. I. Montoya Ramírez (eds.), págs. 225-246.

Montoro del Arco, E. T. (2006): Teoría fraseológica de las locuciones particulares. Frankfurt, Peter Lang.

Ruiz Gurillo, L. (1997): Aspectos de fraseología teórica española. Valencia, Universitat de València.

Sun, Weizhang (1989): Hanyu shuyuxue (La fraseología china). Changchun, Jilin Daxue Chubanshe.

Tannen, D. (1987): "Repetition in conversation as spontaneous formulaicity”, Text, 7, págs. 215-243.

Wang, Chongfeng (2008): “Changyong suyu chuangxin huoyong litan (La manipulación creativa de los suyu de uso común)", Chinese Language Learning, 6, p. 71.

Wang, Dechun (1987): Xiucixue cidian (Diccionario de retórica). Hangzhou, Zhejiang Jiaoyu Chubanshe.

Wu, Fan (2014): La fraseología en chino y en español: caracterización y clasificación de las unidades fraseológicas y simbología de los zoónimos. Un estudio contrastivo. Tesis doctoral inédita, Universidad Autónoma de Madrid.

Yang, Xingfa, Wang, Faguo y otros (2005): Hanyu shuyu cidian (Diccionario de unidades fraseológicas en chino). Chengdu, Sichuan Cishu Chubanshe.

Zuluaga Ospina, A. (1997): "Sobre las funciones de los fraseologismos en los textos literarios", Paremia, 6, págs. 631-640.

Zuluaga Ospina, A. (2001): "Análisis y traducción de unidades fraseológicas desautomatizadas", PhiN, 16, págs. 67-83: www.phin.de (09-01-2012).

\section{Fuentes de los textos usados como ejemplos}

Ba, Jin (2007): Ba Jin sanwen (La prosa de Ba Jin). Beijing, Renmin Wenxue Chubanshe.

Lu, Xun (1983): Lu Xun xuanji (Antología de Lu Xun), Tomo I. Beijing, Renmin Wenxue Chubanshe.

Ma Feng, Ba Jin, Ai Wu y otros (1978): Jianguo yilai duanpian xiaoshuo (Antología de novelas cortas desde la fundación de la R. P. China). Shanghai, Shanghai Wenyi Chubanshe.

Qian, Zhongshu (1997): Weicheng. Beijing, Renmin Wenxue Chubanshe.

Qian, Zhongshu (2009): La fortaleza asediada. Barcelona, Anagrama. Trad. Taciana Fisac.

Zhang, Ailing (1991): Zhang Ailing wenji (Obras completas de Zhang Ailing). Hefei, Anhui Wenyi Chubanshe. 


\section{RESEÑAS}





\title{
JOSEFINA PRADO ARAGONÉS Y Ma VICTORIA GALLOSO, EL LÉXICO DISPONIBLE DE EXTREMADURA Y COMPARACIÓN CON EL DE ANDALUCÍA, HUELVA, SERVICIO DE PUBLICACIONES DE LA UNIVERSIDAD DE HUEVA, 2014. 225 PÁGS., ISBN: 978-84-16061-39-6
}

\author{
Javier de Santiago Guervós \\ Universidad de Salamanca \\ jguervos@usal.es
}

El presente estudio encuentra sus raíces en una obra anterior de las mismas autoras, junto al profesor portugués Manuel Célio Conceição, titulada La disponibilidad léxica en situación de contacto de lenguas en las zonas limítrofes de Andalucía y Extremadura (España) y Algarve y Alentejo (Portugal), Huelva, Universidad de Huelva, 2010, 447 págs. En esta obra, los autores dan un paso necesario en la investigación conjunta del Proyecto Panhispánico de Léxico Disponible, y destacan, con buen criterio, que la situación geográfica fronteriza es un hecho determinante para el léxico de los hablantes. Buena prueba de ello es la entrada muchachinho con chalequinho (centro de interés Alimentos y bebidas) que aparece también en el listado español. Se trata, efectivamente, de muchachinos con chaleco, una receta extremeña de judías pintas guisadas, que posiblemente transcriba un estudiante extremeño. La cuestión de interés estriba en el hecho de que se transcriba gráficamente como si fuera portuguesa y que, por esta razón, posiblemente, el encuestado la pronuncie como si esta fuera portuguesa. Este ejemplo es uno de tantos que muestran que la situación fronteriza otorga unas características propias al léxico local.

A grandes rasgos, podemos decir que lo que se aprecia en los análisis es que el léxico disponible de los hablantes preuniversitarios de español y portugués es similar, con una diferencia poco significativa, y que los centros de interés responden a parecidos patrones en ambas lenguas: los porcentajes de dichos centros también son muy similares, así como sus índices de cohesión. Aun así, la muestra española presenta mayores resultados absolutos, debido a su mayor tamaño por el número de centros encuestados. Asimismo, los resultados sociolingüísticos arrojan tendencias parecidas en ambos países: se observa mayor disponibilidad léxica en hombres que en mujeres y en habitantes de zonas urbanas que de zonas rurales. Sin embargo, los autores señalan un dato discrepante respecto al patrón general observado en estudios previos de disponibilidad léxica: en estas áreas fronterizas, la muestra portuguesa sigue la tendencia en cuanto a nivel de estudios de los progenitores: los clasificados con estudios superiores muestran mayor disponibilidad léxica frente a los de estudios elementales, y éstos frente a los de primarios. Por su parte, la muestra española presenta una idiosincrasia poco común: la mayor disponibilidad léxica se encuentra en el grupo cuyos progenitores tienen estudios elementales, en segundo lugar, aquellos cuyos progenitores son analfabetos, en tercer lugar, los que tienen estudios superiores, y en cuarto lugar, los que tienen estudios primarios. Tal vez esta discrepancia pueda ser debida a una clasificación errónea de los analfabetos y, por ello, los autores plantean la necesidad de realizar más estudios para confirmar o desmentir este dato. 
Como vemos, se presenta un trabajo detallado que se ajusta al formato de estudios de léxico disponible que se están realizando actualmente en nuestro país y en el ámbito hispánico. Los datos se ven claramente reflejados en tablas y gráficos insertados en el texto, que analizan y comparan la muestra española con la portuguesa, tanto en términos generales como por centro de interés, y en la sección sociolingüística atendiendo a las variables socioeconómicas de los encuestados.

El nuevo estudio supone una importante y definitiva contribución al ámbito del Proyecto Panhispánico que lidera el profesor Humberto López Morales, que se suma a los trabajos ya realizados por una de las autoras, $\mathrm{M}^{\mathrm{a}}$ Victoria Galloso y completa prácticamente el estudio de las ciudades que conforman la Ruta de la Plata (Ávila, Salamanca, Zamora, Cáceres, Badajoz y Huelva), comparándolo, en este caso, con el de todos los léxicos disponibles de Andalucía.

Es, pues, una investigación rigurosa que aporta información muy valiosa y que, además de sus cualidades intrínsecas, tiene el valor adicional de que se incorpora a un fructífero proyecto panhispánico, cuyas pautas metodológicas generales han sido seguidas al pie de la letra, lo que facilita las comparaciones de los resultados obtenidos por los distintos estudiosos: las encuestas se han centrado en los dieciséis centros de interés que estudian los distintos equipos hispánicos de este y del otro lado del Atlántico; se han tomado como informantes a los alumnos preuniversitarios que realizan segundo curso de Bachillerato; se ha dado el mismo tiempo para las respuestas en cada centro de interés; se han utilizado los procedimientos generales para la edición de los datos y se han hecho los cálculos del índice de disponibilidad a través del programa Lexidisp. Todas estas decisiones han permitido que los datos de Extremadura hayan podido ser integrados en el proyecto panhispánico y que, a su vez, puedan ser comparados con los que han resultado de las investigaciones andaluzas.

Lo dicho anteriormente no significa que las autoras no se planteen críticamente algunas de las bases del proyecto panhispánico y propongan unas soluciones siempre apropiadas, muy bien razonadas y adaptadas a la realidad que estudian. La explicación de la muestra elegida y de los criterios de edición seguidos en la elaboración de los listados definitivos es detallada y convincente. Este es un terreno muy complejo porque implica tomar numerosas decisiones sobre muchos aspectos concretos en los que es difícil conseguir una sistematización que contente totalmente al investigador. Pero las autoras siempre aportan soluciones muy justificadas (incluso en aquellos pocos ejemplos en que otros investigadores hubieran, posiblemente, elegido otros caminos). En todo caso, siempre tienen presente que lo importante es que los matices diferenciadores no impidan o dificulten la comparación interdialectal.

El trabajo presenta, asimismo, un excelente análisis cuantitativo de los datos, con una aportación muy valiosa sobre las diferencias ocasionadas por los factores extralingüísticos contemplados en la investigación. Como señalan las autoras, tras su detallado estudio, este ámbito del análisis requiere trabajos futuros que ayuden a explicar la diferencia entre los subfactores sociales.

El Léxico Disponible de Extremadura y comparación con el de Andalucía es un importante estudio descriptivo de la realidad léxica de la comunidad extremeña, a lo que se une la valiosa comparación con los datos producidos por las investigaciones paralelas en las ocho provincias andaluzas. Su interés no reside solo en sus valores propios; hay que considerar también la importancia de que los datos extremeños se incorporen al Proyecto Panhispánico de Disponibilidad Léxica. 


\title{
GALLARDO PAÚLS, BEATRIZ Y HERNÁNDEZ SACRISTÁN, CARLOS (2013): LINGÜÍSTICA CLÍNICA. UN ENFOQUE FUNCIONAL SOBRE LAS ALTERACIONES DEL LENGUAJE. MADRID: ARCO/LIBROS. 196 PÁGINAS
}

\author{
INMACULADA BLEDA GARCÍA \\ Universidad de Murcia \\ inmaculadaconcepcion.bleda@um.es
}

Lingüistica clínica. Un enfoque funcional sobre las alteraciones del lenguaje recoge la propuesta de Beatriz Gallardo Paúls y Carlos Hernández Sacristán para replantear metodológicamente el estudio de las alteraciones lingüísticas. Su objetivo es precisar qué directrices debe seguir la lingüística aplicada al ámbito clínico, así que defienden que, analizando el discurso, es posible describir la conducta verbal atípica convenientemente fundamentada desde un enfoque funcional, el que atiende a los usos comunicativos reales, dependientes siempre del contexto. En última instancia, en un marco interdisciplinar, esta nueva orientación posibilita el estudio de la etiología de tales alteraciones $\mathrm{y}$, por tanto, el diseño de terapias de rehabilitación más eficaces.

Los autores, ambos catedráticos de Lingüística en la Universidad de Valencia, parten de la idea de que el lenguaje constituye la esencia del ser humano, tanto a nivel cognitivo como en su vertiente sociocultural, de manera que las personas con una alteración lingüística ven afectada la base de su propia subjetividad. Un déficit verbal condiciona la visión que tienen de sí mismos y su visión de los demás, y repercute también en las personas de su entorno o en las que en algún momento interactúan con ellos, que han de reestructurar el proceso comunicativo poniendo en práctica habilidades de compensación. Incluso el propio código lingüístico adapta sus recursos y sus valores para alcanzar la eficacia pragmática y lograr satisfacer así las necesidades comunicativas de los hablantes. Lo fundamental es atender al uso real de la lengua y, en función de los factores contextuales (situación, canal, etc.), considerar el valor funcional de las diversas producciones, al margen de su nivel de complejidad o de perfección formal.

Quien padece un déficit lingüístico ha de implicarse activamente en el proceso de rehabilitación, al igual que las personas de su entorno (interlocutores clave). A partir de una muestra significativa de conducta verbal, es posible determinar qué habilidades lingüísticas se encuentran preservadas; estas suponen el punto de partida para recuperar las que se han perdido o las que están distorsionadas, ya que seguramente facilitarán el proceso. La clave es el efecto de "lenguaje rehabilita lenguaje", teniendo siempre en cuenta, por tanto, a la persona con el déficit lingüístico, a las personas que la rodean, el contexto en el que se comunican y la reorganización de los recursos lingüísticos de los que disponen.

Una vez establecidas las líneas generales de su planteamiento, los autores estructuran la obra en cuatro capítulos, que van focalizando la atención en aspectos cada vez más 
concretos. Realizan un breve recorrido histórico por las teorías utilizadas tradicionalmente para el estudio de los déficits lingüísticos, con el objetivo de justificar su enfoque funcional; explican este de manera más detenida; y lo aplican luego, a modo de ejemplo, a los déficits relacionados con sintaxis y con semántica léxica y a las dificultades de gestión discursiva. Los ejemplos de fragmentos conversacionales, numerosos y muy acertados, complementan y aclaran la exposición teórica y, aunque se relacionen sobre todo con la afasia, las nociones metodológicas que defienden Gallardo Paúls y Hernández Sacristán en este trabajo se pueden aplicar perfectamente a cualquier otro déficit lingüístico.

En el primer capítulo, "Pragmática clínica: fundamentos y aportaciones", los autores enmarcan su planteamiento en un marco teórico. En los años 80 se comenzó a trabajar en lingüística clínica a través de la pragmática, recurriendo a técnicas para el registro, la transcripción y el etiquetado de datos que se empleaban ya para el estudio del discurso típico. A diferencia de los enfoques gramaticales y formalistas, que entienden el lenguaje como un conjunto de niveles independientes entre sí, la pragmática le ofrecía a los estudios clínicos la posibilidad de valorar el uso efectivo del lenguaje: las personas que sufren déficits, con dificultades pero también con propósitos interaccionales, procuran rentabilizar sus recursos pragmáticos en los contextos en los que se encuentran, ya que, como sabemos, el grado de competencia lingüística y el de competencia comunicativa no siempre se corresponden.

Todo déficit lingüístico ocupa un punto concreto dentro de un espectro y, para establecer ese punto, es necesario aplicar pruebas estandarizadas y otras de validez ecológica. Gallardo Paúls y Hernández Sacristán describen brevemente algunos protocolos de evaluación pragmática, como el PCA (Profile of Communicative Appropriateness), de Claire Penn, entre otros. Destacan sus aspectos positivos, pero señalan también que la mayoría de ellos dispone de una fundamentación teórica escasa, a menudo resultan demasiado subjetivos, y privilegian algunos elementos lingüísticos en detrimentos de otros que pueden ser igual de importantes.

En cualquier caso, el déficit lingüístico supone un proceso de implicación y adaptación por parte del afectado y de sus interlocutores. Por ejemplo, a raíz de la alteración, el paciente utiliza una determinada conducta verbal con más frecuencia que antes, recurre a una conducta nueva o modifica el valor de alguna que ya usaba pero que emplea ahora con una carga funcional diferente. Estos recursos son fundamentales como punto de partida de la rehabilitación logopédica, porque surgen de manera espontánea y su uso se automatiza, es decir, se ajustan al contexto con flexibilidad. De hecho, debido a estas conductas verbales atípicas, la figura del interlocutor clave asume gran parte de la responsabilidad de la gestión conversacional. Así, una persona afásica puede ocultar o, al menos, disimular sus dificultades expresivas haciendo que su interlocutor active su capacidad inferencial para completar los enunciados que él interrumpe o para interpretar los que parecen no cumplir el principio de cooperación de Grice (los que no respetan la máxima de cantidad, por ejemplo).

El segundo capítulo, "Caracterización funcional del déficit lingüístico", es el más importante para comprender en qué consiste el cambio metodológico de Gallardo Paúls y Hernández Sacristán. Tradicionalmente los déficits lingüísticos se han descrito siguiendo una "evaluación diferencial", esto es, el dominio lingüístico de la persona afectada era el resultado de restar al dominio pleno uno o varios "módulos", los componentes gramaticales alterados. Primaba la expresión sobre la comprensión, la forma sobre el significado, la mera materialidad de los enunciados sobre su funcionalidad o su valor comunicativo real. Sin em- 
bargo, el enfoque funcional modifica esta postura, aunque en cierto sentido sea compatible con ella: tiene en cuenta diversas variables cognitivas y los condicionamientos que imponen los diferentes contextos comunicativos; entre ellos se encuentra el hecho de no asignar a las formas lingüísticas un valor absoluto para todos los interlocutores y en todos los contextos, sino un valor relativo en función del nivel de competencia de los interlocutores y la situación comunicativa concreta en la que se encuentren.

El lenguaje no relaciona de manera unívoca significantes y significados ${ }^{1}$, sino que existe cierto grado de libertad que, desde un punto de vista lógico, parece redundante. Sin embargo, la redundancia del código lingüístico permite que este se adapte a situaciones que afectan a su funcionamiento (un entorno ruidoso, por ejemplo) y se reorganice a nivel funcional cuando sea preciso, dando lugar así a usos creativos o metalingüísticos, por ejemplo. Aquí quedan comprendidas también las estrategias de adaptación o compensación de las personas con déficits lingüísticos y de sus interlocutores. Es posible sortear ciertos obstáculos porque las lenguas son redundantes, es decir, disponen de recursos variados para expresar un mismo contenido.

No obstante, es evidente que las personas con déficits lingüísticos ven alterado o restringido su acceso a la función simbólica del lenguaje. El signo lingüístico es a la vez, según Bühler, símbolo (lo representado), síntoma (el emisor) y función (el receptor), componentes que se corresponden, respectivamente, con la función representativa, expresiva y apelativa del lenguaje. El hablante tiene una intención comunicativa y, gracias a la función ejecutiva, orienta ese propósito hacia una conducta verbal eficaz. En esto consiste la función simbólica del lenguaje, manifestación, en última instancia, de la subjetividad del hablante. De hecho, lo auténticamente específico del lenguaje no es ninguna propiedad inherente al código, como argüían los formalistas, sino el uso eficaz y pertinente que hace de él una comunidad lingüística.

Así pues, los déficits se manifiestan siempre en un contexto, en los usos reales, y estos deben constituir la base de las descripciones clínicas. Los datos conversacionales auténticos demuestran que los déficits son asistemáticos, es decir, los hablantes no cometen siempre los mismos errores. Por tanto, la lingüística clínica y la logopedia deben establecer tendencias y caracterizaciones generales siempre individualizadas ${ }^{2}$.

La concepción modular del lenguaje ha seguido un criterio semiótico que divide la lengua en niveles totalmente aislados entre sí y considera que cada déficit afecta a un determinado nivel, mientras que el resto permanece intacto y ningún factor externo al código lingüístico puede solventar tal daño, pero un déficit lingüístico consiste precisamente en disociar a nivel perceptivo dos elementos interdependientes. De ahí que estos autores defiendan que todas las categorías del lenguaje se encuentran en todos los componentes de la descripción lingüística. Recuerdan que la lingüística perceptiva establece cuatro tipos básicos de relación entre unidades lingüísticas, al margen del nivel al que pertenezcan (fonético,

1 Cualquier déficit lingüístico supone cierto grado de disociación entre el significante y el significado. Por ejemplo, la anomia implica severas dificultades para encontrar los significantes; la ecolalia, por el contrario, las tiene al atribuir significados a tales producciones.

2 Como primera aproximación global, Beatriz Gallardo Paúls ha diseñado el PRESP, "Protocolo Rápido de Evaluación Pragmática", creado a partir de los datos conversacionales del corpus PERLA. Se trata de una herramienta de aplicación rápida que pueden emplear incluso los logopedas que carezcan de formación pragmática específica. Su objetivo es orientar la intervención, ya que informa acerca de las habilidades de pragmática general y específica $\mathrm{y}$ de las habilidades de base gramatical. 
morfológico, sintáctico, etc.): la rección, que implica la aparición de una unidad lingüística si ha aparecido previamente otra concreta; el orden, que da pertinencia a la disposición de los elementos en la cadena lingüística; la integración, que aúna lo estrictamente gramatical con su uso contextualizado; y la concordancia, que atribuye un valor categorial determinado a los elementos con una misma marca formal.

El tercer capítulo, "Aspectos de la evaluación funcional en sintaxis y semántica léxica", concreta y ejemplifica lo expuesto en el apartado anterior. Los autores han afirmado que todo déficit verbal afecta de manera transversal a los diferentes niveles de organización del sistema lingüístico, así que ahora se centran en algunos aspectos de sintaxis y semántica léxica para justificarlo.

Por una parte, en el caso de la sintaxis, proponen que la descripción clínica de los déficits lingüísticos maneje tres conceptos básicos. Estos se relacionan de manera inclusiva, es decir, cada uno queda comprendido en el siguiente: la sintaxis infradeterminada, muy poco especificada formalmente, requiere de ajustes o aproximaciones por parte del interlocutor porque media una gran distancia entre lo que se explicita en el enunciado y el contenido que se quiere comunicar; la sintaxis proximal necesita que el contexto contribuya a la creación del significado; y la sintaxis distal es la característica de las producciones más elaboradas.

Como hablantes, sabemos que un mismo contenido proposicional se puede expresar a través de formulaciones sintácticas muy diferentes y, entre todas las posibilidades, elegimos la que nos parece más acertada, según el contexto y las máximas conversacionales. Sin embargo, para describir los déficits lingüísticos se han utilizado durante años materiales descontextualizados y basados en un registro formal escrito, es decir, de sintaxis distal, a pesar de que un hablante competente modula la complejidad formal de sus enunciados siguiendo una motivación pragmática. Esta variabilidad natural debe ser tenida en cuenta en lingüística clínica $^{3}$, ya que, según revelan los datos conversacionales, las personas con afasia no logran acceder al extremo de la sintaxis distal y se mueven fundamentalmente en los otros dos ámbitos; su capacidad de variabilidad, por tanto, se encuentra restringida.

Por otra parte, en el ámbito de la semántica, los autores utilizan como ejemplo de su planteamiento las relaciones léxicas. Vistas con una perspectiva funcional, estas enlazan directamente con la neuropsicología cognitiva: los tipos básicos de relación léxica reflejan los esquemas cognitivos según los que se organiza el léxico mentalmente. Estos esquemas permiten ordenar y sistematizar la actividad lingüística, pero en realidad se comportan de modo flexible y se adaptan con facilidad a las situaciones comunicativas. El uso funcional de estas relaciones léxicas, en definitiva, depende de la activación de la función simbólica del lenguaje, que, según hemos mencionado anteriormente, se encuentra alterada en las personas con déficits lingüísticos.

Así, la sinonimia permite adaptar la capacidad referencial de los elementos léxicos, al margen de su carga connotativa (en casos de anomia, los sinónimos pueden actuar como equivalentes a las unidades léxicas bloqueadas). La homonimia activa la capacidad metalingüística, ya que una persona con anomia no logra acceder a la palabra que necesita pero

3 En el ámbito de la sintaxis, además de la variabilidad natural de los enunciados según el contexto, es importante también advertir la influencia de la tipología de la lengua que hable el paciente. Los autores insisten en que los protocolos y las baterías de evaluación no se pueden trasladar sin más de una lengua a otra; precisan de una adaptación sociolingüística y pragmática que garantice su validez. 
quizás sí es capaz de dar información sobre sus rasgos formales o sobre su significado (fenómeno "punta de la lengua"). De forma similar funciona la antonimia; se puede recurrir a ella como método de aproximación a un elemento léxico inaccesible porque, obviando las diferencias denotativas y connotativas, entre una palabra y su antónimo existe necesariamente algún rasgo semántico común. Finalmente, la hiponimia y la hiperonimia evidencian la jerarquización del léxico; en casos de déficit, el nivel de especificidad de un término concreto se ajusta a las necesidades discursivas, coincida o no con la ordenación estándar.

En el cuarto y último capítulo, "Conversación y déficit", Gallardo Paúls y Hernández Sacristán continúan justificando la validez de su enfoque funcional a partir de ejemplos, en este caso procedentes de la gestión discursiva. Asumen que los hablantes con déficits apelan a las habilidades lingüísticas, psicológicas y sociales de los interlocutores, rentabilizan al máximo las habilidades preservadas y activan estrategias de compensación para intentar alcanzar la eficacia comunicativa, pero, a pesar sus esfuerzos, los hablantes sin déficit lingüístico acaban asumiendo una responsabilidad mayor que condiciona su actuación conversacional y su conducta verbal en tres aspectos clave: la estructura y la gestión del turno, la organización de secuencias y la coherencia.

En primer lugar, dado que las personas con déficits lingüísticos tienen serias dificultades para gestionar sus turnos de palabra en la conversación, suelen recurrir a actos de habla activadores de inferencias (interjecciones o actos locutivos muy breves que delegan en el interlocutor la construcción del significado, la interpretación plena) y a tareas de edición (pausas oralizadas o actos borrador, como circunloquios o reinicios). Gallardo Paúls y Hernández Sacristán recuerdan a este respecto la diferencia entre un déficit fluente y uno no fluente: el primero afecta al eje paradigmático, y de él resulta el paragramatismo; el segundo repercute en el eje sintagmático y genera agramatismo. Aunque esta clasificación se diseñara en un principio para las afasias, se puede aplicar a los déficits lingüísticos en general.

Mientras que los planteamientos formalistas pretenden evaluar la fluidez mediante tareas completamente ajenas al lenguaje natural (enumerar unidades léxicas con un determinado rasgo fonológico, por ejemplo) y relacionadas más bien con la memoria o la atención, el enfoque funcional atiende a las relaciones sintagmáticas y a las variables contextuales. Maneja factores como la agilidad del turno (el número de turnos por minuto en una conversación), el índice de participación conversacional (las muestras de competencia social y comunicativa del hablante) o el grado de predictibilidad (las restricciones sintácticas, semánticas y pragmáticas que establece cada turno con respecto al siguiente; a mayor predictibilidad, mayor fluidez conversacional).

En segundo lugar, la organización secuencial de toda conversación se ve condicionada cuando alguno de los interlocutores sufre un déficit lingüístico porque se producen con frecuencia turnos de solapamiento, que requieren un reinterpretación de los elementos afectados, y las secuencias, formadas a partir de pares adyacentes (turnos vinculados por una relación de predictibilidad), suelen ser más breves. El hablante sin déficit produce a menudo secuencias laterales de rectificación para proporcionar turnos de apoyo, aclaraciones, ayudas para el acceso léxico o para la explicitación de las intenciones comunicativas, etc. Resuelve los problemas que surgen en la conversación para evitar así posibles fracasos conversacionales.

En tercer lugar, la coherencia se mantiene con una transición temática fluida, convirtiendo en tópico de la conversación un aspecto relacionado con el tema inicial. Cuando participa 
en la conversación una persona con un déficit lingüístico, nuevamente rectificar y reorientar la conversación con la ayuda del interlocutor resulta de vital importancia para garantizar una progresión temática eficiente.

En conclusión, estudiar el lenguaje con una perspectiva funcional implica abordar tanto sus aspectos formales como las características de la situación comunicativa, es decir, tanto el código del lenguaje como los factores que constituyen el contexto en el que este se utiliza. Las personas con déficits lingüísticos mantienen sus intenciones comunicativas, así que participan en la conversación tratando de explotar sus recursos, pero sus dificultades indudablemente repercuten en su vida social. Por tanto, el enfoque funcional del que han de partir los logopedas para decidir la estrategia a seguir durante la rehabilitación debe huir de pruebas descontextualizadas y apoyarse en datos conversacionales reales, procurando que el afectado y las personas de su entorno se impliquen activamente en el proceso. El trabajo de Beatriz Gallardo Paúls y Carlos Hernández Sacristán proporciona una base teórico-práctica coherente y relevante para quienes trabajan en el ámbito de la lingüística clínica, puesto que valora los logros de planteamientos anteriores, pero propone a la vez una metodología alternativa (o complementaria, no obstante, en algunos puntos) que permitirá describir y, por tanto, tratar mejor las alteraciones en la competencia comunicativa que sufren las personas con algún tipo de déficit lingüístico. 

